\title{
The strategic use of patents in standardization in relation to US, European and Chinese competition law
}

Citation for published version (APA):

Heckman, M. J. C. (2016). The strategic use of patents in standardization in relation to US, European and Chinese competition law. [Doctoral Thesis, Maastricht University]. Datawyse / Universitaire Pers Maastricht. https://doi.org/10.26481/dis.20160422mh

Document status and date:

Published: 01/01/2016

DOI:

10.26481/dis.20160422mh

Document Version:

Publisher's PDF, also known as Version of record

\section{Please check the document version of this publication:}

- A submitted manuscript is the version of the article upon submission and before peer-review. There can be important differences between the submitted version and the official published version of record.

People interested in the research are advised to contact the author for the final version of the publication, or visit the DOI to the publisher's website.

- The final author version and the galley proof are versions of the publication after peer review.

- The final published version features the final layout of the paper including the volume, issue and page numbers.

Link to publication

\footnotetext{
General rights rights.

- You may freely distribute the URL identifying the publication in the public portal. please follow below link for the End User Agreement:

www.umlib.nl/taverne-license

Take down policy

If you believe that this document breaches copyright please contact us at:

repository@maastrichtuniversity.nl

providing details and we will investigate your claim.
}

Copyright and moral rights for the publications made accessible in the public portal are retained by the authors and/or other copyright owners and it is a condition of accessing publications that users recognise and abide by the legal requirements associated with these

- Users may download and print one copy of any publication from the public portal for the purpose of private study or research.

- You may not further distribute the material or use it for any profit-making activity or commercial gain

If the publication is distributed under the terms of Article $25 \mathrm{fa}$ of the Dutch Copyright Act, indicated by the "Taverne" license above, 
The strategic use of patents in standardization in relation to US, European and Chinese competition law 


\title{
The strategic use of patents in standardization in relation to US, European and Chinese competition law
}

\author{
DISSERTATION \\ To obtain the degree of Doctor \\ At Maastricht University \\ On the authority of the Rector Magnificus, \\ Prof. dr. L.L.G. Soete \\ In accordance with the decision of the Board of Deans, \\ To be defended in public \\ On 22 April, 2016, at 10.00 hours
}

by

Mr. Mathieu Joseph Caspar Heckman 


\section{Supervisors}

Prof. mr. Anselm Kamperman Sanders PhD (Lond.)

Prof. Meir Pugatch (Lond.)

\section{Assessment Committee}

Prof. dr. Michael Faure (Chairman)

Dr. Tsai-fang Chen (National Chiao Tung University, Hsinchu, Taiwan)

Prof. dr. Gerard-René de Groot

Prof. dr. Nicolas Petit (University of Liege, Belgium)

Prof. dr. Masabumi Suzuki (Nagoya University, Nagoya Japan)

Prof. dr. David Townend 
穷则变, 变则通, 通则久

Any circumstance hitting a limit will begin to change. Change will in turn lead to an unimpeded state, and then lead to continuity.

易经 (yi jing) 



\section{Acknowledgements}

The PhD journey was a fascinating experience. A conference at the Academy of European Law (ERA) in Trier, Germany, raised my interest in the intersection of competition law and intellectual property rights. Prof. dr. Hanns Ullrich explained the finer details of the apparent tensions between patents and competition law. At the time, I decided to focus on the strategic use of patents in standardization in the telecommunications sector. The choice of the telecommunications sector was motivated by the fact that, at the time, this sector was not very developed and promising for the future. A few years later, major competitors did engage in "patent-wars" in different jurisdictions all over the world.

To give my research an international perspective, looking at the US, EU and Chinese competition law was a very obvious choice. In my earlier work, I was responsible for international relations at a Dutch Polytechnic college and, consequently, I had contacts with an interesting network of international universities and companies.

First, I have to thank my supervisor Prof. Anselm Kamperman Sanders for his interesting comments on the various drafts of this PhD thesis. His expertise in the global developments in intellectual property law, involvement in Chinese academia, and leadership in the Institute of Globalization and International Regulation (IGIR) were "essential" for my research.

My co-supervisor Prof. Meir Pugatch often used his expertise and professional experience to draw my attention to the functioning of modern technology markets. Again this perspective was crucial for the completion of this dissertation.

I also thank the members of the Assessment Committee who kindly agreed to read and evaluate the dissertation: Prof. Michael Faure, Prof. Gerard-René de Groot, Prof. David Townend, Prof. Masabumi Suzuki, Prof. Tsai-fang Chen, and Prof. Nicolas Petit.

I am also indebted to Zuyd Polytechnic, which, in particular represented by Kitty Kwakman, provided me with the time and facilities to carry out this research. I would also like to thank Jimme Keizer for providing me with motivating support during my years of research. During my research I had the good fortune to discuss the subject of this PhD with many practitioners in the field of standards, patents and competition law. Maurits Dolmans, Trevor Soames, Kai Jakobs, Rudi Bekkers, James Killick, John White, 
David Barron, Luc Peeperkorn, Yanfeng Xiong, Pierre Regibeau, and many others, all provided insights at a time when their agendas were more than full.

For the European perspective, I had the opportunity to participate in a closed meeting of the DVB-pool, during which licensing arrangements (including royalty rates) were discussed. Roberto Dini (Sisvel International) and Carter Eltzroth (DVB) both made this possible; thanks again.

My eternal gratitude goes to the staff of the law libraries at the Chinese University of Hong Kong, Penn State University and especially the Max Planck Institute for Innovation and Competition in Munich.

The Chinese researchers at Maastricht University: He Tianxiang, Wang Jie and Lu Tian helped me to gain a better understanding and translation of Chinese court decisions and we became good friends.

At the MHMS, I would like to thank the dean and his management team for their support. I am very grateful for the support of Jos Maas, Neville Backler and Jill Penders, who all shared valuable time and knowledge with me.

My deepest gratitude goes to the two women in my life. We got Lilly, our Staffordshire Bull Terrier, from the Rescue Service at the beginning of my research. Although it first seemed that I rescued her, during my research, her attitude managed to rescue my PhD-dissertation several times.

Finally, I have to thank my wife Diana for coping with me during the PhD journey. She had to bear my absent-mindedness and the fact that I became a bit cynical. She also contributed her fair share in the completion of this study and without her help and support this dissertation would not have been possible.

Matt Heckman, February 2016 


\section{Content}

$\begin{array}{ll}\text { Acknowledgements } & 7\end{array}$

$\begin{array}{ll}\text { List of Abbreviations } & 17\end{array}$

CHAPTER 1 Introduction $\quad 21$

1.1 Introduction $\quad 22$

Overview of the chapters: $\quad 25$

The first chapter - Introduction $\quad 25$

The second chapter-Standards: definition, overview and relevance 25

The third chapter - Competition policy, patents and standard setting 26

The fourth chapter - Innovation policy and standardization: the perspective of China, an emerging economy 26

The fifth chapter - Patent Pools and competition law 27

The sixth chapter - Patent pools in the US 28

The seventh chapter - The EU approach towards patent pools 28

The eighth chapter - Patent pools inside the People's Republic of China 29

The ninth chapter - Main findings and conclusions 30

1.2 Research Question 33

1.3 Methodology $\quad 34$

Basic terms $\quad 38$

Background $\quad 43$

Valorization $\quad 45$

$\begin{array}{lll}1.4 & \text { Approach } & 46\end{array}$

CHAPTER 2 Standards: Definition, overview and relevance 51

2.1 Innovation and global standardization 53

2.2 Diffusion of innovation: standards and network externalities 55

2.3 Economic characteristics of network industries 57

2.4 Standards 58

2.4.1 Introduction $\quad 58$

2.5 Definition of standards 59

$\begin{array}{ll}2.6 & \text { Categories of standards }\end{array}$

2.6.1 Open standards $\quad 62$

2.6.2 Open standards and open source $\quad 65$

2.7 EU and standards 66

2.7.1 Competitiveness of the EU ICT sector and standardization 72

2.8 The United States and standards 74 
2.9 The EU-US cooperation in the Transatlantic Trade and Investment

$\begin{array}{ll}\text { Partnership and standards } & 77\end{array}$

2.10 China and standards $\quad 79$

2.10.1 Standardization and classification of Chinese standards 79

2.11 Chinese technology standards 82

2.11.1 Overview of different approaches by the Chinese government, comparing international and national standards 83

2.12 The European Union and Chinese standardization 86

2.12.1 Comparison of the different approaches of the EU, US and China to standardization 88

2.13 Conclusions 89

CHAPTER 3 Competition policy, patents and standard setting 91

3.1 Part A Competition policy and patents 93

3.2 Competition policy and Intellectual Property 96

3.3 Complexity of the legal aspects of standard setting 98

3.4 Standardization and competitive conduct 100

3.5 Economic analysis in relation to standard setting and antitrust policy 102

$\begin{array}{lll}3.6 & \text { Patents, standardization and efficiency } & 103\end{array}$

3.7 Part B Patents included in standards and competition policy concerns 106

3.8 Strategic use of patents: EU perspective and the example of ETSI 107

3.9 The Strategic use of patents: the US perspective 110

3.10 The strategic use of patents: The perspective of China 113

3.11 Implications for competition law enforcement in the telecommunications $\begin{array}{ll}\text { industry } & 116\end{array}$

$\begin{array}{ll}3.12 \text { Royalty stacking } & 119\end{array}$

3.13 Important elements in the discussion on the tension between standards, $\begin{array}{ll}\text { patents and antitrust } & 121\end{array}$

FRAND licensing terms $\quad 121$

$\begin{array}{ll}\text { Injunctive relief } & 124\end{array}$

Cross-licensing 124

Patent pools 125

"Ex ante auctions" 125

3.14 Non-Practicing Entities (NPE), Patent Assertion Entities, Patent Trolls 127

3.15 Patent Misuse in relation to standard setting 129

3.16 The Princo decisions and the boundaries between Patent Misuse and antitrust laws 133

3.17 Conclusions 135 
CHAPTER 4 Innovation policy and standardization: the perspective of China - an emerging economy

4.1 China's Innovation policy and IPRs

4.1.1 Patents and second-tier innovation

4.2. The Chinese indigenous innovation policy

4.2.1 The possible theft of Intellectual Property Rights in China from a US Perspective

4.2.2 Indigenous innovation and its effects on standards

4.2.3 The influence of the US on standardization in China

4.2.4 The influence of the European Union on the PRC standardization policy

4.3 Standards and their contribution to economic development and competition 164

4.4 The development of standardizing in the PRC and the impact of intellectual property rights.

IP abuse in the field of technology transfer in China

4.4.1 The development of national Chinese standards in the sector of Telecommunications

4.4.2 The WAPI and TD-SCDMA standards

4.4.3 The Chinese WAPI standard

4.4.4 Main problems for Foreign Direct Investment in China in relation to standardization processes.

4.4.5 Utility Model Patents

4.5 The legal positioning of patents in standards in China

4.5.1 CNIS: Disposal Rules for the Inclusion of Patents in National Standards

4.5.2 Revisions in the Chinese Patent Law

4.6 The interface between standards and patents in developing countries

4.6.1 Competition law and the protection of intellectual property in a developing country

4.7 Conclusions

CHAPTER 5 Patent pools and competition law

5.1 Introduction

5.2 The concept of a patent pool

\subsubsection{Antitrust interest related to patent pools}

5.3 Competitive analysis of patent pools

5.4. The competitive relationship of patents in the pooling agreement

Question A- What is the exact relationship of the patents in the pool to each other? Are they substitutes or complements?

5.4.1 The relationship of participating companies in the pool

Question B-What type of relationship do the participating companies in the pool have to each other? Are they active on downstream markets or are they vertically integrated firms? 
5.4.2 The patent pool and the relevant technology market

5.4.3 Patent Pools: overlapping ownership 214

5.4.4. Participation in the patent pool 216

5.5 Licensing in the patent pool

Question C-Is the technology embedded in the pool exclusively available through the pooling agreement? Are individual licences available? Are there elements of a tying agreement?

5.5.1 Licensing in the patent pool

5.5.2 Compulsory licensing

5.6 Patent pools, NPEs and the potential to innovate

Question D-Does the patent pool agreement have a positive or a negative impact on the licensee's potential to innovate?

5.6.1 The new phenomenon of defensive patent pools

CHAPTER 6 Patent pools in the US

6.1 Historical overview of the development of patent pools in the US 239

6.2 The Nine No-No's 240

6.3 US case law: move from per se approach to rule of reason 240

6.4 The 1995 IP Guidelines $\quad 241$

6.5 The system of Business Review Letters (BRLs) 242

6.6 The Business Review letter of the $3 \mathrm{G}$ Platform patent pool and current investigations: MPEG LA; the H.246 patent pool, RFID BRL, IPXI BRL 245

$\begin{array}{lll}6.7 & \text { Case law } & 248\end{array}$

6.8 Conclusions 253

CHAPTER 7 The EU approach to patent pools 257

7.1 Historical overview of the EU and patent pools 259

7.2 Standardization Agreements, Patents and the Guidelines on the Horizontal $\begin{array}{ll}\text { Cooperation Agreements } & 261\end{array}$

7.3 Safe harbour provision for standardization agreements 262

7.4 The 2004 Technology Transfer Block Exemption Regulation 264

7.5 Technology Transfer and patent pools: a European Perspective 269

7.6 The legal positioning of patent pools 270

7.7 The revision of the EU Technology Transfer Regulation 272

7.8 The adopted version of the TTBER 276

7.9 Recent developments in patent pools 280

7.10 Case study the DVB pool and Negative disclosure 281

7.11 The element of arbitration in the DVB patent pool 284

7.12 Case law in the European Union $\quad 287$

7.13 Recent views of the Commission on the injunctions and SEP debate. 293 
7.15 The Opinion of Advocate-General Wathelet in the Huawei-ZTE case 301

7.16 The decision of the Court of Justice in the Huawei v. ZTE case. 302

7.17 Conclusions 304

CHAPTER 8 Patent pools in the People's Republic of China 311

8.1 General discussion of the Anti-Monopoly law, policy and enforcement 314

8.2 The AML and its relation to technology transfer 319

$\begin{array}{ll}\text { 8.3 Interpretation of Article 55 AML } & 321\end{array}$

8.4 Exemptions and defences for monopolistic agreements under Article $55 \mathrm{AML} 323$

8.5 Enforcement Guidelines for the application of the Anti-Monopoly Law in the field of intellectual property rights 326

8.6 Patents, Standards and the National Intellectual Property Strategy 329

8.7 The MIIT Template for IP Policies in Industry Standards Organizations

8.8 The AML Enforcement Guide in relation to Intellectual Property, on patents and standards

8.9 (Draft/Interim) regulatory measures for standards involving patents 334

8.10 American Bar Association Comments on the Draft Regulatory Measures on National standards involving patents of the PRC 336

8.11 Relevant general case law on the intersection of IP and competition law

8.12 The CHINT vs. Schneider case

8.13 Case Chaovang Xingnuo: Instruction Letter on "Patents Used for Standards Setting Constitutes Infringement "

8.14 The Qihoo 360 v. Tencent case

8.16 Case Huawei v. InterDigital

8.17 Recent developments in China's antitrust enforcement involving standards and patents.

$8.1825^{\text {th }}$ US-China Joint Commission on Commerce and Trade (JCCT)

8.19 Summary of the different approaches in the case law of the US, EU and China in relation to patent pools

8.20 Patent pools as a possible solution for the tensions in the incorporation of essential patents in Chinese standards

8.21 Patent pool case law Philips 4C DVD patent pool case in China 359

8.22 MPEG-2 case

8.23 The AVS patent pool

8.24 The IGRIS alliance

8.25 Other relevant Chinese technology laws 
9.1.1 The relationship between patents and innovation 378 Answers

Question 1: What is the position of the concept of patent pools in the competition policy of the US, EU and China?

Question 2: How do the management rules of a patent pool influence the legality of the patent pool?

Question 3: How do standardization policies differ in the various countries and what is the impact upon competition?

Question 4: What are new IP business forms and how can they be distinguished from patent pools and how do they influence the standards and patents discussion?

Question 5: What are the different attitudes towards FRAND rate setting, SEPS and injunctions in the three jurisdictions?

Final thoughts:

What does the future bring?

9.2 Nederlandstalige samenvatting: Standaarden, patenten en

concurrentieregels, de bijzondere positie van patent pools.

Vraag 1:Welke positie neemt het concept van een patent pool in binnen het

mededingingsrecht van de Verenigde Staten, de Europese Unie en

China?

Vraag 2: Wat is de invloed van de managementregels van een patent pool op de beoordeling van de legaliteit van de patent pool?

Vraag 3: Op welke wijze verschilt het standaardiseringsbeleid in de drie landen en welke invloed heeft dit op de mededinging?

Vraag 4: Welke nieuwe ondernemingsvormen ten aanzien van intellectueel eigendom kunnen er worden onderscheiden en welke invloed oefenen deze uit op de discussie omtrent standaarden en octrooien?

Vraag 5: Wat zijn de belangrijkste ontwikkelingen binnen de drie landen omtrent de begrippen FRAND-voorwaarden, standaard-essentiele octrooien en het gebruik van dwangbevelen?

Afsluitende opmerkingen:

Toekomstige ontwikkelingen

Bibliography

Blog

Book

Book section

Cases

Conference proceedings 
Electronic article

Generic source

Government documents

Hearing

430

Journal article

430

Legal rule or regulation

434

Manuscript

434

Newspaper article

435

Online database

435

Report

435

Thesis

438

Webpage

438

Curriculum Vitae

441 



\section{List of Abbreviations}

$A B A$

AML

ANSI

Art.

AVS

$B R L$

CAFC

CD

CDMA

CEN

CENELEC

CFIUS

CODEC

CRA

DAB

DIN

DoJ

DRM

DVB

DVD

EC

EEA

e.g.

EN

EPO

ESO

Et al

ETSI

ETUI

EU

EVD

Fed.Cir.

FDI

FTC

FRAND

GPN

GSM
American Bar Association

Anti-Monopoly Law

American National Standards Institute

Article

Audio Visual Standard

Business review Letter

Court of Appeals for the Federal Circuit

Compact Disk

Code Division Multiple Access

Comite Europeen de Normalisation

Comite Europeen de Normalisation Electrotechnique

Committee on Foreign Investment in the United States

Coder-Decoder

Charles River Associates

Digital Audio Broadcasting

Deutsches Institut fuer Normung

Department of Justice

Digital Rights Management

Digital Video Broadcasting

Digital Versatile Disks

European Commission/European Community

Economic Espionage Act

for example

European Norm/European Standard

European Patent Office

European Standardisation Organisation

and others

European Telecommunications Standards Institute

European Trade Union Institute

European Union

Enhance Versatile Disc

Federal Circuit

Foreign Direct Investment

Federal Trade Commission

Fair, Reasonable and Non-Discriminatory terms and conditions

Global Production Networks

Global Standard for Mobile Communication 


\begin{tabular}{|c|c|}
\hline 3GPP & $3^{\text {rd }}$ Generation Partnership Project \\
\hline ICT & Information and Communications Technology \\
\hline IEEE & Institute of Electrical and Electronics Engineers \\
\hline IPRs & Intellectual Property Rights \\
\hline ISO & International Standards Organisation \\
\hline ITA & Information Technology Agreement \\
\hline ITC & International Trade Commission \\
\hline ITU & International Telecommunications Union \\
\hline ITU-T & Telecommunications Standardization Sector \\
\hline JEDEC & Joint Electron Device Engineering Council \\
\hline LTE & Long Term Evolution \\
\hline MOFCOM & Ministry of Commerce \\
\hline MOST & Ministry of Science and technology \\
\hline MPEG & Moving Picture experts Group \\
\hline NDRC & National Development and Reform Commission \\
\hline NGMN & Next Generation Mobile Networks \\
\hline NPE & Non-Practising Entities \\
\hline NIS & National Institute of Standardisation/National Innovation System \\
\hline NORMAPME & $\begin{array}{l}\text { European Office of Crafts, Trades and Small and Medium sized Enter- } \\
\text { prises for Standardisation }\end{array}$ \\
\hline RAND & Reasonable and Non-Discriminatory terms and conditions \\
\hline PAE & Patent Assertion Entities \\
\hline PRC & People's Republic of China \\
\hline$R \& D$ & Research and Development \\
\hline RF & Royalty free \\
\hline SAC & Standards Administration of China \\
\hline SAIC & State Commission for Industry and Commerce \\
\hline SDRAM & Standard for computer memory \\
\hline SEC & Securities and Exchange Committee \\
\hline SDO & Standard Development Organisation \\
\hline SEI & Strategic Emerging Industries \\
\hline SIPO & State Intellectual Property Office \\
\hline SME & Small and medium-sized enterprises \\
\hline SOE & State Owned Enterprise \\
\hline SPC & State Planning Committee \\
\hline SSO & Standard Setting Organisation \\
\hline TBT & Technical Barriers to Trade \\
\hline TD-SCDMA & Time Division Synchronous Code Division Multiple Access \\
\hline TFEU & Treaty on the Functioning of the European Union \\
\hline TTBER & Technology Transfer Block Exemption \\
\hline TTIP & Transatlantic Trade and Investment Partnership \\
\hline
\end{tabular}


TRIPS

UMTS

UPC

USPTO

W3C

WAPI

WIPI

WiFi
Trade Related Intellectual Property Rights

Universal Mobile Telecommunications System

Unitary Patent Court (system)

United States Patent and Trade mark Office

World Wide Web Consortium

WLAN Authentication and Privacy Infrastructure

Wireless Internet Platform for Interoperability

Wireless Network 

CHAPTER 1

Introduction 


\subsection{INTRODUCTION}

Historically, the goals of competition law and intellectual property law seemed to be contradictory. In the 1950's and 60's the view was that intellectual property rights regimes created monopolies which, on the one hand, would spur innovation while, on the other hand, the aim of competition law was to eliminate monopolies. Therefore, the relationship between intellectual property law and competition law has always been an intriguing subject. Recently this relationship gained more interest and importance for several reasons. One reason is that the volume, scope and the financial value of intellectual property rights have increased globally. Secondly, competition authorities struggle with a number of questions relating to the exercise of IP rights, e.g. the holder's right to exclude, the acquisition of intellectual property rights leading to anticompetitive behaviour, IP bundling/extension of IP rights, patent settlements etc. Thirdly, the discussion has gained more relevance in the context of the emergence of new technologies and globalization. At the moment, there is general consensus that IP laws and competition laws both seek to promote innovation and consumer welfare.

The increasing complexity of technical systems makes innovative products more vulnerable to IP attacks. Elements like the interoperability of products and interdependence of systems have given the patent owner more power. A patent can be used to block interoperability, prevent competition on downstream markets or to block the production of competitive products entirely. ${ }^{1}$

Production is often based on cooperative innovation, which leads to more patent owners, increasing the royalty fees and the number of patent owners. Global Production Networks (GPNs) are characterized by IP ownership in different parts of the vertical markets, in different jurisdictions.

The competitiveness of trading blocs is largely influenced by standardization. The current negotiations of the Transatlantic Trade and Investment Partnership (TTIP) include a section on a common harmonized approach towards the regulatory environment of standard setting in the EU and US. ${ }^{2}$

The US Trade Representative Michael Froman said recently:

"Over decades, differences in our regulatory and standards approaches have created unnecessary barriers, raising costs, deterring trade and investment, and negatively impacting our competitiveness and our consumers. As traditional barriers like tariffs and duties have decreased, these standards and regulatory issues have emerged as

\footnotetext{
${ }^{1}$ In the Microsoft case, the European Court of Justice established that the patent rights were used to prevent competition on neighbouring markets. The production of products can be blocked if a patent on one component is essential for the production of the entire product.

${ }^{2}$ Some commentators hold the opinion that emerging markets like Brazil and China might be left out by the current transatlantic cooperation. EurActiv: EU lawmaker 'TTIP is not a monster'.
} 
the greatest potential impediment to further integration of the world's two largest markets."3

Standardization leads to more cost-efficient production and lower consumer prices. Standards are also required for the interoperability of different technical products, but the IP rights within the standard can be applied to exclude competition and rival technologies. The patent owner may obtain market power if his patent is included in the standard and it proves to be essential in nature.

In the US, the Department of Justice (DoJ) and the Federal Trade Commission (FTC) undertook joint hearings and examined several topics relevant to this discussion. In 2007, the American Antitrust Modernization Commission published a report on the intersection of Antitrust and IP and the DoJ and the FTC initiated cases against information technology companies that resulted in the Microsoft, Intel and Rambus decisions. Later cases of the FTC would be FTC v. Dell and FTC v. Negotiated Data Solution.

In the European Union, the Commission introduced the new Technology Transfer Block Exemption Regulation in 2004 and one year later the Commission adopted a landmark decision in the Astra-Zeneca case. Later involvement of the EU Commission in antitrust cases relating to the alleged misuse of the patent system includes Commission v. Rambus, Nokia, TI, Broadcom, Ericsson, and NEC. Recent case law suggests a growing divergence between the EU and US competition authorities over the application of antitrust rules in relation to IP rights.

China adopted competition law in September 1993. The conversion of the central planning economy to a socialist market economy necessitated the regulation of anticompetitive practices. In 1978, China started a process of economic reforms that is still ongoing. The result has been a decline in the importance of state-owned enterprises and the emergence of China's private sector. The Chinese government made a strategic choice by distinguishing between "non-essential" industries and industries that are considered to be important for the national security and economic development of China. In the first category (machinery, electronics, chemicals), the government wants to refrain from too much interference. In the second category (electricity, petroleum, banking, aviation), the government wants to keep an influential position by maintaining state-owned companies. In these sectors, the government is both the regulator and the owner of the industries, and therefore this context is particularly interesting for the intersection of standards, patents and competition policy. For legal comparison purposes, China is more relevant than Korea and Japan since, in the latter countries, the national competition law is heavily based upon the US and EU systems. India has not yet fully developed its antitrust laws and, at the regional level, there are major differences in the extent of the developments.

\footnotetext{
${ }^{3}$ Remarks by US Trade Representative M. Froman on the United States, the European Union and the Transatlantic Trade and Investment Partnership Office of the United States Trade Representative.
} 
The PRC antitrust system was mainly based on the principles of both EU competition law and US antitrust law. The current economic transformation from a centrallyplanned economy to a market economy highlights specific issues in the competition context: the role of state-owned enterprises, perceived excessive competition in the PRC's economy and the possibility that standards be used to protect the national industry in China. Given the key role of PRC in the present global economy, the tension between competition law and intellectual property rights has also led to new initiatives and cases in China. For foreign investors, the enforcement priorities of China's antitrust authorities can have a major impact on their access to the market in the PRC.

Significant topics at the intersection of IP and Antitrust are: horizontal/vertical Iicensing arrangements, cross-licensing, tying agreements and resale maintenance. My main interest is limited to the application of competition rules to patent pools, patent ambush and patent hold-up in relation to standardization. The main research question addresses the effect of competition rules on the strategic behaviour of companies within standardization in the telecommunications industry. The question is: how does a change in the antitrust policy influence the behaviour of companies and what are the legal rules that are instrumental in the achievement of the goal of the maximization of social welfare? In order to gain deeper insight into these effects, this research will address the following question:

What is the position of the instrument of a patent pool in the discussion on the strategic use of patents and competition law in the European Union, US and China?

In this context, the research methodology of law and economics has been chosen, since it includes an economic analysis of the behavioural effects of the law. This theory uses the presumption that the legal rule is known to all the companies and actors in the relevant field. The dynamic and rapidly changing environment of technology markets requires an investigation into the economic impact of the legal changes in the regulatory environment. The combination of patent law and competition law requires an interdisciplinary approach. A closer look at the economic effects of both legal systems will explain possible changes in behaviour that can be aligned with policy objectives. ${ }^{4}$ Some commentators believe that competition lawyers do not always fully understand the intellectual property law dynamics of modern technology markets. ${ }^{5}$ Competition law is sometimes very pragmatic and based upon economic norms. Patent law is often accused of leading to excessive situations, especially in relation to standards. The economic effects of these excesses are not directly addressed by patent law but more often corrected by competition law. ${ }^{6}$

\footnotetext{
${ }^{4}$ Cooter and Ulen, Law \& Economics page 7.

${ }^{5}$ Sir R. Jacobs wonders why technology markets are moving so fast if there are many "hold-up" problems in reality. Competition Authorities Support Grasshoppers: Competition Law as a treat to Innovation page 18.

${ }^{6} \mathrm{Wu}$ (Tim) Intellectual Property Experimentalism by Way of Competition Law page 38.
} 


\title{
OVERVIEW OF THE CHAPTERS:
}

\author{
The first chapter - Introduction
}

The first chapter provides the setting and an explanation of the research question. The research question is: What is the position of the instrument of a patent pool in the discussion on the strategic use of patents and competition law in the European Union, US and China? Related to this research question, four different themes can be identified:

- Differences in the standardization policy between the European Union, US and China

- The management of SEPs in the three different jurisdictions

- Patent pools as part of the solution for the problem of patent thickets

- Lessons to be learned from the experiences in the US, EU and China

For a proper understanding of the intersection of standardization, IP law and competition law, the basic terms will be explained. Within the overview of the different approaches to the existing tension between IP law and competition law, the instrument of a patent pool will be introduced and explained. The methodological approach of this project concludes the introduction.

The second chapter - Standards: definition, overview and relevance

The second chapter will deal with the relationship between standards, innovation and intellectual property rights. The globalization of innovation and the diffusion of new technology led to more standardization. The definition and the different categories of standards will be explained. In the second chapter, an overview of the different standardization systems in all three jurisdictions (the EU, the US and the PRC) will be presented. A comparison between the different approaches of the EU, US and China to standardization will be presented.

Key questions:

- What is the relevance and importance of standardization in the EU, US and China?

- What impact does the TTIP have on this discussion?

- What are the various forms of IP abuse in standardization?

- What are the possible solutions to prevent this abuse? 
The third chapter-Competition policy, patents and standard setting

An important strategic choice for antitrust authorities is to what extent they should influence the nature of competition in particular markets. The involvement of competition authorities can depend on the dynamics of different relevant markets. This chapter will concentrate on the different approaches and strategic choices that the relevant authorities (US, EU and China) made in relation to standard setting. By discussing the policies and, more importantly, the relevant case law, the influence of the antitrust authorities on the process of standard setting and SSOs will be investigated. The US perspective is summarized in the 2007 FTC Report Promoting Innovation and Competition, which was followed by two workshops (Standards and Patents in 2010 and NPEs in 2013). The evolving relationship between patent misuse and standardization is analyzed by reflecting on patent misuse from an IP and antitrust perspective. The economic analysis of the use of patents in standards first addresses the Princo and Orange Book cases. The tension between competition policy and standard setting is sometimes resolved by using the instruments of cross-licensing or a patent pool.

Key questions:

- What is the influence of the exclusivity of the patent right in the standardization discussion?

- What is the approach towards the governance of standardization in the US, EU and China?

- How are the problems of patent hold-up, patent ambush and royalty stacking addressed?

- What is the role of the doctrine of essentiality and legality of patents included in standards?

- How does the concept of patent misuse influence the discussion of the strategic use of patents in standards?

- Should technology markets be regulated by antitrust law or by IP regimes?

The fourth chapter - Innovation policy and standardization: the perspective of China, an emerging economy

The fourth chapter highlights the importance of standardization for the growing Chinese economy and the concept of the Chinese indigenous innovation policy. It also discusses the strategic character of patents in standards. The linkages between patents, standards and innovation will be examined as well as the different approaches by the EU, US and China. It is important for the reader to understand that the number of pa- 
tent registrations is steadily rising in China. The Chinese government subsidizes patent registrations and, in comparison to the US and EU, Chinese patent declarations are increasing in an unprecedented way. The sheer volume and quality of patent registrations creates new challenges for the IP law system. Recent court cases hint at a direction in which Chinese courts use their national competition law system to encourage the growth of national standards. It seems that, where the Chinese patent law legislation is lagging behind, competition law is applied to protect the interests of the Chinese industry. In its policy of national innovation champions, foreign companies must carefully weigh the use of their patents and royalty rate setting in China.

The application of Chinese antitrust laws to intellectual property laws, especially patents rights, will concentrate on the discussion of the general application of Article 55 of the PRC Anti-Monopoly law. Relevant issues are the qualification of IP rights related to monopolies and liability for monopoly conduct. Consequently, the PRC antimonopoly rules in relation to standard-related patents will be examined. This part will concentrate on the historic overview from the policies and cases of the past to the new approaches in the present context of the liberalized economy in the PRC. The adoption and application of standards in a practical context will provide more information on the current approach. This chapter will also form the basis of a more detailed discussion of recent cases involving SEPs in China in chapter 7.

Key questions:

- What is the concept of the Chinese indigenous innovation policy and its impact on standardization?

- What are the basic requirements for China to increase its level of participation in international standardization?

- What is the role of the high royalty payments obligations of China in the standardization process?

- What are the effects of the developing Chinese antitrust enforcement in relation to standardization?

\section{The fifth chapter - Patent Pools and competition law}

To illustrate the importance of standardization for the European Union, the draft EU regulation of standardization and, in particular, the importance of standardization in the ICT sector will be discussed. Economic research on the innovation benefits of patent pools provides various conclusions. In relation to the subject of patent pools, various elements will be reviewed, such as recent developments and the position of patent pools in relation to standardization, the contribution of patent pools to innovation processes and the inclusion of substitute patents in the pooling agreement. The current 
general legal environment for patent pools will be evaluated and some comments on the current state of the US system will be made. Recently, new business forms, such as Non-Practicing Entities (NPE), have gained political and academic attention. At present, the distinction between Patent Assertion Entities, NPEs and patent pools is difficult to make.

Key questions:

- What is the exact relationship between the patents in the pool?

- What sort of relationship do participating firms in the pool have to each other? Are they active on downstream markets or are they vertically integrated firms?

- Is the technology embedded in the pool exclusively available through the pooling agreement?

- What is the view of the FTC on patent pools and new business models to monetize patents?

- How do patent pools contribute to the innovative capacities of firms?

The sixth chapter - Patent pools in the US

In this chapter, the historical development of the legal regulation of patent pools will be examined, using the United States as an example. The DoJ has made some interesting changes in its attitude towards patent pools that provide interesting background information. In order to evaluate this development, the development of the IP Guidelines in the US, the system of Business Review Letters (BRL) and the relevant case law will be examined. From the case law, it can be concluded that Standard Essential Patents (SEP) are in the centre of the discussion on the legality of patent pools. Subsequently, other important features of the patent pool, such as tying clauses, overlapping ownership and the licensing terms of the patent pool will be addressed.

Key questions:

- How does the system of the BRLs function?

- What are the lessons to be learned from the current investigations?

The seventh chapter - The EU approach towards patent pools

In this chapter, the EU policy in relation to patent pools will be investigated. I will take the general framework of the present Technology Transfer Block Exemption Regulation as a starting point. An overview of the functioning of the DVB-pool highlights some of the most important practical challenges and solutions. The Orange Book standard case underlines both the important influence of German courts in this discussion and also 
the different interpretations expressed in relation to this case. Other case law includes a discussion of the preliminary ruling and the decision in the Huawei v. ZTE case.

Key questions:

- What is the stance of the EU Commission on patent pools in the new TTBER?

- How does the safe harbour model for patent pools inside the EU function?

- What are differences between the EU and the US in relation to SEPs?

- What are the lessons that China can learn from the present negotiations on the TTIP agreement?

\section{The eighth chapter - Patent pools inside the People's Republic of China}

The subject of technology licensing is of strategic value to the government of China. In the present conversion process, the Chinese government wants to change its position as a standards-taker to an economy that develops new standards, applicable on a global basis. Chinese manufacturing companies act as licensees for Western developed technology, leading to a heavy royalty burden which contributes substantially to the cost prices of high-tech products. Since the emergence of the Chinese "Indigenous Innovation Policy", 7 Western companies have been afraid of being discriminated against, and the lack of clarity and uniformity has made the risk management of technology licensing in China very challenging and unpredictable.

On the other hand, there is presently an environment in which the Chinese business community is complaining about insufficient possibilities to influence and to contribute to the development of globally accepted standards. The Chinese innovation policy uses different strategies resulting in considerable impacts for technology markets and consumer welfare. Recent cases underline the strategic value of patents in standards and for the political and legal attention of Chinese authorities. The position of the patent pool in the Chinese standardization environment is compared to the EU and the US.

Key questions:

- What is the influence of the Chinese innovation policy on standardization in China?

- What is the stance of the Chinese court on SEPs, FRAND and injunctions?

- What are the conclusions of the case law in China (related to patent pools)?

- How can China learn from the past experiences in the EU and the US?

\footnotetext{
${ }^{7}$ See also chapter 4 for a further introduction.
} 
The ninth chapter - Main findings and conclusions

The main elements that constitute a pro-competitive patent pool will be identified. The management of a patent pool requires a certain level of coordination; the project will describe how this can be done in an acceptable form. In this respect, attention will be paid to the internal management rules of a pool, the royalty rate setting and a dominant position of a patent pool. A comparison of the regulatory framework for patent pools in the US, EU and China will be made.

The research will look at the position of the Chinese indigenous innovation policy and how this impacts the antitrust policy.

The current strategic positioning of standardization in the TTIP and the future reaction of China are developments for the future. China wants to be included in global standard setting and will adopt an IP/competition policy that fits these needs. Conditions that must be met to increase the contribution of Chinese standards will be indentified.

The discussion of the inclusion of non-essential patents in the patent pool illustrates the lack of economic research in this area. The rise in the number of patents included in a patent pool and questions on the legality of the patents justify a closer monitoring of patent pools by the competition agencies.

The distinction between new business forms of monetizing IP (NPEs, PAEs) and patent pools is becoming more difficult to make. The IP landscape is rapidly changing and trying to adopt to new technology markets. Competition authorities are confronted with new challenging business forms. In my view, it is not the business form but the market behaviour of firms that leads to positive or negative competitive effects.

Key questions;

- What is the position of the concept of patent pools in the competition policy of the US, EU and China?

- How do the management rules of a patent pool influence the legality of the patent pool?

- How do standardization policies differ in the various countries and what is the impact upon competition?

- What are new IP business forms and how can they be distinguished from patent pools and how do they influence the standards and patents discussion?

- What are the different attitudes towards FRAND rate setting, SEPs and injunctions in the three jurisdictions?

The objective of chapter 1 is to make the reader aware of the global importance of standardization. Standards play a major role in innovation and innovation determines to 
a large extent the competitiveness of a trading bloc. The most important elements of the discussion on standards, patents and competition law will be explained. The present tension between IP law and competition law will be highlighted. Subsequently, various basic forms of remedies will be explained, illustrating the different approaches of competition law.

The systems of IP law and competition law both share the objectives of promoting innovation and consumer welfare. The patent system aims to prevent the imitation or copying of patented goods and the competition law system seeks to prevent the abuse of the patents rights by the patent-holder.

Within the patent system, patent licensing agreements can have competitionpromoting effects, since they facilitate the efficient transfer of technology. On the other hand, patent licensing agreements can also lead to an abuse of a dominant position or a geographical market division.

Standardization processes may increase competition, since the adopted standard is most often the best available technology that will be offered at a reasonable price and will be continually improved in the future. However, competition law concerns will be raised as soon as the standardization process is manipulated to enable patent holders to gain unfair competitive advantages. The technologies in standards are most often protected by patents. Patent owners take a specific interest in standardization. The patentee can demand higher royalties or introduce unreasonable terms after the adoption of the standard. The ownership of patents in a standard could lead to the blocking of rival companies and to the exclusion of competitors on downstream markets. The de facto monopoly of the patent owner could be used as leverage for other products that the patent owner produces or sells.

The importance of standards has risen dramatically in the telecommunications sector. Interoperability and interconnectivity and the exchange of data have all been facilitated by telecom standards. Standards enable new innovations to improve the functionality of mobile phones. International telecom standards increase consumer welfare. Greater efficiencies and lower consumer prices expanded the market for telecom products. This growing popularity also increased the competition on and for telecom markets. The "standard wars" in the telecom industry were fuelled by major financial interests. At the beginning of this research project, mobile phones had not yet gained the present popularity. Nowadays, smart phones provide for most of the profit margins of some of the best performing companies in the world. Competitiveness in the telecom sector is not driven by patents but by standardization. Standardization in the telecom sector leads to collective innovation.

The new to-be-developed $5 \mathrm{G}$ telecom standard is not just limited to smart phones but also to the Internet of Things. The current legislative environment for smart phones might be the basis for the evaluation of standards for driverless cars in the future.

The increased competition on the telecom market is closely monitored by competition authorities. By scrutinizing the telecom market, both the US and EU tried to set the 
right framework for principles that might even be applied outside the smart phone markets. The legal rules for technology transfer in general will be influenced by the decisions in the field of patents and standards. The attraction and dimension of the Chinese telecom consumer market was recognized at a slightly later moment. Given the nature of telecom standards, Chinese companies first looked at their domestic market and later at international markets. Defining and implementing a Chinese telecom standard on a global basis would give Chinese companies a competitive edge. At the moment, Chinese firms often face high royalty payments to foreign companies, necessitated by the inclusion of foreign patents in international standards.

The special position of patents regarding standardization is also noticed by competition authorities. Possible areas of interest from a competition law perspective are patent ambush, patent hold-up and royalty stacking. Patents can have pro-competitive effects or they may act as barriers to entry onto markets. Especially patents that are essential for the functioning of a standard are very valuable. These "essential patents" are an integral part of the discussion.

After the adoption of a standard, the non-disclosure of essential patents or the disclosure of licensing terms during the standardization process may directly conflict with antitrust laws.

To address these effects, many remedies have been developed. Concepts such as Fair and Reasonable Non-Discriminatory licensing terms (FRAND), cross-licensing or the instrument of a patent pool have been developed in this regard.

Some of these solutions may also directly affect competition. The management of a patent pool directly involves horizontal coordination between the participating members, which might negatively affect competition. Examples would be the possible restriction of a downstream price and outputs, price-fixing or exclusion of third parties from the relevant market. The objective of this project is to provide an explanation for the question of how the different regulatory regimes of the US, EU and China and the patent-policies of standard-setting organizations within the standardization context influence the strategic use of patents by multinational enterprises active in the field of telecommunications in different markets. Furthermore, the influence of self-regulation or the public regulation of patents in standards, more specifically of patent pools in different markets, will be studied and commented on. The major aim of this research is to provide new insights into the legality of the setting up, operation and management of patent pools. What are the different elements within the patent pool that can possibly infringe antitrust rules and how do the regulatory environment (antitrust authorities and SSOs) and the firms react to guarantee the proper functioning of a patent pool by providing pro-competitive effects?

To study this influence, this project will focus on the competition law environment of the US, the European Union and China in relation to the strategic use of patents and the implications for antitrust. 


\subsection{RESEARCH QUESTION}

The main research question addresses the effect of competition rules on the strategic behaviour of companies within standardization in the telecommunications industry. The question is: how does a change in the antitrust policy influence the behaviour of companies and what are the legal rules that are instrumental in the achievement of the goal of the maximization of social welfare? In this context, the research methodology of law and economics has been chosen, since it includes an economic analysis of the behavioural effects of the law. This theory uses the presumption that the legal rule is known to all companies and actors in the relevant field. The dynamic and rapidly changing environment of technology markets requires an investigation into the economic impact of the legal changes in the regulatory environment. In order to gain deeper insight into these effects, this research will address the following question:

What is the position of the instrument of a patent pool in the discussion on the strategic use of patents and competition law in the European Union, US and China?

This research question centres on different themes. The themes that can be identified are the following:

\section{a) Differences in standardization policy}

The differences in the governance of standardization reflect the diversity in innovation policy, technology development, competitive dynamics, and the history of the three jurisdictions. A comparison of the legal environment of standardization in the US and EU might provide valuable lessons for the regulation of standardization in China. The discussion of the standardization policies appears mainly in part of chapter 2 and chapter 4 .

\section{b) The management of SEPS}

The development of interoperability standards is hindered by the strategic management of patents in standards. The effectiveness of competition law (or patent law) to regulate standardization on technology markets will be compared in the US, the EU and China. At the centre of this discussion are standard essential patents (SEPs). Although the EU and the US are struggling to find a proper assessment base for SEPs, a consensus seems to be emerging, also as a background to the TTIP agreement. This leaves the question of how China is going to react to this possible emerging consensus on SEPs and standardization. The concept of SEPs is introduced in chapter 2. At the end of the chapters 6, 7 and eight the case-law will concentrate on the legal assessment of SEPs.

\section{c) Patent pools as a solution for the problem of patent thickets}

Problems like patent thickets, patent ambush and royalty stacking can be addressed in different ways. Possible remedies are cross-licensing, patent pools or a revision of pa- 
tent law. This study will concentrate on the instrument of patent pools as a possible solution. New business forms, such as patent assertion entities (PAEs) and NonPracticing Entities (NPEs), reflect changes on the technology market. These business forms can be difficult to distinguish from patent pools and this study will discuss the consequences for the application of antitrust laws in this field. The concept of the instrument of a patent pool is discussed in general terms in chapter 5 . Chapter 6 will look at the legal position of patent pools in the US. Chapter 7 discusses the EU stance on patent pools. Finally, chapter 8 addresses patent pools as a possible solution for specific Chinese problems.

\section{d) Lessons to be learned from the experiences in the US, EU and China.}

Although the US and the EU are struggling with the legal assessment of SEPs, a consensus seems to be emerging. Recent developments like the TTIP and the new EU TTBER are the basis of a common understanding on the legal aspects of standardization. Patent pools can be a solution for the Chinese problems in the field of the management of SEPs. China can draw upon the US and European experiences and take valuable lessons that can be implemented in Chinese competition law for technology transfer. The main findings and conclusions can be found in chapter 9.

At the end of every chapter, the main conclusions will be summarized according to the above-mentioned structure and sub-headings.

\subsection{METHODOLOGY}

The law and economics approach was chosen because of the characteristics of the research question. I will use the example of the concept of a monopoly to explain the methodological choice for law and economics. Patents convey a temporary monopoly upon the patent holders; a valuable invention can lead to a monopoly if there are no substitute goods. As a result, the patent holder can receive monopoly rents. The telecommunications industry has characteristics of a natural monopoly. With a natural monopoly, the increase in production will lead to lower production costs. The theory of the natural monopoly states that the cost of production is the lowest when one company serves the market. A natural monopoly is an economic interpretation of the concept of monopoly. The difficulty of a natural monopoly is that it would be inappropriate to try to achieve a level of competition that destroys the benefits of the natural monopoly. A single firm is, in this situation, the cheapest way of producing goods for the market. ${ }^{8}$ A natural monopoly is different from a statutory monopoly, which is based on the law. The definition of the concept of monopoly differs in the economic and legal sense. A monopoly is often defined in relation to market power, which is a very important ele-

\footnotetext{
${ }^{8}$ For more background see Wish, in Competition Law $6{ }^{\text {th }}$ edition page 10.
} 
ment in the economics of competition law. Market power is often explained as the difference between the actual prices of a firm and the marginal costs of production. In the economic meaning, a monopoly often refers to a market situation that enables the firm to engage in certain types of behaviour. In the context of standards and patents, it is of the essence to distinguish the monopoly that is the result from the statutory patent right from the monopoly that is the result of the market power (i.e. market share) of the firm. Standard essential patents are often developed by successful firms that already have substantial market power. Antitrust enforcers are not against monopolies, in principle, but they are more interested in the actual effects that the monopoly has on the competitive processes on this market. ${ }^{9}$

An IP monopoly refers to the fact that a patent gives the owner the absolute monopoly over the use, sale and production of an invention, although it is limited to a period of 20 years. The ownership of a patent does not automatically lead to a monopoly but possibly enables monopolistic power, depending on the availability of alternatives. The possibility of monopolistic behaviour can thus be based upon two different elements: the patent right itself or the collaboration between patent owners who already posses considerable market power, independently from the existence of the patent right. $^{10}$

The law and economics approach has the advantage of including the arguments and empirical research of economists, which is very important in antitrust law. In general, but particularly in the case of China, one also has to note that political dimensions may influence the adoption of economic theories within antitrust. Changes in the enforcement policy in competition law very often coincide with new economic paradigms that support the new policy. ${ }^{11}$ Economic policies and antitrust policy do influence each other significantly. ${ }^{12}$ This, in my opinion, justifies a law and economics approach.

Alternative approaches would also have been possible. The discussion of the strategic use of patents in standard setting is also closely linked to the North-South dialogue. Developed economies (e.g. EU, US) are protecting their markets and seek global dominance by "monopolizing" the development of new standards. Emerging economies (e.g. China) seek a new role and understand the relevance of international standards for their competitiveness. From a development studies perspective, a methodological approach that centred on the link between innovation and industrial policy could also have been very interesting. Given the major influence of the economic analysis in the discussion on standards, patents and competition law, I resorted to the law and economics approach. Personally, I found, by investigating the legislative documents and

\footnotetext{
${ }^{9}$ For more background see Motta, in Competition Policy page 40.

${ }^{10}$ See also Colston and Galloway, in Modern Intellectual Property law page 33-34.

${ }^{11}$ See also Monti, in EC Competition Law page 54.

12 This tradition of the influence of economic analysis was historically more prevalent in the USA than in the EU or China.
} 
consequently the case law, that this approach was best suited to come up with some practical considerations.

Standardization strengthens the effect of the natural monopoly, since users value the standard higher if it is used by more consumers. Finally, network effects may lead to "the winner takes it all" scenarios. The development of standards in the telecommunications industry poses new challenges for competition policy. The economic evaluation of the effects on the reaction of competition policy to standards and patents is extremely important.

The research methodology used in this thesis mainly consists of an analysis of the provisions of the national patent laws of the United States and China in relation to technology transfer in general and patent pools in particular. For the European Union, I decided to concentrate on the Community laws related to technology transfer, especially the TTBER and its Guidelines. For an overall understanding, I studied the general framework of the competition laws of the United States, the European Union and China.

Especially in intellectual property law and competition law, it is crucial to understand and respect the national challenges at this intersection. This understanding may enhance a deeper dialogue between the developed and developing countries. A comparison of the two leading antitrust systems (US and EU) with China reveals possible alternatives and different solutions to address the problems. ${ }^{13}$

The US antitrust framework was studied by first looking at the relevant US antitrust laws and the enforcement policies of the Federal Trade Commission (FTC) and the Department of Justice (DoJ). Both have published two reports on the overlap of competition policy and intellectual property rights and, in 2007, the Antitrust Modernization Commission also published a relevant report. An analysis of the relevant case law includes the decisions in Microsoft, Intel and Rambus, as a starting point, and continues with decisions such as the Princo and the Orange Book cases. Recent case law has focused on elements such as patent misuse and the inclusion of non-essential patents and injunctions and SEPs. In the United States, the International Trade Commission has been active in this field and the relevant decisions have been analyzed. The US Chamber of Commerce in China and the American Bar Association published reports that were relevant for this study. The Federal Trade Commission organized workshops first on standards and patents, followed by a session on Non-Practising Entities. Both were accessible by live transmissions on the internet. The Business Review Letters provided deeper economic analysis (e.g. on the essentiality test). Finally, speeches by senior FTC/DoJ officials explained the current views and enforcement policies.

The EU perspective was studied by looking at the relevant regulatory framework, the relevant case-law and interviews with policy makers within the EU Commission. The Commission published a Technology Transfer Block Exemption Regulation (TTBER) in 2004 and later adopted guidelines on the application of article 81 of the EC Treaty to

\footnotetext{
${ }^{13}$ Dinwoodie, in Methods and Perspectives in Intellectual Property page 27.
} 
technology transfer agreements. In 2002, the Commission published a comfort letter on the standard of $3 \mathrm{G}$ and the relevant case law includes European Commission v. Rambus and Nokia, TI, Broadcom, Ericsson, Nec and Panasonic v. Qualcomm. The 2014 TTBER was studied along with recent investigations involving Samsung, Google/Motorola and the preliminary ruling and court decision in the Huawei v. ZTE case. Also the 2010 Horizontal Guidelines contained elements that were relevant for the discussion.

Economic research was studied to understand the relationship between the different types of patents in the pool.

For the European perspective, I had the opportunity to participate in a closed meeting of the DVB-pool during which licensing arrangements (including royalty rates) were discussed. Information has also been gathered by speaking with lawyers who represented companies in SEP/injunction cases before the European Court of Justice. Conversations with some of the EU Commission officials that drafted the new TTBER provided valuable background to the new regulation.

Academics and industry representatives involved in standard-setting projects highlighted some aspects that are normally not obvious to lawyers. Regarding the SSOs, I had the opportunity to discuss the ETSI IPR-policy with two of their former managers. Discussions with the authors of the "Regibeau-report" made some of the reasoning of the report more accessible.

The Chinese Anti-Monopoly Law in relation to possible abuse of IP rights, especially patents, was examined by studying the applicable laws and a discussion of the relevant case law. As a starting point, I looked at an International Trade Commission report (US) to understand the perspective of foreign investors in relation to IPRs in China. The Chinese indigenous innovation policy and its effect on standards were studied. The national innovation policy also explains the rise in patent registrations and the slow development of Chinese technology standards. A comparison of the EU and Chinese standardization laws identified similarities that can be relevant for the application of competition law in both jurisdictions.

The general application of article 55 of the PRC Anti-Monopoly Law was studied in relation to standard-related patents. The PRC adopted a Standardization Law in December 1988 and the Chinese Patent Law came into force in 1985. Both have been used as a starting point and the following laws have been studied. The general case law on IP and competition law in China and the specific cases on patent pools showed a growing interest in the subject of patent pools as a solution to the problem of standards, patents and hold-up or patent ambush. At the moment, there are many draft regulations (on patent pools, on the application of the AML in relation to intellectual property rights etc.) that are regularly published. The comments of the US (e.g. the American Bar Association) and the European Union and of foreign firms are evaluated by the Chinese authorities and contribute to the development of Chinese standards.

Researching the topic of standards, patents and competition law creates new challenges in respect of the Chinese context. The US and European setting was analyzed by 
examining the relevant laws and policy documents on technology transfer, standard setting and antitrust. Case law in both jurisdictions often further clarified the basic legal principles covering patents, standards and competition law. More insights were obtained from the conclusions of academic articles and interviews with regulators, practitioners and academics. The Chinese setting did pose methodological challenges, since the closed character of the Chinese legal system and the possible political sensitivities of the discussion prevented some of the scholars and experts from speaking openly and/or from being cited. Many experts wished not to be quoted and gave general statements. At the start of my research, standardization in the telecommunications industry and patents in relation to competition law was regarded as an interesting subject, but nothing out of the ordinary. Three years later, multinational companies like Apple, Samsung, Google and Microsoft were fighting fierce legal standards-battles and asking for injunctions on the infringement of "standard-essential patents." The monetary aspects of this discussion have dramatically increased with the rise in the popularity of smart phones. As a consequence, companies that were willing to discuss some of their experiences in 2010 are, at the moment, very reluctant to cooperate with academic researchers. Sometimes I had to resort to "off-the -record" statements and nonattributable comments and observations.

It has to be noted that the legal developments in this area are rapidly-evolving and often uncertain, especially in the Chinese context. This research is intended to be current until July, 2015, but there are ongoing developments in the intersection between patents, antitrust laws and standards that were obviously not covered after this date.

\section{Basic terms}

\section{Patent ambush}

The patent owner who participates in the process of standard setting may conceal existing patents or pending applications which are essential to the implementation of the standard under discussion. The aim of the patent owner is to enforce the patent rights after the standard has been adopted and to license the patent on unreasonable terms and conditions. The patent owner creates a trap by not disclosing the patents that are relevant for the standard. The user of the standard is often not aware of the existence of the patents. Consequently the patent owner seeks excessive high royalty fees or an injunction. Alternatively, the patent-owner can make a license promise that is changed after the user is committed to the standard. Patent ambush is often a strategic behaviour, the standard is created without it being known that the essential patent is part thereof. If the SSO knew of the existence of the essential patent in the standard, the patent owner would have to agree to license on fair, reasonable and non-discriminatory terms FRAND. 
The classic case in the field of patent ambush is Rambus Inc. Rambus did not disclose essential patents for the DRAM chip that were part of the JEDEC standard. The Dynamic Random Access Memory patent enabled the interoperability of computer components. Consequently, Rambus required exceptionally high royalty fees. The EU Commission concluded that Rambus had abused its dominant position, since it was able to charge high royalty fees based on the intentional deception of the DRAM-patent. Rambus decided to settle the case by not charging royalty fees for the DRAM technology in the original JEDEC standard. For the use of the DRAM chip in other standards, Rambus decided to cap its royalty fees to a minimum.

\section{Patent hold-up}

When the patent owner waits to reveal and enforce his intellectual property rights until other companies have sunk investments into the standard, this creates a patent holdup. For licensees, it becomes impossible to switch to an alternative technology standard and the licensor can demand higher royalty fees for his patent. Patent hold-out occurs as soon as the patent owner delays the negotiations to become the last licensor to obtain maximum leverage. ${ }^{14}$

"After the standard is set, the owner of a patent essential to that standard identifies a patent, or attempts to impose licensing terms, that SSOs members could not reasonably have anticipated. [Moreover,] it is not a commercially reasonable option to abandon the standard and attempt to create an alternative, due to the costs of the standard setting process itself or the costs of developing products incorporating the alternative standard." (G.F.Masoudi, DoJ, 2007). ${ }^{15}$

The "hold-up" problem could also take the form of a standard affected by a number of patents owned by different patent-owners. Due to the number of patentees, the total royalty claim might exceed reasonable terms and consequently hinder the implementation of the standard.

The growing proliferation of IP forms has led to new forms of IP-like business patents, software patents, data-protection rights, and business forms such as NonPractising Entities which, according to some IP experts, might lead to too much protection in relation to the costs invested in $R \& D$.

In principle, it is assumed that all registered patents are valid, even though weak patents can be declared invalid after a costly trial. Therefore patent owners may use injunctions to demand maximum royalties for the patent. The threat of the injunction enables the patent owner to charge the extra costs that are related to the lock-in effect into his technology. The costs of switching to another technology are the added maximum royalties that exceed the incremental or economic value of the patent. This means

\footnotetext{
${ }^{14}$ Balto, Barriers to Competition on the Innovation Superhighway: How the Lack of Antitrust Scrutiny of Patent Pools Deters Competition page 6.

${ }^{15}$ Masoudi, DoJ, Antitrust Enforcement and Standard Setting: The VITA and IEEE letters and the "IP2" report.
} 
that the basis of the demanded royalty fee is the total sum of the costs of switching to another technology. These switching costs are relevant since the user is locked into the standard or cannot choose alternative technical solutions. Hence, the user would be prepared to pay royalty fees that exceed the economic value of the patent. The extra royalty demands will lead to higher consumer prices, undermine competition on the relevant market and deter innovation.

\section{Royalty stacking}

In a case where a single product is covered by patents with multiple owners, the manufacturer is confronted with a cumulative royalty burden. The situation in which the patents may be owned by an individual firm could often lead to a lower royalty rate. Royalty stacking is also sometimes referred to as double marginalization. The problem is that individual patent owners who engage in a patent hold-up seek to maximize their profits but do not consider the cumulative burden of all royalty costs. If the total sum of royalties exceeds monopoly rent, this leads to inefficiencies and reduces the profits of all firms. In a recent Working Paper, some scholars showed that the royalty fees of a mobile phone are between $\$ 121-\$ 124$ and the components price is almost equal to $\$ 120-\$ 140 .{ }^{16}$ The problem of royalty stack is also often referred to as the "Cournotcomplements problem". From the later discussion of the case law in the United States, it becomes evident that not all judges agree on this principle. Some judges like to see evidence of the royalty stacking in the case at hand, while others do not require this. The problem of royalty stacking is increased by the emergence of Non-Practicing Entities (NPEs). The NPEs will be discussed later in detail in chapter 3 section 3.14.

The business model of the NPE consists of always seeking monopoly rents. Since NPEs do not produce on the market, cross-licensing is not an option. The market behaviour of NPEs may lead to a duplication of the monopoly rents, because of the Cournot/complements problem.

A more elaborated discussion of royalty stacking can be found in chapter 3 , section 3.12 .

\section{Patent thicket}

The concept of a patent thicket was first introduced by Carl Shapiro in 2001 and refers to the situation in which the innovator has to conclude various licensing deals with multiple patent owners. Shapiro used the following definition: the "dense web of overlapping intellectual property rights that a company must hack its way through in order to actually commercialize new technology". ${ }^{17}$

\footnotetext{
${ }^{16}$ Amstrong, Mueller and Syrett, The Smartphone Royalty Stack: Surveying Royalty Demands for the Components Within Modern Smartphones.

${ }^{17}$ Shapiro, "Navigating the Patent Thicket, Cross Licenses, Patent Pools and Standard Setting," in Jaffe et al., Innovation Policy and the Economy, Cambridge: MIT Press (2001), page119-150.
} 
Smart phones are covered by hundreds of different patents, owned by hundreds of companies. It seems that patent thickets are often linked to major new technological innovations. The development of new successful products requires a market equilibrium, in which patent thickets are unavoidable. As long as the patents in the new innovation are valid and of significant value, patent thickets will be difficult to avoid. One of the classical instruments to avoid a patent thicket is the patent pool. A patent pool is an agreement between two or more patent owners to enter into a license agreement with each other or with other parties.

\section{Patent pool}

In a patent pool, patent owners have aggregated their patent rights. The patent pool will license the assembled patents to members and non-members of the pooling agreement. The patent pool is a business model according to which patents that are essential for a product or a standard are administered jointly. Companies participating in the patent pool are allocated licensing fees that are collected by the pool. There are different models of the allocation of the licensing fees, but they are often linked to the value of the patent within the standard or product. The patent pool creates certainty with regard to the cost of the included technology. If all the patents in the patent pool are essential and the licensing fees are known, the problem of royalty stacking is solved.

Standards often consist of a number of patents owned by a number of different patent owners and therefore problems will occur regarding the coordination of the different patents. The total sum of transaction costs of the licensing negotiations with the different patent holders and the accumulated royalties might increase the costs for the implementation of the standard. The total sum of transaction costs can be reduced by the formation of a patent pool. The patent pool enables patent owners to license their patents in a fair, reasonable and non-discriminatory way. For the patentees, there is the advantage of using the pooled patents in a standardized license. A crucial element of patent pools in relation to competition law is the licensing terms and conditions (e.g. royalty rates, terms of the contract, etc.).

In order to ensure fair and equal treatment of the patent holders, patent pools often include a most-favourable royalty clause so that licensees are charged the same level of royalties. Since patent holders participate on a voluntary basis, disagreements on the licensing terms and conditions often lead to disputes or the formation of a new patent pool. A main characteristic of patent pools is that they require coordination and agreements between possible competitors to manage the patent rights in the standard. This type of interaction between companies which normally compete with each other automatically raises the concern and interest of competition authorities. The legality and effectiveness of patent pools depends to larger extent on the patents that are included. To analyze this, different categories of patents can be distinguished. 


\section{(Standard) Essential patents}

The definition of standard essential patents has led to intense debate. Essentiality can be linked to two different aspects of the patent. On the one hand, the patent may be absolutely necessary in technical terms and it is impossible to "invent around" the patent. A second interpretation is that the patent is essential since there are no economically feasible alternatives. The evaluation of the essentiality of the patent is the task of an independent expert. ${ }^{18}$ In the discussion on SEPs, the determination of the relevant FRAND licensing terms plays a major role.

\section{Complementary patents}

Patent pools and standards may contain several patents that are not in direct competition which each other but are necessary to cover an innovative product. Complementary patents can have pro-competitive effects, since they lower the total royalty rate and thus give direct benefits to consumers. ${ }^{19}$

\section{Substitutable patents}

Substitutable patents compete with each other directly for the preference of the licensee. The inclusion of substitutable patents may raise the total royalty fee and, hence, consumer prices, possibly foreclosing technology alternatives. Substitutable patents can be used to make it more difficult to "invent around" a specific technological solution. The discussion on the various classifications of patents will be explained in chapter 5 , section 4.

\section{Blocking patents}

Blocking patents prevent the use of another patent and often block the development of new technology alternatives. Improvements may effectively be stopped since the new innovation is based upon the blocking patent and needs a license to use it.

\section{FRAND (Fair Reasonable And Non-Discriminatory terms)}

The standard-setting organizations developed the concept of FRAND, Fair Reasonable and Non-Discriminatory terms, as part of their intellectual property rights (IPR) policies. The above-mentioned patent ambush, patent hold-up and royalty stacking necessitated the SSO to develop the FRAND-concept. Companies aiming to contribute to an SSO standard must commit to applying FRAND-conditions. The FRAND licensing terms protect technology implementers but also guarantee a fair reward for patent owners. The definition of FRAND commitments has led to a large global debate. Especially the terms

\footnotetext{
${ }^{18}$ The independence of the expert is sometimes difficult to guarantee. Technological changes may change the "essentiality" of a patent after the standard is established.

${ }^{19}$ Ibid note 3.
} 
fair and reasonable have been the subject of many court cases. The FRAND-licensing terms are at the centre of the legal debate on Standard Essential Patents (SEP).

\section{Background}

Most of the products currently traded were developed in compliance with specific (technical) standards. Standardization of products improves the quality of products and services and creates easier access to new markets. From a government's perspective, standardization supports public safety and health policy, trade policy and industry policy. For consumers, the increased level of interoperability of products could lead to better functionality of products, more competition and, consequently, to more choice and lower prices. Standardization can give a competitive advantage to companies, since standards lower the costs relating to research and development and the manufacturing of products, thus becoming a strategic business element. To achieve the abovementioned benefits, standards should be easily accessible to those companies who want to implement the standards. Practically speaking, there are two different types of standards, de facto standards and de jure standards. A de facto standard is a standard created by market forces, through wide implementation by companies and general acceptance by consumers, without its regulation of or adoption by a formal standardsetting body. De jure standards are developed by formal standard-setting organizations (SSOs). The standard-setting organization facilitates the harmonization of standards and deals with conformity assessments. SSOs can be organized in an international, regional or national context.

Occasionally, companies will cooperate in a consortium to establish technical standards in a relevant field or industry. "Open standards" are particularly interesting for companies. "Open standards" are standards that are available to the general public and are developed or approved and maintained via a collaborative process. They facilitate interoperability and data exchange among different products or services and are intended for widespread adoption.

Technology has become more and more important in the global economy. Standardization needs to incorporate the best available technology. This innovative technology is often protected by patents. Companies need to recoup their R\&D investments by monetizing their intellectual property, in this case patents. In the last decade, firms started to use their patents in standardization is a strategic manner. Patents represent a substantial value of the standard. The standard itself can become very valuable in case of world-wide acceptance. Implementers and users of the standard can experience a lockin effect into a standardized technology. The critical mass of followers and the R\&D investments already made result in high switching costs, which make alternative technologies impossible in practice. The patents in standards can be classified in different categories. Most important are the standard essential patents (SEPS). Without these 
SEPs the standard cannot function. The classification as essential is linked to the absence of technological or economically viable alternatives to the SEP.

The strategic use of the SEP may take the form of a patent ambush, in which the patent holder does not disclose the fact that he owns an SEP. In the case of patent holdup, the patent holder waits to disclose the patent to seek monopoly rents. Other problems are royalty stacking, which is the cumulative burden of all high royalty terms and patent thickets. Patent thickets describe the fact that, for example, a smart phone standard consists of hundreds of different SEPs.

Since 2010, the smart phone market has witnessed many disputes concerning patents in standards. For example, Google's Android system is under constant attack. Firms like Apple, Oracle, Microsoft, Gemalto, British Telecom, Nokia, and Fuji Film have initiated patent infringement cases against Google or its subsidiary Motorola Mobility. ${ }^{20}$ Likewise, the smart phone wars between Apple and Samsung gained some notoriety.

The tension between the necessity to guarantee the wide and easily facilitated dissemination of standardized products and the desire of companies to get financial incentives for their innovation and research and development efforts can be solved in different manners. The SSOs have introduced self-regulatory mechanisms in their patent policies that must ensure transparency and accessibility to patented technologies. Patent owners are required to comply with early disclosure of their essential patents and patent applications.

Another alternative is cross-licensing between different firms. Yet another different approach is the formation of a patent pool, the major aim of which is to address the problem of high cumulative royalties in the implementation of standards. A patent pool is presumed to reduce transaction costs and facilitates cross-licensing agreements to prevent patent hold-ups.

The possible abuse of the patents in standards is very often linked to the licensing policy of the patent holder. The FRAND-commitments are a consistent part of the evaluation of the licensing terms. FRAND means Fair, Reasonable and Non-Discriminatory licensing conditions. The definition and application of the FRAND principle has led to heavy debate. The FRAND commitments are also very closely linked to the legality of injunctive relief. Injunctions are often used by the patent holder against licensees who infringe patent rights. One of the competition risks is that injunctions are used as leverage against willing licensees. Injunctions can also act as a barrier to entry for a specific market.

The companies active on the global technology market are challenged by the different approaches of the three jurisdictions. The case of China requires even more attention, since it also concerns the transition process of a socialist free market economy to a complete free market economy.

\footnotetext{
${ }^{20}$ Mueller, Companies worth $\$ 1$ trillion are suing others over Android's alleged patent infringement.
} 
Patent pools can be a solution for the problems of the strategic use of patents, but they must be carefully analyzed. Patent pools can have pro-competitive effects, such as the reduction of transaction costs and the enhancing of efficiencies. Negative effects of patent pools could be price-fixing, the foreclosure of market or aggregate output restrictions for competitors.

The strategic use of patents is at the intersection of IP law and competition law. To discuss this problem in three different jurisdictions, China, the European Union and the United States, is a complicated challenge. There are three major themes: standardization, patent law and competition law in three different trading blocs. This amounts to at least six different themes. To complicate things further, competition policy is enforced by different institutions in the US (Department of Justice, Federal Trade Commission and the International Trade Commission). In China, three competition law agencies exist: the Ministry of Commerce in China (MOFCOM), the National Development and Reform Commission (NDRC) and the State Administration for Industry and Commerce (SAIC). In the European Union, the main enforcer of competition law is the European Commission.

The telecommunications sector was chosen for this examination, since it is one the fastest growing industries. Smart phone standards are applied in all the three jurisdictions. The importance and the size of the consumer markets in the three jurisdictions require competition authorities to monitor these telecom markets closely. Finally, patent pools are also prominently active in the telecommunications market.

\section{Valorization}

The valorization of my research will be evidenced in the following ways. I plan to start a blog in the field of my research that deals exclusively with the position of patent pools in China, the European Union and the United States. Although general blogs on essential patents exist, no specific attention is paid to patent pools. Moreover a direct comparison of the functioning of patent pools in China, the European Union and the United States does not exist. The blog will give information on court cases, policy initiatives and the general background of technology transfer by means of patent pools. I have already established contacts with patent pools inside the European Union to support this concept with necessary information and contacts.

The second part of the valorization lies in the fact that I will be the chairman of the Working Committee that has to develop and implement an Intellectual Property policy for the Zuyd Polytechnic in Maastricht. Zuyd Polytechnic has 14,000 students and is conducting applied research through research centres and centres of expertise. At present, Zuyd Polytechnic does not have any regulation on the handling or the management of intellectual property. In order to facilitate the valorization of the applied research in Zuyd, a proper IP-regulation must be implemented. 
Finally, I participate in a follow-up project that examines the intersection of IP law and competition law. The purpose of the research project is to analyze approaches adopted to injunctive relief in patent law in various leading jurisdictions around the world. The jurisdictions are the following: Germany, the UK, the Netherlands, China, Poland, Japan, South Korea, and the United States. The project was recently approved and funding has been provided by the Polish government. The participating researchers will write country reports that will be presented during two seminars and a conference in June 2016. At the end of the project, a book will be published with the results and findings.

\subsection{APPROACH}

The intersection of patent and competition law is an interesting but complicated subject. The inclusion of standardization policies of governments and standard-setting organizations does not simplify the discussion. The application of this research in three different jurisdictions (European Union, United States and China) has proven to be challenging. The following approach was chosen:

Chapter 1 sets the research question and the background to the discussion. An early introduction to the basic terms facilitates the understanding of the complex situation. Importantly, chapter 1 explains the four central themes of the main research question.

Chapter 2 discusses the link between innovation and global standardization. Standards facilitate innovation and competitiveness. In order to understand the implementation and diffusion of innovation, the reader must understand the influence of network externalities on standardization. The network effects can have serious implications for achieving the winning standard and thus competition law. The consequences of these network effects will be further examined in chapter 3. An overview of the definition and the different categories of standards helps to gain an understanding of the discussion between licensed and open innovation technology transfer. Again, this is a basic requirement for the discussion of the competition law implications in chapter 3 . For the three jurisdictions, chapter 2 explains the "national standardization" policies. The TTIP must be seen as a possible blocking instrument against future Chinese exports. US and European policy makers try to influence the evolving Chinese system of standard setting. The chapter concludes with a comparison of the different standardization systems, which later helps to provide an understanding of the influence of the innovation and standardization policies in competition law enforcement.

Chapter 3 explains the intersection between patents, standards and competition law. Whereas chapter 2 showed the relevance of standardization for innovation and competitiveness, this does not explain the attention of policy makers. The chapter is divided into two parts. In part A, I discuss the interest of competition authorities in patents, which represents a traditional tension between the right to exclude and the 
protection of social welfare. This is followed by a general discussion of the complexity of a legal analysis of standardization. Standardization may lead to competitive conduct by companies. Chapter 3 shows that an economic analysis is necessary to understand the effects of the strategic use of patents in standards. Within this economic analysis, efficiency plays a major role. Part A explains some of the basic general concepts that are needed to initiate the specific discussion on the strategic use of patents in part B.

Part B of chapter 3 gives an overview of the different views of competition agencies in the three jurisdictions on the strategic use of patents in standardization. This part demonstrates the link between national innovation policies, national standardization systems and ultimately the enforcement agenda of the competition agencies. A deeper look into the basic concepts extends the discussion to injunctive relief and new business forms of monetizing intellectual property. Finally, patent misuse is discussed with an examination of the Princo decisions in the US. The outcome of the Princo decisions on bundling various types of patents is needed to understand the discussion on patent pools in chapter 5 . The central role of the FRAND commitments already becomes apparent in chapter 3.

Chapter 4 deals exclusively with China. A separate chapter on China is justified because of the indigenous innovation policy of China. This policy differs distinctively from the EU and US innovation policies and has a serious impact on the discussion. Later chapter 8 demonstrates that this indigenous innovation policy also has a strong influence on the application of the Anti-Monopoly Law and patent pools.

In order to understand the practical implications of the setting, chapter 4 uses the example of the WAPI and TD-SCDMA standards to highlight most of the aspects discussed in chapters 2 and 3. Both examples also clarify the special position of developing countries in the discussion on standards and patents. This chapter also addresses patent pools for the solution of some of the problems regarding standardization and competition law.

Chapter 5 gives an overview of the general characteristics of patent pools. The reader must be able to understand the pro-competitive and negative effects of patent pools on competition. By using four central questions, I discuss the competitive relationship of the different types of patents, the participation rules and more importantly the royaltysharing agreements. Although chapter 5 has a general character, some of the basic elements were originally created in US law. In the United States, patent pools gained greater popularity earlier. Key elements are FRAND, the essentiality of patents and the licensing conditions of patents. The conclusion of chapter 5 must be that the instrument of a patent pool can solve some of the standards/IP problems, but a very careful analysis is necessary. In order to a have a detailed analysis, the remaining chapters address the specific evaluation of patent pools per jurisdiction.

Chapter 6 gives a historical overview of the legal analysis of patent pools in the US. By elaborating on the Business Review Letters of the DoJ and the FTC, a general understanding is achieved. The case law of the United States, where attention is paid to re- 
cent cases, concludes the chapter. This structure is also followed in the next chapters on the EU and China. First there is adiscussion of the relevant legal framework, which is followed by the most recent case law. The case law is predominantly centred on the definition and application of FRAND principles, often in relation to injunctive relief.

Chapter 7 uses the EU Guidelines on Horizontal Cooperation as a starting point. Next there is a discussion of the 2004 Technology Transfer Block Exemption (TTBER) followed by a discussion of the TTBER adopted in 2004. A case study of the DVB pool will point at the most important elements of the discussion in the EU. I was able to attend the royalty discussions of this patent pool, which provided some interesting insights. Again recent case law concentrates mainly on FRAND and injunctions. In this chapter, is becomes apparent that both the European standardization system and the EU laws on Technology Transfer are more appropriate as a reference for China than for the US in practice.

Chapter 8 concentrates on the Chinese setting. This chapter is complicated by the existence and competition between different Chinese ministries, competition agencies and national standardization bodies. The Anti-Monopoly Law takes a central position in this discussion. The discussion of art.55 AML, together with Guidelines and interpretations, sets the scene. But the MIIT template and the National Intellectual Property Strategy all have different views on this subject. The discussion of the case law is most important. The case law is first discussed in relation to the general intersection of IP and competition law. Later I look at specific and recent cases on patent pools in China.

Chapter 9 draws conclusions on the basis of the four different parts of the subquestions of the main research question. 


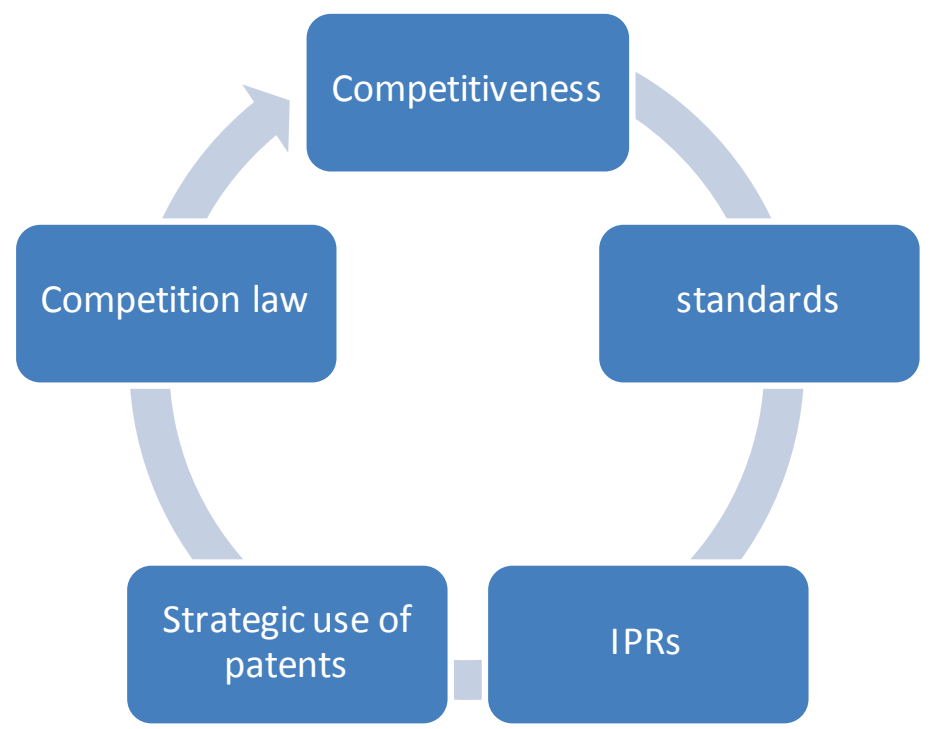





\section{CHAPTER 2}

Standards:

Definition, overview and relevance 



\subsection{INNOVATION AND GLOBAL STANDARDIZATION}

The globalization of international trade has led to the internationalization of production and consequently to the transfer of technology by multinational operating enterprises. Already, in 1958, Dunning noted the influence that US multinational enterprises (MNEs) had upon technological developments and the rise of production in the UK. Later, theories on the product cycle model (Vernon 1966) linked the growth of US Foreign Direct Investment (FDI) to new industry innovations in Europe. ${ }^{21}$ A second effect of MNEs has been the globalization of the innovation process, initiated by entering new markets through instruments like FDI but also by exports, outsourcing of production, jointventures, licensing, cross-patenting and cooperation in the field of technological and scientific research.

The globalization of the innovation process can take different forms. A first starting point is often the international exploitation of innovative products and/ or services that were created in the 'home state'. The increased level of international trade flows and of cross-border patent applications indicate the international character of the transfer of knowledge and technology. ${ }^{22}$ According to OECD statistics Medium-low tech manufacturing accounted for $20 \%$ of the total manufacturing trade in 2007 and High-tech manufacturing accounted for $39 \% .^{23}$

This chapter will outline the basic elements of the discussion on standards and patents, starting with the globalization of innovation, before moving on to the importance of standards and, moreover, of network externalities. Standards can be classified in different categories and developments, such as open source standards, have added new dimensions to the discussion. At the intersection of patents, standards and competition law, the key issues are patent hold-up, patent ambush and consequently the strategic use of patents in standards. Among the different solutions for the aforementioned problems, patent pools occupy an interesting position in the discussion.

The globalization of innovation is also reflected by the growing number of crossborder patents resulting from the activities of MNEs. Companies have internationalized their innovative activities for different reasons. Firstly, location conditions outside the home state can optimize the use of the existing assets and resources in the research and development process. This is referred to the home-base exploiting (HBE) or an asset-exploiting activity. In this way, the core of the R\&D activities remain in the home state of the MNE and the transfer of knowledge flows from the home state to the host state. The host state is often an attractive consumer market and the products/services are adapted to local demands and preferences. The strategic management of innova-

\footnotetext{
${ }^{21}$ Rugman and Brewer International Business Oxford page 157.

${ }^{22}$ Fagerberg and Mowery The Oxford Handbook of Innovation page 320.

${ }^{23}$ OECD Science, Technology and Industry Scoreboard / 2009 / International trade by technology intensity.
} 
tion and research activities is coordinated by the central management in the home state, with little or no direct influence from the subsidiary in the host state.

Home Based Augmenting activities result from the desire of companies to augment new knowledge bases, to create new competencies and enhance new capabilities not available in the home state. The host state's economy provides spill-over effects from local or regional innovation systems and the structure of industrial activities. New technological assets are created (or existing assets improved) by using complementary location-specific advantages, such as the availability of specialized expertise, relevant sector clustering and spin-offs (e.g. Silicon Valley).

The HBA activities can also be explained by the agglomeration forces within regional economic development. Two important factors in the host state are the intellectual resources of the knowledge base economy and the protection provided by IP laws. The strategic augmenting activities are often motivated by technology-sourcing and, sometimes, there is a development of an asset-exploiting to an asset-augmenting strategy. In the literature, several studies hint at the fact that FDI related to high-tech products is very often asset-augmenting based. ${ }^{24}$ The concept of "Revealed Technological Advantages" (a patent-based indicator) is used to illustrate that foreign investors often locate their subsidiaries in areas where these companies experience a gap in their home state competencies and expertise. Le Bas and Sierra came to different conclusions in a study in which they noted a concentration of both national and international investments in "centres of excellence" in specific technological fields. Other studies found both strategies not to be mutually exclusive; both could be used in a given market. ${ }^{25}$ The location of innovative activities of MNEs is directly influenced by the abovementioned agglomeration (concentration) and dispersion forces in a given region. Narula and Zanfei identify four categories of factors that influence the location decisions regarding the innovation activities of firms. ${ }^{26}$

The first factor they mention is the cost of integrating activities in the local context of the market. Foreign investors need to internalize the location-specific advantages of the host market into their R\&D activities in order to gain the full benefit of these advantages. The foreign investor must integrate into the relevant innovation networks of the host state and this could lead to considerable investments and constraints on financial and human resources.

Secondly, the factor of local technological opportunities and constraints leads to the necessary investments in the host state, which can easily increase the costs of the international R\&D activities.

The next factor relates to the size of the company and the structure of the market. For small and medium-sized companies (SMEs), internationalizing their innovation activ-

\footnotetext{
${ }^{24}$ Cantwell and Piscitello page 92.

${ }^{25}$ Le Bas and Patel 2007 page 19.

${ }^{26}$ Narula, and Zanfei, (2005). Globalisation of innovation page 331.
} 
ities will often lead to a considerable increase in costs that are often not affordable. Depending upon the characteristics of the product and thus the market, manufacturing and research and development need a certain degree of proximity, necessitating the international strategy of the innovation.

The last factor concerns the challenge of managing the international R\&D activities. The coordination of the innovation activities and the management of the R\&D initiatives of an MNE can be quite demanding. ${ }^{27}$

Economic globalization has increased technological convergence, but distinct national differences will remain. Firms have entered into international strategic technological partnerships in order to match the demands of consumers, and to guarantee a rapid expansion and geographical dispersion of their technology.

\subsection{DIFFUSION OF INNOVATION: STANDARDS AND NETWORK EXTERNALITIES}

The effectiveness of the innovation process is closely linked to the diffusion process of the new technology. Diffusion means that producers and consumers replace an old technology with a new technology and that there is a general acceptance and market relevance of the innovation. Diffusion is an integral part of the system in the process of open innovation. For network goods, diffusion is absolutely crucial. Network goods can be defined as goods that rely on standards to guarantee the communication between consumers of the goods and/or services. The adoption rate of the new technology enables the users to communicate and builds a large customer base that justifies investments in new innovations of the product or service. Network industries form a large part of the global economy and some industries have a very fast growth rate. The network effect means that the value of the product (in this case telecommunications) increases with the number of consumers that use the product. Network effects may positively affect competition on the market since consumers benefit from the product becoming more used.

Elements like telecommunications, the World Wide Web, broadcasting services, computer hardware and software increasingly gain strategic importance for the competitiveness of a regional trading bloc or an individual country. In the diffusion process of innovations, standards play a major role, often accelerating the adoption of the new technology. In this context, the modern economic literature indicates a clear relationship between standards and "network externalities". ${ }^{28}$ Network externalities in the consumer adoption of new technologies exist when the value of the good or service to

\footnotetext{
${ }^{27}$ Fagerberg and Mowery page 334.

${ }^{28}$ Fagerberg and Mowery page 471.
} 
the individual consumer increases the greater the total group of consumers of the good or service becomes.

These increasing returns to scale in consumption (or network effects) are characterized by a market where the value of the purchased good to the buyer is higher when more units of the good are sold to other consumers. The network effects can take two different forms. Direct network effects occur when an increase in the size of the network automatically leads to an increased number of users who communicate through the network. Indirect network effects occur when an increase in the size of the network expands the number of complementary products or services available to the user of the network. $^{29}$

Examples of network externalities are:

- Network of ATM machines. The indirect network effect is established by the fact that the larger the size of the network, the more opportunities that are created to use the ATM card and, consequently, the value of the network to the user is increased;

- Computer operating systems that are popular with many users enable more efficient file transfers (direct network effects) and the growth in application software, in combination with the growth in size of the network, providing the consumer with more choice (indirect network effects).

Within the network industries, a distinction can be made between unsponsored and sponsored industries. With the unsponsored industries, firms cannot or will not influence the adoption process of consumers. Therefore, the competition between the products or services is only influenced by consumer behaviour. In the sponsored industries, the consumer preference for products can be heavily influenced by network externalities, which may even undermine the importance of intrinsic product characteristics. Some consumers might prefer the Mac network but, ultimately, they may make the decision to join the larger Windows network because the wider acceptance of Windows provides both direct and indirect network externalities.

Another feature of unsponsored network industries is that the network externalities can lead to a dominance of the network of the early adopters. Later users of the 'losing' product will experience high switching costs and, as a consequence, it might be difficult to switch from the 'wrong' network to the 'right' network, since this necessitates the coordination of the switch of a large number of users.

Sponsored network industries consciously attempt to influence the nature and pace of the adoption of the new product or service as part of their business strategy. The winning network becomes the standard to follow and is created, to some extent, by

\footnotetext{
${ }^{29}$ Besen and Farrell (1994). Choosing how to compete: Strategies and tactics in standardization page 123.
} 
consumer preference. The strategy of the sponsored network industries can include the following tactics:

- Introduction of the product to the early adopters at a relatively low price in order to influence the decision-making process of the late adopters and to build an early lead in the market.

- Facilitating the development of compatible products by providing relevant technological information to the suppliers of compatible products.

- Pre-announcing products in order to discourage adopters from choosing a rival network.

- Maintaining permanently low prices for the product to guarantee a wider and expanding user base for the early adopters

The economic benefits of becoming the "winning" network has, in several cases, led to battles between sponsored network industries to become the preferred standard. This consumer preferred standard does not necessarily have to be the best technological option available, since this network might prove to be too costly, the timing of entering the market may have been badly timed or the network may have used an ineffective marketing strategy.

On the other hand, the network that provides the market standard may have used the best tactic for a fast and wide rate of adoption of the innovation. The network technology firm that established the "winning" standard obviously wants to recoup some of their early investments by cashing in on the revenues of the sale of their network technology. Access to the network can be denied or made unreasonably difficult, thereby directly influencing competition in the relevant market. Often firms will make strategic use of their intellectual property rights in relation to the adopted standard.

\subsection{ECONOMIC CHARACTERISTICS OF NETWORK INDUSTRIES}

In general, network industries that use standards have some very specific economic characteristics:

- Since communication between the users of network technology is an important trait, the network industries can get monetary rewards from both sides of the network. Developers of computer software can charge both the server and the user of the software. In the telecommunications industry, both parties in the communication can be charged. Network industries can apply sophisticated price discrimination schemes that include all users of the product or service. 
- Network industries benefit from a larger community of users of their product or service and every new user will add value but often they are not compensated for this fact.

- A quick expansion of the network will enable a faster diffusion of the innovation, resulting in a much faster market penetration that can have severe impacts on the competition in the relevant market.

- In some network industries (e.g. operating systems), an extreme relationship between market shares and profits can be observed. The inequality of market shares is directly linked to the network effects - a considerable market size will cause many complementary goods to be developed, which directly increases the value of the network good and, indirectly, the value of the complementary goods.

The above-mentioned characteristics of network industries are achieved by the use of standards and can have serious implications for competition in the relevant markets where the good or service is offered to the users.

\subsection{STANDARDS}

\subsubsection{Introduction}

Innovation directly contributes to the competitiveness of a regional trading bloc. The Lisbon Agenda of the European Union stresses the strategic importance of innovation and developed policy initiatives to support the innovative activities of firms. Within the innovation process, standardization has clear benefits for the adoption, diffusion and cost-effectiveness of new products or services. Standardization of products improves the quality of products and services and creates easier access to new markets. From a government perspective, standardization supports public safety and health policy, trade policy and industry policy. For consumers, the increased level of interoperability of products can lead to a better functionality of products, more competition and consequently more choice and lower prices. Standardization can give a competitive advantage to companies, since standards lower the costs relating to research and development and the manufacturing of products. Thus, they become a strategic business element.

To achieve the above-mentioned benefits, standards should be easily accessible for those companies who want to implement the standards. The growth of the information and communication technology sector has increased the impact that standards have on the innovation processes and, consequently, on the ability to compete within the globalized world economy. 
The current negotiations on the Transatlantic Trade and Investment Partnership between the EU and the US also focus on standards as an important instrument. The EU stance is that the transparency and the predictability of the standard-setting process are the key factors. ${ }^{30}$ The development of international standards would reduce costs for consumers and increase efficiency.

\subsection{DEFINITION OF STANDARDS}

Standards in the ICT industry enable the interaction of products and components and create a common language that strengthens the network effects of the innovation. The markets of the ICT industries have a large number of interdependent suppliers and are characterized by very rapid technological changes. ${ }^{31}$ Given the strategic value of the standards, it is important first to clarify the definition and the different types of standards.

According to the ISO/IEC Guide 2:2004 Standardization and related activities: General vocabulary, the term "standard" is defined as a:

"document, established by consensus and approved by a recognized body, that provides, for common and repeated use, rules, guidelines or characteristics for activities or their results, aimed at the achievement of the optimum degree of order in a given context." 32

Standards can appear in two different forms: mandatory standards and voluntary standards. The mandatory standards aim to protect human, animal or plant life, the environment and are created and protected by a government. On the other hand, voluntary standards are developed by standard-setting bodies (SSOs) and enable the interoperability or compatibility of products developed by different firms. ${ }^{33}$

The SSOs establish new voluntary standards by broad consensus among interested parties. The ISO/IEC definition does not cover the standards that were developed by market forces in a less formal way and therefore it seems inappropriate for use within the context of this study. The Agreement on Technical Barriers to Trade (TBT Agreement) makes a clear distinction between standards and technical regulations. The TBT Agreement defines a standard as a:

\footnotetext{
${ }^{30}$ EU Commission: Initial EU Position Paper on TTIP: Technical Barriers to Trade page 1.

${ }^{31}$ Simcoe(2005) Open Standards and Intellectual Property Rights Open Innovation: Researching a New Paradigm. Oxford University Press.

32 International Organization for Standardization (ISO) ISO/IEC Guide 2:2004 Standardization and related activities -- General vocabulary.

${ }^{33}$ Standard Setting Organizations are sometimes also named Standard Development Bodies (SBOs).
} 
"document approved by a recognized body, that provides, for common and repeated use, rules, guidelines or characteristics for products or related processes and production methods, with which compliance is not mandatory." ${ }^{34}$

Standards may also include or deal exclusively with terminology, symbols, packaging, marking or labelling requirements as they apply to a product, process or production methods. ${ }^{35}$ According to the TBT Agreement, standards are set on a voluntary basis and technical regulations have a mandatory character. The major aim of the TBT Agreement is to ensure that standards do not create new barriers to international trade. National standards may contain elements that specifically relate to national culture, levels of income or national security and or health and safety requirements. These national elements can limit access to national markets for foreign firms. The TBT Agreement applies general WTO principles, such as national treatment and the most-favoured nation principle, to standards in order to guarantee transparency, openness and coherence in the setting and application of national standards. As a result, most Standard Setting Bodies adhere to the Code of Good Practice for the Preparation, Adoption and Application of Standards (Annex 3 of the TBT Agreement).

For developing countries, the TBT Agreement foresees special and differential treatment given the financial and technical resources that are necessary for the implementation of international standards. This will be discussed in more detail in chapter 4 , section 4.6.

In contrast, the Standard Setting Organizations often use different definitions. The ETSI developed the following definition:

"A technical specification approved by a recognized standardization body for repeated or continuous application, with which compliance is not compulsory and which is one of the following:

- international standard: a standard adopted by an international standardization organization

- European standard: a standard adopted by a European standardization body

- national standard: a standard adopted by a national standardization body and made available to the public." ${ }^{36}$

The approval of the standard by the members of the SSO (e.g. ETSI) is led by the quality and thus the market-relevanceof the standard. Since compliance is not compulsory, the members of the SSO are relatively free in their choice for the most appropriate standard. Allen and Sriram identify different types of standards:

\footnotetext{
${ }^{34}$ WTO ANALYTICAL INDEX: Technical Barriers to Trade Agreement.

${ }^{35}$ Ibid note 23.

${ }^{36}$ EU Directive 98/34/EC definitions.
} 
1. Classic measures or metric standards are used to measure all comparable quantities against this standard, like the kilo for mass standard; these standards have a primary fundamental character and enable consumers to compare prices, features and functions of different competing products.

2. Process-oriented standards are used to describe a methodology of actions or processes, thereby ensuring the consistent and repeatable testing of products.

3. Performance-based standards, for which the methodology or process is not prescribed but a certain performance level must be achieved by implementing the standard. Performance-based standards frequently appear in the field of health and safety.

4. Interoperability standards, ensure the communication, flexible operation or interconnection between systems that use the same physical entity or data. The generic models facilitate, for instance, the same use of specific software. ${ }^{37}$ In practice, specific standards can posses features of all four of the types mentioned above.

In this research, I will concentrate on interoperability standards within the telecommunications industry.

\subsection{CATEGORIES OF STANDARDS}

The categorization of standards can take different forms. The most traditional way of placing standards into categories is by differentiating between de facto standards and de jure standards. A de facto standard is a standard created by market forces through its wide implementation by companies and its general acceptance by consumers, without being regulated or adopted by a formal standard-setting body. De jure standards are developed by formal standard-setting organizations (SSOs). The standard setting organization facilitates the harmonization of standards and deals with conformity assessments. SSOs can be organized in an international, regional or national context. Occasionally, companies will cooperate in a consortium to establish technical standards in a relevant field or industry. "Open standards" are particularly interesting for companies. "Open standards" are available to the general public and are developed or approved and maintained via a collaborative process. They facilitate interoperability and data exchange among different products or services and are intended for widespread adoption. $^{38}$

\footnotetext{
${ }^{37}$ Allen, and Sriram, (2000) page 171-181.

${ }^{38}$ International Telecommunications Union (ITU) Definition of "Open Standards".
} 
Park classified standards according to their economic effects, which resulted in the following four categories: ${ }^{39}$

1. Compatibility and Interface Standards. Park used the example of the ICT industry and linked compatibility standards to the economic effects of network externalities and high switching costs.

2. Minimum Quality and Safety Standards. These standards provide relevant information to the consumer, provide market segmentation on the basis of minimum quality and support the market-driven development of standards.

3. Variety Reduction Standards. In this case, the standards limit products to a certain range or number of characteristics. As a consequence, the costs of the production of the good are reduced, benefiting from the economies of scale.

4. Information and measurement standards, providing technical information and improving the effectiveness of research and development by guaranteeing standardized measurement systems.

An analysis of the economic effects of these categories was developed by Blind, who draws the conclusion that standards are less important in less R\&D intensive industries and patents gain more importance in sectors with a higher intensity of R\&D. ${ }^{40}$

\subsubsection{Open standards}

"Open standards" are particularly interesting for companies. They are standards that are available to the general public and are developed or approved and maintained via a collaborative process. "Open standards" facilitate interoperability and data exchange among different products or services and are intended for widespread adoption. ${ }^{41}$ There is no general consensus on the definition of an "open standard". The wording of the concept of open standards obviously leads to some confusion within the relevant market. Within the literature on innovation, there is a strong movement towards "open innovation". Open innovation is a process by which firms incorporate externally generated knowledge into their own innovation process and, conversely, allow internally generated expertise to be used in the innovation process of outside firms. Open innovation speeds up the process of innovation, makes specialized knowledge available and is facilitated by the strong growth in the ICT sector. Within open innovation, companies develop open standards adopted by the market. Specifically within the ICT sector, most innovations are part of open source processes.

\footnotetext{
${ }^{39}$ Park(2010). Patents and industry standards: Edward Elgar Publishing.

${ }^{40}$ Blind and Jungmittag (2005). Trade and the Impact of Innovations and Standards: The Case of Germany and the UK.

${ }^{41}$ Ibid note 38 .
} 
Open source development is an open process of software development, aimed at a continued improvement of the product or service. Open architecture refers to a system whose internal and external interfaces are defined by open standards. ${ }^{42}$

"At the heart of the open source model of innovation is the sharing of (source) code, free of charge, leading to innovative projects that are not valued upon commercial terms but rather attract new contributors based on the technical merits of the project." 43

According to the World Intellectual Property Organization (WIPO), open standards share the following characteristics: (i) the specification is publicly available at no cost or for a reasonable fee to any interested party; (ii) any IP rights necessary to implement the standard are available to all implementers on reasonable and non-discriminatory (RAND) terms, either with or without payment of a reasonable royalty or fee; and (iii) the specification should be in sufficient detail to enable a complete understanding of its scope and purpose and to enable competing implementations by multiple vendors. ${ }^{44}$ For example, ITU-T defines "open standards" as follows: ${ }^{45}$

"Open Standards' are standards made available to the general public and are developed (or approved) and maintained via a collaborative and consensus driven process. 'Open Standards' facilitate interoperability and data exchange among different products or services and are intended for widespread adoption."

The Global Standards Cooperation is a forum in which the top standards officials from the US, Canada, the EU, China, Japan, Korea, Australia, and the ITU-T discuss their standard work programmes and identify areas for collaboration and ways to accelerate the creation and adoption of global standards for the industry. Recently this forum again stressed the importance of the development of open standards.

Other elements of "Open Standards" include, but are not limited to:

- collaborative process - voluntary and market driven development (or approval) following a transparent consensus-driven process that is reasonably open to all interested parties.

- reasonably balanced - ensures that the process is not dominated by any one interest group.

- due process - includes consideration of and response to comments by interested parties.

\footnotetext{
${ }^{42}$ Krechmer(2006). Open standards requirements. International Journal of IT Standards and Standardization Research.

${ }^{43}$ Dapp and Bernauer (2009). Hot Debate About Chilling Effects: Do Software Patterns Hamper/Free Open Source Software Development.

${ }^{44}$ Ibid note 22 page 41.

${ }^{45}$ Ibid note 38.
} 
- intellectual property rights (IPRs) - IPRs are essential to implement the standard to be licensed to all applicants on a world-wide, non-discriminatory basis, either (1) for free and under other reasonable terms and conditions or (2) on reasonable terms and conditions (which may include monetary compensation). Negotiations are left to the parties concerned and are performed outside the Standard Development Organization (SDO).

- quality and level of detail - sufficient to permit the development of a variety of competing implementations of interoperable products or services. Standardized interfaces are not hidden or controlled other than by the SDO promulgating the standard.

- publicly available - easily available for implementation and use, at a reasonable price. Publication of the text of a standard by others is permitted only with the prior approval of the SDO.

- on-going support - maintained and supported over a long period of time

Tiemann uses the case law of US courts as a basis and comes to the following definition: ${ }^{46}$

"The standard is documented and can be completely implemented, used, and distributed royalty free (just as the W3C requires of any standard submitted to them). Implementations of the standard may be extended or offered in subset form. However, certification organizations may decline to certify subset implementations, and may require that extensions also satisfy the criteria of an Open Standard."

Dolmans includes different elements in the definition of open standards:

1. Open access to the decision-making process.

2. Open (transparent and undistorted) procedures.

3. Open (published, pro-competitive) goals.

4. Open (published, objective, relevant, qualitative, and verifiable) criteria for technology selection.

5. No over-standardization, avoiding design specifications allowing maximum consumer's choice and product differentiation.

6. Open access to the standard; the standard is well-documented and published and can be implemented by interested parties. ${ }^{47}$

\footnotetext{
${ }^{46}$ Tiemann (2006). An objective definition of open standards. Computer Standards \& Interfaces page 497.

${ }^{47}$ Dolmans and Piana (2011). A Tale of Two Tragedies-A plea for open standards page 122.
} 


\subsubsection{Open standards and open source}

Open standards and open source are often used in the same context. A fine example of open source standardization is OASIS, a member-led, international non-profit standards consortium for global e-business and information technology. ${ }^{48}$ The consortium drives the development, divergence and adoption of open standards. Within open source standard-setting, two different types of licenses prevail: 1) highly permissive licenses, with regard to which no conflicts with patents will arise; and 2) copy-left licenses, with regard to which a modified version must be licensed on the same terms as the original, not allowing any additional requirements. The Free and Open Source Software development (FOSS) has as characteristics that:

- redistribution is permitted without a need to pay fees for distributed copies;

- $\quad$ the source code is available and may be modified; and

- modified versions may be distributed with permission for others to do all of the above.

The FOSS dynamic development process will be brought to an end if a patent license is required that imposes fees. In 2007 the EU Commission authorized a study on the impact of Free/Libre/Open Source Software (FLOSS) and the main findings concluded that FLOSS accounted for $20.5 \%$ of the total software investments in the European Union. Another conclusion was that FLOSS was threatened by policy initiatives to protect the interests of old business models, thereby limiting innovative progress and competitive gains. The open source movement urges the EU Commission to consider a "Software Interoperability Directive" to ensure a participative standardization process and vendor independence in the development of standards. The FLOSS development changes the traditional proprietary business model of patenting software into a new model of innovation, questioning the need for the commercialization of the new invention. ${ }^{49}$ Companies such as HP, IBM, Novel and Sun participate in open source innovation, proving that developing software in a collaborative effort and distributing it without charge is a feasible business option.

The open source movement, advocating freely available software in relation to standardization, does raise some very basic discussions in the context of free versus licensed technology:

- Who uses and re-uses the licence rights?

- Is the standardization and thus technological progress better served by written licences or self-executing terms?

\footnotetext{
${ }^{48}$ See for more information: www.oasis-open.org

49 Dapp: The effects of software patent policy on the motivation and innovation of free and open source software developers, page 2 .
} 
- What is the exact role of standardization efforts? Do they induce or follow innovation?

- Do trading blocs use the regulatory environments for standards as a mandate or as an incentive for innovation and/or competitiveness? ${ }^{50}$

To limit the scope of this project, I will concentrate my research on the transfer of licensed technology.

\subsection{EU AND STANDARDS}

\section{EU Competitiveness through standardization}

The EU regulation on standardization implements the policy that the European standardization systems must meet the EU's challenges and needs. The European Parliament (hereinafter EP) pleaded for a more effective and efficient system. The new standardization package is linked to the Strategy $2020 .^{51}$ The EU has set a goal to increase the participation of SMEs in the standardization efforts and to extend the new regulation not only to goods but also to services. The main principles of the European standardization system are national delegation and respecting the private nature of standards that are made on a voluntary basis. In order to make standards meet business needs they should be privately funded and evolve from a bottom-up approach. Only in case of safety matters would a direct public interest allow direct interference by national or European authorities. In the EU system, a strong cooperation between society, stakeholders and especially SMEs is envisaged. It is important to understand that, since the standards are sector specific, their requirements are also related to the relevant market. In general, the EU needs to increase the speed of the standards-development system in ICT in order to remain competitive in the global market-place. ${ }^{52}$ The new regulation establishes a system allowing for ICT consortia to participate in standard-setting activities. Evaluating the policy of the European Union in the field of standards, a few questions can be raised. From a competition policy perspective, the policy choice to have a preference for privately funded, bottom-up approach standards is remarkably different from the US and Chinese standards policy and has, for instance, strong implications for the financing system for standardization. Discussions revolve around issues such as who finances the standardizing bodies and who sets their agenda?

\footnotetext{
${ }^{50}$ Some of these points were discussed during the IPR-standards conference organized by the EU Commission on 22 November 2010 in Brussels.

51 The European Union wants to become the most competitive knowledge-based economy in the world by 2020.

${ }^{52}$ Comments made during the World Standards Day 2011 Brussels 14 October 2011 by the Rapporteur for the EP.
} 
- Should there be a Community-based system?

- Are the European standards still voluntary?

One of the traditional reasons to promote standards is the argument that they favour economies of scale and reduce costs for consumers. However, it could be the case that consumers have to pay the price twice. First, the costs of standardization are internally accounted for in the end consumer price. Second, the consumer could pay the price for oligopolistic behaviour by the firms involved in the standardization. In order to achieve convergence between European and internationally developed standards, the Commission installed task-forces with the US and Japan. These task-forces are part of the DG External Trade and it would be interesting to see if their cooperation is linked to the cooperation between the DG Competition and the US FTC and DoJ.

"The standardisation process should promote innovative solutions instead of sponsoring the existing solutions of the companies. The technical complexity of the ICT industry and the previous discussed difficulty to distinguish between essential and nonessential patents, make it doubtful that the competition policy can successfully accomplish this task which is also closely linked to the European industrial policy."53

During the preparatory work for the draft regulation the EP made the following recommendations: monopolies should be eliminated, more attention should be paid to the drafting of standards, the process should be accelerated, and there should be more focus on the problem of blocking patents. The EP struggled in its discussions to find a proper balance between centralizing and harmonizing the standard procedures but at the same time respecting the needs and influence of market forces. ${ }^{54}$ For the latter, a special task could be assigned to DG Competition, but at the same time DG External Trade and even the demands of the industrial policy and the internal market must be considered, since better standards can revive the internal market. One of the key industries of the internal market is the European ICT sector. The Commission has just recently understood that, in this field, the EU efforts are lagging behind the US achievements. A recent industry report (Rebooting Europe's High Tech Industry) concluded that Europe does not have sufficient large high-tech companies to compete with the US and Asia. High fragmentation, a shortage of funding and an innovation deficit (share of European companies' patent filings) are some of the main problems of the sector.

The European Commission has acknowledged the importance of standards on several occasions. Commissioner Almunia (DG Competition) said the following in July 2010:

\footnotetext{
53 Some commentators submit that a strong political influence in competition policy blurs the boundaries between competition policy and industrial policy.

54 One of the initiatives to speed up the process of standardization is the use of "Pre-Standards". PreStandards are in principal identical to national technical specifications, meaning that national technical solutions compete to become the draft of an European Standard. See for more information: CEN/CENELEC Guidance documents Faster delivery of European Standards and other deliverables.
} 
"When it comes to standards some minimum requirements must be met to be ensure that the positive effects of standardization can fully materialize. We have identified these requirements in the Commission's draft guidelines on horizontal agreements which include an extensive discussion of standardization... In the IPComm and Rambus cases, the Commission has already shown that it is ready to intervene under competition rules to enforce these principles. With the draft horizontal guidelines we are seeking to encourage standard bodies to avoid those weaknesses and failures in the first place."

The relevance of standards to the competitiveness of EU industries was also commented upon by Commissioner Kroes (DG Information Society-Digital Agenda) in June 2010:

"Some standard-setting bodies already have ex-ante disclosure rules, so why not all of them? This is a matter of efficiency in my opinion. And surely, as a matter of effectiveness, when the Commission mandates standard bodies to draw up a standard it should have the right to be more demanding on the standardization process, to ensure that standards are less when it comes to their adoption. We could also think about enticing other standard bodies to adopt such rules, for example by giving their outputs preferential treatment when approving them as European standards. Finally, why not tie the public financing of standards bodies to the existence of good ex-ante rules?"

Later, Commission Kroes made the following comment:

"Let's imagine two competing standards that are both technically excellent for a certain task but differ in the level of constraints for implementers. Which of these two standards do you think will see more implementation and use, including for unforeseen purposes? The one that you can download from a website and that you can implement without restrictions? Or the other one which you have to buy, which is restricted to certain fields of use and which requires royalty payments for embodied intellectual property rights (IPR)? The answer is obvious. And that is why everybody who cares about interoperability should care about the financial conditions for the use of standards as well as the indirect constraints imposed on third parties: the fewer constraints the better."

The EU Commission set out its political agenda in the 2010 Digital Agenda Communication. The Commission expressed its intention that Europe's standard-setting framework must catch up with fast-moving technology markets, because standards are vital for its interoperability. The Commission will continue its review of the European standardization policy and will focus on giving more guidance on transparent ex-ante disclosure rules for essential intellectual property rights and licensing terms in the context of 
standard setting, to be provided inter alia in updated antitrust rules on horizontal cooperation agreements. ${ }^{55}$

This guidance should result in lower royalty demands for the use of standards and consequently lower market entry costs. Core aims of the flagship Digital Agenda project include improved access to the content of standards, the promotion of open and interoperable systems and open standards.

Standardization has an impact on various EU policies. The Commission issued a communication in the field of its industrial policy, 'An Integrated Industrial Policy for the Globalisation Area Putting Competitiveness and Sustainability at the Centre Stage', in which standardization is identified as a key policy to reap the economic benefits of harmonization and economies of scale. ${ }^{56}$ This communication highlights standards and patents as necessary elements for an integrated policy approach to enhance the competitiveness of the EU at a global level and competitiveness-proofing of all EU-policies.

Early in 2011, the Commission presented a new strategy to promote standardization via a new standardization communication and a new legislative proposal. A leading role is placed in this context on the ICT industry and its strategic impact on the competitiveness of the European Union. The Commission has issued a White Paper on ICTStandardization. Industrial policy and competition policy provide two different perspectives on the same economic processes (see also 2002 EU Competitiveness Report chapter on increasing synergy between the EU's Enterprise and Competition policies and an updated analysis included in the 2011 Competitiveness Report). At the moment, the view of the Commission on standardization (DG Enterprise and Industry) seems to focus on the principle of legal certainty, guidance and neutrality towards standardization and the use of different/new business models, encouraging innovation, economic growth and effectiveness. The guidelines on horizontal cooperation are based on the following principles: ${ }^{57}$

- Pro-active guidance (art. 101-102)

- Business model neutrality

- Protection of intellectual property rights (IPRs) to the largest possible extent

- Providing clarity on the "safe harbour" concept

- FRAND

\footnotetext{
${ }^{55}$ Source: A Digital Agenda for Europe 2010 page15 par.2.2.1.

${ }^{56}$ Commission of the European Union. (2010). An integrated industrial policy for the globalisation era. Putting competitiveness and sustainability at centre stage. Communication from the Commission to the Council, the European Parliament, the European Economic and Social Committee and the Committee of the Regions. Brussels: European Union.

${ }^{57}$ EU Commission conference Tensions between intellectual property rights and standardisation: reasons and remedies 22 November 2011 Brussels. A more detailed discussion will follow in Chapter 7, section 7.2.
} 
In October 2012 the EU Commission adopted a new regulation on standardization. The regulation has four different themes. The first theme is the transparency and participation of all relevant stakeholders in the standardization process. Access to the standardization process is facilitated and the group of stakeholders also includes consumer groups, SME's and environmental and social interest groups. The idea is that standardization is not just open to multinational firms but to all relevant parties. It is interesting that the Commission may request (mandate) standardization bodies to initiate the development of specific standards. ${ }^{58}$ The mandated European standards will support and strengthen general EU common policies (internal market, public procurement, interoperability). The regulation further comprises elements such as the financing of European standards and a specific section on ICT technical regulations. ${ }^{59}$

The EU Commission can also exercise further influence on standard setting using annual work programmes. The Annual European Standardization Work Programme 2012 identifies the various policy priorities of the EU Commission. ${ }^{60}$

Standardization is also related to the SME policy of the European Union, since small and medium-sized enterprises provide most of the economic growth in the EU. There is also an obvious connection to the industrial innovation policy of the European Union and, last but not least, the Commission is directly involved in the work of standardizing bodies such as CEN/CENELEC, as a part of the coordination of specific horizontal policies.

In the European Union, the formal standardization process is concentrated on the activities of three standardization institutions: the European Committee for Standardization (CEN), the European Committee for Electro-technical Standardization (CENELEC) and the European Telecommunications Standard Institute (ETSI). The legal framework concerning the three institutions is the abovementioned Directive 98/34/EC, followed by Regulation 1025/2012, which are also the basis for the European Standardization System (ESS). The Council of Ministers adopted a special decision (87/95/EEC) for the creation of standards in the ICT sector, addressing the industry's need for the interoperability of newly developed technology. The 2013 annual Union Work Programme for Standardization mentions the specific importance of the development of standards for wireless communications in paragraph 2.2.12. ${ }^{61}$ The ESS lays down a framework for

\footnotetext{
${ }^{58}$ Three different types of mandates can be identified: standardization mandates that specifically request the development of a European standard; programming mandates that elaborate a standardization programme and study mandates that investigate the feasibility of the development of a European standard. EU Regulation 1025/2012.

${ }^{59}$ EU Regulation 1025/2012.

${ }^{60}$ EU Commission, Commission Staff Working Document /Annual European Standardization Work Programme 2012.

${ }^{61}$ July 2013 the annual Union Work Programme for Standardization: "The development and updating of harmonised standards under existing mandates is essential. The Commission may prepare new mandates on: (1) development and maintenance of mobile communications standards (UMTS, LTE, LTE advanced...) in the
} 
standardization in relation to the free movement of goods, services and information, preventing the (re)-emergence of technical rules that will act as barriers to trade inside the internal market, which would seriously undermine the EU's competitiveness and innovation efforts. From a global perspective, the ESS should have a leading role in the creation of new international standards, which might be adopted or derived from European standards, further improving the strategic positioning of the European Union in international trade.

As mentioned above, the standardizing institutions have agreed to specific policy objectives to ensure the effectiveness of their operations and the ESS in general. These objectives are the following:

"Demonstrate through transparent, inclusive, balanced and consensus-based processes their capacities to operate standardization activities efficiently and with the participation of all relevant industrial, societal and public stakeholders;

- Operate a coherent, market-relevant system in which rules of standstill, national transposition and withdrawal apply, where any stakeholders can make requests for European standardization work;

- Work according to the principles of the WTO/TBT Agreement "Code of Good Practice for the Preparation, Adoption and Application of Standards" (Annex 3);

- Cooperate among themselves, to implement wherever possible their common agreement** and their common objectives, and to formulate medium term strategic recommendations for standardization;

- Take initiatives, individually or collectively, to promote the European model, their expertise and standards deliverables at the world level including collaboration with other bodies to increase the attractiveness of the ESS." 62

The text of the Directive 98/34/EC and Regulation 1025/2012 closely follow the reasoning of the WTO/TBT Agreement "Code of Good Practice for the Preparation, Adoption and Application of Standards", which aims to include all interested parties, openness, transparency of the standard setting process, impartiality and consensus-based decision making and a balanced representation of all the stake-holders in the standard-setting process.

CEN and CENELEC are comparable to the International Standards Organization (ISO) and consist of the National Standard Bodies/ National Standard Committees of the EU and EFTA Member-States, Croatia and the representatives of the "European Neighbourhood countries". Both organizations apply the "national delegation principle", in which national delegates represent the common opinion of all the national stakeholders

framework of the 3rd Generation Partnership Project (3GPP)" http://eur-lex.europa.eu/LexUriServ/LexUri Serv.do?uri=COM:2013:0561:FIN:EN:PDF

62 Ibid note 55 pages 8 and 9. 
who have already made a decision by consensus at national level. Representatives of special interest groups (like ETUI AND NORMAPME) participate as observers in the formal standardization process and give necessary and relevant outsider's input. The initiative for a new standardization project can be taken by members of the SDO, the technical committee of the SDO or by the EU Commission. The technical committee deals with the operation part of the standard setting and the technical board ultimately takes the decision whether or not to adopt the proposal for a new standard. The members vote on the acceptance of the new standard. The decision-making process for the creation of new standards is based on the principle of weighted voting of the European Treaties.

\subsubsection{Competitiveness of the EU ICT sector and standardization}

As an industry, the ICT sector has a high degree of convergence in terms of platforms, systems and interoperability of technology. The technical developments have created greater uniformity and standardization has been a major tool in achieving this aim. The regulatory environment for the ICT industry stands in stark contrast to this. Due to the principle of subsidiarity and the interests of public bodies and other stake-holders, the European Union failed to reach the same level of uniformity as the US, Japan or even China. The result is a fragmented European market for ICT-products, where national interests still sometimes prevail and overall competitiveness is lagging behind. Interoperability seems to be the most important remedy for this negative fragmentation of the market and, with the specific characteristics of the network effects of the telecommunications market in mind, standards and the intellectual property rights involved become strategically more important. In terms of competitiveness, the technical convergence that the ICT industry has achieved must be matched by a regulatory coherence in the $\mathrm{EU}$, in order to fully benefit from the industry's competitive potential. ETSI is the European Telecommunications Standards Institute. ETSI initiates standards upon request by its members or having been given the mandate to do so by the EU Commission. ETSI was the first SSO to give a strategic reaction to the 1992 Communication on Intellectual Property rights and Standardization of the EU Commission. The Commission urged SSOs in this Communication to adopt a code of practice and guidelines to prevent their work from raising conflicts with Article 85 and Article 86 EEC Treaty. ${ }^{63}$

For a standard-setting body, it is reasonably difficult to strike the right balance between the interests of the different stakeholders. The patent right holders want a reasonable return for inserting their patent into the standard and thus commercializing the product concerned. Business owners want to produce and market standard conforming goods and services under profitable conditions. For the consumers, both the price and

\footnotetext{
${ }^{63}$ Commission Communication on IPRs and Standardization, COM 92/445, October 22, 1992, page 32. Articles 85 and 86 EEC-Treaty are now replaced by articles 101 and 102 TFEU.
} 
the interoperability are the two main interests. The SSO wants an effective and efficient standardization process. In a breakfast speech, Commissioner Neelie Kroes stated the following:

"Proprietary technology is at the heart of Europe's success in second and third generation mobile technologies, for example. Intellectual property protection for technology will always be necessary to give just rewards for investment in R\&D. There will always be an important place for proprietary technology and formal proprietary standards"

On the subject of informal standards she explained the legal conditions:

"First, the de facto standard could be subject to the same requirements as more formal standards:

- ensuring the disclosure of necessary information allowing interoperability with the standard;

- ensuring that other market participants get some assurance that the information is complete and accurate, and providing them with some means of redress if it is not;

- ensuring that the rates charged for such information are fair, and are based on the inherent value of the interoperability information (rather than the information's value as a gatekeeper)." 64

ETSI already changed its IPR-policy in 2006 with the following provisions:

"Without prejudice to ETSI IPR Policy and other sections of this Guide, voluntary, unilateral, public, ex ante disclosures of licensing terms by licensors of Essential IPRs are not prohibited under ETSI Directives. Licensing terms from such disclosures may, in some circumstances, improve transparency for individual Members in considering technologies for inclusion in standards and technical specifications. "65

In relation to the ex ante commitments, some scholars favour the creation of a fixed royalty cap, thereby clearly communicating the maximum royalties that can possibly apply. In this system, the maximum total sum of royalties would be a percentage of the overall licensee's revenues. A possible danger in terms of competition policy would be the lack of price competition for the essential patents within the standard. ${ }^{66}$

During the last decade, the views on the relationship between IPRs and their effect on innovation have changed dramatically. Especially in the ICT sector, new business models evolved that did not directly rely upon strong and effective protection of intel-

\footnotetext{
${ }^{64}$ Speech of N. Kroes, Breakfast Seminar 10 June 2008 Being open about standards.

${ }^{65}$ ETSI Guide on IPRs, Version endorsed by General Assembly \#48 on 22 November 2006, page 15.

${ }^{66}$ See for a more in-depth discussion: Piesiewicz and Schellingerhout Intellectual Property Rights in Standard Setting from a Competition Law Perspective in Competition Policy Newsletter No.3 2007.
} 
lectual property assets. The implementation of a complex standard would lead to high investments for the arrangements with the multiple patent holders and, consequently, the cumulative royalty fees. Open source or service-based business and even the emergence of non-practising entities led the way forward. There seems to be a consensus that IP rights and interoperability are closely linked and are both major factors to achieve success. A full participation of all relevant stakeholders in the standardization process is of crucial importance. IPR policies of SSOs that would limit or even exclude membership/participation would be in direct conflict with the goal of achieving global competitiveness.

\subsection{THE UNITED STATES AND STANDARDS}

In the United States, the standardization process is coordinated by the American National Standards Institute (ANSI), which promotes and creates voluntary standards and represents the US in non-treaty international and regional standard-setting processes. In the United States Standard Strategy, direct reference is made to the WTO TBT Agreement and, consequently, the US Standards Strategy established the following principles: transparency, openness, impartiality, effectiveness and relevance of the standards in relation to public or private needs, decision making based upon consensus, adherence to the principle of due process and technical assistance for developing countries. $^{67}$

In 2004 the US DoJ implemented the Standards Development Organization Advancement Act. ${ }^{68}$ The purpose of this Act was to extend the protection of the National Cooperative Research and Production Act (NCRPA) to standard setting organizations. The consequences were the following: no application of the treble damages rule and the application of the rule of reason approach to SSOs. ${ }^{69}$

The National Cooperative Research and Production Act (NCRPA), amended by the Standards Development Organizational Advancement Act, refer to situations in which the antitrust laws do not apply to SDOs. Acccording to Lundqvist, standard-setting organizations no longer benefit from this framework in cases of collusion, group boycotting and exclusionary standards. ${ }^{70}$

The first major difference between the European and the US system is the voluntary character of the US standards. The US standardization infrastructure is a decentralized system embedded in the belief that the national government should not control but

\footnotetext{
${ }^{67}$ United States Standards Strategy Committee: United States Standards Strategy page 6.

${ }^{68}$ United States Standards Development Organization Advancement Act Public Law 108-237.

69 Lundqvist comments that the term SDO has a special meaning within the NCRPA framework. SDOs are accredited by the International Standards Organization or the International Electronic Commission. SSOs also include groups of private companies or consortia.

${ }^{70}$ Lundqvist page 170.
} 
should rather support and strengthen standardization efforts. The system of standard setting in the United States is divided into different industrial sectors through market forces, according to which Standard Developing Bodies (SDOs) and conformity assessment bodies create new standards, not upon the request of the government (in the EU system the Commission can request the creation of a specific standard) but as a reaction to the interests and needs of private and public bodies and the consumers. ANSI takes a leading role in coordinating the different standard-creating processes of the numerous SDOs. Participants in the US system can be very diverse and wide-ranging. Scientific and professional organizations, such as the American Society of Safety Engineers (ASSE) or the American Society of Mechanical Engineers (ASME), provide input from the professional perspective. Trade associations in some cases create standards for partitioned markets like telecommunications, just like the Institute for Electric and Electronic Engineers (IEEE) develops new standards within the electronic industry. Due to the globalization process and the rapid technological developments in the ICT-sector, a relatively new phenomenon is standard setting by consortia, in which a group of companies work together to find an accelerated solution for a specific market need.

From a policy point of view, the US government, contrary to some other approaches, does not dictate the standard-setting agenda but has made a deliberate choice only to support and coordinate the processes. The National Institute of Standards and Technology (NIST) was established by the US government in 1995 to coordinate standard policy among the federal bodies. Some of these relevant public bodies are the US Department of Commerce, the US Department of State and the Office of the US Trade Representative. From a competition policy perspective, the Federal Trade Commission (FTC), the International Trade Commission (ITC) and the US Department of Justice (DoJ) take a keen interest in the standardization processes. The cooperation between the United States and the European Union in the field of intellectual property rights and industry standards is one of the interest areas of the Transatlantic Economic Council. The Transatlantic Economic Council has as its purpose to strengthen and support transatlantic economic integration and to increase the competitiveness of both the EU and the US. Annex 3 deals with the protection of intellectual property rights and Annex 7 on innovation and technology specifically mentions in point I: "to launch our Standards Dialogue as an overarching framework to discuss specific standards-related issues". ${ }^{71}$

The US Department of Justice states that industry standards are the drivers of the modern economy, since they reduce the production costs for firms and consequently result in lower prices for consumers. The use of standards will increase the available choice for consumers, have positive effects on efficiency and innovation processes and serve as "fundamental building blocks for international trade". Standards enable the interoperability of communication services such as the internet and wire telecommuni-

\footnotetext{
${ }^{71}$ See for more information: Framework for advancing transatlantic economic integration between the European Union and the United States of America Washington, 30 April 2007.
} 
cations. The United States Standards Strategy adopts a sector approach, meaning that specific industry sectors develop their own standards according to the market needs. Contrary to the European Union, the United States relies more on market-forces in their standards policy approach. In this market-related approach, the strategic use of intellectual property deserves the full attention of competition law enforcers.

More specifically, Gerald Masoudi, former deputy Assistant Attorney General of the Antitrust Division of the U.S. Department of Justice said:

"The goal of policies involving IP, licensing, and standards should be to promote efficiency, just as it is with antitrust policy. Static efficiency occurs when firms compete within an existing technology to streamline their methods, cut costs, and drive the price of a product embodying that technology down to something close to the cost of unit production. Static efficiency is a powerful force for increasing consumer welfare, but an even greater driver of consumer welfare is dynamic efficiency, which results from entirely new ways of doing business."

Economists now recognize that the gains of dynamic efficiency, also called "leapfrog" competition, can far outstrip the gains from incremental, static improvements. It follows that policy makers should pay particular attention to the impact of laws and enforcement decisions on dynamic efficiency.

In the United States, case law has also made reference to standardization:

"Private standard setting advances (the goal of maximizing consumer welfare) on several levels. In the end-consumer market, standards that ensure interoperability of products facilitate the sharing of information among purchasers of products from competing manufacturers, thereby enhancing the utility of all products and enlarging the overall consumer market... This, in turn, permits firms to spread the costs of research and development across a greater number of consumers, resulting in lower per-unit prices... Industry-wide standards may also lower the costs to consumers of switching between competing products and services, thereby enhancing competition among suppliers." 72

The Federal Trade Commission made the following comment: "Conduct that leads to the artificial standardization of products-often due to misuse of the standard setting process- may serve to deter entry, exploit rivals, secure market power, or preserve dominance." 73

The Third circuit decision in Broadcom vs. Qualcomm in September 2007 further explained:

"We hold that:

1. in a consensus-oriented private standard-setting environment,

\footnotetext{
${ }^{72}$ Source Broadcom Corp v. Qualcomm, Inc, No. 06-4292.

${ }^{73}$ See table of cases Rambus Inc., In the Matter of. Federal Trade Commission, Federal Trade Commission.
} 
2. a patent holder's intentionally false promise to license essential proprietary technology on FRAND terms,

3. coupled with an SDO's reliance on that promise when including the technology in a standard, and

4. the patent holder's subsequent breach of that promise, is actionable anticompetitive conduct."

In the same judgment the Court also stated:

"Deception in a consensus-driven private standard-setting environment harms the competitive process by obscuring the costs of including proprietary technology in a standard and increasing the likelihood that patent rights will confer monopoly power on the patent holder... Deceptive FRAND commitments, no less than deceptive nondisclosure of IPRs, may result in such harm." "74

The United States Standards Strategy mentions the aim of promoting a consistent world-wide application of internationally accepted standards. The US strategy wants to encourage the consistent implementation of basic principles relating to the development of standards. ${ }^{75}$

Another example of US case law referred to the competition law (antitrust aspects):

"Private standard setting by associations comprising firms with horizontal and vertical business relations is permitted at all under the antitrust laws only on the understanding that it will be conducted in a nonpartisan manner offering precompetitive benefits." ${ }^{\prime 76}$

\subsection{THE EU-US COOPERATION IN THE TRANSATLANTIC TRADE AND INVESTMENT PARTNERSHIP AND STANDARDS}

As stated in the introduction to this chapter, the current negotiations on the TTIP between the EU and the US also include talks on standards. The starting point for this discussion was the document "Building Bridges between the US and EU Standards Systems". ${ }^{77}$ One of the main principles is to strengthen the application of the WTO Code of Good Practice on the Preparation, Adoption and Application of Standards. In general, the consensus is that both the EU and the US should follow the WTO TBT Committee

\footnotetext{
${ }^{74}$ Broadcom Corp. v. Qualcomm, Inc., No. 06-4292 (3d Cir. Sept. 4, 2007).

75 The United States Standards Strategy also refers to the National Technology Transfer and Advancement Act (NTTAA) page 10.

${ }^{76}$ Source Allied Tube \& Conduit Corp. v. Indian Head, Inc, 486 US 4921988.

${ }^{77}$ Commission of the European Union, Building Bridges Between the U.S. and EU Standards Systems.
} 
Decision principles. ${ }^{78}$ These principles include consensus, openness, impartiality, transparency, and coherence.

The EU will make drafts of the three standardizing bodies (CEN, CENELEC and ETSI) available online in order to avoid duplication. In the same manner, the US government will encourage ANSI to provide more transparency and opportunities for foreign stakeholders to be involved in the standard-setting process. ${ }^{79}$

The EU and US want to develop more common standards and increase their cooperation in International Standards Bodies. One example is the Global Standards Cooperation forum as discussed earlier in this chapter. An analysis carried out by the Centre for Economic Policy Research (CESR) suggested that greater conformity between EU and US standards would also allow for indirect spill-over effects. Given the size of the US economy and the EU internal market, global businesses may have more incentives to adjust to the commonly developed standards in the EU and US. ${ }^{80}$ A German study shows that more jointly created standards would increase the competitiveness of EU small and medium-sized companies and their exports to the US. ${ }^{81}$

As a reaction, two European Standard Bodies (CEN/CENELEC) identified possible future challenges: ${ }^{82}$

- the substantial differences between the EU and US in relation to the definition of international standards.

- the current lack of reciprocity in relation to market access through standards and standards development.

- "the need to achieve comparable levels of predictability concerning the use of standards in support of legislation."

- the need to encourage more technical cooperation between companies on both sides of the Atlantic Ocean.

- national conformity assessments may not lead to market distortions. Moreover these conformity checks might violate the WTO TBT Agreement.

The US counterpart of CEN/CENELEC, ANSI, also reacted in a positive way and supports the ongoing TTIP negotiations in this field.

\footnotetext{
${ }^{78}$ WTO TBT Committee /1/REV.10. Decision of the Committee on Principles for the Development of International Standards, Guides and Recommendations with Relation to Articles 2, 5 and Annex 3 of the Agreement.

79 The text states that the EU Commission wants: "consensus standards developed through an open and transparent process and that are in use in the global marketplace."

${ }^{80}$ Commission of the European Union, The Transatlantic Trade and Investment Partnership: The Economic Analysis explained page 10.

${ }^{81}$ Felbermayr, Larch, Flach, Yalcin and Benz, Dimensionen und Auswirkungen eines Freihandelsabkommens zwischen der EU und den USA page 29.

${ }^{82}$ The European Committee for Standardization (CEN) Position Paper on EU-US Transatlantic Trade and Investment Partnership (TTIP).
} 
Two comments of the US Trade Representative Michael Froman describe the current US views on the subject of standards in the TTIP negotiations:

"Restricting standards development to nationality-based processes is a tempting way to carve out market share for national constituencies, but the costs are too high, not just for trading partners, but for standards-setters and regulators forced too often to leave cutting-edge technical solutions out in the cold."

He also said:

"We have seen this in the incredibly innovative area of information technology, where ultimately, the need for interoperable standards encouraged the EU to join the U.S. in working with private sector-led standards. But in other areas, an inability to incorporate the best ideas from market-driven standard setting processes has discouraged innovation and interoperability, increased costs and reduced competitiveness." 83

At the time of writing (summer 2015), the TTIP negotiations on standards were facing some challenges. Both the EU and US could not agree on the definition of an "international standard". In reality, US standards have a more widespread application in global terms, but the EU still seeks to find a compromise.

\subsection{CHINA AND STANDARDS}

\subsubsection{Standardization and classification of Chinese standards}

In the People's Republic of China (PRC), the standard system uses four different classifications: National Standards, Professional Standards, Local Standards, and Enterprise standards. National standards define nationwide technical requirements. Professional standards occur in the absence of national standards and apply to specific professional requirements. Local standards relate to specific local health and safety regulations in the absence of national and/or professional standards. In case no national, professional or local standards have been developed, industry can create their own standards for commercial purposes. The Chinese standards system differentiates two classes of standards: mandatory standards and voluntary standards. Mandatory standards protect human health, personal property and safety; all other standards can be categorized as voluntary standards.

The National Intellectual Property Strategy of the government of China mentions in Section 17 that the PRC wants to formulate and improve the national policies related to

\footnotetext{
${ }^{83}$ Froman.M. (2013). Remarks by U.S. Trade Representative Michael Froman on the United States, the European Union, and the Transatlantic Trade and Investment Partnership.
} 
standard setting and to streamline the use of patents in a standard. According to the Strategy, firms and industry organizations should pro-actively participate in the establishment and creation of internationally accepted standards. In the $11^{\text {th }}$ Five Year Plan for 2006-2011, standards are seen as an important instrument to leapfrog innovation, with specific emphasis on the high-tech and ICT sectors.

The basic policy concerning the formulation of China's national standards includes:

"... related state principles, policies, laws and regulations shall be carried out in the formulation of national standards; the formulation shall be conducive to ensuring people's safety and health, protecting the interests of consumers as well as the environment; conducive to rationally utilizing national resources, promoting the scientific and technological achievements, improving economic performance, and comply with the use requirements, and conducive to the general use andinterchangeability of products, try to attain advanced technology, economical and reasonable, safe and reliable and coordinated and matching; conducive to promoting the foreign economic cooperation and foreign trade." 84

In relation to international standards, China wants Chinese firms to adopt international standards, participate in the standard setting in the international context, use foreign advanced standards, and formulate national Chinese standards in relation to international standards. This policy aims to minimize the gap between national Chinese standards and international standards, thereby increasing the market access of Chinese products to foreign markets. The policy does, however, foresee the adjustment of international standards to national Chinese standards, due to climatic and geographical factors or basic technological difficulties. In this adjustment process, the proposed changes incorporated in the national Chinese standard should be kept to a minimum, rational and necessary scope. Article 9 of the Standardization Law of the PRC states that standards should promote the rational use of the country's resources, a wider utilization of scientific and technological gains and the enhancement of economic returns. Furthermore, Chinese standards must conform to operation instructions, increase the universality and inter-changeability of products and be technologically advanced and economically rational. Article 11 stresses the importance of cooperation with foreign countries to promote economic and technological progress. As a practical example, CEN, CENELEC, ETSI, and the European Commission and EFTA have seconded a European standardization expert to China (SESEC). ${ }^{85}$ This expert is responsible for increasing the cooperation between China and Europe in the fields of standardization and con-

\footnotetext{
${ }^{84}$ EU-China Standards Information Platform, Guide on the Implementation of Standards in China (Draft) page 10.

${ }^{85}$ Information and communication technology is one of the selected priority areas for the SESEC expert. In the current phase, this project also aims to monitor the standardization efforts in China at the provincial level more closely. For more information on this project see: http://www.cencenelec.eu/intcoop/projects/visibility/ SESEC/Pages/default.aspx
} 
formity assessment. The expert also identifies specific standardization needs from China and monitors developments in the standardization landscape in China. Another important feature is the gathering of regulatory and standardization intelligence in China. Standardization in China is part of a process in which R\&D activities lead to IPRs and standards which are then applied in testing and validation and consequently lead to certification and public procurement.

The $11^{\text {th }}$ Five Year Plan for 2006-2011 frequently mentions standardization as an important instrument to leapfrog innovation especially in in the high-tech and ICT sectors. In China, standards are regarded as a tool to support firms provided by the government. Standardization is mostly initiated and coordinated by national ministries who are responsible for different industries. This leads to an apparent lack of transparency, which makes the standardizing efforts in China more difficult to understand from a European or US perspective.

The Standardization law of the People's Republic of China provides a description of the standard setting process in chapter 2. National standards shall be defined for technical requirements that necessarily need to have a uniform definition. In cases where there are no national standards, but practical trade concerns necessitate a uniform approach, trade standards can be formulated. These trade standards shall be established by "competent administrative authorities under the State Council" and have to be coordinated by the State Council. As soon as national standards are developed in the same field, the trade standards will be replaced directly by the national standards. In the absence of both national and trade standards, a regional or municipal authority has the right to develop local standards, which can be revoked by the creation of either national or trade standards.

Standardization in China includes the following relevant parties: the Standardization Administration of China (SAC), the Ministry of Industry and Information Technology (MIIT), China Association for Standardization (CAS), China National Institute of Standardization (CNIS), China Electronics Standardization Institute (CESI), and the China Communications Standards Association (CCSA).

The Standardization Law of the PRC does allow the establishment of enterprise standards, in the absence of national or trade standards. The enterprise standards developed by firms have a more detailed and stricter regime than the national or trade standards and their use is encouraged by the Chinese government. Article 7 of the Standardization Law distinguishes two different categories for national or trade standards: compulsory and voluntary standards. Standards directly related to the safety of the person and of property have a compulsory character; all others are voluntary.

The formulation of standards in China includes the involvement of the following actors: trade associations, scientific research institutions and academic organizations. The draft text of the standard is defined by a committee of experts on the specific technology and is then evaluated by the standardizing organization. After the adoption of the text, an automatic review system is initiated to examine the relevance of the formu- 
lated standard, "in the light of scientific and technological development and the needs in economic construction". 86 The implementation of compulsory standards is, by their nature, mandatory; the Chinese government strongly recommends the implementation of voluntary standards by firms.

The Chinese system has four different categories of standards: national standards (guobiao), coordinated by SAC or MIIT, industry standards (hangbiao) developed by industry associations or SDOs, local standards (dibiao) developed by provincial administration, and enterprise standards (qibiao) developed by individual companies. ${ }^{87}$

The product authentication of the goods subject to the standard is guaranteed by certificates issued by the standardization administration department under the State Council.

The technical requirements for goods that are to be exported is governed by the specific contractual provisions. Goods that do not meet the requirements of the standard, although they use the certification, could result in both civil and criminal proceedings for the firm concerned. As a consequence, a firm can be fined, the sale of goods can be stopped and personnel involved with the supervision of the implementation of the standard can be subjected to disciplinary actions and/or criminal actions. ${ }^{88}$ As mentioned before, there is an apparent lack of transparency in the standard-setting processes in China. Standards are often developed behind closed doors with only the participation of selected (state-owned) firms.

From a policy point of view, the Chinese government stresses the importance and development of energy- and resource-saving standards. Other politically sensitive issues in the Chinese standard debate are safety- and security-related standards for mining, traffic and environmental protection, but also security issues related to cyberspace, media-content, access to the internet, etc.. The Chinese government is constantly involved in the discussion on technology transfer and IP policies to leapfrog industrial development and to support the conversion process of the Chinese economy. The signing of a Memorandum of Understanding (MoU) between CEN, CENELEC, ETSI, and the Standardization Agency of the People's Republic of China (SAC) led directly to the establishment of the CESIP (China-EU/EFTA Standardization Information Platform), which makes the information on both systems more easily accessible and more understandable. ${ }^{89}$

\subsection{CHINESE TECHNOLOGY STANDARDS}

After the accession of China to the WTO, non-tariff barriers gained importance in China's trading policies. In global trade, standardization can give a competitive advantage

\footnotetext{
${ }^{86}$ Article 13 Standardization Law of the PRC.

${ }^{87}$ Ong Strategies for Participating in China's Standards Regime.

${ }^{88}$ Standardization Law of China Ibid note 83.

${ }^{89}$ CESIP China-EU/EFTA Standardization Information Platform website: https://webgate.ec.europa.eu/cesip
} 
to the country or trading bloc developing a world-wide accepted standard. The following quote from a Chinese civil servant is often used is this context and underlines the importance of standards for the Chinese economy: "Domestic standards are critical for China's development. First tier companies sell standards. Second tier companies sell patents. Third tier companies sell products." 90

A common practice of the Chinese government is to develop a national standard that differs slightly from the internationally accepted standard. By developing its own national standard, Chinese companies do not have to pay royalty fees to foreign patentowners. The $12^{\text {th }}$ Five Year Plan for the Internet of Things expresses the aim of establishing more than 200 Chinese standards before 2015. The size of the Chinese consumer market is a convincing argument for foreign companies to accept national Chinese standards instead of international standards. For the PRC government, standards are directly linked to national economic growth strategies, moving from cheap labour manufacturing to more value-adding economic activities. Interoperability standards are extremely important, since they facilitate the participation of Chinese firms in global production networks and enable the latecomers to the innovation process to catch up with the EU, Japan and the US.

\subsubsection{Overview of different approaches by the Chinese government, comparing international and national standards}

\begin{tabular}{|c|c|c|}
\hline Technology-Product Category & International Standard & Chinese Standard \\
\hline Wireless-Home Networking & Wi-Fi & WAPI \\
\hline Wireless-Mobile TV & 3G; WiMAX & TD-SCDMA; McWii \\
\hline Wireless-Storage & RFID & China RFID \\
\hline Security-Personal Computers & TPM (Trusted Protocol Manager) & $\begin{array}{l}\text { TCM (Trusted Cryptographic } \\
\text { Manager) }\end{array}$ \\
\hline $\begin{array}{l}\text { Consumer Electronics-Terrestrial } \\
\text { TV }\end{array}$ & DVB-T & DTMB (Compulsory) \\
\hline $\begin{array}{l}\text { Consumer Electronics-Satellite } \\
\text { DTV }\end{array}$ & DVB-S & ABS-S \\
\hline Consumer Electronics-IPTV & Open IPTV & CCSA \\
\hline Video Codec & Various MPEG formats & AVS \\
\hline DRM (Digital Rights Management) & Marlin, OMA DRM, or DTCP-IP & China DRM \\
\hline
\end{tabular}

Traditionally, standards were used to support the progressive specialization of countries, supporting the aforementioned US view on innovation. In the present business environment, standards reduce transaction costs and enable the production of goods in

\footnotetext{
${ }^{90}$ Atkinson Report, Enough is Enough: Confronting Chinese Innovation Mercantilism page 42.

${ }^{91}$ Charlton \& Wei (2010). Doing Business in China page 44,
} 
different parts of the world. The present plurality in standardization practices and legal antitrust regulation is caused by the diversity in standardization capabilities of countries and trading blocs.

Dieter Ernst made interesting observations on the relationship between intellectual property rights and economic development and the consequences thereof for standardization processes. His main point is that IPR protection and enforcement can contribute to the economic development of a country, on the condition that the IPR regime is part of an innovation strategy that tries to develop a broad-based innovation structure leading to more advanced absorptive and innovative capabilities for firms in that country. ${ }^{92}$ The theoretical distinction between standards as a public good (free, collective good) and patents (private good, exclusive use by the patent owner) is becoming more complex, especially in a business environment like China. In the EU and the US, success of standardization is measured by return on investment (recoup argument), rent-seeking strategies and a high market-share. Latecomers to standardization like China, starting from a different market presumption, may use different factors to evaluate the success of standards.

Ernst gives the following summary:

"- maximization of learning effects and standardization capabilities;

- the avoidance of strategic patenting by owners of essential patents that could block innovation;

- reduction of licensing costs to avoid getting caught in the so-called patent trap;

- broadening of the scope for innovation to avoid technology lock-in by not blocking foreign standards;

- the protection confidentiality, integrity, and availability of data through information security industry standards;

- the facilitating and broadening of the diffusion of best-practice productivityenhancing generic technologies;

- initiatives that create open and transparent standardization processes that are in line with WTO and other international regulations;

- supporting and effecting governance mechanisms and institutional architecture of international standards-setting bodies;

- the development of a capacity for flexible and fast adjustments, in cases where policies do not produce the expected results." 93

\footnotetext{
92 Ernst, Standards Innovation and Latecomer Economic Development, East-West Center page 9.

93 Ibid page 14.
} 
The conclusion is that China cannot simply copy or imitate the European or the US standards system models. The aims of the Chinese standardization policy are three-fold:

- "National Chinese standards are a reaction against the high royalty fees and the limited means to create new barriers to entry as a result of the WTO commitments.

- Standards are a policy-tool for the planned development of an increasingly market-oriented economic regime.

- The TD-SCDMA standard was developed to be more complementary with Western telecom standards and is therefore part of a mixed network." 94

The TD-SCDMA standard will be discussed in chapter 4.

In respect to the last point, it can be noticed that the Chinese government is in the middle of a learning process in relation to the growing complexity of global ICT standardization. The Chinese government is struggling with balancing the different interests in ICT standardization. As a latecomer economy, China has to accept that the ICT standards are developed for a multinational business and that strategy and invention does not only affect the Chinese market.

Experts see a new shift from the traditional indigenous innovation policy to a policy that embraces the participation of MNCs in standard-setting processes and supply-chain management. The development of national Chinese standards in the telecom sector is expensive, raises questions about interoperability and is not consumer friendly. A stronger participation in international standard development prevents lock-in to national Chinese standards that might conflict with WTO commitments. ${ }^{95}$ Chinese participation in the LTE standard, which is largely defined by the market, is another indication of this policy move.

Cultural, historical and political reasons prevent a truly commercial, market-led standardization process in China, although global trade and the interdependence of global production networks necessitate a certain level of convergence of the different

\footnotetext{
${ }^{94}$ Some scholars, such as Suttmeier (2005) in A new techno-nationalism? China and the development of technical standards, see this as an example to block FDI from the Chinese market and describe this as "techno-nationalism". The traditional answer of the PRC government is that they conduct a policy of "technology neutrality". Some commentators developed the concept of the "social-shaping of technology (SST) relating to the unpredictability and dynamism of modern technological innovation. The interdependence of Chinese firms and FDI is a reality. In the telecom industry, the Chinese companies need MNCs for the software and chipsets and the MNCs need the Chinese firms for access to the Chinese market and for the joint development of TD-SCDMA compatible systems. See for more background information Article: From 3g to 4G: standards and the development of mobile broadband in China, Seoul conference.

${ }^{95}$ WTO ANALYTICAL INDEX: Technical Barriers to Trade Agreement, The Chinese government must react to the political pressure of the EU and USA to meet the WTO technical neutrality requirement. Furthermore the interests of Chinese equipment suppliers and the demands of the national and export markets need to be matched.
} 
systems. Ernst advocates a hybrid system of both the US and present PRC system for the Chinese economy. ${ }^{96}$

The European system of standardization could be more suitable for the specific Chinese needs and demands, since it still has some semi-governmental influences (EU) and does not rely completely on market forces to come up with the appropriate standard. Especially latecomer economies to the innovation and standardization environment would limit their risk by allowing more market-influence but still giving the central government the opportunity to lead some of the standardization efforts. The leapfrogging of economic development in China is supported by industrial policy tools that still discriminate against foreign innovative products. An ETSI-style of standardization, which combines both market influence and governmental influence, could lead the way for standardization in China.

Some scholars favour a hybrid system of the present Chinese government-led standardization system and the US system that relies on market forces, open trade and strong IPR enforcement. The EU system of standardization does allow for the influence of both market parties and public needs and could serve the Chinese requirements better, since the risks of the free market are limited. In the present catch-up phase of latecomer economies like the PRC, a full reliance on open market forces might not always serve consumer welfare. Given the interdependence of international production processes, the Chinese government has to change its present system to continue the leapfrogging efforts of its economy.

In the WTO Trade Policy Review 2012 on China, members still expressed the desire that China increases the transparency of its national standards and collaborates to a greater extent with international standardization organizations. In relation to IPRs, problems were identified in the field of technology transfer and the enforcement of intellectual property rights. ${ }^{97}$

\subsection{THE EUROPEAN UNION AND CHINESE STANDARDIZATION}

In the European Union, standardization supports the goals of single market integration. In individual Member-States, such as Germany, standards also support industrial export policy, whereas in the US standards support the development and the direction of specific industry sectors, for example, ICT. There are three European standardization organizations: ETSI, CEN and CENELEC. European standards are developed on an individual basis but the European Union may request the European standardization organizations to develop European norms. This request takes the form of standardization mandates, leading to harmonized standards. In the ICT sector, the EU explicitly requested that ICT

\footnotetext{
${ }^{96}$ Standards Innovation and Latecomer Economic Development Dieter Ernst, East-West page 15.

${ }^{97}$ WTO Trade Policy Review of China 2012 http://www.wto.org/english/tratop_e/tpr_e/tp364_crc_e.htm
} 
standardization supports EU policies such as health, transport, the Internet of Things, etc. $^{98}$

Jakobs mentioned, in a recent paper, that a major focus of the Chinese innovation strategy is to develop R\&D in support of standardization. ${ }^{99}$ In the same article, the author refers to a presentation by Levin, a representative of the ITU. Levin concludes that, in order to breach the Standardization Gap, China needs to involve more private parties in the standardization process. The present level of coordination and cooperation between the government and private parties is insufficient and not comparable to European practices. International standard organizations like the ITU should encourage the PRC government to participate on a wider basis in its processes. At the moment, Technical Standardization Committees consist mainly of academic experts and no or very few representatives from the business world. During the development of the text of a standard, there is no open consultation phase and no real influence of firms that may voice the needs and demands of the Chinese consumer market. ${ }^{100}$ A major challenge for the Chinese government is to adjust the national technology policies that directly dictate the formulation of and participation in standardization to the rapidly changing technological developments.

The new objectives of the Chinese standardization policy are:

- National security goals: technological independence of Western technologies.

- Flagship standards, like TD-SCDMA and AVS, must demonstrate the technical abilities of China.

- The export of national Chinese standards to other countries.

Rongping and Zhouliang come to the following conclusions:

- The Standardization Law of China is not flexible enough to meet the demands of the rapidly developing technology markets.

- There is no direct relationship between technical standardization processes and technological innovation policies in China.

- There is insufficient coordination between the different stake-holders, central, regional and local government, different national ministries and private parties. $^{101}$

\footnotetext{
${ }^{98} 2010$ - 2013 ICT Standardisation Work Programme for industrial innovation' [EC, 2012].

${ }^{99}$ Looking East - How Does Europe Perceive the (Future) Role of China in ICT Standardisation? Jakobs page 11.

${ }^{100}$ The Role of Standards in National Technology Policy in China, Zhuoliang Institute of Policy and Management, Chinese Academy of Sciences page 7.

101 Ibid page 20.
} 
The Chinese and European systems of standardization show some similarities. The EU system operates on the basis of co-regulation; companies and governments work closely together. The Chinese system is closer to the European system, in which the state acts as a facilitator of the standardization process. The US system is more in direct competition with the PRC standardization system and perceives the Chinese standardization efforts as a direct threat (mercantilist policy). Some scholars hold the opinion that the EU takes a more relaxed stance on the Chinese standardization policies, although problems in the IPR-field still remain. The policy implication is that the EU and China should work more closely together, which could also have consequences for competition policy regulation.

\subsubsection{Comparison of the different approaches of the EU, US and China to standardization}

The standards environment is a complex interaction of different actors and methods used to create standards. To enable the exchange of technical information ultimately leading to a new standard, engineers, scientists, manufacturers, and the public sector need an infrastructure to operate the standard-setting process. Globally, the infrastructure of standard setting varies greatly. In the European Union and in the Pacific Rim, a system of formal standardization was introduced, consisting of centralized Standard Setting Organizations (SDOs) or Standard Setting Organizations (SSOs), funded and officially recognized by governments and other public bodies. The European Union Directive 98/34/EC gave CEN, CENELEC and ETSI official recognition as formal standardization institutions. The characteristics of formal standardization institutions guarantee a certain "fairness" of the system of standardization with elements such as openness to participate, decision making based on consensus, the principle of due process, open access to documentation and respect for the position of intellectual property rights. The latest EU Regulation 1025/2012 recognized that standard-setting organizations are subject to competition law and are considered to be an undertaking. ${ }^{102}$

In the United States, standardizing bodies have no unified agenda; they are decentralized and funded by the contributions of their members, limiting their effectiveness compared to their European counterparts. Next to the official standardizing institutions, there are also consortia, which are companies and universities involved in the concept of open innovation that can be defined as informal standardization bodies. The United States government does not have a formal role in the standardization and the process is purely led by companies. The US standardization strategy promotes voluntary standards based upon the principles of consensus, openness and transparency.

102 EU Regulation 1025/2012 article 13. (http://eurlex.europa.eu/LexUriServ/LexUriServ.do?uri=OJ:L:2012: 316:0012:0033:EN:PDF) 
In China, standards are part of governmental policy and a tool to support national industry. The responsibility for the agenda for drawing up new standards lies primarily with the relevant national Chinese industry. Recently Chinese companies have gained more influence in this process.

The European Union can mandate the development of a standard, e.g. a telecommunications standard by ETSI. Although only a limited number of EU standards are created by mandate, this puts the European system, in the position between the complete voluntary, market-driven US-system and the government-led Chinese system.

In the comparison, it can be noticed that the European and Chinese standardization systems have more similarities. In both systems, the Technical Committees consist of Working Groups. The Working Groups draft a standard, which can be reviewed after consultation of the stakeholders. Although the involvement of stakeholders in Technical Committees involves relevant stakeholders, it is very challenging for foreign companies to actually participate in the standard setting. Finally the Chinese Standards Administration of the People's Republic of China (SAC) has to approve of the standard.

\subsection{CONCLUSIONS}

The main aim of this chapter is to stress the importance and relevance of standards for the innovation processes in three of our major trade blocs: the European Union, the US and China. The present tension between IP laws and competition laws in the field of standardization was touched upon briefly. Standards may hinder innovation by exclusively promoting national technology, although better foreign alternatives are available. The major aim of the WTO TBT Agreement is to prevent standards from creating new obstacles to international trade. Standards are ruled both by IP laws and competition laws and the prominent part that standards take in the current TTIP-discussions illustrate their strategic importance. Jointly developed EU-US standards will give competitive advantage to their industries, but especially to SMEs on both sides of the Atlantic. Although the TTIP is often associated with trade liberalization, some commentators see it as a defensive manoeuvre against the growing influence of emerging economies (e.g. China). ${ }^{103}$

This chapter provides an overview of the most important elements of the standardization discussion. The different categories of standards and classifications were explained. EU standardization is clearly connected with industrial policy, the Digital Agenda and the competitiveness of the ICT industry. The European Standardisation System supports the main objectives of the EU. To facilitate this process, the EU Commission can mandate the development of new standards to the European SSOs.

\footnotetext{
${ }^{103}$ Steinbock, The Emerging US-EU-Asia Trade Triangle CHINA US Focus.mht http://www.chinausfocus.com/ finance-economy/the-emerging-us-eu-asia-trade-triangle/
} 
For the United States, ANSI manages a standards system that is based upon voluntary standards. The United States Standards Strategy is based upon the principles of the WTO TBT Agreement.

The Chinese system of standardization is not voluntary but it is characterized by a strong governmental influence. The plurality of actors involved and the different policy objectives increase the complexity of the system. Both the European Union and the US try to influence the standardization in China.

In order to gain an understanding of the scene, this chapter was concluded with a brief comparison of the three standardization systems.

The next chapter will discuss the intersection of competition law and IP law in more depth. The main antitrust concerns in relation to IP in standards will be explained from the different perspectives of the US, EU and Chinese regulators. Possible solutions for the abuse of IPRs in standardization processes will be evaluated in relation to the basic analytical concepts of US antitrust law, EU and Chinese competition law. The European and US antitrust laws have a longer tradition in the field of IP and competition law. From an initial negative stance, both agencies developed a positive attitude towards the use of patents in standardization. I will show how this development was led by economic influences. The economic analysis remains at the centre of the antitrust discussion. Especially in the case of China, special attention must be paid to its current position as a standards taker. In the next chapter I will focus on the importance of economic research and the relevance thereof for an antitrust analysis of the strategic use of patents in standardization.

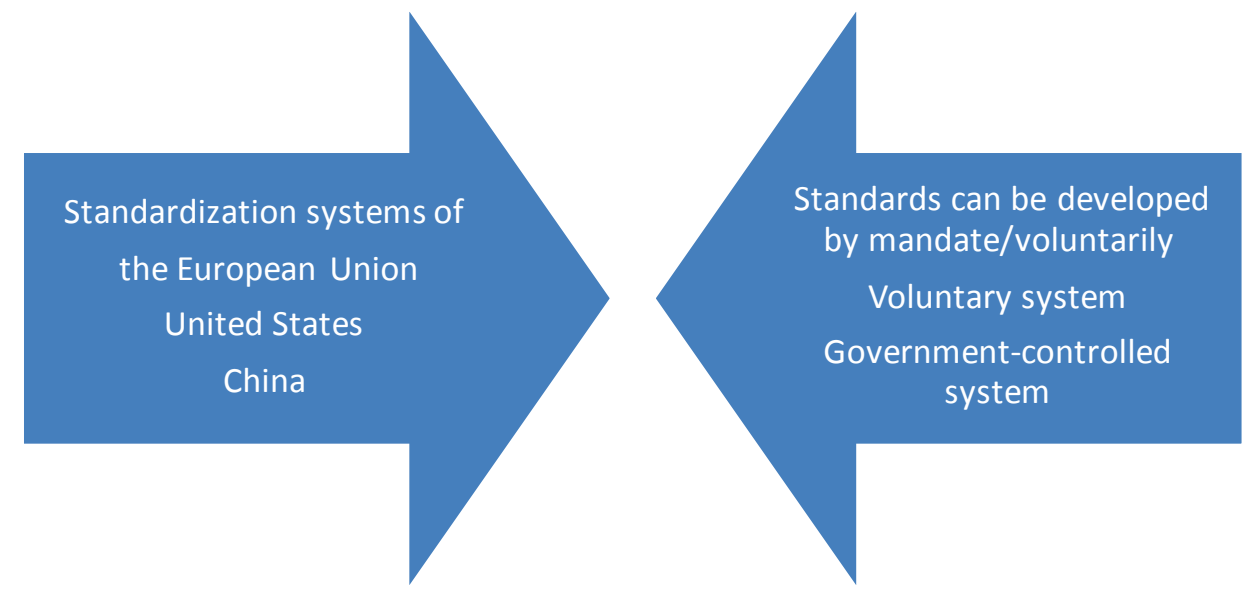




\section{CHAPTER 3}

Competition policy, patents and standard setting 



\subsection{PART A COMPETITION POLICY AND PATENTS}

This chapter will give a more in-depth view of the current debate. To facilitate this indepth understanding, this chapter is divided into two parts. Part A will focus on the general aspects of competition law in intellectual property and standardization. The complexity of the intersection of both fields and competition law will be explained. Part A will conclude with a general examination of the necessity for competition authorities that monitor patents and standards to carry out economic analyses. Part B will examine more specifically the strategic use of patents in standardization in the three jurisdictions. Since this research concentrates on the telecommunications sector, Part B also investigates the antitrust concerns and enforcement implications for this specific market. For a better understanding of the complexity, the most important elements of the discussion will be explained in detail.

The reader will understand the possible negative impact on competition of the strategic use of patents in standard setting. But a closer look also reveals the complexity of the discussion. Part of the complexity is related to the fact that there is often "miscommunication" between intellectual property and competition lawyers. Both fields use different starting points for discussions on this theme. The patent system is currently under fierce attack. Although most of the criticism is justified, there are presently no realistic alternatives. The patent system created technology markets that otherwise would not have existed. Antitrust agencies are very interested in the definition and application of validity and essentiality criterions. As stated in the opening lines of the paragraph on methodology, the concept of a monopoly has different meanings in economics and law and it is often confused. Petit introduced the concept of "stealth licensing". Stealth licensing refers to the phenomenon that patent owners see their rights of exploitation limited by agencies, antitrust enforcers and courts across the world. In the definition of the concept, Petit explains the construction in which a patent right equals a monopoly. ${ }^{104}$

As explained earlier, a monopoly in the context of standard setting can be based upon the market share/market power of the company that owns the patent or on the patent right itself. The distinction between these two is essential for the discussion and for the question whether the criterion of market power (in the EU context) is fulfilled. For a patent right to be equal to a monopoly, per se, simplifies the discussion and the

\footnotetext{
${ }^{104}$ In this context the author refers to CJEU, C-468/06 to C-478/06, Sot. Lélos kai Sia EE and Others v GlaxoSmithKline AEVE, [2008] ECR 1-7139: §64 "a medicine is protected by a patent which confers a temporary monopoly" and Commission Decision, Google/MMI: $\$ 54$ "The specificity of SEPs is that they have to be implemented in order to comply with a standard and thus cannot be designed around, i.e. there is by definition no alternative or substitute for each such patent. Therefore, each SEP constitutes a separate relevant technology market on its own."
} 
burden of evidence for competition authorities. This example demonstrates the complexity of the discussion. ${ }^{105}$

At the end of this chapter, the example the concept of patent misuse provides a fresh and interesting perspective on the standards-patents discussion. This concept raises the question whether it should be antitrust or IP law that is best suited to regulating technology markets. Economic analysis proves to be at the heart of the matter. Elements such as the classification of patents, the impact on competition policy and the different EU and US perspectives demonstrate that there is no easy solution for the "problem of patents in standards". Some of the economic research in this field is still developing and the development of competition law would immensely benefit from the input of good, independent economic research in this field.

Some presumptions are easily applied by antitrust authorities, although economists sometimes hold a very different view.

In the present standard-setting environment, patents are still a predominant feature, despite the rise of open source development. Companies like IBM publicly favour open source development of their technology but they carefully administer and manage their patent portfolios. A patent portfolio illustrates the innovativeness of a firm and can be reflected in a specific marketing policy. The use of patents in a proposed standard can suggest and underline the exclusivity of the related product or service and can directly exclude competitors from using the standard. More importantly, patents are used as trade tools to do business with competitors via cross-licensing. The role of patents in a standard- setting context is of growing concern for competition authorities. A patent will automatically involve a certain amount of coordination between the patent holder and the implementer of the technology. The high number of patents in a standard will automatically lead to intense contacts between various firms in different stages of the commercialization of products and or services. Some scholars argue that a patent licensing agreement constitutes by nature a settlement of a dispute on intellectual property rights. ${ }^{106}$ The licensing agreement royalty rate is heavily influenced by the technical ability of the licensee to develop possible alternative technologies. If the licensee can use alternative technologies, this reduces his dependence on the patents of the licensor. Even the instrument of cross-licensing, which is very common in the standardsetting process, is dictated by the weight of the respective IP portfolios of the different participating companies. The economic value of the IPRs in mergers and acquisitions and the strategic management thereof also requires careful consideration.

There is little doubt that the standardization of technology leads to economic advantages for the relevant trading bloc. The interoperability of different technologies gives access to a wider market and influences the competitiveness of both trading blocs as well as individual companies. Given this strategic importance, competition authorities

\footnotetext{
${ }^{105}$ See also Petit, Stealth Licensing page 13.

${ }^{106}$ C. Shapiro Antitrust limits to patent settlements RAND Journal of Economics Summer 2003.
} 
have developed a keen interest in the standardizing process and its possible negative influence on competition in recent years. Standardization has limited the oversight of national authorities in the international competitive environment. The R\&D activities in the globalized telecommunications industry are centred around the concept of Global Production Networks (GPN). By diversifying their production around the world, multinational enterprises can engage in forum selection, making the control of (regional) standardization efforts more difficult.

The discussion on the relationship between competition policy and intellectual property rights (i.e. patents) is very complicated and heavily debated. The positive influence of patents on innovation can be summarized in the following way: patents give inventors rewards and incentives for their work (recoupment) and protect the inventor against infringements by other parties. By nature, patent holders need to disseminate the results of their inventions, thereby promoting knowledge diffusion and the development of new technologies based on the original patent, via licensing agreements. Patents also decrease inefficient investments in the development of out-dated technologies.

Machlup justifies the patent system on the following grounds: patents provide the developer with an incentive for his inventive work. Not just the invention itself but also investments on further development can be motivated by the patent right. The temporary monopoly of the holder of the patent right is an adequate compensation for making his secret publicly known. In the view of Machlup, the patent system creates a technology that probably would not have existed in the absence of the protection and rewards of the patent framework. ${ }^{107}$

Scherer and Ross explain the role of patents in technological innovation. The basic logic of the patent system includes the notion of "sunk" investments. This notion plays an important role in the economic analysis of patents in standards. The word "sunk" refers to the situation that the front-end investments are made and consequently the inventor must hope that the after commercialization, post invention prices will be high enough to recover the initial investments. This expectation will be supported by the temporary protection from imitating competition. Patents give the owner a property right which can be used to recoup the original sunk investments. This is a fundamental rule that should be respected throughout the patents and standards discussion. Likewise,although presently new future scenarios are being developed, there is still no alternative for the patent system which could be used in the technology market. ${ }^{108}$

Whereas the positive contribution of patents to innovation has never led to serious discussions, the present rapid development of new technologies has cast some serious doubts on the efficiency of the instrument of a patent as facilitator for technological progress and change. In a policy document focusing on future developments, the Euro-

\footnotetext{
${ }^{107}$ Machlup, page 167.

${ }^{108}$ Scherer and Ross page 622.
} 
pean Patent Office already considered various and different scenarios for the future role of patents. ${ }^{109}$ The major concern in relation to innovation lies in the exclusive character of the patent. This exclusivity may prevent or hinder competition and could hamper the efficient location of resources. The exclusivity of the patent right enables the holder:

- $\quad$ to have temporary advantages during the pending application

- to acquire a monopoly position based on the merits of the technology

- in case of essential patents, the holder will be invited to participate in the standardization process

- to charge royalty fees for the use of the patented technology

- $\quad$ to upgrade the public image of the firm (for future investors)

- $\quad$ to exclude others from making, using or selling the patented invention

- to sell, transfer or abandon the patent ownership.

The transferability of the patent right enables the holder to concentrate on his innovative capabilities and outsource the enforcement of his rights to third parties.

Patents can confer a monopoly position upon the holder of the rights. Since antitrust laws almost automatically oppose monopoly positions held by firms, this makes the relationship between doctrine addressing patents and competition policy troublesome. This tension is intensified by the fact that patent theory does not strictly clarify the boundaries of the legitimate use of the patent grant. The tension between the IP and competition law system is becoming more apparent. Some scholars believe that competition law should address the failures of the patent system. Others believe that IPRs should not be treated differently from any other property right. Lundqvist makes the correct statement that patents and competition cannot exist without each other. Patents enable the trading of inventions and thus competition. As concluded above, patents create incentives to develop new products which increase the competition on technology markets. ${ }^{110}$

\subsection{COMPETITION POLICY AND INTELLECTUAL PROPERTY}

The following examples of national innovation policies illustrate that governmental intellectual property strategies influence their competitiveness and that some coordination with their competition policy would be necessary. The US 2010 Joint Strategic Plan

\footnotetext{
${ }^{109}$ European Patent Office Scenarios for the future: how might IP regimes evolve by 2025? What global legitimacy might such regimes have?

${ }^{110}$ Lundqvist page 89.
} 
on Intellectual Property Enforcement mentions as one of its major goals "the promotion of innovation and security of America's comparative advantage in the global economy" ${ }^{111}$ Later, the same document refers to the use of trade policy tools to promote the enforcement of US Intellectual Property rights in order to secure the competitive positioning of the US. The European Union Industrial Property Rights Strategy of 2008 stresses the importance of intellectual property rights and more in particular patents for the EU Single Market, but it also states:

"Despite these benefits, industrial property rights are not an end in themselves. Policy needs to consider the trade-off between offering an exclusive right and the diffusion of new products and processes in order for industrial property rights to continue to produce economic and social benefits in the future."112

In the same document one section is specifically devoted to the interplay between intellectual property rights and competition.

The Commission starts by explaining that the creation, registration and enforcement of intellectual property rights (i.e. patents) in general do not violate EU competition rules. As a classic example of the infringement of competition rules by IPRs, the Commission mentions the case of patent ambush in a standard-setting process and goes to great lengths to explain how the ex ante rules of SSOs can have a pro-competitive effect. Ex ante rules refer to the obligation that patent owners disclose their patents and licensing terms before the standard is established. It is very interesting to note that the report concludes that, in general, it is not the task of the EU competition authorities (the Commission) to evaluate the rules of SSOs but to support the different industry sectors by giving some guidance on what constitutes anti-competitive elements in their IP policies. Thus, the Commission has started with an approach which is partially continued in the guidelines for Horizontal Agreements in their competition policy. The EU Industrial Property Rights Strategy led to another Commission report, "Towards an increased contribution of standardisation to innovation in Europe." ${ }^{113}$ In this report, the intersection of IPRs and competition policy is identified as an area for further study and research. The Commission encourages SSOs to use FRAND rules in their IP policies but also announces the launch of a fact-gathering study in the above-mentioned field. ${ }^{114}$ The 2008 EU Strategy report failed to address alternative business models relating to IPRs (FLOSS, open source innovation) and excluded certain instruments (such as trade secrets) from the discussion. The main reason for this approach was possibly linked to

\footnotetext{
${ }^{111}$ Executive Office of the President of the United States: 2010 Joint Strategic Plan on Intellectual Property Enforcement p.3.

112 Idem p.5.

${ }^{113}$ The Commission of the European Union: Towards an increased contribution of standardisation to innovation in Europe; Communication of the Commission to the Council, the European Parliament and the Economic and Social Committee.

114 Idem p.10.
} 
the economic interest that EU-based multinational enterprises had in maintaining the current patent-focused standardizing, although, with fast-moving technologically-based industries taking the lead, the reality might be very different. Given the strategic aim of innovation and the Lisbon Agenda, it is questionable whether this stance of the Commission will support the global competitive positioning of the European Union. ${ }^{115}$

The US International Trade Commission (ITC) published a report which specifically mentions the difficulties that SMEs face regarding the use of patents in standardization. The costs of participating in or adhering to the standards process are an important trade barrier for US firms. ${ }^{116}$

A leaked document of the TTIP negotiations shows that the US and the EU are keen on "streamlining" their differences in national patent law systems. Both trading blocs want to achieve more international cooperation and thereby pave the way for jointlydeveloped IP in standards. ${ }^{117}$

\subsection{COMPLEXITY OF THE LEGAL ASPECTS OF STANDARD SETTING}

The intersection of standard setting, IPRs and competition law has become more and more complex in recent years. In a way, standards have some of the same characteristics as IP rights. From an economic perspective, they both produce increased welfare through product improvement, not a process which decreases the marginal costs of the product. Standardization increases the societal value by improving both the horizontal and vertical compatibility of products and thereby also creating a downstream market. At the same time, standard setting facilitates exclusion (a common feature of patent rights) and collusion. As a result, antitrust authorities should identify the circumstances that lead to anticompetitive effects of the use of standards and pay special attention to these circumstances, possibly addressing them through the regulatory framework of the SSOs. The emergence of the "new economy" in the nineties and the present economic environment, in which telecommunication companies compete via rapidly changing

\footnotetext{
${ }^{115}$ For the relevance of open source innovation see also: Rayna et al Large-Scale Open Innovation: open source vs. patent pools; Lambardi: Software Innovation and the Open Source Threat.

${ }^{116}$ United States International Trade Commission report, Trade Barriers That U.S. Small and Medium-sized Enterprises Perceive as Affecting Exports to the European Union states: "Respondents reported that numerous EU trade barriers, particularly standards-related measures, limit SMEs' exports to the EU more than those of large exporters". "They explained that while complying with standards, technical regulations, and conformity assessment procedures is costly for larger firms, it is potentially prohibitive for SMEs because many costs are fixed regardless of a firm's size or revenue. Respondents also cited difficulties involving trade secrets, patenting costs, and logistics challenges, especially customs requirements, Harmonized System classifications, and the EU's value-added tax system. Trade financing in the EU was reported to be a lesser problem. It also cites industry-specific barriers.

${ }^{117}$ See for more background: Ress: Knowledge Ecology International Leaked EU analysis of TTIP IPR negotiations.
} 
technologies, has made the discussion of standardizing and competition policy very complicated. The classic answer from Neoliberal economists is that the deregulation of the telecommunications sector and the privatization of former state-owned enterprises would be the way forward.

The deregulation of the telecommunications sector saw the emergence of strong globally active firms. In order to protect consumers against a few dominant companies, competition authorities closely monitor the actions of the firms.

In this sector, one complicating factor is the existence of network externalities (discussed in chapter 2), which leads to "the winner takes all" effects and gives unreasonably high profits to the most successful technology embedded in a standard. Globalization of the trade in telecommunication services and products has led to increased Foreign Direct Investment (FDI) firstly in the Triad countries and later in new emerging markets. ${ }^{118}$ The geographical location of the FDI is influenced by the national regulatory environment in the fields of competition law, tax competition and, to a lesser extent, intellectual property rights protection. The bundling of these factors results in integrative complexity, since the interaction of intellectual property (such as patents) in the standard-setting process can be used for anti-competitive means. Elements such as the globalization of production and of the research and development process, together with the rapidly developing technology in the telecommunications sector add to the complexity and integration of different factors relevant to the discussion. Last but not least, the difference in economic growth and development between the various trading blocs like the US, the European Union and the PRC has a major impact on the policies in both the field of intellectual property law and of competition law. The discussion of China's indigenous innovation policy in the next chapter will illustrate that emerging economies call for a distinct approach to competition policy and to intellectual property rights in the standardization process. Another clear problem is the difference between the fast-moving technological developments in the telecommunications industry in contrast with the much slower developments in the legal regulatory environment. The emergence of new business models, related to the commercialization of new technology, proves that the present regulation of intellectual property rights cannot match the speed of technological change in some sectors. ${ }^{119}$

\footnotetext{
118 Innovation, competition, standards and intellectual property: policy perspectives from economics and Drahos and Maher. This article gives a historical overview from an Australian/New Zealand perspective.

${ }^{119}$ Not just the FLOSS and open source movement but especially in the software industry highly permissive licences are used by MIT, BSD and Apache. Also the use of "copyleft licences" is a new innovative way of dealing with the changes in the software industry. The FLOSS movement aims at a participative process between the EU and SSOs to ensure vendor independence in the standards development process. Lobbyists of the open source movement want the EU Commission to initiate a Software Interoperability Directive along the lines of the Interconnection Directive.
} 


\subsection{STANDARDIZATION AND COMPETITIVE CONDUCT}

The process of standard setting itself (without possible abuse of intellectual property rights) is evaluated in different ways in the US, EU and China. In general, the standardization process and its contribution to dynamic efficiency and thus innovation has already raised a few interesting debates. Standards can cause higher transaction costs, a slowing down of the innovation process, inferior technologies to be included in the standard and, last but not least, they can be used as a barrier to trade. For individual firms, participating in the standard-setting process will directly increase costs, creating uncertainty as to the legal status of their contributions to the technological standard. ${ }^{120}$

In the economic discussion, an interesting element is the timing of the establishment of the standards within the life-cycle of a new innovative product. The early adoption of a standard in the life-cycle of a product defines the winning technology and limits the uncertainty for other competitors, consumers and manufacturing firms in the downstream market. At the same time, the early adoption could lead to a lock-in situation with a suboptimal technology and high switching costs. A later adoption could result in the adoption of the best technology (optimal technology) in the standard, but the uncertainty about the winning technology might create splinter markets and reduced efficiencies. ${ }^{121}$ In network industries like telecommunications it is important to reach a critical mass point: the minimum size of the network that, given the costs and the structure of the relevant market, leads to a possible adoption of the standard. Economides argues that high marginal costs will directly influence the minimum size of the critical mass point. ${ }^{122}$ For the standard-setting context, this implies that early ex ante communication of both essential patents and licensing terms, can have a positive effect on the minimum size of the critical mass point and thus on the adoption of the standard in the market.

Ex ante communication means that IP right holders communicate what their maximum royalty rates and the most restrictive licensing terms would be in case their technology is selected within the standard. The ex ante declarations are made before the standard is adopted.

The exact timing of the communication of the ex ante policies can also influence the establishment of the critical mass point and have strong financial implications. ${ }^{123}$ Does ex ante mean before patent holders have already made their sunk R\&D investments?

\footnotetext{
${ }^{120}$ The confidentiality and dissemination rules of the SSOs are not always very clear. For some SSOs it is not clear whether the contribution to the standardization process constitutes prior art.

${ }^{121}$ For a basic overview see Hemphill: US Antitrust Policy, Interface Compatibility Standards, and Information Technology p.8.

${ }^{122}$ Economides and Himmelberg: Critical Mass and Network Evolution in Telecommunications in Toward a Competitive Telecommunications Industry: Selected Papers from the 1994 Telecommunications Policy Research Conference.

${ }^{123}$ Ann Farrar in FTC Workshop on Intellectual Property Rights in standard setting: Tools to prevent patent hold-up.
} 
The promoters of ex ante commitments often support their claims from the perspective of the licensors and implementers of the standard. At the same time, SSOs would have to balance the interests of the innovators, since the associated risks can also lead to firms holding up their investments in R\&D. From a social welfare point of view, the protection of consumers is one of the main goals of antitrust policy. Economists raise the point that the development of detailed ex ante policies by SSOs will increase the financial burden for the standard and that, consequently, the added costs will be charged to the consumers. It would be interesting to research whether the adoption of ex ante commitments versus the enforcement of ex post competition policy has an impact on the costs of the product or services that have to be charged to the consumer, which could ultimately be a benchmark for the choice made by competition authorities.

Recently, innovation economists have contributed interesting elements to the discussion. Spulber claims that technology standards do not confer market power on patent owners. In his reasoning, technology standards are endogenous, since standards and competitive conduct are jointly determined. The complexity of the interactions makes it difficult to draw causal links from technology standards to the competitive conduct of firms. Spulber challenges the traditional line of causation from technology standards to the conduct of IPR owners to innovative efficiency. ${ }^{124}$ In his view, technology standards are the result of innovative efficiencies resulting from competition and cooperation between technology firms.

Economic research raises interesting questions about the standard and competition law discussion. Elements like the influence of the critical mass point in standards for telecommunications and, consequently, the timing of ex ante communication policies of essential patents and licensing terms can be highly influential. This raises the question whether, in the interests of consumers, ex ante commitments or post-competition enforcement should be favoured by competition authorities on social welfare grounds.

Recent input from innovation economists challenges the causal inferences between standards and competitive conduct and it provides interesting elements for future research. It raises the point whether antitrust enforcers should also use empirical evidence from the fields of innovation economy and industrial organization to fully understand the functioning of technology markets.

\footnotetext{
124 Spulber moves away from the traditional Industrial Organization theory of the "Standards-Conductperformance" paradigm to a model that looks at the strategic interaction of companies during standardization. In the latter model, antitrust analysts would have to develop game theory approaches in evaluating the impact on innovation. The application of the game theory model also reflects the influence of the Chicago school (of antitrust) and modern Industrial Organization theories.
} 


\subsection{ECONOMIC ANALYSIS IN RELATION TO STANDARD SETTING AND ANTITRUST POLICY}

For many years, antitrust authorities favoured the notion of static efficiency. The more recent attention on dynamic efficiency has directed the economic research in competition matters towards the relevance of market structure. David J. Teece argues that, in the economic analysis, antitrust regulators should put more emphasis on changes in external conditions, new innovative products and new business models. Static competition is often limited to price competition without incremental innovations and does not reflect the present state of global (telecommunications) trade. The analysis of dynamic efficiency in network markets is more complicated, since the complexity, uncertainty and speed of innovative developments necessitate a different approach compared to the traditional methods. ${ }^{125}$

The necessity for economic analysis in antitrust cases is even stronger in disputes involving intellectual property rights. The existence of network effects and the vastly expanding global market opportunities have led to competition for the market instead of competition on the market in IP-related industries. ${ }^{126}$ The emergence of Global Production Networks (GPN) and the different approaches of national jurisdictions to the strategic use of patents in standards have led to forum shopping, which could easily influence FDI. The incorporation of economic analysis in US antitrust law was mainly initiated by the Law School of the University of Chicago, where price theory and microeconomics were integrated into the analysis of antitrust cases. ${ }^{127}$ In 1978 , Schmalensee made a case for the proper selection and application of specific economic models to antitrust cases. ${ }^{128}$ The use of standard economic models in antitrust would give unsatisfactory results in more complicated cases. The definition of the relevant market or of predatory pricing requires very detailed and specific economic models to analyze the actual effects on competition in the case at hand. For the discussion on the strategic use of patents in standards, this implies that, at least for the US setting, the use and selection of the appropriate economic model to analyze the actual effects on competition and innovation are extremely important. In US antitrust law, shifts in economic theory have a direct effect on the enforcement of US antitrust rules. Some authors have argued the case for the application of behavioural economics to the antitrust field. ${ }^{129}$

\footnotetext{
${ }^{125}$ Teece favours the application of both behavioural and evolutionary economics at firm level.

${ }^{126}$ See also Ginsburg and Fraser, The Role of economic analysis in Competition Law 2010.

${ }^{127}$ In 1974, Professor Posner published his book economic Analysis of Law and in 1978 Bork applied economics specifically to antitrust law in his book The Antitrust Paradox. The importance of economic analysis was further developed with the SSNIP-test relating to the definition of the relevant market.

${ }^{128}$ Schmalensee, The Use of economic Models in Antitrust: The Real Lemon Case (1979) 127 University of Pennsylvania Law Review 994.

${ }^{129}$ See also Bailey Behavioural Economics : Implications for Antitrust Practitioners The Antitrust Source June 2010.
} 
Antitrust cases in the sector of telecommunications are fact-specific and the assumptions on the decision-making processes of both consumers and producers allow for the application of non-standard economic models. The existence of network effects and the unreasonable impact of creating the winning standard could justify the application of behavioural economics to antitrust cases in telecommunication industries, to some extent. For general goods, it is assumed that consumers are identical in their valuation of competing network goods. The case of telecommunications, however, suggests that competing standards can coexist when consumers have developed heterogeneous preferences for specific goods. This limits the application of general economic models used in antitrust cases to the telecommunications sector.

The identification of the shifts in economic literature relating to the beneficial effect of the use of patents in standards on both innovation and competition is therefore essential. A paradigm shift, for example in the US context, will not, however, directly lead to changes in the enforcement of US antitrust law. The change in economic thinking must be widely accepted and established before it can have an impact on the legal decision making. The emergence of paradigm shifting in economic thinking in relation to patents and standards possibly predicts changes in the enforcement of the antitrust rules in the three jurisdictions. Since the application of economic analysis to antitrust cases started in the US, I will take this jurisdiction as example.

\subsection{PATENTS, STANDARDIZATION AND EFFICIENCY}

The starting point of the US Department of Justice (DoJ) is that standardization improves competitiveness. In order to facilitate this process, intellectual property rights in standards monetize and recoup the investments of innovative companies. The DoJ finds that the licensing of IPRs in standards can have pro-competitive effects at the end of this process. Since standards have a positive effect on innovation and, consequently, innovation results in consumer benefits, the US Department of Justice concludes that, in principle, standardization promotes efficiency, which is one of the major aims of antitrust law. The doctrine of the efficiency of social welfare is very prominent in competition laws in both the US and the EU. However, the question must be asked how do we define efficiency? ${ }^{130}$ Thomas O Barnett, Assistant Attorney General of the US DoJ, defined efficiency as, "the measure as to how much wealth is created in proportion to the inputs used." In this context, a distinction can be made between static and dynamic efficiency. Static efficiency is the streamlining of production using existing methods, but dynamic efficiency consists of using newly developed methods and techniques to improve production. Economic research has acknowledged the fact that the advantages of

\footnotetext{
${ }^{130}$ Economists within the antitrust field discuss different goals: competition policy should either achieve a total surplus or just a consumer surplus.
} 
dynamic efficiency easily surpass the benefits of static efficiency. The notion of dynamic efficiency allows for leapfrogging, which is especially important in the telecommunications industry with its strong network effects. Antitrust laws in the US aim to "protect and enhance competition and consumer welfare" ${ }^{131}$ Although there is some debate surrounding this, consumer welfare is seen as the situation of consumer surplus, defined as the difference between the actual price paid for the product by the consumer and the maximum price that the consumer would be willing to pay for the product. The consumer surplus is positively influenced in the following cases:

1. The price of the product is reduced.

2. The quality of the quantity purchased at the same price increases.

3. Substitute goods with improved technology are for sale.

Traditionally, antitrust policy always focused on the first two points but, with the emergence of new technological products, dynamic efficiency has gained more attention from competition authorities. Especially in the United States, antitrust authorities have a long tradition of incorporating economic analysis into the framework of their policies. US economists strongly believe in the relevance and societal impact of antitrust policy in relation to the regulation of markets. Since, in the US free market system, competition both supports allocative and productive efficiency, market failure must be avoided at all costs. However, the US antitrust regulators strongly believe in the self-correcting mechanism of the free market. According to the enforcement policy principles of the DoJ, markets correct failures and not government interactions. The antitrust authorities will intervene when a company violates an antitrust rule, which is officially known as the "effects-based theory". The effects-based theory does not make the monopolization or attempts thereof illegal, but the illegality occurs as soon as the monopolization has actual anti-competitive consequences. ${ }^{132}$ As a consequence, it can be stated that the US antitrust policy does not generate dynamic efficiency, but it seeks to create an economic environment that enables and fosters important innovations. ${ }^{133}$ Within the standardsetting context, this raises questions and dilemmas. The standard-setting process and the IPRs, in the form of patents, in principle both encourage dynamic competition. The inclusion of patented new technology and the subsequent licensing of the adopted standard enables innovative companies to recoup some of their investments in R\&D. The problem arises, however, as soon as the IP system is used to prevent other companies from competing with the firms owning the technology embedded in the standard.

\footnotetext{
${ }^{131}$ Statement of Deborah Platt Majoras, Chairman, Fed. Trade Commission, before the Antitrust Modernization Commission (March 21, 2006). See also Brooke Group Ltd. v. Brown \& Williamson Tobacco Corp., 509 U.S. 209, 221 (1993) (referring to the antitrust laws' "traditional concern for consumer welfare").

${ }^{132}$ The application of the effects-based theory has been widely discussed in relation to the Microsoft case.

133 Thomas Barnett of the DoJ often cites both Schumpeter as well as the Solow model for the empirical analysis of the link between dynamic efficiency and increased economic growth.
} 
According to the principles of the antitrust system, competition should be used to encourage companies entering into competition with others for the patented technology to be included in the standard. Already in 1995, the DoJ concluded that the general antitrust principles also apply to intellectual property rights. ${ }^{134}$ In the same document, it is stated that the absence of efficiency-enhancing integration of economic activity will make it impossible to justify breaches of the antitrust rules. This stresses the importance of proper economic analysis of the efficiency effects of the use of patents within standardization. Moreover, this also raises questions about the correct level of IP law protection to encourage dynamic innovation. In the absence of a uniform globalized approach, this can undermine the competitiveness of individual countries or trading blocs, since the relevance of dynamic efficiency and the methods of analysis differ per trading bloc.

The importance of dynamic efficiency for innovation is beyond any doubt. How to analyze the notion of dynamic efficiency within the standardizing context is insufficiently clear and differences (e.g. lack of predictability of the economic analysis) between the three jurisdictions can have a strong impact on the enforcement of competition rules within the standard-setting context. ${ }^{135}$

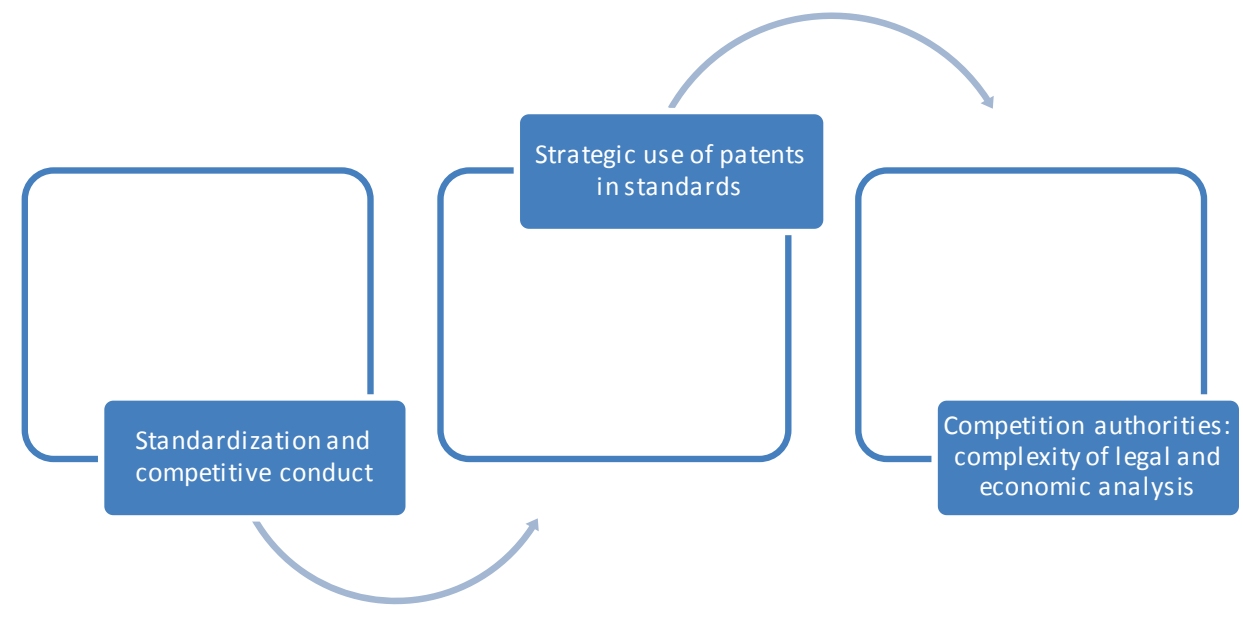

\footnotetext{
${ }^{134}$ U.S. Department of Justice and the Federal Trade Commission: Antitrust Guidelines for the Licensing of Intellectual Property DoJ.

135 In a later discussion I will compare the US and the European Union framework. The US system's longer tradition of economic analysis has clarified the "weighting of static vs. dynamic efficiency" to a larger extent than in the European Union. Unfortunately most of the economic research has been more inclined towards static efficiency instead of researching dynamic efficiency.
} 


\subsection{PART B PATENTS INCLUDED IN STANDARDS AND COMPETITION POLICY CONCERNS}

The registered patent gives the patent owner the right to exclude others from using his technology. The patent owner can give other firms access to his inventions via the method of licensing. Licensing can create more revenues for the patent owner and leads to increased diffusion and dissemination of the innovative goods. The economic impact and contribution to competitiveness is mostly determined by the licensing terms. Patent owners can license individual patents or, more often, use package deals which offer a lower royalty fee than the total sum resulting from all the individual patents. Two or more firms holding substantial IP portfolios (or even a firm just holding one essential patent to the technology), use cross-licensing to exchange their valuable IP-assets. In the case of cross-licensing, all companies are entitled to use each other's patents, often without charging any reciprocal royalties.

From the perspective of competition policy enforcers, this is almost ideal, since there is dissemination and diffusion of the patented technology without any increase in the marginal costs of the firms involved. At first sight it looks like cross-licensing should not involve any antitrust concerns, but in the case of probabilistic patents, invalid patents or patents of bad quality, the barter-trade assumption upon which the crosslicense is based is no longer valid and could lead to competition policy concerns. ${ }^{136}$ In the case of Non-Practicing Entities (NPEs), cross-licensing is much more complicated, since these firms only monetize their intellectual property rights and are not actively involved in innovative efforts themselves.

Making general statements in this field can be hazardous, since the specific characteristics of individual markets dictate their preferences in relation to the handling of IPRs in standards and, accordingly, competition authorities should also distinguish their enforcement approach. In the case of the telecommunications sector, concepts such as switching costs and lock-in effects must be evaluated in relation to the special dynamics of the relevant market. For this market, the switching costs do not only apply to the purchase of the original (primary) good but also to the purchase decisions relating to complementary (secondary) goods in the downstream market. The definition of secondary markets within the recent rate of development in telecommunications is not easy and the case law in the three different jurisdictions (especially in the US) has so far been contradictory. Most SSOs require their members to disclose intellectual property rights and licensing terms. The traditional answer has been that essential patents must

\footnotetext{
${ }^{136}$ In 2005, Carl Shapiro, Chief Economist of the Federal Trade Commission (FTC), wrote an article on probabilistic patents. One of his conclusions was that half of the litigated patents were invalid, since patent holders had failed to pay the maintenance fees before the end of the term, thereby proving the marginal value of the patent for the holder
} 
be licensed on FRAND terms. This has led to a global debate on the precise content of the FRAND conditions.

\subsection{STRATEGIC USE OF PATENTS: EU PERSPECTIVE AND THE EXAMPLE OF ETSI}

The disclosure of ownership of essential patents can be linked to either general disclosure commitments or specific disclosure commitments. For the competition authorities to take a genuine interest, it would be important to know the frequency and the dimensions of the strategic use of patents in their jurisdiction. The European Union commissioned a report on the strategic use of patents and its implications for enterprise and competition policy. ${ }^{137}$ The report noted the following key findings and policy conclusions:

1. The patenting behaviour of high-tech firms is affected by an escalation mechanism.

2. The report gave empirical evidence of a large increase in the volume of patent applications, led by the tendency of firms to use patenting strategies. The quality of the patent applications has decreased. ${ }^{138}$

3. Patenting strategies, because of their complexity limit the transparency of the IP business strategy of these firms.

4. Firms use two distinct types of patent strategies: firstly, the use of patents as important assets in the negotiating processes with other firms; or, secondly, patents will be used to restraint or block other competitors in their business expansion.

5. Firms engage in patent portfolio races as an essential business strategy.

For competition policy, the report makes the following policy observations:

a. The report suggests a sector approach of competition authorities in relation to the regulatory environment for the specific markets. The characteristics of the technology competition in the relevant individualized market must be understood by the regulators.

b. Patent rights determine, to a substantial extent, the bargaining power of firms in the negotiating process with other firms. Although this can have serious anti-

\footnotetext{
${ }^{137}$ Harhoff: The strategic use of patents and its implications for enterprise and competition policies.

${ }^{138}$ The same report notes that the level of opposition to patent applications has decreased, noticeably also in the field of telecommunications p.262.
} 
competitive implications, empirical evidence does not directly show a negative effect on the R\&D efforts of the participating companies.

c. Licensing is a key instrument against the abusive use of patent portfolios. From a research point of view, licensing is difficult to understand since reliable data is very limited.

Unfortunately, the report does not contain research on the link between the strategic use of patents and product market innovation, nor is there any detailed information on the effects of the patent portfolio races on product market competition.

As mentioned earlier, most SSOs established IPR-policies. In the next paragraph, the IPR policy of the European Telecommunications Institute will be discussed.

ETSI, the European Telecommunications Institute, has a membership of more than 700 organizations, which are not just limited to the European Union. Many of the ETSI members (national administrations, public telecommunications operators, manufacturers, private service providers, research institutions, and consumers) come from outside the European Union and benefit from the standardizing efforts of ETSI. ETSI has an IMFstyle decision-making process, wherein the voting rights are weighted according to the membership fees paid, which, in turn, depends on the member country's GDP or on the company's membership turnover. The creation of EU-specific standards is based upon consensus and National Standards Organisations must ensure the involvement of all relevant stakeholders at the national level. The national discussion on the proposed standard must provide all relevant parties with sufficient opportunities to influence the national decision.

ETSI produces between 2,000 and 2,500 standards annually. The ETSI standards support EU policies such as the New Approach, the interoperability regulation under the Single European Sky programme, Horizon 2020, and the Digital Agenda. ETSI supports EU legislation by producing many harmonized standards that are used in combination with EU directives. The ETSI standards that are mandated do not become automatically mandatory. ETSI standards can be in competition with international standards. Only $10 \%$ of ETSI standards were mandated by the EU; the remaining $90 \%$ were initiated by ETSI's members.

In practical terms, the standardization work is carried out in Technical Committees. The Technical Committees are open to all ETS members. In the Technical Committees, participating members submit technical proposals to be included in the standard. If the technical proposals are patented and strictly necessary for the standard, they then become Standard Essential Patents (SEPS). In order to regulate the tension between the patent (restrictive use) and the standard (free or collective use), ETSI developed an IPR policy. 
In its IPR policy, ETSI states the following provision:

Policy Objectives (Article 3):

"3.1 ... the ETSI IPR POLICY seeks to reduce the risk to ETSI, MEMBERS, and others applying ETSI STANDARDS and TECHNICAL SPECIFICATIONS, that investment in the preparation, adoption and application of STANDARDS could be wasted as a result of an ESSENTIAL IPR for a STANDARD or TECHNICAL SPECIFICATION being unavailable. In achieving this objective, the ETSI IPR POLICY seeks a balance between the needs of standardization for public use in the field of telecommunications and the rights of the owners of IPRS.

3.2... IPR holders, whether members of ETSI and their AFFILIATES or third parties, should be adequately and fairly rewarded for the use of their IPRs in ${ }^{139}$ the implementation of STANDARDS and TECHNICAL SPECIFICATIONS."

The basic principle of the ETSI, IPR policy is that members have an obligation to inform others of the ownership of essential patents related to the proposed standard. ETSI will require the patent owner to give an "irrevocable undertaking in writing", within three months, stating that the patent will be licensed under FRAND-terms. ${ }^{140}$

Article 4 of the IPR policy of ETSI aims to prevent patent ambush and was adopted after some political pressure by the EU Commission (DG Competition). ${ }^{141}$

\section{ETSI and the strategic use of patents}

After patent ambush, the transfer of patent rights is also often motivated by strategic considerations. ETSI recognized this fact in article 6 of the IPRpolicy, where is stated:

"FRAND licensing undertakings made pursuant to Clause 6 shall be interpreted as encumbrances that bind all successors-in-interest. Recognizing that this interpretation

\footnotetext{
${ }^{139}$ ETSI IPR policy. In clause 15 (6) of the IPR policy ETSI gives a definition of an "essential patent": "ESSENTIAL" as applied to IPR means that it is not possible on technical (but not commercial) grounds, taking into account normal technical practice and the state of the art generally available at the time of standardization, to make, sell, lease, otherwise dispose of, repair, use or operate EQUIPMENT or METHODS which comply with a STANDARD without infringing that IPR. For the avoidance of doubt in exceptional cases where a STAND$A R D$ can only be implemented by technical solutions, all of which are infringements of IPRs, all such IPRs shall be considered ESSENTIAL. Further clarification is provided in the IPR Guide of ETSI: IPR Guide, para. 1.5:

In simpler terms, an "essential IPR" is an IPR which has been included within a standard and where it would be impossible to implement the standard without making use of this IPR. The only way to avoid the violation of this IPR in respect of the implementation of the standard is therefore to request a license from the owner.

${ }^{140}$ See also art. 6.1 ETSI IPR Policy "The above undertaking may be made subject to the condition that those who seek licences agree to reciprocate". In the original proposal ETSI included the element of maximum cumulative royalties for standard essential patents that would be set by ETSI.

${ }^{141}$ Upon request of the EU Commission the original wording of " becomes aware of" was changed into "reasonable endeavours". See also presentation Kassie Smith ; Standard setting and IP At the IP and Competition Law conference Brussels September 2013 The Commission insisted that firms do not have the duty to do searches but it is not exactly clear what " reasonable endeavours" mean in practice.
} 
may not apply in all legal jurisdictions, any Declarant who has submitted a FRAND undertaking according to the POLICY who transfers ownership of ESSENTIAL IPR that is subject to such undertaking shall include appropriate provisions in the relevant transfer documents to ensure that the undertaking is binding on the transferee and that the transferee will similarly include appropriate provisions in the event of future transfers with the goal of binding all successors-in-interest. The undertaking shall be interpreted as binding on successors-in-interest regardless of whether such provisions are included in the relevant transfer documents". ${ }^{142}$

Concerned parties may use the ETSI IPR database to check for applicable FRANDlicensing declarations. The legal effect of the FRAND declarations that patent owners make to ETSI is questionable. In principle, this is a declaration under French contract law and could lead to a breach of contract law case. Recently, major patent owners (e.g. Nokia) sold a substantial part of their patents to Non-Practising Entities who are not members of ETSI. Bosch transferred their patent portfolio to IPComm, which urged the EU Commission to demand a declaration from IPComm that they agreed to license their standard essential patents on FRAND terms. ${ }^{143}$ The phenomenon of NPEs will be discussed later in this chapter.

It is important to note that ETSI does not determine FRAND rates but leaves this to the parties in the licensing agreement or to the courts. Although some academics see a role here for ETSI, they have repeatedly refused to take a leading role in the FRANDdiscussion. $^{144}$

\subsection{THE STRATEGIC USE OF PATENTS: THE US PERSPECTIVE}

In the United States, the interest of the Federal Trade Commission in the discussion on the strategic use of patents was formulated in the Antitrust Enforcement and Intellec-

\footnotetext{
${ }^{142}$ For more background see: IPR Guide, para. 4.2:

"Taking into account the importance of a robust standards system, those implementing ETSI standards should be able to rely on licensing undertakings provided in accordance with Clause 6.1 of the ETSI IPR Policy, regardless of any change in the ownership of the relevant IPRs. To that end, it is desirable that, to the maximum extent possible in each legal jurisdiction, when ownership of an ESSENTIAL IPR is transferred, any applicable licensing undertaking should automatically transfer to the new owner. Some legal jurisdictions may already provide for the achievement of this result. However, ETSI recognises that this result may not be certain in all legal jurisdictions."

${ }^{143}$ At a later stage I will discuss the present concerns in the USA on the transfer of patent portfolios to NonPractising Entities, the FTC proposed to initiate a study (6b) into this specific technology market.

${ }^{144}$ The EU Commission gives some general guidelines on FRAND in the Horizontal Guidelines para. 289-290, but it leaves the determination in specific cases to arbiters and relevant courts. See also for the later discussion of the Press release Statement of Objections in the Motorola case.
} 
tual Property Rights report, Promoting Innovation and Competition (2007). ${ }^{145}$ In this report, the FTC states that the conditional refusal to license patents must be regarded as anti-competitive and can be prosecuted by antitrust authorities (FTC). In a workshop on Standards and IP, organized by the FTC, expert panel members active in the field of standardization reported very limited cases of patent hold-up in SSOs' practices. However, the European findings in relation to the poor quality of patents, the increased volume of registrations and their strategic use as a business strategy can easily be copied for the US context. Farrell and Shapiro examined the economic impact of patents of different validity in 2008 and came to the conclusion that patents possessing a weak quality could have various negative effects, such as patent hold-up, unnecessary high royalty rates and added costs to the consumer. ${ }^{146}$ In the standardization context, the following circumstances described in the next paragraph can lead to antitrust cases.

The positioning of the patent owner within the standardization process can change during this process. If the SSO requires an early communication of the disclosure of the IP-rights on the technology brought into the discussions, this is often regarded as having positive effects on innovation and the adoption of the standard. Early disclosure rules or even mandatory disclosure rules theoretically enhance the chances that the technology will be adopted. In the economic literature, there is no common empirical evidence that mandatory disclosure rules (with punitive damages) lead to a lower level of abuse of the system. The idea is that, with a voluntary disclosure system, firms can develop or implement alternative technologies or negotiate favourable licensing terms. Before the adoption of the standard, most of the power is held by the Board of the SSO and sometimes by the purchasers of the licensed technology (establishing a buyers' cartel or an oligopoly). ${ }^{147}$ After the adoption of a new standard, the embedded patented technology can become a major source of market power for the patent owner, especially since the application of the patent for different uses might become obvious. The early ex ante disclosure of patents cannot prevent a strong ex post market power by holders of essential patents, since the standard was evolving during the time the disclosure was made and more extensive use of the patent was only discovered after its market introduction.

What is the ex ante value of a patent? Is it the difference between the asking price and the market value? The notification of the asking price can differ enormously with the ex post market value. From a practical point of view, is the timing of the ex ante disclosure of crucial importance? What is the optimal timing for ex ante disclosure? Generally, practitioners agree that as early as possible would be the best timing, but some SSOs have as a rule that the best time is 30 days before the vote on the standard.

\footnotetext{
145 US Department of Justice and the Federal Trade Commission: Antitrust Enforcement and Intellectual Property Rights: Promoting Innovation and Competition.

${ }^{146}$ Farrell and Shapiro How strong are weak patents http://www.aeaweb.org/articles.php?doi=10.1257/ aer.98.4.1347

${ }^{147}$ The FTC qualifies the joint discussion of licensing terms by licensors as pro-competitive.
} 
ETSI often applies ex post disclosure rules in order to understand the complexities of newly evolving technologies. ${ }^{148}$ Late disclosure, or ex post disclosure, may indicate a hold-up intention, although the case law is inconclusive. ${ }^{149}$ The timing aspect is important because it can also lead to a reverse hold-up situation when buyers of the patented technology put pressure on the holder of the patent rights. For the innovators, the optimal timing would probably be the moment before patent holders have made their sunk investments. The Rambus case shows that essentiality is a minimum requirement for disclosure, but it does not define essentiality in commercial or technical terms, thereby allowing firms to use the commercial essentiality in relation to their business strategy, as a possible justification. Does an ex ante disclosure requirement effectively prevent the strategic use of patents in a standard-setting context?

The members of an SSO will have collective discussions on the selection, choice and evaluation of substitute technologies. From a competition policy perspective, an SSO is a meeting point for competitors who are interrelated and active in the same horizontal or vertical markets. In the US system, licensors of the standard are allowed to engage in ex ante joint negotiations of royalty terms, since this collusion will be evaluated under a rule of reason approach and will not directly constitute a per se violation. The first concern is whether this leads to the choice of the best technology in the standard or results in the most cost-efficient technology being incorporated into the standard. The choice for sub-optimal technology will have a negative impact on the consumers' interests and the level of royalty fees might have an influence on the definite selection of the technology to be implemented in the standard. The ex ante communication of licensing terms resolves the lack of predictability of the future costs of implementing the standard. Users of the standard want to have an overview of the maximum royalty rates and the types of restrictive conditions that will be used. Given the fact that most SSOs have made a choice to include the compulsory application of FRAND-conditions in their IPpolicies, this can have negative results. The application of the FRAND conditions limits the economic incentives available for innovative firms. Patent owners often set very high prices (within the FRAND framework) in order not to be limited in the future when their patents can have other uses than originally foreseen. In order to balance this influence, the FTC allows collective bargaining by users on the licensing terms of the standard. The FTC argues that the essential patents give their owners incremental market power and, therefore, are welfare enhancing and protect the interests of consumers. ${ }^{150}$

Under the EU regulatory framework, this joint ex ante negotiating effort would probably qualify as a form of horizontal price fixing by oligopsonists sharing patented

\footnotetext{
${ }^{148}$ FTC Workshop on Intellectual Property Rights in standard setting: Tools to prevent patent hold-up Official transcript.

${ }^{149}$ See US case law: True Position/Andrews case.

${ }^{150}$ Sidak Patent Holdup and Oligogsonistic collusion in standard setting organizations Journal of Competition Law and economics 2009.
} 
technology. ${ }^{151}$ The policy choice of the FTC clearly favours the licensees over the licensors, since competitors exchanging future pricing strategies would automatically be qualified as a per se violation. Perhaps the FTC reckons that the cost of the collusive behaviour of the licensees is lower than the costs to social welfare in case of a patent hold-up. Would this mean that the price information of the patented technology is just another technical feature of the standard? The theory of this opportunism, which is often cited in this context, is successfully countered by some scholars. Geradin and Farrar show that the premise of the existence of alternative technologies available next to the standard does not always occur in practice. ${ }^{152}$ Also, the standard-setting process increases costs for licensors, limiting their additional financial rewards. In the economic literature, there is no direct empirical evidence supporting some of the assumptions used by the FTC. Unlike other case law, such as Rambus, Dell and Unocal, the licensees were not misled by wrong information, but the potential hold-up could have been the result of a high royalty fee, which might have reflected the true market value of the innovative product. The other assumption is that the reduction of royalties in the downstream market will be translated into lower consumer prices, thus justifying the antitrust perspective. In this context, a comparison between the handling of this problem in the three different jurisdictions is very interesting.

Does the joint collective negotiating of licensing conditions (royalty rates) constitute an antitrust violation in the three different jurisdictions, and what are the economic theories supporting these views of the competition law enforcers?

\subsection{THE STRATEGIC USE OF PATENTS: THE PERSPECTIVE OF CHINA}

For this research, it is interesting to look at the PRC policy in relation to patents that are included in standards. The Standardization Administration of China (SAC) issued a draft on the "Provisional Rules Regarding Administration of the Establishment and the Revision of National Standards Involving Patents" in November 2009. In the words of the draft, the SAC declares its intention to "[use] its powers to impose lower royalty rates on patent owners and [encourage] the future use of compulsory licensing under the patent law to avoid perceived windfalls to patent owners, particularly foreign ones". ${ }^{153}$ The draft contains interesting and revealing elements.

"Article 8: A patentee and its affiliate taking part in the drafting of a standard will be deemed as having granted a free license by failing to make disclosure as required above and shall bear due legal responsibility for the losses caused to the formulation

\footnotetext{
${ }^{151}$ Under the new Horizontal Guidelines this would not be part of the "safe harbour" concept.

${ }^{152}$ See also Geradin and Farrar the Logic and Limits of Ex Ante Competition in a Standard Setting Environment Competition Law International Vol.3 No.1 Spring 2007 page92.

153 http://www.sac.gov.cn/templet/default/ShowArticle.jsp?id=5298 [^]
} 
or implementation of a national standard by their purposeful concealment of the patent information."154

The intention of Article 8 seems to hint at a free licensing system within the standard setting and refers to losses caused by the purposeful concealment of patent information. The latter directly describes patent ambush and patent hold-up. The deliberate withholding of patents would result in liability under Chinese national law.

"Article 9: When a patent is involved during the formulation and revision of a national standard, PSTC or UIC shall obtain in time the patentee's irrevocable written statement on patent licensing.

The statement shall include the following, from which the patentee shall select one item:

1. The patentee agrees to license, on a free-of-charge, reasonable and nondiscriminatory basis, to any organization and individual to implement the patent when implementing the national standard;

2. The patentee agrees to license, on a reasonable and non-discriminatory basis, any organization and person to implement the patent when implementing the national standard at a price significantly lower than the normal royalties;

3. The patentee does not agree to license patent in either of the two ways listed above. If the patentee has selected (3) above, the standard shall not contain any provisions based on the patent." 155

This article foresees that parties in the standardization process will include their IPRs on the basis of royalties significantly lower than normal royalties. The text of this article is insufficiently clear and is open to various interpretations. Since the publication of the

\footnotetext{
${ }^{154}$ Unofficial English translation.

${ }^{155}$ Unofficial English translation The ANSI policy in the USA uses the following wording: The ASD shall receive from the patent holder or a party authorized to make assurances on its behalf, in written or electronic form, either:
}

(a) assurance in the form of a general disclaimer to the effect that such party does not hold and does not currently intend holding any essential patent claim(s); or

(b) assurance that a license to such essential patent claim(s) will be made available to applicants desiring to utilize the license for the purpose of implementing the standard

either: (i) under reasonable terms and conditions that are demonstrably free of any unfair discrimination; or (ii) without compensation and under reasonable terms and conditions that are demonstrably free of any unfair discrimination. The ISO/ITU/IEC uses the following wording: 2.2 the patent holder is willing to negotiate licenses with other parties on a non-discriminatory basis on reasonable terms and conditions. Such negotiations are left to the parties concerned and are performed outside ITU-T/ITU-R/ISO/IEC. Similarly the wording of the ETSI provision: 6.1 When an ESSENTIAL IPR relating to a particular standard or technical specification is brought to the attention of ETSI, the Director-General of ETSI shall immediately request the owner to give within three months an irrevocable undertaking in writing that it is prepared to grant irrevocable licenses on fair, reasonable and non-discriminatory terms and conditions under such IPR to at least the following extent. 
draft, the SAC has received many complaints from foreign parties and, currently, there is the expectation that the text will be replaced by wording that describes licensing based on RAND conditions. ${ }^{156}$ This possible change can be explained by the fact that Chinese companies are also developing patents that need to be traded or swapped with foreign firms that have IPR portfolios.

"Article 13: For a compulsory national standard that indeed needs to involve a patent, the patentee shall grant licenses free of charge or the national administration department of standardization shall request the related departments to consult with the patentee about disposal of the patent." 157

In this case, the SAC describes the concept of compulsory or free licensing in mandatory standards. Compulsory licensing is rarely used in the free market economies of the Triad countries, since it undermines the basis of innovation policy and the rewards thereof (recoupment argument). The PRC's membership of the WTO means that the Chinese government must adhere to the rules and regulations of the TRIPS Agreement relating to compulsory licensing.

In December 2012 the SAC published a new draft of the "Regulatory Measures on National Standards Involving Patents (Interim) (Draft for Public Comments) ("2012 Draft Measures")".This draft addressed some of the concerns of the 2009 draft text, but several points still need further clarification:

- Does the word patent solely refer to Chinese patents or also to the patents that are registered outside the PRC?

- Article IV, Section 1 states: "[i]n principle, mandatory national standards shall not involve patents".

- The text of the draft no longer refers to compulsory licenses but Article II, Section 4 mentions the following:

"Organizations or individuals participating in the formulation or revision of national standards shall be legally liable for their failure to follow the aforementioned requirements to disclose the essential patents held by them."

Unfortunately it is not explained what legally liable means and what the possible consequences are.

The 2012 draft of "Regulatory Measures on National Standards Involving Patents" removed some of the concerns of foreign firms in relation to compulsory licenses, but both the main principle and the definition of "legally liable" are still risk factors for foreign firms that participate in standard setting in China.

\footnotetext{
${ }^{156}$ Ernst Indigenous innovation and globalization page 61.

${ }^{157}$ Unofficial English translation.
} 


\subsection{IMPLICATIONS FOR COMPETITION LAW ENFORCEMENT IN THE TELECOMMUNICATIONS INDUSTRY}

In the telecommunications sector, technical aspects of interconnection are crucial to the functioning of the industry. As the example of the Chinese government policy in relation to standard setting for telecommunications will illustrate, a government, but more often a firm or a group of firms, can own essential technology for the functioning of the network. In economic literature, this is defined as a one-sided or two-sided bottleneck. In telecommunications, one-sided bottlenecks were often linked to charging high prices for the use of the specific technology by one single company, often a monopolist. In the case of two monopolists, each holding a specific bottleneck, both necessary for operating the telecommunications network, the result is defined as a two-sided bottleneck. The deregulation of the telecommunication sector in both the EU and the US has abolished many of the one-sided or two-sided bottlenecks. In both jurisdictions, the fast-pace of technological progress in the telecommunications sector could result in the creation of new bottlenecks, which can have anti-competitive effects. In the case of China, telecommunications is still a heavily regulated sector of economic life, but policy makers could draw inspiration from the US and European experiences in this field. The deregulation of network industries was based on the perception that monopoly power was mainly based on the existence of the network effects and that, as soon as all competitors could gain access to the network, competition would automatically take place. Consequently, ex ante regulation would provide for a naturally competitive environment. In reality, the complexity of network markets is not always fully understood by the competition regulators. Some economists favour the co-existence of both ex ante regulation and ex post competition policy. ${ }^{158}$

For this research, this poses interesting new questions relating to the level of regulation in the telecommunications industry. Standards in the telecommunications industry would be best served, in theory, by ex post competition policy, given the steady and fast rate of innovations in the industry. Introducing the wrong ex ante regulation might create more negative effects on dynamic efficiency than ex post competition regulation. This certainly applies to the market situation in the US and the EU, since the industry has been deregulated extensively and access to infrastructure is fairly easy, with the result that competition take place on this basis. In the PRC, the telecommunications sector is still heavily regulated and, consequently, the functioning of the network industry differs from its counterpart in the US and the EU. In Western economies the deregulation of the telecommunications sector was achieved by giving future competitors

\footnotetext{
${ }^{158}$ Jodar-Rosell and Gual make a case for the co-existence of both systems, since, in their opinion, the boundaries are blurred, they promote a revision of the EU Competition Policy on basis of better-informed, sector specific enforcement for key network industry sectors. See also their article The Strange Couple: Regulation and Competition Policy in Network Industries.
} 
access to the telecommunications market and due to legal and ownership unbundling. ${ }^{159}$ In China, the government not only directly influences the standard setting but also uses the ownership of the infrastructure to influence the market by tipping it in favour of indigenous standards. This is not always successful, since network externalities also aggravate the lack of consumer confidence. ${ }^{160}$ This difference in the level of deregulation of the telecommunications industry in the three jurisdictions has a direct impact on the establishment of the different competition regimes.

By its nature, standard setting causes a dilemma for firms active in the relevant market whether to choose for the compatibility of their new innovation or not. Incompatibility of the new innovative product embedded in a standard can create market power for the participating firms and for firms manufacturing goods that are complementary to the standardized product. The interaction between the firms of the standardized products and those producing complementarities can easily lead to vertical integration or downstream market coordination, with possible anti-competitive results in the market. These forms of vertical market integration can take the form of price discrimination, discriminating licensing terms, grant-back provisions and lock-in effects that justify the interest of the competition authorities in the standard-setting process. The lock-in effect into the technology used in the standard has negative effects on dynamic efficiency and can slow down the speed of the innovation process considerably, which is crucial to the competitiveness of the three individual jurisdictions. Other reasons for concern with respect to competition law would be margin squeezing, tying agreements and refusal to give access to essential facilities. ${ }^{161}$ These considerations provide additional challenges for competition enforcement in network industries using standards. See also the earlier discussion of network effects in chapter 2, section 2.2.

1. In a network industry, authorities must use market inequality/equilibrium as a starting point and not the notion of perfect competition.

\footnotetext{
${ }^{159}$ The EU relied on three basic principles to create competition in the telecommunications sector: the establishment of common technical standards, liberalization of the services market and privatization of former SOEs. See for more background Baskoy The Political Economy of the European Union Competition Policy A Case Study of the Telecommunications Industry.

${ }^{160}$ The Chinese government does export its national telecommunications standards to developing countries in Africa, were the standards (although not yet proven in the market) are accepted because of their lower price.

${ }^{161}$ Relevant EU case law Margin squeeze: Telefonica and Deutsche Telekom, Discriminatory pricing strategies: France Telekom The essential facilities doctrine is well-recognized in US competition law. A court (Alaska Airlines, Inc. v. United Airlines, Inc., 948 F.2d 536, 542 (9th Cir. 1991) gave the following definition:

"The essential facilities doctrine imposes liability when one firm, which controls an essential facility, denies a second firm reasonable access to a product or service that the second firm must obtain in order to compete with the first."

In the European Union, the doctrine of essential facilities was first developed under the heading of Article 82 EEC-Treaty, the prohibition of abuse of a dominant position. In cases like Commercial Solvents, the essential facilities doctrine was defined as a subversion of the refusal to deal. The court case involving Bronner paved the way for a much wider application of the essential facilities doctrine in EU competition law.
} 
2. Standard Setting Organizations will first compete for the market and afterwards in the market.

3. High market shares/profits can be the result of network effects and not necessarily of anti-competitive actions of participating firms.

4. The anti-competitive effect in relation to consumers should be a benchmark, since the inequality of the market automatically affects the competing firms.

5. In the sector of the telecommunications industry, it is difficult to distinguish whether the winning technology was selected on the basis of technical superiority or on the basis of the anti-competitive strategies of the firms involved. ${ }^{162}$

6. The specific character of both standards and network industries requires competition authorities to apply appropriate economic models to evaluate the antitrust effects on the relevant markets.

7. Differences in economic analyses and models used can influence the competition policy in the US, EU and PRC.

8. The telecommunications sector in the US, EU and China has seen different levels of government deregulation. The apparent lack of deregulation in China, in combination with the national indigenous innovation policy, poses extra challenges with regard to the impact that the network effects have on both innovation and foreign investments.

9. A clear and transparent economic model to analyze the anti-competitive effects of the use of patents in standards will enhance legal certainty and, consequently, the FDI decisions related to country selection and modes of entry. ${ }^{163}$

The telecommunications sector has both demand-side and supply-side economies. More users will create a bigger market and all companies manufacturing components in the downstream market can lower their costs. The rewards for creating the winning standard are very high and, as a result, firms have engaged in a standards war to create the standard that is adopted by the market. From a competition policy point of view, this leads to several problems. First of all, will firms be selected on the basis of their financial or human resource-based ability to keep competing? The common feature of cross-licensing can leverage the playing field to a limited extent. Secondly, it is questionable whether the war of the winning standard is a real competition on merit. The

\footnotetext{
${ }^{162}$ In legal literature there is a debate whether it should be the role of sector-specific regulation or competition policy to prevent anti-competitive abuses.

${ }^{163} \mathrm{~A}$ comparison can be made with the effects that the modernization of EU competition law had on the electricity sector. The choice for a more economic approach led to positive effects on the investmentdecisions of firms operating on the EU electricity market. For a deeper understanding see Hauteclocque, Legal Uncertainty and Competition Policy in Deregulated Network Industries: the Case of Long-Term vertical Contracts in the EU-Electricity Markets.
} 
standards battle is influenced by the following factors: IPRs, the image/reputation of a firm and control over an installed base of users. Obviously, the innovative capacities of the company and first entry into the market also create advantages in the standards war. Although competition authorities have accepted the legality of the cooperation of possible competitors in the standard-setting process, the three jurisdictions have different interpretations on what constitutes legal or illegal collusion between firms in this context. This difference in interpretation is based on their competition policy, which must be evaluated in the broader context of the innovation policies of the individual jurisdictions.

The definition of anti-competitive conduct in the telecommunications sector is directly linked to the background of the innovation strategies of the US, the European Union and China.

\subsection{ROYALTY STACKING}

Innovative products in the telecommunications sector often contain hundreds of patents in the individual standard. The implementers of the innovative products often need licenses and have to pay royalties in order to legally use the technology in the standard. High-tech products are often faced with the "complements problems", as identified by the French scientist Augustin Cournot. ${ }^{164}$ The complexity of the product requires many different components in order to be made. If these different parts can be produced by just one single firm it would considerably reduce costs and thereby the price for the consumers. The present state of the telecommunications industry shows a highly fragmented market, with global production and innovation networks, characterized by many different horizontal complementarities, which might lead to increased prices for consumers. The downstream market firms must obtain many different licenses and consequently the royalty payments will increase to a level where it is possibly no longer commercially attractive to manufacture the goods. For the individual owner of essential patents, it might be very challenging to understand the influence of his royalty rate on the total package of all royalty rates of the essential patents in the standard. An individual holder of essential patents can examine whether his own royalty rate is within the FRAND conditions, but the effect of his rate on the cumulative rate is difficult to evaluate. The aggregated total of all individual royalty rates leads to negative externalities because of the differentiated manufacturing.

There is some academic debate on whether royalty stacking is a major concern for industry and thus should be addressed by competition authorities. Gerardin, Farrar and Padilla researched the problem of royalty stacking within the setting of the 3G-standard and came to the conclusion that there was no empirical evidence that royalty stacking was a problem in reality. However, in their economic model, they assumed that all pa-

\footnotetext{
${ }^{164}$ Cournot; Researches into Mathematical Principles of Wealth 1838.
} 
tent owners used identical royalty rates and that there was no heterogeneity in the essential patents. ${ }^{165}$ To this researcher, these are unrealistic assumptions for the market of telecommunications products and for incremental innovations in general. In the paper that instigated this discussion, Lemley and Shapiro use the standard economic theory of Nash bargaining, in which the royalty rate is determined by the payoff that each party would receive if the negotiations on the royalty rate broke down. ${ }^{166}$ The authors discuss a "reasonable royalty floor" for cases in which the patent owner must receive financial compensation for an infringement of his patent. The reasonableness is hereby directly linked to the infringement and not enhancing the profit margins of the patent owner. The importance of the proper economic analysis of "reasonable royalties" is a key element of the discussion of balancing the relationship between the licensors and licensees. The doctrine of injunctive relief is introduced to address this problem and will be discussed later in this chapter.

In a later paper, Gerardin explores the boundaries to be set for minimum and maximum cumulative royalty levels. Another problematic discussion is the transfer of RAND conditions in the case of a new owner or in the case of bankruptcy. The general assumption is that RAND commitments travel globally, but foreign jurisdictions could make the enforcement of the commitments very challenging. Regarding the bankruptcy of the patent holder, Section 258 of the US Bankruptcy Code protects the interests of licensees but the same protection is not always available in other jurisdictions. ${ }^{167}$ Does due diligence apply in the case of the takeover of a small company by a bigger company holding a major patent portfolio?

In the European Union, unfair or discriminatory pricing strategies violate Article 101 TFEU, since these strategies can directly cause consumer harm as competition on the proposed standard will be discouraged and downstream markets could suffer from a lack of investments for the development of complementary products. Article 102 TFEU could also be brought into the picture, since the unfair pricing strategy could prevent a successful implementation of the standard or continuing investments in new generations of the original standard. Some authors introduce economic game theory to this discussion. In this scenario, co-licensors will set their royalty rates very high to match the monopoly rent of the first-mover-licensor. In practice, it might be very challenging to have a proper understanding or estimate of the monopoly rent, which makes this a more theoretical but very interesting assumption. ${ }^{168}$

\footnotetext{
${ }^{165}$ See note 43 . The authors also make the assumption that the essential patents must be held by numerous distinct patent owners, otherwise it would be easy to negotiate. Royalty stacking might also be related to the perception of the individual patent owners and not just limited to the number of patent owners.

${ }^{166}$ Lemley and Shapiro; Patent Holdup and Royalty Stacking Competition Policy Center, Institute of Business and Economic Research, UC Berkeley page 6.

${ }^{167}$ Apparently German law put an end to cross-licenses to protect other companies and licensors. See also FTC Workshop: How to prevent patent hold-up, Official transcript.

${ }^{168}$ For more background-information see also Dolmans, A Tale of Two Tragedies A plea for Open Standards.
} 
Outside the standards context, mainly in the field of bio-technology, there is the problem of royalty packing. Royalty packing occurs when there is a necessity to bundle one technology with other technologies. Although no use of this problem in relation to standards has been found, it could be possible in a case where there is a complete new use for the technology protected by essential patents, outside the direct scope of the standard. ${ }^{169}$ In the bio-technological market, companies use agreements on the floor and ceiling level of royalty fees to prevent royalty stacking and royalty packing. Other alternatives are to use a patent pool or cross-licensing. Cross-licensing can initiate the interest of antitrust enforcers, since the basis of the cross-licensing does not always have to be a royalty-free exchange of patents. In this context, other licensing elements can also be relevant in addition to royalty fees. ${ }^{170}$

It is unclear whether royalty stacking frequently occurs in the telecommunications industry and whether competition authorities should address this problem in practice.

One alternative to the counterbalance of royalty stacking is the establishment of a patent pool. The patent pool unites a group of owners of essential patents who offer a joint licensing agreement in which all essential patents of the standard are included. The US DoJ and the FTC have acknowledged the legality and pro-competitive effect of collaboration between competitors within the patent pool. ${ }^{171}$ Another suggested solution can be an auction system, which implies that the SSO chooses from different offers by the patent holders.

\subsection{IMPORTANT ELEMENTS IN THE DISCUSSION ON THE TENSION BETWEEN STANDARDS, PATENTS AND ANTITRUST}

\section{FRAND licensing terms}

It is generally agreed that IP law and antitrust law both encourage or support innovation, by stimulating the diffusion of technology and thus contributing to the welfare of consumers. Within this process, standardization supports the introduction of new technology to consumers and theoretically also lowers prices for consumers. Standardization benefits from the economies of scale and the winning standard will be used by consumers on a broad basis. As a consequence, the position of patents in standards gains more importance, since patents make new technologies accessible to new standards.

The financial rewards and the protection of the patent system must motivate entrepreneurs to submit their innovative technologies to standardization. If the exercise of

\footnotetext{
169 Jones; Problems with Royalty Rates, Royalty Stacking and Royalty Packing Issues Intellectual Property Management in Health and Agricultural Innovation: A Handbook of Best Practices.

${ }^{170}$ Layne-Farrar and Lerner, To join or not to join: Examining patent pool participation and rent sharing rules International Journal of Industrial Organization 29 (2011) pages 294-303.

${ }^{171}$ In 1926 the horizontal IP restraints doctrine was developed in the General Electric case (1926).
} 
the patent right outside the standardization environment is more attractive, new technologies may no longer be included in standards. Patents are market enablers, since they allow early investment in research and development. Patents limit the use of technology but not the access to knowledge. If the most efficient technology becomes the standard, then innovation is accelerated and competitiveness will increase. However, there is also the distinct possibility that the IP system or, more particularly, the patent will be used to frustrate the standard-setting process. The tension between the necessity to guarantee a wide and easily facilitated dissemination of standardized products and the desire of companies to attract financial incentives for their innovation and research and development efforts can be solved in different manners. The SSOs have introduced self-regulatory mechanisms in their patent policies that must ensure transparency and accessibility to patented technologies. From a legal point of view, it is an interesting question to research to what extent SSOs should prevent the misuse of the standardsetting process. Under Article 101 TFEU, does the SSO have an obligation to prevent the abuse or would this be stretching the scope of Article 101 TFEU and the real possibilities for the SSOs to influence the process too far? Chapter 2 discussed the implications of standard setting for competition law. The SSOs conclude contracts with the technology firms that implement their innovations by means of standards. Both parties are bound by the contractual arrangement, and the applicable contract law. The EU court case Astra Zeneca introduced the notion of the "duty of good faith", which may also apply to SSOs.

The FRAND principle might impose the obligation upon SSOs to prevent participants from using the standard-setting process to achieve anti-competitive goals. During the standard-setting process, expectations are raised that the technology will be made available at reasonable and not excessive prices. Another question is what would happen if one of the participants in the standard setting left the standard setting process temporarily (e.g. Rambus case), thereby not having a dominant position during the whole period? The SSOs are developing new business models as a reaction to the rapid changes in the standards environment.

FRAND commitments are at the heart of this discussion. These licensing terms must find a balance between the need to diffuse new technology to a wide public using standards and the requirement to give proper compensation to the holders of standard essential patents. In the context of this thesis, FRAND is also important, since Chinese companies claim that they have to pay unreasonable royalty fees for Western technology. The case law regarding FRAND is continuously expanding. In recent years, FRAND played a major role in relation to injunctive relief. For the discussion of patent pools, FRAND is a crucial factor with regard to analyzing the legality of the pool. Elements such as the determination of the royalty base or the calculation of FRAND royalties have a direct impact on the discussion about patents and standards.

Two components dominate the FRAND discussion: 
- The need to reward the patent holder adequately for making investments in the new technology. The royalty rate and other licensing terms must motivate the patent holder to participate in the standardization process. The FRAND terms also provide transparency and certainty to patent holders.

- Licensors must be able to rely on the availability of the technology that was adopted with FRAND commitments. Technology implementers must be guaranteed that the FRAND promise can actually be used in practice. The FRAND principle is a direct voluntary contract between the patent holder and the SSO. For the technology implementers, this implies that the standard-included technology can be used using the FRAND terms.

The FRAND terms avoid charging so-called "monopoly rents". After the inclusion of the patent in the standard, the patent owner imposes exploitative or restrictive licensing terms that lead to either excessive fees or to a monopoly on the downstream market. In a dynamic market, patent owners may continue to use the monopoly on the downstream market to influence the formulation of the follow-on standards, since competitors may not want to participate in the standard setting or may invest less in future innovations.

The concept of FRAND, fair, reasonable and non-discriminatory licensing terms, has proven to be quite difficult to implement. One obvious problem is the determination of reasonable cumulative rates, considering the patent landscape and the estimated value of the technology. But the determination of the individual rate can also cause problems in relation to the question of whether the patent share reflects the actual contribution. Uncertainties also exist regarding the legal enforcement of the FRAND conditions. FRAND is intended to maintain the delicate balance between the interests of the intellectual property holder and the needs of the broader set of companies that need access to the essential intellectual property. ${ }^{172}$

This balance is a crucial factor, but the perspective is often on licensees, with less attention on the risks of the licensors or innovators. Some of these risks are securing capital, finding patents and consequently getting into the standard. Furthermore, it is challenging to quantify the damage caused to the IP holder or the possible negative effect on innovation. It is an interesting question whether a court should determine the FRAND rate. Does the number of patents influence the FRAND rate? Do FRAND commitments apply to transfers, to the new owners of patents? The FRAND promise is a license or a promise to license. The patent owner must be willing to discuss the terms and conditions of the licensing agreement, otherwise this would constitute a refusal to license.

The discussion of the FRAND rate also raises questions about a possible relationship with the concept of abuse of a dominant position (Article 102 TFEU). Where do the

\footnotetext{
${ }^{172}$ The essentials of intellectual property Signals research group 2010.
} 
most favourable terms for the patentee end and where does the abuse start? Some authors refer to the hold-up value of the standard essential patent, which is only relevant in case of an injunction. If injunctions are not available, it might be more of a challenge to define the FRAND value.

The elements of fair and reasonable of the FRAND concept are sometimes defined as the hypothetical commercial negotiation between a willing licensor and a willing licensee. ${ }^{173}$ Other relevant elements that are mentioned in this discussion are the conduct of licensees, discounts for early licensing, public statements by licensors, commercial proxies, and the technical contribution of the patent to the standard.

\section{Injunctive relief}

The holders of SEPs can seek injunctive relief against the infringers of their patent right. This is the most basic aspect, regardless of whether the patent in the standard is essential or not. The patent right is an exclusive right, and injunctions prevent infringers from continuing their illegal behaviour. Injunctive relief enables the patent holder to prevent the sale, production or use of the product that infringed their patent right. In case of the smart-phone wars, this can effectively stop the introduction of a new product in a specific territory or country. Hence, this can be very attractive in terms of market share or even profits. The patent holder can also ask for monetary compensation or a FRANDroyalty rate as a result of the injunction. The question is whether a patent holder can use an injunction for essential patents, in the case that a FRAND promise was made. The reasoning is that the patent holder can charge unreasonably high royalty fees on the basis of the threat of the injunction. Since the injunction can stop the implementation of the standard or the introduction of new products, this is a realistic option. Others argue that negotiating royalty rates in relation to injunctive relief erodes the value of SEPs and patents in general. The case law regarding injunctions is very interesting since it provides an interpretation and explanation on the FRAND commitments.

As the later discussion will show, injunctions are analyzed in very different ways in the EU, US and China.

\section{Cross-licensing}

The patents that are assembled in a smart phone are owned by multiple patent holders. As explained earlier, this can raise the cumulative royalty burden. One of the instruments to end royalty stacking and patent thickets is cross-licensing or portfolio licensing. Cross-licensing reduces the transaction costs but still encourages innovative companies to seek rewards via the patent system. Traditionally in cross-licensing, two or more companies license their patent portfolios to each other. Usually this involves large

\footnotetext{
${ }^{173}$ Presentation Smith IP and Competition Law Conference September, 262013 Brussels.
} 
blocks of patents on each side, but recently a trend can be noticed that some companies practise cross-licensing on an unequal basis. Cross-licensing can create efficiencies when applied in a field of technology with overlapping patent portfolios. Another advantage is that cross-licensing can provide a truce from standard wars. This may result in more R\&D investments and also provide "design freedom" in technical terms. ${ }^{174}$ On the negative side, cross-licensing (and patent pools) can facilitate price-fixing, market division and coordinate output restrictions among competitors. Other restrictions could be acting as a barrier to market entry or foreclosing innovation.

\section{Patent pools}

Just like cross-licensing, patent pools can both have pro-competitive and restrictive effects. As soon as the standard consists of a number of essential patents owned by a number of different patent owners, problems will occur regarding the coordination of the different essential patents. The total sum of transaction costs of the licensing negotiations with the different patent holders and the accumulated royalties may increase the costs for the implementation of the standard. The total sum of transaction costs can be reduced by the formation of a patent pool. The patent pool enables patent owners to license their patents in a fair, reasonable and non-discriminatory way. For the patentees, there is the advantage of using the pooled patents in a standardized license. A crucial element of patent pools in relation to competition law is the licensing terms and conditions (e.g. royalty rates, terms of the contract, etc.)

In order to ensure fair and equal treatment of the patent holders, patent pools often include a most-favourable royalty clause so that licensees are charged the same level of royalties. Since patent holders participate on a voluntary basis, disagreement on the licensing terms and conditions often leads to disputes or the formation of a new patent pool. A main characteristic of patent pools is that they require coordination and agreements between possible competitors in order to manage the patents rights in the standard. This type of interaction between companies which normally compete with each other automatically raises the concern and interest of competition authorities.

To conclude, it can be said that patent pools (and cross-licensing) must be evaluated by competition authorities in order to analyze their legality.

\section{"Ex ante auctions"}

Standardizing bodies also prevent patent hold-ups through the instrument of "ex-ante auctions", whereby different technology owners are invited to offer the best, cheapest and most appropriate solution for a specific problem and this solution will then become

\footnotetext{
${ }^{174}$ United States Department of Justice and the Federal Trade Commission (2007). Antitrust enforcement and Intellectual property rights: Promoting Innovation and Competition.
} 
the standard. In an ideal situation, the auction takes place before the standard is established, thereby preventing the lock-in effect of the standardized technology. The advantage of the ex ante auction is that it is a market mechanism that encourages intertechnology competition on merits (i.e. price and quality) before the standard is set. Auctions provide certainty as to the terms and conditions to be applied to the standard. $^{175}$

In practical terms, this concept is difficult to implement in industry sectors (e.g. telecommunications) where there are many patents in combination with a highly innovative global setting. Choosing a standard on the basis of an ex ante auction could lead to a lock-in to a specific technology, thus limiting further or different technological developments. Generally, the process of formulating a standard is very lengthy and requires several auctions that still could lead to price-fixing.

The European Commission and other regulators favour ex ante declarations of IP owners, meaning that the IP right holders communicate what would be their maximum royalty rates and the most restrictive licensing terms that they would apply in case their technology would be selected within the standard before the standard is adopted. The ex ante declarations are an important tool to enhance the transparency of the standardsetting process and to gain the trust of all the stakeholders. However, the ex ante declarations do not stop possible abuse of the standard-setting process. On a practical level, the declarations often only give information on essential patents, but licensors need detailed information on their customized license that covers their specific business setting. The instrument of an ex ante declaration is not sufficient to prevent a possible lock-in effect and thus abuse of the system. In general, it can be stated that the lock-in effect cannot be avoided in practice.

Another possible solution to the problems of the existing system lies in the development of standard-related patent registers, which would create transparency during the standard-setting process. For example, the ETSI database makes all information publicly available, leading to the early identification of essential patents. The SSOs developed IPR policies for leverage and to prevent the lock-in effect of the patents implemented in the standard. The SSO needs information on the licensing conditions of the patents as a condition for their incorporation into the standard. Most IPR policies of SSOs use the definition of FRAND licensing terms as a basic condition for their inclusion in the standard.

\footnotetext{
${ }^{175}$ The auction can also show the strength of the "superior technology" before the standard is set. The present EU Technology Transfer Guidelines allow auctions in para. 225; the FTC has indicated that auctions can create legal problems if SSO members commit a group boycott (Sony Electronics Inc. vs. Soundview Technologies, Inc., 157 F. Supp. 2d 180, 185 (D. Conn 2001). Addamax Corp. vs. Open Source Software Found., 888 F. Supp. 274, 278 (1995).
} 


\subsection{NON-PRACTICING ENTITIES (NPE), PATENT ASSERTION ENTITIES, PATENT TROLLS}

In the US, new business models have emerged, such as, for instance, the Allied Security Trust (AST). AST identifies and purchases high-tech patents on the open market and classifies every patent according to their product and technology coverage and acts as a broker to match their clients' patents needs. AST is governed by its members and is also linked to Patent Freedom, whose major aim is to provide information on Non-Practicing Entities (NPEs). NPEs are firms that do not directly sell products or services but only license the intellectual property. Traditionally firms build a patent portfolio and achieve a mutual balance through cross-licensing their patents. Since NPEs only license the intellectual property, the strength and validity of the cross-licensing (counter-assertion) is no longer relevant. The research of Patent Freedom shows that the NPEs consist of a highly diversified, heterogeneous group of companies and 20 out of 325 NPEs are responsible for most of the litigation. Defending against NPEs can be very costly in terms of legal fees -on average the costs are $\$ 2$ million and the NPEs are relatively untouchable. $^{176}$

\section{NPE Litigation Statistics per industry July 2014}

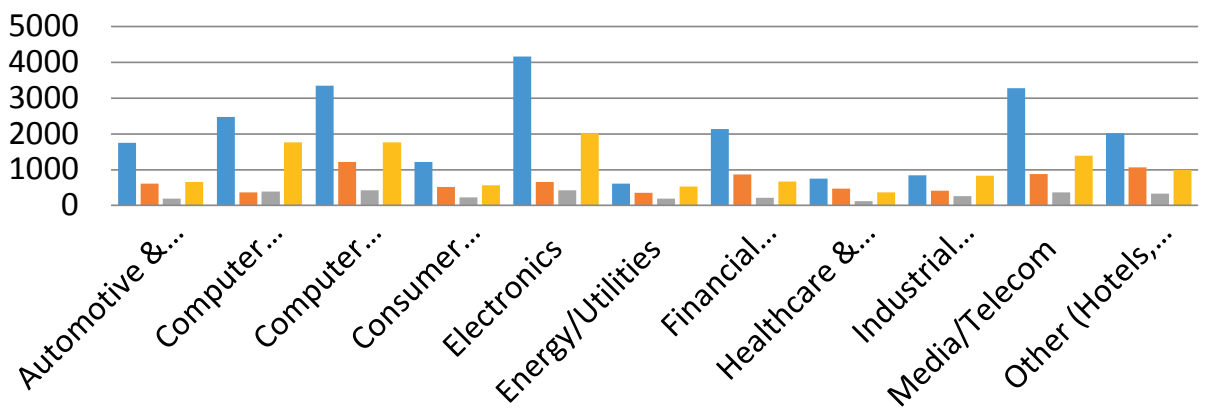

Blue: Operating firm defendants red: Unique Operating companies green: NPEs filing suits purple: Number of litigated patents

\footnotetext{
${ }^{176}$ Price Waterhouse Coopers Patent Litigation Study 2013.

${ }^{177}$ Based on data obtained by evaluating data of Patent Freedom https://www.patentfreedom.com/aboutnpes/industry/
} 
The licensing strategies of companies active in the field of telecommunications take various forms and are constantly evolving. Companies such as Apple and Huawei use a business model that does not use huge patent portfolios. Some critics claim that these companies enter a technology market, use technology protected by IPRs, wait to be sued by patent owners, and consequently enter into licensing contracts. ${ }^{178}$

The first distinction that can be made is in the difference between practicing and non-practicing entities. The practising entities may have different reasons to protect their IPRs, like cross-licensing (to gain design freedom), exploit licensing programs to gain revenues or seek exclusivity of their products on the market. Non-Practising Entities (NPEs) may include inventors, universities, research labs, or firms that do not want to use their patents for manufacturing and therefore decide to license their patents. Universities have a public interest mission and some firms do not have the financial resources to commercialize their patents.

Dolmans also uses the classification of patent aggregators, which means standard patent pools and aggregators who buy up patents but ultimately lead to lower transaction costs. ${ }^{179}$ With the emergence of patent assertion entities (e.g. IPCom, IPVentures) as a new business model, discussions on the legality of their actions started. The FTC gave the following definition of an PAE, an

"entity that uses patents primarily to obtain license fees rather than to support the development or transfer of technology."

and

"firms whose business model primarily focuses on purchasing and asserting patents." 180

According to Joshua Wright of the FTC, the business model of the PAEs relies on the licensing of and the litigation on patents. For most PAEs, R\&D activities are not part of their normal business and they predominantly assert patents, although they might also create patents by themselves. The main characteristic is that they do not practise the patents but some PAEs occasionally do. Although PAEs are often perceived as negative

\footnotetext{
${ }^{178}$ It is common knowledge that Apple does not own many standard essential patents. It is often debated whether Apple acts as an "unwilling licensee", but it is interesting that Steve Jobs stated the following comment in his authorized biography: "I will spend my last dying breath if I need to, and I will spend every penny of Apple's $\$ 40$ billion in the bank, to right this wrong. I'm going to destroy it, because its a stolen product. I'm willing to go thermonuclear war on this." http://news.cnet.com/8301-33617_3-57500246-276/jobs-gets-wishin-thermonuclear-war-at-least-for-now/

${ }^{179}$ Within the chapter on patent pools I will discuss the case of the MPEG pool that led to lower transaction costs. Also defensive patent pools or license facilitators fall into this category. Presentation Dolmans Trolls and Privateers, Brussels IP and Competition law conference September, 262013.

${ }^{180}$ See for more background: What Role Should Antitrust Play in Regulating the Activities of Patent Assertion Entities? Remarks of Wright* Commissioner, Federal Trade Commission http://www.ftc.gov/speeches/ wright/130417paespeech.pdf
} 
for innovation (especially in the US), they symbolize a new business model in the field of IP management. PAEs may contribute to innovation, since they create a market for IPRs that cannot be monetized by the researchers or new start-ups. They also have the additional benefit of informing potential licensees of the latest technological developments and help researchers focusing on innovation instead of monetization. In the case of a patent pool, additional benefits are the reduction of the aggregated royalty fees and the predictability and transparency of licensees.

Patent trolls have a negative impact on innovation and competition. The business model of patent trolls is based upon creating a positive expectation for investors (FRAND-licensing terms, favourable licensing terms, hiding of patents, etc.) and consequently waiting until the defendant has sunk investments into the technology. After the lock-in of the defendant into the technology, patent trolls will then hold up the defendant by using an injunction. Patent trolls have strong patent portfolios and the financial means to threaten the defendant with costly litigation. Another aspect is the charging of "hold-up royalties", consisting of the switching costs, the costs of the patent and the opportunity costs of not taking a license. ${ }^{181}$

The exact differences between patent assertion entities, patent aggregators and patent trolls is not easy to make and should be defined not by the official classification but by the conduct of the participating firms. Since the patent trolls are Non-Practising Entities, the forces of "nuclear deterrence" cannot be used. The invulnerability of the trolls is based upon the absence of downstream markets that might be affected by a counterattack by competitors. ${ }^{182}$

\subsection{PATENT MISUSE IN RELATION TO STANDARD SETTING}

The application of the doctrine of patent misuse in a standard-setting context could provide some relief for the tension between patent law and antitrust law. The doctrine of patent misuse centres on the question whether the patentee broadened the scope of the patent grant with anti-competitive effects. The doctrine is often used in the context of accusations of patent infringement. Antitrust laws elements are used in the patent misuse analysis, since the market power of the patent owner in the relevant market is required to constitute patent misuse. ${ }^{183}$

\footnotetext{
${ }^{181}$ Personal conversation Dolmans Brussels September, 262013.

${ }^{182}$ Although patent trolls are non-practising entities, the troll strategy can also be used by practising entities. Since 2005, the total award of damages awarded to NPEs is growing in relation to damages awarded to practising entities.

For the period 2001-2005, \$10.9 (NPE) vs. \$5.6 (PE) and for the period 2006-2011 \$ 6.9 (NPE) vs \$3.7 (PE) Median damages awarded (in MM) PWC Patent Litigation Study 2012. Litigation continues to rise amid growing awareness of patent value.

${ }^{183}$ See also Addy page 29.
} 
Patent misuse is often applied as an equitable defence in case of the infringement of a patent. The equitable doctrine of "unclean hands" denies an equitable remedy in a case where the plaintiff was violating legal rules or public policy. In the standardization context, a situation can occur in which the holder of a patent will seek to enforce his rights with anticompetitive effects. Although a proven case of patent misuse will not invalidate the patent, the consequence would be that the remedies for infringement will not be applied by the court. The above-mentioned instrument of an injunction is often used as a threat in standardization and can lead to significant royalties (in combination with considerable re-design costs) that are not justified or reasonable, especially in the case of weak or possibly invalid patents. The present US patent laws enable applicants to change or extend their application during the standardization process, resulting in patentees who will amend their pending applications to get as close as possible to the standardized new technology. ${ }^{184}$ The PTO hardly ever rejects a patent application absolutely. Unsuccessful applications will often be re-written and lead to a patent continuation. The unity of an invention is a prerequisite for obtaining a patent, since the patent right can only be linked to one specific invention. Patentees often file a divisional application for the spin-off of the later generation inventions, thereby manipulating this market. The divisional patent is granted the protection of the original parent product. In this way, the patentee can manipulate the continuation of the divisional patenting process to create and include terms later that other firms had no prior notice of, which is not an incentive to invest in R\&D. Some authors consider this to be a case of patent deception in the standardization process but the case law is inconclusive on this point. $^{185}$

Secondly, applicants can antedate standards and remove them as prior art references, since prior art is less available in US standard setting. In relation to patent misuse, the following practical comments can be made:

1. Large patent portfolios make a patent search very difficult and the patented technology may have multiple applications which cannot be identified during the ex ante disclosure. From a business perspective, does ex ante disclosure imply that you can determine royalty fees before you actually understand the market?

2. The present system of internal SSO rules is limited, since the standard may include patents from holders who are not members of the SSO and, consequently, are not bound by the internal rules.

3. Very specific disclosure rules will reveal sensitive information regarding future technology strategies which may be valuable information for competitors.

\footnotetext{
${ }^{184}$ In 1990 Rambus filed a Divisional application for a patent including multiple inventions.

${ }^{185}$ For a further discussion see also Hovenkamp: Patent deception in standard-setting.
} 
4. The technical assessment of "essential patents" will be the task of engineers whose interest might be to withhold information since their bonus payments are based upon the royalties received.

5. Application of the Georgia-Pacific rules (US Plywood case) might be too vague for the context of standard setting. In relation to the valuation of patents incorporated in standards, this raises an interesting question: should it be the economic value of the product or the value related to standardization and the sunk costs? Or should we look at the incremental value over the next-best alternative? Some authors favour the application of an arm's length principle (analogy transferpricing) to determine reasonable rates. The European Union provides a safe harbour in cases where the rates ex ante, do not materially change during the standardization and ex post.

The use of the doctrine of patent misuse in relation to antitrust concerns is centred on the right of patentees to refuse to license their technology under Paragraph 271 (d) of the US Patent Act. As a concept, patent misuse is an extension of the US doctrine of unclean hands, which denies an equitable remedy in cases where the plaintiff was violating public policy. Antitrust authorities do not easily enter the domain of patent law, clear infringements, such as tying patented and unpatented products, fraud in the application to the PTO or sham litigation will cause the antitrust authorities to intervene. The US Supreme Court holds the opinion "that the patent holder has the right to charge as high a price as the market can bear, provided that the patentees do not unlawfully acquire the monopoly or take improper actions to maintain or extend that monopoly." ${ }^{186}$ Furthermore, the Supreme Court stated that: "The objectionable behaviour of concern to antitrust authorities is not the quantum of royalties demanded, but rather the manner through which patentees achieve the ability to extort the industry, and the anticompetitive consequences flowing from this ability." ${ }^{187}$

Patent misuse, just like the application of antitrust rules, requires complex economic analysis. On both sides of the Atlantic, competition law enforcers struggle with the difficulty of quantifying commercially-reasonable royalty rates. This is often used in the US as an argument against the adoption of compulsory licensing. There are fears that compulsory licensing will limit the incentives of companies to invest in R\&D, patentees could face litigation by private parties and the culture of mutual trust in standardization would be undermined, leading to unrestrained litigation that would hamper the progress of standard setting, which would be detrimental to the public interest. ${ }^{188}$ The application

\footnotetext{
${ }^{186}$ See also Rambus Inc., In the Matter of, No. 9302 (Federal Trade Commission 2009) and Verizon Communications Inc. v. Law Offices of Curtis. V. Trinko, LLP 540 US 398, No. 02-682 (United States Supreme Court 2004).

${ }^{187}$ Idem Rambus Inc., In the Matter of, No. 9302 (Federal Trade Commission 2009)

${ }^{188}$ See FTC report Antitrust Enforcement and Intellectual Property Rights: Promoting Innovation and Competition.
} 
of patent misuse would have certain advantages. Authorities and courts would not have to discuss the determination of FRAND or reasonable royalty fees; there would be no application of the dreaded punitive treble damages; and the proven patent misuse would suspend the enforceability of the patent until the misconduct was changed by the patent holder. The doctrine of patent misuse has not been widely applied by US courts.

The concept of misuse was developed to prevent the patent right holder from obtaining rights that clearly go beyond the scope of the original patent right. The original patent right confers a monopoly upon the holder but the first case law in which patent misuse was defined was deeply rooted in IP law. Later, courts started to embed patent misuse in an antitrust context, thereby using antitrust rules to unravel complex cases involving both aspects of intellectual property law and antitrust law. Although the concept of patent misuse was originally developed from an IP law perspective, it is currently unclear whether patent misuse should be placed in antitrust or in IP law. The dominant opinion seems to be that patent misuse is part of antitrust law, and some scholars even doubt the existence of patent misuse outside the scope of the antitrust setting. ${ }^{189}$ The central question is whether the patent misuse has extended the patent monopoly beyond the scope of the IP rights.

Most cases of patent misuse involve the element of tying arrangements - selling, licensing or leasing two or more products together. The patent misuse standard for violating antitrust laws puts its focus heavily on the definition of the patent holder's market power, thereby not paying sufficient attention to the original goal of the patent right, which is the promotion of innovation and competitiveness. ${ }^{190}$ The present situation is unsatisfactory, since patent holders can overplay their hands because patent misuse is not directly embedded in either antitrust or IP law. The severe consequences of successful patent misuse are, on the other hand, strong deterrents in an innovative business climate in which patent holders make substantial investments in R\&D. The decisions of the US Court of Appeals for the Federal Circuit in 2010 in the Princo V. ITC case $^{191}$ seems to have important implications for the discussion. The Court of Appeal distinguished patent misuse from the antitrust law standards and proved that the concept of patent misuse has a broader meaning that extends beyond antitrust laws. As a consequence, a patent holder can break the antitrust rules but not commit patent misuse. The same scenario involving patents has to be examined in the two separate systems, leading to different results.

\footnotetext{
${ }^{189}$ See also Usm Corporation v. Sps Technologies Inc., No. 84-1397 (United States Court of Appeals, Federal Circuit 1985).

${ }^{190}$ Bohannan develops the concept of foreclosure as a central theme for linking patent misuse to an IP law setting. C.Bohannan: IP misuse as foreclosure.

${ }^{191}$ Princo Corp v. ITC 616 F3d. 1318 (Fed. Circ. 2010).
} 


\subsection{THE PRINCO DECISIONS AND THE BOUNDARIES BETWEEN PATENT MISUSE AND ANTITRUST LAWS}

The Orange Book case evolved around a voluntary standard developed by Philips for recordable compact discs (CD-Rs) and rewritable compact discs (CD-RWs). Philips had formed a patent pool and tied essential patents to non-essential patents. Moreover, Sony had developed a competing analogue technology that was also included in the pool and could not be sold separately. In its decision, the ITC applied a rule of reason approach and found that Philips had not included non-essential patents in the pool and the decision not to license the competing Sony technology separately could not be qualified as patent misuse. The Federal Circuit Court reversed the decision by a small majority in its panel and, consequently, the case was referred to the Full Federal Circuit Court for the en banc decision. In the decision of the Full Federal Circuit Court, a distinction was made between the concept of patent misuse and the antitrust violation. The Court used the following words:

"While proof of an antitrust violation shows that the patent holder has committed wrongful conduct having anticompetitive effects, that does not establish misuse of the patent in suit unless the conduct in question restricts the use of the patent and does so in one the specific ways that have been held to be outside the otherwise broad scope of the patent band". ${ }^{192}$

The federal court decisions were divided on the following questions:

1. Is the patent misuse only applicable to those patentees who leverage their patents to obtain economic advantages outside the legitimate scope of the patent?

2. In relation to nascent technologies, is there a necessity to prove the anticompetitive effects and who has the burden of proof?

3. What is the exact relationship between patent misuse and antitrust law in this individual case?

The central question that was raised is, what is the legitimate scope of the patent right? In this relationship, the European Orange Book case is also very relevant. This case will be discussed at a later stage. ${ }^{193}$ For the second question, the patentee has the burden of proof to show the pro-competitive effect and, in the Princo case, the court assured that, under the 'rule of reason' approach, plaintiffs bear the actual burden, thereby extending the approach that was started in the Geneva Pharmaceuticals Technology Corp v. Barr Laboratories Inc. Case. The burden of proof requirement for the patentee

\footnotetext{
192 Princo Corp v. ITC 616 F3d. 1318 (Fed. Circ. 2010).

${ }^{193}$ In this case, the Sony Lagadec technology could not be used on an individual basis to compete with the technology of the joint-venture (Philips-Sony) or the Philips technology.
} 
might be difficult in practice, since the impact on nascent or marginal competition requires again a difficult and in-depth economic analysis.

The relevance of the Princo decisions is that, in practice, US courts have to decide whether patent-related strategies must be evaluated under patent misuse or antitrust laws. From a wider perspective, the example of patent misuse shows the complexity and difficulty of the legal discussion. Strategic behaviour involving patents and standards is challenging competition authorities on a global scale. The discussion involves two different legal components and is further complicated by rapidly developing technology markets.

The Princo decisions have been discussed widely and the three court decisions seem to have had various consequences.

1. In the original case, the Court found that package licensing does not automatically imply a tying arrangement, which is important for patent right holders.

2. In the second decision, the court concluded that the inclusion of essential patents in a patent pool that turn out to become non-essential patents is not directly patent misuse. Given the fact that to determine ex ante the "essentiality" of a patent which might have a different application after the standard is formulated is very difficult, this will ease the burden for potential participants in the standardization process.

3. The final en banc decision clearly distinguished patent misuse from the antitrust violation. The separation of patent misuse and antitrust violations implies that conduct can lead to patent misuse without the infringement of antitrust rules and a violation of the antitrust regime through patent-related conduct is not automatically a case of patent misuse.

4. Patent-related conduct that has exclusionary effects (an analogy with the foreclosure of Bohannan), or a per se violation, will still be prosecuted under either the antitrust rules or the concept of patent misuse.

Although the Princo case law seemed to have clarified the tension between IP law and antitrust law, a deeper analysis shows that some situations remain unclear. In the licensing terms of essential patents, grant-back provisions are often a prominent feature, which can easily lead to antitrust violations, but it would not constitute a patent misuse of the original and, secondly, the grant-back related patent. Also, for tying arrangements, there is no obvious choice between the two possible alternatives. Patentees may use the safeguard of a patent pool or licensing clauses to deflect patent misuse allegations. The Princo decisions hint at a recent choice made by US courts to develop the instruments of patent misuse and the antitrust laws separately. From an IP perspective, a stronger embedding of the concept of patent misuse in a thorough IP law regime would be recommended and would bring the concept back to its initial roots. From a practical perspective, the necessity to replace the well-established antitrust analysis 
tools will lead to an interesting challenge for the US courts to develop a similar set of IP tools to analyze identical cases.

Will the new direction taken by the US courts in the Princo decisions lead the way to a more IP-related use of the concept of patent misuse, and what are the practical consequences of the inclusion of essential and non-essential patents in a patent pool, according to US law?

\subsection{CONCLUSIONS}

\section{Differences in standardization}

The patent right confers a "statutory monopoly" upon the holder of patent rights. The exclusivity of the patent right has lead to reactions such as the open source movement and concerns that patents can have a negative influence on innovation, and standardization. The governance of standard setting in the EU, US and China identifies similar key elements of the discussion.

\section{Management of SEPS}

The first obvious concern is that the standard-setting process itself requires an intense dialogue and communication between potentially competing firms. During the first part of the process, the pre-commercial fostering phase, firms decide on the necessary technologies that should be included in the standard. This can already lead to anticompetitive behaviour since companies may collude to prevent certain technologies from being included in the standard or vice versa. The collaboration between firms in an SSO reduces the costs of a "standard-war" in which two or more firms compete for consumer preference and the winning standard takes all the profits. A coordinated effort by an SSO will reduce the transaction costs of the de facto standard and will lead to more societal benefits and increased overall competitiveness. However, strategic manipulation may occur during the standard setting, the later improper management of the set standard or the management of the IP rights within the adopted standard. This may result in patent hold-up, patent ambush and royalty stacking that can have a negative impact on consumer welfare. Firms are confronted with substantial incurred sunk costs, making it almost impossible to switch to alternative (excellent) technologies. As the previous chapters showed, network externalities play a major role in the adoption of certain new technologies and can hinder the increased adoption of new standards. The SSOs have reacted to these concerns by including ex ante disclosure rules in their IP policies, in an attempt to prevent a patent ambush or a patent hold-up situation. Economic research is not conclusive on the effectiveness of either ex ante disclosure or ex post enforcement within the standardization context. 
This chapter discussed the most important elements of the standards and patents debate. Central to this debate are the FRAND commitments, since FRAND influences injunctions, SEPs and patent pools. But also China's claim that they are facing unreasonable high royalty rates for foreign technology is an important element in this debate.

The enforcement policies of the three jurisdictions regarding the strategic use of patents do not show common ground at first sight. The definition of anti-competitive conduct (especially in the telecom sector) is directly related to the innovation policy.

The problems of royalty stacking, patent thickets, patent hold-up, and patent ambush can be eliminated by the use of either cross-licensing or patent pools. Both instruments can have positive and negative impacts on competition. A detailed analysis by competition authorities is necessary to evaluate the legality of cross-licensing and patent pools.

\section{Lessons to be learned}

Recent US case law relating to the concept of patent misuse has opened up the possibility that in the future (at least in the US) patent-related conduct in the standardization process can be evaluated differently under the antitrust approach or the patent misuse approach. Although the boundaries between both concepts are not completely clear or developed, it offers the chance to subject the exclusive character of the patent right to a more justified analysis which broadens the use and the effectiveness of the patent right (beyond the traditional antitrust scope) for patent holders (including NPEs), licensors and licensees in the standardization process. At the same time, a more detailed explanation of the concept of patent misuse would prevent the current risk of an overinterpretation of the Princo judgment. This judgment seems to strengthen the legal position of patent pools and the licensors in relation to licensees, especially when the system of expert witnesses is implemented.

New business forms have emerged: Non-Practising Entities, patent assertion entities and patent trolls. These companies try to monetize patents in standards in a nontraditional and often illegal manner. The development of these new business forms might lead to confusion with regard to patent pools. Only an analysis of the conduct of these new entities can conclude the legality of their actions.

The example of the concept of patent misuse raises the question whether antitrust law is best suited to regulate technology markets. Many patents are bundled within standards. Making a distinction between the validity and essentiality of patents in a standard proves to be very complicated. However, for the antitrust analysis, it is strictly necessary that the character of the patent can be evaluated, but this analysis does require the application of elements of patent law. It also brings back the discussion as to what the exact role of competition law should be in relation to patent law.

Stronger economic empirical research (including fields such as innovation economics and industrial organization) should be incorporated into the innovation analysis of 
standard setting with IPRs. The results of this research would provide a stronger basis for the application of competition law in relation to standard setting.

Chapter 4 will focus on the position of China as an emerging economy in the discussion of standards, patents and competition policy. The choice to start the discussion with the example of China is motivated by several factors. The first factor is that China is still a standards taker and, as such, still pays (excessive) royalty fees to foreign companies. Secondly, both the growth in patent registrations and the global positioning of China as a trading nation pose interesting dilemmas for policy makers throughout the world. Finally, the third factor relates to the conversion process of the Chinese economy. The relatively new debate on patent law and competition law is not only led by legal considerations but also by socio-economic motives. The move towards a freemarket economy provides for an interesting comparison to the European and US antitrust systems which have been well-developed along economic principles applied to antitrust laws.
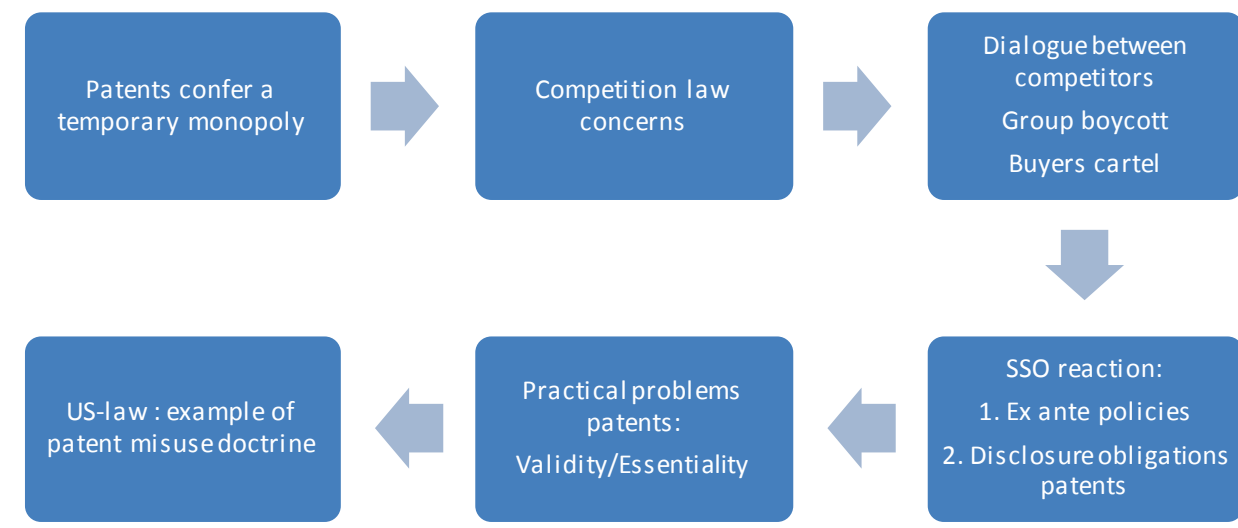

\section{SSO reaction:}

1. Ex ante policies

2. Disclosure obligations patents
Competition law:

efficient tool to regulate technology markets? 



\section{CHAPTER 4}

Innovation policy and standardization: the perspective of China - an emerging economy 

China has an impressive history of inventions dating back centuries. The most famous inventions were papermaking, the compass, gunpowder, alcohol, and the mechanical clock. ${ }^{194}$ Traditionally, innovations have emerged in China to support consumer welfare. In the former Communist planned economy, individual consumers would not play a significant role in the innovation process. Resource planning and technology development were not influenced by purchasing decisions. At that time, China followed a 'functional specialization' approach, meaning that innovation was pursued by clearly separate actors. ${ }^{195}$ In 1993, China implemented a more market-oriented innovation system that would serve the new challenges of globalization and technological developments.

The globalization of trade has increased the perceptiveness of individual trade blocs to external threats. The trade policies of individual countries and, moreover, of trading blocs, often lead to countervailing reactions of other countries and/or trading blocs. Threats are often perceived by other countries in the context of a broader perspective of international economic relations. The trade relations between China and the US are sensitized by discussions concerning the exchange-rate regime, foreign investment rules and outsourcing. Recently, China's innovation policy and the accompanying national legislation have contributed to concerns in both the US and the European Union. The negotiations on the TTIP agreement show that the aim is to "enhance coordination in rules and standards". This aim is closely followed in China. China's growing concern is that the TTIP will be used to strengthen the dominance of the US and the EU in the field of standardization. Recent comments of the China Institute for International Studies reflect the view that harmonization or increased compatibility of Western telecommunication standards will seriously undermine the competitiveness of Chinese telecommunication standards, ${ }^{196}$ which would have a negative impact on the R\&D activities and the marketing and the distribution of Chinese telecom products. Furthermore, it would set back the development of Chinese telecom standards.

China aims to increase the innovative capacity of its firms, and thus their competitiveness, and to limit the country's dependence on foreign technology. Within the innovation policy of China, standardization plays a major role and has attracted more attention from the central government of the PRC, since, in the past, Chinese companies were merely standard takers and, consequently, paid substantial sums for using foreignlicensed products. The standardization processes both in the US and the EU are mainly influenced by their historical development and the present state of modern technology. The influence of the government in the standardizing processes differs per trading bloc. The US standardization setting is characterized by the strong influence of private companies and their commercial interests. In the PRC, it is the government's aim to acceler-

\footnotetext{
${ }^{194}$ http://www.china.org.cn/top10/2011-03/04/content_22054243_8.htm

${ }^{195}$ Orcutt and Shen, Shaping China's Innovation Future, page 19.

${ }^{196}$ See for more background information: The Transatlantic Trade and Investment Partnership: Origins, Objectives and Impact by Hongjian China Institute of International Studies 7 Nov 2013.
} 
ate economic growth and to raise the standard of living in general. The Chinese government has introduced the concept of 'indigenous innovation' to meet this objective.

This chapter address the effects of the increase in patent registrations for standardization. The sheer volume and the quality of patent registrations in China are a growing problem. A discussion of the Chinese indigenous innovation policy will explain the political background and its impact on standard setting. The dimensions of the Chinese consumer market raised the interests of both the US and the EU. Both try to influence the Chinese approach to standardization, since a move towards any of the individual systems will result in great benefits. The importance of standardization in its contribution to innovation and economic development will be elaborated upon. The economic aspects of standard setting, in general but especially in China, justify a pro-active competition policy in this field. A comparison of Korean and Chinese telecommunication standards illustrates different approaches and their consequences for Foreign Direct Investors. The legal positioning of patents in standards in China will be discussed in the context of a rapidly changing legal environment. The chapter will be concluded with a perspective on the role of competition law in relation to standards and the position of antitrust law in developing economies.

\subsection{CHINA'S INNOVATION POLICY AND IPRS}

The Medium and Long-Term National Plan for Science and Technology Development 2006-20 states in section 8 Line 3, "China should implement and promote government procurement for indigenous innovation products." According to the US government, the concept of indigenous innovation is a national policy that favours the protection of nationally produced goods and discriminates against foreign imports. The concept of indigenous innovation is implemented in various fields like government procurement, the standardization of products, the Chinese anti-monopoly law (AML), the protection of intellectual property rights, and the national tax laws of China. At the moment, it is relatively unclear what impact the concept of indigenous innovation will have on future laws and policies. This uncertainty and lack of transparency contributes to a greater element of risk for foreign investors in the PRC. Price Waterhouse Coopers investigated the effect of the PRC'S IP policy on the electronics manufacturing service providers (EMS) and concluded that the Chinese EMS firms do not only manufacture but also develop their own IP. Chinese firms are becoming Original Design Manufacturers (ODM) and therefore have an interest in lowering the royalty payments for foreign technology. Another noticeable effect of the indigenous innovation policy in China is the increase in the total number of invention patents that have been granted to Chinese firms. Between 2001 and 2010, the percentage of domestic patent applications in China in- 
creased by roughly $25 \%{ }^{197}$ Filing for patents is strongly encouraged by governmental policies in China and many incentives (e.g. tax incentives) are awarded to Chinese firms that decide to file a patent application. The 2013 World Intellectual Property Indicators of the WIPO show that China (with 560,681 registrations) has a leading global position in the field of filed patents. In the same report, it was stated that non-resident patent holders account for a large portion of Chinese patents (45.9\%) in force with SIPO. ${ }^{198}$

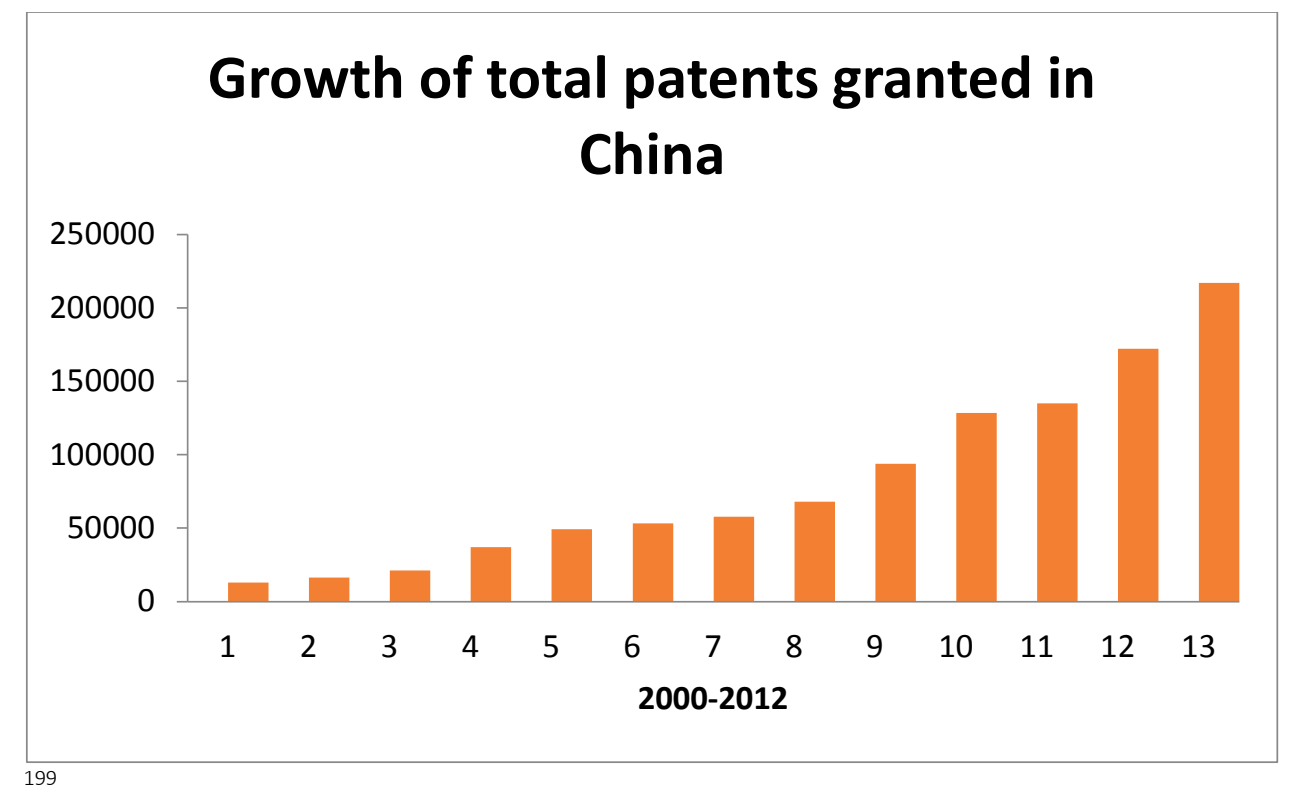

\footnotetext{
${ }^{197}$ SIPO Monthly Statistics Reports.

${ }^{198} 2013$ World Intellectual Property Indicators Report by WIPO page 7.

199 Based on country specific profile WIPO database China Based on country specific profile WIPO database China (http://www.wipo.int/ipstats/en/statistics/country_profile/profile.jsp?code=CN).
} 


\section{Chart III.5}

\section{Structure of IPR administration and enforcement}

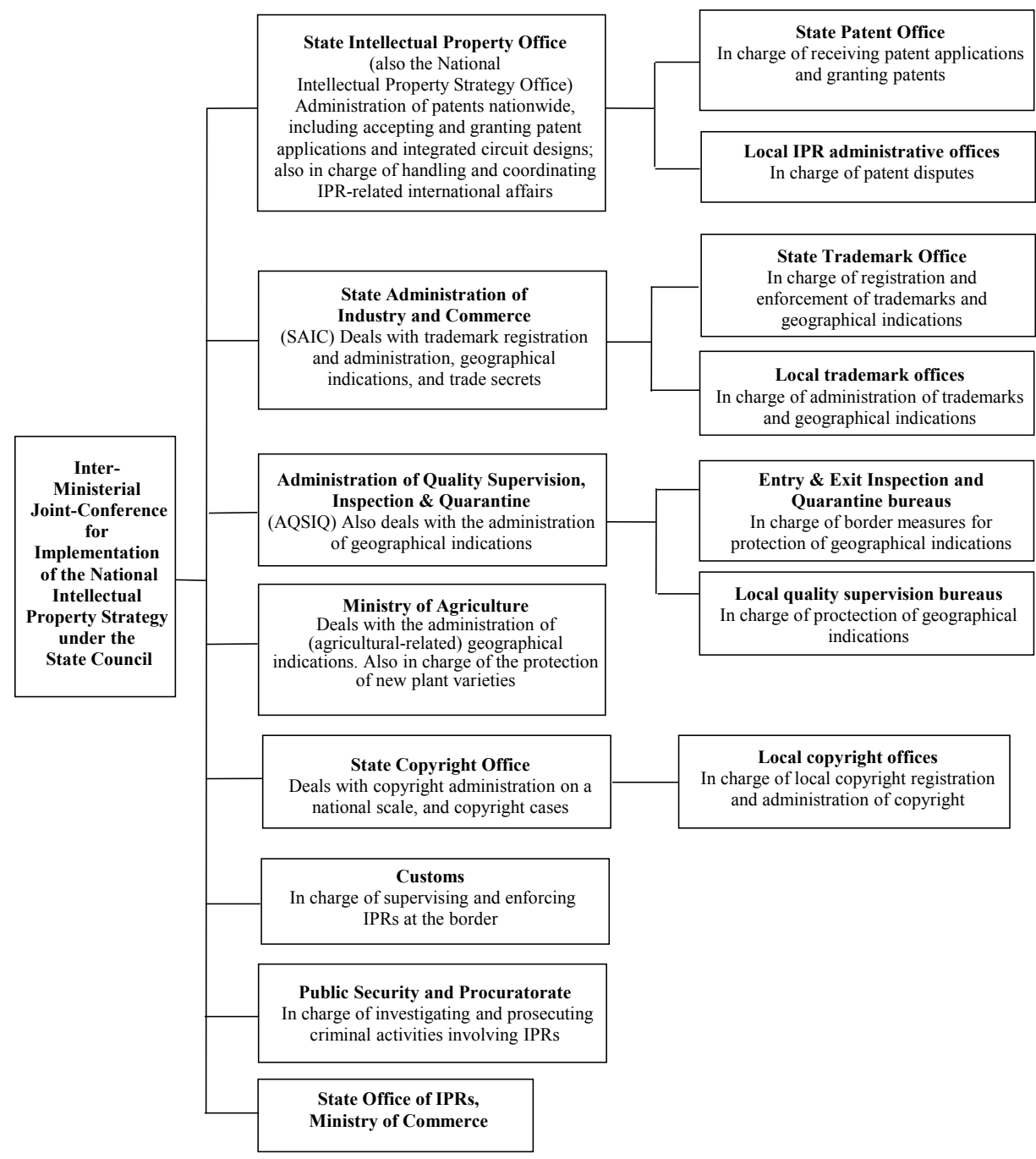

Source: WTO Secretariat, based on China National Intellectual-Property Strategy.

Viewed at: http://www.nipso.cn [in Chinese]; and data provided by the Chinese authorities.

${ }^{200}$ National Intellectual Property Strategy of China 

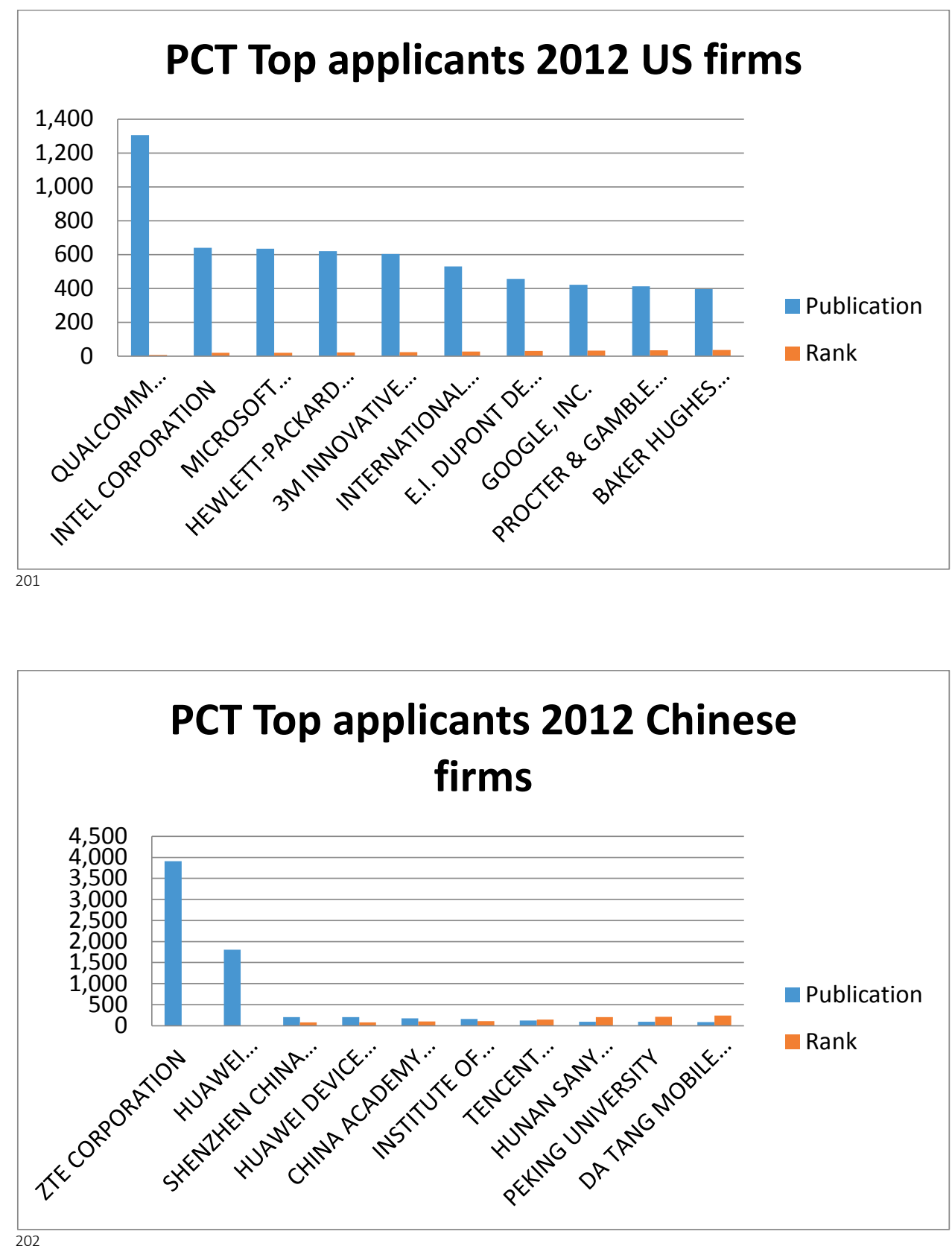

\footnotetext{
${ }^{201}$ Based on the country statistical profile of WIPO, United States of America http://www.wipo.int/ipstats/en/ statistics/country_profile/profile.jsp?code=US

202 Ibid note 201.
} 
The total number of patents granted could be an indication of the relative success of the Chinese indigenous innovation policy, but it would be more relevant to look at a possible increase in the total number of international patent applications by Chinese firms and, for the context of this discussion, the total number of Chinese domestic patents that are used in national or international voluntary standards. An undesirable influence in the standard-setting efforts has been the increase in low quality patent applicants from Chinese firms. The Chinese patent system has three different types of patents: invention patents, utility patents and industrial design patents. The latter two types are not safeguarded by the normal strict Western registration criteria. A more detailed discussion can be found in section 4.4.4.

In the US and European review process, examiners will check for "prior art" in order to determine whether the patent covers new technology that did not exist elsewhere before the registration of the patent. These "junk or petty patents" can easily be declared invalid by a court when they are challenged by a third party. ${ }^{203}$ Since the utility model patents do not undergo "substantive review", they are granted on a registration basis. The application and registration period is much shorter for utility model patents, but in technical terms they provide only marginal technical improvements. Originally, these patents were developed to support the innovation efforts of small and mediumsized companies, but since the Chinese government provides financial incentives for companies that successfully register patents, there has been an increase in the registration of utility model patents for various reasons. ${ }^{204}$ This type of patent protects new technology in relation to the shape, structure, or the combination thereof, for a product which can be used practically. ${ }^{205}$ It is important to note that a granted utility patent does constitute prior art, according to Chinese patent law, and it is most often written in the Chinese language. ${ }^{206}$ With the growing interest in R\&D, Chinese companies are starting to understand the importance of developing an IP portfolio and are starting to use the global IP system to their advantage.

Microsoft, Motorola and Nokia have established R\&D centres in Beijing and there are presently more than 1,200 foreign-owned R\&D centres in China. ${ }^{207}$ R\&D investments are expected to grow from $1.23 \%$ of GDP in 2010 to $2.5 \%$ of GDP in $2020 .^{208}$

Scholars agree on the changing importance of IP in the Chinese economy and, especially, on the growing interest in technology transfer and the knowledge economy. This

\footnotetext{
${ }^{203}$ Abrahams, The Economist pops the China patent bubble.

${ }^{204}$ Guangzhou Hu, Propensity to Patent, Competition and China's Foreign Patenting Surge page 6.

${ }^{205}$ Since the utility patent is granted in a much shorter time, international companies could choose the strategy to file both for an invention patent and a utility patent. After the utility patent is granted, this patent could be abandoned in favour of the invention patent. See also Bob Stembridge: Chinese utility models- a lesser known IP Strategy.

${ }^{206}$ In chapter 6 the Schneider-CHINT case, which is also of importance in relation to utility patents, will be discussed.

${ }^{207}$ Jacques When China rules the world Penguin Books page 215.

${ }^{208}$ Wilsdon and Keeley, China: The next Science Superpower? Demos 2007 page 9.
} 
shift in attitude towards IP could lead to different future developments. Some scholars predict that China will destroy the global IP system, while others see future support and a general enhancement of the IP landscape by the Chinese government and firms. ${ }^{209}$

\subsubsection{Patents and second-tier innovation}

Scholars often debate the possible threat of Chinese mercantilist trade policies on the competitiveness of the US and the EU. Some experts have the courage to voice a different opinion, shedding a new perspective on the discussion that directly affects the relationship between intellectual property rights and antitrust law. Robert D. Atkinson, testifying before the US-CHINA Economic and Security Review Committee on 10 May 2012, explained that the basic trading policies of the US and China differ substantially. These differences have a direct impact on the innovative capabilities of both economies. He started by stating that the US takes the principle of comparative advantage as a starting point for their trading policy. China applies the principle of "Absolute advantage", whereby the economy does not specialize in certain economic activities where they hold a comparative advantage but they simply try to be good at all economic activities and thus develop industrial policies to support this aim. ${ }^{210}$

The US model uses, as basic presumptions, the functioning of a free market, open trade, respect, and the rule of law. This has led to a regulatory environment with strong recognition and enforcement of intellectual property rights. These pre-requisites are necessary to foster a healthy innovation environment. Much of the criticism of the Chinese utility model patents relates to the fact that this is not 'first to-the-world innovation". In fact, most of this criticism is justified, since the majority of Chinese utility patents are simple copies of already registered Western patents. For a minority of Chinese utility patents, and for the Chinese innovation policy in general, it is interesting to draw a comparison with the second type of innovation, "innovation adaption", which simply means taking an existing product or service as a starting point and then improving on this product or service.

This type of innovation is more similar to the first attempt of the Japanese economy in the 1950s to leapfrog its economic development by perfecting products that had originally been developed by foreign companies. In Germany, Japan and China, utility patents are used to get protection for products developed due to fast, engineeringbased innovation. In the United States, most of the current innovation is science-based, leaving less room to apply a utility patent. A direct comparison between Japan, Germa-

\footnotetext{
${ }^{209}$ In 2006, DeWoskin expressed concerns that China would be destroying the global IP system through aggressive governmental policies and illegal technology acquisition and the availability of cheap labour. Stevenson-Yang and DeWoskin: Playing Our Game: Why China's Rise does not Threaten the West (New York: Oxford University Press, 2010) chapter 4.

${ }^{210}$ U.S.-China Economic and Security Review Commission, Assessing China's Efforts to Become an Innovation Society A Progress Report.
} 
ny and China is not justified, since their economies are at different stages of the economic development process and there is a distinct difference in the governmental influence on national innovation policies, the size of the national consumer markets and the increasing level of FDI in China.

The $12^{\text {th }}$ Five Year Plan on National and Social Development declares:

"We should persist in the principle of independent innovation, making key strides, of supporting development, and of providing guidance in the future, increase commonality and capability on core technology breakthrough, and promote the transformation of sci-tech results into real productive force. There is a need to accelerate promoting the state's special major sci-tech projects and implement new knowledgeinnovation and technology-innovation projects in an in-depth manner. We should closely integrate sci-tech progress with the optimization and upgrading of industrial structure and with the improvement of people's livelihood, enhance the capability of making original innovation, of integrating, introducing, digesting innovation, and score new breakthroughs in such areas as modern agriculture, equipment manufacturing, ecology, environmental protection, energy, resources, information network, new materials, security, and health, overcome a number of key core technologies such as core electronic components, very large scale integrated circuit, system software, new varieties of genetically modified foods, making of new drugs. We should enhance basic frontier technology research, and strive to occupy a high ground in future sci-tech competition in life sciences, marine, space, global science, and nanotechnology... We will give play to the state's leading and supporting role for special sci-tech projects, implement industrial innovation development projects, increase taxation and financial policy support, and help high technology industry to become big and strong." 211

The introduction of the concept of Strategic Emerging Industries (SEIs) is a tool to accelerate the development of core technologies which mainly should include Chinese IP rights. SEls are concentrated in seven priority industries: energy saving and environmental protection; new generation of information technology; bio-technology; high-end equipment manufacturing; new energy; new materials; and new energy vehicles. ${ }^{212}$ The SEI strategy will be implemented by using State-Owned Enterprises (SOEs) and supporting industrial policies, such as preference in relation to public procurement, preferential treatment of patent applications, subsidies, and a favourable tax regime. ${ }^{213}$ The strate-

211 "CPC Central Committee's Proposal on Formulating the 12th Five-Year Program on National and Social Development." In: Full text of Communique of the Fifth Plenum of the 17th CPC Central Committee.

${ }^{212}$ China State Council: Decision on Accelerating the Fostering and Development of New Strategic Industries (2010).

${ }^{213}$ Ministry of Science and Technology. Ministry of Finance and State Administration of Taxation of the People's Republic of China. (2008). Notice of the Ministry of Science and Technology, Ministry of Finance and State Administration of Taxation on Issuing the Administrative Measures for Determination of High and New Tech Enterprises. 
gic choice for the SOEs could be undermining competitiveness, since the most successful Chinese companies (e.g. ZTE and Huawei) did not start as SOEs. The supporting role of government procurement can intensify possible network effects in the case of standardization.

This concept, in combination with elements like the indigenous innovation product accreditation scheme for Chinese public procurement, confirms some of the Western suspicions about the mercantilist nature of national Chinese trade policies.

A comprehensive discussion needs to settle on a common definition of innovation. Does it mean "new to world" invention or an improvement of an already patented product?

At the moment, it is difficult to analyze or even understand the Chinese innovation policy and its implications for business strategy. From a US perspective, innovation and competition will excel in efficiently functioning markets that allocate goods and services in order to enhance consumer welfare. Chinese innovation policy is based on fundamentally different concepts of markets, technology transfer and consumer welfare. This complicates a direct comparison between both systems.

Atkinson concludes that US innovation markets function with a mix of risk-taking entrepreneurs, excellent technological developments and, more importantly, a venture capital industry that funds most of the new innovative goods and services.

Breznitz adds to the discussion that the globalization process has fundamentally changed innovation processes. The emergence of Global Production Networks has resulted in an economic interdependence between individual countries and trading blocs. Again, Bretznitz notes that Chinese industries have the ability to innovate in the later stages of production and in different parts of the R\&D and production chain. This specialization in later stages of the production leads to lower profit margins but also to a growing middle class consumer market. The second-tier type of innovations by Chinese firms is sometimes referred to as "design for production". In this type of innovation adaption, the reverse engineering and copying of international products is often used to create products with minor improvements compared to the original products. In combination with the engineering-based approach and their talent pool of foreign-educated engineers, China remains attractive for FDI investment.

\subsection{THE CHINESE INDIGENOUS INNOVATION POLICY}

The definition of indigenous innovation products was initially started in 2006 by a joint effort of the Chinese Ministry of Science and Technology, the Chinese Ministry of Finance and the Chinese National Development and Reform Commission in a document titled Methods for Determining National Indigenous Innovation Products. In 2009, an extra Explanatory Report shortlisted six high-tech industries that produced indigenous 
innovation products, computers, telecommunication installations, modern office equipment, software, new energy, and energy-saving products. ${ }^{214}$ This report had a section on IPRs that led to an intensified debate. It contained the following provision:

"2) A product's IP rights and the condition of rights and interests are clear. Products have 'indigenous innovation' IP rights when: the applying enterprise owns IP rights through its own technological innovation, or obtains IP rights or IP usage rights owned by a Chinese enterprise, state-run institution or citizen, according to Chinese law. At the same time, the applying enterprise's use, disposal or improvement of IP is not restricted by foreign institutions or individuals.

3) The product possesses its own trademark, namely the applying institution has the proprietary rights to the product's registered trademark. The products' marketing trademark must have been initially registered in China, and cannot be restricted by related foreign brands." 215

The text of this provision is very troubling for multinational enterprises active inside the PRC. The underlined section raises questions. Multinationals most often first register their patents abroad and consequently use licensing arrangements for their Chinese subsidiaries.

Foreign companies would have to register their patent portfolio first in China and then in other jurisdictions. In the sector of telecommunications, standards consist of a significant number of patents owned by international companies who have registered their patents globally.

In 2010, the Notification Regarding the Development of Determining "Indigenous Innovation" Products reacted to the heavy criticism from foreign firms by softening the requirements of the definition:

"2. The applying institution legally owns the undisputed domestic IP rights or the right of use of IP for the product through its own technological innovation or grant by another institution.

3. The applying institution legally holds the exclusive rights or right of use to the products registered trademark in China."

Although this widened the definition of Indigenous Products, foreign firms active in China still had fears about the possible effects in the field of government procurement. $^{216}$

\footnotetext{
${ }^{214}$ Peng Heyue China's Indigenous Innovation Policy and its Effect on Foreign Intellectual Property Rights Holders China Law Insight

${ }^{215}$ Peng Heyue China's Indigenous Innovation Policy and its Effect on Foreign Intellectual Property Rights Holders China Law Insight

${ }^{216}$ What is a Chinese firm? The text probably refers to wholly owned enterprises (WOE), joint-ventures with foreign firms and foreign equity joint-ventures. Foreign firms would have to transfer some of their patentportfolio's to their Chinese subsidiaries. It leaves open the question whether local content rules are relevant in this context.
} 
Various stakeholders in the US and the EU issued vehement reactions to the PRC'S concept of indigenous innovation. The WTO issued its $3^{\text {rd }}$ Trade Policy Review of China in June 2010 and noted "concern about China's indigenous innovation policies, and their effect in restricting access for foreign products, investors, technology and intellectual property." In the same report, the WTO concluded that China was making accelerated progress towards comparatively high standards for intellectual property rights by 2020. The legal reaction in the United States included a recent investigation by the US International Trade Commission (No.332-519) on China: Effects of Intellectual Property Infringement an Indigenous Innovation Policies on the US Economy. Part of the reasoning claims that the PRC Innovation policies harm US economic interests in three possible ways: international trade, cross-border royalty flows and foreign direct investment. Furthermore, it claimed that the indigenous innovation policy harms both the US as well as the Chinese economies. In the formal request letter, an analysis of the quantitative effects of the Chinese indigenous innovation policy on the US economy was demanded. The report was submitted to the State Committee on Finance by 2May $2011 .^{217}$

As a counteraction, it has been suggested that governments should introduce patent trade barriers or limit the scope of IP rights that may be transferred to a Chinese legal entity in order to protect local industry and access to valuable technology. ${ }^{218}$ Chinese companies, such as Huawei, publicly state that they have difficulty with the strict indigenous innovation system. ${ }^{219}$ A more open and transparent innovation policy would increase their globally competitive position. ${ }^{220}$ In chapter 8 (section 8.16), recent developments including the Huawei v. InterDigital case will be explained in detail. This will show that innovation considerations have a direct impact on the considerations of Chinese courts, especially in cases involving standards and patents.

Within the innovation policy, China's stance on standardization further undermines the competitiveness of foreign investors and protects the domestic market in China. By creating more national standards, the Chinese government wants to decrease its de-

\footnotetext{
${ }^{217}$ The US International Trade Commission takes an interest in this subject, since, under 337 of the Tariff Act of 1930 (U.S.C.par.337), the International Trade Commission investigates unfair trade practices, in this case the violation of intellectual property rights in relation to imported goods into the United States. The investigations include the abusive use of patents and also the violation of competition laws.

${ }^{218}$ Bucknell, China's National Patent Development Strategy (2011-2020).

${ }^{219}$ Hu.K. (2011). Huawei Open letter (pp. Statement by Deputy Chairman of Huawei Technologies, Chairman of Huawei USA).Huawei posted an open letter to the US government in which it stated: "Unfortunately, over the past 10 years, as we have been investing in the United States, we have encountered a number of misperceptions that some hold about Huawei. These include unfounded and unproven claims of "close connections with the Chinese military," "disputes over intellectual property rights," "allegations of financial support from the Chinese government," and "threats to the national security of the United States". "These falsehoods have had a significant and negative impact on our business activity and, as such, they must be addressed as part of our effort to correct the record."

${ }^{220}$ Figures suggest that most Chinese companies still prefer to purchase foreign technology rather than the self-developed Chinese technology. See also X.Liu and P.Cheng; Is China's Indigenous Innovation Strategy Compatible with Globalization page 34.
} 
pendency on foreign standards by moving outside the global standardizing environment. The Chinese government has noticed that substantial royalty payments have to be made to the foreign-owned IP holders. By creating more standards inside the PRC, Chinese companies can establish and maintain market dominance and introduce new innovative products onto the national and global market. ${ }^{221}$ China's external trade policy is often qualified by other trading blocs as an expression of neo-mercantilist policies, and its standardization policy, in the context of indigenous innovation, is often used as an illustrative example. From the Chinese perspective, the emphasis on becoming a standards creator can also address specific societal needs such as energy, resource management, public health, and security that are directly related to their economic conversion process. The latter points could be valuable in future trade disputes that would be settled by the WTO, especially regarding the weighing of possible exclusions and derogations that the WTO would be willing to temporarily grant to the PRC in relation to the specific societal needs of a developing country in an economic conversion process.

A proper assessment of the effect of indigenous innovation on innovation and/or foreign direct investment is complicated by various factors. China's indigenous innovation policy is supported by substantial government investments concentrated in a few urban centres supporting the national strategy of becoming standard makers instead of standard followers. This policy aims at first generation, radical innovations, in stark contrast to the second generation, incremental innovation efforts in the rural areas of the PRC. The small and medium-sized companies struggle in their efforts to increase their position in the value chain and directly suffer from a lack of subsidies and support as a result of the choice to centralize innovation policies in major urban centres such as Beijing, Tainjin, Shanghai, Guangzhou, etc. ${ }^{222}$ The indigenous innovation policy thus not only has an effect on intellectual property rights and standards but maybe also on regional policy inside the PRC. ${ }^{223}$ Regional differences in the effectiveness of innovation strategies may directly influence the network function within the proposed standard.

In 2008, the PRC issued the National Intellectual Property Strategy China and paragraph 17 deals with the process of standard setting. Standards are the preferred method to facilitate both technology transfer and the commercialization of Chinese technology. The Chinese government considers standards and the accompanying technology as

\footnotetext{
${ }^{221}$ It is interesting that in the 2013 survey of the US-China Business Council, only $40 \%$ of all US companies state that they were able to negotiate normal licensing terms; the remainder $60 \%$ were able to negotiate licensing terms below the commercially acceptable rate. USCBC 2013 China Business Environment Survey Results: Tempered Optimism Continues amid Moderating Growth, Rising Costs, and Persistent Market Barriers page 24.

${ }^{222}$ Winn, Talkstandards ICT \& Indigenous Innovation.

${ }^{223}$ Agglomeration and dispersion forces can have a different influence on regional economic development and innovation. Given the strong differences in regional development in China, the periphery can still be a market for telecommunications standards like 2G, whereas the agglomeration has moved further on. For more information on agglomeration and dispersion forces see Baldwin Economics of European integration p.421.
} 
trade instruments that are used by other trading blocs to discriminate against the PRC. Interestingly an identical claim is also made by the US government against China. Both in the US and in the EU, standards are developed in a coalition between standardizing bodies and industry, and products have to capture a minimum interest in a specific market before they become a standard. To reach this minimum level of commercial interest, network externalities are of strategic importance. In the case of China, the government takes a top-down approach. Standards are created by government institutions and are subsequently introduced into the market, contrary to the processes in the US and the EU. The government claims a more prominent role in the Chinese system in guaranteeing the quality and legitimacy of the established standards. In the conversion process from a planned economy to a free-market economy, Chinese private companies do not always respect intellectual property rights and, consequently, the government has to take a leading role in this field.

In March 2013, SIPO released the National IP Strategy Plan for 2013. In this Plan, SIPO declares to promote the use of IPRs by Chinese firms. One of the elements is the start of specific pilot projects in the telecommunications and mobile phone industry (LTE) to promote the use of IPRs in standardization. ${ }^{224}$

Strategically, this enables the Chinese government to create a "National Champion Ecosystem". ${ }^{225}$ Here, the indigenous innovation policy is part of a wider web of industrial policies that want to protect China from discrimination by foreign companies and their IP policies. The main aim of the indigenous innovation policy is to accelerate domestic economic growth and to raise productivity and the standard of living to that of the Triad countries (US, EU, Japan). The increased innovative capacity of the Chinese economy is an important element in the competition with the other trading blocs, but it must be evaluated against a different background. Whereas innovation is also a key element of the policies of the EU (Lisbon-Agenda) and the US (United States Standard Strategy), China is still struggling with their move towards a more market-oriented economy and, consequently, their innovation policy has different objectives and a different positioning. In order to accelerate innovation by implementing national technology in standards, a new culture has to be nourished to produce quality IP in globallyaccepted standards. Some commentators argue that there is a clash between the Chinese industrial policy and the need to develop international standards, although both

\footnotetext{
${ }^{224}$ The text literally is: "Implement a number of pilot projects on innovation development and application of key industries, promote the materialization, commercialization and industrialization of self-relied IP rights in the large-scale commercialization of next-generation internet and LTE industry development, promote the integration of IPRs and standards in digital television, next-generation mobile communications, nextgeneration internet technology, etc."

Promotion Plan for the Implementation of the National Intellectual Property Strategy in 2013.

${ }^{225}$ McGregor, US Chamber of Commerce China drive for indigenous innovation page 22.
} 
serve the development of innovation. ${ }^{226}$ An interesting perspective would be a comparison of the present level of IP protection within the context of the indigenous innovation policy of China to the levels of IP protection offered by Japan or other Asian economies when they were going through the same stages of economic development and joined the WTO. According to the Flying Geese model of Porter, China is leapfrogging some of the different stages of economic development, which would argue that the situation is not directly comparable to the earlier experiences of Japan and Korea. The leapfrogging of the Chinese industry is more threatening to European and US economic interests, and therefore the reaction of the Triad countries in relation to the lack of IP protection in China will differ from the former Japanese or Korean situation.

After China joined the WTO, the government had to gradually open up its economy and allow foreign companies to become competitors. Just like the state-owned enterprises in the Central and Eastern European Countries, the SOEs felt the foreign competition as an act of discrimination. In 2006, the Chinese government designated some sectors as "economic lifelines" - petrochemicals, telecommunications, coal, aerospace, air freight, and power generators industries. For other sectors, a slow liberalization process was started, allowing foreign companies to enter the markets and enabling possible mergers and acquisitions. Since a national innovation system is heavily influenced by the country's stage of economic development, its future growth model and its traditions, this partially explains the background of the current discussion on indigenous innovation and standardization. Recent court cases involving considerations related to royalty setting by foreign investors will be explained in chapter 8 . Innovation and the role of standards and IPRs take a very different position in China. The innovation policies and the standardization practices in the US and the EU differ but they also share some similarities, since they are embedded in Western economies. The concept of indigenous innovation is a tool to support the leapfrogging of the Chinese economy. This process can be seriously hindered by the Chinese dependence on Western standards. The next part will discuss the effect of indigenous innovation on standardization in China.

\subsubsection{The possible theft of Intellectual Property Rights in China from a US Perspective}

The current policy of the Chinese government in the field of technology transfer was met with heavy criticism in the United States and, to a lesser extent, in the European

\footnotetext{
${ }^{226}$ Will China protect intellectual property? New developments in counterfeiting, piracy, and forced technology transfer hearing before the Congressional-executive Commission on China one hundred eleventh congress second session.

Christopher Murck of the American Chamber of Commerce holds the opinion that the Chinese government wants to increase domestic demand by using its industrial policy. He lists a number of practical cases in relation to standardizing, where the application of indigeous innovation leads to an obvious discrimination against foreign technology included in standards (i.e. WAPI standard must be included in any mobile device).
} 
Union. In May 2013, the National Bureau of Asian Research in the US published a report of the Commission on the Theft of American Intellectual Property (hereafter named the IP Commission Report). ${ }^{227}$ The purpose of the report was to document and make an assessment of the causes, scale and origins of the Theft of American Intellectual Property, concentrating on China as the main offender. In the view of the IP Commission, emerging markets share the following characteristics which make them more vulnerable to violations of IPRs:

- A poorly developed regulatory environment for the management and enforcement of IPRs.

- Strong economic development which is supported by protectionist industrial policies. $^{228}$

- IP theft is often tolerated, if not justified, by national governments to compensate for the inequality between developed and developing countries.

Although the report identifies these common traits in most emerging markets, for example in Brazil, India and Russia, China takes a special position in this discussion because of the scale of IP theft and the national policy on technology transfer. The Chinese government communicated its desire to implement an economic growth strategy led by the acquisition of science and technology in the last two Five Year Development Plans (see chapter 2 for further discussion). In their report, the IP Commission distinguishesd that this would be carried out partly in legal ways (imports, FDI, licensing agreement, and joint-ventures) but also partly in semi-legal or illegal ways (Western companies claim that access to the Chinese consumer market is often made dependent on "forced technology transfer"). ${ }^{229}$ US companies and, consequently, the US government, have been looking for remedies to prevent further IP theft from emerging markets like China. To find a solution for the illegal use of US IP is complicated, since many Chinese exports have short product life cycles and, although the number of trained judges for IP cases is slowly increasing, the institutional capacity is still very limited. Furthermore, the existing trade agreements do not provide adequate remedies. ${ }^{230}$

The suggestions of the IP Commission Report reflect the present political climate in the United States in relation to the illegal use of US IP by Chinese companies. It can be divided into short-tem, medium-term and long-term solutions.

\footnotetext{
${ }^{227}$ The IP Commission Report.

${ }^{228}$ It is interesting that emerging markets make identical claims about the Triad countries.

${ }^{229}$ The strategy of market access for technology is explicitly not allowed under WTO rules, but some multinational enterprises make the statement that this practice is an "unwritten rule in China", especially for the government procurement market. See also the statement by Dr. Breznitz in Assessing China's Efforts to Become an "Innovation Society" - A Progress Report.

${ }^{230}$ The US government and the EU both support capacity building in emerging markets, e.g. as part of the USChina Strategic Economic Dialogue.
} 
Short-term solutions:

- The national security advisor should be the principal coordinator for IP theft by Chinese companies.

- A further strengthening of the ITC 337 process in order to facilitate the sequestering of stolen goods. ${ }^{231}$

- The Secretary of the Treasury should get the authority (upon a recommendation of the Secretary of Commerce) to deny use of the US Banking system to companies that steal IP.

- The Committee on Foreign Investment in the United States (CFIUS) must take violations and the theft of US IP by foreign companies into serious consideration regarding their future investments inside the US.

- The Securities and Exchange Committee (SEC) introduces the binding obligation of the public reporting of stolen IP.

Medium-term solutions:

- Extend the application of the Economic Espionage Act to wider fields of IPRs (like trade secret theft).

- The Court of Appeals for the Federal Circuit (CAFC) should become the appellate court for all actions under the Economic Espionage Act (EEA).

- The Federal Trade Commission must obtain the authority to take severe sanctions against companies that have engaged in IP theft.

Long-term solutions:

- Strengthen capacity building in China to create a better-functioning IP regulatory environment in China itself.

- The US government should convince the Chinese government to change their indigenous innovation policy into a self-innovating economy.

The IP Commission classifies IP theft as a national security issue and accuses Chinese companies of re-engineering products with only minor innovative improvements. ${ }^{232}$ The IP Commission introduced the idea of tackling the incentives for IP theft. The denial of access to the US consumer market would function as a very important lever in the trade dialogue with China. Some US politicians believe that NAFTA, the EU and Japan should

\footnotetext{
${ }^{231}$ Section 337 investigations concern imports into the US that infringe intellectual property rights (i.e. patents) and constitute unfair competition practices.

${ }^{232}$ A Study by the International Trade Commission of 2011 (China: Effects of Intellectual Property Infringement and Indigenous Innovation Policies on the U.S. Economy) estimates that the Chinese IP theft led to \$107 billion losses in annual sales and a possible loss of 2.1 million jobs in the United States.
} 
form a common front against the Chinese government and companies. Reference is often made to the Trans-Pacific Partnership Agreement, a proposed regional trade agreement with countries in the Asia-Pacific region. ${ }^{233}$ The Transatlantic Trade and Investment Partnership (TTIP) Agreement, a future trade agreement between the EU and the US, will strive to implement the highest standards of IPR protection in its treaty.

The recommendation of the IP Commission Report was that Congress and the US government had to introduce a tariff on all Chinese imports which would compensate for $150 \%$ of all the US losses that were caused by Chinese IP theft. ${ }^{234}$ This recommendation is in stark contrast to the present practice of the Chinese government, which frequently asks foreign companies and concerned parties to send in comments on draft guidelines on the application of antitrust rules in IP cases. This practice does suggest a certain degree of willingness to include other trading blocs in the IP dialogue. ${ }^{235}$

In the "2013 Special 301 Report", the Office of the United States Trade Representative (USTR) reviewed the state of IPR protection and enforcement in general terms and submitted country-specific assessments. The analysis of the indigenous innovation policy was summarized in the following conclusions:

- The presence of the above-mentioned "market access for technology" practices in China.

- State-owned enterprises are directed to obtain IPRs from foreign firms operating in China on what is described as "non-commercial terms".

- The failing effectiveness of IPR enforcement in China is giving Chinese companies a competitive advantage in the global market.

- Preferential treatment of products containing national or regional IPRs.

- "Manipulating the standards development process to create unfair advantages for domestic firms, including with respect to the terms on which an IPR is Iicensed". 236

The country-specific report on China again deals with the problem that foreign companies acting in China are often pressured to transfer IPRs to national Chinese companies against their will. National, regional and local government officials use a wide array of

\footnotetext{
${ }^{233}$ In the TTIP, the USA did emphasize the protection and enforcement of IPRs, and the Korea-US FTA (KORUS) has specific provisions on IP protection. Initiatives like the Center for Responsible Enterprise and Trade (CREATE) set as their goal the standardization of best practices for corporate IP policy.

${ }^{234}$ The practical application of this tariff will be very difficult, since it is extremely complicated to calculate the exact amount of losses due to Chinese IP theft.

${ }^{235}$ Some scholars compare the present Chinese policy in relation to IP to the development of the national environmental protection laws in China. Both policies required initial investments in the regulatory framework leading to competitive disadvantages for Chinese companies, but slowly awareness in growing with both the Chinese government and Chinese firms that these are prerequisites for acting in the global marketplace.

${ }^{236} 2013$ Special 301 Report, page 14.
} 
measures to obtain technology from foreign companies in China. These measures include the aforementioned market access, public procurement by the Chinese government, permissions, national Chinese state aids, and special tax provisions for foreign companies active in China. ${ }^{237}$

Another concern relates to the deficiencies of the Chinese Anti Unfair Competition law in relation to the protection of trade secrets.

- In practice, it is difficult and costly to invalidate a utility patent.

- The ownership of a large utility patent portfolio can be used as a bartering tool in cross-licensing negotiations.

- China has a dual filing system, leaving companies the strategic choice to abuse the system by initially filing the patent as both a utility (broad interpretation) and an invention model patent (narrow interpretation) and later making a strategic choice, often for the invention model patent that initially benefited from the protection of the identical utility model patent.

- In 2014, the Supreme Court of China published draft provisions that included an appraisal report for utility model patents. ${ }^{238}$ This draft is part of a bigger movement to change the effectiveness of the Chinese IP system; other elements include the establishment of specialized IP courts and more attention for the commercialization of IP rights and patents. ${ }^{239}$

\section{Personal opinion}

The Chinese economy is one of the main competitors in the field of consumer electronics. Within the market of consumer electronics, standards facilitate the world-wide export activities. China is the most important manufacturer of telecommunication products, but it has to use international standards with foreign patents. Chinese companies need a license to produce a 4G smart phone or DVD6C player.

Patent pools need to comply with the FRAND principles in their licensing strategies. FRAND might have a different meaning for Chinese manufacturers. Chinese firms are often the lowest cost producers. FRAND rates might be fair for producers in countries with high labour costs, but they could have a different interpretation in China. Chinese manufacturers might consider the strategic option of licensing collectives and negotiate a better common deal. Since FRAND also means non-discriminatory, this could be an option. Obviously, the joint licensing negotiations might also possibly conflict with competition law.

\footnotetext{
${ }^{237} 2013$ Special 301 Report, page 33.

238 "Decision of the SPC Regarding Questions of Application of Law in Adjudication of Patent Cases" by the Supreme People's Court of China.

${ }^{239}$ See for more background: Cohen, SPC Publishes Revised Judicial Interpretation on Patent Infringement Litigation for Public Comments.
} 
In the medium and long-term, an obvious choice would be the establishment of more SEPs by Chinese companies. This opens the door to participation in international standardization or the development of globally important Chinese technology standards.

The discussion on the Chinese mercantilist trade policies is often combined with the present view that China is stealing IPRs. The fact that Chinese authorities seek public comments for their competition law proposals, standardization laws and the revision of national patent laws presents a broader perspective.

The Chinese government understood the necessity to cooperate in international standardization. In order to be accepted, the Chinese legal framework is constantly looking for improvements. Without the guarantees of acceptable IP protection in China by Chinese courts, for international standard organizations business as usual will prove to be difficult. Given how relatively short China's history in standardization, IP regulation and competition law is the results may not be underestimated.

\subsubsection{Indigenous innovation and its effects on standards}

The discussion on indigenous innovation and its effects on has a strong impact on intellectual property rights in general and standard-setting in the PRC. China's National Institute of Standardization identifies the following strategic task in the field of standardization:

The fundamental task in China's technical standard strategy for the next 15 years is: to improve the market adaptability and competitiveness of technical standards. To improve the adaptability of technical standards to technological, trade, industrial and market demands.

To develop self-proprietary technical standards independently through effective measures, so as to improve the international competitiveness of China's technical standards and, therefore, increase the international market share of Chinese products. $^{240}$

Regarding the timeframe, China's National Institute of Standardization stipulates the following schedule:

By 2010, form a complete national technical standard system, initially with the over-

all technological level of Chinese standards on a par with that of international standards and technical standards in key areas compatible with international ones.

\footnotetext{
${ }^{240}$ Source power-point presentation conference NIS National Institute of Standardization in China (on file with the author).
} 
By 2020, upgrade the overall technological level of China's technical standards in certain key areas to the internationally advanced level, putting China high on the rank of international standardization contributors.

The emphasis on self-proprietary standards marks a shift in the perspective towards standard setting. China started out as a standard taker, concentrating its initial focus on manufacturing and cheap labour. At the moment, China intends to move from a cocreator of standards to a main standards creator in the future. In the report "China: Intellectual Property Infringement, Indigenous Innovation Policies, and Frameworks for Measuring the Effects on the US Economy", US companies complain that Chinese standard makers have the strategy of making small amendments to international standards with Chinese indigenous technology, leading to increased costs and practical barriers to trade for Western firms. ${ }^{241}$

The National Institute of Standardization foresees the establishment of a voluntary standards system characterized by the creation of market-oriented, industry-led standards with "limited governmental macro-control" . ${ }^{242}$ The NIS wants substantial participation in the international standard-setting activities, meeting the legal demands of the WTO/TBT system and aligning the national Chinese standards with international standards. China wants more involvement in the bilateral, multilateral and regional standardizing negotiations and will support some of its key industries to participate in the development of "prioritized forum, regional alliance and partnership standards." Although the NIS has predicted only limited governmental control, the definition of the abovementioned prioritized forum, regional alliance and partnership standards will probably also be dictated by political choice and not solely by market forces. The United States Standard Strategy of ANSI expects the Chinese standard system to evolve in the same direction, since it mentions on page IV "a universal application of the globally accepted principles for the development of global standards."

\footnotetext{
${ }^{241}$ United States International Trade Commission Report: China: Intellectual Property Infringement, Indigenous Innovation Policies, and Frameworks for Measuring the Effects on the US Economy page 5-15 http://www.usitc.gov/publications/332/pub4199.pdf

${ }^{242}$ Power point presentation NIS National Institute of Standardization in China (on file with the author).
} 


\subsubsection{The influence of the US on standardization in China}

The US government will try to direct the Chinese standard system towards the US-style voluntary standards system, whereas the EU will use its influence to nudge the Chinese system towards the European standards approach. Given the dimensions of the Chinese consumer market, a move towards any of the above-mentioned voluntary standard systems would give either the US or the EU and its industries a substantial competitive advantage. Therefore, it would be crucial to establish a dialogue between the EU and the PRC and to start the effective exchange of relevant information.

The US standards system is based on voluntary consensus standards, which are purely based on the input of private-sector SSOs. The US system is decentralized and can react to rapid technological changes, which is a key advantage for disruptive technology markets. The historical preference of the US government leans towards selfgoverned standards, without too much central authority. As a result, the US standards landscape might give a fragmented and chaotic impression. ${ }^{243}$ Standards are often linked to new innovative US business models and the direct influence of the national government is limited to de jure standards.

A direct copying of the US standardization system will have limited success in China. The Chinese government still holds a strong grip on the national standardization strategy. The US government exercises an indirect influence on standardization through antitrust policies. The more active role of US antitrust policies in relation to standards is motivated by the strategic role of standards in trade facilitation but also by the limits of self-regulating markets. ${ }^{244}$

\subsubsection{The influence of the European Union on the PRC standardization policy}

The United States uses its antitrust policy to balance the various interests in standardization processes. The European Union traditionally holds a different view on the central supervision of standards. The following part will describe the specific European policy in relation to standards and China. The China-EU Standard Information Platform (CESIP) aims to increase the trade flows between the two trading blocs by making the access to information on relevant standards easier. In this way, the Platform addresses one of the main complaints of European multinational enterprises, which is the lack of transparen-

\footnotetext{
${ }^{243}$ See for more background Dieter Ernst, America's Voluntary Standards System A "Best Practice Model" for Asian Innovation Economies? East-West Center 2013 page 21. The US standards system lacks effective coordination since hundreds of private SSOs compete for the market of winning standards. ANSI does not play a very effective role in relation to coordination.

${ }^{244}$ The financial crisis of 2007 led to more active antitrust policies, especially since US innovation economists like Frederic M.Scherer (Harvard University) see antitrust policy as a powerful instrument to enhance innovation and standardization. However, in the opinion of most innovation economists, a certain level of deregulation is necessary in order to compensate for "policy imperfection".
} 
cy of the PRC standardization process. The European Chamber of Commerce issues an annual Business Confidence Survey and, in the 2011 survey, 40\% of European businesses expected the regulatory environment for Foreign Invested Enterprises (FIEs) to deteriorate over the following two years and claimed that the regulatory environment was difficult to understand. The CESIP is a pragmatic approach to open a dialogue between the EU and the PRC.

Since the European Union has not yet concluded a free trade agreement with China, the best available option is the (soon to be concluded) Partnership and Cooperation Agreement (PCA) between both trading blocs. The PCA did establish various dialogue mechanisms to improve communication and understanding in EU-China trade relations. The negotiations on the TTIP agreement between the EU and the US are another important influence. Although this agreement does not affect China directly, it is still a strategic move of Western standard developers who want to keep their strategic advantage. The TTIP is discussed in chapter 1 and chapter 7.

For EU firms trading in China the CESIP is very relevant, since there is a close link between standardization and conformity assessment in China. The market access for imported goods is restricted and filtered through various pre-market approval schemes. Standard setting in China is controlled by the government and, consequently, certification and testing schemes can be used as a further means to restrict or limit the access of foreign products to the Chinese market.

The Chinese Compulsory Certification Scheme uses a catalogue of products based on compulsory national Chinese standards. Secondly, licensing schemes are controlled by the Chinese government and are based on national and industry standards. For imported goods that are not subject to the CCC catalogue or to licensing schemes, access to the Chinese domestic market is free, as long as the product does not endanger public policy, health or the environment. Serious concerns can be raised regarding the protection of intellectual property rights in standards in the economic sectors where China is leapfrogging its industrial development (Flying Geese model), since the process of technology transfer has accelerated and the political interest of the government can easily influence standardizing efforts. In this context, the certification of indigenous products can be used as a strategic tool by the Chinese government and the legality of these actions under the WTO can be questioned. ${ }^{245}$ Imported goods have to be tested in national laboratories controlled by the Chinese government, although most products meet internationally established criteria. The testing and certification procedures can be very time consuming, which hinders the early entry of imported goods into the Chinese market and enables Chinese competitors to gain an important advantage in the standardsetting context, because of the functioning of network externalities.

\footnotetext{
${ }^{245}$ Chinese conformity requirements for imported products are sometimes duplicated and conflicting. In practice, this often leads to a time delay and increased costs for imported products. Under the Technical Barriers to Trade Agreement, discriminatory practices can be challenged.
} 
The current attempt of China to match its technological progress to the Triad countries is supported by the initiative to encourage foreign investors to open research and development centres (R\&D) in China. This initiative has had a direct impact on the standardizing discussion. Joint R\&D centres could be the first step in a closer cooperation between the Chinese and International standardizing bodies and would render the extensive testing and certification processes redundant. Part of the rationale of the indigenous innovation policy is that the PRC wants to become less dependent on Western technology. This dependency is perceived as negative, since it can have implications on national security matters, but the dependency also leads to unfair and unreasonable trade terms for innovative Western technology from the Chinese government. As a counter-reaction, Chinese innovation policies related to patents concentrate on a quantitative approach, in which both SIPO and State-Owned Enterprises must reach a target number of registered patents. This approach favours quantity over quality, undermining the overall quality of patents, making the incorporation of Chinese patents into international standards more difficult. International standards aim to incorporate high quality patents for the best technology available. The European Chamber of Commerce recommends the implementation of an objective evaluation of Chinese (utility/design) patents to increase the overall quality of patents registrations. ${ }^{246}$

The idea of promoting more R\&D related foreign investment in China is negatively influenced by the lack in protection for intellectual property rights there from the point of view of foreign companies. In 2008, the State Council of the PRC issued an Outline of the National Intellectual Property Rights Strategy. Over the last two years, the Chinese government introduced new IPR laws and regulations, including the Patent Law and the Law Against Unfair Competition, which are relevant to the subject of standardization and the concept of indigenous innovation, and they have had a negative impact on the efficiency of the Chinese innovation policy. The legal provisions regarding technology transfer will be discussed in chapter 8 , section 8.2 .

The legal uncertainty surrounding the concept of indigenous innovation and its discriminatory nature towards foreign investment limits foreign enthusiasm in the field of technology transfer. ${ }^{247}$ It is well recognized by multinational enterprises that, despite the various pull factors of the Chinese market, alternative emerging markets, such as India, do exist.

The Standards Administration of China (SAC) developed a Study on the Construction of National Technology Standards System, in which it declared that the PRC wanted to

\footnotetext{
${ }^{246}$ The European Chamber of Commerce makes a comparison to the instrument of the EU Innovation scoreboard. Prudhomme in the report: Dulling the Cutting Edge: How Patent-Related Policies and Practices Hamper Innovation.

${ }^{247}$ One example of a legal rule with a possible discriminatory effect is the concept of "the High and New Technology Enterprise" (HNTE), according to which qualifying companies receive a 10\% corporate tax cut, a $150 \%$ deduction of R\&D expenses and sometimes a business tax deduction. http://www.gov.cn/zwgk/200804/24/content_953215.htm
} 
decrease "the control of foreign advanced countries over the PRC," particularly "in the area of high and new technology", in order to "relieve the adverse impact of foreign products on the China market". ${ }^{248}$

The strategic use of standards as an instrument to limit access to the national Chinese market evolved because traditional trade restrictions, such as high national import tariffs, quantitative restrictions and unfair licensing conditions, have been outlawed by the WTO framework. In relation to this research, it is important to understand that the central government developed an accreditation mechanism for the determination of indigenous products. The indigenous accreditation process will, in the future, also be applied to the telecommunications sector and the standards to be developed therein. Given the strategic importance of the standards discussion for the development of the Chinese economy, the next part will investigate the linkages and contribution that standards make to economic development. The importance of standardization also justifies a stricter application of competition rules in this context. Competition rules serve social welfare and the interests of consumers, but the right level of competition will also guarantee the accelerated economic development of China.

\subsection{STANDARDS AND THEIR CONTRIBUTION TO ECONOMIC DEVELOPMENT AND COMPETITION}

The contribution of standards to the economic development process is not sufficiently clear. The European Union and the US are both struggling with the definition of the proper public policy in relation to standards and the influence thereof on competition and, consequently, on economic development. Standards must be evaluated in the context of the relationship between intellectual property rights and the wider technology and economic development context. Ernst argues that latecomer economies to standardization (e.g. China) are facing higher costs for their standardization efforts. He concludes that, while in the US and the EU the success of standards is measured in commercial terms, for China different criteria should apply. In China, the success of national standardization must be evaluated against the immense challenges of developing a national innovation system, globalized trade and the costly licensing practices of Western companies. ${ }^{249}$

The WTO has eliminated many of the traditional trade barriers that were in use to protect national markets. Standards cannot directly be made subject to trade liberalization, since their main objective is welfare enhancement for consumers and not the protection of national markets. The content of standards differs per country, or even

\footnotetext{
${ }^{248}$ United States Chamber of Commerce: Comments in Response to Draft Guidelines on the Applicability of Article 101 of the Treaty on the Functioning of the European Union to Horizontal Cooperation Agreements.

${ }^{249}$ For more background see, Ernst: Standards, Innovation and Latecomer Economic development: A Conceptual Frame-work page 17.
} 
per trading bloc, since the standard will reflect differences in income levels and purchasing power, different consumer preference schemes, or different production levels. Many multinational enterprises have developed global production networks (GPN) and, especially in the telecommunications sector, we see the emergence of "global network flagships" initiating a wider knowledge diffusion, ${ }^{250}$ which could lead to more knowledge transfer. Knowledge transfer can be prevented by the strategic use of intellectual property rights.

The question is whether the widely-accepted concept of "national innovation systems" (NIS) can be used for China. The NIS theory makes an analysis of the knowledge creation and innovation process in a national economy in relation to economic growth. ${ }^{251}$ The definition shows an obvious weakness of the theory, since it does not take the effects of globalization and international linkages on innovation and economic growth into account. In the context of the development of the Chinese economy, this would be a distinct shortcoming. The NIS theory justifies its ignorance of globalization on two grounds: firstly, globalization effects underline the importance of strong national innovation systems and, secondly, national linkages are more effective than international innovation projects. In the literature, there has been growing attention for Global Production Networks (GPN) and their effects on innovation and knowledge diffusion. The economic rewards of the openness of national innovation systems to cooperation with foreign firms are constantly increasing. ${ }^{252}$ This has led to an internationalization of innovation and R\&D processes. Many Western multinational enterprises have opened or are contemplating moving $R \& D$ centres to China. The present policy focus of China on indigenous innovation hints at a more NIS-oriented approach, which would not give China the necessary benefits from their innovation efforts and, possibly, could undermine their efforts to catch up in the standards race. A more detailed discussion was provided in section 4.3 .

When we apply these theories to the telecommunications sector, the most striking feature is the existence of the network effects in both an interrelated innovation and competition context. The network effects were discussed in the Introduction. ${ }^{253}$ Although the telecommunications sector is traditionally heavily regulated by specific national law, the recent deregulation processes in Western countries has provoked a reaction by competition authorities. The network effects in the telecommunications sector, according to economic literature, lead to a fulfilled expectations demand. ${ }^{254}$ This demand is important in relation to the achievement of critical mass and, because of its nature, network goods can experience an unexpected and sudden expansion of the

\footnotetext{
${ }^{250}$ Source: Ernst and Kim page1418.

${ }^{251}$ Lundvall 1992, Mowery \& Nelson 1999.

${ }^{252}$ Henderson, Dicken 2002.

${ }^{253}$ See Introduction section network effects.

${ }^{254}$ Economides, Competition Policy in Network Industries. The addition of extra users to the network has a benefit for the entire network.
} 
network (the above-mentioned "winner-takes-all principle"). A number of features of network markets are relevant for the competition therein and, consequently, for the success of the innovation process.

For the Chinese setting, this is particularly interesting, since the societal needs in China, as a developing country, differ from those of Western economies. At the end of this chapter, I will look at the specific link between competition policy and developing countries.

In conclusion, a direct comparison of the US, European and Chinese legal rules in the field of the strategic use of IPRs in the standardization context is reasonably complex but, given the interdependence of the three systems within the globalized trade system, it is a strict necessity for multinational companies, national governments, trading blocs, and other stakeholders.

Standardization has a very positive effect on economic development. The network effects of standardization justify a closer investigation of antitrust agencies. Some of the practical results, price-setting, high switching costs and lock-in effects, will have a direct impact on consumers.

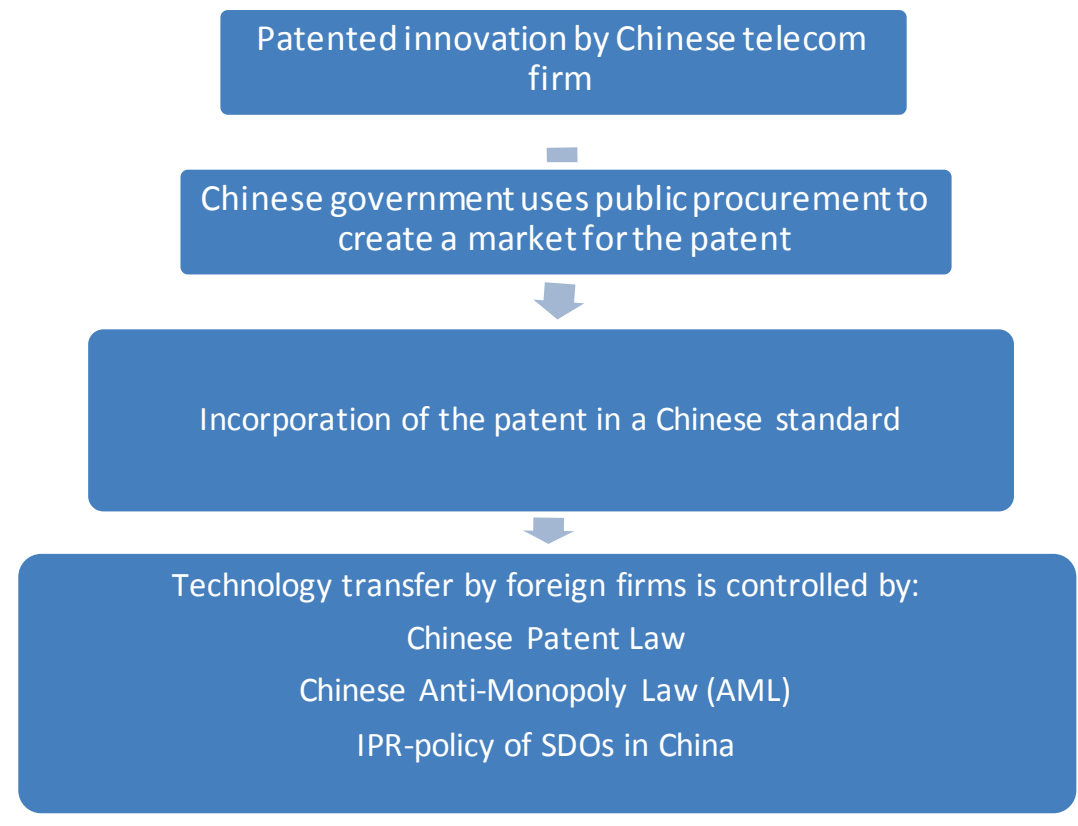

As the figure above shows, standardization and competition are at the heart of the creation of national champions, or multinational enterprises originating in China that are capable of competing with their rival companies in the Triad countries. The building of these national champions is aided by a "web of indigenous innovation policies", as a 
representative of the US Chamber of Commerce defined the combined policy efforts of the Chinese government to support their national companies.

Within the standardization context, step 3 declares that the national standard organizations in China will develop a standard that favours the new product, making it more difficult for foreign companies to compete. The precise definition of the standardizing efforts in relation to indigenous innovation is not sufficiently clear. Foreign investors have regularly made complaints regarding the lack of transparency and the limited access to the national Chinese standardization system. The overall fear of foreign companies active in China is that the development of national Chinese standards may lead to diversified and not widely accepted standards, discriminating against non-Chinese entities. The requirement that the R\&D must take place in China in order to be qualified as an indigenous innovative product can be contrary to the current common practice in the field of telecommunications, where standards are often created in an international setting, surpassing national borders or regional trading blocs. Thus, it is becoming more and more difficult to trace the intellectual property rights to one specific jurisdiction, especially in relation to the concept of open innovation and open standards.

Multinational enterprises also carefully consider where to register their national intellectual property rights (e.g. patents) as part of their global strategic management. One of the research questions concerns the impact of governmental regulations on standards and IPRs on the development of future trade patterns. Baldwin, Ganslandt and Markusen established a model that assumes that a firm must incur fixed costs for the standard requirements of their foreign market, whilst at the same time the variable production costs will increase if the national standard of the foreign market is more restrictive. ${ }^{255}$ The current debate on the influence of the indigenous policy in the PRC will seriously affect the various parts of the strategic management policy of a foreign firm operating in China. One example is the decision of InterDigital to settle its legal dispute with Huawei. This case will be discussed in detail in chapter 8, section 8.16.

The Chinese indigenous innovation policy will influence country selection, the mode of entry, the registration of possible patents, and the management thereof.

US scholars and industry representatives often tend to see a hidden conspiracy and a web of supporting and integrated policies related to indigenous policy that deliberately aims to discriminate against foreign investors and seeks to limit access to the Chinese domestic market. For this researcher, the challenges of creating a coordinated effort in this field, where national, regional and local authorities would cooperate to maximize the gains for national companies, would exceed the current capabilities of the Chinese authorities. It is more likely that the present lack of transparency in relation to the standard-setting environment and some of its elements (like the uncertainty regarding the definition of the accreditation process for indigenous products) is the result of a lack of cooperation between the different Chinese regulatory institutions themselves, who

${ }^{255}$ Chen and Mattoo: Regionalism in Standards page 8. 
all have their own interests in this discussion. There is hardly any research on the apparent fragmentation that local governments cause in the standardization discussion. The common national innovation strategy will be implemented by local governments with a non-standardized approach. Secondly, the example of the telecommunications sector illustrates that the telecommunications policy seeks to promote open networks that are manageable at low costs. However, at the same time, the industrial policy demands a fast expansion of high quality networks. Finally, the media policy favours a more restrictive approach, mainly motivated by security implications.

A second discussion is at the centre of this research, the question of what the exact role of the intellectual property rights that are part of the standards developed in China will be. As stated above, one of the prime concerns of the Chinese government is the relatively high rate of royalties that Chinese companies have to pay for using the intellectual property rights (e.g. patents) in the standards created within the European Union and the US.

\subsection{THE DEVELOPMENT OF STANDARDIZING IN THE PRC AND THE IMPACT OF INTELLECTUAL PROPERTY RIGHTS.}

In China, it is a common belief that standardizing operations must be supervised and coordinated by governmental agencies, to varying degrees. Standards are frequently related to the protection of public health, order and policy or to environmental protection. Also, discussions concerning quality can be better led by the central government, since private companies might have different interests than the protection of the consumer. Some of these beliefs can be directly traced back to the former Communist system and a lack of trust in the private sector in general. As a consequence, the Chinese standardization landscape is not characterized by the same level of openness, transparency and accessibility as the US and European systems. In 2009, the SAC published new rules for standardizing processes.

According to these new rules, foreign firms who are officially registered in China may participate in the formulation and establishment of voluntary Chinese national standards. The eligibility requirements for the participation of foreign firms are up to the discretion of the individual chairpersons of the relevant technical committee, which leaves sufficient room to manoeuvre.

Ernst concludes in a report that, for optimal effect, standards must be contextspecific and take into account the structure and the competitive dynamics of specific markets or industry sectors. ${ }^{256}$ Especially in the technology markets, business models are dominated by intellectual property rights and are scale-intensive. New technology

\footnotetext{
${ }^{256}$ Ernst (2011). Indigenous Innovation and Globalization: The Challenge for China's Standardization Strategy page 28.
} 
development depends on venture capital and private equity, both of which are just beginning to surface in China. The speed to the market is of the absolute essence during the commercialization process and often results in "winner takes all" strategies. See also the previous discussion in section 2.4.

By taking the example of a Chinese national standard in the telecommunications sector, I will try to elaborate on and provide insight into the possible current situation.

\section{IP abuse in the field of technology transfer in China}

China is attractive for firms active in the technology market for various reasons. It offers one of the biggest consumer markets in the world and, as an emerging market, is characterized by a growing middle class with the willingness to spend money. The Bureau of Industry and Security of the US Department of Commerce finds in its research on technology transfer to China that the Chinese government strongly encourages cooperation in the field of high-tech industries. Incentives such as tax rebates, tariff reductions and preferential treatment motivate US firms to do business in China. Although discriminatory practices of the Chinese government are often reported, most companies cannot afford to refrain from participating in the Chinese consumer market. ${ }^{257}$

Common complaints of US and European firms in the field of IP and competition are the following:

- Flagrant and discriminatory promotion of national Chinese standards against international standards.

- Foreign firms have to cooperate with state-led consortia in China for technology development.

- Government intervention in royalty discussions with foreign patent owners.

- Technological standardization in China needs to serve national products.

- Standardization is used by the Chinese government as a market regulation tool.

Another feature is the increasing competitiveness of Chinese firms in the global hightech production market. The growing impact of Chinese telecommunications companies like Huawei on foreign markets has led to interesting reactions. ${ }^{258}$ Huawei applies a business model which does not strongly rely on building a core IP portfolio but concentrates on system delivering to world-wide telecom operators. ${ }^{259} \mathrm{~A}$ US Congress intelli-

\footnotetext{
${ }^{257}$ US Department of Commerce, Bureau of Industry and Security Technology Transfer in China and Doing Business in China 2012 Country Commercial Guide for U.S. Companies

${ }^{258}$ Huawei is often associated with the business strategy of IP Mining. This business practice happens when a firm obtains IP illegally in one country and consequently commercializes the IP in developing countries with weak IP enforcement.

${ }^{259}$ The MIIT initiated a working group consisting of representatives of various Chinese ministeries to evaluate this business model as a best practice. ZTE made early investments in the TD-SCDMA standard and owns most
} 
gence committee presented a report on Monday 8 October 2012 including a warning for the US government not to purchase Huawei telecommunications products because of security risks. ${ }^{260}$ This report could have seriously hindered Huawei's market penetration into the very profitable US telecommunications market.

In the European Union, Member States did not support the initiative of the EU Commission to start an investigation into the Chinese telecom companies Huawei and ZTE. The EU Commission is currently investigating 19 cases of possible dumping and subsidy violations by Chinese companies. Fears of retaliatory consequences and limited access to the Chinese telecom consumers' market are the main reasons that none of the European manufacturers (Ericsson, Alcatel-Lucent, Nokia Siemens) have lodged a complaint against their Chinese competitors. ${ }^{261}$

\subsubsection{The development of national Chinese standards in the sector of Telecommunications}

The telecommunications sector is known for rapid technological change and a global consumer market. These two characteristics have a major influence on the standardization processes within the telecommunications sector. The rapid technological changes pose immense challenges for traditional standardization bodies, since their processes are often too slow to keep up with the necessary developments. The functions of a mobile phone now far exceed its traditional use for voice communication with the inclusion now of various multimedia applications (e.g. route planner for an iPhone) that necessitate the involvement of many different stakeholders in the formulation of the standard. European and US standards have dictated the global playing field for mobile phones for a long time.

Given the sheer size of the Chinese consumer market, the definition of a Chinese national standard would give the PRC a strategic advantage, also since international standard bodies have so far failed to establish a common ICT standard for mobile phones. The European Union and the US were among the first to develop a standardization system. In the literature, it is noted that countries which are the first to adopt standardization strategies often choose for a market-based approach, compared to later adopters who often make the choice for stronger government influence in their standardization processes. ${ }^{262}$

\footnotetext{
of the patents in this standard. Huawei and Apple do not possess a large patent portfolio, which makes crosslicensing unavailable. As a result, both companies will become more involved in litigation. Huawei and ZTE are currently involved in several court cases relating to SEPs in Germany, France and Hungary.

${ }^{260}$ Congress fears the "beaconing" or the transmission of sensitive data back to China Wall Street Journal October 9, 2012 page 23.

${ }^{261}$ Blenkinsop, EU resistant to China telecoms trade case: Sweden.

${ }^{262}$ P.Wang (2014) The latecomer strategy for global ICT standardization: Indigenous innovation and its dilemma.
} 
The success of China's indigenous innovation policy will strongly depend on the level of openness and the possibilities of access for international stakeholders and competitors to their standardization processes. This is a real challenge, since the PRC, in its "standards race" to catch up and to grow to be on a par with the EU and the US, predominantly wants to foster self-reliance on national standards to make China less dependent on international standards. In the catching-up phase, it might be justifiable that, in the case where national or local firms are not yet competitive, a certain level of fostering and protection of infant industries can be provided by the national government. However, it is questionable whether, in the specific case of the telecommunications sector, Chinese firms have not already leapfrogged part of their development cycle and, thus, whether they are still entitled to some form of national protection. The Chinese firms Huawei and LTE are currently engaged in various legal battles concerning standard essential patents in Europe and have become serious competitors for US and European telecom firms. ${ }^{263}$ In section 7.8 .4 more information will be provided on these cases.

When we apply the concept of indigenous innovation to the telecommunications industry, it is clear that it revolves around three major themes:

1. The production of original innovations.

2. The development of integrated innovation systems, a process whereby different new innovations accumulate to a new product.

3. The fostering of the notion of "re-innovation" - new products that are developed on the basis of acquiring and improving imported technologies. The wording of the concept of re-innovation is very similar to the idea of incremental innovation, which is an innovation theory which improves the cost effectiveness and introduction and development phase of a new product but which does not alter the original product in a substantial way. ${ }^{264}$

The ICT industries are often quoted in the literature as a classic example of a sector that can be used as a basis for technological revolution in the catching-up process, since it is one of the fastest growing industries. China is both a user and manufacturer in the market for telecommunications products. National standards developed for the Chinese home market can have the potential to become global standards, given the size and the future growth of the consumer market and the willingness of the central government to invest in substantial funding. In the next section, a comparison will be made between the different approaches in the development of Chinese and Korean telecommunications standards. Both countries are emerging economies, but they have different per-

\footnotetext{
${ }^{263}$ See also for more information: http://www.lightreading.com/document.asp?doc_id=701924

${ }^{264}$ For more background information see; Prud'homme How certain indigenous innovation and other patent policies hamper innovation in China MPRA Paper No. 51710,( http://mpra.ub.unimuenchen.de/51710/1/MPRA_paper_51710.pdf )
} 
spectives in their innovation policies and thus their standardization processes can be identified. The examples illustrate the influence of national industrial and innovation policy concerns in a practical setting. The cases also show a different outcome regarding the acceptance of the standards by consumers.

\section{China: Patents granted for Telecommunications 1999-2011}

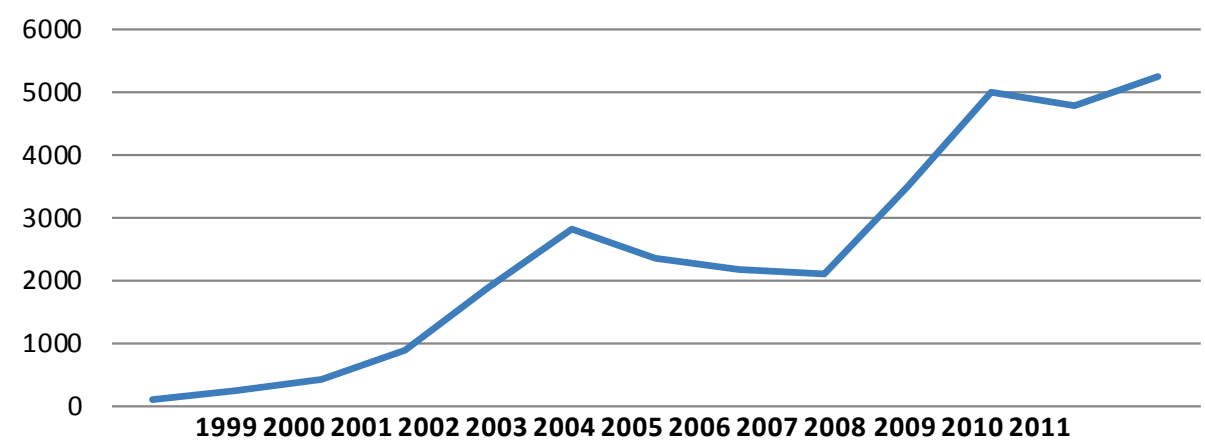

265

\subsubsection{The WAPI and TD-SCDMA standards}

The two best-known examples of national standards are the Wired Authentication and Privacy Structure (WAPI) standard and the Time Division Synchronous Code Division Multiple Access (TD-SCDMA) telecommunications standard. Both national standards were developed and promoted in China in order to make the country more independent of Western standards. Initially, the PRC wanted to make the WAPI standard mandatory but the US government raised serious concerns in the WTO Technical Barriers to Trade (TBT) Committee. See also the earlier discussion on the TBT in the Introduction. As a result, the WAPI standard was not defined as a mandatory standard but was designated as a "priority standard for governmental procurement". The most prominent challenge facing these standards is the successful commercialization and broad acceptance of the standard by the Chinese consumers. As mentioned above, the telecommunications industry is a network industry.

Normally goods that experience higher demand levels will automatically experience a decrease in prices. In the network industries, the demand price schedule does not always show a downward trend. The industries need a critical mass of consumers to enable the proper market introduction of a new innovative good or service. Without a

${ }^{265}$ Figure based on data of WIPO IP Statistics Data Center (http://ipstats.wipo.int/ipstatv2/IpsStatsResultvalue) 
critical mass of users, new consumers are not interested in purchasing the new product and vice versa. The decision-making process of consumers is crucial and can be influenced by strategies and tactics in the standardization process. Network markets are relatively unstable and consumers are heavily influenced by the expectations of the future size of the market for the network product. ${ }^{266}$ The preference of consumers can be led by slightly different features of a new product, which leads to unreasonably high profits for the winning standard ("the winner takes all").

This has significant implications for the competition in the market. At first, firms will heavily compete to become the industry standard, and consequently competition in the market of the chosen standard will start. Firms have to consider whether it is more profitable to enter into horizontal competition in a network market in order to become the winning standard or whether to compete with firms offering a compatible product in the same market.

The tactics in the standardization process in relation to competition can take different forms and depend on the horizontal compatibility strategies of the participating firms. Firms could deploy one of the following strategies:

1. Every individual firm wants to set the industry standard itself.

2. Every firm has a preference for its own technology but wants to promote interoperability with the technology of competitors.

3. Firms prefer to maintain their own technology as a proprietary standard but are open to cooperation with other firms who wish to join their standard.

In case of scenario 1, the firms will start a standards battle for a new market and will be looking for options, such as creating an early and substantial lead in its user base and communicating this to future users. The sales figures can be manipulated and penetration pricing (offering the innovative product for a lower price in order to build a customer base) can help to establish a winning lead over competitors. Within the telecommunications industry, establishing a wide range of complementary products can also help tipping of balance of new consumers to one specific technology and standard. The choice for one technology can also be aided by preannouncing the release of a new product, which can convince consumers not to buy products from competing firms but to wait for the latest technology. The last strategy can easily backfire, since it cannibalizes a firm's current range of products, which could seriously hurt its cash flow. Firms often accompany new products with long-term contracts, offering low prices for the innovative product. If the future costs can be foreseen and are considerably low, this would give the firm a comparative advantage in the standards battle.

Scenario 2 depends on whether the firms agree on the preferred technology. If all firms are in agreement on the preferred technology, the easiest option is to start a

${ }^{266}$ Besen and Farrell p.118. 
formal standardization process by an SDO. In the case that there is no agreement on the preferred technology, competing firms have to be persuaded/convinced to join the network. The FRAND conditions, licensing conditions at low cost and generally acceptable terms for the patents used in the standard can convince rival firms to join the standard. The establishment of a patent pool could also be a persuading factor, as could the promise that rival firms may join in the future development of standards. The recent interest in open innovation can also be linked to scenario 2 .

In scenario 3, firms are often asymmetric and do not enjoy the same position in the relevant product market. One firm might have a dominant position in a market, whereas other often smaller companies want to join their network. The dominant company can often use patents and copyright to prevent other companies from joining their network. Another possibility would be to keep a competitive advantage by a rapid technological developments that cannot be followed by other firms.

The strategies and tactics within the standardization setting can easily interact and interfere with the conditions of the competitive environment. It is therefore almost a natural consequence that competition authorities take a keen interest in these strategies and tactics. ${ }^{267}$

The Chinese 3G wireless standard, TD-SCDMA, was recognized by the International Telecommunications Union (ITU), paving the way for an even wider acceptance. The ITU shortlisted five different standards in its recommendation: the Euro-Japanese CDMA standard, the US CDMA2000 standard, the hybrid Euro-China TDMA/CDMA standard (TD-SCDMA), the EDGE standard (a further development of the $2 \mathrm{G}$ standard), and the DECT standard of ETSI. The WAPI standard did not obtain recognition by the SSOs, probably as it did not include a foreign firm in the project (Siemens supported the TDSCDMA standard). For the development of the TD-SCDMA standard, RMB 25 million was funded by two Chinese government agencies, the Ministry of Science and Technology (MOST) and the State Planning Committee. ${ }^{268}$ The acceptance of the TD-SCDMA standard was heavily supported and coordinated by the Chinese government.

In the commercialization phase of the TD-SCDMA standard, new strategies were used that are not directly possible in a free-market economy. The Chinese government used free spectrum allocation as a strategic means to help the acceptance of their $3 \mathrm{G}$ standard. In the EU spectrum, allocation was traded by auctions, providing national governments with substantial revenues. In markets where the commercialization of the $3 \mathrm{G}$ standard did not have the same speed as the former $2 \mathrm{G}$ standard, high license fess (often due to overbidding in the auction) became a burden for the telecommunication operators. The decision of the Chinese authorities to allocate free spectrum meant a potential loss of income, which would possibly be compensated by the wider adoption of the TD-SCDMA standard. The availability of the wireless spectrum in China is reason-

\footnotetext{
${ }^{267}$ Besen and Farrell.

${ }^{268}$ Whalley p.11.
} 
ably limited, with military use and state television taking the bulk of the spectrum. The introduction of smart phones, which need substantial bandwidth, will not improve the quality of the mobile networks in China.

Secondly, a TD-SCDMA industry alliance was established with eight Chinese manufacturers, including the four most prominent competitors, Datang Mobile, ZTE, Potevio, and Huawei. This industry alliance received government subsidies of RMB 700 million to help the commercialization of the standard. For the market acceptance of a standard, support and joint development with foreign companies is still a crucial factor. Leapfrogging in the development of this telecommunications standard is almost impossible without the cooperation of or strategic alliances with foreign companies who still have an advantage in the latest technology. Even in the TD-SCDMA standard, which is often used as a showcase for indigenous innovation, foreign technology protected by patents is a substantial part of the technology. Firms like Qualcomm, Ericsson, Siemens, AlcatelLucent, and Motorola have essential patents in the TD-SCDMA standard. As well as the industry alliance, a special TD-SCDMA forum was established, consisting of manufacturers and operators, standardizing bodies, and other stakeholders of the standard. Compared to similar forums of competitors (GSM, CDG), the impact and membership of the TD-SCDMA is still somewhat limited. The development of the standard was coordinated by a state-owned enterprise (Datang) and, as well as from the preferential treatment in relation to the spectrum allowance, the government also deliberately delayed the licensing of competing foreign $3 \mathrm{G}$ technology to help the introduction of the TC-SCDMA standard. The accompanying network for the standard was to be developed by China Mobile, although this company had a preference for the W-CDMA standard. The TDSCDMA Industry Alliance (TDIA) mentions in its official mission that the TDIA must "advise the government to adopt important industry policies in favour of the TD-SCDMA standard" and "improve the collective competitiveness of the companies in the alliance". Although the TDIA does not publish its IPR-policy, one of its tasks is to develop a plan for the sharing of intellectual property rights, which could hint at the creation of a patent pool. ${ }^{269}$

The broader acceptance of the standard is hampered by the fact that the standard is a direct result of the indigenous innovation strategy. The objectives for the establishment of the TD-SCDMA standard are not just of commercial nature but can also be traced back to national security issues. From a wider perspective, the successful implementation and commercialization of the TD-SCDMA standard could increase the number of Chinese essential patents, which would give the Chinese government a better position in the negotiations on cross-licensing agreements with Western firms. At the time of writing, some scholars claim that the TD-SCDMA standard is already a Chinese success story, but it is still too early to evaluate its actual impact on the market. Liu and Cheng conclude that the

\footnotetext{
${ }^{269}$ Ernst \& Center (2011). Indigenous Innovation and Globalization: The Challenge for China's Standardization Strategy page 74 .
} 
Chinese government deliberately delayed the licensing of $3 G$ technology, which also delayed the introduction of the $3 \mathrm{G}$ standard in China. At the same time, Datang (SOE) was prevented from forming a joint venture with international firms on the $3 \mathrm{G}$ market, which would have improved the innovative processes within Datang. ${ }^{270}$

For the introduction of standards developed in the US or the European Union, commercial acceptance is the key success factor. The direct return on investment, the gained market share and the value of the essential patents in the standard can indicate the level of acceptance by the general public. For China, the TD-SCDMA standard is a prominent project that must promote the concept of indigenous innovation and some of its expected effects. However, the example of the TD-SCDMA standard shows that the strategy of indigenous innovation strongly depends on cooperation and joint research activities with foreign companies, which contrasts with the basic objective of becoming less dependent on foreign technology, paying less in royalties to foreign firms and creating more standards with essential patents at a national level.

The choice to rely only on national Chinese innovations could possibly cause a fragmentation of the consumer market and hinder the realization of the full potential of the economies of scale. In the catching-up phase, Chinese industry has to use its full absorptive capacity in order to keep up with the rapid change in technology. The adoption of a standard in a network market is heavily influenced by the expectations of the consumers regarding the size of the competing networks. Products that have network externalities are characterized by demand-side economies of scale and, as noted before, this frequently leads to tipping of the market in favour of one particular standard or technology. Other firms must make the correct strategic choice on whether to make compatible products for one specific standard.

In the case of the TD-SCDMA standard, the network externalities do not function in a similar manner to their functioning in the US and EU markets. Despite the various forms of support from the Chinese government (direct funding, preference for the standard in government procurement, discrimination against network owners who refuse to share their infrastructural services), the enthusiasm of Chinese companies for the standard is limited. There is a risk that the network externalities could also allow for the adverse effect on consumer confidence and on the image and branding of Chinese standards globally. Not only would there be negative repercussions for consumer confidence in the TD-SCDMA standard but also on the future ability of China to become a standard developer for the next generation of telecommunication standards (TD-LTE). Both national and foreign investors would be hesitant to finance new Chinese innovative projects and the current clash of interests and lack of coordination between the various elements of the Chinese government (central, regional and local) could intensify.

\footnotetext{
${ }^{270}$ The $3 G$ Standard Setting Strategy and Indigenous Innovation Policy in China: Is TD-SCDMA a Flagship? In Danish Research Unit for Industrial Dynamics, www.druid.dk DRUID Working Paper No. 07-01 http://www3.druid.dk/wp/20070001.pdf
} 
At the moment, it looks like the TD-SCDMA project is opening up to new foreign partners. Companies such as Nokia wish to build a stronger presence in the Chinese market as a reactive strategy to declining global sales. In the chapter on the EU and patent pools it will become clear that Nokia is currently changing its business strategy. Nokia wants to concentrate more on the management of their patent portfolio and less on manufacturing. Both politically and economically, a future cooperation between PRC and Taiwanese firms in relation to the TD-SCDMA standard is very promising. Taiwan is host to some of the most innovative telecommunications firms in the world (such as Asus, HTC and Acer) and a closer cooperation with mainland Chinese companies could possibly open up the world market to their new innovative products. The Chinese attempts to deliver a global standard with the TD-SCDMA project show that future cooperation with Taiwanese firms could vastly improve the quality and acceptance of new Chinese standards.

Scholars are divided on the necessity of government regulators to interfere with the standard-setting process in case of goods that show network effects. In the case of the TD-SCDMA standard, it is questionable whether this is a standard developed by an SSO or whether this is a mandated standard set by the Chinese regulators. The level of political and economic support from the Chinese government for the TD-SCDMA standard is unprecedented. Telecommunications products have strong network effects and, consequently, are known for very strong innovation developments. The standardization challenges in China have been met with a different perspective than in competing trading blocs like the US and the EU. Although the standardization effort in the TD-SCDMA standard started as a government-controlled traditional view on innovation, the commercialization phase forced the PRC to allow foreign competitors (Siemens, Nokia, HIC) into the standardization process. The necessity to abandon the concept of purely indigenous innovation is linked to the limited market response in relation to the TD-SCDMA standard.

The lukewarm reaction to the standard (also inside the PRC) is related to several factors. The first factor is that some parts of the Chinese countryside have a relatively low penetration rate of mobile networks, and therefore there is still a market for a less refined standard. Secondly, the TD-SCDMA standard has not yet been subjected to a real market test. Without a wider adoption, the confidence of consumers will be further undermined and the lack of potential foreign investors will continue to become a problem. In terms of the standardization strategy, the key question is how the absence of the compatibility of the standard affects the rate of technological progress (especially in the telecommunications sector) and the timing of the market introduction of the standardized product. ${ }^{271}$

These two factors, the existence and more importantly the strength of the network effects and the pace of the innovation, are both predominant features of the telecom-

\footnotetext{
${ }^{271}$ Gandal page 11 compatibility, standardization and network effects.
} 
munications industry and have also raised the interest of various national and regional competition authorities. China seems to have made a strategic choice for a two-tier approach in relation to the TD-SCDMA standard. In this two-tier approach, the Chinese government has the choice between developing its own national standards, which might also become global standards, or adopting internationally accepted existing standards. One crucial factor will be the cost-effectiveness of one of the two options, but other factors are the policy objective of indigenous innovation (making the Chinese industry less dependent on foreign technologies) and the "inner-circle" character of the present standard-setting environment.

The current standardizing landscape is made up of a relatively small number of SSOs and firms all originating in the traditional Triad countries (US, EU and Japan). As a latecomer to the standardizing community, China has to get access to this inner circle which has been established by governments and firms with a traditional background in economic development and innovation. At the moment, the centrally-led, governmentcoordinated standardization strategy focuses on the development of national innovative products, while the reality of the example of the TD-SCDMA standard shows that standard setting in the globalized economy is diversified by many different stake holders and participants and that innovation processes are not exclusively linked to one single jurisdiction.

In the two-tier approach, China has to face the complexity of the international system and re-define the role of its national standardization policy. The national standardization law in China is being amended at the time of writing, although it is insufficiently clear in which direction the final version will head. Other documents, such as the much debated definition of what defines an indigenous product, give a blurred picture. Both in the EU and in the US many scholars and business representatives have voiced their concerns about the possible strategic definition of what constitutes an indigenous product. The fear that foreign products could be excluded from future government procurement projects or could be discriminated against has been denied by senior Chinese government officials. The experiences with the development of the TD-SCDMA standard make it difficult to draw general conclusions. The question is whether a general pattern may be deduced from other standardization cases. In order to investigate this, the experiences with the Chinese WAPI standard and the Korean WIPI standard will be discussed and compared.

\subsubsection{The Chinese WAPI standard}

The WAPI standard was developed in China to overcome the security problems that were associated with Wi-Fi. As a result, China decided to opt for the WAPI standard, which could also be used in the Chinese market. Initially, the choice was made to give the WAPI standard a compulsory character, making it mandatory for products produced and imported into China. The mandatory requirement led to heavy complaints by for- 
eign firms active inside the PRC and it was argued that the requirement was in violation of the Technical Barriers to Trade Agreement of the WTO. ${ }^{272}$ Consequently, the Chinese government decided to suspend the development of the standard indefinitely and to opt for recognition with the IEEE. ${ }^{273}$ This could have included the development of a formal standard that could later have become an open standard. However, the attempt to gain acceptance of the WAPI standard at the IEEE failed in favour of the Wi-Fi standard and the Chinese authorities started spreading conspiracy rumours against the Wi-Fi alliance. ${ }^{274}$ The end result was that the WAPI standard never reached the commercialization phase.

In Korea, the government and firms faced identical challenges. For reasons of efficiency, the Korean government pushed for the standardization of mobile platforms. Foreign platform providers like Qualcomm demanded high royalty payments, which put Korea at a competitive disadvantage. The government started the development of the WIPI 1.0 standard and, already in the early stages, foreign firms such as Nokia and Sun Microsystems were asked to cooperate and to participate. The Korean standard met with resistance from foreign firms such as Qualcomm and Sun Microsystems, since their Java technology was included in the standard. The Java technology was protected by intellectual property rights and, consequently, Korea still had to pay royalties to Sun Microsystems. ${ }^{275}$ Although the Korean government initially made the choice to allow just one mandatory standard, after the intervention of the UN and the US government, they did allow multiple international mobile platforms. The similarities between the rationale of the development of both standards is striking.

Both standards were intended to become the single mandatory standard, thereby making excessive royalty payments to foreign firms obsolete. In both cases, essential patents held by foreign companies played a major issue but were treated in a different way by national governments. Regarding the technical specifications, WAPI was made incompatible with other international standards (because of security issues). The developers of the WIPI standard made the strategic choice to allow WIPI to be compatible and to interact with other platform standards and thus with foreign firms and their patented technology. The selection of a standard is critically influenced by the market share that can be gained after the introduction period (network externalities). The WAPI standard was introduced after the Wi-Fi standard had already gained a critical mass of users. The WIPI standard was released onto the market when there were different standards fighting for recognition and the users had not yet made a definite choice for one specific market. Oh and Lee come to the conclusion that the differences in outcome can be attributed to three different factors: the openness of the standard and the

\footnotetext{
272 Intel also made the claim that WAPI was backward in technological terms.

${ }^{273}$ IEEE is the Institute of Electrical and Electronic Engineers and develops standards in the technological field. IEEE plays important role in the field of wireless network standards.

${ }^{274}$ See for more comments Lee and Oh: The political economy of standard setters.

${ }^{275}$ Contrary to the original purpose of the development of the WIPI standard.
} 
standardization process, the leading role of the government and the time to marketentry. ${ }^{276}$ This researcher would like to add another important element by combining and specifying the first two interlinking factors. The examples of the TD-SCDMA standard and the WAPI and WIPI standards indicate that the regulation of intellectual property rights in relation to the openness of the standardizing process is influenced by national governments' strategies on innovation policy. Obviously, the most important intellectual property right in this context is a patent. In order to become part of the international standardization community, China needs more investments and participation from foreign firms. In reality, foreign firms tend to be hesitant to participate in Chinese standard setting.

\subsubsection{Main problems for Foreign Direct Investment in China in relation to standardization processes.}

European companies operating in the Chinese standardization environment identified the following key problems: ${ }^{277}$

- Limited information available on patents that are implemented in Chinese mandatory standards.

- National standards are intentionally developed to support the technical capabilities and know-how of Chinese SOEs.

- Technical requirements based upon the protection of national security favour Chinese domestic standards.

- The unwillingness of Chinese firms to license essential patents.

- The growing emergence of Chinese Non-Practising Entities. (This is also a consideration for Chinese courts see recent InterDigital v. Huawei case in section 8.16

- The limited accessibility of the Technical Committees of Chinese Standards means that foreign companies cannot enter into patent pool agreements.

- Only $46 \%$ of the 20,000 national standards in China are derived from international standards.

- The general participation of foreign-owned firms and foreign companies in the standard-setting processes is limited and proves to be cumbersome in daily practice. $^{278}$

\footnotetext{
${ }^{276}$ Lee and Oh: The political economy of standard setters page 670.

277 Prudhomme Dulling the Cutting Edge: How Patent-Related Policies and Practices Hamper Innovation page 100.

${ }^{278}$ See also speech of Pangratis, EU Ambassador to China before the World Trade Organization.
} 
In my personal view, the main problem is that the standards in China are made by the government and not by companies. The standard-setting organizations are controlled by the Chinese government, which also acts as the arbiter in case of a dispute. This last point can pose a problem for foreign companies. The Chinese SSOs provide a very diverse picture regarding the participation of foreign stakeholders. Some SSOs do allow foreign companies, while others have a closed character. In case the foreign company is allowed to participate, this can only be as an observer.

The foreign companies are confronted with a very complex system of Chinese standards. The sheer volume of standards produced, the lack of coordination between the different SSOs and the different governmental interests result in an complexity. This (unwanted) complexity is in reality already a barrier to participate in Chinese standardization.

\subsubsection{Utility Model Patents}

The WIPO country statistical profile of China shows an impressive rise in the number of patent registrations in the last few years. The vast majority of patent applications were for utility model patents. The utility model patent is not exclusively restricted to China, since countries such as Australia, Japan, South Korea, and Germany also apply the same type of patent in their national IP system. The utility patents provide a protection of only ten years and the registration requirements and examination are less rigorous compared to model invention patents. There are two main reasons for the high rise in utility patent applications: the indigenous innovation policy campaign provides incentives to Chinese companies to register as many patents as possible ${ }^{279}$ and a change in judicial decisions, starting with the CHINT-Schneider case. This case will be discussed in detail later in this chapter. The sheer increase in the volume of Chinese utility patents causes a number of problems:

- The substantial number of utility patents creates a patent thicket for foreign companies active inside the PRC.

- Although at least half of the utility patents can be classified as junk patents, they cannot be ignored since these patents can be used against the original innovators in licensing negotiations and can be used against infringement claims by foreign firms.

- The search and clearance investigations concerning patents in China have become almost impossible.

\footnotetext{
${ }^{279}$ The Chinese National Patent Development Strategy (2011-2020) aims to raise the number of patent filings to 2 million by 2015 , both for domestic and foreign firms.
} 
- Non-Practising Entities are becoming the main companies to register and own utility patents, thereby becoming patent trolls. Relatively low litigation costs, the ease of getting an injunction on a utility patent and the general increase in patent cases have led to more NPE activity in the telecommunications sector. ${ }^{280}$

- In practice, it is difficult and costly to invalidate a utility patent.

- The ownership of a large utility patent portfolio can be used as a bartering tool in cross-licensing negotiations.

- China has a dual filing system, leaving companies the strategic choice to abuse the system by initially filing the patent as both a utility (broad interpretation) and an invention model patent (narrow interpretation) and later making a strategic choice, often for the invention model patent that initially benefited from the protection of the identical utility model patent.

- In 2014, the Supreme Court of China published draft provisions that included an appraisal report for utility model patents. ${ }^{281}$ This draft is part of a bigger movement to change the effectiveness of the Chinese IP-system. Other elements include the establishment of specialized IP courts and more attention for the commercialization of IP rights and patents. ${ }^{282}$

\footnotetext{
${ }^{280}$ Moga, “China's Utility Model Patent System: Innovation or Deterrent?” U.S. Chamber of Commerce, November 2012, http://uscham.com/V5aXyq. page 23.

281 "Decision of the SPC Regarding Questions of Application of Law in Adjudication of Patent Cases" by the Supreme People's Court of China.

${ }^{282}$ See for more background: Cohen, SPC Publishes Revised Judicial Interpretation on Patent Infringement Litigation for Public Comments.
} 


\section{Growth of total patents granted in}

China

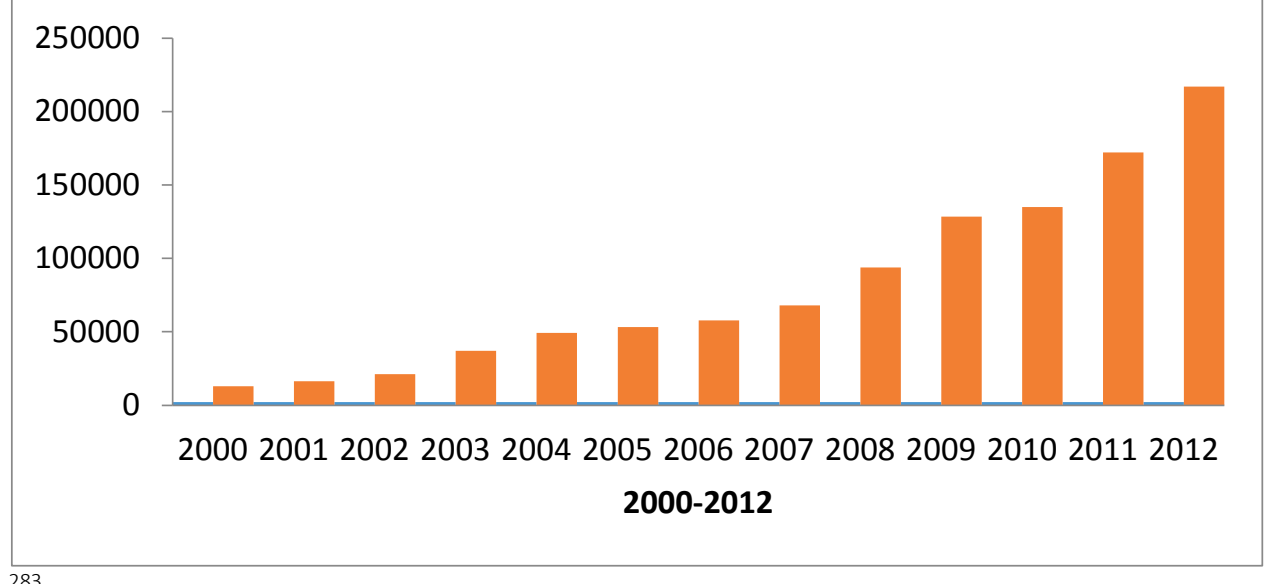

\section{Growth of utility model grants in China 2000-2012}

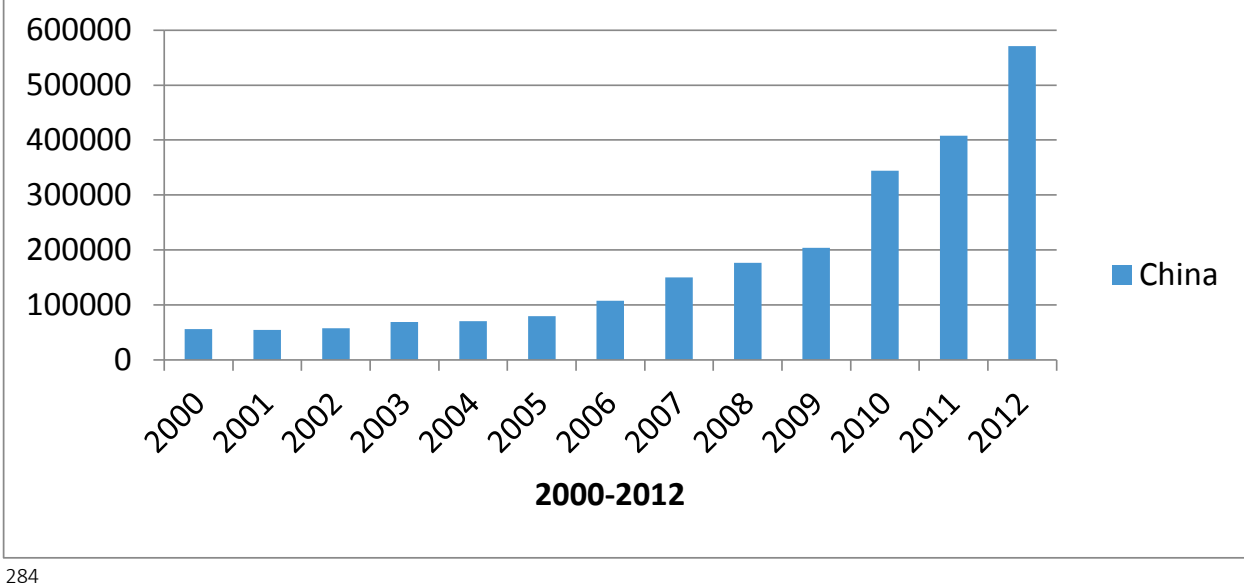

\footnotetext{
${ }^{283}$ Source: WIPO Statistic 2013 (http://ipstats.wipo.int/ipstatv2/IpsStatsResultvalue).

${ }^{284}$ Source: WIPO Statistic 2013 (http://ipstats.wipo.int/ipstatv2/IpsStatsResultvalue).
} 


\subsection{THE LEGAL POSITIONING OF PATENTS IN STANDARDS IN CHINA}

For this research, it is interesting to examine the PRC policy in relation to patents that are included in standards. The Standardization Administration of China (SAC) issued a draft on the "Provisional Rules Regarding Administration of the Establishment and the Revision of National Standards Involving Patents" in November 2009. In the wording of the draft, the SAC declares its intention to "[use] its powers to impose lower royalty rates on patent owners and [encourage] the future use of compulsory licensing under the patent law to avoid perceived windfalls to patent owners, particularly foreign ones". ${ }^{285}$ The draft contains interesting and revealing elements.

"Article 8: A patentee and its affiliate taking part in the drafting of a standard will be deemed as having granted a free license by failing to make disclosure as required above and shall bear due legal responsibility for the losses caused to the formulation or implementation of a national standard by their purposeful concealment of the patent information." 286

The intention of Article 8 seems to hint at a free licensing system within the standard setting and refers to losses caused by the purposeful concealment of patent information. The latter directly describes patent ambush and patent hold-up. The deliberate withholding of patents would result in liability under Chinese national law.

"Article 9: When a patent is involved during the formulation and revision of a national standard, PSTC or UIC shall obtain in time the patentee's irrevocable written statement on patent licensing.

The statement shall include the following, from which the patentee shall select one item:

3 The patentee agrees to license, on a free-of-charge, reasonable and nondiscriminatory basis, to any organization and individual to implement the patent when implementing the national standard;

4 The patentee agrees to license, on a reasonable and non-discriminatory basis, any organization and person to implement the patent when implementing the national standard at a price significantly lower than the normal royalties;

\footnotetext{
${ }^{285}$ http://www.sac.gov.cn/templet/default/ShowArticle.jsp?id=5298 [^]

${ }^{286}$ Unofficial English translation.
} 
5 The patentee does not agree to license the patent in either of the two ways listed above. If the patentee has selected (3) above, the standard shall not contain any provisions based on the patent." 287

This article foresees that parties in the standardization process will include their IPRs on the basis of royalties significantly lower than normal royalties. The text of this article is insufficiently clear and is open to various interpretations. Since the publication of the draft, the SAC has received many complaints from foreign parties and, currently, there is the expectation that the text will be replaced by wording that describes licensing based on RAND conditions. ${ }^{288}$ This possible change can be explained by the fact that Chinese companies are also developing patents that need to be traded or swapped with foreign firms that have IPR portfolios.

"Article 13: For a compulsory national standard that indeed needs to involve a patent, the patentee shall grant the license free of charge or the national administration department of standardization shall request the related departments to consult with the patentee about disposal of the patent."289

In this case, the SAC describes the concept of compulsory or free licensing in mandatory standards. Compulsory licensing is rarely used in the free market economies of the Triad countries, since it undermines the basis of innovation policy and the rewards thereof (recoupment argument). The PRC's membership of the WTO means that the Chinese government must adhere to the rules and regulations of the TRIPS Agreement relating to compulsory licensing.

In December 2012 the SAC published a new draft of "Regulatory Measures on National Standards Involving Patents (Interim) (Draft for Public Comments) ("2012 Draft

\footnotetext{
${ }^{287}$ Unofficial English translation The ANSI policy in the US uses the following wording: The ASD shall receive from the patent holder or a party authorized to make assurances on its behalf, in written or electronic form, either:

(a) assurance in the form of a general disclaimer to the effect that such party does not hold and does not currently intend holding any essential patent claim(s); or

(b) assurance that a license to such essential patent claim(s) will be made available to applicants desiring to utilize the license for the purpose of implementing the standard

either: (i) under reasonable terms and conditions that are demonstrably free of any unfair discrimination; or (ii) without compensation and under reasonable terms and conditions that are demonstrably free of any unfair discrimination The ISO/ITU/IEC uses the following wording: 2.2 the patent holder is willing to negotiate licenses with other parties on a non-discriminatory basis on reasonable terms and conditions. Such negotiations are left to the parties concerned and are performed outside ITU-T/ITU-R/ISO/IEC. Similar the wording of the ETSI provision: 6.1 When an ESSENTIAL IPR relating to a particular standard or technical specification is brought to the attention of ETSI, the Director-General of ETSI shall immediately request the owner to give within three months an irrevocable undertaking in writing that it is prepared to grant irrevocable licenses on fair, reasonable and non-discriminatory terms and conditions under such IPR to at least the following extent.

${ }^{288}$ Ernst Indigenous innovation and globalization page 61.

${ }^{289}$ Unofficial English translation.
} 
Measures")". This draft addressed some of the concerns of the 2009 draft text, but several points still need further clarification:

- Does the word patent solely refer to Chinese patents or also to the patents that are registered outside the PRC?

- Article IV, Section 1 states: "[i]n principle, mandatory national standards shall not involve patents".

- The text of the draft no longer refers to compulsory licenses but Article II, Section 4 mentions the following:

"Organizations or individuals participating in the formulation or revision of national standards shall be legally liable for their failure to follow the aforementioned requirements to disclose the essential patents held by them."

Unfortunately, it is not explained what "legally liable" means and what the possible consequences are.

The 2012 draft of "Regulatory Measures on National Standards Involving Patents" did remove some of the concerns of foreign firms in relation to compulsory licenses, but both the main principle and the definition of "legally liable" are still risk factors for foreign firms that participate in standard setting in China.

\subsubsection{CNIS: Disposal Rules for the Inclusion of Patents in National Standards}

The China National Institute of Standardization (CNIS) has a main task,

"to conduct all-round, strategic, and comprehensive research of standardization during the development process of economy and society, to research and develop comprehensive fundamental standards, as well as to provide authoritative standards information services" 290

In January 2010, the CNIS published the Disposal Rules for the Inclusion of Patents in National Standards. The rules were formulated to end the inconsistency in the work of the Standardization Technical Committee and are a part of China's (SAC) Proposed Regulations for the Administration of the Formulation and Revision of the Patent-Involving National Standards. ${ }^{291}$ Some commentators raise questions regarding the scope of the rules and wonder whether the Disposal Rules only apply to patents granted by the Chinese State Council or to all patents within the global trade community. ${ }^{292}$

\footnotetext{
${ }^{290}$ Webpage CNIS http://en.cnis.gov.cn/

${ }^{291}$ Willingwyre, Inside Views: China's Latest Draft Disposal Rules For Patents In Standards A Step Forward?

292 See for more comments: Gallagher American Intellectual Property Association AIPLA comments on the Disposal Rules page 2
} 
The Disposal Rules do not underline the strict application of the wording on the significantly lower royalty rates. Article: 4.3 .2 of the Disposal Rules states,

"Patent licensor should select one of following three items when filling the Patent License Statement Form:

a) RAND-Royalty Free License; b) RAND License; c) None of above." 293

The RAND Licensing terms are, however, not just limited to reciprocity, compensation and defensive suspension, but they define the commitment of the licensor to negotiate the licensing terms on RAND terms. The text of Article 4.3.1, stating that the Patent licensor should fill the Patent License Statement Form, gives the impression that a license is granted after the completion of the requirement. The statement of the licensor will only commit to negotiate a license with a future licensee and does not constitute a license in itself. Finally, the Disposal Rules do not offer any clarification on the definition of what forms an essential patent in this context.

The rules provide the following text from Article 3.1 about an Essential Patent:

"There is no commercially feasible implementation to avoid infringing a patent claim of such an essential patent when implementing a standard."

Within this definition, there is no clear distinction between an essential patent and essential claim. In the patent policies of the Triad countries there are often references to the concept that an essential patent contains at least one essential claim. The distinction between essential patent and essential claim has not been elaborated upon. Many patents contain various claims; some might be essential and others not. The definition of essential patents is relevant for the disclosure and is important for the licensing. As long as the definition is not crystal clear, these factors remain risk elements in Chinese standard setting. Furthermore, the use of the concept of commercial feasibility is neither widespread nor recognized in Western legal cultures. The notion of commercial feasibility seems to include complementary technologies based on the original standard and gives no certainty as to the status of new technology based upon but developed after the standard was created.

The rules on disclosure are mentioned in Article 4.1.1 of the Disposal rules. This section states: "The TC or responsible units should encourage participating or nonparticipating entities or individuals, during the process of formulation/revision of a standard, to disclose known or potential patents related to the standard as early as possible." From the wording of Article 4.1.1, it is unclear who the parties that should

\footnotetext{
${ }^{293}$ It is interesting to note the official definitions of the RAND license in the Disposal Rules: RAND License: Subject to the right of reciprocity or defensive suspension, a royalty fee-based license is granted by a licensor to standard implementers to implement an Essential Patent adopted by the standard under reasonable and non-discriminatory conditions. RAND Royalty Free License: Subject to the right of reciprocity or defensive suspension, a royalty free license is granted by a licensor to standard implementers to implement an Essential Patent adopted by the standard under reasonable and non-discriminatory conditions.
} 
participate in the standard setting are. Does this mean that foreign patent owners must disclose and submit patent information to the relevant Chinese institutions? Even more confusing is the text that non-participating parties should disclose their patents to the Chinese authorities, which is a requirement that does not exist in the US and European standardizing processes. Does the disclosure requirement only apply to essential patents or patents with an essential claim? The wording suggests that the disclosure requirement applies to all patents within the standard setting. Apart from the obvious burden for the patent holder, early disclosure could also lead to over-disclosure, which is another undesirable effect.

During the preparatory research stage, Article 5.1 orders the standard proposer to start a patent search as part of the patent disclosure. The proposed patent search is an extra financial investment that could hinder parties from participating in the standardizing process and that could demotivate patent owners from participating in the delayed process. Article 4.1.1 requires parties to disclose "known patents", which, in practice, might be difficult. Just like US and European multinational enterprises, Chinese firms have growing patent portfolios which are difficult to coordinate. The requirement of Article 4.1.1 may hint at a patent search. Even more surprising is the statement in Article 5.9, which states that the patent license statement related to the standard will cease to exist after the withdrawal of the national standard.

Finally Article 4.6 explains the relationship between national Chinese standards and international standards. The wording of Article 4.6 does not explain the exact obligations of the participating firm or, indeed, the non-participating firms to the standardizing procedures. ${ }^{294}$ For non-participating firms it would be impossible to monitor every future Chinese standard to evaluate whether their patents are relevant. If Chinese standards are completed on the basis of international standards, this would also imply possible copyright issues, since foreign standards are often protected by national copyright laws. It seems to be very positive that the Disposal Rules no longer mention compulsory licensing, which was one of the major concerns of foreign companies working inside the PRC. Apart from the rules on patents in standards, it is also relevant to look at developments in the Chinese Patent Law. Any changes in the legal treatment of patents in China will also indirectly affect the incorporation of patents in standards in China.

\subsubsection{Revisions in the Chinese Patent Law}

The Chinese Patent Law was revised on 1 October 2009. The original law was passed in 1984 and it was amended on two occasions, first in 1992 and later in 2000. The third revision of the Chinese Patent law is related to the release of the National IP Strategy (NIPS) in 2008, which aimed to implement full and effective IP protection by 2020 . The

\footnotetext{
${ }^{294}$ See also the US-China Business Council comments on Draft National Standard Disposition rules for the Inclusion of Patents in National Standards.
} 
first two amendments created more rights for patent owners, thereby meeting some of the necessary commitments of China's entry into the WTO. The latest amendment of the PRC's Patent Law had different aims and objectives. Against the background of the indigenous innovation policy, the Patent Law aimed to strengthen the position of patent holders and facilitate the process of legitimate technology flows via the instrument of patents. A second challenge addressed by the amended Patent Law is how to harmonize the differences between the Chinese legal patent framework and the international patent treaties, thereby encouraging technology transfer by foreign direct investors.

The revision of the Patent Law in 2009 led to the following major changes.

In the patent-granting process, firms no longer have to file patents for inventions made in China first within the PRC and later in other markets. The former requirement was previously stated in Article 20 of the Patent Law (2008) and intended to promote the utilization and commercial exploitation of patents inside China, but, due to the globalisation of trade and a more intensified use of cross-licensing, the rationale of this requirement no longer seems to be valid. The compulsory examination by SIPO, before any foreign patent applications were made, was distrusted by foreign stakeholders and could have been used to protect Chinese national interests. Under the new rules, any firm, either Chinese or foreign, has the strategic choice to either file the inventions made in China firstly in the PRC and then to obtain permission from the Chinese authorities for filing abroad or to decide to file first outside China, in which case SIPO must still perform a security check related to "national defence or other national vital economic interests". This raises two interesting questions: what will be the strategic considerations for firms to first file inside or outside the PRC and will the "national security check" be used by SIPO or the Chinese government in general to act as a barrier to trade? The practicalities of the security check, mainly the duration of the process, could hinder the rapid commercial utilization of a patent, especially in sectors like telecommunications, where even in Western economies the patent-granting process is too slow for the product life cycle of some of the products. ${ }^{295}$

Another change was that foreign-owned companies are no longer limited to using patent agencies assigned by the Chinese authorities (SIPO), but they can now use any agency that is recognized under Chinese law. ${ }^{296}$

One of the most important changes involved the new rules on the absolute novelty standard as laid down in Articles 23 and 24 of the Patent Law. The old version of the Chinese Patent Law made use of the concept of relative novelty, which has now been replaced by absolute novelty. As a consequence, there are no longer restrictions on the

\footnotetext{
${ }^{295}$ In the Western economies, the concept of open innovation has been developed to overcome this problem. Given the short life span of some new products, firms sometimes decide to opt for not even filing or registering their patents. The Implementation Rules of the Patent Law give SIPO a total of six months to investigate the security check regarding the patent application. The application must be done in the Chinese language, which could urge foreign firms to file in China and abroad.

${ }^{296}$ Article 19 Chinese Patent Law.
} 
use of novelty outside China, whereas, before, this would have destroyed the novelty requirement. Prior art and prior design are now formulated as:

"The prior design referred to in this Law means any design known to the public before the filing date of the patent application in China or abroad." 297

And

"Any invention-creation for which a patent is applied shall not lose its novelty if, within six months before the filing date of the application, one of the following events has occurred:

1. it was exhibited for the first time at an international exhibition sponsored or recognized by the Chinese Government;

2. it was made public for the first time at a prescribed academic or technical conference; or

3. it was disclosed by any person without the consent of the applicant."298

In the field of jointly-owned rights in patents, the revised law takes the contractual freedom between the participating parties as its starting point. In the absence of an agreement, any co-owner may independently exploit or license others to exploit the patent through ordinary licences. The article also mentions that all royalties resulting from the licensing will be shared by all co-owners. This article might be relevant for the operation of a patent pool. Article 16 of the Patent Law gives the inventor or creator "a reasonable remuneration based on the extent the invention-creation is applied and the economic benefits it yields." 299

The new law also gives the applicant the possibility to choose between the patents of inventions-creations and patents for utility models, but for one invention only one type of patent will be granted. In practice, it could still be difficult for foreign firms to invalidate a Chinese application for a utility or design patent that violates an existing

\footnotetext{
${ }^{297}$ Article 23 Chinese Patent Law.

${ }^{298}$ Article 24 Chinese Patent law. In the Implementing Rules of the Patent law, the SIPO is given the power to look carefully at applications that may seriously lack innovative features or an inventive step. The rise of socalled "junk patents" has led to some concerns and hopefully the increased powers and policy attention of SIPO can address this problem in the future.

${ }^{299}$ The implementing rules of the Chinese patent law give further reference in Rule 77." Where the entity to which a patent right is granted has not entered into a contract with the inventor or creator on the manner and amount of the reward as prescribed in Article 16 of the Patent Law, nor has the entity provided it in its rules and regulations formulated in accordance with the laws, it shall, within three months from the date of the announcement of the grant of the patent right, award to the inventor or creator of a service inventioncreation a sum of money as prize. The sum of money prize for a patent for invention shall not be less than RMB 3, 000 Yuan; the sum of money prize for a patent for utility model or design shall not be less than RMB 1, 000 Yuan."
} 
foreign-owned patent. Foreign investors still have to give proof of a conflict of rights which might be difficult and costly to prove. ${ }^{300}$

The new Patent Law failed to clarify one of the biggest concerns of foreign investors - the conditions for the compulsory licensing of technology. Compulsory licensing is a nightmare for foreign-owned technology, since it creates temporary governmentgranted monopolies and therefore directly clashes with the interests of many IP owners.

Article 48 states:

"In any of the following cases, the patent administrative department under the State Council may, upon the application of that entity or individual, grant a compulsory license to exploit the patent for the invention or utility model:

1. where the patentee after the expiration of three years from the date of granting the patent right, and the expiration of four years from the date of filing, has not exploited the patent or has not sufficiently exploited the patent without any justified reasons;

2. where it has been legally determined that the enforcement of the patent right by the patentee is an act of monopoly, to avoid or to eliminate the adverse effects caused to competition." 301

The phrase "sufficiently exploited the patent without any justified reason" is extremely vague and met substantial global resistance. In the context of abusive use of patents in the standardizing process, such as patent ambush or patent hold-up, the text of Article 48 could be very relevant and effective. At the time of writing, it is insufficiently clear how restrictive SIPO and the State Council will apply the text of Article 48 in practice, but in the standard-setting context it would be very relevant to study. The second paragraph explicitly mentions the negative influence of a strategic use of a patent right on the competition in the market, which is the essence of this study.

Another feature of unfair competition is the passing off of patents. Article 63 addresses the passing off of anther party's patent as one's own patent. It could be argued that this provision should be part of the competition law framework, but presently this matter is regulated by the revised Chinese Patent Law. ${ }^{302}$

\footnotetext{
${ }^{300}$ PRC New Patent Law Implementing Rules Baker \& McKenzie.

${ }^{301}$ Article 49 of the Patent Law gives the Chinese government authority to grant compulsory licensing in the case of a national emergency or an extraordinary state of affairs.

${ }^{302}$ Article 63 mentions a fine structure with a maximum of an amount four times the total of the illegal earnings. Given the profitability and the difficulty of calculating the earnings in the telecommunications sector, it is questionable whether these fines will have a deferring effect especially compared to the fine structure in the EU and US competition law.
} 
A possible new revision of the Chinese Patent Law could include new changes in relation to the determination of the amount of damages, the introduction of punitive damages and an increased liability of infringing parties. ${ }^{303}$

The balance between competition law and the protection of IP rights through an effective sector is always hotly debated. In the context of the economic conversion process in the PRC, this is an even more complicated discussion. Part of the complexity lies in the fact that IP rights are important for the recoupment argument for the original inventor. Since most of the innovation processes and, consequently, IP rights, such as patents, were developed in Western industrialized countries, the latter had a strong interest in protecting intellectual property rights. The developing countries were very often subjected to unfavourable trade terms in relation to IPRs, which hindered their further economic growth. In the case of China, it is questionable where the country stands in terms of innovative capacity. Is China formally still a developing country in terms of innovation and competitiveness, with just a limited capacity to innovate in the global market? Or is the Chinese indigenous innovation policy an example of discriminatory trade policies enacted by a global superpower? The answer to these questions has serious policy implications for the role of patents in the standardization processes and the reaction of the Chinese competition authorities. In a wider context, given the strategic importance of standards in international trade, there is a broader consideration of the influence of standardization on the global competitiveness of trading blocs in general.

\subsection{THE INTERFACE BETWEEN STANDARDS AND PATENTS IN DEVELOPING COUNTRIES}

The example of China illustrates that the regulatory environment surrounding IPRs in standards can be used to promote national economic interests. The reasoning is that, while IPRs encourage innovation with a limited right to exclusivity for the owner, private standards are created for the benefit of the general public, either by the Chinese government or by a group of firms. In the latter case, the Chinese government allows a group of companies to cooperate and exchange relevant market information. Normally this type of behaviour would be addressed and punished by national competition authorities because of the possible anti-competitive effects. In the case of China, the crucial discussion is how the national government will balance the rights of the IP owners, the interests of consumers in general and the global strategic positioning of the PRC in the international business community in relation to the present economic conversion process. In Western economies, such as the US and the EU, the balancing act does not

\footnotetext{
${ }^{303}$ See article Shira: Comments Sought for Draft Revision to Patent Law and article Barraclough, Concerns raised over Chinese Patent Law amendment.
} 
include the added challenge of the economic conversion process. The viewpoint that is held by many developing countries is that IPRs in international standards are held by companies from industrialized countries and this leads to abuse of the IPRs.

The definition of abuse from both parties to the discussion is inconclusive. The US and the EU refer to patent ambush, patent hold-up and royalty stacking. In developing countries, patent pools are also sometimes seen as a form of abuse of IPRs, since they incorporate the management and the commercialization of patents held by foreign companies that are being sold to manufacturing firms located in developing countries. Whereas patent pools normally fall outside the scope and attention of Western competition authorities, this might be different in developing countries or, more specifically, China.

Developing countries often make the claim that the high level of royalty payments (see previous discussion of Chinese TD-SCDMA and WAPI standard) and the high costs of litigation weigh heavily in the discussion of patents in standards. Traditionally, in the Western setting, high royalty payments could be prevented by cross-licensing. It will be interesting to see whether, with the present increase in patenting in the PRC and the growing patent portfolios of Chinese multinationals, this argument will remain intact. In 2005, China presented concerns the WTO relating to the application of Article 2.4 of the WTO/TBT Agreement, which asks Members to adopt international standards to reduce the costs of international trade. According to China, this requirement is troublesome for developing countries which cannot always afford the transfer to licensed technology. ${ }^{304}$ During these discussions, China did not propose a solution for the problem to the TBT Committee. China wanted to discuss the position of IPRs in standards explicitly but, after two years of negotiations, the proposal was suspended. The main opponent was the US government, which claimed that the subject of IPRs in standards fell outside the scope of the TBT Agreement.

In relation to the adoption of international standards by developing countries article 12.4 of the annex states:

"12.4 Members recognize that, although international standards, guides or recommendations may exist, in their particular technological and socio-economic conditions, developing country Members adopt certain technical regulations, standards or conformity assessment procedures aimed at preserving indigenous technology and production methods and processes compatible with their development needs. Members therefore recognize that developing country Members should not be expected to use international standards as a basis for their technical regulations or standards, in-

\footnotetext{
${ }^{304}$ Government of China, "Intellectual Property Right (IPRs) Issues in Standardization, Communication from the People's Republic of China, (G/TBT/W/251, 25 May 2005)" and WTO: "Fourth Triennial Review of the Operation and Implementation of the Agreement on Technical Barriers to Trade under Article 15.4", (G/TBT/19), 14 November 2006. Later Denmark made another reservation in relation to open standards and "interoperability".
} 
cluding test methods, which are not appropriate to their development, financial and trade needs."

In a later study on patents in standards from 2009, the WIPO did not address this subject specifically. Some authors have linked Article 27 of the TRIPS Agreement to IPRs in developing countries. Article 27 states that, in the context of public order, the patentability of a subject can be refused on the basis of the protection of public order. ${ }^{305}$ For this researcher, the negative impact on the innovative capacity of firms would far outweigh possible beneficial public order effects. Other issues raised in this discussion have centred on Article 31 of the TRIPS, claiming that compulsory licensing (an important feature of the Chinese Patent Law) leads to "an unreasonable exploitation of the normal use of a patent". Obviously, the definition of the normal use of a patent is, in this case, directly influenced by national political and economic beliefs and would not be valid in a free market economy. Finally Article 40 of the TRIPS Agreement allows Members to take measures through their national competition system to address possible abuse of competition by means of intellectual property rights. In the following section, the relationship between intellectual property rights and the Chinese competition law framework will be discussed.

\subsubsection{Competition law and the protection of intellectual property in a developing country}

Scholars agree that the system of competition law takes a different place in developed and developing countries. Faure mentions at least three reasons that justify this distinction:

1. The complexity of competition law, necessitating a highly developed legal profession and a corruption-free environment.

2. "Regulatory capture", meaning that government regulators have very close ties to industry.

3. Countervailing public policy, claiming that domestic firms must be protected in order to compete in the global economy. ${ }^{306}$

In the Introduction, some of the existing tensions between competition law and the protection of intellectual property rights were already discussed. In developed countries intellectual property rights, in particular patents, need to be enforced to promote inno-

\footnotetext{
${ }^{305}$ See also UNOCAL-case, relating to a mandatory gasoline standard that could have a considerable price impact.

${ }^{306}$ See for more background: Faure and Zhang: Competition Policy and Regulation Edward Elgar 2011. Ulen The uneasy case for competition law and regulation as decisive factors in development: some lessons for China page 36.
} 
vation. Without financial rewards, there would be considerably fewer incentives to innovate. For the competition law context, patents have the additional characteristic that they convey temporary exclusivity and thus market power. This market power will raise the interest of competition authorities. The presumption of power is given different interpretations in various jurisdictions. In the US, a landmark case in 2006 involving Illinois Tool Works showed that the Supreme Court no longer applied the interpretation that a registered patent created a presumption of market power on the part of the patentee. ${ }^{307}$ The main discussion centres on finding the proper balance between the interests protected by competition policy and the interests covered by the intellectual property regime. Hovenkamp makes the observation that it is difficult to involve consumers in the IP law versus competition law battle. Although competition law serves consumer welfare, it is normal that manufacturers are much more involved in the debate on technology transfer. ${ }^{308}$

In this context, Cheng mentions that both competition law and patent law take into consideration allocative efficiency and dynamic efficiency aspects. ${ }^{309}$ Whereas competition law mainly deals with allocative considerations, like the reasonableness of the price for consumers and the cost-efficiency of producers, dynamic efficiency gains are growing in importance.

Dynamic efficiency gains consist of new technological progress that leads to newer and better products, which would not have been developed without any incentives. Patents are a key instrument for the promotion of dynamic efficiency, since they reward the inventor with temporary exclusivity and financial rewards. Both competition law and patent law share the common characteristic that they have to balance the allocative efficiency gains with the dynamic efficiency gains. ${ }^{310}$ In this context, Kaplow developed a test to determine whether competition law should allow a specific exploitation of a patent right (i.e an exclusive licence) in relation to societal needs. The practical applicability of the ratio test of Kaplow is very limited, since for business life it is very challenging to determine the desirable optimum patent life. Although the test is not very practical, it does draw attention to the balancing of both allocative and dynamic efficiency gains, which could be very relevant for a developing country. To strike the balance in favour of dynamic efficiency gains, meaning that competition law gives way to a more permissive and wider exploitation of patents by the patent holders could be counterproductive in developing countries since they might lack national firms with sufficient resources to acquire the patented technology legally. This would directly hinder the innovation capacity of the national industry.

\footnotetext{
${ }^{307}$ Independent Ink Inc. v. Illinois Tool Works, Inc., 547 U.S. 1002 (2006).

${ }^{308}$ See Hovenkamp Consumer Welfare in Competition and Intellectual Property Law page 63.

${ }^{309}$ Cheng Striking a balance between competition law enforcement and patent law etc. page 669.

310 If the exploitation of the patent results in production below the competitive level, the allocative efficiency loses out and results in a deadweight loss.
} 
In the reverse situation, in which allocative efficiency gets the upper hand, the possibilities for exploitation of the patent are rather limited, giving more advantages to national industry to obtain the patented technology by a compulsory licence and also by giving a wider interpretation to the essential facilities doctrine. ${ }^{311}$ Cheng also distinguishes the difference between developing countries that can be classified as "imitators" and developing countries that qualify as "innovators". Clearly, China belongs to the second category, which would not directly justify favouring only allocative efficiency. ${ }^{312}$ The innovative capacity of the Chinese economy has increased dramatically in the last decade. The growing number of patent applications in China is an obvious indicator. The emergence of major Chinese telecommunications companies, such as Huawei and ZTE, which have started to build their own extensive patent portfolios, would not justify an exclusive focus on allocative efficiency in Chinese competition law. Chinese multinational enterprises can only start competing globally when they have the opportunity to engage in the establishment of international standards, co-developed in China in cooperation and coordination with other international firms, thereby creating Global Production Networks. In a later article, Cheng discusses the effectiveness of the patent system in developing countries in relation to innovation. The main point of discussion is whether the consumer markets of large developing countries should remunerate the innovation efforts of multinational enterprises through the patent system. ${ }^{313}$

Various interesting conclusions were drawn:

- The recoupment argument of the patent system does not always provide the most effective incentive for innovation projects. According to Cheng, in the interface between patents and competition policy, the balance should be moved more towards competition policy and less towards the IPR system.

- Antitrust policies and the underlying basic economic principles should be tailored to the needs of specific individual countries. In the case of developing countries, different principles should apply to guarantee social welfare. ${ }^{314}$ This is an interesting comment, since, in the interface of patents and standards, developing countries have the tendency to follow the best practices of mainly the US and the EU. Divergence in this specific field could be more rewarding and could make a stronger contribution to social welfare than convergence. Unsurprisingly, developed countries and multinational enterprises strongly support the conver-

\footnotetext{
${ }^{311}$ Cheng Striking a balance between competition law enforcement and patent law etc. p 674. The essential facilities doctrine will be discussed in a later chapter.

312 Li concludes in her book: Imitation to Innovation in China EE on page 161 that Chinese companies do not only register more patents, but that these patents also lead to more innovations.

${ }^{313}$ Cheng: A Developmental Approach to the Patent-Antitrust Interface Northwestern Journal Of International Law \& Business 33:1 (2012).

${ }^{314}$ Cheng, page 79 see note 279. In different jurisdictions, competition authorities take a different stance on the effectiveness of markets. The FTC and DoJ strongly believe in the self-correcting capabilities of competitive markets. For developing countries different socio-economic factors may apply.
} 
gence of national legislations in the field of competition law and intellectual property rights.

\subsection{CONCLUSIONS}

\section{Differences in standardization}

The Chinese approach of the indigenous innovation policy is an interesting starting point for the discussion of the strategic role of patents in standards. The impact of this concept is still relatively unclear for a number of reasons. First, the definition of indigenous products has gone through various "development stages". These stages are characterized initially by a very restrictive Chinese definition, which definitely exceeded the international norms in standard setting and raised criticism of foreign stakeholders. This initial stage seems to be followed by a pragmatic reaction of the Chinese government to make adjustments that would satisfy the international standards community. The lack of coordination and the different interests of the Chinese actors regarding the standardization part of the indigenous policy seem to hint at possible liberalization and more openness and transparency in the system. Given the unpredictability of the Chinese indigenous innovation policy, the recent signals for the relaxation of the rules are more likely to have occurred from the uncoordinated effort of the participating governmental actors.

The necessity of a more open and accessible system of standardization has been shown by comparing the different outcomes of the Chinese WAPI and the Korean WIPI standard. The relative success of the commercialization of the Chinese TD-SCDMA standard stressed the need to participate in international innovation networks in order to guarantee the development of an international standard. The case of the TD-SCDMA standard highlighted the special characteristics of network goods and explains the competition law interest in network industries.

The main challenge for the Chinese government is to balance and incorporate some of the elements of the market-led approach to standardization in their own country. The globalization of international trade and the increasing complexity of technology markets complicate this balancing act.

\section{Management of SEPS}

Patents play a central role in the standards discussion since the burden of high foreign royalty payments was one of the main motivations to promote the development of national indigenous standards. A look at the regulation of patented technology in China shows that, for foreign investors, there are still serious concerns in relation to the ambiguity surrounding the rules for standard essential patents, patent disclosure and licens- 
ing, which stress the importance of monitoring the future developments in the Chinese Patent Law.

This existing ambiguity hinders the increased development of interoperability standards in China.

Chapter 5 will examine in detail patent pools as a possible solution to the problem of patent hold-up and royalty stacking. Patent pools have traditionally been mentioned as a possible solution for the management of SEPs. I just concluded that the legal evaluation of SEPs in general is evolving and therefore the next chapter will provide a more indepth analysis. Patent pools have obvious advantages, since they provide a one-stop shop at reduced costs and increased efficiency. Patent pools provide for a meeting of possible competitors and can become a forum to exchange relevant market information at the cost of consumers and competitors. An easy evaluation cannot be made and not only the concept but also the management of patent pools can be an important element in the evaluation. An investigation into the economic effects of patent pools may clarify the legal situation.

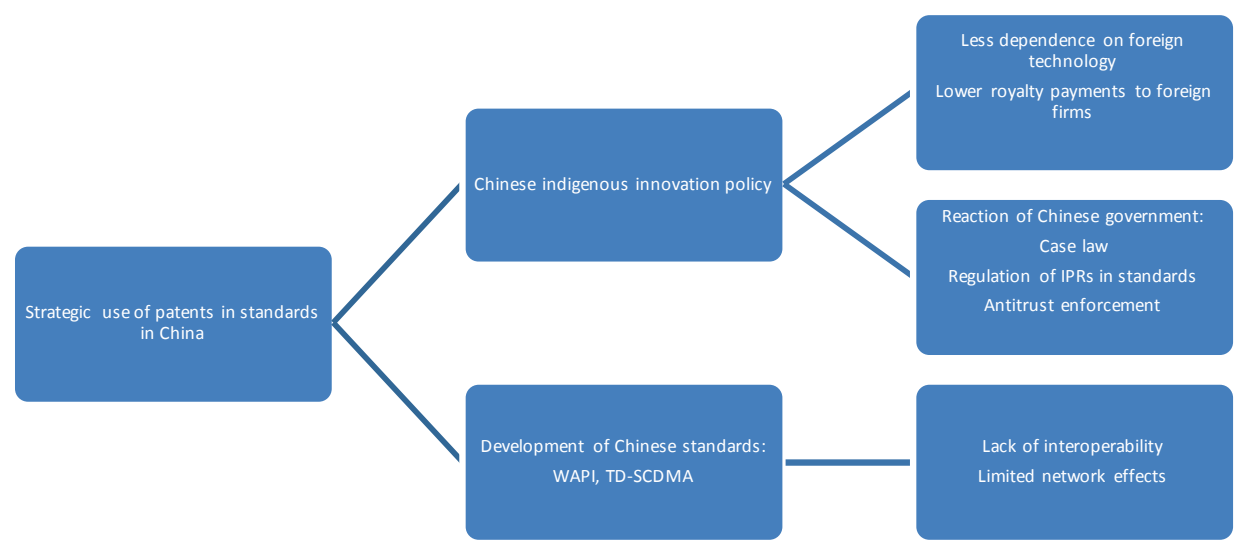




\section{CHAPTER 5}

Patent pools and competition law 



\subsection{INTRODUCTION}

This chapter aims to introduce the concept of a patent pool to the reader. A historical overview shows the development phase of intellectual property rights and competition law. Antitrust law regarded IPRs as distinctively different and held a negative attitude towards patents. This per se approach, whereby all IPRs were suspicious, changed with the emergence of the rule of reason. US case law clearly demonstrates that IPRs can have positive effects on innovation and competition. As stated before, the question remains why some antitrust scholars choose to see IPRs as different from other property rights?

The rise of the global knowledge economy during the last 30 years has led to a growth in the use of intellectual property rights in general and of patents in particular. The increase in patent registrations, technological change and combining IPRs with commercial business strategy complicates the present IP environment. In an earlier chapter, some of the problems associated with the exercise of patents in standardizing projects were discussed. Antitrust authorities must decide to what extent they should influence the nature of technology markets. Technology markets are heavily influenced by the patent regime and by standardization and both aspects are difficult to understand for antitrust lawyers. The economic analysis of the use of the patents in standardization is very important for the legal evaluation.

The globalization of trade created Global Production Networks that are not hindered by national legislative borders and technology embedded in a standard is not solely covered by national law. New business models (NPEs) and strategies that might have a negative effect on competition inside the common market are emerging. In the first chapter, the illegal concepts of patent ambush, patent hold-up and patent thickets were discussed. Due to the rate of technological change, the IP regulatory environment sometimes lags behind the technical realities and society is left questioning the monopoly position of the patent holder. Some scholars have considered the concept of a patent pool to address some of the aforementioned challenges. The instrument of a patent pool has been heavily debated within the context of innovation policies and competition policy.

A patent pool is a consortium of two or more companies that agree to cross-license their patent rights related to a specific technological product or service. The telecommunications industry uses standardization to disseminate new technology. Interoperability is a key feature of smart phone technology and patent pools can assemble all the relevant patents related to a specific standard.

In this chapter, the historical development of the legal regulation of patent pools will be examined, using the United States as an example. The DoJ has made some interesting adjustments to its attitude towards patent pools that provide interesting background information. In order to evaluate this development, the development of the IP Guidelines in the US, the system of Business Review Letters (BRL), as well as the rele- 
vant case law will be investigated. From the case law, it can be concluded that Standard Essential Patents (SEP) are central to the discussion on the legality of patent pools. Consequently, other important features of the patent pool, such as tying clauses, overlapping ownership and the licensing terms of the patent pool will also be addressed. New business models, such as Non-Practising Entities (NPEs) and Patent Assertion Entities (PAEs), will be compared to patent pools.

In the conclusion, the current US legal environment for patent pools will be evaluated and comments will be made on the current state of the US system.

\subsection{THE CONCEPT OF A PATENT POOL}

The joint exploitation of patent rights by their owners in a collective agreement has economic benefits. Patent pools have existed for many years in the manufacturing industry, starting with sewing machines, but recently they have drawn the attention of the biomedical industry, especially in relation to AIDS/HIV-related medicine. ${ }^{315}$ Patent pools are regarded as pro-competitive, and they provide certainty to companies that want to use the patent rights. For the inventor, the patent pool provides an incentive to bring his technology onto the market without costly litigation. The fact that the most important patents are gathered in a patent pool increases the efficiency of the technology markets.

In relation to the patent thicket problem (the situation in which multiple patentees own overlapping sets of patent rights), patent pools are often cited as the main remedy.

One of the major advantages of a patent pool is its characteristic of transactional efficiency. Patent pools can clear blocking patents, limit the emergence of possible costly legal disputes and enhance network interoperability, which, in the context of standardization in the telecommunications industry, facilitates further rapid technological progress and the competitiveness of the sector.

A patent pool clarifies the uncertainty of possible patent claims, the outcome of time-consuming court cases and distributes the business risks among members of the pool, thereby enabling smaller firms to share in the success of the pool, and it also counters spill-over effects. ${ }^{316}$

A patent pool agreement needs to be distinguished from a package license. An individual company can make the business decision to license several patent rights in a package license, without opting to combine its patents with another company's patents

\footnotetext{
${ }^{315}$ See for a further discussion on public policy and patent pools Lerner and Tirole: Public Policy towards Patent Pools in: Innovation Policy and the Economy, Vol. 8 (2007), pages 157-186.

316 "The pooling of patents, licensing all patents in the pool collectively, and sharing royalties is not necessarily an antitrust violation. In a case involving blocking patents such an arrangement is the only reasonable method for making the invention available to the public", International Manufacturing Co. v. Landon 336 F.2d 723, 729 ( $9^{\text {th }}$ Circ. 1964).
} 
to establish a patent pool. In a patent pool, separate firms offer their patents under joint management, administered either on their own or by a third separate entity. Both patent pools and package licenses clear blocking patents and integrate complementary patents resolving the problem that is sometimes referred to as the "anti-commons". ${ }^{317}$

\section{The advantages of the use of patent pools within standardization processes}

The obvious advantages of patent pools have already been discussed. Within the context of standards, patent pools can also provide a higher level of transparency for licensors and licensees and future adopters of the standard. Normally, the patent pool administrator will work for all the firms in the agreement, and decision making is done by consensus, with an equal vote for every participating licensor. A patent pool can support the adoption of a standard in a better and faster way, since it leads to more transparency and predictability for licensees. ${ }^{318}$

Some patent pool administrators claim that the mix of different firms results in a fairer and more market-appropriate royalty fee. The maximum return for patents policy is weakened by the different interests of the firms in the pool. ${ }^{319}$ The efficiency of the patent pool, therefore, would depend on the question of whether all of the licensors in the market have contributed all of the essential patents to the patent pool.

A second important condition would be the independence of the patent pool administrator. An external administrator can act more independently than an internal administrator, in the case of business or legal disputes, and can decide on the fairness and non-discriminatory level of the royalty rates. In a patent pool, royalty rates for the complete package deal can be set to encourage the adoption and growth of a standard. An attractive royalty rate will result in achieving the critical mass of followers of the standard necessary to optimize the network externalities of the telecommunications market.

A standardization body is interested in a patent pool as an instrument to facilitate the rapid technology transfer from innovation to final products and/or services. This is sometimes referred to as the shop window of technology, the fact that the collective licensing agreement speeds up the process of commercialization. ${ }^{320}$ The patent pool plays a role in the patent evaluation process, by evaluating the patents' essentiality, and manages the licensing administration. If an agreement on the patent pool is reached

\footnotetext{
${ }^{317}$ See also article Heller and Eisenberg Can Patents Deter Innovation? The Anticommons in Biomedical Research 280 Science 698 (1978). Michelman defined the problem of the anticommons as: "a type of property in which everyone always has rights respecting the objects in the regime, and no one, consequently, is ever privileged to use any of them except as particularly authorized by others". Colangelo concludes that the patent right to exclude can lead to a situation in which the IPRs are actually underused page 61.

${ }^{318}$ Transparency is one of the main interests of the EU Commission in relation to the management of a patent pool. See draft guidelines TTBER page 64 .

${ }^{319}$ Comments made by Roger Ross President Via Licensing Brussels Workshop on patent pools May 2012.

${ }^{320}$ Serge RAES ITU Workshop on Standards and Intellectual Property Rights (IPR) Issues New Delhi, India, 1920 December 2011.
} 
within a short time-span, this eliminates some of the deficiencies of bilateral licensing agreements. Disadvantages remain, however, such as an unbalanced negotiating position for SMEs and often time-consuming and complicated discussions. Since the patent pool has global license coverage, this minimizes the risk of expensive patent infringement actions. A reduction of internal licensing and negotiation costs also makes the patent pool attractive from a financial point of view.

These advantages can only exist when the formation of the patent pool is completed in a timely manner. For operators, patent pools have the advantage that the costs of acquiring the technology become much more market related and that, for the direction of future business policy, the essential patents have been defined, thereby reducing the burden of the essential patent portfolio management. The reduced risk in terms of patent litigation could also influence the stock market's perception of the standard. For a successful operation of the patent pool in the standardizing context, large patent holders must make the strategic decision to license their IPRs via the patent pool.

\subsubsection{Antitrust interest related to patent pools}

Ullrich explains the interest of competition policy enforcers in patent pools by referring to the multi-layered structure of patent pools. ${ }^{321}$ Patent pools have many points of interaction between the members of the patent pool. The internal arrangements of the patent pool bring possible competitors in the same product market together. On the other hand, a situation can occur where pool members are active not only in the technology market, but also in the product market, complicating the situation even further. The pooling agreement also takes into account the joint relations of all members vis-àvis third parties (licensees). Overall, it can be concluded that the patent pool agreement is a complex legal contractual arrangement which could lead to the possible exchange of relevant market information or strategic behaviour of the companies participating in the pool.

Although patent pools promote transactional efficiency by reducing the costs of the individual license agreements, they also require common management and coordination of activities which might easily be misinterpreted as cartel-like behaviour. Joint coordinated activities of competitors are often the basis of concerted practices. The European Court of Justice explained concerted practices as the coordination of activities between two or more companies with the aim of limiting the risks of competition by changing the normal market conditions. This leaves it up to competition authorities to determine the normal market conditions in the relevant market.

Possible negative effects of patents pools are often linked to the above-mentioned coordinated activities, leading to members in the pool collectively fixing prices, introducing coordinated output restrictions or jointly sharing relevant market,information.

\footnotetext{
${ }^{321}$ Ullrich in Drexl: Research Handbook on Intellectual property and Competition Law page 143.
} 
Another antitrust concern is the possibility that patent pools can suppress and raise costs for actual or potential competitors. This can be based on the following strategies.

a. The firms participating in the pool have an incentive to eliminate competition in the relevant technology market.

b. Patent pools may acquire market power by including non-essential or invalid patents in the pool.

Since we are discussing the concept of a patent pool within the standardizing context, this implies further complications. The standard-setting process already involves a group of companies cooperating to find the appropriate technical solution for a new tobe-developed standard. Therefore, in the case of standard setting, members of a patent pool could hinder future innovation by discouraging investments in new research and development that could lead to a new standard for the product concerned. Participating firms in the patent pool could strategically use the package license to introduce, support and/or maintain a standard that is less innovative, less attractive in technological terms, more expensive, or more favourable to domestic or regional interests than the alternative solutions, thus undermining technological progress and benefits which could otherwise be conferred on the consumers. These possible negative consequences have attracted the interest and scrutiny of competition authorities globally.

\subsection{COMPETITIVE ANALYSIS OF PATENT POOLS}

Colangelo summarizes the key legal questions in relation to patent pools as the following:

Question A- What is the exact relationship of the patents in the pool to each other? Are they substitutes or complements?

Question B- What type of relationship do the participating companies in the pool have to each other? Are they active on downstream markets or are they vertically integrated firms?

Question C-Is the technology embedded in the pool exclusively available through the pooling agreement? Are individual licences available? Are there elements of a tying agreement?

Question D- Does the patent pool agreement have a positive or a negative impact on the licensee's potential to innovate? ? $^{322}$

${ }^{322}$ Colangelo page 49. 
The analysis of these questions will mainly focus on US law. Patent pools were first developed in the United States. Therefore, this is the jurisdiction in which most of the legal analysis and case law has been developed. This analysis is required since patent pools can make substantial contributions to consumer welfare and competition. On the other hand, patent pools can also facilitate price fixing and or reduce the aggregate output of the pooled technology. Both aspects justify a detailed examination of the four questions mentioned above.

\subsection{THE COMPETITIVE RELATIONSHIP OF PATENTS IN THE POOLING AGREEMENT}

Question A- What is the exact relationship of the patents in the pool to each other? Are they substitutes or complements?

Question A is answered in the following parts:

- Economic research on the impact of patents on the functioning of the patent pool.

- The essentiality criterion in US anti-competitive analysis

One of the key issues in relation to this question is the classification of the different patents in the pool. Another question is what is the exact relationship of the patents in the pool to each other? Are they substitutes or complements? Within patent pools, various types of patents can be included, both complements and substitutes. The inclusion of complementary patents in a pool is very often regarded as welfare enhancing and, consequently, it is allowed. The decision to incorporate substitute patents in a pool is very often met with a hostile reaction from competition law authorities. Substitute patents cover alternative ways to achieve a technical result and the inclusion of the substitute patents makes it more difficult to invent around the essential technical standard. Inclusion of substitute patents may suppress the development of alternative technologies and result in anti-competitive effects. ${ }^{323}$

In the BRLs in the MPEG-2 and DVD cases, the Department of Justice came to the conclusion that the pool only consisted of complementary, valid and essential patents and that, consequently, the pooling agreement had pro-competitive effects and was legally allowed.

Within industrial organization literature, scholars make a distinction between explicit and tacit impediments to competition. Although the explicit impediment seems to be very obvious, it is more challenging to identify the exact boundaries of tacit impedi-

\footnotetext{
${ }^{323}$ See again case Princo Corp v. International Trade Commission (PRINCO CORPORATION AND PRINCO AMERICA CORPORATION, V. INTERNATIONAL TRADE COMMISSION, and U.S. PHILIPS CORPORATION).
} 
ments to competition. Tacit impediments to competition occur when firms in the pool internalize the impact of pricing decisions on the demand for products that are trying to compete with products based on the essential patents. In reality, it is almost impossible to distinguish between complements and substitute patents in a patent pool. One obvious indicator could be the number of potential substitute patents controlled by firms participating in the pool or patent pools that have overlapping membership.

The validity of the patents in the patent pool will have a direct effect on the level and nature of competition in the market. Individual weak or invalid patents cannot have a negative influence on competition, but, within a patent pool, either by contractual agreement or because of the legal weight of the pool members, other firms might choose not to challenge the validity of certain patents. Similar to substitute patents, invalid or weak patents deter new innovations that normally would have occurred, thus undermining competitiveness.

Current patent pools often contain hundreds of essential, complementary and valid patents, according to the patent pool participants. One of the leading patent pools, MPEG LA, has over 1,000 patents in some of their individual programs. An independent expert, who has to investigate the essentiality of these patents, would be facing a very serious challenge. The increase in the volume of patents included in the pool makes it difficult to evaluate the validity and the character of the patents. ${ }^{324}$ The volume of patents would require substantial financial investments in order to challenge the essentiality or validity through litigation. Massive patent pools will deter the development of alternative technologies and/or open source technologies. ${ }^{325}$

Patent pools are a traditional answer to the problem of patent thickets, patent holdup, and royalty stacking. Many patent pools consist of hundreds of essential patents that have been evaluated by independent experts. The risk of inclusion of nonessential patents is increasing, thereby possibly hindering new technology and raising the prices for consumers. The inclusion of substitute patents can be motivated by different strategic reasons but will have anti-competitive effects. The evaluation of the essentiality and validity of patents is crucial since, in its absence, the patent pool may contribute to royalty stacking.

\section{Economic research on the impact of patents on the functioning of the patent pool}

Blind, Baron and Pohlmann undertook economic research related to patent pools and standards as a reaction to famous court cases like Qualcomm v. Broadcom, Infineon v. Rambus, etc. Their research interest is centred on the impact that essential patents

\footnotetext{
${ }^{324}$ Recent initiatives to outsource substantial parts of patent portfolios, e.g. such as the sale of Nokia patents to Mosaid contribute to the excessive growth in size of patent pools.

${ }^{325}$ Open source innovators do not have large defensive patent portfolios and therefore have insufficient leverage against proprietary patent pools.
} 
have on the standardizing processes and on patent pools. The main conclusions were the following:

- A high number of essential patents in a standard reduces the likelihood that the standard will soon be replaced but encourages a constant upgrading of the existing standard.

- The use of patent pools in standardizing has a positive effect on the number of filings and declarations of essential patents, but the certainty of the legality of the patent pool is an influential factor.

- The rewards for essential patents included in a standard influence the investment in $R \& D$ of the companies participating in the pool. Excessive rewards for essential patents may create patent races and encourage a lower investment level in relation to $R \& D{ }^{326}$

The main conclusion of their research is that essential patents have a special position in the dynamics of innovation. Essential patents contribute to the technical improvements of a standard and the coordination of the licensing of essential patents in a patent pool leads to strategic behaviour in relation to the timing and volume of patent declarations inside the pool.

In conclusion, The Philips judgment is frequently quoted as marking the beginning of a new more liberal stance by US antitrust authorities in relation to patent pools. The decision insufficiently explains the future consequences of adding non-essential patents in a tying agreement to the patent pool. The lack of economic theory underlying the decision increases the legal uncertainty in relation to the aspects of both market dominance and non-essential patents, which could influence the strategic decisions of multinational enterprises in relation to the formation and jurisdictional positioning of their future patent pools.

\section{The essentiality criterion in the US anti-competitive analysis}

Since the decision in the Standard Oil patent pool case, the US antitrust authorities have strongly favoured an economic-based analysis over a purely patent-law based analysis. Within the economic-based approach, the essentiality test was a significant factor which swayed the opinion of the courts. The IP Guidelines of 1995 do not formally bind US courts in evaluating the legality of patent pools. US courts will use the rule of reason approach to weigh the pro-competitive and anti-competitive effect of the patent pool. Applied to practical cases, this means that US courts will:

- $\quad$ check the validity of the patents in the pool;

\footnotetext{
${ }^{326}$ A patent race means that companies want to include as many essential patents as possible into the new standard, before the decision on the final adoption of the standard is taken.
} 
- $\quad$ use the independent witness mechanism to identify the essential patents in the patent pool;

- examine the essential character of the patents;

- control the availability of non-exclusive licences to the pool;

- check whether there is no limitation in relation to the development of alternative technologies caused by licences;

- look for grant-back provisions that are limited to essential patents and governed by reasonable terms;

- welcome the existence of royalty allocation formulae within the patent pool;

- encourage the establishment of a dispute settlement mechanism in the pool;

- control the safeguard mechanisms for sensitive business information within the pool. $^{327}$

Essentiality of the patent is defined by the substitute character of the technology. If the technology has a substitute character, patents in the pool will compete directly with each other. The inclusion of multiple substitute technologies within a patent pool increases the probability that the owners of the competing technology will no longer compete but could possibly coordinate their prices, leading to both price-fixing and, consequently, exaggerated royalty rates. Substitute patents are not formally identical to non-essential patents, since the substitute patents can be necessary to make the patent pool function, especially in the case of standardization. ${ }^{328}$ The terminology and classification of patents as substitutes and thus non-essential can be very confusing.

Nelson contends that:

"By controlling technologies that are practical substitutes, the pool obtains the ability to increase licensing fees above competitive levels in a manner that would not be possible if there were competition among substitutable patent technologies. Moreover, when there are not close substitutes for downstream products that rely on the pooled technology, the patent pool may also be able to increase the price of the manufactured products." 329

The importance of the essentiality of the patents in the pool has been underlined in the BRLs of the DoJ and the FTC. The BRLs are part of the DoJ Prior Review process. In this process, the firms that want to establish the patent pool agreement submit a detailed letter including a description of their intended course of conduct. The Department's reaction can be two-fold; either they express privately that there are still reasons for

\footnotetext{
${ }^{327}$ Verbeure page 116.

${ }^{328}$ See in the same line of reasoning Newberg page 622.

${ }^{329}$ Nelson: Patent Pools: An Economic Assessment of Current Law \& Policy, page 543.
} 
concern or they publish a BRL. In this letter, the DoJ explains and elaborates on its own findings and understanding of the possible anti-competitive effects of the patent pool agreement.

The DoJ indicates that "at present" it does not have the intention to start proceedings against the intended patent pool. The prior review process can delay the start of the patent pool by 6 to 18 months and, as the DoJ only evaluates proposed conduct, the end result does not give sufficient certainty to the parties concerned. The Department could still initiate proceedings if the market conditions changed, the actual conduct does not correspond with the intended conduct or as soon as there is a policy change by the Department of Justice in the field of antitrust.

In the assessment of the DVD 3 pool, the DoJ and FTC clearly identify essential patents as patents for which there were no economically viable alternatives. The same reasoning is applied by both US agencies in the DVD 6C BRL, emphasizing the crucial importance of the essential character of the patents included in the pooling agreement. $^{330}$

In the 3G Patent Platform, essential patents were defined as, "claiming an apparatus, a method or a process necessary for the compliance of the $3 G$ Standards." 331 In the framework of the $3 G$ Patent Platform, a Common Administrator (CA) and an Evaluation Service Provider (ESP) manage a process in which independent experts evaluate and determine the essentiality of the submitted patents. Licensors cannot control or influence the independent experts. ${ }^{332}$ This marks a significant contradiction, since earlier it was concluded that, within standard setting, it is not always the best technology that makes it into the standard. When applied to patent pools, there could be a difference between using the definition of economically non-viable alternatives and the use of experts who determine the technically essential patents.

Some authors suggest that essential patents are necessarily complements, do not compete with each other and, in combination, make up a single product. By the same reasoning, non-essential patents can be substitutes (rather than complements) and can possibly foreclose markets with anti-competitive effects. ${ }^{333}$ Most of the literature hints at a technical nature of the essentiality of the patent, but some elaborations in the BRLS refer to clear commercial analysis to determine whether a patent is essential. The FTC explained in its BRLs that a neutral third party must examine the essentiality of the patent and that the firms participating in the pool must be willing to license their patents individually. A basic entry requirement for a firm wishing to participate in a patent

\footnotetext{
330 DVD 6C Business Review Letter states: "The proposed licensing program would require licensors and licensees alike to agree to license to each other not only their present 'essential' patents, but also any ones they obtain in the future. The pro-competitive benefits of such a requirement are clear."

${ }^{331}$ Platform Specification par. 3.1, 5, 6.4, 7.1 and Choumelova in: Competition law analysis of patent licensing arrangements - the particular case of 3G3P

${ }^{332}$ 3G Patent Platform Partnership Business Review Letter

${ }^{333}$ Presentation by Jeffrey Blumenberg
} 
pool should be the fact that the firm owns one or more essential and valid patents. Both the technical and commercial essentiality of a patent can change when a technology develops further.

In the case of the fast-moving telecommunications industry, this could be a difficult factor, especially since some of the firms possess very substantial patent portfolios. In the analysis of merger cases, the FTC established the doctrine of killer patent portfolios, which can also be relevant for the analysis of essential patents in patent pools. ${ }^{334}$ These killer patent portfolios can be used as a deterrent for competitors and can result in a Cold War-type of status quo.

The classification of a patent as essential will also become a proxy for determining the value of the patent. In some analytical patent valuation models, the characteristics of the patent directly influence the value of the patent and can be linked to the forward and backward diversity of technology using statistical analysis. ${ }^{335}$

It seems that the Philips decision of the International Trade Commission created some uncertainty on the definition of an essential patent. Analysis of the case law and BRLs illustrates the fact that there is no consistency in the interpretation of the doctrine of an essential patent. The influence or inclusion of non-essential patents within the patent pool, in the antitrust analysis of the legality of the pooling agreement, is open to different interpretations. From a technical perspective, it is clear that, sometimes, nonessential patents need to be incorporated into the pool to make the product function. The relationship of the essentiality claim to non-essential patents and to the determination of an essential patent is also insufficiently clear. The DoJ has linked essentiality to a literal interpretation of essential technical requirements or economically viable alternatives and provides different views in its BRLS.

This poses a major challenge for the US courts applying antitrust rules to patent pools. Before the Philips judgment, the common opinion linked the tying of essential and non-essential patents in a pool to anti-competitive behaviour. This tying arrangement seemed to foreclose competition in downstream markets. ${ }^{336}$ The Philips decision of the International Trade Commission illustrated that a package licence containing both essential and non-essential patents is not an infringement per se, but it should be examined under a rule of reason approach. This could imply that the patents within a patent

\footnotetext{
${ }^{334}$ See also case In the Matter of Ciba-Geigy Limited, Ciba-Geigy Corporation, Chiron Corporation, Sandoz Ltd., Sandoz Corporation, and Novartis AG.

${ }^{335}$ In this analysis, both the numbers of citations received by a patent and the number of prior art references made by a patent correlate to the value of the patent. Research related to the GSM standard (ETSI) and WIFI 802-11 (IEEE) suggests that essential patents receive considerably more citations than general or substitute patents. Patent originality shows that the patent right draws from various technology fields, indicating a more original innovation and a greater downstream market impact of the patent. See also: Kramer, Valuation and assessment of patents and patent portfolios through analytical techniques The John Marshall Review of Intellectual Property law L.463 (2007).

${ }^{336}$ See in the same line: A. Hadjis: Patent Pools gain Popularity. Assuming that the participating firms have market power.
} 
portfolio no longer always need to be made available on an individual basis and that patent pools might take a less cautious and more aggressive approach in deciding on the patents to be included in the pool.

Another consequence is that infringers of patent rights of the pooling agreement will have to be more cautious when using the patent misuse defence. Above, it was stated that, because of this decision, the doctrine of patent misuse can only be successfully applied in the case of actual anti-competitive effects on the relevant market. The effect of the Princo decision is probably limited, since the court explained that the analysis used should be applied and evaluated on a case-by-case basis. The court merely decided that the availability and existence of commercially feasible alternatives caused some of the essential patents to be considered non-essential patents. These nonessential patents, for which commercially feasible alternatives did not exist, consequently cannot foreclose competition, since competing alternatives do not exist.

Regarding the tying arrangements, the Court clearly distinguished the tying of patents to patents from the tying of products to products. In relation to the character of essential patents, the Court acknowledged the fact that technological progress can cause essential patents to become non-essential, leading to more uncertainty and more costly litigation. This could motivate companies to commit unfair practices, which could undermine the basic principles of patent law. The effects on patent pools that are part of standardization would be very profound. The standardization process would be slowed down, legal uncertainty would increase and technology firms might strategically use different positions in the US, the EU and the PRC. The MNEs would face a higher financial and administrative burden, leading to the avoidance of participating in the same patent pool in the US and the EU. The creation of sub-pools, especially for the US, the European Union or the PRC would limit some of the obvious advantages of patent pools in general, e.g. the reduction of transaction costs, efficiencies, network effects, positive effect on innovation, etc.

The US courts seem to take a more permissive stance on the packaging of both essential and non-essential patents. As a direct consequence, patent pools will increase in size, which makes it more difficult to evaluate the validity and essentiality of patents. In the absence of stricter control, it is more likely that large patent pools will include weak or invalid patents and thus violate antitrust laws by hindering innovation. 


\subsubsection{The relationship of participating companies in the pool}

Question B-What type of relationship do the participating companies in the pool have to each other? Are they active on downstream markets or are they vertically integrated firms?

Question B will be answered in the following sections:

- The patent pool and the relevant technology market

- Patent pools overlapping ownership

- Participation in a patent pool

Continuing with the key analytical questions, question B stated: What type of relationship do the participating companies in the pool have to each other? Are they active on downstream markets or are they vertically integrated firms? In the downstream market, price-fixing by firms operating the patent pool would result in a violation of competition or antitrust rules. To fix prices directly would be easy to detect, and therefore often this violation is a result of the indirect effect on the competition in the downstream market between firms that license the patents from the patent holder. The impact of royalty fees on the pricing policy of these firms can be difficult to measure. Enforcement agencies admit that it is challenging to define market share in technology markets and data on royalties is often not available. As a solution, agencies use the principle of the footprint on the technology market for products to evaluate the impact on the technology market. $^{337}$

Alternatively, competition can be hindered by licensing terms that assign certain compulsory geographical territories or exclusive areas of use for the package deal patent rights.

\subsubsection{The patent pool and the relevant technology market}

The choice to use a patent pool is directly influenced by the characteristics of the relevant market. In a complex, heterogeneous technology market, the interests of the different stakeholders are very diverse. The choice of different business models makes the task of finding a mutual understanding within the patent pool very challenging. The FRAND framework provides greater flexibility to the various firms to conclude bilateral licensing agreements that are custom-made for the individual interests of the contracting firms. A bilateral licensing agreement can consider the difference in patent portfolio strength, the size of the company and business model. In a patent pool agreement, the traditional view is that the licensor is the technology developer and the licensee is the technology user;

\footnotetext{
${ }^{337}$ Seminar CIR December 2013 Leuven University comments Peeperkorn EU Commission.
} 
these traditional roles are no longer clearly defined or separated in current high-techn markets. The licensing objectives of downstream and upstream market firms can clash or be difficult to align into a common patent pool policy. Numerical proportionality rules favour bigger firms, whereas the strategic value of the patents of SMEs can also be substantial but not directly recognized in this system. Normally, royalty payments are distributed per patent, but, to encourage a wider participation of SMEs, some patent pools have the preference for a per company distribution of royalty revenues.

Bilateral agreements have a slightly higher risk of legal uncertainty in relation to the FRAND conditions, but this risk can also not be excluded in a patent pool agreement. As a rule of thumb, one in ten negotiations leads to a successful patent pool. ${ }^{338}$ During the often lengthy negotiations, patent owners cannot commit themselves. A greater the number of participating firms, not only will slowdown the decision-making process but might also add further complexity in this not very transparent market. Some scholars argue that bilateral licensing in a heterogeneous market such as telecommunications provides better market efficiency than patent pools. This argument must be central in the discussion of competition authorities, since it is directly related to consumer welfare and the competitiveness of a regional trading bloc.

Is market efficiency better achieved through bilateral licensing agreements or through patent pools, especially in fast-moving technology markets in which the commercial interests of the participating firms also change rapidly?

From a policy perspective, the EU wants to promote the use of IPRs (patents) in standards. ${ }^{339}$ At the moment, the EU has not expressed a clear preference for the business models used in this context. Policy initiatives such as the DG Enterprise White Paper, the Guidelines on Horizontal Cooperation and the adopted review of the TT Guidelines are business-model neutral. The main objective of the EU is to encourage investment, innovation and competition. Therefore, it is interesting to examine economic research on the market-efficiency of patent pools.

\subsubsection{Patent Pools: overlapping ownership}

In recent economic literature, an interesting discussion has evolved on the question of whether horizontal price collusion is facilitated by the pooling of vertically related patents held by firms with overlapping membership. ${ }^{340}$ A vertically integrated firm conducts re-

\footnotetext{
${ }^{338}$ Discussions during the Brussels workshop on patent pools May 2012. Comments made by Jari Vaario of Nokia. Nokia is currently active as a licensor in five patent pool agreements. As a licensee Nokia is in three active patent pools and both as a licensor and licensee Nokia is in one active patent pool.

${ }^{339}$ See policy initiatives like the Unitary Patent Protection, Innovation Union.

${ }^{340}$ Gallini: Competitive Price Coordination in Technology Sharing Agreements University of Columbia May 2011.
} 
search and manufactures a product based on a standard. ${ }^{341}$ If the firms participating in the patent pool internalize their pricing strategy in the pool, based on the profit margins of the products covered by the other overlapping patent rights outside the patent pool, the competition between the products outside and inside the patent pool could be affected. This would constitute a more tacit infringement of competition rules, led by pricing decisions for products outside the pool that are owned by firms participating inside the patent pool. In the industrial organizational literature, this situation is attracting more interest from researchers. Traditionally, this literature has identified a few key factors in the discussion of the legality and anti-competitive effects of patent pools:

- A pool of complementary patents can have pro-competitive effects on the relevant market, both with horizontally and vertically integrated firms participating in the patent pool.

- From an economic perspective, efficient antitrust policy for patent pools would enable the pools to establish consumer benefits that would be at least equal or more than the consumer benefits achieved by firms competing in uncoordinated input pricing strategies. ${ }^{342}$

- Even when the patent pool only consists of valid, essential and complementary patents, the ownership of downstream substitutes could be coordinated by the participants in the pool.

- In the above-mentioned case, companies might decide to forego the development of technically superior alternative technologies, thereby reducing their contribution to innovation and limiting the contribution to social welfare and consumer benefits.

- The question of whether the pool members' contribution to the pool is symmetric or asymmetric will directly influence their pricing strategy.

Firms are competing on the basis of technology platforms. This means that the patent pool does not have to contain the best available technology but, more importantly, the platform must be supported by complementary products that help gain the confidence of consumers.

The general policy recommendation of Gallini includes a recommendation that antitrust authorities should also look at the nature of the competitive relationship between the patent right owners, both related to products inside the pool and to competing products outside the pool. In the Industrial Organization literature, the debate centres on the question of whether the present IP system (i.e. patent pools) encourages innovative firms to participate in patent pools, balancing the economic benefits versus the

\footnotetext{
${ }^{341}$ Layne-Farrar, Lerner: To join or not to join: examining patent pool participation and rent-sharing rules page 294-303.

${ }^{342}$ Shapiro Antitrust limits to patent settlements 2003.
} 
costs of the IP system and the contribution to social welfare. Understanding the reasons that firms want to join a patent pool would help the antitrust enforcers to prioritize their policy in relation to patent pools.

\subsubsection{Participation in the patent pool}

Within the standard-setting context, patent pools are frequently used as an instrument to give advantages to both patent right owners and consumers. However, even in this situation, the decision to join the patent pool is made on a voluntary basis. The first dilemma for a firm would be the decision whether to license their patents on an individual basis, in a pooling arrangement or with a combination thereof.

If the firms of the patent pool are also active in the downstream market, they might not want to create new competition by licensing their patents to third parties. Two different stages need to be distinguished: firstly, the negotiations directly concerned to the formation of a patent pool and, secondly, the decision of whether a firm wants their patents to be part of a patent pool within a standard. Existing cross-licensing agreements with other firms, uncertainty about the validity of the patent or the strategic use of the patent in a soon-to-be-developed product or standard can be legitimate reasons that a company would choose to license their patents individually.

The earlier discussion of the US antitrust rules shows that the patent pool will normally consist of essential, complementary patents that need to be used in combination in order to implement the relevant standard. The SSO normally uses an independent expert to verify the essential character of the patents, although this essentiality is sometimes contested.

The negotiations on the establishment of the patent pool are not necessarily limited to discussions on the licensing terms. Governance rules related to the management of the pool or the rules on firms leaving the pooling agreement can already deter patent owners from engaging in the pooling effort. During these initial stages, communication and coordination between competitors has occurred, which could also lead to a patent pool different from the original one being formed. ${ }^{343}$

Research by Bekkers reveals rapid growth in expenditure on R\&D. This has led to a strong growth in patent registrations and in the diversity of patent owners. ${ }^{344}$

In the same article, the authors identify three types of patent pools:

1. A Joint Licensing Program (JLP), which is a licensing program combining the relevant patents and offering the package at a pre-determined royalty rate to licen-

\footnotetext{
${ }^{343}$ See also Merges 1999. Institutions for intellectual property transactions: the case of patent pools.

${ }^{344}$ Uijl, Managing Intellectual property Using Patent Pools: Lessons from the Three Generations of Patent Pools in the Optical Disc Industry page 4.
} 
sees. The JLP offers one technology, is not open to new licensors and, consequently, has low negotiating costs for the establishment of the patent pool.

2. A regular Patent Pool, the classic example of which is the highly successful MPEG LA pool. In this type of pool, new licensors can be admitted and one technology is covered by the patent pool.

3. A "Pool of pools"; this type of patent pool addresses the complexity of modern technology markets. The pool covers multiple generations of technology. The technology offers backwards compatibility and increased convergence of different functionalities with other products (e.g. smart phones). ${ }^{345}$

Recent examples of the "pool of pools" model include technology for the 4G LTE standard. In this field, two patent pools are in existence (Via Licensing and Sisvel). These pools included technology of different generations in order to achieve backward interoperability also. This means that, with a 4G mobile phone, it should also be possible to use previous generations of mobile phone standards. The Pool of pools has high negotiating costs and, since the willingness to cooperate is a decisive factor, competition authorities should effectuate more supervision on the establishment of this type of pool. The process of technological co-creation can easily lead to the foreclosure of markets or the collusive behaviour of firms. Technology markets nowadays see a growing fragmentation of IPRs, for which patent pools could be a viable solution. The increased costs of bilateral licensing and the one-stop shop advantage make patent pools an attractive option. ${ }^{346}$

The development of the Pool of pools business model does bear some antitrust risks. The convergence of functionalities makes it more likely that downstream markets can be affected by the patent pool. The common use of ICT standards in different unrelated industries makes the definition of the relevant market even more complicated. Although the instrument of a patent pool is still a trustworthy solution to address the problem of patent hold-up and royalty stacking, agencies will have to monitor the effect of these enlarged patent pools on completion and innovation more closely.

\subsection{LICENSING IN THE PATENT POOL}

Question C-Is the technology embedded in the pool exclusively available through the pooling agreement? Are individual licences available? Are there elements of a tying agreement?

Question C will be answered in the following sections:

\footnotetext{
${ }^{345}$ Unfortunately these technical aspects also increase the fragmentation of IPRs.

${ }^{346}$ See also note 266 page 20.
} 
- $\quad$ Licensing in the patent pool

- Compulsory licensing

Returning to the overview of the key analytical issues leads to the question: Is the technology embedded in the pool exclusively available through the pooling agreement? Are individual licences available? Are there elements of a tying agreement? The markets that are affected by standard setting are the so-called innovation markets. Innovation markets consist of both consumer end-products but also the licensing, sale and purchasing of technology. ${ }^{347}$ The FTC and the DoJ created a safe harbour for firms that only possess a small market share in the technology market. The Competitor Collaboration Guidelines explain that the safe harbour is applicable as long as the joint market share of all participating parties does not exceed 20\%. The Intellectual Property Guidelines also use the criterion of $20 \%$ as the threshold for possible action. The patent pool arrangement often leads to a bundling of patents that are grouped in a blanket licence.

Uncertainties do exist in relation to the accusation that patent pools have distinct features of a tying agreement and with regard to which antitrust authority the supervisory task of these agreements should be given. The Federal Trade Commission (FTC) may "define and proscribe an unfair competitive practice, even though the practice does not infringe either the letter or the spirit of the antitrust laws." 348

This statement from the Supreme Court would empower the FTC to go beyond the strict boundaries of Section 5 of the Sherman Act and the provisions of the Clayton Act when evaluating the tying aspects of patent pools.

Within the case law, the existence of substantial market power in the relevant market, possibly leading to a monopoly in the relevant market, is an important factor in the evaluation process by the FTC and DoJ. For the competition law analysis, the most worrying factor is that consumers will forgo the purchase of a product or service since the monopolist continually increases his price at the expense of consumers. This phenomenon is defined by economists as deadweight loss, reducing allocative efficiency. ${ }^{349}$ The concept of market power must be given a different interpretation in the case of network industries, i.e. telecommunications. Economists have shown that, in network industries, the positive network externalities may lead to a natural monopoly, initiated by the demand side rather than the supply side. Consumers benefit from the direct use of the product or service but also benefit from an increase in use of the product or service by other consumers. ${ }^{350}$

Until now, antitrust authorities have not yet developed a uniform and transparent method of analyzing the impact of positive market externalities and, thus, a reasonably

\footnotetext{
${ }^{347}$ See FTC Antitrust Guidelines for the Licensing of Intellectual Property para. 3.2.1.-3.2.2.

${ }^{348}$ FTC v. Sperry \& Hutchinson Co., 405 U.S. 233 (1972).

${ }^{349}$ The reduction of allocative efficiency is linked to the misallocation of resources.

${ }^{350}$ See for a wider explanation Pohlmann: Six essays on patenting and coordination in ICT standardization: Empirical analyses of essential patents, patent pools, and standards consortia.
} 
high market share in competition cases. To complicate the analysis, firms in network industries may decide to implement tying arrangements in order to facilitate and support the positive network externalities, creating a critical mass for the product or standard. Standardization itself is a prime example of a strategic decision made by firms to cooperate in a horizontal agreement, to maximize the benefits of the positive network externalities. $^{351}$

In the Microsoft case, the DoJ applied a theory on network externalities, by claiming that the dominance of Microsoft created barriers to entry of other competitors. During the appeal, the court determined that Microsoft had created its dominant position on the basis of competition on merit (due to the positive network externalities). The Court of Appeal recognized the relevance of the extent of the network benefits to the antitrust violation discussion. The specific nature of network industries, especially in relation to patent pools, could justify a more detailed analysis of the effects that positive network externalities can have on tying agreements, predatory pricing or exclusive dealing arrangements. Since more consumers have a positive effect on the network, traditional anti-competitive measures could be justified in the case of network industries, since a larger and more substantial network could lead to more social benefits, i.e. lower prices for consumers and more access to new technology.

The maximization of allocative, productive and dynamic efficiency is one of the prime goals of competition authorities world-wide; enforcement authorities should consider the impact of the network externalities in the functioning of the patent pool in their legal analysis of patent pools. Lack of a clear and consistent method of analysis will contribute to legal uncertainty in relation to patent pools. ${ }^{352}$

\subsubsection{Licensing in the patent pool}

The next major decision that the participating firms have to take regards the licensing terms of the patent pool. The licensing terms bear a direct relationship to the ability of licensees to contribute to innovation. The guidelines and enforcement policies of the antitrust authorities have led to a set of common practices. Most recent patent pools are examples of mixed bundling, meaning that the licences can be obtained on an individual basis outside the pool and as a package licence within the pool. The choice of the licensee to purchase an individual licence or the package deal could have serious consequences for the royalty fees to be paid.

The price of the independent licence is set by bilateral negotiations, whereas the collective fee of the patent pool is part of the royalty sharing agreement within the patent pool. In order to prevent the problem of a hold-up, some scholars have argued

\footnotetext{
${ }^{351}$ See for further discussion Priest Rethinking Antitrust Law in the Age of Network Industries page 9.

${ }^{352}$ For more economic analysis see also Economides Antitrust Issues in Network Industries in The Reform of EC Competition Law, Ioannis Kokkoris and loannis Lianos (eds.), Kluwer (2008).
} 
that firms within the pool should be allowed to discuss their intended royalty rates ex ante, before the standard is set. This would provide the advantage that the royalty rate could be part of the competitive environment for choosing the standard. Other experts would like to introduce joint ex ante royalty auctions or discussions to provide transparency in the standard-setting process. Both SSOs and patent pools have reacted reluctantly, fearing the accusation of price-fixing. ${ }^{353}$ The discussion of the royalty rates should be distinguished from the establishment of royalty-sharing agreements.

The royalty structures can be based on the total sum of units sold or on a fee related to the sale of the individual unit. Farrar distinguished three different forms of royaltysharing rules:

1. Royalty-free licensing.

2. Numeric proportional sharing rules, in which firms receive a proportional share of the total royalties received in the pool, distributed on the basis of the number of essential patents that are included in the pool. A variation of this method is the patent points system, where the use of patents leads to a country allocation and, consequently, a distribution system linked to the ownership of the patents. $^{354}$

3. Value proportional rules, whereby the value of the patent in the pool determines proportionally the amount of royalties to be received by a firm. ${ }^{355}$

Innovative royalty sharing systems give a premium to patent owners who make their patents available for enforcement and compliance, since these are in the interest of both licensors and licensees. As such, royalty-sharing schemes directly impact innovation and the willingness of licensors and licensees to invest in the development of new technology.

The prior discussion of the Philips decision in relation to including non-essential patents to the pool is also relevant for the royalty-sharing rules. In recent economic research, some scholars draw attention to the timing of the introduction of new patents to the pool and its possible strategic motivation. Lampe and Moser concluded that the expectations of the return on investment of inputs into a patent pool can prompt the strategic filing of patents by firms in the pool. ${ }^{356}$ The choice of different forms of royalty-sharing agreements can promote or deter firms from multiplying the number of patents that are contributed to a patent pool. The multiplication of the patents can

\footnotetext{
${ }^{353}$ See also Platt Majoras, Chariman of the Federal Trade Commission, RECOGNIZING THE PROCOMPETITIVE POTENTIAL OF ROYALTY DISCUSSIONS IN STANDARD SETTING", Speech September, 23, 2005. The Chairman recognized possible pro-competitive effects, but introduced a balancing test of the FTC relating to this topic.

354 Sisvel presentation Noordwijk 2011.

355 Supra note 48.

${ }^{356}$ See Lampe Moser Do Patent Pools Encourage Innovation? Evidence from the19th Century Sewing Machine Industry NBER Working Paper No. 15061.
} 
directly influence its quality and contribution to innovation and social welfare and should, consequently, draw the attention of competition law enforcers. Only in the case of royalty-free licensing should this not be a direct concern, although the multiplication of patents could also be motivated by different business models in relation to the downstream market. ${ }^{357}$

The numeric proportional sharing rules are used by MPEG LA in different formats. In general, MPEG LA distributes the royalties according to the number of essential patents contributed to the standard. In other standards (e.g. MPEG 2), the essential patents are actually weighted per country. In this model, more patents mean more revenue, so the incentive to add less important essential patents increases, while the quality of the patents that are introduced at a later moment could decrease. Since the quality of the patent is not assessed, this opens the door to the strategic filing of patents. In the second case, using value proportional rules, the quality of the patents is assessed, but there still could be reasons to include numerous patents. ${ }^{358}$

As discussed earlier, there are different interpretations on the definition of an essential patent. The DoJ used the lack of technical alternatives as a definition, but later the definition also included the criterion of economic feasibility, incorporating commercial aspects into the discussion. Most patent pools meet the preferences of the antitrust authorities by using an independent expert to evaluate the essential character of the patents. This system is supported and encouraged by the competition policy enforcers, but there is doubt as to the independence of the experts, since they are employed and paid by the patent pool or SSO and it these parties who choose the evaluation criteria. $^{359}$

The role of the independent expert is crucial for the evaluation of the activities of the pool and possible enforcement actions by antitrust institutions. Alternatively, firms in the pool can collectively decide on the essentiality of the patents, leaving the possibility for possible misuse of the system.

Various scholars have linked the timing of the introduction of new patents to the pool, after the standard was set, to the changing quality of the new patents, suggesting that this leaves room for strategic behaviour. ${ }^{360}$ At the same time, the conclusion can be drawn that, at a later stage, the number of patents added to the pool increases, whereas the quality of the patents decreases. A number of explanations have been given for

\footnotetext{
${ }^{357}$ Royalty-free licensing could give firms access to the technology of other companies.

${ }^{358}$ The number of essential patents directly correlates to the distribution of the revenues of the royalty haring agreement

${ }^{359}$ Firms participating in the pool can design the criteria to meet their specific patent contributions in the pool The FTC gives a vague explanation in a Business Review Letter: "The Consortium appears structured to preserve the patent expert's independence regarding his decisions about each patent's essentiality to the Gen-2 standard. He is to be paid by the hour regardless of the outcome of his determination and his decision is binding, although he can be asked to reconsider his finding for an additional fee and others can engage him to review his prior determination that a patent is essential" FTC Business Review Letter to the RFIC-consortium.

${ }^{360}$ Bekkers, Layne-Farrar and Tirole and Lerner
} 
these conclusions. The first explanation lies in the technological progress made since the standard was adopted. The first wave of patents to be incorporated into the standard is likely to be part of basic research leading to incremental innovations. Later patents deal with a standard which is narrowing down in a technical sense and they tend to have a more applied character. ${ }^{361}$

In economic research, the quality of patents is often evaluated by using forward citations as an indicator, since the follow-up innovations can be seen as proof of the quality of the original patent. ${ }^{362}$ Baron et al conclude that there is a direct relationship between the royalty-sharing rules and the pattern, timing and quality of the patents introduced into the patent pool. Firms already operating in the pool find it relatively easy to introduce patents with decreasing quality, since they have inside knowledge of the operation of the pool and the patent pool has an interest in keeping outside firms out of the agreement, since the rent division changes with the introduction of new firms. ${ }^{363}$ For vertically integrated firms, who may contribute essential patents but also act as licensees, joining the pool enables them to discuss prices and royalty rates, which is in their direct self-interest. The intention of establishing a patent pool can initiate a patent race, diverting investments into the creation of more but weaker patents to be placed in the patent pool in the standard. These investments could alternatively be used for more incremental innovations, leading to more consumer benefits. ${ }^{364}$ The inclusion of the weaker patents after the standard was set may lead to the patent pool harbouring weak patents that could have been challenged if they had been licensed on an individual basis, leading to possible invalidity or a lower royalty fee. It would be very interesting to see the reaction of competition policy enforcers to a patent pool that is established before the standard is set. These elements show that the royalty-sharing rules influence the investment decisions regarding the type and volume of new inventions. As such, royalty-sharing agreements can stifle the innovative capacity of firms. This should justify a closer monitoring of these arrangements by competition authorities.

At the time of writing, competition authorities show very limited interest in the royalty-sharing rules of patent pool agreements. One of the advantages of implementing a patent pool into a standard is the reduction of transaction costs, contributing to social welfare. Economic research suggests that rent-seeking strategic patent introductions into the pool could have an adverse effect. Strategic patent introductions can lead to new patent thickets, the phenomenon that patent pools seek to prevent. The FTC

\footnotetext{
${ }^{361}$ The type of patent can be further investigated by introducing a patent generality index, discussing the general character of the patent. This index is also occasionally linked to the quality of the patents.

${ }^{362}$ This method has its limitations, since its application shows different outcomes in various economic sectors Some experts favour a compounded use of forward and backward citations and family size.

363 Two possibilities: existing royalties remain the same after the introduction of new patents or an increase based upon the critical value of the new essential patent.

${ }^{364}$ For more conclusive research see: Baron and Pohlmann: Patent Pools and Patent Inflation, the effects of patent pools on the number of essential patents in standards.
} 
seems to be willing to discuss the legality of joint royalty discussions ex ante, since they can have a pro-competitive effect. However, without providing more transparency and guidance, both SSOs and patent pools will still fear the legal uncertainty surrounding possible accusations of price-fixing. Since this discussion is at the heart of the matter, i.e. the contribution of patent pools to innovation, competition authorities should investigate the effect of royalty-sharing agreements on possible restrictions of R\&D investments.

\subsubsection{Compulsory licensing}

Interoperability is the key factor for the success of standards. Some commentators believe that this feature justifies the use of compulsory licences. In EU competition law there is a notion that a firm does not have a general duty to license, but that only exceptional circumstances necessitate the introduction of compulsory licensing. This phenomenon has been discussed in recent EU case law.

\subsection{PATENT POOLS, NPES AND THE POTENTIAL TO INNOVATE}

Question D-Does the patent pool agreement have a positive or a negative impact on the licensee's potential to innovate?

Question D is answered in the following sections:

- Innovation benefits of patent pools

- New business models to monetize patents

\section{Innovation benefits of patent pools}

The innovation benefit of patent pools has been heavily debated. Some empirical studies have found that patent pools have a negative effect on innovation. Baron and Pohlmann conclude that the use of patent pools in standardization leads to patent races that have a negative impact on innovation. ${ }^{365}$ Originally, patent pools were regarded as the purest solution for the problem of patent thickets.

The theoretical advantages of patent pools have been discussed previously, but, in practice, competition authorities should pay more attention to the royalty-sharing agreements. The distribution of the collectively gained royalties from the patent pool agreement can have a direct influence on innovation. In general, royalties are distributed by the numbers of patents that a firm holds within the patent pool. As a conse-

\footnotetext{
${ }^{365}$ Patent Pools and Patent Inflation The effects of patent pools on the number of essential patents in standards Baron and Pohlmann.
} 
quence, many firms, especially SMEs, have the urge to include as many essential patents as possible in the standard. This has the ironic effect of patent pools initiating a race to establish a high number of essential patents into the patent pool, although the patent pool is an instrument to overcome the problem of patent thickets. The practical effect would have to be that, where patent thickets may include many complementary patents, patent pools may only contain essential patents. The quality of the patents in the pool must be higher than those in a patent thicket.

Baron and Pohlmann investigated the relationship between the number of patents in the standard and the likelihood of patent pool formation and also the relationship between the commercial value of the standard and the creation of a patent pool. The commercial relevance of the standard is very obvious in the field of telecommunications, meaning that this would result in a higher number of essential patents in the standard. The creation of a patent pool normally starts with the publication of a call for patents that are essential for the standard. Firms wishing to participate in the patent pool must issue their patent declarations before this call. After the initial negotiations for the creation of a patent pool have started, late-comers to these negotiations will have a competitive disadvantage in terms of negotiating power. An early commitment to the patent pool will give the firm the advantage of owning essential patents in the pool and the theoretical power to influence the decision making in relation to new firms that want to be included in the patent pool. Baron and Pohlmann considered that patent pools, in combination with standardizing projects, increase the total number of patents declared. This fact does not directly provide any conclusions on the effect of patent pools on innovation.

The question is whether the additional R\&D expenditures of the firms in the patent pool lead to substantial improvements in the standard. ${ }^{366}$ Economic research strongly suggests that patent pools have a significant impact on both the number of patent declarations but also on the timing of patent declarations. The prospect of the creation of a patent pool leads to a significant increase in patent declarations. This patents race does not provide the standard with better quality patents, especially in the case that the royalty distribution agreement is based upon the number of patents held by each firm. The economic research indicates that the general positive effects of patent pools still outweigh the negative effects on social welfare. Competition policy enforcers must carefully monitor the fact that patent pools may result in an increased number of patent declarations which do not necessarily contribute to innovation and, therefore, to competitiveness.

Using patent pools as a remedy for patent thickets can enhance some of the same effects, for example, an increased number of patent declarations. Since the participating firms in the pool play an important role in the decision making, there is also a risk

\footnotetext{
${ }^{366}$ Econometric research would be needed to investigate the effect of increased R\&D investments on the quality of standards. Baron and PohImann used a negative bionomial regression estimator for this article.
} 
that newly admitted essential patents to the pool are not strictly necessary, they increase the costs for licensees and the downstream market and have a negative effect on competition.

The negative effect on competition is created by the fact that firms in the pool seek rent sharing strategies and pull these resources from real innovative investments. Some firms will continue to invest in R\&D aimed at smaller, less incremental innovations that do not increase the quality of the standard substantially. ${ }^{367}$ A distinction between the contribution that essential patents make to the standard in combination with more differentiated royalty-sharing agreements would create a better return of investment in innovation policy terms. The aforementioned One-Blue concept does create more value for holders of technologically significant patents and makes the gathering of these types of patents into a patent pool more attractive. ${ }^{368}$ The uneven treatment of the different types of patents and their contribution to the standard will deter some patent holders from joining a prospective patent pool. In the present ICT business sector, the financial rewards for being included in the standard are so lucrative that it hinders the formation of patent pools and, if a patent pool is created, the risk of a patent race undermines the overall quality of the patents included. ${ }^{369}$

Competition authorities should investigate the effect of patent pools on innovation, more specifically, the effect of patent pools on the number and the timing of patent declarations.

\section{New business models to monetize patents}

At the start of this chapter, four key elements were identified. Question D asked: Does the patent pool agreement have a positive or a negative impact on the licensee's potential to innovate? In order to answer this question, I will also look at recent developments in relation to Non-Practising Entities, patent trolls and patent assertion entities. For a practical perspective, a discussion of the $4 G$ standard will follow.

Originally, one of the main functions of patent pools was to bring technology to the market. With the emergence of NPEs, patent pools can also be used to block alternative technologies from entering the market. Mosaid Technologies acquired 2,000 patents from Nokia in order to help the monetization of these patents. Mosaid will get one-third of the royalty revenues and the remaining part will be shared by Nokia and Microsoft. ${ }^{370}$ Some commentators identified the risk that Microsoft and Nokia can increase the costs

\footnotetext{
${ }^{367}$ This is a process of upgrading existing standards instead of creating new standards for innovative technology.

${ }^{368}$ In the current system, holders of significant patents might opt out of the patent pool.

${ }^{369}$ Layne-Farrar, Lerner, (2008), To Join or Not to Join : Examining Patent PoolParticipation and Rent Sharing Rules, Working Paper on the same subject but in general conclude that patent pools will lead to more patent declarations.

${ }^{370}$ Nokia Sells 2,000 Patents Mosaid Technologies Will Share in Revenue Wrung From Wireless Know-How Article Wall Street Journal 2 September 2011.
} 
for competitors in the Android market by, indirectly, through Mosaid, increasing the royalty fees for licensees. Licensees will pay higher royalty fees as long as they are lower than the litigation costs. In 2012, the DoJ approved the acquisition of Nortel's patents portfolio by the Rockstar consortium. This consortium consists of Apple, Microsoft, Research in Motion, Sony, EMC, and Ericsson. One of the key factors in the approval was the relatively low market shares of RIM and Microsoft and the assertion by Apple that they would license on FRAND terms. ${ }^{371}$ The current trend of the acquisition of large patent portfolios, in combination with the outsourcing of patent monetization, will again increase the size of patent pools. The legal boundaries between pro-competitive pools and patent assertion entities that harm innovation will become more difficult to draw. This calls for more a pro-active enforcement and evaluation of antitrust laws in relation to patent pools, NPEs and PAEs. The effect on open source development can be very dramatic when large patent portfolios are no longer directly owned by the original patent holders.

In the US, the PAEs have also attracted political attention. In February 2013, President Obama stated:

"The folks that you're talking about [PAES] are a classic example; they don't actually produce anything themselves. They're just trying to essentially leverage and hijack somebody else's idea and see if they can extort some money out of them... [Our] efforts at patent reform only went about halfway to where we need to go and what we need to do is pull together additional stakeholders and see if we can build some additional consensus on smarter patent laws. ${ }^{372}$

This White House Report does not distinguish between Non-Practising Entities (negative impact), Patent Assertion Entities (neutral or positive impact on innovation) and patent pools. The report claims that PAEs use the assumption that patent claims will often be settled out of court and that PAEs play no role in technology transfer. The report does not favour a ban on PAEs but proposes three remedies that are also relevant for patent pools:

- Increase the quality of patents in relation to novelty and non-obviousness.

- Reduced disparity of litigation costs between PAEs and their defendants.

- Greater adaptability of the US innovation system to new business models and the changing technology. market. ${ }^{373}$

\footnotetext{
${ }^{371}$ Trolls and privateers. IBC Conference Brussels 2013

${ }^{372}$ PATENT ASSERTION AND U.S. INNOVATION report page 2.

373 Ibid page 13.
} 


\section{The $4 G$ standard}

Regarding the contribution of patent pools to innovation (question D), the development of the $4 \mathrm{G}$ standard is used as an practical example. The developers of the $4 \mathrm{G}$ standard (also known as Long Term-Evolution technology LTE) made the strategic choice to opt for patent pools for the further development and commercialization of the standard. Three patent pools were developed: one by Sisvel (an Italian company specializing in patent pools) and two by US companies, Via Licensing and MPEG LA. The standard developers seek to achieve a critical mass for the adoption of the standard by facilitating licensees with the development of the different patent pools. Another, unofficial, incentive for the formation of the patent pools for the $4 \mathrm{G}$ standard can be the amount of litigation related to the previous $3 G$ standard. Legal experts claim that Qualcomm was at the heart of many of these disputes concerning patent rights. ${ }^{374}$

In 2008, a group of US companies initiated two new patent pools in an attempt to force Qualcomm to lower its royalty fees and, in this way, facilitate further innovations for the new 4G standard. When confronted with allegations of abuse, Qualcomm counsels stated that these discussions only revolved around contractual issues, thereby being part of contract law dictated by the regular forces of supply and demand. ${ }^{375}$ The strategic stance of Qualcomm can be influential, since patent pools need a critical mass of licensors in order to be successful. Qualcomm, the largest CDMA patent owner, did not participate in the 3GPP patent pool and, consequently, the CDMA patent pools did not prove to be very successful. ${ }^{376}$

The Italian firm Sisvel manages and initiates patent pools, with the LTE pool specializing in the 4G standard. In April 2008, seven major firms in the field of telecommunications made the strategic decision to opt for "a reasonable maximum aggregate royalty level for [all] LTE essential IPR in handsets is a single-digit percentage of the sales price (i.e., <10\%)." 377

In order to achieve this goal, the NGMN Alliance conducted a market-research ("Trusted Third party IPR Process") to gather information on the ex ante licensing terms, including the royalty rates, for the licensing of the LTE technology. This research might have already attracted the interest of antitrust authorities, since, although the licensors gave the information on an anonymous basis, this could still be very relevant market information and lead to possible collusion.

\footnotetext{
${ }^{374}$ Qualcomm was involved in legal battles with Broadcomm and Nokia on the WCDMA standard and with Nokia on the high level of their royalty fees.

${ }^{375}$ Comments Oualcomm Legal counsel Standards \& Patents Conference London 2010.

${ }^{376}$ In practice we regularly notice that important firms stay out of the patent pool: with the 3G (W-CDMA) apart from Qualcomm also Motorola, Nokia and Ericsson did not participate in the patent pool.

377 Sisvel presentation Noordwijk 2011 http://ec.europa.eu/dgs/jrc/downloads/events/20110428-ttocircle/jrc_20110428_ttocirle_brufani.pdf
} 
The independent firm dealing with the administration and management of the patent pool must guarantee that the firms do not exchange relevant business information, either between themselves or information coming from licensees.

From a practical point of view, the early publication of the royalty structure and rates will provide transparency to future licensees and could facilitate early success in reaching a critical mass for the adoption of the standard. This would have a positive effect on innovation. Early adoption is only possible when all the relevant patent owners can be identified; this can be done through the instruments of self declarations by the companies involved, specialized IPR landscape studies or by automatic patent analysis tools. ${ }^{378}$

For the licensee, it is important to start a patent clearance search, to investigate whether all the necessary patents are integrated into the patent pool. Other important considerations would be the inclusion of grant-back provisions and a most-favoured nation provision. ${ }^{379}$ These elements will be discussed in the next chapter. The characteristics of the business sector will also play a significant role in the functioning of patent pools in standardization. The product life cycle and the preferred business models will influence the willingness to participate in patent pools. ${ }^{380}$

Overall, it can be concluded that patent pools may make a positive contribution towards the innovative capacity of both licensors and licensees. The case law provides evidence of the fact that antitrust agencies should take a much closer look at some of the institutional and managerial aspects of the patent pool. Further economic research is necessary and should include elements of behavioural economics, industrial organization and innovation economics. The present environment of technology transfer is too complicated to be limited to only a legal antitrust analysis. In order to fully understand the dynamics of technology markets, competition authorities would be well advised to broaden the base of economic analysis that is used.

\subsubsection{The new phenomenon of defensive patent pools}

The emergence of Non-Practising Entities (NPEs) has divided the IP community into different camps. Some associate NPEs with aggressive business strategies, in which the large patent portfolio will be used to file patent infringement claims against other firms

\footnotetext{
${ }^{378}$ Currently Prof. Gambardella of the University of Bocconi is developing an automatic patent analysis tool, using semantics analysis and statistical analysis of both the characteristics of the patent and the licensor.

${ }^{379}$ Grant-back provisions are a contractual obligation that further inventions on basis of the original patent will be made accessible to the original inventor. The Most-Favoured Nation licensing part states that licensors will get the same deal and will not be undercut. Comparable to the WTO Most-Favoured Nation treatment clause, which requires that the reduction that was awarded to one Member will automatically be made available to all Members.

${ }^{380}$ GlaxoSmithKline started a patent pool to tackle diseases in Third World countries, based on a model of open innovation, with mixed reactions of the pharmaceutical industry Aziz (2011). Swimming in the patent pool. Intellectual Property Magazine.
} 
that do not accept the non-exclusive licence. ${ }^{381}$ Others see the NPEs as a new innovative way of monetizing patents that otherwise would not have any value. As a new strategy against the NPEs, or "patent trolls", defensive patent pools/ aggregators have been established. In this concept, a group of operating firms purchase problematic patents from the market before an NPE has the opportunity to get hold of these patents. The patents acquired by the pool will be licensed to any interested party for the costs of purchasing the patent and the administration of the patent pool. The major aim of the defensive patent pool is not to generate revenues but to get some of the "problematic patents" off the market. ${ }^{382}$ One example of a defensive patent pool is the Open Innovation Network (OIN), a company that aims to protect open source products like Linux. Defensive patent pools buy patents to stop them being bought by PAEs and generally do not seek to generate revenue from their purchased patents. The business model of the RPX Corporation requires participants to pay an annual subscription fee, but in return RPX will identify and purchase patents that can be used against their subscribers. RPX itself does not monetize their patent portfolio or aggressively litigates patents. All members of RPX receive a licence for the patents. A variation on this model is the Allied Security Trust (AST), which operates on a non-profit basis and does not use its own capital but solicits its members to obtain funding for the purchase of patents. ${ }^{383}$

\section{Tacit patent pools}

The concept of tacit patent pools refers to the practice in which companies give access to each other's patents without charging licensing fees and promise to refrain from filing patent infringement cases on a non-contractual basis. Hovenkamp submits that tacit patent pooling is attractive to small and medium-sized companies that are threatened by patent thickets. Tacit patent pooling is also relevant for the patent paradox in which companies invest in large patent portfolios, although the value of the individual patents does not show a positive return on investment. ${ }^{384}$ Injunctions also are another important influence on the concept of tacit patent pools. This aspect will be discussed in the next chapter.

\section{Privateers}

Firms in the ICT sector initiated a new business strategy by using PAEs as an instrument to possibly harm competitors. In the normal situation, major competitors in the technology market have created a situation of Mutually Assured Destruction on the basis of their patent portfolios. Both the ownership of SEPS and/ or a large portfolio of non-

\footnotetext{
${ }^{381}$ As a result of the US Court of Appeals for the Federal Circuit decision in Sandisk Corporation vs. STMicroelectronics Corp. NPEs first file an infringement claim and later try to negotiate a licence.

${ }^{382}$ At the time of writing, three defensive patent pools exist: RPX, Allied Security and Intellectual Ventures.

${ }^{383}$ For more background: Millien: Defensive Patent Pools: There are Surprisingly Few Options in IP watchdog.

${ }^{384}$ Hovenkamp: Tacit Patent Pooling.
} 
essential patents will make it very difficult to design around the competitors' patents. This often leads to cross-licensing and deters companies from costly litigation. However, firms may spin off their patent portfolio to a PAE, which is not vulnerable to counterattack since they do not produce goods. The principle of mutually assured destruction will no longer apply.

Whereas the original patent owner could not charge high royalty fees, the PAE may do so, which creates a double-dip effect. The double-dip means that the costs for rival companies are raised and that the PAE also generates revenues. Theoretically, it would also be a method to evade the FRAND promise, but case law in the EU and US has prevented this step in practice. ${ }^{385}$

Patent Assertion Entities can lead to pro-competitive effects since they create a market for small and medium-sized companies or university researchers that do not have the intention or financial means to commercialize their inventions. PAEs establish a new market for these types of inventions and also inform other parties of the technological progress. Similar to regular patent pools, PAEs may reduce the transaction costs but must meet the earlier-mentioned conditions of patent pools. These conditions are: non-restrictive membership, the application of FRAND licensing terms, only including essential patents, and open licensing strategies. This leads to the conclusion that it is difficult to draw a black and white conclusion on the legality of PAEs. Their contribution to innovation and competitiveness depends on the licensing practices of the PAEs. The PAE may create the problem of royalty stacking (Cournot problem) but, if the abovementioned conditions are met, could also form the solution to the problem. If the PAEs determines its royalty base on the lock-in effect of the technology and not on the ex ante value of the patent to the standard, this will lead to negative effects on innovation. The royalty stacking may also be related to unintended behaviour, since PAEs lead to further fragmentation of patent ownership, especially in the form of privateering. The real problem arises as soon as the PAE gives a FRAND promise and consequently waits for the standard to be established and a lock-in effect occurs. The licensee experiences high switching costs and is threatened by an injunction leading to a hold-up problem. The high switching costs enable the PAE to ask for very high (hold-up) royalty rates. It is difficult to litigate against the PAE since it has a large patent portfolio and, since it is non-practising, it cannot be attacked on the downstream markets. Both in 2011 and 2012 companies like Apple, Microsoft/Nokia and Ericsson started to sell off large parts of their patent portfolio to PAEs. ${ }^{386}$

One major advantage of privateering is that the manufacturing firm sells off their patents to a third company and therefore can no longer be directly sued but can use the third company to litigate with other companies.

\footnotetext{
${ }^{385}$ The EU demanded a promise from IPCom and in the USA there was the N-Data case. The splitting up of patent portfolios may lead to multiple monopoly rent (Cournot-effect) which was discussed earlier.

${ }^{386} 2011$ Apple created Digitude; Microsoft/Nokia transferred its patent to MOSAID; Ericsson spun off patents to Unwired Planet.
} 
The difference in business form between a defensive patent pool, tacit patent pool, Patent Assertion Entity, and privateers might be difficult to distinguish in practice. It is not the business form but the conduct that decides on the legality of the business operation.

This conduct may take different forms:

1. Inducement: creating an environment where companies want to invest in attractive licensing agreements, leading to a lock-in effect and consequently not following the raised expectations (promissory estoppel).

2. Ambush: waiting until the companies are locked-in to the technology, leading to a hold-up situation that creates high switching costs or opportunity costs leading to unfair dealings. ${ }^{387}$

The transferability of patents is a basic feature of IP. Like any other property right, it can be sold, licensed or transferred. This principle was already discussed in an earlier part on the functioning of technology markets in section 3.2. Since the patent is a right to exclude, PAEs may sue other companies, especially to stop freeriding. ${ }^{388}$ In disputes concerning SEPs, the FRAND promise is a sufficient tool to guarantee a fair treatment (e.g. the IPCom case). Although transferring patents to PAEs limits cross-licensing, this is not an obligation and, sometimes, two manufacturing firms may also not agree on cross-licensing. The emergence of these IP management forms is a sign that the IP ecosystem is changing and adapting to different needs for the monetization of patents. Collecting royalties by IP management firms is a normal function related to the IP portfolio. Although, in the present regulatory climate, PAEs have a bad reputation, a more careful weighing of the pro-competitive effects versus anti-competitive effects would be required. The increased action of PAEs has led to increased litigation and higher costs, but the limited case law does not justify the conclusion that PAEs only have negative effects on the competition in technology markets.

\section{Possible solutions}

Patent pools and defensive patent aggregators are an effective remedy against abusive behaviour by PAEs and privateers. Obviously, they have to use FRAND licensing terms, be open to new members and have no restrictive licensing strategies. In the US, an important improvement would be the introduction of the "losers pay the legal costs" principle since it will increase the costs of "strategic litigation". An important factor for the strategy of the trolls is the availability of injunctions. In the US, injunctions are discretionary and would be best served by applying the eBay principles. This case was discussed in section 3.13. In the EU, injunctions are rules in competition law and the

\footnotetext{
${ }^{387}$ See also Dolmans, Ilan: European Antitrust and Patent Acquisitions: Trolls in the Patent Thickets in Competition Law International, Vol.8 No.2 August 2012.

${ }^{388}$ Freeriding refers to the situation in which users of IP do not pay for their licenses.
} 
case law is in full development. The EU Commission might also take a closer look at privateering strategies that aim to raise the costs for competitors (of the original company that sold the patent portfolio). Restrictive licensing terms that harms competitors can be addressed under Article 101 TFEU, since its directly harms, distorts or hinders competition. Royalty stacking that occurs because of the patent disaggregation can be seen as a form of abuse of a dominant position and can be investigated under Article 102 TFEU.

The distinction between different forms of patent pools, PAEs and NPEs is difficult to analyze. The changing IP environment in technology markets leads to new innovative ways of monetizing patent portfolios. More important than the business form would be an evaluation of the actual business conduct in the market. There could be a thin line between a defensive patent pool, a pro-competitive PAE and a legitimate tacit patent pool. The new phenomenon of privateers in particular requires careful evaluation in the future.

Competition law does offer solutions to the royalty stacking of PAEs. Patent pools can be an effective remedy if they apply FRAND licensing terms. Injunctions are the basis of patent-troll behaviour. In order to understand the position of patent pools in this discussion, a better understanding of the discussions on FRAND and injunctions is necessary.

\section{Joint defence systems in patent pools}

The companies that are cooperating in the patent pool can further increase efficiency by handling their defences in a collaborative manner. Joint defence systems can appear in three different formats:

1. Different law firms, each representing individual defendants collaborate and consequently different law firms representing different defendants work together.

2. Some companies join together with one law firm.

3. The group of all defendants is represented by one single law firm.

Joint defence systems are often used by firms who are attacked by patent trolls or NonPractising Entities. Sharing the total costs among all or some of the defendants facilitates a court case against patent trolls. Patent trolls try to settle out of court to prevent the defendants from paying high legal costs. Obviously, joint defence systems do require some coordination between the participating firms.

According to some scholars, joint defence against claims of invalidity or patent scope hint at the existence of substitute patents within the patent pool. It can be stated that a joint defence by pool members is more efficient in the case of substitute patents, 
but there could be various reasons for a patent pool to adopt a joint defence system. ${ }^{389}$ Hovenkamp submits that a joint defence system can have pro-competitive effects. The shared, reduced legal costs lead to increased efficiency and possibly lower consumer prices.

Joint defence agreements within SSOs can, by nature, also have anti-competitive effects. By definition, a joint defence agreement necessitates that firms have a minimum level of coordination of their economic activities. Joint defence agreements sometimes preclude firms from making individual settlements outside the pool. The activities of the firms that are coordinating their joint defence is protected by the NoerrPennington rule, unless the firms jointly exercise settlement authority.

The Noerr-Pennington rule evolved from a series of cases before the US Supreme Court. According to this rule, two or more companies may petition the government to enact laws or to take other action without violating antitrust laws. ${ }^{390}$ A joint action in relation to sharing costs and exchanging case-relevant information should be tolerated. ${ }^{391}$ The Noerr immunity rule was applied in a standard-setting context. The crucial question is whether the relevant standard-setting conduct must be seen as the petitioning of government authorities or must be qualified as independent commercial business conduct. In the first scenario, the Noer immunity rule is applicable, while in the second case it is not applicable. ${ }^{392}$

A relatively new concept of a joint defence patent pool is the concept of Intellectual Ventures. The business model of Intellectual Ventures is not entirely transparent. The company claims it to be a new innovative business model, engaged in every step of the IP marketplace. Intellectual Ventures invests in IPRs, although it is not sufficiently clear whether they act as a patent troll or as a venture capital investor. The company has a joint defence system and an insurance scheme for its investors. ${ }^{393}$ The company is an example of the rapidly changing IP marketplace. At the time of writing, it is not the definition of the business model but more importantly the actual behaviour of the company that determines its pro- or anti-competitive effects.

\footnotetext{
${ }^{389}$ Choi presents an economic analysis concluding that, with the existence of a joint defense system in a pool, all patents must be challenged simultaneously in order to have the highest chance of success. Patent Pools and Cross-Licensing in the Shadow of Patent Litigation November 2003 University of Michigan CESifo 1070. It would be interesting to see an economic analysis of the effects of joint defence agreements on actual competition.

${ }^{390}$ The rationale of the Noerr doctrine is that the Bill of Rights takes precedence over the Sherman Act. See also FTC report Enforcement Perspectives on the Noerr-Pennington Doctrine FTC Staff Report 2006.

${ }^{391}$ See also Lemley in: IP and Antitrust: An Analysis of Antitrust Principles Applied to Intellectual Property law Volume 1 Aspen Publishers.

${ }^{392}$ ABA Handbook on the Antitrust Aspects of Standard Setting page $1592^{\text {nd }}$ edition.

393 Intellectual Ventures developed the idea of an "Invention Gap", which is the gap between the IPRs thatcompanies own and the IPRs that companies actually use.
} 


\subsection{CONCLUSIONS}

The general discussion on patent pools and their legality presents a blurred picture. The traditional view is that patent pools provide more efficiencies, reduce transactional costs and contribute to social welfare. Another aspect of patent pools is that they require coordinated actions by possible competitors. Price-fixing, reduction of aggregate outputs, foreclosure of markets and barriers to entry of the market will have a negative effect on competition. Since patent pools were first predominantly featured in the US, this jurisdiction remains the starting point for the legal discussion. This chapter shows that the legal analysis of patent pools is complicated.

It is generally accepted that patent pools containing complementary patents contribute to consumer welfare, whereas the inclusion of patents that are substitutes hinders competitiveness and has a negative impact on social welfare. To structure the analysis, four questions were answered.

Question A- What is the exact relationship of the patents in the pool to each other? Are they substitutes or complements? Obviously there is no simple answer to this question. Competition authorities used definitions linked to technical necessity but also to the absence of economically viable alternatives to define the essentiality of the patent. The use of independent experts may facilitate this discussion. Essentiality is closely linked to the substitute character of the technology. It is important that the classification of a patent as essential is also a proxy for determining the value of the patent. Competition authorities are divided on the definition of essentiality and on the legality of including non-essential patents in the pool. The emergence of patent pools with large patent portfolios increases the risk of including non-essential patents.

Question B- What sort of relationship do the participating companies in the pool have to each other? Are they active on downstream markets or are they vertically integrated firms? Patent pools are growing in size. Companies must first decide whether to join the patent pool and consequently whether the patent pool should be part of a standard. Research shows the emergence of a new "Pool of pools" concept that is linked to the complexity of modern technology markets. These pools have high negotiating costs and can bear some antitrust risks. When firms are active on downstream markets, the incentive to join a patent pool can be decreased. Antitrust regulators should pay more attention to the licensing practices in the patent pool. The royalty sharing rules of the pool are very important. Economic evidence hints at rent-seeking strategic behaviour inside patent pools. This could mean that patent pools contribute to the patent thicket and increase transaction costs. Authorities should therefore investigate the effect of the royalty-sharing agreements on competition and indirectly on innovation (e.g. R\&D investments).

Question C- Is the technology embedded in the pool exclusively available through the pooling agreement? Are individual licences available? Are there elements of a tying agreement? Competition authorities have not yet developed a coherent instrument to 
analyze the market power of patent pools. Pools nearly always offer their patents as a bundle. This has consequences for the definition of market power. Tying requires market power. Patent pools can facilitate tying agreements. Tying appears when the licensee can only obtain a specific patent when he also accepts the rest of the bundle of patents. If the patent pool uses exclusive licences, this leads to the obstruction of competition.

Question D- Does the patent pool agreement have a positive or a negative impact on the licensee's potential to innovate? Patent pools must be carefully analyzed to evaluate their effects on innovation. Competition authorities should investigate the number and timing of patent declarations in the establishment of a new patent pool. The recent emergence of new business forms in the standards and patents field has complicated the discussion. The changing technology markets initiated new innovative ways to monetize patents. The distinction between Non-Practising Entities, patent assertion entities, patent trolls, and patent pools is not always evident. Not the business form but the actual market behaviour should lead the enforcement agenda of competition authorities. Again this discussion shows the centrality of FRAND as part of the solution.

\section{Patent Pool can a have pro-competitive or negative impact on competition}

4 questions: 1 . Relationship and

classification of patents in the patent pool

2. Participation in the patent pool and the relevant technology market

3. Licensing in the patent pool

4. Does the patent pool contribute to the ability of the licensee to innovate? 



\section{CHAPTER 6}

Patent pools in the US 



\subsection{HISTORICAL OVERVIEW OF THE DEVELOPMENT OF PATENT POOLS IN THE US}

The antitrust analysis of patent pools concentrates on the horizontal elements of the cooperation between the pool members and the vertical restrictions that apply to licensees.

In the United States, the Federal Trade Commission and the Department of Justice traditionally held the view that patent pools and package licences resulted in anticompetitive effects and, in the 1960s and 1970s, pools were listed in the "Nine NoNo's". Historically, the US antitrust authorities, in the landmark case Standard Oil Co. Vs United States, ${ }^{394}$ introduced the notion that, in a patent pool, patents should be available to everyone "on reasonable terms", thereby "such interchange may promote rather than restrain competition."

The reasonable terms did not directly influence the royalty rate, since this was still seen as a privilege deriving from the nature of the patent right. The Standard Oil judgment highlighted the positive and pro-competitive effects of a patent pool agreement. Most of the patents in the Standard Oil cases were continued developments after the first basic patent. The Court established the fact that the basic patent could block the further developed technology but not vice versa. In this way, the basic patent right was one-way blocking. In the case of two-way blocking patents, the costs for the consumer can increase considerably. The two-way blocking patents have a negative effect on both upstream and downstream markets and seriously hinder onward innovation. Companies cannot implement follow-on innovation and a static situation arises. Later I will describe the "grant-back" provisions that enable the further development of patented technology. In the recently adopted version of the TTBER, the EU Commission pays considerable attention to grant-back clauses. See for further discussion section 6.4.2.

When each licensee acts independently, the total sum of royalties will easily surpass the total cost of a package licence deal from a patent pool. From an economic and social welfare perspective, it makes sense to integrate two-way blocking patents in a patent pool agreement. ${ }^{395}$

In the 1970s, the Department of Justice took a very strict approach towards patent licensing in general. With the introduction of the Nine No-No's, the DoJ moved towards a policy that viewed many patent licensing practices as a per se violation of the antitrust rules. In the system of per se violations, the business conduct always constitutes an infringement of competition law, cannot be excused and will automatically be declared illegal.

\footnotetext{
${ }^{394}$ Standard Oil Co. of New Jersey v. United States 283 US 163 (1931).

${ }^{395}$ See also Lerner and Tirole "Efficient Patent Pools". This also sometimes referred to as the Double Monopoly-problem.
} 


\subsection{THE NINE NO-NO'S}

The Nine No-No's are the following:

1. Requiring a licensee to purchase unpatented materials from the licensor (tying).

2. Requiring a licensee to assign to the licensor patents issued to the licensee after the licensing arrangement is executed.

3. Restricting a purchaser of a patented product in the resale of that product.

4. Restricting a licensee's freedom to deal in products or services outside the scope of the patent.

5. Agreeing with a licensee that the licensor will not, without the licensee's consent, grant further licences to any other person.

6. Requiring that the licensee accept a package licence.

7. Requiring royalties not reasonably related to the licensee's sales of products covered by the patent.

8. Restricting the licensee's sales of goods made with the licensed patented process.

9. Requiring a licensee to adhere to specified or minimum prices in the sale of the licensed products. ${ }^{396}$

The anti-competitive effects of patent pools can include price-fixing. In United States $v$. Line Materials Co., the court considered that the possible danger of price-fixing outweighted the lifting of blocking patents by the pool. ${ }^{397}$ In the early case law, courts also used imposed minimum prices for downstream products as a reason to object to patent pools.

\subsection{US CASE LAW: MOVE FROM PER SE APPROACH TO RULE OF REASON}

In 1986, the Court of Appeals for the Federal Circuit clarified the doctrine of patent misuse in the case Windsurfing International, Inc $v$. AMF, Inc. ${ }^{398}$ In the analysis, the court left the per se approach and introduced a rule of reason approach (based on economic analysis), explaining that the patentee must have broadened the physical or

\footnotetext{
${ }^{396}$ See also Homiller Patent Misuse in Patent Pool Licensing: From National Harrow to the Nine No-No's to Not Likely Duke Law and Technology Review No.7 2006.

${ }^{397}$ United States v. Line Material Co. 33 U.S. 287 (1948) ABA Handbook on Antitrust Elements of Standard Setting page 132.

398782 F.2d 995 (Fed. Circ 1986).
} 
temporal scope of the patent right with the anti-competitive effect. ${ }^{399}$ The rule of reason approach finds its roots in the assumption of the Chicago School that, in principle, markets function effectively and that pro-competitive business behaviour should be supported and not discouraged. ${ }^{400}$

The rule of reason approach led to the following conclusions:

- The combination of complementary patents in a patent pool has a procompetitive effect. ${ }^{401}$

- Substitute patents are not, by definition, anti-competitive but should be evaluated on a case-by-case basis.

- The FTC and DoJ, in their rule of reason approach, will not generally evaluate the reasonableness of the royalties as formulated by the administration of the patent pool. The enforcement agencies monitor the formation and administration of the patent pool.

\subsection{THE 1995 IP GUIDELINES}

In 1995, the Department of Justice issued new Guidelines for the Licensing of Intellectual Property (hereafter referred to as the "1995 Guidelines") underlining the positive effects of patent pools. One of the positive effects of a patent pool agreement is the fact that blocking patents can no longer be effectively used by firms intending to frustrate the system. A blocking patent stops firms from using new technology, since a second patent cannot be used without the original blocking patent. Patent pools promote the dissemination of new technology automatically giving access to both patents, thereby clearing the blocking effect of the original patent. ${ }^{402}$ On the same page, the DoJ and FTC acknowledge that patent pools integrate complementary technologies, which is very important for standard setting and thus competitiveness. Firms participating in patent pools also share technological information, which otherwise would be part of trade secrets. Some scholars argue that patent pools can even forestall government policy, since it is better to initiate a patent pool than to be forced into compulsory licences. $^{403}$

\footnotetext{
${ }^{399}$ In 1998 Congress enacted the Patent Misuse Reform Act, in which it is required that actual market power on the relevant market by the patentee is shown by the firms using the doctrine of patent misuse (the infringers of the patent right).

${ }^{400}$ See also J. Drexl in Competition Policy and the Economic Approach page 322.

${ }^{401}$ The FTC report, Antitrust Enforcement and Intellectual Property Rights: Promoting Innovation and Competition states: "may have the pro-competitive effect of lowering the total royalty rate to licensees, thereby lowering the final product cost to consumers."

4021995 FTC Antitrust Guidelines for the Licensing of Intellectual Property Guidelines page 28.

${ }^{403}$ Verbeure et al Patent Pools and Diagnostic Testing Trends in Biotechnology page 116.
} 
As mentioned above, patent pools bear the risk of foreclosing markets and restricting competition as a result of the coordinated efforts of managing the patent pool. In the 1995 Guidelines, the DoJ, together with the FTC, started to outline its new economic analysis of the legality of patent pools under US antitrust laws. The following practices were identified as anti-competitive:

- Collective price or output restraints, if they do not contribute to an efficiencyenhancing integration of economic activity among participants.

- Limiting or excluding access to the technology incorporated in the patent pool (again it must be shown that the firms operating in the patent pool have substantial market power and prevent other firms from competing).

- When a patent pool is a disguise for naked price-fixing or market division, the per se rule will become applicable.

- When the actual effect of the patent pool (including horizontal competitors) is to diminish the level of competition in the relevant market.

- When a patent pool agreement has provisions requiring newly developed technology to be licensed to other pool members at minimal costs. This provision hinders the return of investment and discourages firms from making new investments in innovation processes.

- Group boycotts and resale price maintenance provisions in the patent pool agreement.

Balto summarizes that the most important pro-competitive elements of a patent pool under the Antitrust IP Guidelines should:

- Integrate complementary technologies.

- Lead to a reduction of the transaction costs.

- Clear any blocking patents that would render the pool less efficient.

- Reduce the need for litigation relating to licensing.

- Promote further dissemination of the technology covered by the pool. ${ }^{404}$

\subsection{THE SYSTEM OF BUSINESS REVIEW LETTERS (BRLS)}

In order to create more certainty, the Antitrust Division of the Department of Justice has used its Business Review Letters (BRL) as an instrument of clarification to give as-

\footnotetext{
${ }^{404}$ Balto (2013). Barriers to Competition on the Innovation Superhighway: How the Lack of Antitrust Scrutiny of Patent Pools Deters Competition.
} 
surance to individual patent pool arrangements. The BRL gives firms certainty about the legality of initiating a patent pool agreement under the US antitrust laws. This system provides firms with the opportunity to receive guidance from the Department of Justice in relation to the scope, interpretation and application of antitrust rules relating to a patent pool. The instrument of Business Review Letter is most often requested in two fields, joint ventures and with regard to the exchange of business information. The latter clearly refers to patent pools since (horizontal) competitors often not only exchange information but also coordinate their economic activities within the management of a patent pool.

The instrument of the BRLs has recently received some criticism. Balto mentions the following limitations of the BRL system:

- Their prospective character.

- The decision is based on the information as provided by the application, although technology markets develop rapidly.

- Enforcement agencies must make a decision based on limited predictive powers.

- The continuous developments in technology markets call for a more modern form of supervision. ${ }^{405}$

The recent criticism of the system of BRLs touches upon the discussion of whether the relatively delayed supervision of patent pools is still appropriate for modern technology markets. A more proactive approach would allow the enforcement agencies to monitor the functioning of the pool after its formation more closely.

The Department of Justice has issued a number of BRLs dealing directly with the protection of intellectual property rights within the context of standard setting. On 26 June 1997, Business Review Letter 98-C evaluated the package licence agreement of essential patents for the MPEG-2 standard. MPEG is a standard used for digital video compression. Nine companies held patents that were considered to be essential for the MPEG-2 standard. These companies wanted to commercialize their patent rights via an independent jointly-owned agent (MPEG LA) that would offer the essential patents of the aforementioned nine companies in a package deal. In December 1998 and in June 1999, similar business review letters were issued in relation to a DVD standard. ${ }^{406}$ In both cases, the DoJ took a very positive approach towards the patent pools, mainly because of the following contractual provisions therein:

1. The patent portfolio was limited to essential patents, which, because of their nature, do not compete with each other.

\footnotetext{
${ }^{405}$ Balto (2013) Barriers to Competition on the Innovation Superhighway: How the Lack of Antitrust Scrutiny of Patent Pools Deters Competition.

${ }^{406}$ See US Department of Justice, Antitrust Division, Business Review Letter, 16December 1998 and 10 June 1999.
} 
2. The essential patents can be licensed both collectively and individually.

3. The firms in the patent pool agreed to issue world-wide non-exclusive licences.

4. The royalties for the patents were directly related to the use by the licensee.

5. The licensees were not restricted by the licensors in the patent pool to develop or create alternative technologies.

6. Licensees were required to grant back non-discriminatory, non-exclusive licences in order to use essential patents.

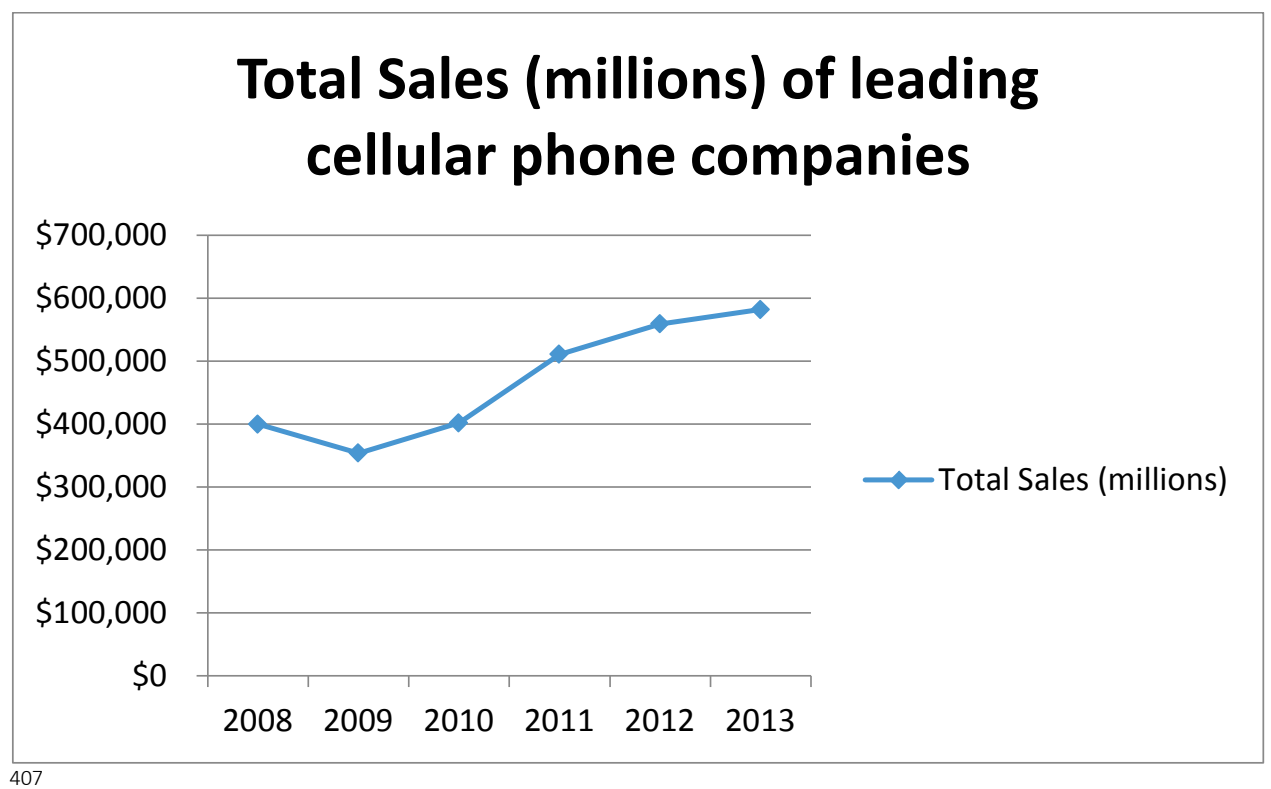

${ }^{407}$ Based on figures of Malinson, licensing mobile technology will become even more essential. 


\section{Total R\&D (millions) leading cellular phone companies}

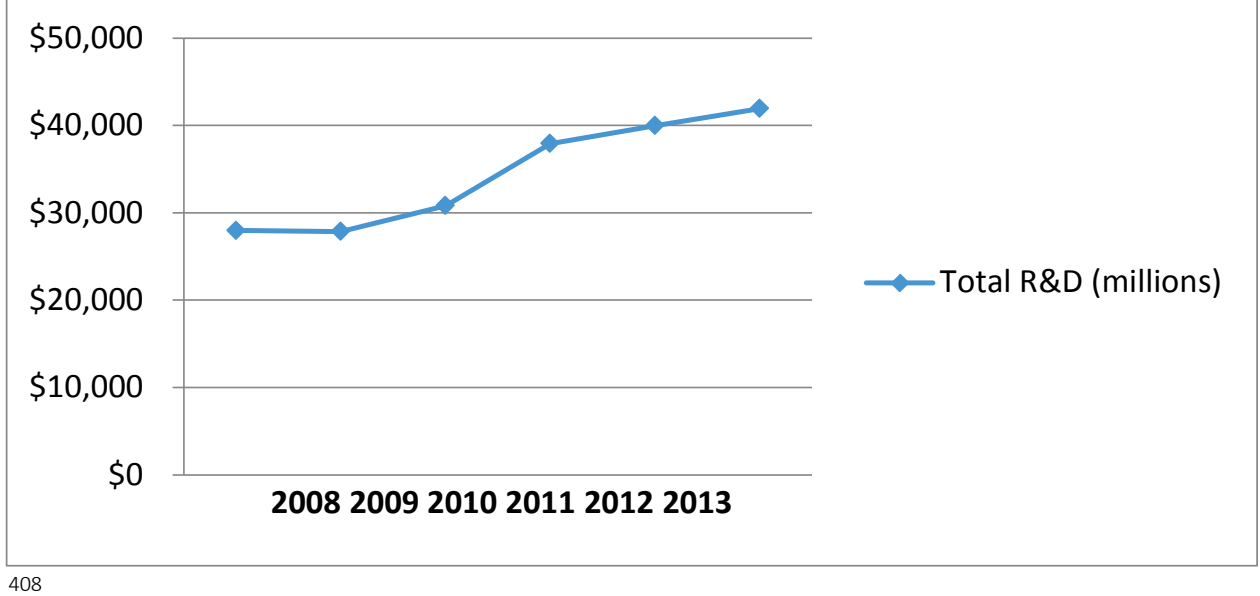

6.6 THE BUSINESS REVIEW LETTER OF THE 3G PLATFORM PATENT POOL AND CURRENT INVESTIGATIONS: MPEG LA; THE H.246 PATENT POOL, RFID BRL, IPXI BRL

In November 2002, the DoJ issued a BRL for the 3G Platform patent pool. The DoJ considered the following elements in its evaluation of the pooling arrangement:

- $\quad$ the separation of licensing functions

- a large class of potential owners of essential patents

- whether it does not prevent competition for differing, substitutable 36 technologies

- $\quad$ whether the grant-back provision is limited to essential patents. ${ }^{409}$

MPEG LA H.246 patent pool

The H.246 patent pool concentrated patents for the high-definition video encoding standard (video compressing technology) and consists of more than 1,700 patents. In March 2011, the DoJ initiated an investigation into whether the actions of MPEG LA were hindering the development of the rival VP8 standard developed by Google. The

\footnotetext{
408 Ibid.

${ }^{409}$ Business Review Letter3G Patent Platform Partnership.
} 
VP8 standard is based on patent-free technology and is an example of open-source technology development. Google decided to bring the VP8 standard to the market through royalty-free open licensing. As a reaction, MPEG LA asked their members whether they held essential patents that were also used in the VP8 standard. Consequently, MPEG LA claimed that some of the VP8 technology infringed essential patents which were held by their members. The DoJ has not made the status of their investigation public, but it seems that MPEG LA has developed a strategy of suppressing rival standards by questioning the legality of the open-source and royalty-free licences. This strategy (from one of the major patent pools in the world) can hinder the development of open-source technology by simply creating uncertainty in relation to the legality of the VP8 standard. Open-source innovators do not have strong patent portfolios or the financial means to engage in lengthy litigation. Again, the question must be raised whether all 1,700 patents in the $\mathrm{H} .246$ pool are essential and valid. The undermining of competing technology will definitely limit the pro-competitive aspects of a patent pool.

\section{The RFID consortium patent pool}

In October 2008, the DoJ issued a BRL on the patent pool of the RFID consortium. The RFID patent pool comprises patents that are necessary for the implementation of a standard for radio-frequency ID labels and readers (automatic identification and data capture technology). The patent pool would only consist of essential patents. ${ }^{410}$ In its analysis, the DoJ mentioned the following elements: the pool limited the risks of holdup and royalty stacking and actually reduced transaction costs for licensees. The pooling agreements contained important safeguards: an independent expert certifies the essentiality of the patents, a system whereby invalid, non-essential or non-enforceable patents are removed from the pool and licensing on a non-discriminatory basis. Further positive elements include: allocation of royalties is related to the number of patents in the pool and grant-backs are limited to essential patents, which make the DoJ conclude that they will not take any antitrust action against the RFID-patent pool. ${ }^{411}$

\section{The IXPI BRL}

On 26 March 2013, the DoJ issued a negative BRL regarding the IXPI-pool. IXPI is a company that specializes in the exchange and trading of intellectual property rights. The main aim of the IXPI exchange is to provide more transparency and efficiency to IPR licensing. The trading on the IXPI exchange is based on a Unit License Right (URL). According to IXPI, the unit license right is: "a non-exclusive license right that is priced by

\footnotetext{
${ }^{410}$ Business Review Letter to RFID Consortium LLC. The criterion of essentiality was defined as follows: "necessarily infringed or as to which a license is necessary as a practical matter because there are no economically viable substitutes to [m]ake, use or sell RFID products in compliance with the Gen-2 standard." (RFID) Participant Agreement, supra note 11, §1.1; see id. §§ 3.1-3.2.

${ }^{411}$ Ibid note 410 .
} 
the market and sold on a non-discriminatory, standardized technology unit basis". IXPI wanted to become the main marketplace for trade in licensing. ${ }^{412}$ The IXPI was founded with input from corporate, business and university IP owners. The DoJ did acknowledge some of the benefits of the IXPI exchange. Increased licensing efficiency can lead to downstream users experiencing efficiencies because of the lack of costly negotiations. Price-transparency is another important consequence and the DoJ specifically refers to FRAND licensing. Consequently, the pooling element was recognized as being efficient. $^{413}$

However, the DoJ also concluded that: "The Department has greater confidence assessing the competitive effects of patent pools when patent holders contribute only complementary patents because "[c]ombin[ing] complementary factors of production... is generally procompetitive." The pool may have the pro-competitive effect of reducing the total royalty rate to licensees, thereby reducing the final product cost to consumers. In contrast, a pool that includes substitute (i.e., competing) patents may be able to raise royalty fees and "[can] raise competitive concerns" by reducing competition among the patented technologies. It may, however, be reasonable to include substitute patents in a pool if, for example, the inclusion of substitute patents does not enhance market power or if the pool creates significant efficiencies that outweigh the risks of competitive harm.

The DoJ also commented that the IXPI could exclude or limit the independent licensing of IPRs outside the pooling agreement. This would have a negative consequence on competition on the technology market. Another problem arises when the traded IPR is part of a standard. In the IXPI mechanism, this would mean that the IPR cannot be traded outside the IPXI framework, which would have a negative effect on competition and indirectly on innovation. Finally the DoJ wants more guarantees that the IXPI will not facilitate the sharing of competitively sensitive information. ${ }^{414}$

The DoJ does not often elaborate on the elements that render patent pools illegal. The IXPI concept has efficiencies that are not outweighed by the negative drawbacks. The DoJ found it especially difficult to allow a revolutionary new licensing model that could have a strong impact on rapidly changing technology markets.

The example of the IXPI BRL shows that a new patent pool must carefully consider the positive and negative effects on the technology market. Technology markets and their proper functioning are important for social welfare. New ideas that are not yet

\footnotetext{
${ }^{412}$ For more information see the IXPI website: https://www.ipxi.com/

${ }^{413}$ The Business Review Letter states: that it "will aggregate patents from multiple patent holders in a variety of industries. IPXI's platform for pooled ULRs has the potential to generate additional efficiencies by reducing the time and expense of acquiring and disseminating all the pooled patents to potential licensees, reducing the amount of stacked royalties, ${ }^{(34)}$ clearing blocking positions, ${ }^{(35)}$ and integrating technologies that are necessary to practice an industry standard or a field of use."

Response To Intellectual Property Exchange International, Inc.'s Request For Business Review Letter.

414 Ibid note 413
} 
proven and can provide unexpected effects are not in the interests of antitrust enforcers and the fast-moving technology markets are strategically too important to experiment on.

\subsection{CASE LAW}

The 1995 IP Guidelines and the competitive relationship between patents MPEG2 versus SUMMIT/VISX

In 1995, the Department of Justice, together with the Federal Trade Commission, issued new Guidelines on the Licensing of Intellectual Property Rights and the MPEG-2 Business Review Letter; both put emphasis on the essentiality of the patents in the pool:

"The limitation of the Portfolio to technically essential patents... reduces the risk that the Portfolio will be used to eliminate rivalry between potentially competing technologies." 415

The MPEG-2 patent pool contained a package licence but each patent within the pool was also available on individual terms from the firms participating in the pooling agreement. The MPEG-2 BRL does not elaborate on the meaning of "essentiality" but some scholars, such as Homiller, use part of the letter to equate essential patents to blocking patents, ${ }^{416}$ although this might be a very broad interpretation.

The MPEG-2 pool is often regarded as the perfect example of a patent pool approved both by the DoJ and the FTC. In its structural framework, this pool is very similar to the BMI case (Broadcast Music, Inc. v. Columbia Broadcasting System) in which a blanket licence was used to license broadcasting rights. ${ }^{417}$ In the BMI case the court already recognized that "the blanket license was already developed out of the necessity of the marketplace." 418

The pro-competitive elements of the MPEG-2 pool were easy to identify: the combination of 27 patents, at one common set price, which reduced transaction costs and thereby promoted the dissemination of new technology based upon the MPEG-2 standard. More specifically, the hindering or limiting of competition by the patent pool was prevented by several specific measures, such as the fact that licensing agents were specifically prohibited from transmitting "competitively sensitive information among the Licensors or other licensees". In this case, the royalty rates contributed only a small

\footnotetext{
${ }^{415}$ MPEG Business Review Letter.

${ }^{416}$ Homiller gives the following interpretation:

"the prospective licensee is being compelled to accept no more than he would, in any event, have to obtain in order to make worthwhile a license under any of the patents", which means in his view essentiality is very similar to blocking, a reasoning that is supported by the 1995 IP Guidelines.

${ }^{417}$ Broadcast Music, Inc. v. Columbia Broadcasting System, 441 US 1 (1979).

${ }^{418}$ Broadcast Music, Inc. v. Columbia Broadcasting System, 441 U.S. at 20.
} 
part to the price of the MPEG-2 product, so the actual negative effect on competition could be ignored.

The SUMMIT/VISX Pool is at the other end of the scale. In this patent pool, technology related to laser machines used for refractive eye surgery was combined in the socalled PPP-pool (Pillar Point Partnership), and consequently PPP licensed back all the patents to the two original firms that had established the patent pool. Third-party licences could only be obtained from the original founding firms. During the existence of the patent pool, no patent rights were licensed to third-party firms in the laser industry.

In March 1998, the FTC started a case against the SUMMIT/VISX pool on grounds of price-fixing and, more importantly, the exclusion of competitors from the relevant market of laser machine manufacturing. In the analysis, the FTC noted that SUMMIT/VISX had pooled complementary and competing patents together in the pool. Since there was no evidence of blocking patents, the result was that the pool held all the patents essential for the US market for laser refractive surgery machines. In the comparison of the cases it becomes evident that both the Supreme Court and the FTC carefully monitored the scope of the patents in both pooling agreements, although with a different end result.

In the case of the MPEG-2 pool, some scholars make the point that the strategic considerations differ from the SUMMIT/VISX pool. ${ }^{419}$ The MPEG-2 pool was an attempt by the participating firms to set a standard for the market of video compression, benefiting from the apparent network externalities and ultimately making profits from the sales volumes of the MPEG-2 based hardware. In the context of the standardization attempt, the participating firms wanted to persuade companies to adopt the MPEG-2 standard with the following elements:

- a relatively low royalty rate

- the exclusive inclusion of essential patents in the pool ${ }^{420}$

- granting access to all interested parties (which both guarantees the maximum benefit of network externalities, as well as the approval of the FTC).

The SUMMIT/VISX pool was based on a very innovative technology, characterized by high investments in R\&D by small firms just starting in the market, contrary to the wellestablished firms in the MPEG-2 case. The invalidity of the patents would have ruined the business strategy, which concentrated on lower costs for the laser refractive surgery machines but higher revenues from the per-procedure fees for the use of the laser surgery devices. The SUMMIT/VISX patent pool was dissolved after the complaints were discussed with the FTC. The SUMMIT/VISX patent pool tried to conspire to fix prices and create a monopoly.

\footnotetext{
${ }^{419}$ See also Newberg, Antitrust, Patent Pools and the Management of Uncertainty page 28.

${ }^{420}$ As certified by the independent expert review mechanism, which will be discussed later.
} 
The patent pool agreement avoided the risks of costly and possibly lethal litigation. As soon as the laser surgery machines of other competitors received FDA approval, the SUMMIT/VISX pool might have adopted a more positive attitude towards third-party licensing. In order to understand the competitive effects of patent pools correctly, courts have to utilize technology market analysis and evaluate the relationship between the different patents in the pooling agreement. For a full assessment of the competitive impact of the patent pool, participating firms could provide more transparency of their business strategy, thereby motivating some of the strategic choices made in the management of the patent pool.

\section{U.S. Philips Corp. v. International Trade Commission}

In the U.S. Philips Corp. v. International Trade Commission case (the details have been discussed above, chapter 3 , in relation to patent misuse), the package deal clearly also included non-essential patents. The Federal Circuit Court made some interesting observations while disagreeing with the International Trade Commission:

1. The Federal Circuit Court did not qualify mandatory licensing as a misuse per se but decided to apply the rule of reason.

2. The Federal Circuit Court distinguished tying between patents from tying arrangements between patents and products. ${ }^{421}$

3. The Federal Circuit Court made the point that parties did not have to use nonessential patents and that it was not sufficiently clear that the royalty fees were also directly based upon the non-essential patents.

4. There was inadequate proof that commercially viable alternatives existed for the non-essential patents and that such competitive technologies was actually foreclosed for licensees.

5. There was no proof that the non-essential patents were included in the price, so they were basically free of charge and did not influence the licensees.

6. The Philips package deal also contained non-essential patents, but, according to the Federal Circuit Court, Philips could have charged identical royalty fees for a package that only contained essential patents. See the following quote:

"... would have the perverse effect of potentially putting a party owning both an essential patent and a nonessential but related patent in a worse position than a party

\footnotetext{
${ }^{421}$ In the case of tying patents, misuse can be analyzed per se or under a rule of reason approach: Virginia Panel (1997). Under the rule of reason it can be qualified as misuse when it would lead to restraints on a specific market Monsanto v MacFarling (2004) "safe harbor" on tying issue applies to conditioning patent license on another patent license or on purchase of product unless the patent owner "has market power for the patent or patented product on which the license or sale is conditioned."
} 
owning only the essential patent. The party owning only the essential patent would be free to charge any licensing fee up to the maximum that a manufacturer would be willing to pay to practice the patented technology, while a party owning both the essential patent and a nonessential patent would be barred from extracting that maximum licensing fee for its essential patent and assuring the manufacturer that it would not be subject to suit on the nonessential patent." 422

This comment by the Federal Circuit was met with considerable debate and criticism, mainly related to the economic analysis that was actually used by the Federal Circuit Court. The comment seems to imply that a patent pool holding both essential and both non-essential patents would be in an equal position to a patent pool purely consisting of essential patents. The Court follows the reasoning that a licensor can base his maximum royalty rate solely on the essential patents, since the licensee is willing to pay, given the blocking nature of these patent rights. Again, this reasoning would strongly support the view that "blocking" and "essential" have an identical meaning in this context. In reality, the difficulty might be to distinguish the non-essential patent from the essential patent and to evaluate the commercial value of the non-essential patent. Economic literature showed that the value, the scope and the nature of a patent during the standardization process can change.

Earlier, the relevance of the correct timing of the formulation of the standard was discussed. The exact timing of this formulation can have serious implications for the ex ante licensing terms but also for the scope and the nature (essential versus. nonessential) of the patent in the portfolio.

With the Philips judgment, a new era began in which the per se violation of patent misuse in a patent pool (unless very obvious and clear from the Guidelines of the DoJ and the FTC, e.g. extending the scope of the patent right) was replaced by courts applying a rule of reason approach, giving the firms united in a patent pool agreement considerably more room to exploit their patents to the maximum and to plan their business tactics.

Patentees wishing to use the patent misuse defence in a patent pool setting must show evidence of the actual violation to competition in the relevant market; a rather theoretical assumption that competition may have been distorted no longer suffices.

A second conclusion derived from the Philips judgment is that the US courts no longer painstakingly condemn the accidental or incidental inclusion of non-essential patents in the pool. Given the rapid pace of technological progress, in combination with globalized production networks, it is almost impossible to qualify patents as completely non-essential, since the meaning and application of a patent within a standardization process can be altered rapidly because of new technological insights and developments. In a case where a defendant can show that there were alternative technological solutions for the non-essential patents within the patent pool and that licensors were not

${ }^{422}$ U.S. PHILIPS CORP. v. International Trade Commission 424 F.3d at 1192. 
prepared to consider these possible alternatives (thereby deterring the application of the alternative technologies by the licensees), courts still may agree with a claim of patent misuse. $^{423}$

From an economic perspective, the most important issue within the antitrust evaluation of a patent pool is the relationship between the patents within the pool. This economic relationship can have various forms: blocking, complementary, competing, unrelated, essential, and unessential. The traditional concern of antitrust authorities is the impact that patent pools have on allocative efficiency. The patent right is used to exclude other parties, so that the sharing of patents in a pool is basically a mutual agreement between patent owners to waive their exclusive patent rights. ${ }^{424}$ The major interest in the protection of dynamic efficiency means that antitrust authorities need to examine the economic relationship between the pooled patents and their impact carefully.

The practical problem regarding this assessment is that the economic relationship between the patents in the pool can have combined characteristics. The relationship can both be complementary and horizontal or competing and vertical. I have already indicated the challenging character of the task to distinguish essential and non-essential patents. The application of the rule of reason analysis enables the US courts to investigate all relevant factors to establish the effect that the pool has on competition. More specifically, the courts will evaluate the effect of the pooling agreement on the technology market (e.g. market power within the relevant market). Applied to the context of dynamic efficiency, this would prompt the authorities to look at the effect that the pool has on innovation incentives. ${ }^{425}$

In the case United States v. Line Materials Co., ${ }^{426}$ the Supreme Court reviewed a cross-licensing agreement between two manufacturers of electric products. In this case, the patents were valid and blocking so the pooling agreement made further innovations technically possible and increased social welfare. The Supreme Court condemned the arrangement as a per se violation, but, in the context of dynamic efficiency, this raises the point of the double marginalization problem, meaning that the costs of having two separate monopolists is considerably higher than the cost of a single combined monopolist. Under the rule of reason approach of Philips, the decision in Line Materials would have been different, evaluating the pro-competitive effects of the agreement.

Analyzing the stance of the US antitrust authorities on patent pools, history shows that, initially, patent pools were regarded as per se violations of competition, but this gradually developed into a rule of reason approach. Within this rule of reason approach, the essentiality test seems to be a prominent feature. Generally, many scholars hold the view that the inclusion of essential patents in the pool has pro-competitive effects,

\footnotetext{
${ }^{423}$ See article Homillier section 40.

${ }^{424}$ Andewelt, Analysis of Patent Pools Under the Antitrust Laws.

${ }^{425}$ See also Newberg, Antitrust, Patent Pools and the Management of Uncertainty page 14.

${ }^{426}$ United States v. Line Material Co.333 US 287 (1948).
} 
whereas the existence of non-essential patents in the pool might indicate a possible violation of competition rules. The Philips judgment seems to suggest that the economic relationship between the patents in the pooling agreement is a decisive factor for the effect that the pool has on dynamic efficiency.

The Philips judgment justifies a closer look at the classification of patents in the patent pool. The discussion mainly concerns the essentiality criterion.

\subsection{CONCLUSIONS}

\section{Patent pools as a solution to the problem of patent thickets}

The problems of royalty stacking and patent thickets are addressed by solutions in the form of cross-licensing, changes in patent law or patent pools. This study looks at patent pools in more detail.

Patent pools pose a unique dilemma for competition authorities. Depending on the management and licensing practices, patent pools may have a distinctive positive or negative impact on innovation.

SSOs take a defensive stance on the issue of patent pools and their joint discussions on royalty rates and royalty-sharing systems. The FTC and the DoJ seem to take a more liberal and progressive stance on these discussions and patent pools in general. In her speech "Recognizing the pro-competitive potential of royalty discussions in standard setting" on 23 September 2005, Deborah P. Majoras, Chairman of the FTC, said that: "Joint ex ante royalty discussions do not warrant per se condemnation". . 427

Applying the rule of reason approach to the future royalty discussions, and to the approval of patent pools in general, can easily be justified on the basis of recent economic research. ${ }^{428}$

The DoJ and FTC have developed a framework through their IP Guidelines and BRLs that clearly supports the pro-competitive benefits of patent pools (in a standard-setting context). The US enforcement agencies will first evaluate the impact that the patent pool agreement has on the technology market, which means that the agencies will determine whether the patent pool has included substitute technologies in their pool.

The difficult discussion on complements, essential and substitute patents will be handled by an independent expert. The real independence of the expert is not always sufficiently clear. The management and administration of the pool can be the responsibility of an independent third licensor or a licensor appointed by the firms operating in the patent pool. The US agencies do not seem to care much about this choice. Given the fact that pool members are often vertically integrated firms, the effect on downstream markets should raise the concern of the antitrust authorities.

\footnotetext{
${ }^{427}$ http://ip-updates.blogspot.com/2005/09/ftc-chairman-addresses-patentee-hold.html

${ }^{428}$ See also Leveque Standards and Patent Pools November 2008 lecture in Zurich.
} 


\section{Lessons to be learned}

The interpretation of the Philips decision (the inclusion of non-essential patents is not patent misuse) led to intense debate. The exact effect of the decision remains unclear and the application of patent misuse to patent pools should be further clarified. The bundling of essential and non-essential patents in a pool still requires very careful consideration.

Patent pools often have a prominent market position. The present smart-phone wars show that the financial stakes in the telecommunications market are extremely high. Stepping outside the regulatory antitrust boundaries can be very profitable for patent pools, thus justifying a constant oversight of the pool's activities by the FTC and DoJ. The MPEG LA pool has been the subject of strong criticism for failing to use independent experts continuously and claims that their ventures into different business activities might not meet the original approval of the BRL. ${ }^{429}$ The US agencies take a much more liberal stance on the level of the royalty charge than the EU Commission, reflecting their choice for the economic-based approach and the influence of market forces.

New innovative solutions to some of the structural problems in the market (i.e. patent thickets), such as defensive patent pools and tacit patent pooling, provide interesting alternatives for the future. The DoJ explained its view on the legality of some of the aspects of patent pools in recent BRLs. The RFID decision was clear cut and provided transparency. The inclusion of only essential patents in the pool and more importantly a wide range of safeguards within the pooling arrangement convinced the DoJ. On the other hand, it became clear in the latest decision in the IPXI-case that the DoJ is unwilling to give new business models a positive clearance without sufficient safeguards. It is also evidence of the fact that US authorities are concerned with the proper functioning of technology markets and are not prepared to take any risks with business models that may have a negative impact in the future.

The emergence of PAEs and Privateers did provoke pro-active reactions of competition authorities. The distinction between these new business forms cannot be made easily and an evaluation of their legality should be based on their conduct. PAEs are not necessarily anti-competitive and may lead the way to new IP management and monetization forms of patents. ${ }^{430}$ Both the US and EU are struggling to find a proper assessment base for patent pools in their national competition policies. The rapidly developing global technology markets challenge the flexibility and substance of antitrust systems. Patent pools can be the obvious solution for the problem of royalty stacking, created by patent troll activities. Crucial factors in patent troll behaviour are injunctions and the

\footnotetext{
${ }^{429}$ See for more detailed information: Guest Post on Patent Pools and Competition - Patent Law Blog PatentIyo.com

${ }^{430}$ See also presentation Jenni Lukander: Non-Practicing Entities by Contrast at IP \& Competition Law conference, Brussels 26 September 2013.
} 
creation of FRAND expectations that are consequently not met. Instead, the patent troll or aggressive PAE will wait for the lock-in effect and charge high royalty fees under the threat of an injunction. For the understanding of the position of the patent pool in this discussion, a better understanding of injunctions and FRAND rates is essential.

In relation to standardization, it has to be noted that there is a growing number of patents to be included in a patent pool. This makes it more difficult to evaluate the validity and the essentiality of the patents. Firms participating in a patent pool may include weak or invalid patents, since the independent evaluator cannot examine hundreds of patents effectively.

The blocking of alternative technologies or cost-raising activities in relation to competitors can be facilitated by a patent pool. The system of BRLs has limited coverage since the enforcement agencies focus on the start-up of the patent pool. Once the patent pool is approved, the DoJ and FTC no longer carefully monitor the level of royalty rates or the validity of patents. ${ }^{431}$ Regarding this enforcement strategy, a newcomer like China to this antitrust field would be well-advised not to just copy the BRL system but also to include elements of permanent supervision of the functioning of patent pools. Since patent pools have a positive effect on innovation in principle, China should concentrate not just on the start up but also the management of a patent pool.

The changes in the patent pool system reflect the changes in the technology market. The rise in large patent portfolio owners can have an impact on downstream licensorlicensee relations. Antitrust agencies would be well advised to take a closer look at these effects.

For a global production network firm, which is typically for the telecommunications sector, the divergence of policies and enforcement priorities in relation to patent pools can be challenging.

In the next chapter, I will discuss the regulations and the policy views of the European Union and the developments in relation to litigation will be discussed. The European Union has adopted a new TTBER which gives specialized attention to patent pools. Although the concept of a patent pool is regarded as a multi-party agreement, the TTBER Guidelines do pay attention to patent pools.

\footnotetext{
${ }^{431}$ Many patent pools show in their lists that patents have expired but this does not affect the original royalty rate.
} 


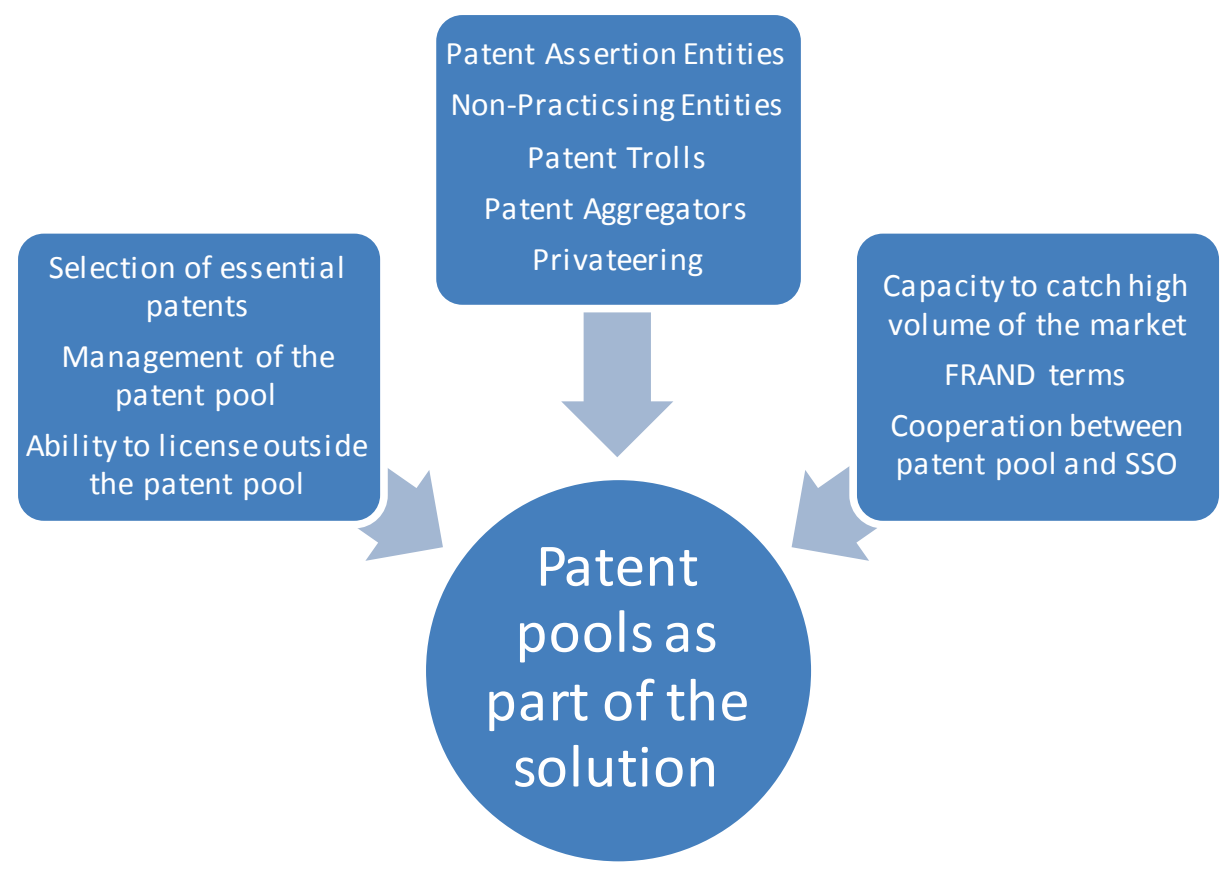




\section{CHAPTER 7}

\section{The EU approach to patent pools}

Patent pools or Technology pools (since they can also contain other types of IP) still attract the attention of the European Commission. Since they are gatherings of competitors, a cautious approach must be taken to evaluate possible anti-competitive effects.

This chapter will show that the essentiality criterion is at the centre of the discussion. The new TTBER created a clear safe harbour. Through the TTBER Guidelines, the EU wanted to provide more clarity on specific elements of technology transfer. This chapter concentrates on the linkages between standards, competitiveness and technology transfer from a European perspective. The discussion on essential and non-essential patents will also be addressed, but it has a different outcome than in the US scenario. By using the case study of the DVB pool, I will also evaluate more innovative ways of managing a technology pool. This chapter will be concluded with an overview of recent EU case law which hints at the future direction this area will take.

The current legal framework of the European Union will be discussed by using a historical perspective as a starting point, before moving on to the rules on Horizontal Cooperation Agreements, followed by the old and new TTBER regime. Recurring themes are the different types of patents inside the patent pool and the contribution of patent pools to innovation.

The EU Commission has addressed the competition law concerns related to the use of patents in standards in different ways. The first reference point is the early case law on the strategic use of patents in standardization. Famous cases such as Rambus and Qualcomm explain the interest of the Commission in the licensing practices of standard essential patents (SEP). The Rambus case was discussed in the first chapter. The Commission held the opinion that Rambus violated Article 102 TFEU by requiring an unreasonably high level of royalties for its patents. The Rambus case is often used to explain patent ambush, since Rambus acquired a market position by not disclosing the fact that it had essential patents for the JEDEC standard. In the second case, a group of firms brought a case against Qualcomm for charging excessively high royalty fees. The argu- 
ment was that the level of royalty fees was not in conformity with the FRAND commitment of Qualcomm. During the investigation, the Commission found it almost impossible to determine what the exact level of FRAND royalty fees should have been. On 3 of April 2012, the Commission opened investigations against Motorola for the apparent abuse of its patents rights in the standard-setting context. ${ }^{432}$ These three cases highlight both the interest that the EU Commission takes in the discussion on the use of patents in standards and also the complex nature of the legal and economic discussion on this subject.

On 15 June 2012, the Vice-President of the EU Commission, Joaquin Almunia, declared in a speech ("Higher Duty for Competition Enforcers") in Madrid that:

"As to the third principle [of the European Commission's guidelines on horizontal cooperation agreements], we need to clarify what are the implications of FRAND and how FRAND negotiations should be conducted. These questions are the core of a few cases we have opened recently involving companies such as Apple, Samsung, Motorola and Microsoft."

"However, industry too has a role to play in guaranteeing the proper functioning of the standardisation system. I would therefore strongly encourage industry players to come together in the relevant standard-setting organizations and elaborate clear rules on the basis of these guiding principles to prevent the misuse of standardessential patents." 433

In relation to the second citation, a coalition of sixteen multinational enterprises (the Tech coalition) sent a letter to the EU Commission expressing their concerns that the $15^{\text {th }}$ draft of the rules of procedure for the Unified Patent Court (UPC) might lead to two negative effects. Companies expressed their concerns that abuse could take place via bifurcation and/or through using injunctions.

Bifurcation refers to the common practice that companies first obtain an infringement ruling, in combination with an injunction for an EU-wide ban on imports, before the validity of the patent is examined. Companies expressed their fears that the resulting unfair litigation might drive future investments outside the EU.

The second point concerning injunctions deals with the EU-wide application of an injunction. The wide ban might lead to increased action by PAES and, following the US experience, will increase the costs and duration of litigation. The threat of an injunction might give parties substantial bargaining power, resulting in unfair trading practices. ${ }^{434}$

\footnotetext{
${ }^{432}$ Press release EU Commission 3 April 2012 E: $\backslash$ EUROPA - PRESS RELEASES - Press Release - Antitrust Commission opens proceedings against Motorola.

433 http://europa.eu/rapid/press-release_SPEECH-12-453_en.htm

${ }^{434}$ The purpose of the single invalidity rule for the $\mathrm{EU}$ is to decrease the number of weak patents in litigation. Some firms fear the risk of automatic provisional injunctions without evidence. The wording of the text says: Rule 221(2) Court "may" require reasonable proof patent is "valid and infringed"- Rule 221(3) Court "may" apply balance of interest test.
} 
This chapter will start with a historical overview of the position of patent pools in the EU legislation. Consequently, the legal treatment of standardization agreements will be covered in relation to the Guidelines on Horizontal Cooperation Agreements. Following this, there will be an investigation of the EU policy in relation to patent pools, taking the general framework of the present Technology Transfer Block Exemption regulation as a starting point. To illustrate the importance of standardization for the European Union, a discussion of the draft EU regulation of standardization will follow. In relation to the subject of patent pools, various elements will be reviewed, including recent developments and the position of patent pools in relation to standardization, the contribution of patent pools to innovation processes and the inclusion of substitute patents in the pooling agreement. An overview of the functioning of the DVB pool will highlight some of the most important practical challenges and solutions. Finally, the Orange Book standards case will underline both the important influence of German courts in this discussion and also demonstrate the different interpretations that are expressed in relation to this case and the possible emerging division between German courts and the EU Commission.

\subsection{HISTORICAL OVERVIEW OF THE EU AND PATENT POOLS}

In the European Union, patent pools initially had the same bad image as in the United States. Starting in the 1930s, patent pools were regarded as an optimal forum for collusion, price-fixing and generally were supposed to have a negative effect on consumer welfare and, consequently, violate European competition laws. The first important patent pools concentrated on the aircraft and automobile industries and already made a distinction between normal and exceptional patents. The first category of patents would not receive any royalties, whereas the latter group would be rewarded with royalty payments. ${ }^{435}$ Historically, the main purpose for the establishment of patent pools was to avoid costly litigation between the different parties active in the relevant sectors. For the competition authorities, the following elements are very relevant:

- The existence of valuable intellectual property which can be used to strategically influence the market behaviour of the patent pool participants and their possible competitors.

- The division and distribution of the royalty payments for the use of the IP rights.

- The necessity for the firms forming the patent pool to have regular meetings and possibly a joint administration structure to administer the operation of the patent pool.

\footnotetext{
${ }^{435}$ See for more background information: Manufactures Aircraft Assoc. Inc. v United States, 77 Ct. Cl. 481, 487 (1933).
} 
- Patent pools lead to an exchange of information between possible competitors, which could lead to collusion.

It is interesting to note that, already in the $19^{\text {th }}$ century, firms would classify the types of patents in the pool and accordingly decide whether royalty payments applied. ${ }^{436}$ For a considerable period, the European Union did not take a major interest in the existence or the functioning of patent pools.

A change was brought about by the EU policy in the field of technology licensing. The new developments in the 1980s prompted a renewed interest in patent pools, both by the firms and by the enforcers of competition policy. With the emergence of new complementary technologies, the licensing arrangements became a closely intertwined web of legal relations between many companies trying to arrange bilateral licensing agreements to prevent the fragmentation of the technology market. The rapid technological developments in the ICT sector were accompanied by an increase in the number of new patent pools. Patent pools became an instrument to facilitate the production and distribution of goods and services that otherwise would have been blocked by complementary patents. Multiparty licensing allows firms to achieve more efficiency which, in the end, will lead to lower consumer prices, better consumer welfare and, as such, should be promoted by competition regulators. The problem of the patent thicket, leading to the tragedy of the anti-commons, as discussed in the previous chapter, ${ }^{437}$ can be prevented by patent pools. Another competitive advantage of patent pools is the fact that they have a positive effect on the price-setting for the different patents combined in the pooling agreement. The Cournot effect demonstrates that the prices of individually licensed patents are ultimately always higher than the price of a pooling of complementary patents and, thus, patent pools again can positively influence competition. $^{438}$

The rise in the number of patent pools and their more strategic positioning within the business environment has justified a more intense review by the EU Commission as competition law regulators. As in the other regional legal systems, this automatically leads to a tension between the intellectual property law regime and competition policy. Most of the concerns of the competition law regulators relating to patent pools are directly linked to deficiencies in the patent law system, which explains the tension between both systems.

\footnotetext{
${ }^{436}$ The distinction between normal and exceptional patents is very similar to the recognition of essential patents in the recent discussions on the use of patents within standardization.

${ }^{437}$ The tragedy of the anti-commons refers to the situation where resources are underused since firms have to obtain a large number of patent licences to start the production of their goods or services.

${ }^{438}$ See chapter 2 for a full discussion of the Cournot problem, which was later also discussed by Shapiro in Navigating the patent thicket: Cross licenses, patent pools, and standard setting.
} 


\subsection{STANDARDIZATION AGREEMENTS, PATENTS AND THE GUIDELINES ON THE HORIZONTAL COOPERATION AGREEMENTS}

The Commission's approval of Google's take-over of Motorola can be seen as the starting point of the EU policy. This merger (notified under Article 4 of Regulation 139/2004) included 8,000 Motorola patents, some of which were standard essential patents. On 16 December 2011, the Commission started proceedings against Honeywell and on 30 January 2012 against Samsung. Samsung asked for an injunction on the basis of infringements of SEPs which, according to the EU Commission, could lead to an abuse of a dominant position (Article 102 TFEU).

Standardization agreements are regulated by the Guidelines on Horizontal Cooperation Agreements, which were adopted by the Commission in December 2010. One of the main principles is that the Commission can mandate an SSO to develop a standard and use this later as a basis for a new regulation. The presence of patents in the standard changes the open standard into a closed standard protected by IPRs. Ownership of the most important patents, SEPs, can confer market power on the patent owners, especially in the case of overlapping IPR ownership.

In the Guidelines, the competition policy concerns start with the fact that the ownership and exercise of SEPs may give the owners control over the relevant product or service market. This control may constitute a barrier for competitors to enter this relevant market. The dominant position gives firms the opportunity to:

- charge exceptionally and/or discriminatory royalty rates

- refuse to license the SEPs to other firms

- thus restrict access to the standard and, consequently, to the market for other companies.

The problem is that the level of market power can only be examined on an individual basis, so the Guidelines do not use the presumption that the ownership of SEPS automatically leads to market dominance. ${ }^{439}$

\footnotetext{
${ }^{439}$ Intellectual property laws and competition laws share the same objectives of promoting innovation and enhancing consumer welfare. IPRs promote dynamic competition by encouraging undertakings to invest in developing new or improved products and processes. IPRs are therefore in general pro-competitive. However, by virtue of its IPR, a participant holding IPR essential for implementing the standard, could, in the specific context of standard setting, also acquire control over the use of a standard. When the standard constitutes a barrier to entry, the company could thereby control the product or service market to which the standard relates. This in turn could allow companies to behave in anti-competitive ways, for example by 'holding-up' users after the adoption of the standard either by refusing to license the necessary IPR or by extracting excess rents by way of excessive royalty fees thereby preventing effective access to the standard. However, even if the establishment of a standard can create or increase the market power of IPR holders possessing IPR essential to the standard, there is no presumption that holding or exercising IPR essential to a standard equates to
} 


\subsection{SAFE HARBOUR PROVISION FOR STANDARDIZATION AGREEMENTS}

The Guidelines on the horizontal co-operation agreements provide a safe harbour exception for standardization agreements that are capable of creating market dominance but are acceptable if they meet the following criteria:

- Agreements should not have the obligation that parties must comply with the standard in question.

- Participation in standard setting must be unrestricted and accessible to all concerned parties in the relevant market.

- The selection procedure for creating the standard must be transparent.

- Ex ante good faith disclosure of SEPS are undertaken by the participating parties in the development process of the standard.

- Licensing is on basis of FRAND commitments. ${ }^{440}$

The Guidelines provide the following comments on the key provisions of para. 280, Unrestricted Participation and Transparency:

"All firms in the relevant technology market have the opportunity to participate in the formulation of the standard. Transparency must guarantee that the participating firms can get the relevant information on the standard-setting process at any moment."

On the subject of good faith disclosure: the Guidelines require the firms to pursue reasonable endeavours in relation to the disclosure of essential patents for the standard.

Regarding the subject of FRAND terms the Guidelines state: In order to prevent patent hold-up, most SSOs introduced the requirement that firms give a promise that essential patents will be licensed on FRAND terms. This promise cannot have a completely irrevocable character, as firms may still retract their technology before the standard is established. If SSOs required irrevocable licences on FRAND terms, this would amount to compulsory licensing and undermine faith in standard setting in general. $^{441}$

As soon as a standardization agreement falls outside the safe harbour provision, the Commission will use an effects-based assessment to examine the legality of the agreement. In this assessment, the Commission will examine the accessibility of the standard,

\footnotetext{
the possession or exercise of market power. The question of market power can only be assessed on a case-bycase basis. Guidelines on Horizontal Cooperation Agreements, para. 269.

440 "Where participation in standard-setting is unrestricted and the procedure for adopting the standard in question is transparent, standardization agreements which contain no obligation to comply with the standard and provide access to the standard on fair, reasonable and non-discriminatory terms will normally not restrict competition within the meaning of Article 101(1)."

${ }^{441}$ For a further explanation, see also Geradin: The EU Commission policy towards the licensing of standardessential patents: Where do we stand? Page 1126.
} 
the openness of the selection procedure of the standard, the market shares of the parties, and the existence of alternative standards. ${ }^{442}$ Article 101 para. 3 TFEU may provide another escape route for the agreements that fail the effects-based test. ${ }^{443}$

The main issues raised by the Google-Motorola decision are:

- Do SEPS create market dominance per se? No. SEP is problematic when the SEP creates a separate market through its own technology, since competitors cannot design around the SEPs.

- The threat of an injunction may negatively influence competition, for example, the patentee could enforce unreasonable licensing conditions, excessive royalty rates or cross-licensing requirements.

- Injunctions lead to temporary absence in fast-moving technology, provoking ex post opportunism by SEP owners.

- SEP owners waive the right to demand an injunction, but, when the licensee refuses to negotiate the licensing terms, this leads to an inverse patent hold-up. ${ }^{444}$

In May 2013, the Commission sent a Statement of Objections to MMI in relation to a possible abuse of a dominant position. MMI tried to enforce an injunction against Apple, on the basis of SEPS, with a FRAND licence. Apple proved to be a willing licensee but nevertheless $\mathrm{MMI}$ continued with its case. ${ }^{445}$

Meanwhile the volume of case law in this sector is constantly increasing, leading to interesting alternative solutions. Royalty capping refers to the agreements that the royalties that can be charged for unidentified SEPs are limited and concerned parties agree to refrain from injunctions. ${ }^{446}$

Ex ante auctions exist between different technologies, (already discussed in section 2.14.1), whereby the downstream firms choose the best technical solution in relation to their investments. Royalty-free requirements may lead to a compulsory licence. SSOs collectively negotiate royalty rates on behalf their members, which might directly in-

\footnotetext{
${ }^{442}$ Bonadio: Standardisation Agreements, Intellectual Property Rights and Anti-Competitive Concerns.

${ }^{443}$ In order to be accepted agreements must: give consumers a fair share of the benefits; while the Commission encourages ex ante disclosure of maximum royalty rates; and they must give equal treatment to all assignees.

${ }^{444}$ Ibid note 441. Geradin holds the opinion that charging higher royalty rates ex post rather than ex ante should be allowed, since parties will only recognize the technical possibilities after the adoption of the standard.

${ }^{445}$ The Commission gave an example of an unwilling licensee: "a potential licensee which remains passive and unresponsive to a request to enter into licensing negotiations or is found to employ clear delaying tactics cannot be generally considered as 'willing'"." Memo, European Commission, Antitrust: Commission Sends Statement of Objections to Motorola Mobility on Potential Misuse of Mobile Phone Standard-Essential Patents.-

${ }^{446}$ This proposal changes the character of the patent right and could lead to a compulsory license approach.
} 
fringe EU competition rules. Last but not least, some scholars link the failure to disclose SEPS to the doctrine of equitable estoppels. An infringer would have to show that he relied upon the patentee's misleading behaviour and that he acted in good faith.

\subsection{THE 2004 TECHNOLOGY TRANSFER BLOCK EXEMPTION REGULATION}

The first attempt to regulate technology transfer by means of patent pools was made in Regulation 19/65. This Regulation declared in Article $1(1)^{447}$ that a distinction should be made between bilateral and multilateral agreements, which complicated the legal framework that applied to patent pools. With the revision of Regulation 19/65 and the introduction of a new regime in 2004, the Commission used the new Regulation $772 / 2004$ to clarify its position on patent pools. In the 2004 Regulation, patent pools were not subjected to the block exemption mechanism, thereby underlining the special position of the patent pool in the EU's enforcement policy. Recital 7 of the aforementioned regulation declares:

"This Regulation should only deal with agreements where the licensor permits the licensee to exploit the licensed technology, possibly after further research and development by the licensee, for the production of goods or services. It should not deal with licensing agreements for the purpose of subcontracting research and development. It should also not deal with licensing agreements to set up technology pools, that is to say, agreements for the pooling of technologies with the purpose of licensing the created package of intellectual property rights to third parties." 448

The decision to place the concept of patent pools outside the block exemption mechanism did not increase the legal certainty for firms participating in a pooling agreement. These firms had to use a method of self-assessment, applying the Guidelines of the Regulation 772/2004 to the individual patent pool. As we will see later, this situation bears strong similarities to the recent developments on the EU enforcement front. The

\footnotetext{
${ }^{447}$ Without prejudice to the application of Council Regulation No 17 and in accordance with Article 85 (3) of the Treaty, the Commission may by regulation declare that Article 85 (1) shall not apply to categories of agreements to which only two undertakings are party and: (a) - whereby one party agrees with the other to supply only to that other certain goods for resale within a defined area of the common market; or

- whereby one party agrees with the other to purchase only from that other certain goods for resale ; or

- whereby the two undertakings have entered into obligations, as in the two preceding subparagraphs, with each other in respect of exclusive supply and purchase for resale;

(b) which include restrictions imposed in relation to the acquisition or use of industrial property rights - in particular of patents, utility models, designs or trademarks-or to the rights arising out of contracts for assignment of, or the right to use, a method of manufacture or knowledge relating to the use or to the application of industrial processes.

${ }^{448}$ COMMISSION REGULATION (EC) No 772/2004 of 27 April 2004 on the application of Article 81(3) of the Treaty to categories of technology transfer agreements.
} 
Technology Transfer Guidelines 2004 (hereafter called TT Guidelines) give a specific definition of the concept of a patent pool:

"Technology pools are defined as arrangements whereby two or more parties assemble a package of technology which is licensed not only to contributors to the pool but also to third parties. In terms of their structure technology pools can take the form of simple arrangements between a limited number of parties or elaborate organizational arrangements whereby the organization of the licensing of the pooled technologies is entrusted to a separate entity. In both cases the pool may allow licensees to operate on the market on the basis of a single licence." 449

The same 2004 TT Guidelines explain that, where a patent pool is linked to a specific standard, this support does not have to be exclusive. Patent pools may support different standards and thereby increase competition. ${ }^{450}$ Participants in a patent pool agreement must both conclude a cross-licensing agreement and a pooling agreement.

The cross-licensing agreement is related to the production and distribution of the goods and thus the relevant product market, whereas the patent pool agreement deals with conditions that the patent pool applies in its licensing to third parties, thus the technology market. In the analysis of the effect of a patent pool on competition, both agreements and their practical effects must be clearly separated. As mentioned earlier, the patent pool agreement falls outside the scope of the block exemption, but the cross-licensing agreement is evidently covered by this mechanism, which can lead to complicated practical effects.

This stance of the Commission distinguishes the right to license technology collectively in a package deal (the patent pool agreement) from the right to use the licensed technology for the production of goods. ${ }^{451}$ For the legal assessment of patent pools, it means that the internal rules for the functioning of the pool and its members must be separated from the contract provisions dealing with the licensing of the pooled technology to third parties, although interrelations between both contractual agreements will also exist. As Hanns Ullrich argues, the specific market in which the firms operate can also influence the choice of applicable rules to be followed. ${ }^{452}$ Companies active in the technology market will rarely choose to include a licence exchange provision, whereas for firms concentrating on the production of goods, this might be a much more obvious choice. Although the 2004 TT Guidelines do not specifically deal with patent pools, they do pay considerable attention to cross-licensing agreements. ${ }^{453}$

The interrelationship between the internal rules relating to the functioning of the pool and the external rules for third-party licensing complicates the legal analysis. At

\footnotetext{
${ }^{449}$ EU Technology Transfer Guidelines note 210.

${ }^{450}$ EU Technology Transfer Guidelines note 211.

${ }^{451}$ EU Technology Transfer Guidelines, para 41.

${ }^{452}$ Research Handbook on intellectual property and competition law , EE, page 144.

${ }^{453}$ EU Technology Transfer Guidelines paras. 78, 204 and 208.
} 
first sight, a clear distinction seems to be easy to make, but a closer look reveals the underlying structures and difficulties. The TT Guidelines contain precise provisions relating to cross-licensing, which apply directly to both the internal cross-licensing as well as to the external cross-licensing. The main limitation for general cross-licensing agreements is explained in Article 4(1) TTBER:

"Article 4 of the TTBER contains a list of hardcore restrictions of competition. The classification of a restraint as a hardcore restriction of competition is based on the nature of the restriction and experience showing that such restrictions are almost always anti-competitive. In line with the case law of the Community Courts(39) such a restriction may result from the clear objective of the agreement or from the circumstances of the individual case." 454

Normally, it can be expected that cross-licensing agreements of the patent pool can enjoy the benefit of the safe harbour if they respect the above-mentioned hardcore restrictions.

For further use in this chapter, an overview of these hardcore provisions is provided here:

"Article 4(1) lists the hardcore restrictions for licensing between competitors. According to Article 4(1), the TTBER does not cover agreements which, directly or indirectly, in isolation or in combination with other factors under the control of the parties, have as their object:

a. The restriction of a party's ability to determine its prices when selling products to third parties;

b. The limitation of output, except limitations on the output of contract products imposed on the licensee in a non-reciprocal agreement or imposed on only one of the licensees in a reciprocal agreement;

c. The allocation of markets or customers except

i) the obligation on the licensee(s) to produce with the licensed technology only within one or more technical fields of use or one or more product markets;

ii) the obligation on the licensor and/or the licensee, in a non-reciprocal agreement, not to produce with the licensed technology within one or more technical fields of use or one or more product markets or one or more exclusive territories reserved for the other party;

iii) the obligation on the licensor not to license the technology to another licensee in a particular territory;

\footnotetext{
${ }^{454}$ EU Technology Transfer Guidelines Art. 4 (1).
} 
iv) the restriction, in a non-reciprocal agreement, of active and/or passive sales by the licensee and/or the licensor into the exclusive territory or to the exclusive customer group reserved for the other party;

v) the restriction, in a non-reciprocal agreement, of active sales by the licensee into the exclusive territory or to the exclusive customer group allocated by the licensor to another licensee provided that the latter was not a competing undertaking of the licensor at the time of the conclusion of its own licence;

vi) the obligation on the licensee to produce the contract products only for its own use provided that the licensee is not restricted in selling the contract products actively and passively as spare parts for its own products;

vii) the obligation on the licensee in a non-reciprocal agreement to produce the contract products only for a particular customer, where the licence was granted in order to create an alternative source of supply for that customer;

d. The restriction of the licensee's ability to exploit its own technology or the restriction of the ability of any of the parties to the agreement to carry out research and development, unless such latter restriction is indispensable to prevent the disclosure of the licensed know-how to third parties." 455

The internal pooling agreement, as was shown in the previous chapter, can already attract the interest of competition policy enforcers. In recent years, most of the attention was focused on the internal distribution of royalties, joint-defence systems and the possible exchange of relevant information between pool members. Both in the literature as well in the guidelines and the Business Review Letters (BRLS), the selection of the patents to be included in the pool and the pricing policy in the form of royalties have been discussed extensively. ${ }^{456}$ In most of these discussions, insufficient attention was paid to the interrelationship of the different agreements with patent pooling and the effect of the relevant market on the possible strategic use of the instrument of patent pool agreements. The strategic use of a patent pool becomes even more relevant for competition policy within the context of standard setting. Both the Rambus and Dell cases already showed early on that the use of patent pools in standardization may lead to a very strategic approach to commercialize new technology. ${ }^{457}$ Whereas the strategic use of essential patents during the formulation of the standard is very well known, the reverse situation can also be very interesting. A firm holding valuable or essential patents might consider refraining from participating in the standardization, given the fact that their superior technology would be chosen anyway. It is questionable

\footnotetext{
${ }^{455}$ EU Technology Transfer Guidelines Art. 4.2.

${ }^{456}$ See also the discussion in the previous chapter.

${ }^{457}$ As discussed earlier, in both cases these firms did not acknowledge the ownership of essential patents during the standardization process leading to have criticism of competition authorities.
} 
whether competition enforcers can effectively prosecute a company owning superior technology which does not want to participate in the standard setting. The use of standards, especially European developed standards, has become increasingly important for the EU. Again the present negotiations on the TTIP stress the importance of standardization for the competitiveness of the European Union.

For a standard-setting body, it is reasonably difficult to strike the right balance between the interests of the different stakeholders. The patent right holders want a reasonable return for including their patent in the standard and thus commercializing the product concerned. Business owners want to produce and market standard-conforming goods and services under profitable conditions. For the consumers, both the price and the interoperability are the two main interests. The SSO wants an effective and efficient standardization process. In a breakfast speech, Commissioner Neelie Kroes stated the following:

"Proprietary technology is at the heart of Europe's success in second and third generation mobile technologies, for example. Intellectual property protection for technology will always be necessary to give just rewards for investment in R\&D. There will always be an important place for proprietary technology and formal proprietary standards."

On the subject of informal standards she explained the legal conditions:

"First, the de facto standard could be subject to the same requirements as more formal standards:

- ensuring the disclosure of necessary information allowing interoperability with the standard;

- ensuring that other market participants get some assurance that the information is complete and accurate, and providing them with some means of redress if it is not;

- ensuring that the rates charged for such information are fair, and are based on the inherent value of the interoperability information (rather than the information's value as a gatekeeper)." 458

ETSI already changed its IPR policy in 2006 with the following provisions:

"Without prejudice to ETSI IPR Policy and other sections of this Guide, voluntary, unilateral, public, ex ante disclosures of licensing terms by licensors of Essential IPRs are not prohibited under ETSI Directives. Licensing terms from such disclosures may, in

\footnotetext{
${ }^{458}$ Speech N. Kroes Breakfast Seminar 10 June 2008 Being open about standards.
} 
some circumstances, improve transparency for individual Members in considering technologies for inclusion in standards and technical specifications." 459

In relation to the ex ante commitments, some scholars favour the creation of a fixed royalty cap, thereby clearly communicating the maximum royalties that can possibly apply. In this system, the maximum total sum of royalties would be a percentage of the overall licensee's revenues. A possible danger in terms of competition policy would be the lack of price competition for the essential patents within the standard. ${ }^{460}$

During the last decade, the views on the relationship between IPRs and their effect on innovation have changed dramatically. Especially in the ICT sector, new business models evolved that did not directly rely upon strong and effective protection of intellectual property assets. The implementation of a complex standard would lead to high investments for the arrangements with the multiple patent holders and, consequently, the cumulative royalty fees. Open source or service-based business and even the emergence of Non-practising entities led the way forward. There seems to be a consensus that IP rights and interoperability are closely linked and both are major factors in achieving success. A full participation of all relevant stakeholders in the standardization process is of crucial importance. IPR policies of SSOs that would limit or even exclude membership/participation would be in direct conflict with the goal of achieving global competitiveness.

\subsection{TECHNOLOGY TRANSFER AND PATENT POOLS: A EUROPEAN PERSPECTIVE}

The latest review of the Technology Transfer Guidelines was necessary because the current block exemption expired in April 2014. Licensing agreements that have the effect of restricting, preventing or distorting competition are illegal under Article 101 TFEU. Because of the positive effects of patent pools on both competition and innovation, generally these types of agreements can benefit from the above-mentioned block exemption. The relatively new effects-based approach of DG Competition in relation to the use of IPRs in standard setting has also encouraged the renewed interest in patent pools. However, it would be too easy to solely link the increased popularity of patent pools to this enforcement policy. Since the establishment of the TT Guidelines in 2004, the environment of technology transfer has been developing continuously.

First, the industry environment has changed. Technological progress, in combination with globalization, has led to both increased consumer demand and the emergence of Global Production Networks (GPN), meaning that telecommunications goods and ser-

\footnotetext{
${ }^{459}$ ETSI Guide on IPRs, Version endorsed by General Assembly \#48 on 22 November 2006, page 15.

${ }^{460}$ See for a more in-depth discussion: Piesiewicz and Schellingerhout Intellectual Property Rights in Standard setting from a Competition Law Perspective in Competition policy newsletter No.3 2007.
} 
vices are no longer linked to one specific jurisdiction but result from business activities centred in various regional trading blocs (NAFTA, EU and China). Secondly, business conduct has changed since 2004 High profile cases like Rambus, Qualcomm and Microsoft signalled a new type of business behaviour in relation to the licensing of IP in standard-setting procedures. The establishment of Non-practising entities (NPEs) has led to many legal debates and controversies. Overall, it can be concluded that, at the time of writing, valuable patents in standards in the telecommunications industry are managed in a much more strategic way than in 2004. As a reaction, the question is raised as to whether the regulatory framework should be further developed, adapted or fundamentally changed.

Furthermore, there is the question of which regulatory framework should be applied to the discussion of patent pools within the standard-setting context. In this context, both patent law and competition law are relevant, and it would be interesting to note whether and which one of these systems should take preference and thus a leading role in this discussion. Since patent pools are part of standardization, should the original goal of standardization and technology transfer, the promotion of the EU's competitiveness, form a central part of the discussion? The new TTBER Guidelines pay considerable attention to patent pools. The main reasoning is that patent pools, just like the IP policies of SSOs must guarantee that patent owners license their SEPS on FRAND terms. Recent case law has focused on the discussion of SEPs and injunctions. From a completion policy perspective, patent pools mainly prevent injunctions and make SEPs readily available to licensees. The IP system is contributing to the discussion in a negative way, since it seems that it is nearly impossible to increase the quality and the validity of the patents used in standardization.

The question must be posed: should patent pools be primarily regulated by patent law or by competition rules? The focus of recent case law would favour a competition law approach towards patent pools. Alternatively patent law has to provide better solutions for the problem of invalid and poor quality patents.

\subsection{THE LEGAL POSITIONING OF PATENT POOLS}

The EU Commission decided in the current TT Guidelines to position the patent pools outside the block exemption. The main reasoning behind this idea was that patent pools are formed to facilitate the transfer of technology, by means of patents, to third parties. The difference with cross-licensing or general licensing agreements lies in the fact that patent pools are not directly related to production. As discussed in the previous chapter, the US government and the EU Commission seem to have a strong preference for the inclusion of essential patents in the patent pool. Recent case law in the United States hints at a possible new judicial direction, whereby the inclusion of non-essential 
patents is also permitted. Generally, the quality of patents has been steadily decreasing over the last few years. Before starting a discussion on the inclusion of essential or complementary patents, we must first investigate how to improve the general quality of patents in the patent pool. Since the patent pool is a one-stop shop, the licensee should be entitled to receive high quality patents. A few prerequisites could possibly guarantee a higher quality of the patents included. The EPO made the following suggestions: ${ }^{461}$

- The examiners should be experts in the relevant technical field and be aware of the state of the art technology.

- At the moment of the search, prior art should be available to evaluate.

- The patentability criteria of clarity and conciseness should be more strictly applied.

- Examiners should have the opportunity to use efficient and updated search engines.

The EPO favours a closer cooperation with the other major patent offices, the so-called IP5, composed of JPO, USPTO, EPO, SIPO, and KIPO. This attempt to achieve closer cooperation and a more coordinated exchange of information and best practices would match with the globalized business operations of the key firms active in the field of telecommunications. Lack of common documentation and classification leads to trade barriers, which result from different approaches to patent law and innovation systems in the different trading blocs. This divergence clearly should be solved by remedies originating in the patent law system and cannot be corrected by the competition and antitrust systems. At the same time, the EPO has set an example, with the conclusion of MoUs and Cooperation agreements with the EU Commission, on best practice that must be followed by the other Patent Offices in order to realign the policy agendas of both the regulators and the Patent Offices. The business community is already reacting to the development of patent landscapes in the most important new key technologies. Providing more transparency must be a major objective for the Patent Offices, which will directly contribute ${ }^{462}$ to the competitiveness of the relevant geographical area. Some academics and practitioners would encourage a closer cooperation between the EPO and SSOs in the field of standards, which would lead to more consumer benefits. This suggested cooperation might be justified on practical grounds but would substantially change the role of Patent Offices in the discussion of the strategic use of patents within standards.

Another alternative method of support to licensing negotiations is the clearinghouse arrangement. This arrangement tries to match providers and users of goods, services and technology and delivers secondary services, such as support to the licens-

\footnotetext{
${ }^{461}$ Brussels EU Commission workshop on patent pools April 2012.

${ }^{462}$ A new initiative in this field is the Smart Grid patent mapping project between the IPO and the IEEE.
} 
ing negotiations, royalties collection and the formulation of a standard. One of the most efficient clearing-house arrangements on patent information is Espacenet, the online information portal of the European Patent Organization. ${ }^{463}$

Next, the question can be put, should Patent Offices play a different role, in possible cooperation with SSOs, in the standards discussion, in order to improve the quality of patents?

\subsection{THE REVISION OF THE EU TECHNOLOGY TRANSFER REGULATION}

The TTBER expired in April 2014. The EU Commission launched a public consultation procedure to get input for the new TTBER, which became applicable as of $2014 .{ }^{464}$ To support the academic foundation for the new TTBER, a study was commissioned, namely the "Assessment of the potential anticompetitive conduct in the field of intellectual property rights and assessment of the interplay between competition policy and IPR protection." ${ }^{465}$ The author of this report, Regibeau, expresses the following antitrust concerns in relation to patent pools:

- An increase in the level of royalties.

- The exclusion of rival firms.

- The exclusion of rival technologies.

- The exclusion of rival standards.

For the purpose of understanding the underlying economic principles that apply to patent pools, the literature overview refers to a random selection of various academic articles relating to patent pools.

In the report, it is concluded that exclusion rules for the membership of patent pools can be beneficial to social welfare. Representatives of the EU Commission expressed personal views that the new proposed TTBER basically functions as a safe harbour.

The hardcore provisions of the new TTBER are listed below.

\section{Hardcore restrictions}

"1. Where the undertakings party to the agreement are competing undertakings, the exemption provided for in Article 2 shall not apply to agreements which, directly or

\footnotetext{
${ }^{463}$ See for more background information: van Overwalle et al: Dealing with patent Fragmentation in ICT and Genetics: Patent Pools and Clearing Houses.

${ }^{464}$ The public consultation resulted in 58 replies. Most firms had the feeling that the proposed new TTBER was a stricter regime.

${ }^{465}$ Regibeau: Assessment of potential anticompetitive conduct in the field of intellectual property rights and assessment of the interplay between competition policy and ipr protection.
} 
indirectly, in isolation or in combination with other factors under the control of the parties, have as their object any of the following:

(a) the restriction of a party's ability to determine its prices when selling products to third parties;

(b) the limitation of output, except limitations on the output of contract products imposed on the licensee in a non-reciprocal agreement or imposed on only one of the licensees in a reciprocal agreement; the allocation of markets or customers except:

1. the obligation on the licensee(s) to produce with the licensed technology only within one or more technical fields of use or one or more product markets,

2. the obligation on the licensor and/or the licensee, in a non-reciprocal agreement, not to produce with the licensed technology within one or more technical fields of use or one or more product markets or one or more exclusive territories reserved for the other party,

3. the obligation on the licensor not to license the technology to another licensee in a particular territory,

4. the restriction, in a non-reciprocal agreement, of active and/or passive sales by the licensee and/or the licensor into the exclusive territory or to the exclusive customer group reserved for the other party,

5. the restriction, in a non-reciprocal agreement, of active sales by the licensee into the exclusive territory or to the exclusive customer group allocated by the licensor to another licensee provided the latter was not a competing undertaking of the licensor at the time of the conclusion of its own licence,

6. the obligation on the licensee to produce the contract products only for its own use provided that the licensee is not restricted in selling the contract products actively and passively as spare parts for its own products,

7. the obligation on the licensee, in a non-reciprocal agreement, to produce the contract products only for a particular customer, where the licence was granted in order to create an alternative source of supply for that customer;

(c) the restriction of the licensee's ability to exploit its own technology or the restriction of the ability of any of the parties to the agreement to carry out research and development, unless such latter restriction is indispensable to prevent the disclosure of the licensed know-how to third parties. 2. Where the undertakings party to the agreement are not competing undertakings, the exemption provided for in Article 2 shall not apply to agreements which, directly or indirectly, in isola- 
tion or in combination with other factors under the control of the parties, have as their object any of the following:

i) the restriction of a party's ability to determine its prices when selling products to third parties, without prejudice to the possibility of imposing a maximum sale price or recommending a sale price, provided that it does not amount to a fixed or minimum sale price as a result of pressure from, or incentives offered by, any of the parties;

ii) the restriction of the territory into which, or of the customers to whom, the licensee may passively sell the contract products, except:

1. the restriction of passive sales into an exclusive territory or to an exclusive customer group reserved for the licensor,

2. the obligation to produce the contract products only for its own use provided that the licensee is not restricted in selling the contract products actively and passively as spare parts for its own products

3. the obligation to produce the contract products only for a particular customer, where the licence was granted in order to create an alternative source of supply for that customer,

4. the restriction of sales to end-users by a licensee operating at the wholesale level of trade,

5. the restriction of sales to unauthorised distributors by the members of a selective distribution system;

iii) the restriction of active or passive sales to end-users by a licensee which is a member of a selective distribution system and which operates at the retail level, without prejudice to the possibility of prohibiting a member of the system from operating out of an unauthorised place of establishment.

Where the undertakings party to the agreement are not competing undertakings at the time of the conclusion of the agreement but become competing undertakings afterwards, paragraph 2 and not paragraph 1 shall apply for the full life of the agreement unless the agreement is subsequently amended in any material respect. A material amendment includes the conclusion of a new technology transfer agreement between the parties concerning competing technologies, which can be used for the production of products competing with the contract products."

In order to provide a better understanding of the proposed TTBER, the EU Commission also published draft Guidelines. The Guidelines give the following background information on the safe harbour: 
"The creation and operation of the pool generally falls outside Article 101(1) irrespective of the market position of the parties if all the following conditions are fulfilled:

a. participation in the standard and pool creation process is open to all interested parties;

b. sufficient safeguards are adopted to ensure that only essential technologies (which therefore by necessity are also complements) are pooled;

c. sufficient safeguards are adopted to ensure that exchange of sensitive information is restricted to what is necessary for the creation and operation of the pool;

d. the pooled technologies are licensed into the pool on a non-exclusive basis;

e. the pooled technologies are licensed out to all potential licensees on FRAND terms

f. the parties contributing technology to the pool and the licensees are free to challenge the validity and the essentiality of the pooled technologies, and;

g. the parties contributing technology to the pool and the licensee remain free to develop competing products and technology."

Companies that stay clear of the hardcore provisions and follow the Guidelines will not face prosecution.

The Guidelines further state that:

"In assessing the possible competitive risks and efficiencies, the Commission will, inter alia, take account of the transparency of the pool creation process; the selection and nature of the pooled technologies, including the extent to which independent experts are involved in the creation and operation of the pool; and whether safeguards against exchange of sensitive information and independent dispute resolution mechanisms have been put in place."

The new TTBER again raised some questions at the time of development:

- Why did the Commission make the choice for two different instruments that both cover patent pools, The Horizontal Cooperation Agreement regulation and the TTBER?

- Companies could be outside the scope of the new TTBER, but still be innovative. How does the TTBER measure the positive effect on innovation?

\footnotetext{
${ }^{466}$ Guidelines on the application of Article 101 of the Treaty on the Functioning of the European Union to technology transfer agreements DRAFT COMMUNICATION FROM THE COMMISSION page 63
} 
- What is the exact relationship between the new TTBER and the Block exemptions in the field of Horizontal Cooperation Agreements, R\&D agreements and Specialization agreements? It seems that the TTBER would be subsidiary to the Horizontal Cooperation Agreement, but what does this mean in practice? ${ }^{467}$

- The new TTBER frequently uses market shares in its concept. In technology markets, market shares are difficult to assess. Will market shares in the downstream market be used as a proxy for calculating the product market and the geographical market? How do the market shares function for non-competitors in case of substitutable technology?

- The new TTBER and the new Guidelines do not specifically clarify the position of companies in a patent pool that decide to license their technology outside the pool. Does this also mean that the legal position of the company is outside the new TTBER? Since the TTBER only covers bilateral agreements, would a multilateral agreement between patent pool members and licensees be outside the new TTBER? The EU Commission has recently expressed the view that licensing agreements between the patent pool and third parties fall outside the scope of the new TTBER. Licensing out of the pool will be regulated by the new Guidelines.

- Surprisingly, the new TTBER does not contain provisions on NPEs. Why not?

- How does the licensor-licensee relationship differ from the business relationships in R\&D agreements?

The new TTBER is a balancing act between the innovation activities of the licensor and the desire of the licensee to challenge invalid patents. The relationship between the licensor and licensee may differ per technology market. As an example, in the biotechnology market, the licensee might be the stronger and more powerful market and the licensor is potentially weaker party and must be protected.

\subsection{THE ADOPTED VERSION OF THE TTBER}

The new TTBER was adopted on 21 March 2014 and entered into force on 1 May 2014. The TTBER includes a transitional period of one year which enables companies (if necessary) to change their agreements. It is remarkable that the new TTBER will run until 2026, which is an extension of two years above the normal duration of block exemption

\footnotetext{
${ }^{467}$ Stakeholders still need clarification on the text: "directly and exclusively related to the production of contract products", which is the test for the application of the new TTBER. Firms must first address the Horizontal BER and ask what is the predominant feature of the transaction? It still causes uncertainty when the IPR input is not exclusively used for the production of contract goods.
} 
regulations. Especially on fast-moving technology markets, this results in both certainty but also sometimes lack of flexibility. ${ }^{468}$

Regarding the main changes in the TTBER, it is important to understand that the new TTBER is subsidiary to the horizontal BERs on specialization and R\&D. Because of the conflict of law rule, the application of the TTBER and the horizontal BERs simultaneously is not possible and the latter provisions prevail.

The system of the new TTBER uses the classification of hardcore restrictions and excluded restrictions. Agreements that contain hardcore provisions automatically fall outside the safe harbour. A major change was made in the field of the use of restrictions. Article 4 (2) states that licensees should be free to sell passively to any customer. Whereas hardcore restrictions have the presumption that they are negative, excluded restrictions do not affect the complete agreement. Only the restriction itself is not covered by the safe harbour, but the remaining part of the agreement is not affected. A detailed reading of the new TTBER shows that the incentive to innovate is very important for the EU Commission. One example is that all exclusive grant-back provisions are now excluded restrictions. ${ }^{469}$ The exclusive character of the grant-back provision would mean that the licensee can no longer use his own invention. This would reduce the incentive to innovate for the licensee. Other changes relate to termination clauses that can have the same effect as non-challenge clauses. In general, nonchallenge clauses may have a positive effect since they have a filtering function and can be used to distract invalid patents from technology markets. In the context of royalty negotiations for exclusive licences between small licensors and (big company) licensees, the licensor can experience some negative effects. When termination clauses are part of non-exclusive agreements, they are classified as excluded restrictions.

The Guidelines of the new TTBER clarify the distinction between competitors and non-competitors on technology markets. The Commission paid attention to the problem of IP invalidity and the uncertainty that this creates on the market, and tried to provide more guidance. The Guidelines also clarify blocking situations with potential competitors. Because of the recent attention for reverse payment settlements, the Guidelines contain new provisions on settlements. In principle, settlements fall outside the scope of the TTBER. Settlements may save costs and time and generally lead to beneficial outcomes. The benefits of settlements are clarity, the removal of invalid patents and thus it is beneficial to society. In a landmark case in 2013, FTC v. Actavis, competition authorities investigated settlements in patent litigation. In the Actavis case, a brand name pharmaceutical manufacturer reached a settlement with a generic rival. The manufacturer was challenged on the validity of its patents and consequently paid

\footnotetext{
${ }^{468}$ In a personal conversation, one of the developers of the TTBER, Mr. Peeperkorn, stated that it is unusual for this type of legal instrument to have a limitation in time. In a global context, the FTC/DoJ and Chinese legislators have not limited their instruments in duration. Since the overall structure of the new TTBER remains the same, the Commission choose for an evolutionary approach.

${ }^{469}$ The distinction between severable and non-severable improvements for grant-backs no longer exists.
} 
the generic rival to delay its entry onto the market. The suspicion was that this settlement divided the patent profits between the two companies at the expense of consumers. As a result, the Guidelines include a new section of patent settlements, defining important elements for their evaluation. As soon as reverse payment settlements include delay or limited entry and are concluded between actual or potential competitors and there is a risk of market allocation or market sharing, this could fall under the hardcore restrictions of article 4 (c)/(d). ${ }^{470}$

\section{The TTBER Guidelines and patent pools}

The old TTBER was never applied to classical patent pools. The obvious concern of the EU Commission is that patent pools involve gatherings of competitors. In the Guidelines, the Commission declares that technology pool that solely or pre-dominantly consist of substitute technologies must be seen as a price-fixing cartel. ${ }^{471}$ Technology pools that are related to a standard may limit innovation and lead to the foreclosure on new technologies on the market. Since technology pools are multi-party agreements, all participating companies agreed on mutual terms and therefore the agreement is not addressed by the TTBER.

The Guidelines provide a safe harbour for technology pools when the following basic principles are met:

a. participation in the pool creation process is open to all interested technology rights owners;

b. sufficient safeguards are adopted to ensure that only essential technologies (which therefore necessarily are also complements) are pooled;

c. sufficient safeguards are adopted to ensure that exchange of sensitive information (such as pricing and output data) is restricted to what is necessary for the creation and operation of the pool;

d. the pooled technologies are licensed into the pool on a non-exclusive basis;

e. the pooled technologies are licensed out to all potential licensees on FRAND terms;

f. the parties contributing technology to the pool and the licensees are free to challenge the validity and the essentiality of the pooled technologies, and;

\footnotetext{
${ }^{470} \mathrm{~A}$ major factor is the question whether there is a monopoly rent share between the companies that conclude the agreement. The Lundbeck case is very relevant here and is being appealed at the time of writing.

${ }^{471}$ Technology Transfer Block Exemption Regulation Guidelines para. 4.4.
} 
g. the parties contributing technology to the pool and the licensee remain free to develop competing products and technology. ${ }^{472}$

Regarding the formation and the operation of the technology pool, the Guidelines state that the following factors are relevant: the transparency of the pool creation process; the selection and nature of the pooled technologies, including the extent to which independent experts are involved in the creation and operation of the pool and whether safeguards against exchange of sensitive information and independent dispute resolution mechanisms have been put in place. ${ }^{473}$

The open participation should be guaranteed by selecting pooled technologies on the basis of price/quality criteria. In the section of the selection and nature of pooled technologies, the Commission simplifies the academic discussion on complements and substitute technologies. The Commission does introduce a "demand based evidence" for the complements, thereby hoping that the market can clearly distinguish between complements and substitutes. In the evaluation of the pooled technologies, familiar criteria like the ability to license parts of the technology individually and separately occur, but also there is some guidance on the royalty-fee setting. The Commission explains that the total sum of all the separate licences should not exceed the sum of the package of licences for all the pooled technologies.

The inclusion of substitute technologies amounts to collective bundling and pricefixing, thereby violating Article 101 (1) TFEU. Substitute technologies are in principle not tolerated by the EU Commission, which is very strict in comparison to the US evaluation by the FTC/DoJ.

Later on in the Guidelines, the Commission does develop a more "rule of reason"like approach towards the inclusion of substitute/ non-essential technologies in the technology pool. In paragraph 265, the Commission gives the example of a technology pool that restricts competition but still could be acceptable under Article 101 (3). This would hint at a policy whereby technology pools must be evaluated on a case-by-case basis. The evaluation of individual technology pool agreements will focus on the market position of the pool, possible foreclosure of alternative technologies or technology pools and hardcore provisions within the pool agreement. The Guidelines do not specifically address the royalty setting after the formation of the pool, although, from the general remarks, it can be concluded that they must remain FRAND based. The following sections on the selection and operation of independent experts are more aligned with the US practice.

Finally, the exchange of sensitive information between pool participants should be prevented by safeguards that can be evaluated by the EU Commission. The Commission tried to provide more clarity on the specific elements of the legality of technology pools

\footnotetext{
472 Technology Transfer Block Exemption Regulation Guidelines para. 4.4.1.

${ }^{473}$ Technology Transfer Block Exemption Regulation Guidelines para. 4.4.1.
} 
but a closer look reveals that the most important questions have not been thoroughly discussed.

The new TTBER is a balancing act between the innovation activities of the licensor and the desire of the licensee to challenge invalid patents. The relationship between the licensor and licensee may differ per technology market. As an example, in the biotechnology market, the licensee might be the stronger and more powerful market actor and the licensor is potentially weaker and must be protected.

The question remains whether the TTBER has tipped the balance in favour of the licensees. Although the general idea behind the TTBER is that innovation must be encouraged to favour competition, the current TTBER can be a disincentive to join technology pools or standardizing committees. Licensees are in the best position to challenge the validity of patents, whereas in theory the licensor needs to keep control over the use of his technology by the licensee.

\subsection{RECENT DEVELOPMENTS IN PATENT POOLS}

An example of a recently established patent pool is the One Blue patent pool created by Sony, Panasonic and Philips, as the original founding fathers, later followed by Cyberlink, Hitachi and Samsung. The pool concentrates on essential patents for Blu-Ray disc products. One remarkable feature of this recent patent pool for the optical standards of Blu-Ray products is the fact that the included essential patents cover every standard for the Blu-Ray products. This characteristic will almost automatically lead to litigation on the essential patents in the future. The recent case law on the conflict between Apple and Samsung showed that commercial interests force companies to start suing each other in various jurisdictions.

Normally, a patent pool directly addresses one specific standard, but the coverage of all applicable standards is likely to be a unique feature. In the case in which the pool does cover all standards, the theoretical point of reduction of transaction costs becomes a very practical and prominent feature. It is interesting to note that one of the licensors claims that, by making life easier for the licensees, this will automatically lead to fewer disputes between licensors and licensees. ${ }^{474}$

Another innovative feature of this patent pool is the way the pool's participants deal with the so-called free-rider problem. Free riding refers to the situation in which only a limited number of licensors take and pay for enforcement actions against licensees. As a result, the non-participating firms will directly benefit from the enforcement action, but the licensors that started the action will also face legal costs, judicial uncertainties and possible legal counter claims from the accused licensees. With the introduction of a

\footnotetext{
${ }^{474}$ Peters in One-Blue: a blueprint for patent pools in high-tech page 39 Intellectual Asset Magazine September/October 2011.
} 
collective defence agreement against infringements of licensees, all licensors have to commit themselves and the essential patents to legal actions against infringers. From a competition policy perspective, this raises the question whether a collective defence agreement exceeds the legitimate limits, since individual licensors no longer have the discretionary power to decide if or when to start an individual enforcement action. The collective defence agreement of the patent pool could be in direct conflict with the provisions in the Guidelines that do not allow the exchange of sensitive information between pool members. ${ }^{475}$

A second interesting contractual element of the One Blue patent pool is the strategic decision to implement a system of per-batch licensing. This system practically leads to licensing per shipment of products (per batch) instead of the general practice of licensing the products in total over a fixed number of years. The per-batch system was introduced to prevent the situation arising in which a licensee does not pay royalties even though the licensee did conclude the licensing agreement. It gives the unwilling licensee legal protection from the agreement, but the decision not to pay the applicable royalties creates a competitive advantage. In this situation, licensors must initiate legal proceedings to recover the royalty payments due. ${ }^{476}$ The introduction of this system does create added costs for the faithful licensees and mainly serves the interests of the licensors. It is questionable whether and to what extent the burden of these added costs should be carried by the licensors.

\subsection{CASE STUDY THE DVB POOL AND NEGATIVE DISCLOSURE}

In chapter 5 , the $4 \mathrm{G}$ standard case was discussed in relation to the contribution of patent pools to innovation from a US perspective. To compare the US and EU perspective, the characteristics and rationale of the DVB pool will be discussed. The DVB project deals with standards for Digital Video Broadcasting (DVB). The standards have been widely adopted globally, both in the EU and in the US. The DVB project has an interesting IPR policy, since it includes the instrument of negative disclosure. The negative disclosure policy means that IPR holders must use FRAND conditions in their licensing terms, unless the IPR holder gives notice of the unavailability of the FRAND licensing terms. In most SSOs, the rule is applied exactly the other way around: the IPR holder discloses his essential patents and gives assurances that he will license the essential patents on FRAND terms. This system is known as affirmative disclosure. ${ }^{477}$ DVB takes an innovative bottom-up approach. The input into the commercial feasibility of a new

\footnotetext{
${ }^{475}$ Communication from the Commission: Guidelines on the application of Article 101 of the Treaty on the Functioning of the European Union to technology transfer agreements page 66.

${ }^{476}$ Philips first introduced this per batch system for DVD players, as it also makes it easier for custom officials to detect infringements.

${ }^{477}$ Elzroth IPR policy of the DVB Project: Negative Disclosure, FR\&ND Arbitration Unless Pool Rules OK p.2.
} 
product is delivered by representatives from four different sectors: infrastructure provision, consumer electronics, regulators and content providers. These stakeholders can rapidly react to market changes and provoke the creation of a new standard. ${ }^{478}$ For the role of standards in the EU's industrial policy, it is important to distinguish the DVB's bottom-up approach from the top-down approach, which bears the risk that a national government will support a standard that is not adopted by a critical mass of consumers and, due to the network externalities, a different standard will gain more consumer recognition. ${ }^{479}$ The DVB project includes regulators and representatives of various business levels in the digital broadcasting industry in its decision-making process. For the adoption of the standards, DVB established formal links to ETSI and CENELEC. The recent informal discussions on the approval of ex ante royalty rates by regulating bodies, paves the way for standard-setting organizations to be more actively involved in licensing terms discussions. The fact that this is not yet officially approved makes the discussion of licensing terms in SSOs still very sensitive. SSOs still form a group of potential and actual competitors and therefore any discussion on licensing can have repercussions from competition regulators. In the past, SSOs have always clearly separated the technical side of standard setting from the commercial part of agreeing on licensing terms. In the present commercial climate of the telecommunications industry, it would be somewhat naive to maintain that the engineers or representatives discussing the best technical solution will not have any interest in the commercial gains at stake. The regulatory authorities will focus on the fact that the technical side of adopting the best available technology can already be implemented with the commercial stakes and, thus, the licensing terms remaining in the back of the minds of the Technical Committee. Against this background, the positive attitude of competition authorities towards patent pools can be explained. When establishing a patent pool, it is questionable whether this can be done within the regulatory framework of an SSO or whether it should be done outside this context. In practice, it seems that these discussions start in an unofficial manner on the brink of the SSOs. ${ }^{480}$

DVB closely cooperates with ETSI and CENELEC for the formal adoption of its standards. As a result of the Rambus case, ETSI reviewed its IPR policy and thereby indirectly influenced the DVB project. Most IPR policies in this field address regulatory, industrial and business needs. This mixture of stakeholders is reflected in the decision of the IPR policy makers to include more innovative or well-established elements. Since the decision making in this field is based upon consensus, the considerations for the IPR policy and the strategic reasons for forming a patent pool are often related to the number of firms holding essential patents, the firm's size and their commitment to joint coopera-

\footnotetext{
${ }^{478}$ This is also interesting in relation to the effectiveness of the EU's industrial policy.

${ }^{479}$ See example of the Chinese telecommunications standard TD-SCMA as discussed in chapter 2.

${ }^{480}$ For more background see article Elzroth page 24.
} 
tion and innovation efforts. It could be interesting to investigate, in practical cases, whether an overlap between these different types of considerations exists. ${ }^{481}$

The DVB pool formulated its IPR policies in two different committees, each representing different stakeholders of the technology. As an alternative to the affirmative disclosure of essential patents, DVB gave its members two opportunities to withdraw their patents from the process. The first chance to withdraw was after the adoption of the specification and the second was very close to the adoption of the standard. This procedure could, in a technical way, still have a blocking effect, since withdrawal at the very last stage could result in the acceptance of a lesser technology, which is undesirable from a competitive perspective. The justifications for withdrawal after the technical specification has been set are two-fold. Article 14.1 states that IPRs do not have to be licensed on FRAND terms if it concerns patents "for which it will not or has no free right to make licences available." ${ }^{482}$ Theoretically the patent holder could have given an exclusive licence to a third party, although it raises the question of why this firm would decide to participate in the DVB project. Secondly, Article 14.3 mentions the following reason: "the Member can demonstrate that a major business interest will be seriously jeopardized." ${ }^{483}$ The definition of "major business interest" is not clarified and it would be very interesting to hear the views of the DVB on this subject.

Article 14.5 of the DVB IPR policy declares:

"14.5 This Article covers digital video broadcasting via satellite, cable, terrestrial and broadband wireless (MMDS, LMDS, etc) means and incorporating the global MPEG2 standard for source coding and multiplex to the extent possible, together with the relevant aspects of the related receiving equipment (including in each case scrambling) and does not cover associated matters such as conditional access. For the avoidance of doubt Article 14 does not cover the IPR arising from the MPEG2 standard itself". ${ }^{484}$

The point raised about the subject of "conditional access" is interesting. This refers to the technology that is used to manage access to electronic information. Electronic access technology can be used in an anti-competitive way, leading to a monopolization of

\footnotetext{
${ }^{481}$ The commercial success of a standard may depend on the legal certainties regarding the royalty levels. Any clarification by means of establishing a patent pool would facilitate the adoption of the standard.

${ }^{482}$ Article 14.1: Within 90 days from notification of approval of a specification by the Technical Module, each Member shall, on behalf of itself and its affiliated companies, submit to the chairman of the Steering Board a list of all the IPRs owned or controlled by the Member or any of its affiliated companies, to the extent that the Member knows that such IPRs will be necessarily infringed when implementing such specification and for which it will not or has no free right to make licences available.

${ }^{483}$ Article 14.3: A Member shall have the right up until the time of final adoption as a standard by a recognised standards body of a specification approved by the Steering Board to declare to the DVB Steering Board that it will not make available licences under an IPR that was subject to the undertaking for licensing pursuant to Article 14.2 above, only in the exceptional circumstances that the Member can demonstrate that a major business interest will be seriously jeopardized.

${ }^{484}$ DVB IPR policy article 14.5.
} 
the consumer group. The rapidly advancing technology can create a technical bottleneck which makes it difficult for newcomers to enter the market. The technical dominance of the standard can lead to a lock-in situation in the absence of interoperability alternatives; the consumer is virtually locked into the standard because of the financial burden of the switching costs. ${ }^{485}$ This is an example where the lock-in effect is not limited to the firms participating in the various parts of the distribution chain but finally it also directly affects the consumers, justifying a closer examination by competition policy enforcers.

\subsection{THE ELEMENT OF ARBITRATION IN THE DVB PATENT POOL}

The innovative character of the DVB pool also becomes evident in the concept of using arbitration as a means of dispute settlement between DVB members. The IPR policy already contains a provision that DVB members, in case of a notice of the unavailability of the IPR, will not constitute a claim of willful patent infringement, possibly leading to substantial financial damages. In Article 14.7 the members agree on the use of arbitration as a dispute-settlement mechanism. ${ }^{486}$ This provision can obviously only be used by members of the DVB project. An obvious dispute might arise over the definition of the licensing terms, more specifically the FRAND terms. Arbitration is often criticized since it is expensive and can take a long time before a decision is made. In the case of the DVB project, the initial choice for arbitration was motivated by an earlier failed attempt by ETSI to include arbitration as a form of dispute settlement. Since the DVB is a private organization, it does not carry the political burden of ETSI. The combination of patent pooling and arbitration seems to have had a decreasing effect on the number of disputes that have arisen. From a technical perspective, the DVB members develop technical specifications which, subsequently, can be adopted by a formal standardizing body, such as ETSI or CENELEC. In the latter case, it does mean that a firm participating in the DVB project will be subjected to two different systems of IPR policies. In the first case (DVB), a system of negative disclosure means that the firm does not have to reveal its essential patents, unless these cannot be licensed on FRAND terms. As soon as an SSO implements the DVB specifications into the standard, the IPR policy moves to a positive disclosure, requiring firms to communicate their essential patents. This combi-

\footnotetext{
${ }^{485}$ For more background see the study of Herberger: Controlling Access to Content - Regulating Conditional Access in Digital Broadcasting.

${ }^{486}$ Article 14.7: Each Member hereby agrees, on its behalf and on behalf of its affiliated companies, that, subject to clause 14.9 of this Article 14, all disputes with any other Member of these statutes (MoU) regarding solely the terms and conditions of licences arising in connection with the undertaking in this Article 14 shall be finally settled under the Rules of Conciliation and Arbitration of the International Chamber of Commerce by three arbitrators appointed in accordance with such Rules. Arbitration shall take place in Frankfurt, Germany. German substantive law shall apply. The language of the arbitral proceedings shall be the English language unless agreed otherwise between the Members.
} 
nation of IPR policies leads to stacking, but at the same time it could lead to strategic behaviour by firms involved in the standardization.

The World Intellectual Property Organization (WIPO) has an Arbitration and Mediation Centre. This Centre could also give decisions in SEP/FRAND-disputes. It is a neutral forum, with the obvious advantage that is has experts in the field that can apply procedural flexibility. In particular, the confidentiality and the protection of the privacy of parties are relevant for SEP/FRAND disputes. The most important limitation is that parties need to achieve consensus to use arbitration and the decision has an inter pares effect, as no public precedent is created for future reference. Examples of using arbitration can be found in: DVB, VITA, Blue Ray Disc Association and the Open Mobile Alliance. The ETSI IPR policy specifically refers to mediation. ${ }^{487}$

The question arises: should SSOs be advised or encouraged to adopt the arbitration as a dispute settlement mechanism?

The legal counsel of DVB, Carter Elzroth, claims in an article that their choice by DVB for the substantive law of Germany was made purely because of operational circumstances. ${ }^{488}$ The choice of Germany as a forum selection has more than just operational consequences however. German courts are relatively popular for conducting patent infringement proceedings. German courts have adopted groundbreaking decisions in the aforementioned disputes related to refusals to license, in particular. The refusal to license can violate Article 102 TFEU. In a number of court cases, the European Court of Justice established four cumulative requirements: ${ }^{489}$

- Indispensability of access, which is relevant in relation to standardized technology.

- Exclusion of "effective competition".

- Negative effect on innovation, new products cannot evolve, technological progress is limited.

- $\quad$ There is no objective justification for the refusal to license. ${ }^{490}$

The choice of Germany as the preferred jurisdiction has some strategic consequences, although this was not obvious in 2008. Germany has the best-performing economy in the EU at the time of writing, thereby constituting one of the most profitable telecom-

\footnotetext{
${ }^{487}$ There is a WIPO Model Submission Agreements to facilitate referral of FRAND/SEP disputes to WIPO Center, see WIPO ADR for FRAND Disputes.

${ }^{488}$ Eltzroth (2008). IPR Policy of the DVB Project: Negative Disclosure, FR\&ND Arbitration Unless Pool Rules OK Part 1.

${ }^{489}$ The relevant court cases were Volvo v Meng (ECJ, 1988) - design protection, Magill (ECJ, 1995) - copyright, IMS Health (ECJ, 2004) - copyright and Microsoft (CFI, 2007) - trade secrets.

${ }^{490}$ See also the comments made by Drexl: Competition Law Defenses to Patent Infringement in Germany Consequences for EU Law on 28 April 2011.
} 
munications consumer markets in the world. The German courts are famous for their expertise in patent law cases, since their technology-driven economy values intellectual property rights. The court proceedings are, in comparison to the UK, relatively cheap, but still fast and efficient. The EU rules on jurisdiction enable firms to sue firms for patent infringements that occur in Germany. In general, firms have the tendency to see German patent courts as a testing ground for the EU market and will settle their disputes based upon the decision by the German court. Other strategic considerations for choosing German courts are the possibility to apply both EU and German competition law to the disputed case and the fact that German judges decided classic cases in the past. Richard Vary, Head of IP Litigation for Nokia, explained that, although there is no single strategy for patent litigation, using the German system holds definite advantages.

The German patent court system uses a split approach. Strategically, it can be interesting to get an injunction (a higher test) before the patent is invalidated (a lower test). ${ }^{491}$ The court examining the infringement will use a very broad test, whereas the validity court will be much more focused. The patent court in Mannheim has evolved as the premier court for patent cases in Germany, based on the timeframe for delivering the decision (on average seven months) and the experience of judges in relation to telecommunications cases, who deliver quick and well-reasoned decisions.

At the same time, choosing a UK court for a validity test of the patent could also prove to be rewarding. A possible declaration of invalidity of the patent in a UK court would support an injunction case in Germany. ${ }^{492}$ The establishment of the EU Unitary Patent Court system is expected to lead to a radical shift to patentee-friendly courts. ${ }^{493}$ As a consequence, some manufacturers might place distribution centres outside the UPC court's jurisdiction to escape the patentee-friendly environment.

The Unitary Patent Court system could provoke FDI -investments outside the UPC jurisdiction.

\section{France as an alternative forum for enforcing SEPS?}

The strategic role of ETSI in the development of telecom standards such as the $2 \mathrm{G}$ (GSM), $3 G$ (UMTS) and 4G (LTE) is beyond any doubt. ETSI has an IPR policy that tries to find a balance between the development of standards and the interests of the IPR owners. The ETSI IPR policy is governed by French law (Article 12 ETSI IPR policy). This justifies a closer examination of the treatment of SEPs under current French law. In comparison to Germany or the US, the French case law is developing in a somewhat more limited way.

\footnotetext{
${ }^{491}$ The same strategy can also be used in China, where Chinese firms can sue two or three times for invalidity before the injunction case will start.

492 In the UK court, the instrument of Expedition could move the case forward in the queue, which is important in order to get a quick decision.

493 Discussion with Richard Vary Nordic IPR 2013 conference.
} 
The first case that dealt with the definition of essential patents in France was the French Telecom/TCT Mobile case ${ }^{.494}$ The case before the Court of First Instance in Paris found that the essentiality of a patent is uncertain and needs to be established by a court ${ }^{495}$ Regarding the FRAND commitment, French law does not provide a clear definition. According to a prominent French IP lawyer, Marina Couste, the FRAND commitment must be seen as a "stipulation pour autrui". This is a tripartite mechanism based on article 1121 of the French Civil Code. In this mechanism, ETSI must be seen as the stipulator that obtains from the promissory, in this case the patentee, the granting of a FRAND licence for the user of the standard. ${ }^{496}$ Couste mainly takes the principle of freedom to contract as a basis for the FRAND discussion. This means that the potential licensee should not act in bad faith. Acting in bad faith could lead to tort liability and the payment of damages. Examples of bad faith could be: despite negotiations no real willingness to conclude a contract, stalling the negotiations or ending the negotiations at a final stage without proper justifications. The French case law on bad faith in contract law is very extensive and could also be used in the future by litigants for SEP disputes involving ETST-encumbered patents. In a recent case from October 2014, the French Supreme Court allowed patent owners temporary measures, even though the patents had expired (details of the case are not available at the time of writing). In the near future, a few SEP cases will be decided by French courts, which might lead to another alternative forum for litigating patents.

ETSI's IPR policy is governed by French law. French contract law has extensive rulings on the principle of bad faith that may also be applied to the SEP discussion. In the near future, more SEP cases will be decided by French courts, which might lead to interesting results.

\subsection{CASE LAW IN THE EUROPEAN UNION}

\section{The Standard-Spundfass case}

One of the classic cases in the EU was the decision of the German Federal Supreme Court in Standard-Spundfass in 2004. In this case, the refusal to license was evaluated by German competition law using Section 20 para. 1 of the German competition law

\footnotetext{
${ }^{494}$ FRANCE TELECOM, TDF and others vs. TCT MOBILE EUROPE, ORANGE VALLEE, 22.11.2012, RG n¹0/18196.

${ }^{495}$ In the present case, it is demonstrated by the evidences in the debates, that the standard ISO/IEC 11172-3 published in its French version for the first time on January 8, 1993 has implemented the patent EP 532 owned by the company INSTITUT FÜR RUNDFUNKTECHNIK (...).

"Consequently, all products bearing the mention DVB-TNT necessarily propose to customers the technology retained in the ISO/IEC 11172-3 standard and the manufacturers of these products must have concluded a license agreement with the SISVEL company or they would commit an infringement of the above-mentioned patents."

${ }^{496}$ Based on a personal discussion with Marina Couste, held on 3 December 2014 in London.
} 
(Act Against Restraints of Competition/Discrimination). This case discussed essential patents included in a standard established by an SSO. The main conclusion of the German Federal Supreme Court was that the standard attributed the market to the patent holder, not the technological superiority of the patents. The industry standard left potential entrants to the downstream market no alternative choice of technology, with the resultant situation that the patent gave market dominance to the patent holder, which, in his licensing practices, restricted access to the market, thereby discriminating and thus violating competition rules.

Furthermore, this application of the legal rationale of the case was specifically limited to standards and the duty to license the patents, which always exists; the discrimination does not have to be shown before the court.

\section{The Orange Book standard, a competition law solution?}

The Orange Book standard case dealt with technology for rewritable discs and the judgment was delivered by the German Federal Supreme Court in 2009. This case was already mentioned earlier in this chapter. In this case, the plaintiff, Philips, demanded injunctive relief for an infringement of its patents. The most important question was: can the standard be used without a licensing agreement? The court noted the following points in its answer:

- The German Bundesgerichtshof accepted the antitrust law compulsory licence defence.

- The general application of the principle of good faith weighs the consequences of the injunction against the duty to deal.

- The plaintiff has to act as a good licensee would, showing good faith, meaning that the validity of the patent must not be questioned and the plaintiff has to act according to reasonable and fair licensing conditions and show his willingness to meet these licensing requirements and pay royalty fees.

- The patent owner does not abuse his dominant position if:

A. The market dominating position of the patent owner was obtained on grounds that the patent adheres to a standard.

B. The licensee has to make an unconditional offer that the patent owner cannot reject.

The Orange Book case shows that a FRAND commitment is a declaration of intent by the patent owner to grant a licence to parties that are willing to agree to act as "willing licensees". Lundqvist makes the correct statement that the consequences of the Orange Book decision should not be underestimated. If infringers of SEPS act as willing licensees, the patent owners no longer have access to injunctive relief. This would almost 
hint at a compulsory licence scheme and more importantly, it means that intellectual property rights are treated differently compared to normal property rights. ${ }^{497}$

The Commission's Statement of Objectives in the Samsung case of 21 December 2012 states that, in a case in which the patent owner gave a FRAND commitment and the licensee is seriously willing to negotiate the FRAND rate, failure to do so by the patent owner and consequently asking for an injunction harms competition rules. Dutch courts have had a different stance in relation to actions for injunctive relief. ${ }^{498}$ In the Apple vs. Samsung case (March 2012), the Court in the Hague held that asking for injunctive relief may lead to the exclusion of products from the high-tech market and could possibly distort licensing negotiations.

In March 2013, the District Court in Dusseldorf, decided to postpone its decision in the Huawei/ZTE case in order to ask for a preliminary ruling (Article 267 TFEU), so that the ECJ would clarify:

- The relevant standard under Article 102 TFEU

- The requirements of "willingness to negotiate" or "unconditional offer to conclude License agreement" (if the respective standard is relevant). ${ }^{499}$

Many legal experts expected the District Court of Dusseldorf to lean towards the existing Orange Book standard. This would mean that the application of the conditionality of

\footnotetext{
${ }^{497}$ See also Lundqvist page 327.

498 IGIR Expert Lecture 31 May 2013 Relevant Case: Philips vs. SK Kassetten and Apple vs. Samsung (14 March 2012).

499 The questions of the preliminary ruling were the following: Does an SEP owner who declared his willingness to grant a license to all third parties on FRAND terms before a standard-setting organisation, abuse his dominant position on the market if he seeks injunctive relief against a patent infringer who has declared his willingness to negotiate such a license; or is the abuse of a dominant position only presumed, if the infringer has made a binding unconditional offer to the SEP owner which the SEP owner cannot refuse without inequitably obstructing or discriminating the infringer and if the infringer, in anticipation of the granted already complies with the contractual obligations regarding the past use of the patent?
}

2. If an abuse of a dominant position should already be presumed resulting from the infringer's willingness to negotiate: Does Article 102 TFEU require any specific substantive and/or temporal criteria to be satisfied for the willingness to negotiate? Can such a willingness already be presumed, if the patent infringer merely (orally)declares his willingness to enter into negotiations in general terms or does the infringer have to have entered into negotiations, for example, by offering specific terms and conditions under which he is willing conclude a license agreement?

3. If an abuse of a dominant position should require the submission of a binding and unconditional offer to conclude a license agreement: Does Article 102 TFEU require any specific substantive and/or temporal criteria to be satisfied in relation to such an offer? Does the offer have to include all commercial terms that are usually included in license and unconditional offer to conclude a license agreement?

4. Does Article 102 TFEU require any specific substantive and/or temporal criteria to be satisfied in relation to such an offer? Does the offer have to include all commercial terms that are usually included in license? See for more background: Gallasch, The referral of Huawei v. ZTE to the CJEU: Determining the future of remedies in context of standard essential patents page 2201334 E.C.L.R., Issue 8. 
the standard would be handled in a lenient way. ${ }^{500}$ The explanation of the ECJ could also harmonize the approach towards injunctions involving SEPs. A more harmonized case law would prevent companies from forum shopping, since the example of the decision of the The Hague District Court illustrated that the Orange Book standard is not followed by all national courts in the EU.

In May 2013, the EU Commission decided to reiterate the Samsung standard in their Statement of Objections to Motorola:

"In addition, in the Commission's preliminary view, the fact that the potential licensee challenges the validity, essentiality or infringement of the SEP does not make it unwilling where it otherwise agrees to be bound by the determination of FRAND terms by a third party. In the case at hand, Motorola required clauses that prohibited such challenges by Apple, even after Apple had agreed to be bound by a third party determination of the FRAND terms. The Commission's preliminary view is that it in the public interest that licensees should be able to challenge the validity, essentiality or infringement of SEPS."

"the Commission takes the preliminary view that the seeking of an injunction for SEPS can constitute an abuse of a dominant position in the exceptional circumstances of this case - where the holder of a SEP has given a commitment to license these patents on FRAND terms and where the company against which an injunction is sought is willing to negotiate a FRAND licence."

The text directly addresses the interpretation of the Orange Book standard by the lower German courts. This raises the question of the proper role of the EU Commission. Should the EU Commission DG Competition give guidance to national courts on FRAND and injunctions? It is most likely that the Commission could set general guidelines on FRAND but not determine individual rates. The Commission can give guidance on the royalty base. Nevertheless, it is very surprising that the EU Commission is continuing with cases, even though there has been a request for a preliminary ruling from the ECJ on the subject of injunctions. It is very unlikely that the Commission would give guidance to the ECJ. The preliminary ruling of the ECJ will be binding on the Commission and have a strong impact on the current cases that the Commission has not yet suspended.

At the time of writing, it is insufficiently clear whether the Orange Book standard decision influences other defences in the intersection of IP and Competition Law. The impact of competition policy seems to be particularly limited in this field. In the relationship between German and European competition law, the impact of this decision on the enforcement of EU competition law has also become more complicated. In relation to US antitrust law, it is again interesting to evaluate this decision in view of the US

\footnotetext{
${ }^{500}$ Discussion with German legal practitioners, Brussels IP \& Competition Law conference 26 September 2013.

501 European Commission, Samsung-Enforcement of ETSI standards essential patents (SEPS), MEMO/ $12 / 1021$.
} 
decision in the eBay case, although a duty to license does not seem evident at this time in the United States.

In the eBay/MercExchange case, US courts used patent law to stop PAEs from using injunctions. The court concluded that an injunction is related to equity. The US courts developed a four-part test for the granting of an injunction:

1. The plaintiff must have suffered irreparable damage.

2. There should be a balance of hardship between the plaintiff and the defendant.

3. A permanent injunction would harm public interest.

4. Other legal remedies, like a damages award, are inadequate. ${ }^{502}$

In January 2013, the FTC reached a settlement in the Google/MMI case. The Consent Order focused on the strategy of Google/MMI to use injunctions for their FRANDencumbered SEPS. Basically, the FTC only allowed Google/MMI to ask for injunctive relief in the case of recalcitrant unwilling licensees, who do not want to enter into negotiations. The FTC laid out specific conditions that justify a request for an injunction:

Google was permitted to seek injunctive relief only in the following four narrowlydefined circumstances:

1. the potential licensee is not subject to United States jurisdiction;

2. the potential licensee has stated in writing or in sworn testimony that it will not accept a licence for Google's FRAND-encumbered SEPs on any terms;

3. the potential licensee refuses to enter a license agreement for Google's FRANDencumbered SEPs on terms set for the parties by a court or through binding arbitration; or

4. the potential licensee fails to assure Google that it is willing to accept a licence on FRAND terms. ${ }^{503}$

The decision of the German Federal Supreme Court addressed both the admissibility and the content of a competition law defence in a conflict between patent law and the access of technical standards. In a prior decision, the Court discussed the refusal of a company to license competitors in the same market. ${ }^{504}$ In the Orange Book case, the context was different, since it involved a refusal to license non-competitors. The German Supreme Court did accept the admissibility of the competition law defence but

\footnotetext{
${ }^{502}$ The result of the eBay test is that injunction requests are now granted at $75 \%$, while it used to be $95 \%$. See also Chien \& Lemley, Patent Holdup, the ITC, and the Public Interest.

503 Analysis of Proposed Consent Order to Aid Public Comment: In the Matter of Motorola Mobility LLC and Google Inc., File No. 121-0120, at 6, available at http://ftc.gov/os/caselist/ 1210120/130103googlemotorolaanalysis.pdf.

${ }^{504}$ Standard-Tight-Head Drum case German Supreme Court 12 July 2004, 36 IIC 741 (2005).
} 
narrowed the conditions of admissibility. This decision was a strict, but patenteefriendly decision.

The decision has serious repercussions for firms deciding to initiate an action for injunctive relief. Ullrich raises the interesting question whether this means that the burden of proof for injunctive relief has been simply modified or if it is a more substantial decision in the relationship between patent law and competition law. ${ }^{505}$ Introducing more restrictive conditions for the admissibility of competition law in disputes concerning the use of patents in standardization shifts the advantage of the balance between proper remuneration of patents in standards and the possible risk of violation of competition rules in favour of the patentee. The balance between the legal rules on patents and competition law is even more sensitive in the case of standardization. The recent court cases against market-dominant firms like Microsoft have provoked many academic discussions on the parameters used by regulatory bodies in relation to dominance. When has a firm become too dominant?

Some scholars compare the network externalities benefits and the monopoly costs. ${ }^{506}$ Network externalities returns consist of the value that the consumers attain from the wider adoption of the product or services. The wider adoption leads to increased development of complementary goods, more compatibility and, consequently, to more efficiency in the further funding of R\&D projects, which also benefits the consumer. The monopoly costs relate to the fact that the dominant firm can charge higher consumer prices and the development of alternative technologies is halted. A firm has the ability to influence the development of the monopoly costs by deliberately charging lower than the maximum consumer prices. The second element of monopoly costs that can be influenced is controlling the business environment of the relevant product market. In this business environment, firms can choose to support selective suppliers or complementors and thereby dominate the market. This discretionary power of firms is mostly governed by the application of competition law to the use of patents in standard setting.

The ultimate goal of competition law in this context is to encourage and support the development of innovation-driven technology markets enabling the relevant trading bloc to become more competitive in the global market place.

The interpretation of this goal is strongly dictated by the characteristics of national technology markets. Given the very strong position of Germany in the EU technology market, the impact of the Orange Book case should not be underestimated. The German Supreme Court made the use of the competition law defence dependent on the ability of the user of the standard to show that the conditions of the licence are abusive. This undermines the effectiveness of the instrument of injunctive relief and shifts the

\footnotetext{
${ }^{505}$ Regarding the burden of proof, Ullrich states that the Court follows the reasoning that the injunctive relief would be used to obtain better licensing conditions.

${ }^{506}$ See also Schilling: Strategic Management of technological Innovation McGraw-Hill page 85.
} 
balance clearly in favour of the interests of the patentee. Defending the interests of the patentee corresponds with the present German business culture, which nourishes the development and rewarding of technological innovation. Ullrich and other scholars fear that this could lead to a "technological splendid isolation" of the German industry in the global market for technological innovative products. ${ }^{507}$

The Orange Book decision of the German Supreme Court has been interpreted in various different ways. The lack of certainty and the importance of Germany as a catalyst for the European technology market could have serious consequences for the relationship between patent law and competition law. The preliminary ruling of the ECJ tried to clarify the situation and initiate a more harmonized approach towards injunctions in the EU. The EU Commission is searching for a proper role in this discussion and might become more proactive in formulating general guidelines on FRAND and the royalty base.

\subsection{RECENT VIEWS OF THE COMMISSION ON THE INJUNCTIONS AND SEP DEBATE.}

On 29 April 2014, the EU Commission accepted legally-binding commitments by Samsung related to SEPs.

Samsung committed itself not to seek injunctions against companies who become part of a specified licensing programme. Samsung will refer all disputes related to FRAND rates to a court or, if both parties agree, to an arbitrator. In a reaction, VicePresident Almunia stated that: "In this context, I welcome Samsung's commitment to resolve disputes on standard essential patents without having recourse to injunctions in a way that could harm competition ${ }^{508}$

Samsung initiated this five-year programme to address some of the objections made by the EU Commission. This programme has the following elements: a negotiation period of a maximum of 12 months and, in case of no agreement, a third party (court or arbitrator) will set the FRAND rates.

This withdrawal is seen by some commentators as a further erosion of the fundamental rights by patent owners in reaction to "regulatory antitrust activism". Scholars argue that the case law on the abusive use of injunctions is still developing, but, to prevent heavy fines, some firms are consciously limiting the rights of exploitation of their patent rights. ${ }^{509}$

On the same day (29 April 2014), the EU Commission adopted a decision that Motorola Mobility abused its dominant position by seeking and enforcing an injunction

\footnotetext{
${ }^{507}$ See Ullrich in Drexl, Research Handbook on Intellectual Property and Competition Law page 6.

${ }^{508}$ EU Press Release 29 April 2014 Antitrust: Commission accepts legally binding commitments by Samsung Electronics on standard essential patent injunctions .

${ }^{509}$ See also Petit "Stealth Licensing" page 20.
} 
against Apple based on a SEP. Motorola enforced an SEP-based injunction against a willing licensee (Apple), which had a negative impact on licensing negotiations and can exclude Apple products from the market. In this case, Apple acted as a willing licensee, since it accepted to pay the FRAND royalty fees that were determined by a German court. Nevertheless Motorola insisted that Apple would not challenge the validity or infringement of Motorola's SEPs by Apple products. Again, Vice-President Almunia reacted with the following: "Our decision on Motorola, together with today's decision to accept Samsung's commitments, provides legal clarity on the circumstances in which injunctions to enforce standard essential patents can be anti-competitive. This will also contribute to ensuring the proper functioning of standard-setting in Europe. While patent holders should be fairly remunerated for the use of their intellectual property, implementers of such standards should also get access to standardised technology on fair, reasonable and non-discriminatory terms. It is by preserving this balance that consumers will continue to have access to a wide choice of interoperable products". 510

The Motorola/Apple case leads to some conclusions regarding the definition of dominance. Relevant factors are: a relevant market of technology products with embedded SEPs, there are no substitutes available on this market, indispensability of the patent with lock-in effects, and, finally, no countervailing buyer power. This means that, if there is no substitute to the SEP, then this forms a separate market. The abuse is related to the specific circumstances: standard setting and the commitment to license on FRAND terms. The text of the Motorola decision stated the following:

(278) Finally, a patent holder, including a holder of SEPS, is generally entitled to seek and enforce injunctions as part of the exercise of its IP rights. The seeking and enforcement of injunctions cannot therefore, in itself, constitute an abuse of a dominant position.

(294) By committing to license on FRAND terms and conditions, Motorola recognised that, given the standardisation context, it has chosen to monetise its standard essential technology through licensing on fair, reasonable and non-discriminatory terms and not to use it to exclude implementers of the GPRS standard provided that it is appropriately renumerated for the use of its technology. On the basis of that commitment, manufacturers of GPRS-compliant products can reasonably expect that Motorola makes its SEPS available on FRAND terms and conditions to all implementers."

This results in anti-competitive effects against willing licensees. The anti-competitive effects are the temporary exclusion from the market and the acceptance of less attractive licensing terms. Apple probably would not have accepted without the threat of the injunction and the negative effects on standard setting.

The following sheds light on the objective justification:

\footnotetext{
${ }^{510}$ EU Press Release 29 April 2014, Antitrust: Commission finds that Motorola Mobility infringed EU competition rules by misusing standard essential patents
} 
(437) (...) With its Second Orange Book Offer, Apple proposed to enter into a licensing agreement with full judicial review and determination of the proposed FRAND royalties with retroactive effect by a court. As regards the scope of the second Orange Book Offer, as outlined in recitals (12)-(126), it covered all Apple products infringing the licensed SEPS in Germany. Hence, this offer was a clear indication of Apple's willingness to enter into a licensing agreement on FRAND terms and conditions.

(439) Second, Apple's initial refusal, after its Second Orange Book offer, to agree to licensing terms that would de facto prevent it from challenging the validity and infringement of Motorola's telecommunication SEPs in Germany is not a sign of unwillingness to enter into a licence agreement for those SEPS on FRAND terms and conditions.

Some EU experts also link this case to the balancing of rights and interests. The rights linked to IP are covered by Article 17 of the EU Charter of Fundamental Rights. In this reasoning, the right to oppose the potential infringements of patent rights through injunctions is a corollary to a property right. ${ }^{511}$

Vice-President Almunia stated: "These principles strike the right balance between the interests of patent holders, who should be fairly remunerated for the use of their intellectual property, and those of the implementers of standards, who should get access to the standardised technology without being "held up" through abuses of market power."

The prohibition decision against Motorola should set a precedent and provide guidance to the industry. ${ }^{512}$ Unfortunately, despite the comments of Almunia, there is still a need for more guidance and an explanation of the Commission's view on injunctions and SEPs. I will give some examples in the following paragraph.

As previously discussed in section 5.5 .2 some commentators believe that compulsory licensing can be relevant since the operability of standards is of crucial importance. Article 102 TFEU states that there is no general duty to license but only exceptional circumstances render the refusal abusive. ${ }^{513}$ In the case law, the ECJ described "exceptional" as a use that excludes other companies from using the property right in a way that is not consistent with its essential function. ${ }^{514}$ Normally applying FRAND terms will

\footnotetext{
${ }^{511}$ Art. 52 (1) of the EU Charter of Fundamental Rights allows restrictions of Article 17 if: provided by the law, motivated by objectives of general interest, do not constitute a disproportionate and intolerable interference impairing the very substance of these rights, necessary to protect the rights and freedoms of others. Motorola referred to the ITT Promedia/Protégé International case.

512 Introductory remarks on Motorola and Samsung decisions on standard essential patents Commission Européenne - SPEECH/14/345 29/04/2014 (http://europa.eu/rapid/press-release_SPEECH-14345_en.htm?locale=FR)

${ }^{513}$ See also the decision in the cases: IMS, Microsoft and Magill.

${ }^{514}$ Examples include:

-a property / upstream supply is indispensable for competition in a neighbouring market and the dominant firm is the only source,
} 
solve this problem. However, it can be concluded that compulsory licensing is appropriate in case of essential patents and that dynamic competition and innovation would be encouraged through the licence. A critical element in the terms and conditions for the compulsory licence is the tying of essential and non-essential patents. Also, it is not clear whether the tying of essential products should be done on a per standard or on a per product basis. For patent pools, this is a very important question. Although patent pool administrators claim that a technical expert checked the essentiality of the patents in the pool, the growth of the volume of patents in a pool make this virtually impossible. The position of FRAND-encumbered non-essential patents is even more difficult. The Motorola and Samsung decisions do not provide any clarification or explanation. Perhaps it would be more relevant to look at earlier case law such as the Microsoft and Commercial Solvents cases.

In principle, Article 102 TFEU does establish certain limits to the exercise of IPRs. However, at the same time, Article 47 of the EU Charter states: "Everyone whose rights and freedoms guaranteed by the law of the Union are violated has the right to an effective remedy before a tribunal". 515

Article 11 of Directive 2004/48/EC on the enforcement of IPRs requires Member States to guarantee that a right to an injunction for infringements of IPRs is available in national courts. A further explanation can be found in the ITT Promedia case. In this case, the ECJ decided that it would only be abusive in exceptional circumstances to start a court case for the protection of intellectual property rights. ${ }^{516}$ In a later case, Protégé International Ltd, the Court found: "it is not a question of determining whether the rights which the undertaking concerned was asserting when it brought its action actually existed or whether that action was well founded, but rather of determining whether such an action was intended to assert what that undertaking could, at that moment, reasonably consider to be its rights." 1517

\footnotetext{
- the property owner refuses to license competitors or customers,

- refusal creates a serious risk of elimination of all effective competition in the downstream market (even though the IPR does not apply to the downstream product or is only a component of it);

- consumer harm by reduction of dynamic competition (including the exclusion of a new product for which there is demand), and

- the refusal to deal lacks objective, proportionate justification.

${ }^{515}$ Article 47 EU Charter.

516 ITT Promedia 17 July 1998 (Case T-111/96) the Court said: "As access to the Court is a fundamental right and a general principle ensuring the rule of law, it is only in wholly exceptional circumstances that the fact that legal proceedings are brought is capable of constituting an abuse of a dominant position." The Court also introduced two specific tests:

the action "cannot reasonably be considered as an attempt to establish the rights of the undertaking concerned and can therefore only serve to harass the opposite party" and "it is conceived in the framework of a plan whose goal is to eliminate competition".

${ }^{517}$ Protégé International Ltd, 13 September 2012 (Case T-119/09).
} 
Other experts see a problem between FRAND defences and the Unified Patent Court (UPC). Article 32 of the UPC Agreement states the following regarding the competence of the court:

a) actions for actual or threatened infringements of patents and supplementary protection certificates and related defences, including counterclaims concerning licences;

Some experts claim that "related defences" could also be a FRAND defence after the Motorola decision. ${ }^{518}$ Article 24 of the UPC agreement declares in relation to the sources of law:

1) In full compliance with Article 20, when hearing a case brought before it under this Agreement, the Court shall base its decisions on:

a) Union law, including Regulation (EU) No $1257 / 2012$ and Regulation (EU) No $1260 / 2012(1) ; \ldots$

e) national law.

This provision further complicates the discussion. National law is only necessary if there is no relevant EU law. The UPC will probably not unify defences, since they should be based on European law and not on municipal law. The UPC may increase the litigation activities of PAEs, since the UPC-awarded injunctions have an EU-wide application. The UPC (under the current rules) will not directly investigate the validity of patents and could encourage forum shopping if the judicial discretion by the court is applied in an inconsistent manner. Bifurcation is also applied in the UPC, leading to the situation that possibly infringement proceedings take less time than the investigation on validity (the injunction gap). PAEs will see the advantages of the UPC system and one of the countermeasures can be the increased use of patent pools and defensive patent aggregators. $^{519}$

The question remains: how will the Unified Patent Court affect the FRAND and injunctions discussion? PAEs could abuse the UPC system, but patent pools would be an effective counterremedy.

\subsection{FRAND ROYALTIES}

At the heart of the discussion on injunctions and SEPS is the actual determination of the relevant royalty rates. Injunctions become relevant after a licensee refuses the FRAND offer that was made by the patentee. In this respect, I would like to emphasize that,

\footnotetext{
${ }^{518}$ Discussion Brussels Matters 19 June 2014 (Chatham House rules).

${ }^{519}$ For more background: PATENT AGGREGATION, DISAGGREGATION, AND INNOVATION Paper for EPO panel discussion by Dolmans Paper on archive with the author, presented at EPO ECONOMIC AND SCIENTIFIC ADVISORY BOARD (ESAB) 25 November 2014.
} 
although most of the attention focuses on FRAND-royalty rates, it is also important to look at the complete set of FRAND terms. Payment conditions and other contractual terms may be equally important. In the following section, I will discuss different models on how to determine FRAND terms and their relevance for patent pools.

Starting with the EU competition policy, it is obvious that there must be a reasonable link between the royalty price and the value of the patent. ${ }^{520}$ For the value, different methods can be used. Often it is seen as the rate that the patent owner could have obtained in a technology auction before the introduction of the standard (ex ante). Two aspects are essential in this discussion: the incremental value and the ex ante moment. The incremental value is established by adding the opportunity cost of the relevant patented technology (the profit that a licensee gains if it does not use an alternative technology) and the price of the next best alternative technology. This assumes that the owner of the patented technology did not exclude competition by purchasing the alternative technologies, which would amount to abuse. The ex ante aspect is relevant since the patented technology might gain extra value ex post, after a lock-in effect has occurred. If there is still competition between patents before the standard is established, this will have an effect on its value. ${ }^{521}$

One practical problem can be the absence of competing technologies or the difficulty of knowing the price of alternative technologies. In the latter case, proxies must be used to find a basis for the FRAND rate. From the US practice, the first choice would be to use the Georgia-Pacific rules. The Georgia-Pacific rules were mentioned in section 3.15 and consist of a set of factors that lead to a royalty rate as it would be set by a willing licensee and willing licensor. Since most licence rates are confidential, it uses a real market approach. Incremental value to the licensee and the communication of licensee and patentee before the standard was set (ex ante) are important factors. In recent US cases, judges have applied the Georgia-Pacific rules in a practical context.

\section{View of Judge Robart in Microsoft v. Motorola (25/04/2013)}

Microsoft wanted to get an ITC exclusion order for the ActiveSync patents against Motorola. Motorola was demanding a royalty fee of $2.25 \%$ for a video and a WLAN standard which was, according to Microsoft, not consistent with the promised (F)RAND terms. Consequently, Motorola tried to get an injunction against Microsoft in Germany but the US court (Robart) prevented this. Germany was probably chosen because of its speed and patentee-friendly climate. Robart consequently set a FRAND rate using some

\footnotetext{
${ }^{520}$ See also court case Swedish Ports.

${ }^{521}$ The EU Horizontal Guidelines also support the importance of ex ante determination: para. 289: "it may be possible to compare the licensing fees charged by the company in question for the relevant patents in a competitive environment before the industry has been locked into the standard (ex ante) with those charged after the industry has been locked in (ex post). This assumes that the comparison can be made in a consistent and reliable manner."
} 
of the Georgia-Pacific criteria on an ex ante basis. In this process, three steps could be distinguished:

- How important is the patent portfolio to the standard?

- How important is the patent portfolio for the products of the infringer?

- Look at comparable licences.

Robart interestingly looked at industry comparators for guidance and used patent pool royalties as a proxy. One important consideration seems to be that ex ante the SEP does not yet have added value, which it will have after the standard becomes established and everybody uses the SEP. As a result, the FRAND rates that were set by Robart were considerably lower ( 0.555 per unit) than the original demand. This approach by Robart met with some criticism. Using the patent pool rate as proxy was, according to some commentators, unfair, since patent pool licensors sometimes use lower royalty fees to support a rapid adoption of the standard in practice. After the initial adoption and implementation of the standard, licensors will make their profits on the downstream markets. This raises a more fundamental question: whether the business model of patent pool licensing can be used as a proxy for FRAND rate setting in general technology licensing?

Robart's decision was based on the principle of the proportionality method. In this method the court analyzes the proportional share of SEPs included in the portfolio of a company to the total sum of SEPs in the standard. The court establishes that a relationship exists between the price of the components in the mobile phone and the royalty rate. $^{522}$ The proportionality analysis looks at the number of SEPs included in the standard and the costs of the components on which the SEP is implemented.

Interestingly, it is also a more fundamental discussion whether the SEP owners should be entitled to receive royalty rates that are based on the pure intrinsic value of the patent or whether the added value of standardization (created by network effects) should also be given to the SEP owners. According to Robart, the value that is created by the network effects, and consequently the increased demand, is the value of the patent hold-up. Some commentators believe that the added value of standardization is a compensation for the risk that innovators took by participating and investing in standard setting. It is argued that the added value of including the SEP in the standard is compensation for the risk that the proposed standard will fail, since there may be insufficient market adoption. In this view, the patent hold-up finances the promotion and costs of the integration of the SEPs and later of the standard in the market.

Further criticism is directly linked to the patent pool as a business form. Patent pools may differ in the overall quality of the patents included. Experts claim that the most valuable and essential SEPs will not be included in patent pool arrangements. The main

522 The price of the component can be found in the "Teardown Reports". 
aim of patent pools is to minimize the royalty rates which will help a faster adoption of the standard in downstream markets. If this would be the case, than choosing a patent pool as a benchmark for FRAND rates would have surprising effects. If the assumption is valid that patent pools strategically set low rates to support the adoption of a standard, one has to evaluate the effectiveness of this strategy. If the practice that patent pools use low royalty rates does not support the adoption of the standard, what does it mean for it basis for FRAND rates? Or, even more importantly, can it be concluded that low FRAND rates do lead to a faster adoption of the standard? The earlier economic research that was discussed suggests that the quality of patents deteriorates after the establishment of the patent pool.

A second important aspect for the use of the patent pool as a basis for FRAND royalty rates are the royalty-sharing agreements of a patent pool. This subject was already discussed previously and the different methods will have a significant impact on the actual royalty rates. Keith Malinson makes the fair comment that non-monetary terms in patent pool arrangements are also very important. Elements such as grant-back provisions, non-assertion and defensive suspension provisions can be equally important. ${ }^{523}$

Later in the same year, Judge Holderman took a slightly different approach in the Innovatio case. Holderman did not specifically look at the importance of the patents to the infringer's products, but he took the chipset as a basis. Holderman rejected the patent pool as a basis for determining the FRAND rates.

Another method was used by Judge Davis in the Ericsson v. D-Link case. ${ }^{524}$ Davis analyzed the hypothetical negotiating between a willing licensee and a willing licensor at the time of infringement and in looked at comparable licences. The first relevant factor is the royalty base. He considered whether the companies opted for a per unit royalty, a running royalty or on a lump sum base. The parties' existing bilateral licensing agreements would provide the best base for determining FRAND damages. This leads to a market approach in theory but, in practice, it will be very difficult to find accurate information, since most bilateral licensing agreements are confidential. ${ }^{525}$ Davis calculated the FRAND rates as a per unit royalty and did not apply the entire market-value rule.

A more academic approach would be the implementation of regressive analysis to FRAND. This method defines the relationship of the royalty rate per patent to the total portfolio of patents in the standard. All these methods focus on the discussion of the appropriate royalty base. In reality, there can be a gap between the real world value and the value that parties may receive in court. Some practitioners have the view that the FRAND royalty is set by the market, otherwise parties will complain and litigate.

Recently US case law used patent pool royalties as a proxy for determining FRAND rates. Does the business model of patent pool justify this application? Within this discussion,

\footnotetext{
${ }^{523}$ Mallinson in Absurd (F)RAND licensing-rate determinations for SEPs page 17.

${ }^{524}$ (2014) ERICSSON, INC. 2 v. D-LINK SYSTEMS, INC., United States Court of Appeals for the Federal Circuit.

525 In principle, patentees could be forced to disclosure the royalty rates to a court, on terms of confidence. Only possibility could be art. 8 of the EU Enforcement Directive.
} 
as a key element, is the question of how to allocate the added value after the standard is established. Should this surplus be allocated to consumers or innovative companies?

\subsection{THE OPINION OF ADVOCATE-GENERAL WATHELET IN THE HUAWEI- ZTE CASE}

Advocate-General Wathelet delivered his opinion on the Huawei-ZTE case (C-170/13) on 20 November 2014. He first comments that the Orange Book case was on a de facto standard and that the referred case was on the LTE-standard and both parties participated within ETSI to establish the relevant standard. The case was referred by the Dusseldorf court that was uncomfortable with applying the Orange Book standard. The A-G starts with the presumption of the existence of a dominant position; he does not directly assume that there is a dominant position. Wathelet suggests that the ECJ should give the following answer:

The fact that a holder of a SEP, that has given a commitment to a standardization body to grant third parties a licence on FRAND terms, makes a request for corrective measures or brings an action for a prohibitory injunction against an infringer, in accordance with Article 10 and Article 11, respectively, of the Enforcement Directive, which may lead to the exclusion from the markets covered by the standard of the products and services supplied by the infringer of an SEP, constitutes an abuse of its dominant position under Article 102 TFEU.

If the SEP holder has not honoured its commitment, even though the infringer has shown that it is objectively ready, willing and able to conclude such a licensing agreement, compliance with that commitment means that, prior to seeking corrective measures or bringing an action for a prohibitory injunction, the SEP holder, if it is not to be deemed to be abusing its dominant position, must - unless it has been established that the alleged infringer is fully aware of the infringement - alert the alleged infringer to that fact in writing, giving reasons, and specifying the SEP concerned and the manner in which it has been infringed by the infringer.

The SEP holder must present to the alleged infringer a written offer of a licence on FRAND terms which contains all the terms normally included in a licence in the sector in question, in particular the precise amount of the royalty and the way in which that amount is calculated.

According to Wathelet the infringer must:

- respond to that offer in a diligent and serious manner

- must promptly present to the SEP holder, in writing, a reasonable counter-offer relating to the clauses with which it disagrees 
- the making of a request for corrective measures or the bringing of an action for a prohibitory injunction does not constitute an abuse of a dominant position if the infringer's conduct is purely tactical and/or dilatory and/or not serious

- if negotiations are not commenced or are unsuccessful, the conduct of the alleged infringer cannot be regarded as dilatory or as not serious if it requests that FRAND terms be fixed either by a court or by an arbitration tribunal

- $\quad$ in that event, it is legitimate for the SEP holder to ask the infringer either to provide a bank guarantee for the payment of royalties or to deposit a provisional sum at the court or arbitration tribunal in respect of its past and future use of the patent.

The fact that the SEP holder takes legal action to secure the rendering of accounts does not lead to an abuse of a dominant position. It is for the national court in question to ensure that the measure is reasonable and proportionate. If the SEP holder brings a claim for damages for past acts of use for the sole purpose of obtaining compensation for previous infringements of its patent, this does not constitute an abuse of a dominant position according to Wathelet. ${ }^{526}$

The next question is whether the ECJ would follow the opinion of A-G Wathelet or apply the Orange Book standard? In my opinion, it is surprising that the A-G does not refer to the ITT-Promedia case. The opinion of Wathelet does not provide more guidance and transparency. If the SEP owner takes the two steps: by informing the infringer and sending a written FRAND offer, does this consequently mean that there is no abuse of dominant position? I think it would be very important to evaluate the reaction of the SEP holder to the attitude of the licensee and its future actions. If the patentee is objectively an objectively willing licensee, the patentee does not have much room to maneuver. Two matters must be distinguished in this discussion: the circumstances that allow for a competition law defense and when is it not allowed to go to court to get an injunction. The licensing counteroffer made by the licensee must be appropriate (especially in relation to the good-faith principle).

In the A-G's opinion, it seems that he is following the reasoning of the Commission in Motorola, which seems to create more duties for potential licensees.

\subsection{THE DECISION OF THE COURT OF JUSTICE IN THE HUAWEI V. ZTE CASE.}

The decision of the Court of Justice in the Huawei v. ZTE case was highly anticipated. The main question was: under which conditions does an injunction based upon a stand-

\footnotetext{
${ }^{526}$ Opinion of the Advocate General Wathelet delivered on 20 November 2014 Case C-170\13 Huawei v ZTE. Court of Justice of the European Union PRESS RELEASE No 155/14 Luxembourg, 20 November 2014.
} 
ard-essential patent violate EU competition law? The Court reached some interesting conclusions:

- SEPs may confer market power in case they are commercially indispensable and create a lock-in effect of the technology

- $\quad$ The market power may not have existed without the standard in which the SEP is implemented

- The exercise of the patent right does not automatically lead to an abuse of a dominant position, only in exceptional circumstances

- The patent holder that gives a FRAND commitment to the SSO thereby creates legitimate expectations

- Access to the ECJ is fundamental (but not unlimited) right

The Court of Justice went on to explain a process in relation to the injunctive relief action. The process consists of the following steps:

1. A notice should be sent by the SEP holder to the alleged infringer

2. The alleged infringer must have the willingness to conclude a FRAND licence

3. The SEP holder must send a written offer, specifying the royalty rate

4. If the alleged infringer does not agree, he can send a counter offer

5. In order to provide certainty to the SEP holder, the alleged infringer must provide security (deposit/bank guarantee

6. The SEP holder and alleged infringer can agree upon a determination of FRAND by an external third party

7. The alleged infringer still has the right to challenge the validity/essentiality of the SEP

This Huawei judgment was expected to deliver a roadmap for injunctions. Unfortunately, the decision still leaves many questions unanswered. What if the licensee does not react to the FRAND offer? Should a court evaluate the FRAND offer of the licensor? Since FRAND can be a range of royalties, what if both offers are inside the bandwidth? The Huawei decision tries to balance the interests of the SEP holder and the implementers. It also seems to balance the right to do business versus the right to seek an injunction, both of which are fundamental rights. The starting point of the Commission, the Advocate General and the ECJ is that a willing licensee must be able to get a FRAND licence. The licensor made a FRAND promise and therefore raised contractual expectations. The difficulty is that, in reality, technology markets are not that clear. Implementers might also have SEPs. Often, the point is raised that limiting injunctions may lead to a reduced participation of patent holders in standardization. Personally, I think that this 
is not realistic. In practice, technology is hardly ever withheld from standards. Given the rise in the number and volume of patent portfolios, there is also a chance that the implementer is not aware of the infringement of the SEP.

Competition authorities have understood that the aim is not to look for the best technology per se. The current approach supports the best technology for the best available price. The task of mediation could be undertaken by the WIPO Dispute Mediation service. They have a specialized mechanism for FRAND disputes. However, mediation requires that all parties agree, which is not likely in case of an injunction.

It is also important whether the decision has any bearing for de facto standards. With de facto standards there is no SSO involvement, and therefore the impact on competition might also differ. Article 101 TFEU regarding the refusal to license could be relevant. Questions also remain regarding the royalty calculation method, which is interesting in relation to patent pools. The royalty base(e.g. smallest component rule of the US) was also not directly addressed in the decisions of the ECJ. Finally, in relation to patent pools, the exclusionary behavior of NPEs and patent trolls are not discussed further in the judgment. NPEs will not try to foreclose markets but will always seek monopoly rents, contributing to the Cournot problem.

\subsection{CONCLUSIONS}

\section{Differences in standardization policy}

The EU wants to increase the volume of European interoperability standards. Patent thickets and the resulting negative impact on standardizing remain as obstacles. New business forms (PAEs and NPEs) that are difficult to distinguish from patent pools have emerged. The European Union has not yet specifically addressed these business forms in the proposal for the new TTBER. Although patent pools are often referred to as a solution for the patent thicket problem, there are also scholars who think that they contribute to the aforementioned problem, and therefore further analysis is necessary to guarantee the proper functioning of the standardization process. The effect of patent pools on innovation can be hampered by the number and timing of patent declarations. An unnecessary increase in the number of patent declarations undermines the original purpose of the pool (i.e. transactional efficiency and avoidance of patent thickets). The contribution of licensees to innovation can also be served by bilateral licensing agreements. The Commission does not seem to have a preference for a specific business model. Standardization is at the heart of the competitiveness of the European industry and, particularly for the European ICT industry, standards are a tool to improve the poor global competitive position.

The recent decisions of the EU Commission (Samsung, Motorola) will not apply to de facto standards (probably the Microsoft case is more relevant). The common legal 
framework for de facto standards is not clear. It leads to the question: is a FRAND commitment necessary for de facto standards? Does the essential facilities doctrine apply to de facto standards?

\section{Management of SEPS}

The European Union made the strategic choice to evaluate the legality of patent pools in competition policy with a rule of reason approach. Patent pools are not directly discussed in the new TTBER, since they are multi-party agreements. However, the current version of the TTBER Guidelines gives the EU Commission the opportunity to clarify some of the uncertainties that are related to the safe harbour system. The safe harbour model lacks legal certainty and the different interpretations of the new Guidelines may hinder the effectiveness of competition law enforcement. This lack of clarity also extends to the legal evaluation of patent pools. The relationship between the various types of patents in the pool is leading the enforcement agenda of the competition authorities. In my opinion, the EU Commission should take a softer stance on the inclusion of non-essential and complementary patents in the pool. On this point a clear division between the EU and US approach is visible.

At the same time, a full effects-based approach to patent pools could result in a proper analysis of the competitive effects. Given the current rise in the number of patents included in a patent pool, possibilities of abuse have increased. Both the EU and US authorities do not directly address this phenomenon.

The formation of a patent pool can result in firms having a dominant position on the EU market. Although the dominant position itself is not a problem, it would be a relatively small step to start abusing that dominant position. The abuse will often be expressed in different forms of market behaviour, such as a refusal to license and/or unreasonable licensing terms, for instance excessive royalty payments. The Orange Book standard defined the abusive behaviour as: The patentee refuses to accept an unconditional offer made by a licence-seeking firm to accept the terms of the license agreement, while the licence-seeking firm does meet all the licensing requirements as laid down by the licensee in the licensing contract, especially in relation to the payment of royalty fees.

The political agenda of the EU Commission seems to focus on the availability of SEPS on FRAND terms. If the EU follows the stance of the Federal German court, there is now a move towards compulsory licensing. From a legal point of view, it is debatable why IPRs are treated differently from other property rights. This makes the discussion whether it is competition law or patent law that should regulate patent pools moot. The national case law is opaque. In Germany competition law applies, but in the Netherlands competition law seems to play a less important role. It raises the question how far national judges will feel bound by the decisions of the Commission? The Commission should promote the uniform application of the law, and the European Court of Justice 
declared that even if a national court already decided in an Article 102 TFEU case, the Commission may take a different decision.

The European Union seems to show a greater willingness (compared to the US) to evaluate the level of royalties that is charged, in relation to a possible abuse of dominant position. ${ }^{527}$ Again the definition of FRAND licensing terms will play a crucial role in the assessment of the abuse of a dominant position. The third-party determination of FRAND rates also includes some risks. One scenario could be that the SEP holder pushes for a court determination of FRAND rates instead of private strategic negotiations. Obviously, arbitration is a risk for both parties, but it could become part of strategic behaviour if the courts have different FRAND determinations.

Regarding FRAND rates, there have been interesting developments in the United States. Different calculation methods have recently emerged: the ex ante method, proportionality method and the regressive analysis method. One variation of the proportionality method used by Judge Robart uses patent pools as proxy for the FRAND rates. This innovative method already met with substantial criticism, but it can have interesting consequences for patent pools.

From a practitioner's point of view, the current (TTBER) safe harbour system facilitates the Commission in decreasing its heavy workload in competition law cases. The interrelation between patent law and competition law is constantly evolving and being re-designed. Although competition law takes a leading role in the standards and patents discussion, clear boundaries have not yet been established.

The Orange Book case showed that the German courts are willing to extend the interpretation of the laws in favour of the patentee, even enabling the court to determine the reasonableness of the royalty fees in the licensing agreement. The divergence in the interpretation of the relationship between IP law and competition law may enhance the development of forum shopping, possibly undermining the effectiveness of the EU competition policy. The preliminary ruling of the ECJ did not really provided more transparency in this discussion. The Opinion of A-G Wathelet specifies the duties of patent holder and infringer, but there is still room for wide interpretation. It seems that national courts decide on what is proportionate and reasonable in terms of FRAND rates. In case the defendant is an objectively willing licensee, the patentee still does not have very much bargaining power. How the SEP holder reacts to the attitude of the licensee is crucial in Wathelet's opinion. The explanation of the competition rules by means of Guidelines could be improved by making comprehensive European and national manuals.

The judgment of the Court of Justice underlined the principle that patent holders should not be able to use an injunction as leverage against a willing licensee. The Court

\footnotetext{
${ }^{527}$ A parallel can be drawn with the Pharma-report of the EU Commission, in which it was stated that the big pharma-companies have court harassing tactics, leading to an imbalance of power between patent holders and SMEs. In this sector the EU Commission also looked at the history of licensing.
} 
recognized the permanent character of a FRAND commitment, which is one of the reasons that the Court is willing to limit the right to injunctions. The ECJ tries to balance the different interests of licensor and licensee. The judgment does not provide clarity regarding the royalty rate setting or the basis thereof. It also leaves issues open in relation to NPEs and patent trolls. Overall it can be concluded that the ECJ continues the philosophy that these cases cannot be dealt with exclusively through the IP context. Clearly, there is a competition law context which should take priority.

\section{Patent pools as a solution for the problem of patent thickets}

Another major competition policy interest for patent pools is related to the internal governance rules of patent pools. Economic research has not fully discussed the benefits of good governance rules for patent pools. The rules would cover the (exclusive) membership rules, decision-making procedures and royalty-sharing agreements. At the moment, it seems unlikely that the EU Commission will follow the US preference for independent patent controllers. The level of openness does contribute to the efficiency level of the patent pool. This openness can lead to collusion as soon as pool members start to exchange sensitive market information. In this context, the US MPEG-2 pool introduced the notion of a "firewall-system". ${ }^{528}$ In this system, a private independent licensing administrator gathers the market-relevant business information (pricing strategies, output data, sales reports, conditions of sale, geographical markets) from the pool participants. The EU Commission prefers patent pools to invite all interested parties to participate in the pooling arrangement. This view undermines the position of the holders of SEPs in the patent pool. The new TTBER does not address non-standard related patent pools, although these pools can have a pro-competitive effect. For patent pools that do not have a dominant position, the EU Commission will probably apply the rules on excessive pricing.

\section{Lessons to be learned}

The EU institutions are struggling with their policy in relation to specific important aspects (e.g. SEPs/injunctions) of the regulation of technology transfer. The division of authority between the ECJ and the EU Commission does not seem to be very clear at the moment. The outcome of the preliminary ruling request shall probably have the same effect as the FTC settlement with Google/MMI. It will further, and in detail, clarify the conditions for permitting injunctive relief inside the EU. The exact determination of the correct level of FRAND rates is the most likely the responsibility of the court system. Most of the attention is focused on the holders of SEPs and the possible abuse thereof. The recent case law also makes it also possible that "formally willing licencees" develop strategic behaviour.

\footnotetext{
${ }^{528}$ See also Liu : A More Economic and Cross-Jurisdiction Study on Patent Pools page 79.
} 
The choice of the Commission to implement a system that evaluates the economic effects of the firm's conduct implies that IP lawyers must gain a better understanding of the applied economic analysis. For the enforcement agencies, a better and more indepth expertise in relation to the economic effects of competition is needed in order to define the concept of social welfare for the specific trading bloc. It is interesting to observe whether the current joint movement of the FTC and the EU Commission to agree on the basic conditions for injunctions will be followed by Chinese regulators.

A common approach to the concepts of SEPS and injunctions will also favour the joint discussions in the field of standardization in the context of the TTIP. A common EUUS understanding on standards will require the Chinese government to carefully reconsider their position. For the Chinese government, it is interesting to see that even wellestablished competition law systems have difficulty understanding and assessing global technology markets. Both the US system of BRLs and the EU TTBER Guidelines framework mainly concentrate on the establishment and the start of patent pools. The unilateral conduct of pool members and management implications of patent pools are often not considered by competition authorities. The EU seems to be more willing to apply a competition law approach to patent pools. Recent case law shows that key analytical issues such as the type and quality of patents and the management of a patent pools continue to be overlooked by both the EU and US authorities.

In the next chapter the main goals of Chinese competition policy in relation to standard setting and patent pools will be discussed in order to find out whether the emerging common agreement on standardization will be followed by the Chinese government. Elements of this discussion include the threat of the TTIP Agreement of the EU and US and the necessity to decrease the total sum of royalty payments by Chinese firms to foreign patent owners. The indigenous innovation policy (discussed in section 4.2) will be at the background of the policy discussion. Whereas both the EU and the US are trying to find a proper basis for the FRAND discussions, we will see that Chinese courts are moving forward in the FRAND cases and take their own direction. 


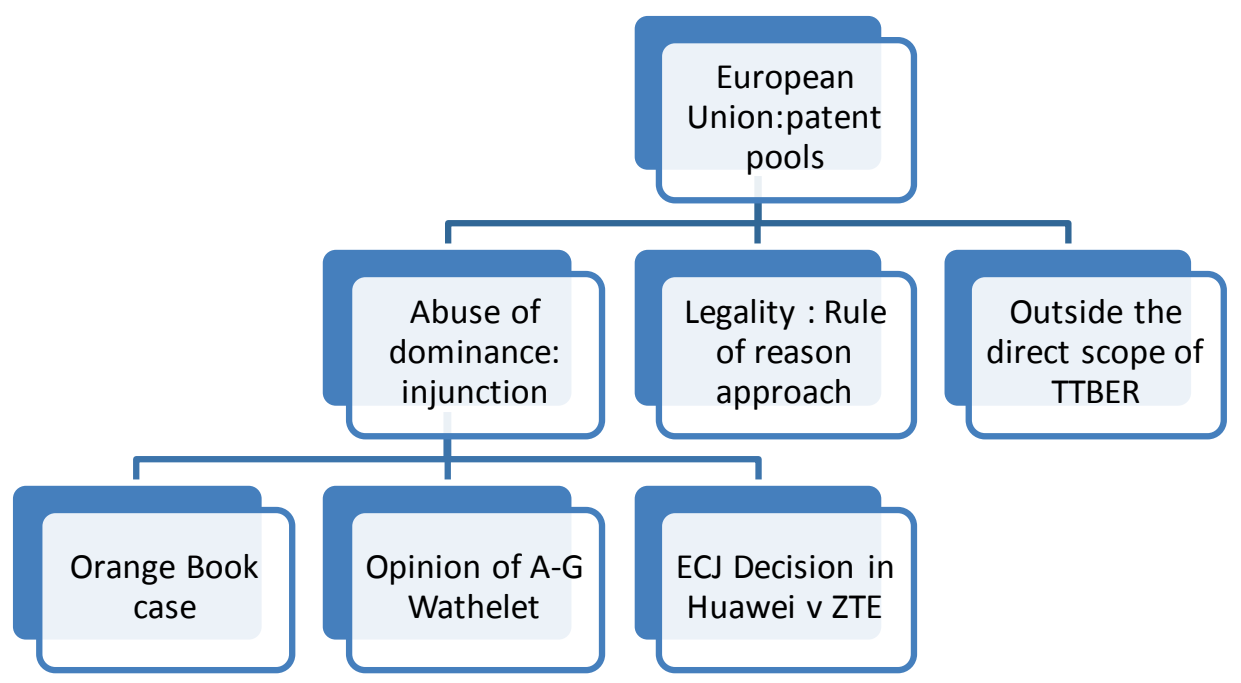





\section{CHAPTER 8}

Patent pools in the People's Republic of

China 

The IP abuse in China is often addressed by the Chinese Anti-Monopoly Law, especially Article 55 AML. After a look at the relationship between the AML and intellectual property rights, the relevant case law will be discussed. Finally patent pools will be investigated as a possible solution for the incorporation of essential patents in Chinese standards. Several cases will be used to gain better insight into the current Chinese legal landscape. This chapter will end with an overview of the draft regulatory measures for standards involving patents in China.

The subject of technology licensing is of strategic value to the government of China. In the present conversion process, the Chinese government wants to change its position as a standards taker into an economy that develops new standards, applicable on a global basis. Chinese manufacturing companies act as licensees for Western-developed technology, leading to a heavy royalty burden, which contributes substantially to the cost prices of high-tech products. Since the emergence of the Chinese Indigenous Innovation Policy, ${ }^{529}$ Western companies fear being discriminated against, and the lack of clarity and uniformity makes the risk management of technology licensing in China very challenging and unpredictable. On the other hand, there is presently an environment in which the Chinese business community is complaining about insufficient possibilities to influence and to contribute to the development of globally-accepted standards. Aside from access to the formulation of Western standards, Chinese firms also have difficulty in understanding and accepting the use of intellectual property rights (i.e. patents) in the development process of standards. China claims that, in their position as a developing country, a special application of both patent laws and competition policy to the standardizing process is justified. The move towards a free-market economy and its position as an emerging market provide for a direct comparison with the existing legal frameworks in the US and the EU almost impossible. Chinese high-tech companies, as well as the Chinese government itself, both lack the experience and the specific knowledge of technology transfer of their counterparts in the Western economy. Another interesting perspective is the role of technology licensing in the overall innovation strategy and Chinese industrial policy.

The industrial policy of the Chinese government is facing a rebalancing challenge. The prior reliance on export and investment-led growth is moving towards an economic model based upon internal demand led by private domestic consumption. The increase in national consumption will see a rise in the licensing of Western technologies in national Chinese products. The enforceability of the technology transfer agreements will often clash with national competition law provisions. The relationship between competition policy and industrial policy has been troublesome in the past, with Western competition authorities often applying competition rules in a dogmatic manner. Chinese industrial policy directly intervenes in the competition law to secure some of their national interests.

\footnotetext{
${ }^{529}$ See also Chapter 4 for a further introduction.
} 


\subsection{GENERAL DISCUSSION OF THE ANTI-MONOPOLY LAW, POLICY AND ENFORCEMENT}

The legal structure of the AML makes a division between policy institutions and enforcement institutions. Policy development is the main task of the Anti-Monopoly Commission, whereas enforcement is divided over several agencies, the Ministry of Commerce (MOFCOM), the National Development and Reform Commission (NDRC), the State Administration for Industry and Commerce (SAIC), and finally the People's Court. After a few years, the first preliminary conclusions on the basis of the existing case law and guidelines can be drawn.

The AML was promulgated by the National People's Congress on 30 August 2007 and entered into force on 1 August 2008. The AML policy contains three main subjects:

1. Merger Control

2. Monopoly or Restrictive Agreements

3. Abuse of a Dominant Position

The merger control provisions of the AML bear some similarities to the EU Merger regulations since, in both systems, mergers or "concentrations" in the AML must be notified if they surpass certain thresholds. ${ }^{530}$ The AML defines a "concentration" as:

\section{- "A merger between two independent companies}

- Acquisition of control of another company by purchasing shares or assets

- Acquire the ability to exercise decisive influence over another company."

The second part of the AML deals with monopoly agreements. These agreements, decisions or other concerted behaviour eliminate or restrict competition within the PRC. This provision has extraterritorial effect, meaning that if a monopoly agreement is concluded outside the PRC, but it leads to elimination or restriction of competition inside the PRC, it can be prohibited by the AML.

The following horizontal agreements have a "monopolistic nature" and are forbidden:

"1. fixing or changing prices of commodities;

2. limiting the output or sales of commodities;

\footnotetext{
${ }^{530}$ The total worldwide turnover in the previous accounting year of all undertakings involved in the concentration exceeds RMB 10 billion (approx. US\$1.460 billion or Euro 1.36 billion), and at least two of such undertakings each has a turnover of more than RMB 400 million (approx. US\$ 58.6 million or Euro 41.5 million) within China in the previous accounting year; or the total turnover in China in the previous accounting year of all undertakings involved in the concentration exceeds RMB 2 billion (approx. US\$292 million or Euro 207 million), and at least two of such undertakings each has a turnover of more than RMB 400 million within China in the previous accounting year. MOFCOM will have 30 days to conduct a preliminary review of the transaction.

${ }^{531}$ Article 20 Anti-Monopoly Law (AML).
} 
3. dividing the sales market or the raw material procurement market;

4. restricting the purchase of new technology or new facilities or the development of new technology or new products;

5. making boycott transactions; or

6. other monopoly agreements as determined by the Anti-Monopoly Authority under the State Council." 532

Article 17 AML states, "Business operators with a dominant market position are prohibited from committing any of the following acts or abusing the dominant market position: 1) Selling products at unfair prices." 533

The application of the unfair pricing concept to IPRs is sometimes debated. Commentators make the point that the application of unfair pricing methods to SEPs might hinder the static and dynamic competition between standards. Since SEPs do not deter entry to the market on a permanent basis, every firm has the choice to participate in the establishment of new standards. The ownership of a 3G SEP does not automatically lead to the implementation of that SEP in the $4 G$ standard. It is very challenging for competition authorities to determine the correct financial compensation for patent owners that will guarantee future innovations. As a result, it can be concluded that unfair prices must only be applied to innovation-intensive industries in exceptional cases. ${ }^{534}$ Since China wants to encourage the development of indigenous innovation in national standards, it has to be very careful in the application of unfair pricing methods to innovative industries in China. The main reason for this is that Chinese innovative companies must have sufficient assurance that their R\&D investments will be recouped. The investments in high-tech innovations can be substantial and risky. If the Chinese firms understand that they possibly get proper a return on investments, then this would be an incentive to invest in R\&D. Nevertheless, it seems that the Shenzhen Intermediate Court applied unfair pricing considerations in the Huawei v. InterDigital case. This case is discussed later in this chapter.

It can be argued that the application of unfair pricing rules in China to innovationintensive industries should only be used in exceptional cases. However, the discussion of FRAND-royalty rates directly looks at pricing strategies.

For vertical agreements, the AML mentions the following prohibitions:

1. fixing the price of commodities for resale to a third party;

\footnotetext{
${ }^{532}$ Article 13 Anti-Monopoly Law (AML).

${ }^{533}$ For the definition of unfair high prices, an analogy can be drawn with Article102 TFEU: "directly or indirectly imposing unfair purchasing or selling prices or other unfair trading conditions." The ECJ explained the concept of excessive pricing in a number of cases (United Brands, Swedish Ports). A similar article does not exist in US antitrust law.

534 Following the reasoning of Evans, Zhang and Zhang in Assessing Unfair Pricing Under China's AntiMonopoly Law for Innovation-Intensive Industries.
} 
2. restricting the minimum price of commodities for resale to a third party; or

3. other monopoly agreements as determined by the Anti-Monopoly Authority under the State Council.

Finally, the abuse of a dominant position in the AML is described as a market position of a firm in the relevant market that gives the firm the ability to control the price and the quantities of the goods and other trading conditions and the ability to block or control the entry of other competing firms into the same relevant market. Article $19 \mathrm{AML}$ gives a summary of the factors determining a dominant position:

"1. the market share of a business operator in relevant market and the competition situation of the relevant market;

2. the capacity of a business operator to control the sales markets or the raw material procurement market;

3. the financial and technical conditions of the business operator;

4. the degree of dependence of other business operators upon of the business operator in transactions;

5. the degree of difficulty for other business operators to enter the relevant market; and

6. other factors related to determine a dominant market position of the said business operator." 135

For the exact evaluation of a dominant position, the AML applies the criterion of the market share:

"1. the relevant market share of a business operator accounts for $1 / 2$ or above in the relevant market;

2. the joint relevant market share of two business operators accounts for $2 / 3$ or above; or

3. the joint relevant market share of three business operators accounts for $3 / 4$ or above.

A business operator with a market share of less than 1/10 shall not be presumed as having a dominant market position even if they fall within the scope of second or third item."

\footnotetext{
${ }^{535}$ Article 17 Anti-Monopoly Law (AML).

${ }^{536}$ Article 18 Anti-Monopoly Law (AML).
} 
"Where a business operator who has been presumed to have a dominant market position can otherwise prove that they do not have a dominant market, it shall not be determined as having a dominant market position." 537

The development of policy is the responsibility of the Anti-Monopoly Commission, which will coordinate and give guidance on anti-monopoly activities. The enforcement of the AML provisions is divided over several institutions. The MOFCOM will lead the enforcement of the Merger rules and the National Development and Reform Commission (NDRC) will deal with price-related violations of the rules on Monopoly Agreements and price-related cases of abuse of a dominant position. The State Administration for Industry and Commerce (SAIC) has the responsibility for non-price related infringements of the Anti-Monopoly Law and non-price related cases of abuse of a dominant position. Again, similar to the EU and US provisions, non-adherence to the rules can lead to heavy fines, ranging from $1 \%$ to $10 \%$ of the annual turnover. The enforcement agencies also impose the confiscation of the financial gains resulting from the infringement of the AML law. ${ }^{538}$

The leniency programme is typical for emerging markets. ${ }^{539}$ The conversion of the planned-economy into a restricted free-market economy and the very recent character of the AML provisions justify the implementation of a leniency programme. The enforcement authorities can mitigate or exempt firms from fines and/or sanctions if the latter have voluntarily reported their violations to the authorities in charge of the AML. The AML does allow for private actions by firms who have suffered losses because of the infringement of the AML law by other firms. This opportunity could be important for foreign late-entries into the PRC technology market. A foreign technology that misuses its IPRs in order to implement monopolistic agreements or abuses their dominant position can be challenged by both Chinese and other foreign firms active in the Chinese IP market. This provides multinational enterprises (for example Google, Apple or Samsung) with the legal situation in which their business practices involving IPRs can be challenged in different national jurisdictions, possibly leading to different outcomes or plaintiffs who use prior precedents in other jurisdictions to get a decision in China.

On 8 July 2014, the State Council of China published a new opinion on "market order". The document is titled "Several Opinions of the State Council Opinions on Promoting fair Competition in the Market to Maintain the Normal Market Order." 540 According to commentators, "market order" is directly related to the intersection of IP and antitrust law, since it is often referred to by the Chinese Anti-Monopoly Enforcement Agencies (AMEA). This policy document mentions the "severely punishing monopolistic con-

\footnotetext{
${ }^{537}$ This provision also refers to the "piracy-defence" strategy of Microsoft.

538 Individuals who obstruct the investigations by the PRC authorities can face criminal penalties. See for more information, report Lapiper; Doing Business in China.

${ }^{539}$ Almost identical provisions can be found in the Brazilian competition law.

${ }^{598}$ The State Council of the People's Republic of China, Several Opinions of the State Council on Promoting Fair Market Competition and Maintaining Normal Market Order.
} 
duct and unfair competition conduct" that must be punished by expanding the joint liability concepts and punitive damages in the Chinese antitrust laws. Further reference is made to monopolistic agreements that "hamper innovation and technological advancement." ${ }^{541}$ It is interesting that the opinion also calls for the "the elimination of duplication multilayered enforcement" of antitrust laws by the three Chinese enforcement agencies. This opinion of the State Council can be given various interpretations. It could mean that more influence will also be given to market forces in the IP/competition law field.

The AML provides legal opportunities for both Chinese technology firms and foreign investors who can be regarded as late-comers to the Chinese IP market.

This implies that foreign companies active in the Chinese market may use different strategies depending on their size and experience in the market. A well-established multinational enterprise, with a long standing track-record in China, will use its present investments in R\&D and technology development as proof of delivering a substantial contribution to the national development in China, one of the exemptions of Article 15 AML. Small or medium-sized companies with a later start of their business activities in China gain access to the market because of the anti-monopoly provisions and the abolition of an abuse of a dominant position.

\section{China: Three antitrust agencies}

China has a unique feature in its enforcement of the Anti-Monopoly Law, since three agencies are engaged in the enforcement. The SAIC, NDRC and MOFCOM all share antitrust enforcement powers. The obvious risk is an overlap in the sector and geographical choice of cases. This phenomenon leads to increased costs for firms since the enforcement agenda and priorities of the three agencies have not been harmonised. Unfortunately this also hinders a uniform structure of regulations, draft measures and guidelines. With this inconsistent approach, firms might want to follow the lowest denominator of the enforcement priorities. ${ }^{542}$ The current system lacks transparency and has a negative impact on the creation of standards and the management of patents included in the standards. In order to participate in international standardization, (Western) stakeholders must know and understand the relevant legal framework.

\footnotetext{
${ }^{541}$ See for more information: Cohen: State Council's New Opinion on Market Order.

${ }^{542}$ See also: Emch, Chinese Antitrust Institutions-Many Cooks in the Kitchen.
} 


\subsection{THE AML AND ITS RELATION TO TECHNOLOGY TRANSFER}

The Chinese Anti-Monopoly Law (AML) was enacted in 2008. In order to meet and implement the requirements of Article 8 of the TRIPS Agreement, Article 55 of the AML states:

"Law does not govern the conduct of business operators to exercise their intellectual property rights under laws and relevant administrative regulations on intellectual property rights; however, business operators' conduct to eliminate or restrict market competition by abusing their intellectual property rights shall be governed by this Law." ${ }^{543}$

The meaning of this article must be explained within the general context of the AML. The law starts with the following objectives and mentions, "enhancing economic efficiency, safeguarding the interests of consumers and social public interest, promoting the healthy development of the socialist market economy." ${ }^{544}$ The first part of the provisions mainly focuses on the prohibition of monopolistic agreements and later continues with the regulation of the illegal abuse of a dominant market position in Articles 13 and 14. ${ }^{545}$ For the context of technology licensing, it is important to note that Article $15 \mathrm{AML}$ gives the Anti-Monopoly Authority the opportunity to exempt firms operating in China from the prohibitions of Articles 13 and 14 for the following reasons:

1. "for the purpose of improving technologies, researching and developing new products

2. for the purpose of upgrading product quality, reducing cost, improving efficiency, unifying product specifications or standards, or carrying out professional labour division;

3. for the purpose of enhancing operational efficiency and reinforcing the competitiveness of small and medium-sized business operators;

4. for the purpose of achieving public interests, such as conserving energy, protecting the environment and relieving the victims of a disaster and so on;

\footnotetext{
${ }^{543}$ Anti-Monopoly Law of the People's Republic of China (AML).

${ }^{544}$ See also Farmer in The Chinese Anti-monopoly Law page 22. Faure, Zhang EE2013.

${ }^{545}$ Art. 17 and art. 18 mention seven different types of abuse: (1) selling commodities at unfairly high prices or buying commodities at unfairly low prices; (2) selling products at prices below cost without any justifiable cause; (3) refusing to trade with a trading party without any justifiable cause; (4) requiring a trading party to trade exclusively with itself or trade exclusively with a designated business operator(s) without any justifiable cause; (5) tying products or imposing unreasonable trading conditions at the time of trading without any justifiable cause; (6) applying dissimilar prices or other transaction terms to counterparties with equal standing; (7) other conducts determined as abuse of a dominant position by the Anti-monopoly Authority under the State Council
} 
5. for the purpose of mitigating serious decrease in sales volume or obviously excessive production during economic recessions;

6. for the purpose of safeguarding the justifiable interests in the foreign trade or foreign economic cooperation; or

7. other circumstances as stipulated by laws and the State Council."

Most scholars agree that these provisions aim to encourage technology transfer from West to East and help to stimulate Foreign Direct Investment (FDI) in Chinese high-tech sectors. ${ }^{546}$ The provisions are, nevertheless, insufficiently clear in their wording and the conditional elements can lead to different interpretations. In order to examine the practical impact, the starting point is to look at the general objectives of the Chinese AML. Article 2 of the AML states that the scope of application is the "monopolistic conduct in economic activities within the territory of P.R. China" but later it also extends the application to "monopolistic conduct outside the territory of P.R. China" if this business practice "results in eliminating or restricting" domestic market competition in China. ${ }^{547}$ Although the stated objectives of the AML show many similarities with other national competition laws, some of the objectives are very specific to the Chinese economy. For example "promoting the healthy development of the socialist market economy"; "improving macroeconomic control" and promoting an "orderly market system" are directly related to the present economic conversion process and cannot be found in Western systems of competition policy. ${ }^{548}$

Farmer underlines that the principles of Article 1-Article $4 \mathrm{AML}$ distinctively differ from the US antitrust principles, which will lead to different outcomes in court cases involving competition law in China. ${ }^{549}$

These objectives raise the question of what the exact role of the AML policy will be, and if there is a closer link between the Chinese competition policy and its industrial policy. ${ }^{550}$ The Chinese government heralds the development of national champions

\footnotetext{
${ }^{546}$ Tian Intellectual property (IP) protection versus IP abuses: The recent development of Chinese IP abuse rules and recommendations for foreign technology-driven companies page 359.

${ }^{547}$ See art. 2 AML Ibid note 564.

${ }^{548}$ The following reasons justify an exemption: (1) for the purpose of improving technologies, researching and developing new products; (2) for the purpose of upgrading product quality, reducing cost, improving efficiency, unifying product specifications or standards, or carrying out professional labor division; (3) for the purpose of enhancing operational efficiency and reinforcing the competitiveness of small and medium-sized business operators; (4) for the purpose of achieving public interests such as conserving energy, protecting the environment and relieving the victims of a disaster and so on; (5) for the purpose of mitigating serious decrease in sales volume or obviously excessive production during economic recessions; (6) for the purpose of safeguarding the justifiable interests in the foreign trade or foreign economic cooperation; or (7) other circumstances as stipulated by laws and the State Council.

${ }^{549}$ Farmer in The Chinese Anti-Monopoly Law, Faure, Zhang 2013 page 22.

${ }^{550}$ In a recent paper Petit and Neyrinck open the academic debate whether it is desirable that the EU would follow the example of the Chinese government and should allow for more influence of industrial policy con-
} 
through its indigenous innovation policy, which may influence the policy of the three $A M L$ enforcement agencies. Already, directly after the introduction of the $A M L$, representatives of the FTC warned against the detrimental influence of industrial policy considerations in the enforcement policies of the AML agencies. ${ }^{551}$ Article $15 \mathrm{AML}$ enables the Chinese competition authorities to exempt certain types of agreements from the general prohibition. Many foreign investors hold the long-term view that the West-East technology transfer can be justified since the AML will not prosecute activities that are beneficial to the Chinese economy. ${ }^{552}$

The relationship between the policy objectives of the AML in general and the Chinese industrial policy, including the doctrine of indigenous innovation, is insufficiently clear for foreign enterprises acting in the Chinese market or acting outside China in a way that might hurt Chinese economic interests.

A first look at the text of Article $55 \mathrm{AML}$ suggests that the $\mathrm{AML}$ is not applicable in the case that firms use their IP rights in a legitimate way, meaning that Chinese competition law and the Chinese IP laws interact at the same level and have equal importance. Most scholars recognize the creation of a safe harbour for high-tech companies exercising their IP rights in the Chinese business environment in this approach. The wording of Article $55 \mathrm{AML}$ is sometimes compared to the US doctrine of patent misuse, whereby the patent holder cannot extend ${ }^{553}$ the use of his patent rights beyond the legitimate scope. A closer analysis of the text of Article $55 \mathrm{AML}$ reveals the criticism that the text is too general and does not define some of the key concepts, such as abuse of the IPR, or clarify the application of Article $55 \mathrm{AML}$ in practice.

\subsection{INTERPRETATION OF ARTICLE 55 AML}

After the introduction of the AML, Article 55 in particular led to much debate relating to its scope, meaning and practical application. The first uncertainty is the relationship between the general prohibitions of the AML and the specific provision of Article 55 in relation to IP rights. One school of thought believes that Article 55 specifies the general prohibition and does not extend the scope of the general rules.

\footnotetext{
siderations in the application of competition law. INDUSTRIAL POLICY AND COMPETITION ENFORCEMENT: IS THERE, COULD THERE AND SHOULD THERE BE A NEXUS?

551 "We hope that the Chinese development of this complex area of law, that even experienced antitrust agencies find difficult, be guided solely by sound competition considerations" Kallay China's New Anti Monopoly Law: An International Antitrust Convergence Perspective. Remarks delivered at Melbourne Law School's Unleashing the Tiger? Competition Law in China and Hong Kong" Conference Melbourne, Australia 4 October 2008. In the field of merger control, Chinese enforcement policy has taken concepts like national economic development and national security into serious consideration, see also art.27 (5) and art.31 AML.

552 Personal conversation Chinese University of Hong Kong.

${ }^{553}$ See also Wang, New Chinese Anti-Monopoly Law.
} 
Others think that Article $55 \mathrm{AML}$ also applies to firms that abuse their IP rights without having a dominant position. This last reasoning is based on the presumption that the legal use of IP rights, like a patent, also automatically leads to a dominant position. ${ }^{554}$ This presumption plays a central role in the debate in China, just as it did in the past in the US and the EU. In both jurisdictions it was doubtful whether IP rights automatically conferred market power, a notion that was rejected later on in history. Other commentators claim that an abusive use of IP rights can be prosecuted under Article 55 AML, without having any dominant position. This problem can be linked to the earlier discussions on monopoly.

The application of Article 55 AML to patents is also subject to several views. Representatives of the FTC voiced the concern that applying differentiated licensing conditions would be considered an abuse of IP rights and therefore illegal. Losing the ability to apply discriminatory licensing terms is one of the basic ways to compete in the field of technology licensing. Masoudi made the comment that the right to exclude others from using the patent is a basic presumption of the proper functioning of intellectual property rights in a competitive economy. To deny this right by qualifying it as an abuse would limit further investments in innovation, slowing down innovation, harming the interests of consumers and reducing productivity gains for the economy. ${ }^{555}$ Most of the present economic research does agree on the fact that discriminatory licensing terms ultimately have a pro-competitive effect and enhance the benefit for consumers.

Foreign firms operating in the Chinese market could foresee their IP infringement proceedings in China being hindered by the application of Article $55 \mathrm{AML}$. Similar to the US situation, Chinese firms could defend against a case brought against them by using Article $55 \mathrm{AML}$. Earlier it was submitted that Article $55 \mathrm{AML}$ has some similarities with the concept of patent misuse in the United States. In the present practice, patent misuse is often applied as a defence against other legal claims made by the patent holder. ${ }^{556}$ Foreign enterprises operating in China have often acknowledged the risk that Article $55 \mathrm{AML}$ can be used by Chinese companies to prevent the enforcement of foreign-owned IPRs in China.

Chinese private businesses, although a majority could still be former State-Owned Enterprises, can easily claim that the infringement action of a foreign firm is abusing their dominant position or is an abusive use of the IPRS and consequently violates Article $55 \mathrm{AML}$. This is similar to the US legal situation, where infringement claims are often countered by the other firm with a defence that the patent is invalid or that there is a

\footnotetext{
${ }^{554}$ Tian The impacts of the Chinese Anti-Monopoly Law op IP Commercialization in China \& General Strategies for Technology-Driven Companies and Future Regulators, quotes the Microsoft case wherein the Chinese authorities refused to accept that Microsoft did not have a dominant position, due to its low market share in China. This so-called piracy defence was of no avail in the test of a dominante position. Section 23.

${ }^{555}$ Speech Masoudi Some comments on the abuse-of-dominance provisions of the China's draft antimonopoly law page 11.

${ }^{556}$ See chapter 5 .
} 
case of patent misuse. The ensuing investigation by one of the Chinese antitrust law agencies could delay the market introduction of new technology and seriously hinder a further dissemination of the standard-based technology because of the lack of network effects. In chapter 4, it was noted that the Chinese government wants to encourage the adoption of Chinese telecommunications standards by limiting or preventing foreign competition on a temporary basis, thereby giving the national standard a possible headstart. This could also be an example of the earlier discussed notion of "stealth licensing". If patent owners expect lower licensing revenues, this could lead to lower investments in R\&D and vertical integration of licensors, and business strategies that have a negative impact on competition. 557

Does the application of Article $55 \mathrm{AML}$ hinder the infringement actions brought by foreign firms in China, since Chinese firms can make the claim that there is a restriction of market competition or an abusive use of IPRs by the foreign firm? Is there a negative impact on FDI investments and the licensing practices of foreign businesses in China?

The first reaction of foreign firms being faced with an Article $55 \mathrm{AML}$ defence in relation to infringement proceedings would be to refer to the exemptions stipulated in Article $15 \mathrm{AML}$, whereby agreements with monopolistic effects can be exempted from the general prohibition if the agreement leads to beneficial effects on research and development or unifies products and standards. ${ }^{558}$ It would be interesting to understand the last phrase of the exemption, since this relates to standards. Which category of standards does Article $15 \mathrm{AML}$ refer to? The adoption of the Chinese AML indicates that the Chinese government takes their WTO commitments seriously and wants to become an active member of the globalized business community, respecting the essential role of IPRs therein. Consequently, the standards mentioned in Article 15 AML must be part of the global standardizing efforts.

\subsection{EXEMPTIONS AND DEFENCES FOR MONOPOLISTIC AGREEMENTS UNDER ARTICLE 55 AML}

The AML wants to balance the interests of promoting competition and encouraging innovation and consumer interests. In the US and European case law, it is evident that there is no conflict between IP rights and competition law. In China, it is difficult to change the misperception that the ownership of patents automatically leads to market power and thus a dominant position. The US and EU experience shows that abuse of IP rights is more likely to be an exceptional case and is definitely not a generalized practice. The question remains whether the pricing of the patented product is fair in relation to the investments made or excessive in relation to the prior investments. A second

\footnotetext{
${ }^{557}$ See also Petit "Stealth licensing" page 20.

${ }^{558}$ See art. $15 \mathrm{AML}$.
} 
complication is that, in high-tech markets, dominance can be the result of a superior quality of the technology, which is typical for patent-dominated industries. As noted above, this means that there is more competition based on substitution, which increases the dynamic efficiency in the market, since there will be further improvements on the original patented product, leading to more consumer choice. ${ }^{559}$

Microsoft introduced the defence of piracy and the non-dominant position for its business practices in China. Due to the high piracy rates in China, Microsoft claimed that, in practice, it could not enforce monopolistic agreements or benefit from its dominant position, since widespread piracy made this impossible. Again, this raises a question of the interpretation of Article $55 \mathrm{AML}$, since it is not sufficiently clear whether the article only applies to dominant or also to non-dominant IP firms.

A broad interpretation of Article $55 \mathrm{AML}$, including abuse by non-dominant IP firms, would render the defence of wide-spread piracy useless, since the prohibition would also apply to non-dominant IP firms.

The AML also refers to other defences in Article 15. Many foreign investors rely on the exemption related to the contribution made to national development. In their reasoning, the quality and quantity of the foreign investments in China contributes to the increased development of the Chinese economy and that, consequently, the Chinese government should, in its legislation and policy, protect the foreign-owned IPRs. ${ }^{560}$ Almost similar to the EU legal provisions of Article 101 TFEU, the exemptions of the prohibition of Article $55 \mathrm{AML}$ apply strict conditions. In order to use the national development defence, consumers must be able "to share the benefits of the agreement", which will not have the effect of "severely restricting competition in the relevant market" ${ }^{561}$ These strict conditions lead again to further discussion, since it is open to interpretation what "consumer benefits", in practical terms, constitutes, and how and when competition in the relevant market is distorted or prevented. Both in the US and EU system, authorities will elaborate on the application of the relevant laws in relation to IP and competition laws. Both systems explain the practical application in Guidelines that also indicate the economic analytical theories that will be used in specific cases, such as for instance, the rule of reason approach in the United States.

The condition that the exempted monopolistic agreement should provide benefits to consumers can be directly related to innovation processes. Technological progress increases economic efficiencies, thereby promoting consumer welfare in three different ways:

1. Lower costs of the product.

\footnotetext{
${ }^{559}$ This does not always mean that the best technology will be chosen or will be included in a standard.

${ }^{560}$ See also the comments of the EU Chamber of Commerce China, suggesting that the Chinese government will only benefit from foreign investors in the long or medium term period if they create a level playing field that does not favour Chinese companies. http://www.chinaipmagazine.com/en/journal-show.asp?id=401.

${ }^{561}$ See art. $15 \mathrm{AML}$
} 
2. New improved products stimulate consumer interest, leading to a higher demand curve and to increased economic growth.

3. Newly developed technologies enable new entrants to start competing on the relevant market.

Innovation is fed by both strong IPR systems and by competitive markets, and innovation in itself serves the consumer interests. This means that both the systems of intellectual property law and the Anti-Monopoly Law need to encourage innovation. The US system wants to enforce its antitrust laws to also seek to maximize innovation incentives, by guaranteeing the proper functioning of intellectual property right laws (stated by James J. O' Connell, Jr. Deputy Assistant Attorney general Antitrust Division DoJ). ${ }^{562}$ O'Connell gave a few recommendations for the relationship between IPRs and the AntiMonopoly Law. One of his first remarks discussed the present US view that an intellectual property (i.e. patent) does not necessarily create market power and that the presumption that a patent automatically confers market power could lead to the wrong application of the Chinese antitrust laws. ${ }^{563}$ In his view, a patented product does not exclude competition. Rather, if the IPRs are properly applied, it leads to more and enhanced competition. In relation to standard setting, this point definitely can be found to be valid if the interoperability of the standard with other technologies is respected. In chapter 4, the beneficial effects of standardization in the Chinese economy have already been discussed. The fact that the Chinese government wants Chinese firms to become standard developers rather than standard takers stresses the positive impact that standards (including many patents) have on the development of the Chinese economy. This implies that Article 55 should recognize the positive effect of IPRs (within the standardization context) on innovation, consumer interests and, consequently, on the development of the Chinese economy.

Prior economic research suggests that competition law should encourage innovation by creating dynamic efficiency. The United States and the European Union hold different views on the appropriate analysis methods to measure dynamic efficiency and, consequently, consumer benefits. In both jurisdictions, economic analysis plays a major role in the assessment of antitrust cases. Cases are evaluated on an individual basis and not by a generalized approach. The US favours an effects-based approach, whereby it is not the specific form of the business activity in itself but, more importantly, the economic effect on competition. ${ }^{564}$ In terms of transparency, both the US and EU competition authorities try to explain their policy by referring to fundamental principles, based on sound economic principles that evaluate whether competition has been distorted or

\footnotetext{
${ }^{562}$ This refers to the recoupment debate. For further discussion see speech O'Connell Jr. Maximizing Incentives to Innovate Under China's Anti-Monopoly Law: Some Fundamental Principles April19, 2008 Beijing China.

${ }^{563}$ Supra note 23 , page 8.

${ }^{564}$ Supra note 584, page 11.
} 
hindered. For China, this is more challenging, given the fact that their economy is still undergoing changes and is possibly moving towards a complete free-market economy. During this process, the regulation of competition plays a major role is safeguarding the interests of consumers and of national economic development. The risks and opportunities for foreign investors in China have often been debated but, likewise, there will be threats by the foreign-led investments in China to both the national economy and the consumers.

A second challenge is posed by the fact that the Chinese efforts in the field of antitrust laws have just recently been developed, and, especially in the field of standard setting and patents, have not yet benefited from much experience. ${ }^{565}$

Should the Chinese antitrust policy be based on fundamental principles that provide transparency to foreign investors and could lead the way forward to a similar approach as that which the EU and US competition authorities have, with specific guidelines for the use of IP in competition law and a more extensive case law?

\subsection{ENFORCEMENT GUIDELINES FOR THE APPLICATION OF THE ANTI- MONOPOLY LAW IN THE FIELD OF INTELLECTUAL PROPERTY RIGHTS}

The relationship between antitrust law and intellectual property law in China is more complicated than in the US and the European Union. In the last two jurisdictions, although historically there have been tensions between both trading blocs, at the moment, authorities are convinced that both systems serve the same goals (i.e. the promotion of innovation and increasing benefits for consumers, leading to enhanced social welfare). In the Chinese legal system, intellectual property law was traditionally regarded as private law, since mainly the interests of private firms and persons were served. The antitrust law was always seen as public law, since the rules protected consumers from a public policy perspective. Although initially viewed as two distinctively different systems, recently Chinese scholars and lawyers have started to accept that both systems are not contradictory but compatible. The conflict between both systems is not caused by the existence of IPRs in itself, but by the fact that these IPRs are used beyond their original legal scope and result in a restriction of competition.

This means that we have to define the justifiable use of patents in standard setting from a competition law perspective. One difficulty is that the abuse of intellectual property rights has been given different interpretations in the EU, the US and China. Whereas this term is clearly defined in the US and the EU, China is still struggling with narrowing the exact meaning of the phrase. Some scholars make a distinction between the abuse of intellectual property rights in itself and the abuse of intellectual property rights

\footnotetext{
${ }^{565}$ O'Connell mentions well-established principles like the notion to protect competition on the relevant market and not just specific (Chinese) competitors as examples of the learning curve
} 
that has anti-competitive effects. Furthermore, they highlight the use of intellectual property rights that causes anti-competitive effects without being an abuse of intellectual property rights. ${ }^{566}$

Both in the US and the European Union, authorities hold the view that IPRs do not automatically confer market power on their owners. The main motivation for this view is the criterion of substitution, or the interchangeability of the products. If substitutes for the product exist, it is more difficult to restrict competition in the relevant market or even in related markets. Nevertheless, Chinese scholars argue that IPRs must be examined seriously, especially in high-tech IP dominated industries.

The application of antitrust law in China should strictly focus on the anti-competitive effects of the IPRs and not on the possible monopoly that is created by the character of the IPRs. As in every jurisdiction, the tension between both systems occurs in relation to the balancing act between the protection of effective competition and the promotion of innovation, with the protection of consumer interests as the final result. In the case of China, this creates a challenge for the authorities, since the government must weigh the different aspects (innovation versus the right level of competition) in a rapidly changing economic environment. In the other legal systems, competition authorities have explained their enforcement policy with the help of Guidelines. Article 9 of the AML provides for the establishment of the Anti-Monopoly Commission by the State Council, which has the task of formulating and communicating Enforcement Guidelines for the AML. The specific Enforcement Guidelines for the application of the Anti-Monopoly Law in the field of intellectual property rights have been assigned to the State Administration for Industry and Commerce. ${ }^{567}$ The actual drafting has been delegated to a research group led by the Enforcement Bureau of Antitrust Law and Anti-Unfair Competition Law of the State Administration for Industry and Commerce.

On 30 October 2012, the American Bar Association Section of Antitrust Law, the Section of Intellectual Property law and the Section on International Law gave their comments on the draft Guidelines. Article 17 discusses the refusal to licence Intellectual Property. The concept of refusal to license is well established in the EU and the US. Article 17 starts by explaining that a refusal to licence is allowed if the refusal has an unconditional and non-discriminatory application. The main criticism of the ABA centred on Article 17 of the Guidelines, dealing with the refusal to license intellectual property rights. the rules explained in Article 17(2) applying the essential facilities doctrine to intellectual property rights are more controversial. ${ }^{568}$ The opening text of Article 17

\footnotetext{
${ }^{566}$ See also Xianlin, The relationship between the antitrust law and the intellectual property protection, 11-32011 Changsha.

${ }^{567}$ Sub note 43, slide 16.

${ }^{568}$ Guidelines Article 17 (2) The intellectual property right refused to be licensed by the undertaking with a dominant market position is an essential element for the licensee to compete in the relevant market, such that the refusal to license that intellectual property right will prohibit the licensee from competing effectively in the relevant market, which will adversely impact competition and innovation in the relevant market and
} 
recognized the inherent right of the owner to refuse the licence of his IPR. This is recognition of the basic function of IPRs; future investments in patents would be endangered if the innovator were not rewarded for his efforts.

The essential facilities doctrine is well recognized in US competition law. A court (Alaska Airlines, Inc. v. United Airlines, Inc., 948 F.2d 536, 542 (9th Cir. 1991) gave the following definition:

"The essential facilities doctrine imposes liability when one firm, which controls an essential facility, denies a second firm reasonable access to a product or service that the second firm must obtain in order to compete with the first." 569

In the European Union, the doctrine of essential facilities was first developed under the heading of Article 82 EEC Treaty, the prohibition of abuse of a dominant position. In cases like Commercial Solvents, the essential facilities doctrine was defined as a subversion of the refusal to deal. The court case involving Bronner paved the way for a much wider application of the essential facilities doctrine in EU competition law. ${ }^{570}$

However, both in the EU or the US, competition authorities have not directly linked the essential facilities doctrine to intellectual property rights. The essence of a patent right is that the inventor may exclude others from using his idea or intellectual property. The application of the doctrine of essential facilities to patents would discourage the patent holder from making future investments in research and development, since the final result would have to be disseminated to competitors.

Some commentators make the point that Article 17 (1) could specifically be applied to the strategic use of essential patents in standard setting. If there were a case of patent ambush or patent hold-up within a newly established standard or if the patent holder did not license on RAND terms, Article 17 (1) could be invoked. The general application of the essential facilities doctrine to IPRs does not correspond with the present developments in the Chinese high-tech sector, since most essential facilities, even in the telecommunications sector, do not have a definite essential character in the sense that substitute technology is not available.

The State Administration for Industry and Commerce issued the fifth draft of the "Guide on antimonopoly enforcement in the field of intellectual property rights." Article 2 discusses the relationship between Intellectual Property Law and Anti-Monopoly Law and states that the AML will become applicable when undertakings abuse IPRs. The

result in consumer needs not being able to be satisfied. Refusal to license intellectual property rights can also be a means for undertakings to impose other restrictive conditions or to engage in tying. The State Council Anti-monopoly Law enforcement agencies will determine the impact on competition by analyzing all relevant restrictive conditions together or by analyzing the tying provisions.

${ }^{569}$ Pitowsky: The essential facilities doctrine under US antitrust law page 2.

570 The concept of essential facilities is complicated. It is often defined as a necessary input that all firms require to operate on the relevant market and which cannot easily be copied or duplicated by firms. Motta page 66. Some scholars also define this as a "bottleneck monopoly". If a firm refuses to provide an essential facility, this could be infringing antitrust law. 
abuse is further explained in Article 3 as use of IPRs outside the "boundaries and purposes of the relevant intellectual property laws", harming the interests of consumers and the public in general. ${ }^{571}$

\subsection{PATENTS, STANDARDS AND THE NATIONAL INTELLECTUAL PROPERTY STRATEGY}

In January 2005, the Chinese State Council initiated a study on the effect and implementation of IPRs in standards. ${ }^{572}$ The objective of the study was to investigate the relationship between standards and IPRs (i.e. patents), to monitor the present international trends in this field and to focus on the ICT industry. The study took the National Intellectual Property Strategy as a starting point. Article 11 states:

"Technological innovation will take legal industrialization as the basic precondition, and make the acquisition of IPRs as its goal, with being accepted by the technical standards as its endeavor direction." 573

In the same context the provision of Article 12 stipulates:

"Choose some important technological areas to create a number of core self-relied intellectual properties and technical standards."

Finally Article 17 states:

"Formulate and improve policies related to standards and to regulate the process of turning a patent into a standard. Enterprises and industry organizations should be supported in actively participating in the formulation of international standards." 575

The Standards Administration Commission of China drafted "Rules on National Standards involving Patents" in June $2009 .{ }^{576}$ Consequently, the SAC asked concerned parties to send comments on the draft proposal in order to, if necessary, amend the definite Rules on National Standards involving Patents. The SAC provided further guidance by issuing an implementation guide, next to the draft rules on national standards involving patents. Article 18 declares:

\footnotetext{
${ }^{571}$ Guide on antimonopoly law enforcement in the field of intellectual property rights (Fifth draft) article 2 and article 3 .

${ }^{572}$ See presentation Chinese National Institute of Standardization, September 2009 Study on patents involved in national standards IPR2-project.

${ }^{573}$ See text article 11 (Outline of the) National Intellectual Property Strategy.

${ }^{574}$ Article 12 (Outline of the) National Intellectual Property Strategy.

${ }^{575}$ Article 17 (Outline of the) National Intellectual Property Strategy.

${ }^{576}$ Draft Rules on National Standards involving Patents June 2009.
} 
"(18) Draft the policy related to IP disposition in technical standards, the patent assessment and implementation, increase the proportion of China's IP in major international technical standards. (MIIT, MOST, AQSIQ)." "577

The basic assumption in the draft version is that compulsory national standards may only include patents on the condition that the patents are part of a royalty-free licence or that an agreement has been reached with the patentees. In relation to voluntary standards, the draft rules declare that patents that are incorporated into standards must be subjected to RAND license terms, provided on a royalty-free basis or at a rate that is "significantly lower than customary royalty". ${ }^{578}$ This obviously raises the old debate on the determination of the RAND royalty fees but, more importantly, it is difficult to assess how a Chinese court will evaluate the lower-than-customary royalty fees. Does the word "customary" refer to customary in the relevant market, the royalty fees for comparable patents or the royalty fees for the patent before it was incorporated into the voluntary standard? Against the background of the Chinese indigenous innovation policy (as discussed in chapter 4), it is interesting to note that the telecommunications industry is one of the seven strategic industries shortlisted in China's $12^{\text {th }}$ Five Year Plan for rapid development. The shortlisted sectors were identified to spearhead China's future economic growth and high royalty fees for foreign-owned patents would render this objective less effective.

Will Chinese courts, in the determination of the justified level of royalty fees for foreign-owned patents in the telecommunications industry, be led by the aims of the $12^{\text {th }}$ Five Year Plan and discriminate against foreign patents in voluntary standards created in China?

The success of the Chinese high-tech companies has also led to the acquisition of Western companies (and their IP portfolio) by Chinese firms. In the US and the EU, the position of patents after a merger or acquisition is not sufficiently clear. It is a common belief that these patents and the FRAND commitments must be respected by the new owner of the IP portfolio. In this scenario, it is not clear how Chinese courts would react, in relation to the definition of lower-than-customary royalty fees. ${ }^{579}$

The growing popularity of IP management firms/PAEs in the EU and US might also spark an interest in China. The globalization of production will ultimately also see the establishment of IP management firms /PAEs in China. The Chinese policy makers may draw from the experiences of the EU and US regulators.

\footnotetext{
${ }^{577}$ See the promotion plan for the implementation plan for the national intellectual property strategy in 2012. ${ }^{578}$ Sofia Chen Draft Provisional Rules-National Standards involving Patents.

${ }^{579}$ In general terms, this discussion is also part of a wider debate within the concept of indigenous innovation. Some US politicians believe that technology transfer is the price that American companies have to pay for gaining market access in China. For more comments see also: China's Five-Year Plan, Indigenous Innovation and Technology Transfers and Outsourcing Hearing before the US-China Economic and Security Review Commission June 15, 2011.
} 


\subsection{THE MIIT TEMPLATE FOR IP POLICIES IN INDUSTRY STANDARDS ORGANIZATIONS}

In November 2014, the MIIT IP Center published a template for IP policies in industry standards organizations. ${ }^{580}$ The MIIT is the Chinese Ministry of Industry and Information Technology, which is very influential, and this draft may result in compulsory legislative measures in the future. The draft included some interesting elements. Article IV, concerning the duty to disclose, mentions: "In no way shall any disclosure duty arising under this IPR Policy be interpreted as requiring Members to conduct a Patent search." The wording regarding the disclosure commitment is very strange and does not specifically refer to domestic or foreign patents. Regarding the licensing of IPRs, the draft gives the following options:

1. Fair, reasonable and non-discriminatory, royalty-free (FRAND RF) licence;

2. Fair, reasonable and non-discriminatory (FRAND) licence.

- For Necessary Claims in connection with any specific final standard where Member is not a participant in the applicable Subgroup which adopts the Draft Standard that becomes such a final standard:

- Fair, reasonable and non-discriminatory, royalty-free (FRAND RF) licence;

- Fair, reasonable and non-discriminatory (FRAND) licence;

- No licensing obligation (No licensing).

With respect to injunctions, the draft text gives the following explanation: "A Member shall not seek injunctive relief against a potential Licensee based on alleged infringement of a Necessary Claim unless the potential Licensee is not subject to the jurisdiction of, fails to participate in, or fails to comply with the outcome of, an independent adjudication, of FRAND licensing terms." Consequently the draft also deals in Article $X$ with the hotly debated FRAND terms: ".... such FRAND adjudication must be made by courts or arbitration tribunals (if mutually agreed) of competent jurisdiction, that can determine FRAND monetary compensation and other licensing terms, and that will adjudicate any related claims and defences such as non-infringement and enforceability." The next article gives guidance on the determination of the FRAND terms and the reasonable royalty rate is based on the following factors:

1. The value contributed to a Compliant Portion by the Necessary Claim shall be assessed against the smallest component or device that is compliant with the Final Standard and that practices the relevant Necessary Claims;

\footnotetext{
${ }^{580}$ Ministry of Industry and Information Technology of the People's Republic of China, Template for IP Policies in Industry Standards Organizations.
} 
2. A reasonable royalty shall also take into account the total aggregate royalties that may apply if other owners of intellectual property demand similar terms.

3. The degree of innovativeness of the Necessary Claims in the standard, the technical area of the standard, the nature of the standard, the implementation scope of the standard, relevant licensing terms and other factors.

4. Other relevant factors concerning licensing matters.

The royalties shall not take into account the value, if any, associated with the inclusion of the Necessary Claims in the Final Standard.

The first factor explicitly mentions the "smallest component or device", which is a surprising factor since it could relate to the size or more like to the value of the component. Article XII discusses the possible reciprocity in using FRAND commitments, but the text is insufficiently clear and conditional. Although the text is vague, the suggested implications of the reciprocity might endanger cross-licensing between Chinese and foreign firms. It seems that article XV specifically monitors PAEs or privateering (according to my own interpretation). The text states: "Members agree that they have not transferred and will not transfer Patents containing essential Necessary Claims for the purpose of evading licensing obligations under this IPR Policy. "

Maybe the most controversial element can be found in Article XXIV: "Any claim relating to this IPR Policy shall be governed by the laws of the People's Republic of China." In comparison, it can be noted that all ETSI contracts are governed by French law. Does this mean that the licence based upon this SDO policy is also governed by Chinese law? How should "a claim" be defined?

The influential MIIT recently published a draft text regarding the regulation of IPRs in industry standards. The section on injunctions does not give any explanation on "willing licensees or willing licensors". The text specifically refers to FRAND terms and explains the basis for the calculation of FRAND rates. Especially the choice for the "smallest device or component" is not in conformity with the present views held in the US and the EU. Although not yet prevalent in China, the draft also tackles the concept of aggressive privateering (in my own interpretation), which could also have implications for patent pools in China.

The MIIT conference on Intellectual Property Standards and Anti-Monopoly Law was held on 10-11 December 2014 in Beijing. At the time of writing, the material was not yet published, but commentators have already published their first observations. Regarding the subject of holdouts, it is interesting that the views of Western and Chinese firms differ. Representatives of Ericsson claim that holdout can be a real problem, but Huawei officials claim that the holdout problem does not exist in China. Regarding the SAIC'S IP Abuse draft, it can be noted that, in the current $7^{\text {th }} \mathrm{draft}$, the essential facilities doctrine is still included but will be applied in a much narrower way. Yang Jie, the Director of SAIC, explained that, within the context of standard setting, IPRs will be treated in the 
same way as other property rights. This means that a SEP no longer automatically constitutes market dominance. An individual case-specific investigation must show that the firm has market dominance within the definition of the AML. Regarding the standard implementation, the guidelines now specifically evaluate legality by looking at the restricting or limiting of competition on the market of the standard. The above-discussed MIIT Template also received some criticism. The main comments of business life was that Chinese IP Courts do not yet have sufficient expertise in deciding on FRAND/Sep cases or injunctions. As was to be expected, many firms objected to the basis of the FRAND-rate setting, the smallest component criterion. In general, firms found the suggested legal structure to be too complicated and felt that the draft template would frustrate cross-licensing efforts ${ }^{581}$

Finally regarding the new Specialized IP Courts in China, participants at the conference worried about the possible case load. The Beijing court, consisting of 22 judges, could be facing a possible workload of 15,000 cases on an annual basis. The introduction of the concept that the Specialized IP Courts must take the responsibility of "technology investigator" was very interesting. This concept foresees installing technical experts that will serve as assistants to the Specialized IP Court judges. ${ }^{582}$

\subsection{THE AML ENFORCEMENT GUIDE IN RELATION TO INTELLECTUAL PROPERTY, ON PATENTS AND STANDARDS}

Article 22 of the Anti-monopoly enforcement guide in relation to IP is titled, "Exercising patent rights during the formulation and implementation of standards." The text gives four possible examples of business behaviour concerning patents and standards that violates Chinese antitrust rules:

1. the patent holder or patent applicant knows or should have known that its patents or pending patent applications may be included in the relevant standards;

2. the patent holder or patent applicant fails to disclose relevant information of its patent or already-publicized patent application information in accordance with the policy prescribed by the standard-setting organizations or authorities;

3. After the standard has been announced, the patent holder asserts its patents that have been included in the standard;

\footnotetext{
${ }^{581}$ For more background information see: A Quick Report on the MIIT Conference including SAIC'S IP Abuse Rules, Patent Law Amendments, MIIT Standardization Policies, Standards and IP Abuse

${ }^{582}$ For more information see: Cohen, Update on Specialized IP Courts.
} 
4. the conduct causes or is likely to have an adverse effect on competition and innovation in the relevant market. ${ }^{583}$

From a literal interpretation of the text, it is unclear whether, as the ABA suggests, the provisions should be read together or that the provision can stand alone and lead to violations of the Chinese AML. ${ }^{584}$

The Guide also specifically asks owners of standard-related patents to indicate the upper limit of the license fee, which must not have increased after the patent was included in the standard.

\section{9 (DRAFT/INTERIM) REGULATORY MEASURES FOR STANDARDS INVOLVING PATENTS}

At the beginning of 2013, the Chinese government published a draft text for regulatory measures for standards involving patents. The draft indicates that the Standardization Administration does not take any responsibility in relation to the validity of the patents incorporated into national standards. Nevertheless, national standards will only contain essential patents. From the draft text, it is not clear whether there is an obligation to disclose essential patents. The wording refers to "encourage", which seems to hint at a voluntary disclosure by the patent owner. ${ }^{585}$

The Standardization Administration of China (SAC) and the State Intellectual Property Office (SIPO) followed up on the draft with the publication of the "Interim Regulations on National Standards Involving Patents," which went into effect on 1 January $2014 .{ }^{586}$ The Interim regulations state that patent owners must disclose essential patents that they have or know about and there is a mandatory requirement that essential patents in standards will be licensed on FRAND terms.

In the case of mandatory national standards, where patent owners do not agree to license on FRAND terms, the SAC and SIPO and other relevant Chinese governmental agencies will start a negotiating process to determine the correct level of royalty rates. It is interesting that the failure to disclose essential patents will be qualified as "a breach

\footnotetext{
583 JOINT COMMENTS OF THE AMERICAN BAR ASSOCIATION SECTION OF ANTITRUST LAW, SECTION OF INTELLECTUAL PROPERTY LAW, AND SECTION OF INTERNATIONAL LAW ON THE SAIC DRAFT RULES ON THE PROHIBITION OF ABUSES OF INTELLECTUAL PROPERTY RIGHTS FOR THE PURPOSES OF ELIMINATING OR RESTRICTING COMPETITION page 439.

584 Ibid note 692 page 28.

585 "Organizations or individuals who have not participated in the formulation or revision of national standards, and yet have knowledge of patents essential to the standard, are encouraged to notify in writing such information to the relevant technical committee or the responsible entity at any stage of the formulation or revision of such standard." Draft text on regulatory measures for standards involving patents.

${ }^{586}$ Interim Regulations on National Standards Involving Patents 2014.
} 
of good faith", a concept that is also clearly present in the motivation of the Huawei/ InterDigital case.

The interim measures give the patent owner the choice of different licensing options: FRAND, no licence or royalty free. For voluntary national standards, patent owners do not have the choice of no licence, since it would automatically remove the patent from the national voluntary standard. As a consequence, in practical terms, it means that the patent owner must give the opportunity to license as soon as he is part of standard setting. Commentators hold the opinion that the SAC deliberately did not specify or clarify the details of the Interim regulation. The first conclusion is that it is absolutely not clear whether the Interim regulation offers the possibility to foreign companies to participate in the development of standards in China. If this would be allowed, then it is even more dubious what the legal position of foreign-owned SEPs is. According to commentators, the main problem is that, although foreign companies can participate in Chinese SSOs, they cannot influence the decision-making process since they do not have any voting rights. ${ }^{587}$

These rules will raise the sensitive subject of the legality of ex ante discussions of licensing terms again before the standard is set. In the EU and the US, the procompetitive effects are recognized, but in the Chinese situation (with the involvement of State-Owned Enterprises and former state monopolies), the business context is distinctively different. Again, it has to be noted that the Interim regulation lacks clarity and that the wording is not unconditional and can be interpreted in different ways.

Although the Interim regulation suggests protectionist tendencies, the economic reality is that, with more and more involvement of Chinese companies in global production networks (GPNs) and a growing involvement of Chinese firms in international standard-setting organizations, China is much more likely to relax its stance on patents incorporated into standards. Whereas Japan made the strategic choice to license foreign technology, China welcomes foreign investments into their national economy. ${ }^{588}$

Suttmeier recognizes that there is no homogeneous approach of the Chinese government in relation to standardization. Although he feels that techno-nationalist tendencies seem to prevail, it should be a task for the foreign investors in China to support the techno-globalists by supporting Chinese standardization efforts and evaluating the different key players and their economic interests. ${ }^{589}$

In an earlier report, Suttmeier already warned in 2008 against a possible scenario in which global standardization could be hindered by national security concerns and finding a balance between national R\&D policies and foreign investors could become chal-

\footnotetext{
587 Jing Managing Intellectual Property 27 February 2014, China Patent: Standards and Patents Policy finally issued.

${ }^{588}$ For more background information see also Kennedy The Political Economy of Standards Coalitions: Explaining China's Involvement in High-Tech Standards Wars page 60.

${ }^{589}$ Standards of Power? Technology, Institutions, and Politics in the Development of China's National Standards Strategy Suttmeier, Yao, and Zixiang Tan.
} 
lenging. ${ }^{590}$ Some of the limitations for the success of the national Chinese innovation system that he mentions still seem to be relevant, such as the limited possibilities for venture capital financing, ineffective public governance, bureaucratic sectionalism, political interference in the economy and the need to strengthen the intellectual property rights system.

Should the Chinese antitrust system compensate for the ineffectiveness of the evolving national intellectual property rights system?

\subsection{AMERICAN BAR ASSOCIATION COMMENTS ON THE DRAFT REGULATORY MEASURES ON NATIONAL STANDARDS INVOLVING PATENTS OF THE PRC}

The Standardization Administration in China (SAC) published draft regulatory measures on national standards on 19 December 2012 for a public consultation procedure. The American Bar Association (ABA) reacted with their comments on 22 January $2013 .{ }^{591}$ The main worries of the ABA were related to the conditional and unclear wording of the draft. It is not clear whether the draft refers only to essential patents in standards or to all patents in a standard. Moreover, doubts are raised whether the draft targets only foreign-owned essential standard patents or also Chinese-owned essential patents. Regarding the disclosure rules, the SAC could benefit from studying the disclosure provisions of both the US and EU regulators, as well as the disclosure rules of the main Western standardizing bodies. The Chinese draft mentions vague terms, such as disclosure of "participants" to the "responsible entity" and patents that are "known to them", making the playing field for patent ambush and patent hold-up for firms very broad. ${ }^{592}$

\footnotetext{
${ }^{590}$ Standards, stakeholders, and innovation China's Evolving Role in the Global Knowledge Economy Kennedy, Suttmeier, Su, page 37.

${ }^{591}$ ABA: Joint Comments of the American Bar Association Section of Intellectual Property Law and Section of International Law on the Draft Regulatory Measures on National Standards Involving Patents (interim) for the People's Republic of China.

592 Disclosure of Patent Information: 1. Organizations or individuals participating in the formulation or revision of national standard shall timely disclose to the technical committee or the responsible entity the essential patents known to them, and provide patent information and corresponding verification materials thereof. 2 . Organizations or individuals who have not participated in the formulation or revision of national standards, and yet have knowledge of patents essential to the standard, are encouraged to notify in writing such information to the relevant technical committee or the responsible entity at any stage of the formulation or revision of such standard. 3. When the department of standardization administration under the State Council publishes information regarding the initiation of national standard project proposals, it shall publicize information on patents involved therein submitted by the technical committee or the responsible entity. 4. Organizations or individuals participating in the formulation or revision of national standards shall be legally liable for their failure to follow the aforementioned requirements to disclose the essential patents held by them. The ABA correctly states that a clear definition of the participant in the standardizing process in necessary. Prior experience has shown that even the domestic Chinese telecommunications standards include the partic-
} 
The wording of Paragraph 4 (Organizations or individuals participating in the formulation or revision of national standards shall be legally liable for their failure to follow the aforementioned requirements to disclose the essential patents held by them) does not encourage participation in the standardizing process, since the aforementioned requirements are not clear and could possibly include the handing over of confidential technical information by foreign firms. ${ }^{593}$

A very important point of discussion is Article 3 paragraph 2 of the draft:

\section{Patent Licensing Declaration}

1. During the formulation or revision of national standards involving patents, the technical committee or the responsible entity shall timely obtain the patent licensing declarations from the patentees/patent applicants.

Such declarations shall include one option selected by the patentee/patent applicant from the following three options:

1. The patentee/patent applicant is willing to license to any organization or individual, free of charge, and on a reasonable and non-discriminatory basis, to practice his/her patent when implementing the national standard;

2. The patentee/patent applicant is willing to license to any organization or individual, on reasonable and non-discriminatory basis, to practice his/her patent when implementing the national standard; or

3. The patentee/patent applicant is not willing to license pursuant to either one of the aforesaid options.

The second paragraph directly mentions the RAND obligation, although the element of reciprocity is not included in the text. The $A B A$ states that the situation could arise whereby a firm that benefits from a RAND licensing commitment could go against the firm providing the RAND commitment for the implementation of the patent in the standard. This comment is at the heart of the discussion, since, at the most, it will be mainly foreign firms that have to give RAND licensing terms to Chinese companies which, then again, could possibly initiate legal action on the basis of Article 3 paragraph 2. As discussed earlier, it again opens the discussion of the reasonable basis of the licence.

On 9 July 2014, the American Bar Association published comments on the SAIC draft rules on the prohibition of abuse of intellectual property rights for the purposes of elim-

ipation of foreign firms leading to complex business relations and uncertainty about the legal treatment of the foreign companies.

593 The text mentions "corresponding verification material" without specifically explaining the scope of this provision. ABA commentators see a possible linkage to confidential technical information, a requirement that would also surpass the requirements of Western standard-setting bodies. 
inating or restricting competition The SAIC published the new draft on 11 June 2014 without Guidelines. The 2012 draft still included Guidelines on the application of the rules.

Article 7 of the 2014 draft does include the application of the essential facilities doctrine to patents. This application is even relatively unique in a global text. ${ }^{594}$ Again it may be questioned what the effect on foreign direct investment might be.

Article 12 of the draft rules deals with patent pools. The text provides the following:

"Undertakings shall not, in the course of exercising intellectual property rights, engage in behaviors to eliminate or restrict competition by taking advantage of patent pools.

Members to the patent pool shall not, by taking advantage of such patent pool, exchange competition-related sensitive information concerning price, output, market division, etc.

They may also not conclude monopolistic agreements prohibited by Article 13 and Article 14 of the AML, except to the extent that they can prove the agreements concluded are in compliance with provisions of Article 15 of the AML.

Undertakings with dominant market positions or the management organization of the patent pool shall not engage in the following behaviors to abuse dominant market positions by taking advantage of the patent pool:

1. to restrain member to the pool from licensing patents beyond the pool as independent licensor;

2. to restrain members to the pool or the licensee from developing independently or jointly with third parties technologies which compete with the pooled patents;

3. to force the licensee to exclusively license back the technologies it has improved or developed to the management body of, or members to, the patent pool;

4. to prohibit the licensee from challenging the validity of the pooled patents;

\footnotetext{
${ }^{594}$ Article 15 reads: "An undertaking with a dominant market position shall not refuse without justifications to license other undertakings to use its intellectual property rights on reasonable terms in the circumstance that such intellectual property rights constitute essential facilities for manufacturing and operating activities. Factors to be considered when determining whether the intellectual property rights constitute essential facilities for manufacturing and operating activities include: whether there are reasonable substitutes to such intellectual property rights in the relevant market; whether such intellectual property rights are essential for other undertakings to participate in

competition in the relevant market; whether refusal to license such intellectual property rights will bring an adverse impact on the competition or innovation in the relevant market; whether the licensing of such intellectual property rights will result in unreasonable damage to such undertaking, etc." http://chinaipr2.files.wordpress.com/2014/07/aba-sal-sipl-sil-saic-ip-abuse-rule-comment-final-package.pdf
} 
5. to provide differential treatment on trading conditions against members with same conditions to the pool or the licensees in the same relevant market. For the purpose of these Rules, "patent pool" refers to a scheme or arrangement whereby two or more than two patent holders jointly license their respective patents to a third party in a form where a joint venture is set up specifically for such purpose or a member to the pool or an independent third party is entrusted with the responsibilities of management."

The wording of this article seems to hint at the situation that certain types of behavior of patent pools are considered as illegal per se. This concept is a clear divergence from the present views in the US and the EU that patent pools should be governed by a rule of reason approach. The adoption of a per se doctrine for certain types of behavior of patent pools under the AML does not give the Chinese authorities any room to stimulate the pro-competitive effects of patent pools. ${ }^{595}$

In the US and EU situation, competition authorities provide extensive guidance on the pro-competitive effects of patent pools through the system of Business Review Letters and the case law that is motivated and published by the Federal Trade Commission and the EU Commission.

The ABA also commented on the Article 13 of the new 2014 draft that specifically deals with the obligation to disclose patents to the SSO. In the 2014 draft proposal, it is stated that companies with a dominant position must disclose their patents to the standard-setting organization and later promise to adhere to the FRAND principles as soon as their patents are incorporated as essential patents in the standard. In the wording of this new provision, it is insufficiently clear whether the disclosure obligation also becomes mandatory for non-SSO members. The ABA expresses the fear that this disclosure obligation could go beyond the normal disclosure requirements that are set by the SSO. The second paragraph of Article 13 is of a more worrying nature, since it seems to suggest that there is a general obligation to license the SEP on FRAND terms, irrespective of the participation in the SSO or the internal requirement of the SSO to use FRAND terms. This would have the practical consequence that undertakings could not have the strategic choice to refrain from participating in standard-setting organizations and opt out of licensing their technology to third parties. A patent owner has the discretion to decide whether to license his SEPs or refrain from this process. The consequence could be that the ownership of SEPs automatically leads to the general obligation to license the patent rights on FRAND terms. The decision to license the SEPS on FRAND terms and whether to participate in standard-setting organizations should be made on a voluntary

\footnotetext{
${ }^{595}$ For more comments see also JOINT COMMENTS OF THE AMERICAN BAR ASSOCIATION SECTION OF ANTITRUST LAW, SECTION OF INTELLECTUAL PROPERTY LAW, AND SECTION OF INTERNATIONAL LAW ON THE SAIC DRAFT RULES ON THE PROHIBITION OF ABUSES OF INTELLECTUAL PROPERTY RIGHTS FOR THE PURPOSES OF ELIMINATING OR RESTRICTING COMPETITION 9 July 2014 page 6.
} 
basis. Making this a compulsory obligation would have an impact on future investment decisions of foreign firms in China. If the patent owner (based upon the strength of his patent) makes the strategic decision to refrain from participation in the standardsetting process and consequently also does not adopt FRAND-licensing obligations, this should be his free choice.

The patent-owner must have the choice to opt out of the FRAND-licensing obligations. The exclusivity and contractual freedom to use the innovation for different purposes remains at the heart of the characteristic of the patent right. Mandatory FRAND obligations will have a decreasing effect on innovation, since the main reason the recoupment of the investments made only has a limited effect. ${ }^{596}$

Article 16 of the 2014 draft deals with patent trolls. As stated earlier, there is no overall consensus on the precise effects of patent trolls or patent assertion entities. Both the US and the EU are struggling with the precise definition and the possible anticompetitive effects of patent assertion entities. There can be a very thin line between patent pools and patent assertion entities, which is often only based on their actual market behaviour. Despite all the negative assumptions, patent assertion entities can sometimes be seen as a new innovative way of monetizing patents and are part of a wider development that also includes privateering.

The wording of Article 15 that deals with PAEs is very broad and can be interpreted in different ways. In the present form, this article could also be used against patent pools that send a perfectly legitimate letter to infringing undertakings. Since both the US and EU are struggling with the phenomenon of PAEs, it would be commended that the SAIC gives further clarification on the meaning of Article $15 .{ }^{597}$

The fact that the ABA frequently gives its opinion and comments on draft proposals may lead to specific dimensions. Petit quoted the FTC Commissioner Ohlhausen in a recent statement:

"our actions, if not properly explained, may send a message to our foreign counterparts that we do not place a very high value on intellectual property rights, which is clearly inconsistent with the appreciation for IP rights that we typically hold in the United States. Let me share with you an example of what I mean. Recently, I was in China attending a conference and meeting with Chinese competition officials. At the conference, I heard people claim that the United States has a well-established essential facilities doctrine, which is not exactly correct. In addition, it was suggested that when read in light of this doctrine, the FTC's Google decision implies that a SEP [Standard Essential Patent] is an essential facility and an unreasonable refusal to li-

\footnotetext{
${ }^{596}$ See also note 595 page 22.

597 The 2014 draft article reads: Undertakings with dominant market positions shall not, upon the expiration or invalidation of their intellectual property rights or in the circumstance that sufficient evidence has been provided by another party to prove relevant act does not constitute infringement of intellectual property rights, excessively issue infringement warning letters to eliminate or restrict competition.
} 
cense that SEP constitutes monopolization. It was further suggested that the best remedy for monopolization with a SEP would be compulsory licensing because permitting more parties to use the SEP would facilitate competition. This is not a correct reading of relevant U.S. Iaw or, in my opinion, of the FTC's decision in Google." 598

The concept of essential facilities was discussed earlier in this chapter. The same phenomenon could easily be happening in the field of SEPS, where Chinese courts may misinterpret US or European court cases without looking at the specific Chinese context, especially in relation to standardization. Given the different goals and development stages of standardization in China, compared to the US and EU, a direct copying of US or European rules might not lead to the desired effect.

The draft regulatory measures on patents in standards have raised uncertainty with regard to the treatment of foreign firms operating in this specific field. The willingness of the SAC to open the discussion with a public consultation does show a more liberal approach to the regulation of standardizing processes. The main criticism of the 2012 rules (e.g. that of the $A B A$ ) is concentrated on the lack of clarity in the wording and the scope of application. Two subjects are predominant in this discussion, the lack of reciprocity in relation to the RAND licensing terms and the general liability of parties involved in the standardizing process. Precisely these discussion points are at the heart of the legal debate, since they have far-reaching consequences for foreign direct investors in the PRC.

The 2014 draft rules show a different picture. The 2014 draft does not include Guidelines which is a missed opportunity. The complex intersection between competition law, standardization and patents does benefit from an extensive explanation and motivation which could be provided by Guidelines. In the present form, the $2014 \mathrm{draft}$ does signal a return to a more conservative stance on SEPS, patent pools and PAEs. Worrying developments are the application of the essential facilities doctrine to SEPS, the possibility that some types of patent pools are ruled by a per se approach and the compulsory obligation to commit to FRAND terms even outside the SSO framework. These developments hint at a more conservative stance on the intersection of patents, standards and competition law. The decision whether the owner of SEPs does participate in standard setting (on FRAND terms) should not be compulsory but a free strategic choice. The obligation to use FRAND terms outside the SSO context could have a deterrent effect on innovation and FDI in China.

\footnotetext{
${ }^{598}$ Petit, Stealth Licensing page 22.
} 


\subsection{RELEVANT GENERAL CASE LAW ON THE INTERSECTION OF IP AND COMPETITION LAW}

The case Sichuan De Xian Science and Technology Co. Ltd vs. Shanghai Suo Guang Electronics Limited and Sony Corporation dealt with the problem of a possible monopoly. In this legal dispute, Shanghai Suo Gang produced batteries under a licence for Sony. The batteries were embedded with an electronic identification system, making it nearly impossible to produce alternative products with a substitute effect. Shanghai Suo Guang argued that Sony had abused their dominant position in the market by using the intellectual property rights linked to the batteries. The Chinese court decided that the patented technology in both the cameras and the original batteries was not used by Sony to prevent the production and usage of other batteries and consequently found no basis for the claim of the abuse of intellectual property rights leading to restricted competition. $^{599}$

This case was decided before the enactment of the Anti-Monopoly Law, but commentators wondered why there was no reference to a possible dominant position in the relevant market and what the factors were for determining a dominant position and a possible abuse of intellectual property rights. ${ }^{600}$ Experience from the European Union shows that IPRs usually relate to different market perceptions: technology markets and product markets. With technology markets, we refer to the commercial opportunities to license the technology for a product or a production process. The product markets are formed by the products that implemented the patented technology. The fifth draft of the Guide explains, in Article 8, the definition of the relevant intellectual property markets. This article shows that both technology and product markets are covered by the AML. Determining factors are the characteristics, the usage and the price-setting of the IPRs that influence the interchangeability or possible substitution of the products in the technology market. In the product market, the same determining factors are directly related to the product. ${ }^{601}$ Depending on the shape and form of future Chinese economic markets, the enforcement agencies must clarify the exact meaning of the relevant market to prevent further confusion. In the US and the EU, companies tend to specialize in specific parts of either the technology market or the product market and sometimes combinations thereof.

The discussion on essential facilities is closely related to the definition of essential patents. In previous chapters, this discussion showed that the definition of essential patents in standard setting has not led to uniform results and economic research data does not give a clear solution.

\footnotetext{
${ }^{599}$ The Chinese court was No.1 Shanghai Intermediate People's Court.

${ }^{600}$ Supra note 43, Xian. Identification of Abuse of Intellectual Property Rights and Monopoly Conducts.

${ }^{601}$ Article 8 of the Guide on antimonopoly law enforcement in the field of intellectual property rights (Fifth draft).
} 


\subsection{THE CHINT VS. SCHNEIDER CASE}

On 26 September 2007, in a first instance judgment a Chinese court ordered the defendant Schneider to pay 330 RMB million in damages to the plaintiff, the Chinese firm CHINT. The legal dispute centred on patents relating to miniature low voltage circuit breakers and was settled by mediation resulting in Schneider paying CHINT more than 16 million Euro. This case dealt with the use of utility patents and raised some questions. Western scholars have often commented on the extensive use of both the utility model and design patents and the often inferior quality thereof. In the balance between the quantity and quality of patents, the latter often wins. Western companies (Schneider is a French company) often complain about the selective tendency of Chinese courts, which seems to result in positive discrimination towards Chinese patent owners.

The current Chinese patent system does not match the needs of the national innovation and technology policies. In the global context, Chinese firms can obtain competitive advantages through the abusive use of utility patents, the difficulties of the administrative processing of large volumes of new utility model patents and the relatively high thresholds for the invalidation of utility patents (compared to invention patents). Other relevant factors strengthening the position of Chinese firms are its obvious home-court advantages and China's first to file system. The National Patent Development Strategy recognized that firms have an "inadequate number of core patents and their ability to use patents is quite poor", concluding that "these problems have largely restricted the role of the patent system in encouraging innovation and promoting economic development." 602

The Schneider case introduced the notion of high financial rewards into the Chinese IPR discussion. Both Chinese firms, as well as Foreign-Direct Investors, will be encouraged to file patent cases in China and the growing legal importance of Chinese patents could also improve the position of the patent holder in terms of cross-licensing. The decision of the Chinese court was in line with the internationally awarded claims, thus further emphasizing the new role of the Chinese IP regulations in the system of Global Production Networks. Some commentators mark this case as a new dawning for the inclusion of the Chinese IP rules in the international IP community, comparing the case to the establishment of the United States Court of Appeals for the Federal Circuit, giving patents a more prominent role in the business environment. ${ }^{603}$

\footnotetext{
${ }^{602}$ National Patent Development Strategy 1-2.

${ }^{603}$ See comments of Burns, Will China Become the World Leader in Patent Litigation?
} 


\subsection{CASE CHAOVANG XINGNUO: INSTRUCTION LETTER ON "PATENTS USED FOR STANDARDS SETTING CONSTITUTES INFRINGEMENT “}

In 2008, the High Court of Liaoning Province discussed a case of possible patent infringement by the firm Chaovang Xingnuo of a patent that was part of a standard issued by the Chinese Ministry of Construction. The Supreme Court (Third Civil Division) sent an instruction letter on "Patents Used for Standards Setting Constitutes Infringement" to clarify the legal positioning. This letter stated:

"Regarding the current reality that China's standard setting organizations do not yet have established patent information public disclosure and use systems for standards, where the patent right holder participates in the standard setting or following his consent, where the patent is included in the national, industry or local standard, it is deemed that the patent holder licenses others to implement the standard and concurrently use the patent, relevant behaviour of others using the standard is not regarded as a patent infringement behaviour as stipulated in Article 11 Patent Law. The patent holder can request the implementing person to pay a certain usage fee, but the paid amount must be significantly lower than a normal licensing fee; where the patent holder has promised to waive the patent usage fee, it shall be proceeded according to his promise." 604

In other cases, Chinese courts considered the impact that the use of IPRs had on the local community. In the case Jingyuan vs. Fushihua and Huayang 2008/2009 (Fujian High Court/SPC) the request for an automatic injunction resulted in a compulsory licence motivated by the public interests at stake.

"In this case, if Huayang company stopped to use the desulphurization equipment, it would produce a negative impact on the local economy and livelihood of citizens. In order to balance the interests of the right holder and the public interests of society, this court cannot sustain the claim against Huayang Co. to cease and desist further use." 605

\subsection{THE QIHOO 360 V. TENCENT CASE}

In March 2013, the Guangdong High People's Court took a decision in a court case between two high profile Chinese internet companies, Qihoo 360 and Tencent. The court had to rule on the question of whether Tencent abused its dominant position. The court found that Qihoo 360 had failed to define the relevant market and that Tencent did not

\footnotetext{
${ }^{604}$ See also presentation of Pattloch Patent case law in China and its impact on protection of innovation EPIP Maastricht conference 10 December 2010.

${ }^{605}$ Idem.
} 
hold a dominant position in the market of instant messaging. Although the market and the dominant position was not proven, the court did continue to evaluate possible abusive behaviour by Tencent. The main argumentation was that the court could give further guidance to other firms operating in the internet/software market. Commentators find this approach interesting for foreign companies that operate in the Chinese hightech market for a number of reasons. Firstly, the court examined the evidence provided by economists in detail. Secondly, the court looked closely at the case law of the EU Commission in the field of mergers (Microsoft/Skype). The court also especially recognized the special dynamics of the rapidly-evolving technology markets in China. ${ }^{606}$

The Qihoo 360 v. Tencent case can be seen as a landmark decision in relation to the analytical approach. In general terms, the case demonstrates that Chinese courts applied a sophisticated competition law analysis, especially concerning the market definition, the abuse of dominance and the tying allegations. Just five years after the introduction of the AML, Chinese courts used economic approaches in their competition law evaluation, just like its counterpart in the EU and US. This introduced the wider and more refined application of modern economic concepts in Chinese competition law, especially in later IPR cases. ${ }^{607}$

For the analysis here, this indicates that Chinese courts are looking to the EU Commission for guidance in economic principles and that the Chinese courts are willing to accept a more profound influence of economic analysis in their decisions. The Court investigated the effects upon dynamic competition and readily accepted economic evidence during the case proceedings.

\subsection{NDRC AND QUALCOMM}

Recently, trade relations between China and the US encountered another setback with the conflicting opinions of both countries in the WTO's Information Technology Agreement (ITA) negotiations. The ITA covers almost 95\% of the global trade in ICT products and services. The Chinese government wanted to exclude 140 products from the ITA agreement, fearing for the liberalization of the ICT market. ${ }^{608}$ Experts explain part of the policy with the Chinese plans to commercialize the fourth generation telecom networks, an operation that is being hindered by IPRs often owned by US companies. ${ }^{609}$

This coincides with the anti-monopoly investigation against Qualcomm. The Chinese National Development and Reform Commission (NDRC) are investigating the royalty setting by Qualcomm for the fourth generation telecom networks. This policy may give the Chinese licensees more leverage during the negotiations on future licensing

\footnotetext{
${ }^{606}$ For more background see comments Adrian Emch, High tech under scrutiny in China.

${ }^{607}$ See also: Evans and Zhang, The Qihoo v. Tencent landmark decision.

${ }^{608}$ See also: S. Tiezzi, US Clash Kills IT Trade Agreement.

${ }^{609}$ See also: Scissors: Theft by other means China's assault on foreign companies Eldeas.
} 
terms. ${ }^{610}$ Since Chinese companies like ZTE, Lenovo and Xiaomi Tech failed to establish a successful national standard, they still depend on foreign technology.

Regarding the protection of patents in standards, the report comes to the conclusion that the text of the 2009 draft on the application of antitrust rules has been amended. The 2009 text hinted at the introduction of a system of compulsory licences for Western products in China. ${ }^{611}$ Fortunately, the new draft published in 2012 no longer refers to these provisions. In general, the conclusions of both the IP Commission and the 301 Special Report are that the access of Chinese goods and services to the US market can be a very important tool. The problem in China is not the lack of IP laws (in 2012 more improvements were made in this field) but rather the actual implementation of national IP laws is problematic. Experts state that the level of IP protection is one of the key indicators of the economic development of a country and that there is a strong correlation between the protection of IPRs and FDI levels.

At a conference in November 2013 sponsored by the Chinese Ministry of Industry and Information Technology, the Chinese government (SAIC) announced a revision of the current articles of the AML in relation to intellectual property. At the same conference, the Supreme People's Court declared that it would revise the policy in relation to injunctions for SEPs. ${ }^{612}$ These recent events might indicate a change in China's official policy in relation to technology transfer with foreign companies in the field of the fourth generation telecom networks.

The commercialization of the fourth generation telecom network in China coincided with a more pro-active antitrust policy from the Chinese government in relation to SEPs.

\subsection{CASE HUAWEI V. INTERDIGITAL}

In 2013, the Shenzhen Intermediate People's Court ruled in the Huawei v. InterDigital case. Huawei had brought two suits against InterDigital in Shenzen. Huawei claimed that InterDigital had abused its dominant position in licensing standard essential patents in China and the US, in the form of tying, differentiated pricing and refusal to deal. In the second suit, Huawei accused InterDigital of being unwilling to negotiate FRAND licensing terms with Huawei.

The Shenzen Intermediate People's Court came to the conclusion that InterDigital had violated the Chinese Anti-Monopoly Law since it had:

- $\quad$ suggested royalty prices to Huawei that had an excessive character;

\footnotetext{
${ }^{610}$ Mukherjee and Alawadhi, China probe may be aimed at Qualcomm's 4G royalties.

${ }^{611}$ In this respect, an analogy drawn with the situation in India were imports of patented products are no longer possible and the alternative is the licensing to an Indian company or manufacturing of the product in India.

${ }^{612}$ Cohen, Qualcomm Subject of AML Investigation - Other Developments on the Way.
} 
- engaged in bundling of both essential and non-essential patents (tying) by InterDigital;

- InterDigital included a grant-back provision in its licensing agreement;

- InterDigital requested the ITC to take action against Huawei, although both parties were negotiating on licensing terms. ${ }^{613}$

The Chinese court required InterDigital to pay $\$ 3.2$ million in damages to Huawei. Interestingly, the court decided that the FRAND terms (which were based on ETSI IPR policy; see also section 3.8) should be evaluated under Chinese law and that the InterDigital royalty rates did not meet the FRAND criteria (see also section 3.13). ${ }^{614}$

The Chinese court did not publish its decision or the basis of the FRAND royalty determination. This lack of transparency coincides with the general lack of clarity on the Chinese antitrust rules in relation to standard essential patents. The determination of the corrected FRAND rate for Huawei was not based upon (published guidelines) so it cannot provide any indication for foreign companies active on the Chinese technology market.

The Shenzhen Court determined that the relevant product market should be a collection of the technology licensing markets of all combined SEPs for the WCDMA, CDMA2000 and TD-SCDMA standards, meaning that every market where the SEP can be licensed in a separate market in which the SEP owner automatically holds a market share of $100 \%$ and thus a dominant position. In the reasoning of the Chinese judges, SEPs have two major features: uniqueness and non-substitutability. This reasoning strengthens the position of (Chinese) plaintiffs in SEP cases against foreign companies. Seeking injunctive relief is comparable to abuse of a dominant position. There are clear parallels to the Motorola v. Google case which was heard before the FTC on 3 January 2013. There also appear to be clear links with the Samsung investigation and EU Motorola decision.

It is interesting to note that the existing US concerns in relation to PAEs (the FTC initiated a PAE study on 27 September 2013) also exist in China. In this context the question is: what are the key characteristics of InterDigital? Is it patent licensing or manufacturing? Chinese regulators share the same concerns, especially in relation to indigenous innovation. The main conclusion for the Chinese regulators should be to clearly distinguish patent pools from PAEs and act accordingly.

Apparently, according to Chinese sources, the Shenzhen court damages calculation are based upon:

A. attorney fees paid by Huawei in the US and China

\footnotetext{
${ }^{613}$ Wong-Ervin in Chinese Court Issues Landmark Decision Determining a FRAND Royalty Rate ABA Intellectual Property Committee tidBits April 1-5,2013 page 1.

${ }^{614}$ ETSI IPR policy is regulated by French contract law.
} 
B. notarization fees paid by Huawei

C. harm to Huawei competitiveness

D. characteristics of InterDigital anticompetitive activities

E. InterDigital intent

F. Seriousness of the harms caused to Huawei

It is very difficult to understand the basis of the calculations of points C-F.

In conclusion, China still wants to clearly indicate the importance of the indigenous innovation policy and technology transfer. Although the decision did provide some guidance, for SEP owners it is still very challenging to understand the Chinese playing field regarding the protection of their IPRs and practical aspects such as royalty-rate setting and injunctions. Chinese courts possibly want to use antitrust law to balance the influence of foreign companies in standard setting. ${ }^{615}$ As a result, it is to be expected that Chinese companies will more frequently challenge foreign companies on the basis of abuse of dominance under the AML provisions. Given the relatively low costs of litigation in China, foreign companies could face a significant increase in legal cases related to royalty setting and payments. The use of injunctions against Chinese companies will become less prevalent. This development draws some comparisons to the Samsung and Motorola statements of the EU Commission in April 2014. Likewise the recent case law in the US on injunctive relief and the FTC study on PAEs demonstrate that technology transfer and SEPs are very high on the agenda of the global antitrust authorities.

Sokol had access to the articles of two Chinese judges written in the Chinese language. He concludes that the court established that InterDigital sought a royalty-free cross-licence in exchange for their standard essential patents. The royalty fees that InterDigital demanded were higher than in other comparable cases (Apple, Samsung). According to Sokol, the judges also considered elements that linked the patent portfolio to the number of employees of the respective companies. ${ }^{616}$ In this researcher's opinion, this factor in the decision could directly relate to the first articles of the AML. The provision of Article 4 to "make and implement ... [regulations] ... suitable for the socialist market economy, [to] perfect the macro control, and improve a united, open, competitive and well-ordered market system" may consider the ratio of patents in relation to the number of employees and, thus, the contribution to the Chinese economy. There might also be some influence of Chinese industrial policy considerations; although Huawei is officially a private company, observers consider Huawei to operate as a stateowned enterprise. ${ }^{617}$ This judgment is also interesting since the Chinese court set a

\footnotetext{
${ }^{615}$ Han Huawei v. InterDigital China at the Crossroads CPI page 9.

${ }^{616}$ Sokol Zheng FRAND in China 1 October 2013 draft.

${ }^{617} \mathrm{Yu}$ and Zhang mention laws and regulations that restrict or exclude competition as a factor for measuring the intensity of industrial administrative monopoly page 200 in Faure \& Zhang The Chinese Anti-Monopoly Law EE 2013.
} 
FRAND rate which, even from a global perspective, is quite rare. It also indicates that the discussion on standard essential patents and the FRAND rates has reached the Chinese courts, which are willing to take a leading role in giving guidance. If Chinese case law is dictated by industrial policy considerations, this might lead to a more patenteefriendly environment. A conversation with a lawyer representing InterDigital in this case confirmed that, in his opinion, industrial policy considerations definitely played a substantial role.

One of the judges explained his personal views on the InterDigital/Huawei case. A Chinese law firm provided me with the text of the interview and I also discussed the content with various Chinese lawyers involved in IPR/Competition law cases. The judgment is based upon two legal principles: good faith and the fact that companies should not infringe upon other company's rights. The IPR policy of ETSI (the SSO based in France under which the FRAND commitment was made) is regulated by Chinese contract law. But more importantly, according to the judge, even if the licensee is not an SSO member, the FRAND promise is still effective. First the statement of the judge and consequently the inclusion and change in the draft rules seem to indicate an important change in the rules regarding FRAND commitments. Since, in this case, InterDigital was the only SEP owner, this fact automatically constituted dominance. Again, this seems to be a confirmation of an earlier stance of Chinese regulators in relation to the definition of market power and dominance. In relation to my later reference of misinterpretation of foreign court decisions by Chinese courts, it is interesting that the Chinese judge stated that Chinese courts normally do not use "foreign legal principles". However, what was relevant in this case is the fact that Canton is qualified as a high-tech hub within the industrial policy of China. As a consequence, the Canton region has many high-tech companies and is more FDI friendly, which makes this case more important. Regarding the content of the case, one of the main problems was the tying strategy of InterDigital. The tying of essential and non-essential patents is a clear abuse. The awarding of the damages was difficult, since apparently InterDigital could not provide details of their actual profits in China. As a consequence, the damages that were awarded were based on the degree of subjective intention which is a concept that comes from Chinese tort law. Apart from the duration of the behaviour of InterDigital, its "subjective fault" was the key problem. The concept of subjective fault is defined by Chinese scholars as market behaviour that is "not common on the relevant market". Also, prevention of competition on subsequent markets is an important element in the evaluation.

On the subject whether the royalty fees were fulfilling the FRAND commitment, the judge mentioned that the following factors were applied in the evaluation of royalty fees:

- The contribution rate of the patent to the standard

- Licensing fees that InterDigital collected 
- Licensing fees for other similar patents

- The impact of the royalty fees and the patent on the development of new technology

- The contribution rate of the patent to the product

- Expectations that were raised during the negotiations

- Sunk costs, the development costs of the R\&D activities must compared to the royalty rate. ${ }^{618}$

The willingness of Chinese courts to take decisions in the setting of FRAND rates heralds a new development in the field of Chinese competition law. The lack of transparency of the court decisions and the suspicion that industrial policy considerations will play a major role increases the uncertainties and risks for foreign firms with standard essential patents in China.

Recently some scholars (Faure \& Zhang) have argued that an extraterritorial application of the AML might be possible in the future. ${ }^{619}$ Article 2 of the AML states: "this law shall apply to the monopolistic conducts outside the territory of the People's Republic of China that has the effect of eliminating or restricting competition on the domestic market of China." ${ }^{620}$ An extraterritorial application of Article $55 \mathrm{AML}$ would have serious implications for the development of telecommunications standards in China. The telecommunications industry is characterized by Global Production Networks and therefore an extraterritorial application would also directly affect foreign firms that are not active in China but could influence Chinese interests.

\subsection{RECENT DEVELOPMENTS IN CHINA'S ANTITRUST ENFORCEMENT INVOLVING STANDARDS AND PATENTS.}

The SAIC initiated an antitrust investigation against Microsoft in June 2014. The main subject is the lack of openness of Microsoft's system and office software source code, which hinders the interoperability with third-party software. As a result, it is difficult for competitors to enter the market and the SAIC also investigates the claim of bundling certain elements in the sale of Microsoft software. ${ }^{621}$

On 11 July 2014 Qualcomm representatives answered the questions of the National Development and Reform Commission (NDRC). The main subject of the discussions was

\footnotetext{
${ }^{618}$ Newspaper interview on the Huawei/IDC case (in the Chinese language) on file with the author.

${ }^{619}$ Faure \& Zhang (2013) Towards an Extraterritorial Application of the Chinese Anti-Monopoly Law That Avoids Trade Conflicts. Geo. Wash. Int'l L. Rev., 45, 501.

${ }^{620}$ Article 2 Anti-Monopoly Law (AML).

${ }^{621}$ See also: Cohen, China's Antitrust Enforcement Continues to Grab the Domestic and International Spotlight.
} 
the investigation into malpractices regarding the bundling of essential and non-essential patents, refusal to license, requiring licensing fees for expired patents, and the basis of the calculation of licensing fees. ${ }^{622}$ In the present climate, experts estimate that, if found guilty, Qualcomm could be punished with a fine of one billion dollars. ${ }^{623}$

The National Development and Reform Commission (NDRC) decided in February 2015 that Qualcomm had abused its dominant position in China. The relevant market was the technology for the SEPs for the CDMA, WCDMA, and LTE standards. The NDIC found that the abuse was based upon the following elements:

- The bundled licences of Qualcomm contained standard essential patents and non-standard essential patents.

- Charging unreasonably high and excessive royalty rates. (In the decision it stated: charging "relatively high royalty rate[s] based on the wholesale net selling price of devices.") 624

- Applying "unreasonable conditions" on the market of baseband chips.

Qualcomm agreed to implement a "rectification plan" that got the approval of the NDRC. The plan contained the following provisions:

1. Qualcomm will no longer bundle Chinese SEPs and non-SEPS

2. To end the "unreasonable provisions" for the baseband chips (i.e. no-challenge clauses)

3. A royalty cap of $5 \%$ for Chinese 3 G SEPs, a royalty cap of $3.5 \%$ for Chinese $4 G$ SEPs using a royalty base of $65 \%$ of the net selling price of the device

4. The licensees of Qualcomm in China could change the terms of conditions of the relevant licensing contracts.

The two recent cases signal a new development in the enforcement of antitrust rules on IPRs. Foreign companies are subjected to energetic efforts of different Chinese regulatory bodies to apply antitrust rules. Foreign companies worry that this is hinting at an indirect form of protectionism. Some companies feel that this is evidence of Chinese "techno-nationalism". In this form of protectionism, Chinese state-owned companies are favoured over foreign companies, which often lack of resources and political networks to influence the enforcement agenda. Some experts also claim that the NDRC is compensating for their waning influencing by subjecting foreign companies to antitrust

\footnotetext{
${ }^{622}$ See also: Ning, NDRC's Qualcomm Decision: A warning to patent-heavy companies.

${ }^{623}$ http://www.chinatradenews.com.cn/founder/html/2014-07/31/content_50664.htm?div=-1

${ }^{624}$ Qualcomm Press Release, “Qualcomm and China's National Development and Reform Commission Reach Resolution -NDRC Accepts Qualcomm's Rectification Plan -Qualcomm Raises Midpoints of Fiscal 2015 Revenue and Non-GAAP EPS Guidance," (Feb. 9, 2015)
} 
investigations. ${ }^{625}$ Although this is an obvious thought, evidence suggests a more neutral enforcement. In February 2013, two Chinese companies were fined \$ 73 million; the Wuliangye Yibin Group and Kweichow Moutai. ${ }^{626}$ Nevertheless, fears remain that the recent actions of the NDRC can also be linked to earlier cases (Huawei vs. InterDigital) and that, as commentators note, competition law is used as "counter strategies to Western IP oppression". ${ }^{627}$

The US and China completed their Sixth Strategic and Economic Dialogue in July 2014. This dialogue also featured IP-related subjects. In relation to the AML, both countries agreed that the main objective of competition law is to promote consumer welfare and economic efficiency in general and not to promote the interests of individual industries or firms. The national competition laws of both the US and China should be based on the following principles: fair, non-discriminatory, objective, and transparent. China declared that it would urge its three agencies involved in anti-monopoly enforcement to provide firms under investigation with transparent information regarding their case. In the official press release of the sixth strategic dialogue, it states that both countries aim at "Levelling the Playing Field and Supporting Fair Competition". ${ }^{628}$ The aim of providing more administrative enforcement transparency was also expressed by China's State Council in November 2013. ${ }^{629}$ Especially IP/Competition law cases in China would strongly benefit from this new policy. This specific case law is often not made available to the public, which hinders a further understanding of the development of the law.

\section{$8.1825^{\text {TH }}$ US-CHINA JOINT COMMISSION ON COMMERCE AND TRADE (JCCT)}

The US-China Joint Commission on Commerce and Trade has become an important forum for government to solve practical issues but foremost to demonstrate the importance of the bilateral trade relationship. The JCCT that was concluded in December 2014 had some interesting provisions directly addressing the competition law differences between both countries. The text stipulated:

\footnotetext{
${ }^{625}$ Gough and Buckley and Wingfield: China's Energetic Enforcement of Antitrust Rules Alarms Foreign Firms.

${ }^{626}$ Recent Developments in Antitrust Enforcement and Litigation in China Involving Resale Price Maintenance

${ }^{645}$ Cohen, Microsoft under Chinese Antitrust Scrutiny? The commentator argues that competition policy wants to promote national Chinese competitiveness rather than competition in itself or on merits (per se).

${ }^{628}$ US Treasury Department Office of Public Affairs Press release on the SIXTH MEETING OF THE US-CHINA STRATEGIC AND ECONOMIC DIALOGUE (US FACT SHEET-ECONOMIC TRACK).

${ }^{629}$ On 20 November 2013 the State Council adopted: "Opinion on Making Publicly Available According to Law Information on Administrative Penalties Concerning the Production and Sale of Fake, Counterfeit and Substandard Goods and Intellectual Property Rights Infringement" mentioned by Cohen, Through a Glass Less Darkly: China's March to Administrative Enforcement Transparency.
} 
"U.S. industry has asserted that China's competition policy enforcement authorities seem to be targeting foreign companies and at times use Anti-monopoly Law investigations as a tool to protect and promote domestic national champions and domestic industries. U.S. industry also has expressed concern about insufficient predictability, fairness and transparency in China's investigative processes, as well as pressure from the Chinese authorities not to seek outside counsel or have counsel present at meetings. China's commitments below help to address several of these concerns."

The suggested reforms are:

"In order to build on the recognition of the United States and China in the Sixth Meeting of the U.S.-China Strategic and Economic Dialogue that the objective of competition policy is to promote consumer welfare and economic efficiency, rather than promote individual competitors or industries, and that the enforcement of their respective competition laws should be fair, transparent, objective, and nondiscriminatory, and China's commitment that its three Antimonopoly Enforcement Agencies (AMEAs) are to provide to any party under investigation information about the AMEA's competition concerns with the conduct or transaction, as well as an effective opportunity for the party to present evidence in its defense:

a. China clarifies that in enforcing the $A M L$, all business operators shall be treated equally.

b. Where AML violations are found, China clarifies that it is to impose enforcement measures that address the harm to competition, and not to impose enforcement measures designed to promote individual competitors or industries"

As regards standard setting between both countries, the text contained the following provisions:

"The United States has agreed to conduct a dialogue with China to reduce uncertainties regarding protections for companies contributing patented technology during standards-setting processes in China. Voluntary, consensus-based technological standards promote innovation, competition and consumer welfare and have helped spur investment and advances in a wide range of industries. Companies contributing patented technology during a standards-setting process typically agree to license their patents under certain terms. These terms need to be agreed voluntarily and free of government coercion or involvement."

"China and the United States recognize that standards setting can promote innovation, competition and consumer welfare. They also reaffirm that IPR protection and enforcement is critical to promote innovation, including when companies voluntarily agree to incorporate patents protecting technologies into a standard. Both sides rec-

\footnotetext{
${ }^{630}$ Fact Sheet: 25 th U.S.-China Joint Commission on Commerce and Trade.
} 
ognize that specific concerns may exist relating to the licensing of standard essential patents that are subject to licensing agreements. China and the United States commit to continue engaging in discussion of these issues"

The fact that the JCCT specifically addresses the IP/standards intersection, underlines the strategic importance of the debate. SEPs are identified as a key issue in this discussion. This interest is nothing new for the US agencies but it does signal that MOFCOM will pay closer attention to standard setting and SEPS. A report by the Information and Technology and Innovation Foundation (The Middle Kingdom Galapagos Islands Syndrome: The Cul de Sac of Chinese Technology Standards) was published in December 2014. This report follows earlier US observations regarding Chinese "techno-nationalist" developments. The report concludes that the creation of Chinese ICT standards is part of its industrial development policy. The development of national ICT standards leads to fewer royalty payments to foreign companies. At the same time, foreign competitors are blocked and the development of global ICT standards with Chinese participation is suffering. Interestingly, the report makes a comparison with Japan and claims that this strategy will in the end undermine the competitiveness of the Chinese ICT industry. The report mentions four main problems of the present Chinese approach:

- Possibly choosing the wrong standard, that will not be supported by the world community

- Delays in the standard development process, means more time to market and risks for commercialization of the standard

- Risk that Chinese standard developers loose track with global developments

- Chinese standards will experience difficulties with interoperability

The report ends with recommendations, the most important being that China should move towards an open-participation model of standardization. Other recommendations were the open access to Chinese SDOs, alignment of international and Chinese standards and more access for foreign technology to domestic Chinese standards. ${ }^{632}$

\section{Xiaomi v. Ericsson case}

In India, Ericsson obtained an injunction against the Chinese smart phone maker Xiaomi in December 2014. According to Ericsson, Xiaomi had not paid any royalties for SEPS owned by Ericsson for the last three years. ${ }^{633}$ This case is interesting, since India is a premium market for the Chinese smart phone manufacturers but also since India and

\footnotetext{
${ }^{631}$ See US Treasury Department Office of Public Affairs Press release on the SIXTH MEETING OF THE US-CHINA STRATEGIC AND ECONOMIC DIALOGUE (US FACT SHEET-ECONOMIC TRACK).

${ }^{632}$ See also: The Middle Kingdom Galapagos Islands Syndrome: The Cul de Sac of Chinese Technology Standards page 28 Atkinson.

${ }^{633}$ See for more information: Gilbert, Xiaomi smartphones banned from sale in India over patent dispute.
} 
Brazil are jurisdictions where courts look at preliminary injunctions without directly investigating FRAND terms. In this case, the Chinese company had not been willing to discuss FRAND rates for three years, which appears to be more like a free-riding case. Recent developments in the trade dialogue between the US and China demonstrate that SEPs and standards will be more closely monitored by US and Chinese authorities

\subsection{SUMMARY OF THE DIFFERENT APPROACHES IN THE CASE LAW OF THE US, EU AND CHINA IN RELATION TO PATENT POOLS}

\begin{tabular}{|c|c|c|c|}
\hline & Licensing & SEPS & Management \\
\hline \multicolumn{4}{|l|}{ US Business Review Letters } \\
\hline $3 \mathrm{G}$ pool & $\begin{array}{l}\text {-Separation of licensing } \\
\text { functions is required } \\
\text {-grant-backs should be } \\
\text { limited to SEPS }\end{array}$ & $\begin{array}{l}\text {-Large class of owners of } \\
\text { SEPS }\end{array}$ & $\begin{array}{l}\text {-Preventing competition for } \\
\text { substitutable standards is } \\
\text { not allowed }\end{array}$ \\
\hline MPEG LA & $\begin{array}{l}\text {-Main intention was the } \\
\text { suppression of rival } \\
\text { standards, mainly open- } \\
\text { source technology }\end{array}$ & $\begin{array}{l}-1,700 \text { patents were all } \\
\text { declared SEPs by MPEG }\end{array}$ & $\begin{array}{l}\text {-High number of SEPs were } \\
\text { used as a deterrent for } \\
\text { litigation }\end{array}$ \\
\hline RFID consortium (approval) & $\begin{array}{l}\text {-Licensing on non- } \\
\text { discriminatory basis }\end{array}$ & $\begin{array}{l}\text {-Independent witness } \\
\text { system to evaluate SEPS } \\
\text {-Invalid patents are } \\
\text { removed from the patent } \\
\text { pool }\end{array}$ & $\begin{array}{l}\text {-Grant-backs are limited to } \\
\text { SEPs }\end{array}$ \\
\hline IXPI & $\begin{array}{l}\text {-The revolutionary new } \\
\text { business model could } \\
\text { have an impact on rapidly } \\
\text { changing technology } \\
\text { markets, which is } \\
\text { considered an } \\
\text { unacceptable risk }\end{array}$ & $\begin{array}{l}\text {-Pool should only include } \\
\text { complementary patents } \\
\text { and not (like in this case) } \\
\text { substitute/competing } \\
\text { patents }\end{array}$ & $\begin{array}{l}\text {-No guarantees against the } \\
\text { sharing of sensitive } \\
\text { information between pool } \\
\text { members } \\
\text { - Efficiencies of the pool are } \\
\text { not outweighed by negative } \\
\text { drawbacks }\end{array}$ \\
\hline \multicolumn{4}{|l|}{ US case law } \\
\hline Intellectual Ventures & $\begin{array}{l}\text {-Relatively low royalty } \\
\text { rates }\end{array}$ & $\begin{array}{l}\text {-Essentiality of the } \\
\text { patents in the pool is a } \\
\text { key element }\end{array}$ & $\begin{array}{l}\text {-Pool is prepared to grant } \\
\text { access to all interested } \\
\text { parties }\end{array}$ \\
\hline SUMMIT/VISX & $\begin{array}{l}\text { - Court applied technology } \\
\text { market analysis on the } \\
\text { effect of the pool on the } \\
\text { competition on the } \\
\text { relevant market }\end{array}$ & $\begin{array}{l}\text {-Illegal pooling of } \\
\text { complementary and } \\
\text { competing patents }\end{array}$ & $\begin{array}{l}\text {-Firms should provide } \\
\text { insight on their business } \\
\text { model/strategy to enable } \\
\text { evaluation of the } \\
\text { competitive impact of the } \\
\text { pool }\end{array}$ \\
\hline
\end{tabular}


CHAPTER 8

\begin{tabular}{|c|c|c|c|}
\hline & Licensing & SEPS & Management \\
\hline US Philips Corp v. ITC & $\begin{array}{l}\text {-Patent misuse as defence, } \\
\text { necessity to show actual } \\
\text { violation to competition } \\
\text { on the relevant market }\end{array}$ & $\begin{array}{l}\text {-Difficulty of economic } \\
\text { evaluation of the } \\
\text { essential/non-essential } \\
\text { patents in the pool } \\
\text { - Do non-essential patents } \\
\text { have an impact on the } \\
\text { royalty base/fee? }\end{array}$ & $\begin{array}{l}\text {-Economic relationship of } \\
\text { the patents in the pool is } \\
\text { extremely important }\end{array}$ \\
\hline \multicolumn{4}{|c|}{ European Union/National Member States } \\
\hline Standard/Spundfass case & $\begin{array}{l}\text {-Standard gives } \\
\text { competitors no alternative }\end{array}$ & $\begin{array}{l}\text {-Patent confers market } \\
\text { dominance to the patent } \\
\text { owner }\end{array}$ & $\begin{array}{l}\text {-Standard restricted access } \\
\text { to the downstream market }\end{array}$ \\
\hline Orange Book case & $\begin{array}{l}\text {-Can the standard be used } \\
\text { without a licensing } \\
\text { agreement? }\end{array}$ & $\begin{array}{l}\text {-If possible infringers of } \\
\text { SEPs act as willing } \\
\text { licencees, patent owners } \\
\text { no longer have access to } \\
\text { injunctive relief }\end{array}$ & $\begin{array}{l}\text {-Frand-commitment is a } \\
\text { declaration of intent with } \\
\text { far-reaching consequences }\end{array}$ \\
\hline
\end{tabular}

\begin{tabular}{|c|c|c|c|}
\hline Chinese case law & & & \\
\hline CHINT-Schneider case & $\begin{array}{l}\text {-Patent dispute between } \\
\text { Chinese and French firms } \\
\text { decided by Chinese court }\end{array}$ & $\begin{array}{l}\text {-Validity and quality of } \\
\text { utility model patents }\end{array}$ & $\begin{array}{l}\text {-High financial rewards ( } 16 \\
\text { million Euro) entered the } \\
\text { Chinese IPR discussion and } \\
\text { had to be paid by the } \\
\text { French company }\end{array}$ \\
\hline Chaovang Xingnuo & $\begin{array}{l}\text {-Patent infringement, } \\
\text { patent was part of a } \\
\text { national standard }\end{array}$ & & $\begin{array}{l}\text {-Patent owner must charge } \\
\text { licensing fees that are } \\
\text { considerably lower than } \\
\text { the normal fees since the } \\
\text { patent is included in a } \\
\text { national standard }\end{array}$ \\
\hline Qihoo360/Tencent case & $\begin{array}{l}\text {-Court recognized the } \\
\text { special dynamics of the } \\
\text { Chinese technology } \\
\text { market }\end{array}$ & $\begin{array}{l}\text {-Economic analysis enters } \\
\text { into the discussion in } \\
\text { Chinese courts }\end{array}$ & $\begin{array}{l}\text {-Although the relevant } \\
\text { market could not be } \\
\text { defined, the court } \\
\text { continued to evaluate the } \\
\text { dominance on the market } \\
\text {-Chinese court looked to } \\
\text { the EU Commission for } \\
\text { reference and guidance }\end{array}$ \\
\hline $\begin{array}{l}\text { NDRC /Qualcomm } \\
\text { investigation }\end{array}$ & $\begin{array}{l}\text {-Royalty-rate setting is } \\
\text { under investigation } \\
\text { Coincides with WTO } \\
\text { Information Technology } \\
\text { Agreement negotiations }\end{array}$ & $\begin{array}{l}\text {-Announcement that } \\
\text { Supreme Court will revise } \\
\text { its policy in relation to } \\
\text { SEPs and injunctions }\end{array}$ & $\begin{array}{l}\text {-China wants to } \\
\text { commercialize 4th } \\
\text { generation telecom } \\
\text { networks; court case gives } \\
\text { Chinese companies more } \\
\text { leverage during } \\
\text { negotiations }\end{array}$ \\
\hline
\end{tabular}


PATENT POOLS IN THE PEOPLE'S REPUBLIC OF CHINA

\begin{tabular}{|c|c|c|c|}
\hline & Licensing & SEPS & Management \\
\hline Huawei/InterDigital & $\begin{array}{l}\text {-Excessive royalty fees } \\
\text { based upon: } \\
\text {-The contribution rate of } \\
\text { the patent to the standard } \\
\text {-Licensing fees that } \\
\text { InterDigital collected } \\
\text {-Licensing fees for other } \\
\text { similar patents } \\
\text {-The impact of the royalty } \\
\text { fees and the patent on the } \\
\text { development of new } \\
\text { technology. } \\
\text {-The contribution rate of } \\
\text { the patent to the product } \\
\text {-Expectations that were } \\
\text { raised during the } \\
\text { negotiations. } \\
\text {-Sunk costs, the } \\
\text { development costs of the } \\
\text { R\&D activities must } \\
\text { compared to the royalty } \\
\text { rate } \\
\text {-Concept of "subjective } \\
\text { fault" (Chinese tort law) }\end{array}$ & $\begin{array}{l}\text {-Bundling of both essential } \\
\text { and non-essential patents } \\
\text { (tying) by InterDigital; }\end{array}$ & $\begin{array}{l}\text { I -InterDigital included a } \\
\text { grant-back provision in its } \\
\text { licensing } \\
\text { agreement; InterDigital } \\
\text { requested the ITC to take } \\
\text { action against Huawei, } \\
\text { although both parties were } \\
\text { negotiating on licensing } \\
\text { terms } \\
\text {-Possible consequences for } \\
\text { the definition of patent } \\
\text { pools and PAEs } \\
\text {-Possible links with } \\
\text { Samsung/Motorola EU } \\
\text { investigations and } \\
\text { Motorola v. Google } \\
\text { investigation by FTC (US) }\end{array}$ \\
\hline $\begin{array}{l}\text { NDRC/Qualcomm } \\
\text { Decision }\end{array}$ & $\begin{array}{l}\text { Unreasonable and } \\
\text { excessive royalty fees }\end{array}$ & $\begin{array}{l}\text { Illegal bundling of SEPs and } \\
\text { non-SEPs }\end{array}$ & $\begin{array}{l}\text { dRectification plan } \\
\text { approved by NDRC } \\
\text { Royalty caps and end of } \\
\text { no-challenge clauses }\end{array}$ \\
\hline Philips 4c DVD patent pool & $\begin{array}{l}\text {-Global Production } \\
\text { Networks lead to the } \\
\text { separation of } \\
\text { manufacturing and R\&D } \\
\text { activities } \\
\text {-Chinese companies } \\
\text { continue to pay high } \\
\text { licensing fees for Western } \\
\text { technology }\end{array}$ & $\begin{array}{l}\text {-Philips withdrew patent } \\
\text { from the pool } \\
\text {-China will start invalidity } \\
\text { proceedings against } \\
\text { essential patents (within } \\
\text { the patent pool) owned } \\
\text { by foreign companies }\end{array}$ & $\begin{array}{l}\text {-China will try to develop } \\
\text { new standards for } \\
\text { established technology } \\
\text { that do not include } \\
\text { foreign-owned patents. } \\
\text {-China will adopt very } \\
\text { favourable pricing } \\
\text { strategies to support the } \\
\text { consumer adoption of the } \\
\text { newly developed Chinese } \\
\text { standard } \\
\text {-China will apply AML } \\
\text { provisions against the } \\
\text { "monopolistic conduct" of } \\
\text { the foreign firms in the } \\
\text { patent pool }\end{array}$ \\
\hline
\end{tabular}




\begin{tabular}{llll}
\hline & Licensing & SEPs & Management \\
\hline $\begin{array}{lll}\text { Chinese AVS pool "Best } \\
\text { practice" }\end{array}$ & $\begin{array}{l}\text {-Standard developed by } \\
\text { the Chinese government }\end{array}$ & $\begin{array}{l}\text {-Distinctive disclosure } \\
\text { requirements } \\
\text {-FRAND commitments } \\
\text { specified by royalty caps }\end{array}$ & $\begin{array}{l}\text {-Royalty fees must } \\
\text { consider the "special } \\
\text { circumstances in China" }\end{array}$ \\
& & & $\begin{array}{l}\text {-Possible ex ante price- } \\
\text { fixing in the EU, US } \\
\text { IGRIS patent pool }\end{array}$ \\
& $\begin{array}{l}\text { Standard initiated by } \\
\text { Chinese firms with } \\
\text { international adoption }\end{array}$ & "One-stop shop" patent & Lack of patent experience \\
& license & Lack of investments \\
\hline
\end{tabular}

\subsection{PATENT POOLS AS A POSSIBLE SOLUTION FOR THE TENSIONS IN THE INCORPORATION OF ESSENTIAL PATENTS IN CHINESE STANDARDS}

The origin of patent pools in Western economies can be traced back to the desire to make technology widely available to firms. A patent pool precludes parties from limiting access to each other's patents and technology markets. In the early 1900s, patent pools enabled rapid technological progress related to products such as airplanes and radios. For a newly evolving technology, a patent pool provides a one-stop shop approach, ending the diversification of the different elements of the relevant technology. Individual negotiations on standard essential patents will increase the transaction costs for Chinese companies and the possibility of a patent ambush or patent hold-up problem remains. Especially in the telecommunications industry, a point can be made for the joint and centralized management of the licences included in a patent pool. According to Price Waterhouse Coopers, the Chinese government is currently using the attractiveness of the access to and the size of its consumer market to develop home-grown standards and, supported by patent pools with low royalty rates, to increase the export of Chinese products to third-world countries. ${ }^{634}$ Although the efforts to create globallyaccepted Chinese standards are not yet very successful, the low royalty rates have had a sobering effect on the Western patent pools that are active in China. The Chinese government justifies its support for this policy with reference to the traditional Western dominance in standard setting and the exclusion of Chinese technology in Western standards. For Western companies, the strategy of using patent pools in China could be attractive since, at a certain stage of the product life cycle, outsourcing of the product in China (via a patent pool) reduces the manufacturing costs and gives Western companies more opportunities to invest in R\&D.

Patent pools increase efficiency and resolve the problem of the patent thicket, according to Professor Hong Yuang, one of the drafters of the AML. ${ }^{635}$ On the other hand,

\footnotetext{
${ }^{634}$ PWC report Redefining Intellectual Property Value the Case of China page 57.

${ }^{635}$ Yong, Basic IP Principles of Antitrust Law.
} 
he acknowledges the risk of possible price/ output control and the use of exclusive licences that leads to unfair competition. In the opinion of Professor Hong Yuang, there can only be an unbiased application of the AML in relation to IPRs for both domestic and foreign firms. ${ }^{636}$ The operation of the Chinese-led Audio Video Coding Standard Working Group of China indicates that a patent pool is the preferred solution to license patents in standards, directly after royalty-free licensing. The increased use of patent pools in China would also support the goal of creating an IP-conscious business culture in China. The patent pool would primarily serve the interests of Chinese companies that export goods, but the pool management could introduce best practices in relation to price-setting, marketing, the collection of royalties and the enforcement of IPRs through the centralized administration. ${ }^{637}$

The earlier chapters have shown that the competition regulators take a particular interest in restrictive elements of patent pools that might hinder competition. By investigating different case studies in China, specific points of interest for the handling of patent pools in the People's Republic of China will be addressed. The AML regulators have declared that, for every specific sector, new Guidelines will be issued. ${ }^{638}$

\subsection{PATENT POOL CASE LAW PHILIPS 4C DVD PATENT POOL CASE IN CHINA}

In 2006, Philips decided to withdraw a patent which was part of the 4C DVD pool, after a complaint was made by five Chinese academics, led by Professor Zhang Ping (of Beijing University). ${ }^{639}$ For the export-based growth model of the Chinese economy (still very prevalent in 2000) a patent pool arrangement is not always positive. The DVD player is typically produced with relatively cheap labour but, in order to export the DVD player, Chinese companies must get a licence to incorporate all the necessary standards. When these licences are part of a patent pool, Chinese companies cannot be treated differently than Western companies (FRAND, non-discriminatory), leading to a competitive disadvantage, since they normally have the lowest labour costs. ${ }^{640}$ The application of the FRAND conditions does not leave negotiating power for Chinese companies, for whom the licensing fee is a more substantial cost than for their competi-

\footnotetext{
${ }^{636}$ Ibid note 661.

${ }^{637}$ PWC report Redefining Intellectual Property Value the Case of China page 58. External administrators, such as, for example, Sisvel, acknowledged this idea.

${ }^{638}$ Yong, The concept of "abuse of IPRs" in Anti-Monopoly Law.

${ }^{639}$ Philips withdraws patents from Chinese DVD pool in Managing Intellectual Property.

${ }^{640}$ Chinese companies have a $\$ 13.80$ royalty payment for DVD 6C products and \$5 for DVD 4C products. Before the FRAND commitments, Chinese production companies were able to negotiate lower royalty payments than foreign firms. Royalty payments based on data of Yuhzen, Wei, Xiaobao, Zhou, \& Lei. (2013). Patent pool analysis based on technical standards: A case study of indigenous alliances in China.
} 
tors. ${ }^{641}$ The origins of the Philips dispute in 2006 can be traced back to 2002. In 2002 Philips lodged a complaint that some Chinese DVD manufacturers used patented technology but failed to pay royalties, giving these Chinese firms a head start and competitive advantages over Western firms. Consequently, Chinese DVD exports were seized at the outer borders in the US and the EU.

The Chinese companies claimed that they were merely assembling plants, that the different parts were bought from suppliers and, thus, that the patent rights were exhausted and royalties were no longer due. This signals a bigger underlying problem, since, with the occurrence of global production networks, research and development activities are often separated from the actual manufacturing, both in geographical terms as well as in corporate identity. ${ }^{642}$ The burden of the royalty fees for the implementation of foreign technology is one of the main drivers of the Chinese indigenous innovation policies. Chinese firms are obliged to pay royalties, which constitute a major part of the cost price for their exported goods. As a result of the DVD wars, China tried to develop its own competing standard EVD (Enhanced Versatile Disc), but this standard never gained commercial success. ${ }^{643}$

Murphree and Breznitz analyzed the official Chinese standardization policy and came to the conclusion that major Chinese firms take a very pragmatic approach towards participation in both domestic as well as international standard setting. They conclude that promoting domestic Chinese standards has led to an increase in the development and participation of foreign firms in competing standards, leading to more standards and increasing confusion, which has a negative effect on innovation. ${ }^{644}$

In the 2006 DVD 4C case, Chinese academics came to the conclusion that Philips included patented technology which had lost its novelty, since the information concerning the technology had already been in the public domain. The invalidity of the Philips patent undermined the legal basis of the inclusion of the patent in the pooling agreement for the DVD 4 C licence. Although Philips did remove the patent, this did not affect the total sum of the royalty payment.

Zhang Ping, the leading academic of the case against Philips, distinguished three different types of patent pools:

\footnotetext{
${ }^{641}$ The Chinese government wanted to include the "charging of excessive royalties" in the field of standardrelated patents as an official trade barrier in the TBT agreement, but it failed to find sufficient support within the WTO.

${ }^{642}$ See also Patent Pools in China by Redfearn in Intellectual Asset Management September/October 2009 page 103. It would be interesting to understand how the Mexican assembling plants (maquiladora industry) is treated under the NAFTA provisions. This might also indicate the emergence of PAEs in China.

${ }^{643}$ Murphree and Breznitz make interesting comments on the lack of coherence and logic in the Chinese standards policy. They wonder why the Chinese government continues to actively promote domestic standardization, even though it is sufficiently clear that their development has a negative effect on innovation and the competitiveness of Chinese firms in the global economy. Standardized Confusion? The Political Logic of China's Technology Standards Policy.

${ }^{644}$ See note 58 .
} 
1. Patent Pools with Sophisticated Administrative Structures, in which the royalties are determined by the patent pool committee and the voting power of the individual members are weighted against the economic value of the patents. An independent expert determines the value and the essentiality of the patents in the pool, which would have prevented a situation like the Philips 4C DVD case in 2006 in China. This type of patent pool reflects the most traditional form of cooperation between patent holders and, due to the neutral and objective element of the independent expert, competition authorities rarely take an interest in this type of pool. ${ }^{645}$

2. Patent Pools on a contractual basis. These pools are characterized by the fact that they apply standardized licensing terms, target industry-specific technology and unite all the relevant patents for an essential piece of technology (e.g. 3C DVD patent pool, 6 C DVD patent pool). As soon as these patent pools are used to commercialize standard technology, Chinese firms can face a disadvantageous position, since they have not always developed a base volume of patents which can be used for cross-licensing. The one-stop shop approach should normally reduce the overall licensing costs and can also be used to influence the competition in the relevant market. This type of patent pool can possibly prevent entry to the market and will be scrutinized by competition authorities. On the basis of Article $55 \mathrm{AML}$, actions could be initiated against such foreign patent pools active inside the PRC.

3. Patent pools supporting standard-related technology, in which patent holders have managed to include their technology into a standard in order to commercialize their patents. The MPEG-2 patent pool is a classic example of a pool which was purely established to bring the MPEG-2 technology to the market. ${ }^{646}$ Obviously, this type of patent pool has caused considerable debate in China and Chinese antitrust enforcers have taken a keen interest in the fundamental role of this type of patent pool in the Chinese economy. The present emphasis on manufacturing in China forces companies to buy foreign technology embedded in standards, often commercializing via the instrument of a patent pool. Chinese technology firms often complain that the major Western companies determine the content of the standard and, consequently, exploit their patent rights through a patent pool. Since China has not yet developed national technology standards that have become a global commercial success, it is to be expected that foreign-owned patent pools supporting a specific standard will be carefully monitored by the Chinese antitrust enforcers.

\footnotetext{
${ }^{645}$ Zhang Ping Analysis on antirust regulation of patent pools.

${ }^{646}$ Membership of the pool consisted originally of eight firms holding 100 essential patents but it evolved into a pool of 20 members holding 425 patents. For more information see Zhang Ping Analysis on antirust regulation of patent pools.
} 
Price Waterhouse Coopers analyzed the reaction of the Chinese government to the $4 \mathrm{C}$ DVD patent pool case and came to the following conclusions:

- China will try to develop new standards for established technology that do not include foreign-owned patents.

- They will adopt very favourable pricing strategies to support the consumer adoption of the newly developed Chinese standard.

- They will start invalidity proceedings against essential patents (within the patent pool) owned by foreign companies.

- They will apply AML provisions against the "monopolistic conduct" of the foreign firms in the patent pool. ${ }^{647}$

Patent pools can also be distinguished by their operating system, meaning that either an independent company handles the management of the patent pool (e.g. Sisvel) or one of the companies holding patents in the pool will be responsible for the licensing agreements.

The rise in the total number of patents granted will give Chinese businesses a better negotiating position to gain membership of future patent pools. Chinese firms have to start building efficient IP portfolios to enable them to establish their own national patent pools or, preferably, to include Chinese patents in international patent pools. The main question is whether the Chinese patents can be qualified as essential patents for which non-Chinese firms have not yet developed alternative or substitute technology. The Chinese Ministry of Commerce (MOFCOM) is taking a keen interest in the discussion on the legal evaluation of standard essential patents. Recent examples of merger approval cases show that the policy of MOFCOM sometimes diverts from the usual practice of the Department of Justice/Federal Trade Commission and the Commission of the European Union. MOFCOM approved the Google acquisition of Motorola conditionally. ${ }^{648}$ MOFCOM recognized the importance of Motorola's patent portfolio and the potential danger that, after the acquisition, Google could exploit their enlarged IPO portfolio. The conditions that were applied to Google were:

- the application of FRAND conditions to standard essential patents (SEPS)

- $\quad$ free and open source use of the Android standard.

The conditional approval of Google's acquisition of Motorola is evidence of a different approach in the economic analysis of antitrust law compared to both US and EU compe-

\footnotetext{
${ }^{647}$ PWC Report; Redefining IP Value Management: The Case of China page 28.

${ }^{648}$ See also, Quinney and Jephcott, China's MOFCOM clears Google/Motorola with conditions: another example of China's divergence from the EU and US antitrust regimes? Interestingly MOFCOM did not recognize a separate market for standard essential patents, organized in a patent pool contrary to the findings of the EU Commission and the DoJ/FTC. See also conversation Thomas Cheng Hong Kong 2012.
} 
tition authorities. For multinational enterprises, this signals that a closer approximation of the antitrust laws of the EU, US and China seems apparent and a careful consideration of the special position of antitrust law in the Chinese economy is absolutely necessary in the risk management process.

\subsection{MPEG-2 CASE}

The MPEG standard was developed by a working committee of the ISO and provides various standards for the embedded coding for digital video and audio. The history of the development of the MPEG standard is often used to illustrate the tension between a patent pool and its customers. The original MPEG-1 standard was approved by the US DoJ and used RAND as the basis for licensing terms. By the time that the MPEG-4 Part 10 standard was introduced, licensing fees had dramatically increased and were rejected by the downstream market. The patent pool was established after the definition of the standard. ${ }^{649}$ In the case of MPEG LA, the patent pool was initially investigated by the DoJ and the Business Review Letter dated 26 June 1997 was the starting point for the recognition of the pro-competitive effects of a modern patent pool in the field of telecommunications. In the Business Review Letter, six factors were considered:

1. The essential character of the patents in the pool.

2. The licensing conditions were applied in a "non-discriminatory way".

3. The MPEG Licensing authority is independent from the licensors, thus preventing the "exchange of competitively sensitive information".

4. The MPEG pool did "not harm the incentives to innovate", meaning that the cost structure of the royalty fee and the freedom to develop alternatives guaranteed further innovation.

5. Grant-back provisions were limited to essential patents, preventing the holders of essential patents from abusing their position. ${ }^{650}$

6. Licensors could end their licence obligations to a specific licensee by using the "partial termination right of licensors".

The failure of market adoption of the MPEG-4 part 10 standard signals the dilemma of the Chinese manufacturing industry which, in the absence of competing standards, was compelled to pay a heavy royalty burden for foreign standards. ${ }^{651}$ Against this back-

\footnotetext{
${ }^{649}$ For further discussion see Tjien Huang, Wen Gao, Cliff Reader Chinese Academy of Sciences: A New Approach for Developing Open Standards with a More Reasonable Patent Licensing Policy page 4.

${ }^{650}$ For a more detailed discussion of these six points, see Kim Junghoon Technical Standard-Setting, Patent Pooling and Competition Policy Indiana University Bloomington page 151-153.

${ }^{651}$ Ibid. Note 651
} 
ground, the Chinese AVS patent pool was established in 2002 to provide a better alternative to the MPEG-4 standard.

\subsection{THE AVS PATENT POOL}

The AVS patent pool is a Chinese standard for the decoding, compressing and processing of digital video and audio. The AVS standard was developed by the Chinese government in order to eliminate the payment of the $\$ 2.50-\$ 4.00$ royalty fee per unit for the MPEG LA standard. China could save \$1 billion if the AVS standard was widely adopted. ${ }^{652}$

The management of the AVS pool aims to find a balance between the interests of the patent owner (foreign firms) and the implementing industries (Chinese firms). ${ }^{653}$ By expressing this aim, the patent pool raises the question of whether standards should be considered as "public goods". ${ }^{654}$ The AVS IPR policy takes an innovative approach, since the licensing policy was developed in conjunction with the technical development of the standard. The AVS pool has distinctive disclosure requirements, since the patent owner must inform the pool about every relevant patent, whether already registered or not, the details of the licensing conditions and future patent applications in case of RAND commitments. ${ }^{655}$ The Advisory Guidelines for the Patent Pool Licence of AVS Standard contain two important elements:

"The Patent Pool Administration should consider caps for the royalties based on market conditions."

"For licenses within the territory of the People's Republic of China, the royalty standard should accommodate the 'special circumstances in China'. In principle, the royalty for consumer-level encoders/decoders within the territory of the People's Republic of China that use AVS Standards should be 1 RMB Yuan per unit."

The background of the "special circumstances" is not further explained. The second paragraph could easily lead to ex ante price-fixing, which is problematic in the US and EU.

\footnotetext{
652 Indigenous standard development in the presence of dominant international standards: the case of the AVS standard in China Vladislav v. Fomin, Junbin Su, Ping Gao.

653 Speech Fomin, Su and Gao on Euras conference: Better standards for the nation. Or how the Chinese "public" AVS standard challenged the international "less public" incumbent. This is just a general assumption, the $28 \%$ of AVS members are located outside the PRC and $20 \%$ of AVS members are multinational Enterprises ${ }^{654}$ Jacques Berleur discusses the tensions between the FRAND obligations and the public interest. By using the MPEG-4 standard as an example, he demonstrates that just $8.4 \%$ of the patents included came from public institutions (e.g. Columbia University, Frauenhofer), thereby private interests have limited the effectiveness of a standard that also serves public interests. In Berleur, Hercheui, Hilty, and Caelli: What kind of Information Society? Governance, Virtuality, Surveillance, Sustainability, Resilience Springer 2010 page 65.

${ }^{655}$ For further discussion see also AVS Guidelines at http://www.avs.org.cn/english/AVSRules.asp
} 
The AVS patent pool developed technology for a CODEC standard, which is currently incorporated into the Chinese National Innovation System (NIS). This strategic decision must support the market adoption of the CODEC standard in China and, consequently, should lead to a global adoption of the standard. The success of this project is hindered by several factors: AVS is managed as a non-profit organization, China has less experience and fewer financial resources for international standardization and most of the patents are developed by Chinese State-Owned Enterprises. ${ }^{656}$

Is the regulatory IPR framework of the AVS patent pool a best practice for patent pools in emerging markets like the People's Republic of China?

\subsection{The IGRIS alliance}

The IGRIS standard was approved by the Chinese Ministry of Information Industry in 2005. The IGRIS standard is a 3C technical standard. The IGRIS alliance consists of the following Chinese companies: Great Wall, Hisense, Lenovo, Konka, and TCL. After the adoption of the standard, the IGRIS alliance was extended with international members, now totalling 113 members worldwide. The participants in the IGRIS standard represent a wide variety of interests, ranging from academic institutions to network operators and software and content providers. In the management of the IGRIS patent pool, the following challenges were identified:

- difficulty to design a royalty-sharing agreement that represents the interests and contributions of all participants;

- lack of investment funding in China;

- lack of competitive strength of participating Chinese companies;

- lack of experience of Chinese companies in global patent strategies. ${ }^{657}$

\subsection{OTHER RELEVANT CHINESE TECHNOLOGY LAWS}

Both patents and competition rules stimulate innovation and have a positive effect on social welfare. The use of a patent can balance the correct level of protection that an innovator needs in order to invest in research and development. Competition policy stimulates efficient markets and protects the interests of consumers. Competition agencies are interested in the use of patents as soon as this leads to anti-competitive effects.

\footnotetext{
${ }^{656}$ See note 72 .

${ }^{657}$ Yuhzen, Wei, Xiaobao, Zhou, \& Lei (2013). Patent pool analysis based on technical standards: A case study of indigenous alliances in China.
} 
European and US experience has taught that the implementation of patents in standard setting and patent pools may lead to a restriction of competition. Other forms are more challenging to evaluate, such as non-practising entities, refusal to deal or patent misuse, and they are more difficult to specifically define as abuse of intellectual property rights. Monopoly conduct related to patents is not exclusively regulated by competition law. Competitors who complain about monopoly conduct can be granted a compulsory licence, according to Article 48 of the Patent Law of the PRC. ${ }^{658}$

Xianlin also refers to a Judicial Interpretation by the People's Supreme Court in 2005 concerning the Adjudication of Technology Contracts, where the Supreme Court gave a very broad explanation of the illegal monopoly of technology. Examples of the latter concept included any restrictions on the acquisition of new technologies or development of competing technologies. Although there is a mirror image in Article 15 providing exemptions, it may prove difficult to claim that consumers obtained a fair share of the benefit from the technological progress. Article 329 of the Chinese Contract Law 1999 declared that the monopolizing of technology, hindering technological progress and the violation of third-parties rights are illegal. ${ }^{659}$ The Supreme Court explained, in the so-called "Interpretation 2005", six possible scenarios for infringement:

"1. Restricting one party from undertaking new research and development on the basis of the contractual subject technology;

2. Restricting one party from obtaining similar technology from competitors of the technology provider in the contract;

3. Restricting the technology accepter from reasonably exploring/commercializing the contractual subject technology (including unreasonable restrictions on the quantity, varieties, price, sales channel or export market of the contractual subject technology);

4. Restricting the technology accepter to accept attached conditions dispensable for exploiting the technology (including purchasing dispensable technologies, raw materials, products, equipment, services or accepting dispensable persons);

\footnotetext{
${ }^{658}$ Article 48: Under any of the following circumstances, the patent administration department under the State Council may, upon application made by any unit or individual that possesses the conditions for exploitation, grant a compulsory license for exploitation of an invention patent or utility model patent:

(1) When it has been three years since the date the patent right is granted and four years since the date the patent application is submitted, the patentee, without legitimate reasons, fails to have the patent exploited or fully exploited; or

(2) The patentee's exercise of the patent right is in accordance with law, confirmed as monopoly and its negative impact on competition needs to be eliminated or reduced.

${ }^{659}$ See also Xiaohai Unfair competition/trade secrets/ know-how page 141 in Chinese Intellectual Property and Technology Laws, ed. Kariyawasam EE 2010.
} 
5. Unreasonably restricting the channels or origins for the technology accepter to purchase raw materials, parts and components, products or equipment, and so forth;

6. Prohibiting the technology accepter from making objections to the effectiveness of the IP of the contractual subject technology, or attaching conditions to the objections made." 660

A second applicable municipal law in China is the "The Regulations on Technology Import and Export Administration of the People's Republic of China 2002", and the Foreign Trade Law 2004 also contains important elements for the regulation of technology licensing. Article 30 enables parties to question the validity of patents, but these laws do have guidelines to explain their scope and application.

Finally the Anti-Unfair Competition Law of China prohibits tying clauses in technology licensing arrangements.

\subsection{CONCLUSIONS}

\section{Differences in standardization policy}

The European and Chinese standardization systems have some similarities. The US standards regime relies heavily on market forces, strong IPR protection and leaves hardly any room for government intervention. Closer cooperation between the EU and China in the field of standardization would also have effects on the way technology transfer is regulated by competition law in the EU and China. Since standardization is influenced by the poor quality of Chinese patents, this also has an impact upon the innovative capacities of Chinese firms. An improvement of the quality of patents makes Chinese companies more attractive for international SSOs and global firms.

A direct comparison of the standardization systems of the US, EU and China is complicated by the Chinese innovation policy. The Chinese innovation policy uses different concepts of markets, technology transfer and consumer welfare. The Interim regulation on patents in standards that entered into force in January 2014 does not clarify the legal position of foreign firms that engage in standard setting in China. Foreign firms do not have voting rights in Chinese SSOs and the recent case law indicates that the development of new Chinese telecommunication standards is supported by both legislative and judicial efforts to promote Chinese firms in standard setting. The development of the fourth generation Chinese telecommunications standard coincided with more and stricter enforcement actions against foreign firms in China and a re-emergence of "techno-nationalism" in China. The decision in the Huawei/InterDigital case directly

\footnotetext{
${ }^{660}$ See the Interpretation of the Supreme People's Court concerning Some Issues on Application of Law for the Trial of Cases on Disputes over Technology Contracts 2005, section 10.
} 
mentions the promotion of Chinese companies in international standardization as one of the influential factors. The draft MIIT Template does specifically address some of the key elements of the standards/patents discussion. The original text of the draft is open to various interpretations. Especially using the smallest component as a basis for FRAND rates is seen as a form of Chinese techno-nationalism and can be distinguished from the US and EU methodology. The development of ICT standards can be directly linked to Chinese industrial policy demands. In order to remain competitive, Chinese SSOs should participate in open participation standardization and allow foreign technology access to Chinese SSOs.

\section{Management of SEPS}

The discussion on the management of SEPs leads to the general policy objectives of the AML but also to the Chinese indigenous innovation policy. The latter is still being further developed but does have a strong influence on the application of the AML. The interpretation of Article $55 \mathrm{AML}$ is seriously hindered by the lack of transparency. The lack of transparency is related to the absence of specific guidelines for the use of IP in standards and the fact that cases are often not publicized. The AML does provide legal opportunities to companies that can be considered as latecomers to the technology market. Recent developments in Chinese case law demonstrate that the Chinese courts do not shy away from discussions involving injunctions, FRAND rates and standard essential patents. The more proactive Chinese antitrust policy in this field coincides with the commercialization of new telecommunications standards in China. The draft regulatory measures on patents in standards are relatively vague. Two problems are: the lack of reciprocity in relation to FRAND licensing terms and the general liability of (foreign) companies participating in the standardization. The Interim regulation on patents in standards provides more transparency. Owners of SEPS must have the duty to disclosure any patents that they own or have knowledge of. The FRAND commitment depends on the character of the Chinese standard (voluntary or mandatory) but, in practice, it does mean for SEP owners that the FRAN promise is compulsory, irrespective of their choice to participate in standard setting. As a consequence, the freedom regarding business strategy is seriously hindered, since FRAND commitments must be followed on the basis of Chinese contract law. In the absence of a FRAND promise, the SAC and SIPO and other Chinese government agencies may enter into negotiations to determine the appropriate licensing rate.

There might be indications that Chinese courts want to apply economic analysis and sometimes follow principles that were developed by the EU Commission. The main evidence for this movement is the approval of Google's acquisition of Motorola. The lack of transparency in relation to the court decisions prevents a proper analysis of their reasoning, however. Commentators hold the opinion that industrial policy considerations are still prominent in the Chinese Anti-Monopoly Law, which could be a risk factor 
for foreign companies in China. Again, the question can be raised whether the Chinese antitrust law should compensate for the ineffectiveness of the national IP system. Parallels can be drawn with the US and EU, with the exception that the Chinese IP system is in a worse state than the US and European IP systems. A complete new dimension is the possible extraterritorial application of the AML to foreign firms that harm Chinese economic interests. The telecommunications industry consists of global production networks and an extraterritorial application of Article $55 \mathrm{AML}$ might have a serious impact on foreign firms but also on Chinese participation in global standardization.

Recent developments in the field of standard essential patents and FRAND reveal a worrying trend. The Huawei/InterDigital case is one of the main points of reference at the moment. The Chinese court based its evaluation of the royalty rate on the following elements:

- The contribution rate of the patent to the standard

- Licensing fees that InterDigital collected

- Licensing fees for other similar patents

- The impact of the royalty fees and the patent on the development of new technology

- The contribution rate of the patent to the product

- Expectations that were raised during the negotiations

- Sunk costs; the development costs of the R\&D activities must compared to the royalty rate

Another conclusion that is the ownership of SEPs leads to two consequences: the SEP owner could automatically have a dominant position (depending on the number of the SEPS in the standard) and the mandatory requirement to disclose the SEPs and the commitment to use FRAND terms in the licensing. SEP owners seem to lose the voluntary option not to participate in SSO activities and must always promise to accept FRAND commitments.

The recent NDRC/Qualcomm decision seems to suggest that the Chinese courts hold that the owners of SEPs have automatically substantial market power and stop competitors from entering the market. MOFCOM will intervene if they think that the management of SEPs can have negative effects for Chinese companies or the Chinese telecommunications market. Whereas the market power of the SEP owner is subjected to economic evidence, the AML agencies seem to automatically assume the notion of market power. ${ }^{661}$

\footnotetext{
${ }^{661}$ This is clearly indicates the different views on the concept of market power between the Chinese courts and antitrust enforcement agencies
} 
As already stated the MIIT draft of December 2014 uses the smallest component as base for the calculation of FRAND rates. The Huawei/InterDigital case uses again different parameters to establish the relevant FRAND-rate. Although this seems to hint at a lack of consistency, the Chinese government initiated to establishment of new specialized IP Courts. These courts will have more specialized knowledge on technology transfer. The start of specialized IP Courts in China strengthens its policy as a technology investigator.

\section{Patent Pools as a solution for the problem of patent thickets}

The experiences of the European and US antitrust authorities have shown that a competition policy analysis of patent pools concentrates on a number of key elements:

- The inclusion of essential patents in the patent pool and the position of complementary patents in the pool;

- What are the safeguards in the selection process of the most suitable technology (i.e. patents)?

- Licensing obligations: free, RAND, collectively, or individually?

- Royalty-sharing agreements;

- Ex ante disclosure terms and disclosure policy;

- How to prevent pool members from exchanging relevant market information (conditions of sale, pricing strategy, R\&D projects)?

- What is the presumed legal position of patent pools; are they in principle compatible with competition policy or in principle illegal?

- What is the contribution of patent pools to the innovation process and dynamic efficiency?

Patent pools could serve specific interests in the current state of IP transition in China. Chinese companies that concentrate on exports could benefit from the use of Westernmanaged patent pools. The effect of the lowering of royalty rates during the product life cycle, through the patent pool, encourages more manufacturing in China. The centrally administered patent pool could raise awareness and respect for IPRs in the Chinese business community.

The July 2014 draft rules on the abuse of IPRs in relation to competition law suggest that in some cases patent pools must be evaluated using a per se approach. The application of the essential facilities doctrine to SEPS and the concerns of tying practices of essential and non-essential patents must be carefully considered by patent pools. The increase in the number of patents included in a patent pool and the difficulty to evaluate the essentiality and validity of the patents create serious risk factors for patent 
pools in China. The draft also discusses PAEs but fails to clarify the legal situation, since its uses a very broad definition of patent assertion entities. The difference between a patent troll, a patent assertion entity, privateering, and a patent pool is sometimes difficult to make and may only depend on the management and commercialization of the patents. In the suggested form, the rules on PAEs form a serious limitation of the ability to monetize patents through new business forms, like privateering. Furthermore, even in the US and EU, clear empirical evidence of all of the negative effects of new innovative business forms has not yet been established. A legitimate patent pool owned by Western companies can easily be qualified as a PAE by Chinese authorities. The present eagerness of Chinese regulators to end "Western IP oppression" by prosecuting companies such as Microsoft and Qualcomm will definitely have an impact on the legal treatment of patent pools in China.

For the moment, this impact means that patent pools must very carefully consider whether they apply the following elements: the bundling of essential and non-essential patents, refusal to license, requiring licensing fees for expired patents, and the basis of the calculation of licensing fees. Regarding the PAEs as a new business model, some scholars think that they offer new ways to monetize unused patents which consequently has a positive impact on innovation. It would be recommendable that antitrust enforcers focus on the market behaviour and not on the business model. Improvement of patent quality and validity together, with a careful monitoring of the use of injunctions, are also key elements in addressing patent trolls.

\section{Lessons to be learned}

Both in the EU and in the US, antitrust agencies are struggling to find a proper basis for and, consequently, a proper assessment of the necessary regulatory framework for patent pools. Economic research is divided on the evaluation of patent pools and, sometimes, it is not independent, since it is sponsored by some of the major stakeholders. The Chinese agencies will find it more difficult to come to a common enforcement policy because of their different, often political, interests. In the present state, both the $A M L$, as well as the draft measures and IP Guidelines, provide an insufficient explanation of the proposed enforcement policy and its economic basis. Most of the criticism of the AML (e.g. the ABA comments) is related to a direct comparison between the European, US and Chinese regulatory settings. Some commentators (such as Mehra and Yanbei) introduce the concept of "Antitrust Functionalism". ${ }^{662}$ This refers to scholars who do not consider the fundamental differences in the Chinese, European and US economies and governmental policies while evaluating the Chinese AML.

The main differences between China and the EU and the US are not just related to the economic conversion process in China but also relate to the experience and case

\footnotetext{
${ }^{662}$ Mehra and Yanbei in: Against Antitrust Functionalism: Reconsidering China's Antimonopoly Law Virginia Journal of International Law Volume 49- Issue 2 page 384. See for further discussion also Daniel Sokol.
} 
law of the competition policy in China. The current situation only shows the initial stage in the development of the PRC policy in relation to standards, patents and patent pools as a possible remedy for some of the current competition problems in this field. The specific Chinese situation has raised the debate on the public function of a standard which, again, might prove to be interesting for the EU and the US, especially in the field of ICT standards.

The present lack of guidance in the intersection between patents, standards and antitrust law in China can have a negative impact on the development of new international standards and the participation of China in standard-setting activities. The uncertainty about the competition law evaluation could further undermine the willingness of SSOs active in China to undertake self-regulation. The three jurisdictions (US, EU and PRC) are facing common themes in this field. To gain effective insights, there first must be cross-agency collaboration between the three anti-monopoly enforcement agencies in China. The next step within China should be across-agency collaboration between the AMEA's and the national intellectual property agencies. The duplicated enforcement by different Chinese agencies continues to be a risk. Institutional knowledge building with EU and US enforcement agencies could also increase the benefits gained.

The complexity of the discussion requires more international cooperation. A parallel can be drawn with international tax law, where the principle of national sovereignty is still very strong. Multinational enterprises created mobile tax bases thereby surpassing national tax laws. In order to improve the accessibility and creation of standards, China should use its special position to learn from more advanced systems. Both cross-agency cooperation and international cooperation are essential to achieve the right balance between patent and antitrust laws. Only with a proper balance can future innovations and consumer welfare be guaranteed.

Recent developments in China might signal a different approach towards the definition of market forces and the commercialization of patents. The outcome of the recent strategic and economic dialogue between the US and PRC suggests that further reforms are on the way. In order to deal with complex discussions like patent hold-up, injunctions and patent abuse, China needs to learn from Western experiences. In its desire to significantly increase the development of Chinese standards, patent pools are a suitable instrument to address the aforementioned problems. Since the problems are centred on the patent/competition law intersection, the latter would be more suitable to deal with the problems. Competition law can be changed much faster, also leading to faster results. ${ }^{663}$ This does not exclude using the patent law system to start amending some of its flaws, since most of the problems are caused by this system.

\footnotetext{
${ }^{663}$ See for more background: Addy TROLLS, HOPPING, AMBUSH AND HOLD-UP:

EMERGING INTERNATIONAL APPROACHES TO THE INTERSECTION OF COMPETITION AND PATENT LAW REGIMES

http://www.dwpv.com/ /media/Files/PDF/IP_Report.ashx
} 


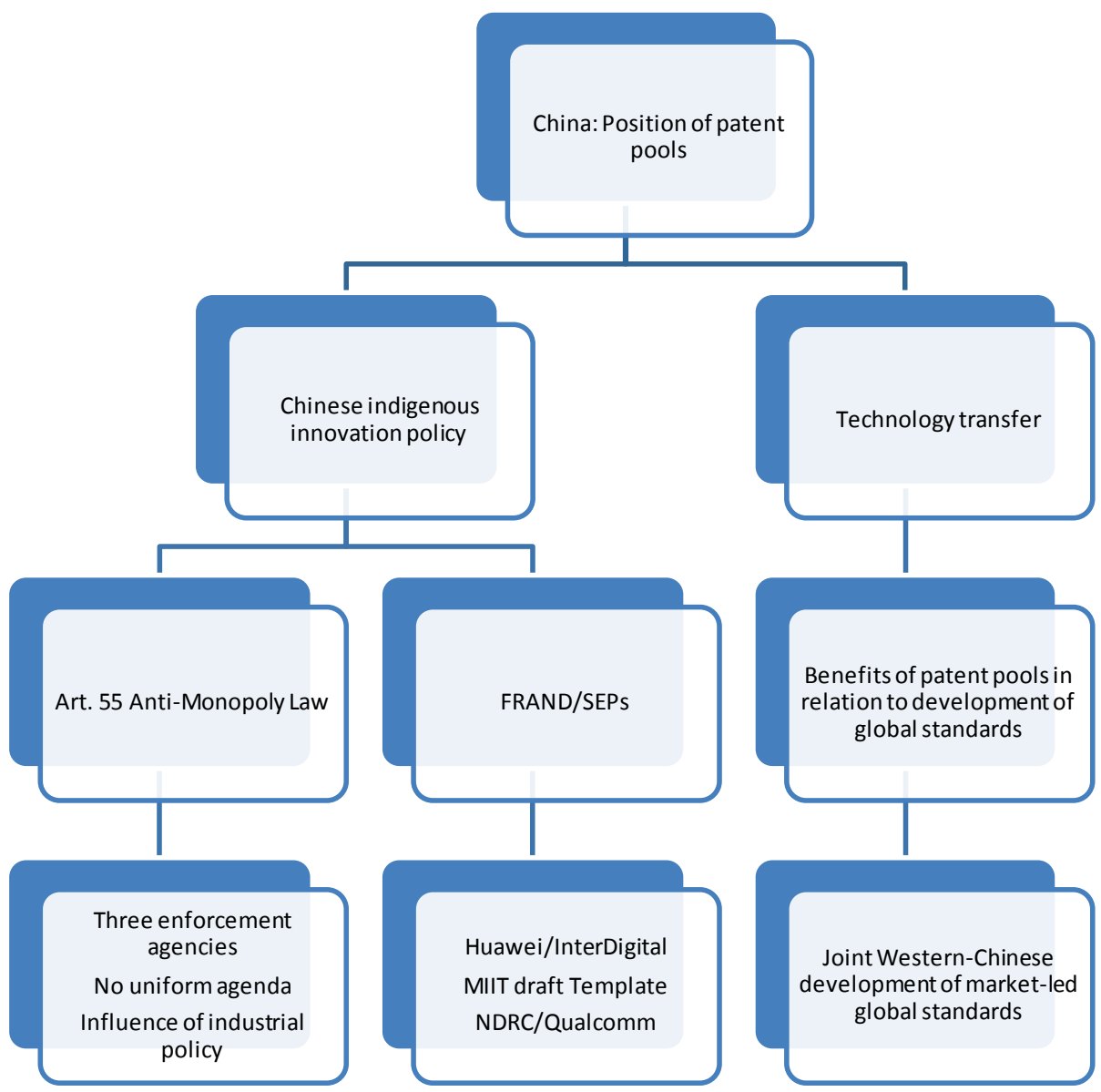





\section{CHAPTER 9}

Main findings and conclusions 

This research project aims to provide a better understanding of the regulatory framework of the competition law of the US, EU and China in relation to the strategic use of patents in standards and the instrument of a patent pool. Technologies embedded in standards are most often protected by patents. The research shows that competition law concerns will be raised as soon as the standardization process is manipulated to enable patent holders to gain unfair competitive advantages. These advantages enable the patent owner to demand higher royalties or introduce unreasonable terms after the adoption of the standard. Strategic patenting has become common practice in the telecommunications industry. Substantial patent portfolios are used as "weapons of mass destruction" to fend off infringement cases by competitors. The strategic use of patents can take the form of patent ambush, patent hold-up or royalty stacking. This study argues that patent pools are a possible solution to the aforementioned problems in the US, EU and China.

In the introduction, key questions were identified to discuss the main research question: What is the position of the instrument of a patent pool in the discussion on the strategic use of patents and competition law in the European Union, US and China?

The key questions were the following:

1. What is the position of the concept of patent pools in the competition policy of the US, EU and China?

2. How do the management rules of a patent pool influence the legality of the patent pool?

3. How do standardization policies differ in the various countries and what is the impact upon competition?

4. What are new IP business forms and how can they be distinguished from patent pools and how do they influence the standards and patents discussion?

5. What are the different attitudes towards FRAND rate setting, SEPs and injunctions in the three jurisdictions?

Regarding question 1, what is the position of the concept of patent pools in the competition policy of the US, EU and China, the following can be stated. The concept of a patent pool is unique, since competitors in a specialized market join forces and cooperate in order to create a mutual benefit, in the form of the collection of royalties. Patent pools can positively address the problems of royalty stacking and patent thickets. Depending on the disclosure requirements, they also prevent patent ambush. 


\subsection{GENERAL REMARKS}

To start this section I will summarize some of the main findings that are required for the discussion of the individual questions.

\subsubsection{The relationship between patents and innovation}

The innovation behaviour of companies was influenced by two import trends: globalization and technological progress. The original idea of the patent was that the patent holder would get temporary freedom to use his invention. Since the invention was also made public, this would lead to spur-on innovations and incentives to invest in R\&D activities. Globalization created Global Production Networks and technological progress increased the fragmentation of the ownership of patents. This fragmentation of ownership is the basis for the problems of royalty stacking, patent thickets and patent holdup. Practically, it leads to a situation in which small and medium-sized companies or start-ups will find it difficult to design around the most important (essential) patents. Although the patent systems recognize its present shortcomings, opinions are divided on the question whether the solution should be found in patent law or in competition law.

\section{Patent and standards}

There is no doubt that standards are the flipside of patents. Standards work on the basis of sharing knowledge and are the fuel for international business. Standards provide market access, dissemination of technology and play a major role in the innovation circle. The engagement of the stakeholders is the key driver for the development of standards and innovation. The three jurisdictions stress the strategic importance of international standards that are "home-grown". In the present negotiations on the transatlantic dialogue between the EU and the US, standards are an important point of discussion. For China, as an emerging economy, it is important to support the "indigenous innovation policy" in order to move from the position as a standards taker (and royalty payer) to a standards developer and (royalties receiver). Practically the US and China can create standards because of their mass of consumers with the same language and culture. The competition policy of the three jurisdictions must guarantee fair access to the market since the time to the market (and network effects) can give a competitive edge. Interoperability is the key element of the dissemination of patent-encumbered standards.

\section{The problems created by the fragmentation of patent ownership}

Patent hold-up is the situation in which a patent owner seeks to get an injunction on a patent in a product and thereby can hold up the complete product. Since there is a lock- 
in situation for the patented technology, users are do not want to be faced with high switching costs and are prepared to pay a much higher price for the patents. Regarding patent hold-ups, complexities arise in relation to determining the appropriate value of the switching costs and the reduction of competition between the ex ante and ex post periods.

Patent ambush is the situation in which a patent owner raises expectations that his patents are free or relatively cheap, but after the user made sunk investments in the production and implementation, it is financially and technically no longer feasible to design around the patents. Hence, a higher royalty fee may be demanded.

Royalty stack refers to the situation that arises when patent owners seek to maximize their profits, but the accumulated total of all royalty demands exceeds monopoly rent, and thus has a negative impact on innovation and consumers.

\section{The strategic use of patents and competition policy}

The strategic use of patents caused concern for competition authorities. The most debated elements are injunctions, which have a far-reaching effect, since they virtually deny market access to competitors. The injunction can be applied in a perfectly justified manner but might also hinder rivaling firms in an illegal way. Other examples of strategic use of patents are huge patent portfolios that make it almost impossible to evaluate the validity of patents and the denial of operability through the use of standards.

\section{New business models that show some similarities to patent pools}

PAEs have emerged as a new phenomenon. Although the patent assertion entities enjoy a bad reputation, it would be too simplistic to come to this the general conclusion. PAEs act in aggressive and defensive manners and not the business form but the actual conduct should be decisive in relation to their legality. The same also applies to privateers. Recently privateering companies have been used by major companies to sell off patents and to outsource the exploitation and the management of huge patent portfolios. This has often resulted in increased litigation on the part of privateers, with negative effects for consumers and innovation.

\section{Solutions to the problem of patent hold-up and strategic use of patents}

The standard-setting organizations have reacted with various solutions: compulsory patent disclosure, ex ante licensing disclosures and FRAND terms. Patent disclosure rules will lead to more competition on merits, and gives an opportunity for ex ante licensing. The gaps in the coverage of the patents are problematic, which given the size of patent portfolios is very difficult to avoid. Ex ante licensing practices are in theory a good solution but, based on the speed of technological progress, are difficult to implement in practice. It could also lead to possible competitive concerns, since it is an agreement between competitors. 
Key elements for the successful use of patent pools as a solution to the strategic use of patents in standards

A. The selected patented technology for the standard must be of the highest quality

B. Patent pools are only successful if they manage to attract the major patent owners (60-70\%) into the patent pool

C. Licensing conditions must balance the needs of the innovators and implementers

D. Pools must have the capacity to catch a high coverage on the market

E. Proper enforcement policies and actions

F. Not too many patent pools should relate to the same standard, in order to prevent fragmentation of the market

G. Patent pools must carefully monitor the time of the start of the pooling arrangement. Starting too late, after the launch of the licensing programme, patents that are included have less innovative value. One example is the Blue Ray Association which, in cooperation with the SDO, found committed firms to establish together a patent pool. The patent pool set up before the technology standard was adopted.

$\mathrm{H}$. Patent owners in the pool should be allowed to license individually on the same terms as the patent pool.

After the general remarks I will return to answer the specific detailed questions

The key questions were the following:

1. What is the position of the concept of patent pools in the competition policy of the US, EU and China?

2. How do the management rules of a patent pool influence the legality of the patent pool?

3. How do standardization policies differ in the various countries and what is the impact upon competition?

4. What are new IP business forms and how can they be distinguished from patent pools and how do they influence the standards and patents discussion?

5. What are the different attitudes towards FRAND rate-setting, SEPs and injunctions in the three jurisdictions? 


\section{ANSWERS}

Question 1: What is the position of the concept of patent pools in the competition policy of the US, EU and China?

US

In the US, the position of patent pools is heavily influenced by the present political sensitivities surrounding patent trolls. The distinction between patent trolls, defensive patent aggregators and patent pools is difficult to make. Patent pools are a possible solution to the tensions created by the strategic use of patents in standards. One of the conditions that must be met is that the patent pool will apply FRAND licensing terms. In order to define FRAND terms, Judge Robart looked at comparable examples for FRAND rate setting and ended up with the application of patent pool rates. This puts the concept of a patent pool in standardization in an awkward position. Many experts severely criticized applying this FRAND method. Patent pools do not always contain the major firms or the best technologies. Furthermore, the royalty rates are sometimes at a lower level, since pool members monetize their patents on downstream markets. Again, this leads back to the manner in which patent pools determine their royalty rates.

Traditionally, SSOs take a defensive stance on the joint discussions on royalty rates in patent pools. Recent economic research shows that joint ex ante royalty discussions among pool members can have a positive effect on innovation. The US authorities (FTC and DoJ) take a more liberal stance and therefore apply a rule of reason approach in relation to the establishment and management of patent pools.

The FTC and DoJ have developed a framework through their IP Guidelines and BRLS that provides transparency, clearance and supports the pro-competitive benefits of patent pools in standardization.

In the US framework, the FTC and DoJ evaluate the effect of the patent pool on the technology market. An important element of this evaluation is the qualification of the type of patents in the pool. A patent pool may consist of essential, complementary and substitute patents. This qualification is handled by an independent expert (whose independence is not always clear). The management and administration of the pool can be the responsibility of an independent third licensor or a licensor appointed by the firms participating in the patent pool. The inclusion of complementary and substitute patents can have an anti-competitive effect. The influence of the Chicago School is apparent in the discussion on the level of royalty rates, where the US takes a more liberalized stance on the basis of its economic-based approach and, consequently, the influence of the efficient working market. Overall the US antitrust agencies see patent pools as twosided markets. Important factors in the evaluation are: the proportional division of markets, the choice of relevant technology and the already-mentioned tying of essential 
and non-essential patents. The main conclusion for the US is that patent pools must be evaluated by antitrust rules with caution.

\section{$E U$}

In the European Union, regulators do not yet share the US fear of patent trolls and PAEs. It seems that the EU Commission takes a more refined stance on the procompetitive effects of PAEs. Two developments would justify a closer look at the effects of PAEs, patent trolls and patent pools. The first reason is linked to the emergence of privateering. Privateering could lead to the evasion of FRAND or other SDO commitments, since patents are frequently transferred to new and different firms. The traditional nuclear deterrence of opposing patent portfolios does not exist since privateers are less vulnerable to litigation and hence increase litigation against other rivalling firms. Some experts feel that privateering should be attacked under Article 101 TFEU, since it is an agreement between competitors to restrict competition. In my personal view, this reasoning is only valid when the intention of effect of this privateering strategy is proven. Other forms of privateering, whereby former manufacturing firms (e.g. Nokia) sell patent portfolios in an pro-competitive way, should be allowed but closely monitored by the EU Commission. Overall it means that these new business forms complicate the discussion of patent pools. Patent pools are sometimes difficult to distinguish from PAEs, patent aggregators or even privateers.

The second reason why the EU Commission must pay more attention to PAEs is the establishment of the Uniform Patent Court (UPC) in Europe. The threat of a patent holdup is seriously increased since injunctions now have a Europe-wide application. The bifurcated system in some Member States leads to the injunction gap. This means that the infringement proceedings concluded before the validity of the patent was established. The infringement might be related to an invalid patent, which troubles negotiations and litigation.

The European Union made the strategic choice to evaluate the legality of patent pools in competition policy with a rule of reason approach. Patent pools are not directly discussed in the new TTBER, since they are multi-party agreements. However, the current version of the TTBER Guidelines gives the EU Commission the opportunity to clarify some of the uncertainties that are related to the safe-harbour system. The safe-harbour model lacks legal certainty and the different interpretations of the new Guidelines may hinder the effectiveness of the competition law enforcement. This lack of clarity also extends to the legal evaluation of patent pools. The relationship between the various types of patents in the pool is leading the enforcement agenda of the competition authorities. On this point, a clear distinction between the EU and US approach is visible.

The European Union mimics the US government in applying a rule of reason approach to the legality of patent pools. The conclusion regarding the revision of the TTBER (the old TTBER expired in 2014) is that the system leads to a lack of clarity, espe- 
cially in relation to the interpretation of the hardcore restrictions. In this policy field, it can be concluded that, contrary to the US government, the EU Commission takes a relatively hard stance on the inclusion of non-essential patents and complements in the patent pool. The conclusion of this study is that the Commission should promote the licensing of technology independently, outside the patent pool. The inclusion of nonessential patents must be justified on transactional or legal grounds. The EU does recognize the importance of patent pools by creating a concise safe-harbour system in the new TTBER. Patent pools would be in the "safe harbour" if they:

- Are open (membership) to all

- Pool members only exchange information that is relevant for the functioning of the patent pool

- The patent pool only contains essential patents

- Patent owners are still allowed to license outside the patent pool

- Licensees are not restricted in challenging the validity or essentiality of the patents in the pool

- Licensees are not restricted in the development of competing technologies/standards outside the patent pool

- Patents are licensed on FRAND terms.

The Guidelines on the new TTBER give more clarity on the specific elements that render patent pools illegal. Since the old TTBER was never applied to classical patent pools, the EU Commission failed to anticipate the development of new business models that are very similar to patent pools.

A full effects-based approach of patent pools would lead to a proper analysis of the competitive effects. Given the current rise in the number of patents included in a patent pool, possibilities of abuse have increased. In the European Union, an emerging debate is the question whether patent pools should be rules by IP law or by competition law. Differences between the Netherlands, where it seems that IP law is more important, and Germany, where apparently competition law prevails, highlight the discussion at the national Member State level. Uncertainty about national court proceedings could easily lead to forum shopping. The EU Commission and the ECJ are struggling with the topic of technology transfer and the labour division between both is not very clear. Despite the Orange Book case, it is also possible that "formally willing licensees" develop strategic behaviour.

The EU does provide guidance in the form of the TTBER Guidelines. These mainly concentrate on the establishment and the start of the patent pool. The EU seems to be more willing to investigate patent pools mainly on competition law analysis. This does mean that some of the problems that relate to the patent law side (patent quality, inva- 
lidity, high number of patents, and SEPs) tend to be overlooked. In the EU, at the moment licensees are in the best position to challenge the validity of patents in a patent pool. Although it is still early days, it could be that the new TTBER has tipped the balance in favour of licensees which could be a disincentive to join patent pools or to participate in standardization efforts. For holders of SEPs, there is a choice to enter into bilateral licensing agreements or patent pools which often can only be decided on a case-by-case basis.

\section{China}

The position of patent pools in the PRC is directly related to the fact that pools offer an easy and relatively cheap access to (Western) technology. The pricing of SEPs is a direct concern for a manufacturing economy such as China. The demand for standardcompliant products is price-elastic. FRAND royalties would in theory increase with patent portfolio strength. Small companies would be better off to participate in a patent pool. More importantly Chinese firms that participate in the patent pool limit the risks of litigation in China and increase the Chinese participation in international standard setting.

Patent pools could serve specific interests in the current state of IP transition in China. Chinese companies that concentrate on exports could benefit from the use of Western-managed patent pools. The effect of reducing royalty rates during the product life cycle, through patent pools, encourages more manufacturing in China. The centrally administered patent pool could raise awareness and respect for IPRs in the Chinese business community. Patent pools have the advantage of providing relative transparency to Chinese regulators and firms. The examples of recent patent pools show that no royalty rates are charged to support the fast adoption of the technology (Blue Ray Special Interest Group). If Chinese firms are able to participate in and contribute to these patent pools, it serves the aim of the Chinese indigenous innovation policy perfectly. If royalty terms do apply, they must reflect FRAND terms and not just FRAND royalty rates.

The July 2014 draft rules on the abuse of IPRs in relation to competition law suggest that in some cases patent pools must be evaluated under a per se approach. The application of the essential facilities doctrine to SEPs and the concerns of tying practices of essential and non-essential patents must be carefully considered by patent pools.

The draft rules on patent pools in relation to the AML identify the following key elements:

- Is the patent pool open and non-discriminatory?

- Do companies participating in the patent pool have market dominance?

- Is the patent pool unreasonably blocking third-party technology?

- Does the patent pool prevent the establishment of substitute patent pools? 
Contrary to the US and the EU, China provides hardly any guidance or interpretation of the draft or interim rules that apply to patent pools. Commentators often think that this is a deliberate policy to achieve maximum flexibility in applying Chinese IP/Competition law rules to foreign firms active in China. In all fairness, it has to be stated that the reemergence of the Chinese "techno-nationalism" is often just a perception in Western minds. Chinese firms have also been prosecuted, but the presence of obvious industrial policy concerns in relation to foreign companies does remain. Patent pools would provide an excellent platform to formalize the cooperation between Chinese and Western companies in the field of standards and patents. However, at the moment patent pools in China are ruled by a mass of Chinese laws which are in different stages of development: drafts, interim measures etc.

The recent signs in the various drafts, interim measures and judicial decisions (e.g. Huawei/InterDigital) do hint at a more conservative stance on the governance of technology transfer in general and patent pools specifically.

\section{Question 2: How do the management rules of a patent pool influence the legality of the patent pool?}

\section{US perspective}

Economic research is inconclusive on the effectiveness of either ex ante disclosure or ex post enforcement rules within standardization. Most SSOs have adopted disclosure obligations in their IPR policies. Recent US law (Princo judgment) seems to strengthen the position of patent pools under the doctrine of patent misuse. The application of the doctrine of patent misuse broadens the scope of the discussion and allows for a more useful and effective investigation of the strategic use of patents than simply limiting the discussion to the strict application of US antitrust laws. Although the risk of overinterpretation remains, the Princo decision does raise controversy on the legality of the tying of essential and non-essential patents. When non-essential patents are free, this would justify the tying arrangement. As a result, patent pools would have to re-examine the status of the patents in their pool and need to adjust pricing strategies. The qualification of the type of patent (essential, non-essential, complementary, competing, or substitute) would require patent law elements in the legal analysis. The discussion of essential patents shows some differences between the US and EU, which could be interesting for Chinese regulators to monitor.

Regarding the joint ex ante royalty discussions, the FTC does seem to favour a rule of reason approach, diverting from the previous per se approach. This change of direction is justified on the basis of recent economic research. In the US, the management and administration of a patent pool can be the responsibility of an independent third licensor or a licensor appointed by firms operating in the pool. At the moment, US antitrust authorities show no preference for either choice. Although firms participating in 
the patent pool are often vertically integrated firms, the effect on the downstream market goes apparently unnoticed for the US authorities. US practice shows that some patent pools (e.g. MPEG LA) do not systematically use independent experts and that enforcement agencies concentrate on the establishment and the start of a patent pool. The possible anti-competitive effects of the management of a patent pool often go under their radar.

The growing number of patents included in a patent pool, make it very challenging to investigate the essentiality or validity of the patents. The present rise in the number of patents in a pool and the difficulty of examining the validity and essentiality of patents in the pool leads to serious problems. The assessment of the pro-competitive benefits of a patent pool must be evaluated against the background of the increasing complexity and growth in the size of patent pools. Large patent pools have the ability to suppress and raise the costs of competition. After approval of the patent pool, the FTC and DoJ no longer carefully analyze the level of royalties or the validity of the patents. Overall, US authorities have a more relaxed stance on royalty levels than the EU Commission as a result of their economics-based approach and the influence of market forces on the rapidly changing technology markets.

\section{EU perspective}

Monopolistic conduct of a patent pool will lead to an enforcement action by the EU Commission. This market conduct is most likely to take the form of a refusal to license or unreasonable licensing terms, such as excessive royalty fees. In relation to injunctive relief, the Orange Book case provided some explanation by stating: if infringers of SEPs act as willing licensees, the patent owners no longer have access to injunctive relief. The impact of this decision could prove to become very important in the future. With respect to licensing terms, the European Union is becoming more eager to evaluate the level of royalty fees that is charged. Competition law seems to take a clear lead in the legal assessment of patent pools, although the discussion is not finalized. The EU Commission has a preference for patent pools that invite all interested parties into the pooling agreement. The EU Commission does not seem to share the US enthusiasm for independent experts, although the system is explained in the TTBER Guidelines. The TTBER does not address non-standard related patent pools, although for other patent pools they provide a safe harbour. For patent pools that do not have market dominance, the EU Commission will most likely apply the rules on excessive pricing in the case of unreasonable royalty fees. The determination of the reasonableness of royalty fees, especially in relation to a FRAND commitment, remains a hot topic. The national courts in the EU (the Netherlands, Germany, and the UK) take a different stance on injunctions and royalty fees. As a result, forum shopping may develop, which possibly undermines the effectiveness of EU competition policy. The preliminary ruling requested by a German only gives limited guidance on this subject. 


\section{Chinese perspective}

The July 2014 draft rules on the abuse of IPRs in relation to competition law suggest that, in some cases, patent pools must be evaluated according to a per se approach. The application of the essential facilities doctrine to SEPs and the concerns of tying practices of essential and non-essential patents must be carefully considered by patent pools. The increase in the number of patents included in a patent pool and the difficulty to evaluate the essentiality and validity of the patents create serious risk factors for patent pools in China.

Recent case law showed that patent pools in China must very carefully consider whether they apply the following elements: the bundling of essential and non-essential patents, refusal to license, requiring licensing fees for expired patents, and the basis of the calculation of licensing fees.

The recent Interim regulation of SAC and SIPO signalled that patent pools must disclose all essential patents that they own or have knowledge of. Irrespective of whether they participate in standardization activities in China or not, failure to do this will lead to a breach of good faith. Firms participating in a patent pool in China should also carefully evaluate whether their patents are part of a standard that has strategic importance in the Chinese industrial policy (e.g. fourth generation Chinese telecommunications standard). If the latter is applicable, this changes the playing field, since patent owners must consider the "special position of the Chinese technology market". Foreign firms may be exposed to multiple enforcement actions of Chinese antitrust agencies and the importance of the standard will partly dictate the enforcement agenda of the Chinese agencies. Overall, foreign patent pools would be well advised to create an early warning system for any signs of re-emerging "Techno-nationalism". The inclusion of Chinese patents in the pool would seem to be an obvious choice, but the quality of Chinese patents must be carefully examined. If the Chinese (or foreign) patents are of minor quality, this could lead to the tying of essential and non-essential patents. Another risk factor is the possible extraterritorial application of the Chinese AML to foreign firms.

This study shows that the management of the patent pool requires a certain level of communication and coordination between the pool participants, who are often competitors in the same technology market. This horizontal coordination could affect downstream outputs and prices, lead to price-fixing or the exclusion of third parties from the technology market, justifying closer attention by competition agencies. Furthermore, internal governance rules, royalty distribution schemes and joint defence mechanisms have not been (carefully) addressed by antitrust enforcers in the US, EU or China.

The main conclusion is that patent pools are pro-competitive in the following ways: integration of complementary technologies, reduction of transactions costs and a clearing of blocking patents. These pools will reduce litigation and help the dissemination of technologies. 
Question 3: How do standardization policies differ in the various countries and what is the impact upon competition?

\section{Standardization in the US}

Standards have many advantages. They can draw on technical expertise of different industry perspectives and lead to fast consensus-based solutions. The competitive concerns in relation to standards are linked to concerted actions among possible competitors. This may take the form of a buyers' cartel or a group boycott. For the implementers, there is a risk that standards eliminate some of the alternative technical solutions that they use at this moment.

One of the problems of patent pools is the intense communication between possible competitors within the pool which might lead to the exchange of market-relevant information. The same applies to standard setting, since participants in the standardization process have a dialogue on the choice of the right technology in the precommercialization phase. This could already lead to the exclusion of rival technologies. Standard setting does provide room for strategic manipulation or the improper management of IPRs in the standard. During the standard-setting process, non-disclosure of patents, discriminatory licensing terms and the collection of royalties in a patent pool might infringe competition laws. Case law has shown that, in the pre-commercialization phase, firms could already decide to exclude other competitors from the standardsetting discussion. The leadership of an SSO to manage the standardization is often institutionalized in its IPR policy. A study of the IPR policies showed that they often contain ex ante disclosure rules and FRAND commitments. Participating companies are obliged to disclose the ownership of essential patents in order to prevent patent ambush or patent hold-up. Economists' research is inconclusive on the effectiveness of ex ante disclosure rules the prevention of patent hold-up and patent ambush. A consensus on the interpretation of FRAND terms is emerging as a result of action for injunctive relief.

The project shows the strategic importance of standardization for innovation and, thus, the competitiveness of the US, EU and China. Standards play a prominent role in the present negotiations on the Transatlantic trade and Investment Partnership (TTIP) between the EU and the US. This development has a direct impact on the application of $\mathrm{IP} /$ Competition laws in this field. As a result, it also heavily influences the competition policy in relation to patent pools.

Standardization in the US is regulated by the Standards Development Organization Act and the National Cooperative Research and Production Act. Both emphasize the voluntary character of the US standards system. This is a decentralized system, based on the principle that standards should evolve from market forces and not be dictated by the US government. The United States standardization bodies concentrate their attention at the moment on PAEs and NPEs. These are new business forms that share some 
similarities with patent pools. Their impact on innovation and standardization is insufficiently clear however, although the general opinion on PAEs and NPEs is negative. Given their possible similarities, they do influence the discussion on the innovation benefits of patent pools.

\section{Standardization in the EU}

The formal standardization process in the EU is concentrated with CEN, CENELEC and ETSI. ETSI has formulated a transparent IPR policy that regulates the strategic use of patents. It is important that ETSI does not determine FRAND rates but leaves this to the firms or the courts. Some academics see this as a missed opportunity and a definite task for SSOs. Open-source standards were developed as a reaction to the frustration of traditional licensing in the software sector. The EU Commission heavily supports open source standard setting and, as a result, new business models in software (e.g. FLOSS) have started to be successful. Another aim of the EU is to increase the volume of interoperability standards. Policy initiatives like the Digital Agenda stress the importance of innovation and thus standards for the European Union. Economic empirical research is divided on the actual effect of patent pools on innovation. The effect of patent pools on innovation can be seriously hampered by the number and timing of the patent declarations. An unnecessary increase in the number of patent declarations limits the original purpose of the pool (i.e. transactional efficiency and avoidance of patent thickets). Recent EU case law does not apply to de facto standards. The legal positioning of de facto standards is not clear in relation to concepts like FRAND commitments or the application of the essential facilities doctrine. Nevertheless, de facto standards play an important role in standardization and innovation.

\section{Standardization in China}

The Chinese standardization landscape is closely linked to national industrial development policies. China wants to become a standards developer and not a standards taker. This aim can be achieved in different ways:

1. Develop Chinese standards, outside the international standards community based on its industrial policy

2. Develop international standards with the participation of Chinese firms, in market-led processes.

The strategic importance (and thus the impact on competition policy) of standardization is demonstrated by the Chinese indigenous innovation policy. The conclusion, in relation to the Chinese indigenous innovation policy and its impact on foreign business practices, is that the interpretation remains relatively unclear. The various development stages of the concept of the indigenous innovation policy initially showed a very strict application of the concept, followed by a more liberal approach after consultation with exter- 
nal trade partners such as the US and the EU. The TTIP solidifies the need to comply with the main Western actors in the field of international standardization. The lack of common interests and the subsequent uncoordinated approach towards standard setting is a risk factor for foreign investors in China. From recent enforcement actions by Chinese regulators (for example, Qualcomm- fourth generation telecom), the conclusion can be drawn that political motives dictate their antitrust agenda. Recent cases again give evidence of industrial policy motives that are applied by Chinese courts to give national businesses an advantage in global trade. A possible extraterritorial application of the Chinese AML to foreign companies might aggravate the situation of foreign companies that affect Chinese economic interests.

The comparison of the case studies of the Chinese WAPI, the Korean WIPI and the Chinese TD-SCMDA standards shows the detrimental effect of the lack of confidence of Chinese consumers in their national standards. Chinese consumers could not create a critical mass of followers to achieve the necessary network effects to establish a successful Chinese telecommunications standard. As a result, the necessity to create more national Chinese standards remains and may influence court decisions involving patent pools.

Standardization in China should follow an open participation model in which foreign technology does have access to Chinese SDOs and Western and Chinese firms through joint cooperation. A choice to develop Chinese standards independently from global technological progress will have very negative effects from a long-term perspective. A closer alignment of Chinese and international standards would already be beneficial from a middle-term perspective.

Question 4: What are new IP business forms and how can they be distinguished from patent pools and how do they influence the standards and patents discussion?

\section{US perspective}

The interest in PAEs and NPEs from an antitrust perspective is mostly concentrated in the US. The literature is divided on the impact that these new business forms have on standardization and innovation. For the discussion here, the main interesting elements are that PAEs share some similarities with patent pools but, more importantly, PAEs may engage in patent hold-up, which is an important element of the PAE business strategy. This strategy is centred on litigation. PAEs often target small and medium-sized businesses, with the accusation that they infringe their patent rights. The possible remedies focus on this strategy. US agencies propose a change to a loser-pays system in a possible case of patent infringement and a better understanding of the actual ownership of patents. For patent pools, it is complicated that PAEs lead to reactions such as defensive patent aggregation in which an independent party buys and consequently 
defends patents against patent trolls. At the same time, some companies such as Nokia pursue the business strategy of privateering, the selling of patents to a third party (Mosaid) for exploitation. In practice there is just a very thin line between patent trolls, PAEs, certain types of patent pools and defensive patent pools and, last but not least, privateering efforts. In reality, operating companies are shareholders or sometimes owners of PAEs. Most of the litigation is still done by practising entities. In the US, there is a movement that abuse of litigation practices should lead to a shifting of costs. Based on equitable grounds, US courts do have the discretionary power to shift costs of the proceedings in exceptional cases.

Competition agencies should not focus on the business form but rather on the market behaviour and the effects thereof in evaluating the legality of the business form. The BRL on the IXPI already showed that the FTC is very hesitant in approving the new revolutionary business forms in technology markets.

\section{EU perspective}

The EU addresses the possible impact of PAEs in the new TTBER, but the lack of PAE litigation does not directly lead to more attention. Commentators link the lack of PAE cases to the loser-pays rule in the EU and the multi-jurisdictional legal environment which limits the possibilities for a patent hold-up. Another important element is the better quality of patents in the EU, compared to the US. A lack of empirical evidence on PAEs in general in the European context frustrates the discussion of the impact of PAEs on business practices in the EU. The EU did consider privateering concerns in the acquisition of part of Nokia's patent portfolio by Microsoft but did not see any anticompetitive effects.

In relation to new innovative approaches, such as defensive patent pooling and tacit patent pooling, the conclusion is that the IP landscaping is changing rapidly and that antitrust law is lagging behind in its development.

\section{Chinese perspective}

The SAIC draft rules on the prohibition of abuse of intellectual property rights for the purposes of eliminating or restricting competition state: Undertakings with dominant market positions shall not, upon the expiration or invalidation of their intellectual property rights or in the circumstance that sufficient evidence has been provided by other party to prove relevant act does not constitute infringement of intellectual property rights, excessively issue infringement warning letters to eliminate or restrict competition. This text has unclear wording and can be given a broad interpretation. China has paid little attention to PAEs, but the risk of the misinterpretation of US enforcement actions against PAEs may have a negative impact on patent pools operating in China. 
Question 5: What are the different attitudes towards FRAND rate setting, SEPS and injunctions in the three jurisdictions?

\section{US perspective}

In the US, courts see the FRAND promise as a contractual obligation, which gives all parties involved the obligation to negotiate in "good faith". Implementers are seen as third-party beneficiaries. The reasonableness of the royalty rates are to be evaluated by using the following factors: the economic value of the patent, the importance of the patent for the standard, the value of the standard in relation to the product and the value of comparable patents. Courts should also consider the possibility of a royalty stack while determining the royalty fee.

Injunctions related to SEPS with FRAND commitments should be granted on a very limited basis. Although a general consensus seemed to be emerging (eBay v. MerCExchange $L L C$ ) concerning injunctions, US courts later rejected the consensus and now use equity principles to decide comparable cases. The eBay case gave the following elements for the analysis: irreparable injury and inadequacy of monetary relief. The balance of hardships mentions a reasonable royalty fee for the SEP owner but also the risk that an injunction excludes an implementer form market access. The problem is that the eBay test is not available to ITC proceedings. The International Trade Commission also does not award damages. The ITC does apply in its analysis for injunctions "public interest factors", such as the effects that the injunction has on "the competitive conditions within the US economy" and on "the United States consumers". The definition of a willing licensee or the legality of tying essential and non-essential patents remain unsolved and therefore should be carefully monitored by patent pools.

The Google Consent Order dealt with the complaint that Google had violated Section 5 of the FTC Act by seeking an injunction against a willing licensee for FRANDencumbered SEPs. The Consent Order declared that Google should have made a written licence offer and had the obligation to negotiate or establish FRAND terms either by arbitration of judicial review.

Recent case law has distinguished various methods of calculating and determining FRAND rates: the application of the Georgia-Pacific rules to FRAND and the proportionality method of Judge Robart (Microsoft v. Motorola) and, in an amended version, by Judge Holderman (Innovatio). Interestingly, the method of Judge Robart uses comparable licences and took a patent pool as its main basis. This leads to an awkward situation, since patent pools are a possible solution for the royalty stacking and patent hold-up problem, but only if the patent pools use FRAND royalty terms. Globally, courts find it difficult to establish the basis for the calculation of FRAND terms, but referring back to the patent pool is a rather strange solution. 


\section{EU perspective}

In the Motorola memorandum, the EU Commission clearly stated that they do not see any role for themselves in determining what reasonable royalty rates are. This function should be undertaken by national courts or by arbitrators. The example of Samsung showed that firms may take a proactive stance to limit the use of injunctions against infringements of SEPs. Recent case law in the EU suggests that the EU Commission favours that standard implementers refer the determination of FRAND rates to a neutral third party, but this should not limit the freedom of licensees to challenge the validity, essentiality or infringement of patents. In the EU system, the Commission does not see a role for antitrust agencies in determining the correct level of FRAND rates.

The Opinion of Advocate-General Wathelet in the Huawei preliminary ruling did not provide the necessary guidance and transparency. The Opinion did give a nuanced reaction to the Orange Book standard and it can be concluded that Wathelet defined more obligations for the infringer to show that he is objectively ready to conclude a contract. The Orange Book might strike an improper balance, since the potential licensee must meet the demands of the patentee. In general, litigation must be equally unattractive for the licensee and patentee. Nevertheless, many uncertainties remained after reading the Opinion of Wathelet. It leaves the general question open whether there is a shift from FRAND-determined royalties to court determined FRAND damages. From a business perspective, FRAND is a peace treaty mutually determined by firms to avoid litigation. The judgment of the Court of Justice underlined the principle that patent holders should not be able to use an injunction as leverage against a willing licensee. The Court recognized the permanent character of a FRAND commitment, which is one of the reasons that the Court is willing to limit the right to injunctions. The ECJ tries to balance the different interests of licensor and licensee. The judgment does not provide clarity regarding the royalty rate setting or the basis thereof.

Some differences remain relatively unclear between the EU and the US. The EU framework only applies to patents granted in the European Union and injunctions inside the EU. The US system applies to patents granted on a global basis. If this is the case, it would have a significant impact on forum shopping and the registration of SEPs. Inside the EU, arbitration must be agreed upon by both parties, whereas in the US it suffices if the licensee wants to refer the case to arbitration. Although these seem to be only small procedural details, they could have important consequences for litigation. In the EU, patent pools must be aware that seeking and enforcing an injunction on the basis of FRAND commitments for SEPs may be qualified as the abuse of a dominant position. The requirement that a firm stops validity or infringement proceedings as a result of an injunction will also be seen as illegal. 


\section{Chinese perspective}

The two court cases Huawei/InterDigital concentrated on SEPs in the Chinese setting. In the first case, four types of behaviour were classified as illegal: the charging of excessive high royalty fees, the tying of essential and non-essential patents, the fact that InterDigital requiring grant-backs from Huawei, and the fact that InterDigital started an action with the ITC, while the negotiations with Huawei were ongoing. The outcome of the second case was that InterDigital had the obligation to offer its SEPs in China on a FRAND basis, although no earlier FRAND commitment was made by InterDigital. The Interim Regulation of the SAC and SIPO stipulates that SEPs must be disclosed and offered on FRAND terms. If companies fail to do this, governmental agencies will start a negotiating process to determine the royalty terms.

The SAIC draft rules on the abuse of intellectual property rights in relation to the restriction of competition of July, 2014 provide interesting elements. The suggested provision on SEPS states that SEP owners have a disclosure obligation even when they are not part of a standard-setting organization. This would have far-reaching consequences, since SEP owners would have to license their SEPS on FRAND terms even when they would decide not to participate in an SSO. Moreover, even in the case where the SEP owner actively participated in the formulation of the standard in the SSO, and the SSO does not require a FRAND commitment, it still would become a mandatory requirement under Chinese law. Ultimately, this leads to a situation in which a refusal to license SEPS, on which no official prior FRAND commitment was made, violates the Chinese AML. At least it should be a requirement that the SEP owner voluntarily made the FRAND commitment. The US ABA even holds the opinion that a mandatory FRAND commitment can violate Chinese patent law. ${ }^{664}$ In practical terms, this mandatory provision opens the door for possible the abuse of foreign SEPs by Chinese SSOs.

The draft MIIT Template of November 2014 uses the smallest component as the basis for the FRAND rate. As was to be expected, this was heavily criticised by both Western but also Chinese companies. Some elements of the draft template would discourage cross-licensing between Western and Chinese companies. Also, the exact legal positioning of standards in the template symbolizes the challenges that the Chinese regulators face in this discussion.

The recent developments in the application of Chinese antitrust laws regarding SEPs have resulted in a greater willingness of Chinese courts to prosecute foreign firms and to apply heavier fines for infringements. The recommendation for foreign firms in China would be to carefully evaluate whether it is advisable to use certain SEPs for the Chinese market. There is already major inconsistency of the treatment of SEPs in China compared to the US and the EU. The doctrine of essential facilities is a clear example of a concept that is explained in different ways in the US, China and the EU, leading to important practical repercussions.

${ }^{664}$ ABA Comments 9 July 2014, page 9. 
The latest decision in the field of standards and patents in China was the NDRC/Qualcomm case. This case can be used to investigate the convergence between the European, US and Chinese views on the discussion.

NDRC imposed a fine of $\$ 975$ million on Qualcomm. The fine is comparable to some of the decisions in the European Union and the United States. The judgment was a very quick and short decision (just as was the case in the EU ten years ago). The Chinese authorities decided a complicated case in a very quick way. Comparing the Chinese and European approach, it can be concluded that they are both quite similar. The NDRC/Qualcomm decision did not address the definition of FRAND. The NDRC did not give specific guidance in the judgement and did not adopt the (US) smallest part component test. Interestingly, the NDRC stated that Qualcomm should not use the royalty base of the wholesale net selling price.

Recently both the NDRC and the European Commission both were reluctant to define FRAND. Obviously, the NDRC decision is geographically limited to China. However, competition agencies in the three jurisdictions are facing similar dilemmas. How far should the control of antitrust agencies go? Should they regulate technology markets or should there be self-regulation by SSOs (supervised by competition agencies)?

The NDRC looked at an "exploitative case" and in Samsung/Motorola the EU Commission discussed an "exclusionary case".

The new $5 \mathrm{G}$ telecommunications standard needs investments for the R\&D activities. World-wide, investors might be threatened by the possible application of the "smallest component" royalty base. This US instrument originates in US patent damages cases but was initially not designed for licensing. Both the European and Chinese agencies seem to understand that patent law is suited to control technology markets. This might even go against the original purpose of patents.

Finally, there might be an emerging consensus that competition agencies should not determine FRAND rates. To complicate the discussion even more, patent courts are better suited to this purpose, since they are closer to technology markets.

\section{FINAL THOUGHTS:}

The United States concentrates its attention on PAEs and NPEs at the moment. These are new business forms that share some similarities with patent pools. For the US evaluation of patent pools, the following critical elements can be mentioned: the character of the patents in the pool, the possibility of individual licensing of the pooled patents, non-exclusive grant-back provisions, and no exchange of sensitive information on downstream markets. Other elements include FRAND terms, independent pool administration, an independent patent evaluator, the freedom of licensees to develop alternative technologies, and disclosure of patents included in the patent pool. The main conclusion is that patent pools are pro-competitive in the following ways: integration of 
complementary technologies, reduction of transactions costs and a clearing of blocking patents. These pools will reduce litigation and help the dissemination of technologies.

In the European Union, a critical point is the moment when a patent pool attains a dominant position. Especially in technology markets, it is extremely difficult to distinguish and separate technology and product markets, making it more challenging to identify abusive behaviour, such as pricing strategies, refusal to license or unreasonable licensing terms. The Orange Book case leads to the conclusion that competition agencies are struggling to give clear guidance in the field of the FRAND commitments. Recent EU cases involving Samsung and Motorola clearly indicate that SEP owners may not seek injunctions against willing licensees. The threat of injunctions can negatively influence licence negotiations, leading to unfair licensing terms which distort competition. The very recent Opinion of Advocate-General Wathelet does not provide clear guidance but seems to steer away from the Orange Book decision. The main new elements are that the patent holder must alert the infringer and explain his reasoning on the SEPs. Consequently, the patent holder must make a written offer on FRAND terms and the precise amount of the royalty. The infringer must react in a diligent and serious manner and present a reasonable counter-offer. It seems that, if the infringer's conduct is purely tactical, there is no abuse of a dominant position by the patent holder. Wathelet still leaves it to the national court to decide what is proportionate and reasonable.

In relation to the FRAND discussion, one option could be the development of an industry-based solution. If the major tech companies agree on a common understanding regarding FRAND and injunctions, regulators would likely follow. In the absence of an industry-based solution, it will be left to courts and arbitrators to apply and interpret the existing framework of rules.

The importance of a better understanding of applied economic analysis within the context of patent pool related cases necessitates a deeper understanding of this field, by both regulators and practitioners.

The research project comes to the conclusion that, in the EU and in the US, antitrust agencies are struggling to find a proper foundation for and, consequently, a proper assessment of the necessary regulatory framework for patent pools. Economic research is divided in its evaluation of patent pools and, sometimes, is sponsored by major commercial stakeholders. The Chinese agencies find it even more difficult to come to a common enforcement policy because of their different, often political, interests. The AML and the IP Guidelines, as well as the standardization strategies in China, are still under development and are constantly changing. Direct comparisons to the US and EU regulatory environment are difficult, as, currently, China is still struggling to create a proper IP and competition law culture. The balancing of the public good versus private commercial interests is challenging. In the Chinese IP landscape, technology transfer and indigenous innovation are determining influences. In the socialist market economy, commercial activities of state-owned enterprises are not driven by market efficiency but dictated by government requirements. Chinese courts and IP law enforcement agencies 
have mixed agendas, in which the protection of foreign IP rights sometimes clashes with the desire to promote the continuous economic growth of the domestic industries. The decision in the InterDigital/Huawei case involved non-economic factors such as industrial policy and standardization concerns. The political agenda of an increase in Chinese standards seems to influence the decision of Chinese courts. Recently, Chinese courts have shown courage by defining FRAND royalty rates, although the basis of the decision has not been published. The feedback of stakeholders in relation to the revision of the European TTBER and the current investigations by the FTC and ITC can help the PRC with the formulation of their own competition policy in relation to standard essential patents. A patent pool can facilitate a smoother and more efficient technology transfer for foreign companies in China, which would benefit all the relevant stakeholders, including the Chinese government. The inclusion of Chinese patents in an international patent pool, in particular, would provide both a stimulus and a learning curve for Chinese companies.

Patent pools could be an interesting alternative to the traditional IP protection of foreign technology in emerging markets. Chinese firms may benefit from Western technology in standards that are cooperatively developed. Fragmentation of the IPR ownership favours patent pools over cross-licensing, which involves increased transaction costs. Western companies would appreciate the increased legal certainty and the possibility of outsourcing more sophisticated forms of manufacturing to Chinese firms. The significant rise in Chinese patent registrations makes the examination of the validity and essentiality of the patents in the pool crucial. If a high number of patents are included in the patent pool, this may result in a patent thicket. Patent pools are a good alternative for the Chinese government and businesses to participate more in standards. In order to promote this notion, it would be advisable that more information be made available about the costs and benefits of patent pools. International but more importantly Chinese standardization organizations must become conscious of the instrument of a patent pool. Incentives could encourage companies to join patent pools. Especially for "weaker parties", such as universities or SMEs, patent pools have benefits, e.g. the joint defence systems. The instrument of patent pools could, as a "preferred licensing tool in standardisation" in China, provide more certainty to foreign companies that are operating in China.

The conclusion for foreign investors in China is to acknowledge the positive development of IPRs in China and to start a dialogue with the Chinese government, competition law authorities, standardization organizations, and Chinese businesses. Best practices and the inclusion of Chinese firms in the international standards environment could be the main instruments to facilitate an improved framework for the use of patents in standards by both Chinese and international firms. 


\section{WHAT DOES THE FUTURE BRING?}

The current enforcement policies of the competition agencies mainly focus on the establishment of patent pools. Management decisions by the patent pool regarding the rate setting and expired patents have not been evaluated, under the assumption that patent pools are pro-competitive. The emergence of "Pool of pools" raises questions about the legality of the patents but also on the foreclosure of downstream markets through the convergence of the functionalities of the standard.

The effect of patent pools on competition through open source developments has not yet attracted the full attention of the regulatory authorities. Open source innovators cannot use strong defensive patent portfolios but they can use patent pools as leverage against the "weapons of mass destruction".

One of the main conclusions is that the inclusion of non-essential patents can have both competitive and non-competitive effects. Economic research has not come up with a definite answer and the changing character of technology markets and the monetization forms of IP necessitate stronger empirical economic research to support competition policy decisions.

Economic literature is decisive on the positive impact of standards and SSOs on innovation. The limitations on the possibilities of injunctive relief can have an impact on SSOs. Technology firms may decide to reduce their participation in an SSO and their standard-setting activities. It would be interesting to research the difference in legal treatment between FRAND commitments that are made within the context of an SSO and those commitments outside the SSO framework. If the latter commitments give firms an advantage, this will encourage the development of de facto standards. Experts hold the opinion that de facto standards are very important for both innovation and competition. For a better understanding of the strategic use of patents, it would be necessary to have access to more economic and econometric research results. It is often assumed that royalty stacking has a negative effect in the value chain and that the royalty costs will be passed on from suppliers to manufacturers and ultimately the consumers.

In the future, there will be a stronger cooperation between the Open Source developers and standardization bodies. Open standards is a phenomenon that is here to stay. Open standards are faster and more transparent. At the same time, this inevitable development also raises more questions. Two main issues need to be clarified: the adoption of open source software in the elaboration of the standard and conversely, the adoption of standards in the open source software community. Cloud computing is often developed with open source software. The $5 \mathrm{G}$ standard incorporates cloud computing in developing the new architecture of the core telecommunications network. What will be the impact of open source software licences and the compatibility of FRAND be? One of the main challenges could be to ensure that the open source software licence does not prevent the licensing of SEPs on FRAND terms or violates the IPR- 
policy of SSOs. ETSI is starting a dialogue with the open source community to address these questions.

From a technical perspective, challenges can be found in the development of the Internet of Things (IoT). In the IoT, a lot of discussion is centred on Big Data. The IoT consists of a range of new technologies that play together. Data moves around without human intervention. Elements like cloud computing, software defined networks (SDN) and networks function virtualization (NFV) all interrelate with each other. The standardization community is still developing new standards in traditional fields. ETSI is involved in NFV standardization, but most other parts are developed by the open source community (with the ability to look at the source code). Although the open development companies sound very idealistic, $80 \%$ of the community is paid by major companies, who consequently decide whether to commercialize the open source technology or not.

Telecommunications standards will be applied in a much wider context in the future, as enabling technologies. This will provide a wider base for the establishment of patent pools.

Another major influence will be the determination of the EU to stop the dominance of US tech giants. Recently, the EU Commission launched a new enforcement agenda against US tech giants. The enforcement agenda has a wide-spread coverage, from the protection of the privacy of EU citizens, to the overall control of the internet. The EU and the US understand that their future competitiveness greatly depends on homegrown high technology. Within this field, standards play a major role and, despite the efforts of the transatlantic dialogue, this might lead to more tensions in the development and management of standards.

The Chinese standard-setting community is more likely to follow a more EU-based approach than the market-led US system. The TTIP agreement is likely to harmonize standard-setting in the EU, US and other parts of the world. China has to give a strategic reaction to these developments, which will directly affect the patents and standardization discussion. For an improvement of the Chinese position in global standardization, it is necessary that the Chinese government provides more transparency regarding the legal setting. The United States and, more importantly, the European Union have a system in which the treatment of IP in standards is communicated. Instruments like BRLs, TTBER Guidelines and well-motivated court decisions help firms to understand the legal environment. A better understanding of the Chinese legal environment might spark a stronger interest of foreign firms in cooperating in standard-setting projects in China. 


\subsection{NEDERLANDSTALIGE SAMENVATTING: STANDAARDEN, PATENTEN EN CONCURRENTIEREGELS, DE BIJZONDERE POSITIE VAN PATENT POOLS.}

Het doel van dit onderzoek is om een beter inzicht te verschaffen in de positie van het concept van een patent pool binnen de discussie omtrent het strategisch gebruik van patenten in standaardiseringsprocessen vanuit het perspectief van het Amerikaanse, Europese en Chinese mededingingsbeleid. De technologie welke deel uit maakt van internationale standaarden is vaak beschermd middels het octrooirecht. Het mededingingsrecht heeft belangstelling voor standaardisering zodra deze negatief worden beïnvloed door octrooi-eigenaren om een oneerlijk concurrentievoordeel te kunnen verkrijgen. Dit oneerlijke concurrentievoordeel bestaat uit het vragen van zeer hoge licentievergoedingen en/of het toepassen van onredelijke licentievoorwaarden, nadat de standaard is vastgesteld. Het strategisch gebruik van octrooien is gemeengoed geworden binnen de telecommunicatie-industrie. Omvangrijke octrooiportefeuilles worden als wapens ingezet om rechtszaken met concurrentie te vermijden. Het strategisch gebruik van octrooien binnen de standaarden kan de volgende vormen aannemen: patent ambush, patent hold-up en royalty-stacking. Dit onderzoek toont aan dat een patent pool een mogelijke oplossing kan bieden voor de bovengeschetste problemen binnen de Verenigde Staten, de Europese Unie en China.

De inleiding schetste verschillende kernvragen omtrent de hoofdonderzoeksvraag: Wat is de positie van het concept van een patent pool binnen de discussie omtrent het strategisch gebruik van octrooien en het mededingingsrecht van de Verenigde Staten, de Europese Unie en China?

De kernvragen zijn de volgende:

1. Welke positie neemt het concept van een patent pool in binnen het mededingingsrecht van de Verenigde Staten, de Europese Unie en China?

2. Wat is de invloed van de managementregels van een patent pool op de beoordeling van de legaliteit van de patent pool?

3. Op welke wijze verschilt het standaardiseringsbeleid in de drie landen en welke invloed heeft dit op de mededinging?

4. Welke nieuwe ondernemingsvormen ten aanzien van intellectueel eigendom kunnen er worden onderscheiden en welke invloed oefenen deze uit op de discussie omtrent standaarden en octrooien?

5. Wat zijn de belangrijkste ontwikkelingen binnen de drie landen omtrent de begrippen FRAND-voorwaarden, standaard-essentiele octrooien en het gebruik van dwangbevelen? 
Betreffende vraag een: Welke positie neemt het concept van een patent pool in binnen het mededingingsrecht van de Verenigde Staten, de Europese Unie en China, kan het volgende worden gezegd. Het concept van een patent pool neemt een special positie in, omdat concurrenten binnen een gespecialiseerd deel van een technologiemarkt hun krachten bundelen en samenwerken met als belangrijkste doel om gezamenlijk licentievergoedingen te verzamelen. Patent pools kunnen een oplossing vormen voor de problemen van royalty stacking en patent thickets. Afhankelijk van de regels omtrent bekendmaking van standaard-essentiele octrooien kunnen patent pools ook patent ambush verhinderen.

\section{De positie van patent pools in de Verenigde Staten}

Van oudsher tonen standaardiseringsorganisaties enige huivering omtrent gezamenlijke discussie betreffende de licentievergoedingen. Recent economisch onderzoek toont echter aan dat gezamenlijke ex ante discussies omtrent licentievergoedingen een positieve invloed kunnen hebben op innovatie. De Amerikaanse autoriteiten: de Federal Trade Commission (FTC) en het Department of Justice (DoJ) nemen een redelijk liberale positie in ten aan zien van deze gezamenlijke discussies en hanteren dientengevolge een "rule of reason" beleid om de oprichting en het dagelijks management van een patent pool te beoordelen.

De FTC en DoJ hebben via het instrumentarium van de "IP Guidelines" en de "Business Review Letters" een systeem ontwikkeld dat leidt tot transparantie en helderheid. Dit systeem onderschrijft duidelijk de concurrentievoordelen van patent pools binnen standaardiseringsprocessen. De Amerikaanse autoriteiten hanteren bij de juridische (mededingingsrechtelijke) analyse van de toelaatbaarheid van patent pools de zogenaamde rule of reason methodiek. Dit betekent dat patent pools niet automatisch in strijd zijn met het Amerikaanse concurrentierecht maar dat per individueel geval de legaliteit wordt onderzocht aan de hand van het effect dat de patent pool heeft op de specifieke technologiemarkt. Belangrijke elementen binnen deze analyse zijn de kwalificaties van het type octrooien, in de vorm van essentiele, complementaire of substitueerbare octrooien. De beoordeling van het type octrooi wordt verricht door een onafhankelijke deskundige (wiens onafhankelijkheid niet altijd duidelijk is). Het management en het beheer van de patent pool kan de verantwoordelijkheid zijn van een onafhankelijke derde partij of een licentiegever welke is benoemd door de andere ondernemingen binnen de patent pool. Substitueerbare octrooien kunnen de legaliteit van de patent pool negatief beïnvloeden. De invloed van de Amerikaanse Chicago School binnen het mededingingsrecht wordt evident in de discussie omtrent de toelaatbare hoogte van licentievergoedingen waarbij de Amerikaanse autoriteiten een meer liberale houding innemen op grond van hun analyse op basis van de economische effecten en de invloed op de marktwerking van de vermeende overtreding. 


\section{Patent pools in de Europese Unie}

De Europese Unie volgt het voorbeeld van de Amerikaanse FTC en DoJ en beoordeelt de legaliteit van patent pools volgens de rule of reason methode. Dit betekent dat een patent pool niet per se strijdig is met het Europese mededingingsrecht, maar dat per individueel geval de invloed van de patent pool op de mededinging op de relevante markt dient te worden onderzocht. Patent pools worden niet heel gedetailleerd besproken binnen de nieuwe Technologie Transfer Groepsvrijstelling (TTBER) omdat het een overeenkomst betreft tussen meerdere partijen. De Richtlijnen inzake Technologie Transfer van de Europese Commissie vermelden een aantal hardcore beperkingen welk in ieder geval tot strijdigheid met de EU concurrentieregels zullen leiden. Binnen de richtlijnen omtrent de Technologie Transfer Groepsvrijstelling, verschaft de Europese Commissie enige duidelijkheid omtrent het zogenaamde "safe harbour" systeem.

Patent pools bevinden zich in een safe harbour indien zij de volgende kenmerken hebben:

- Lidmaatschap is open voor iedere onderneming

- Deelnemende partijen aan de patent pool delen alleen informatie met elkaar welke relevant is voor het goed functioneren van de patent pool

- De patent pool bestaat alleen uit essentiele octrooien

- Licentienemers worden niet beperkt in het aanvechten van de geldigheid of kwalificatie van de octrooien

- Licentienemers behouden het recht om concurrerende technologie of standaarden te ontwikkelen

- Octrooien worden verstrekt op FRAND-licentievoorwaarden.

De safe harbour kan op verschillende manieren worden uitgelegd en de mogelijke verschillende interpretaties ondermijnen de effectiviteit van het Europese mededingingsrecht. Deze mogelijke onduidelijkheid strekt zich ook uit met betrekking tot de regelgeving omtrent patent pools. .

De richtlijnen omtrent Technologie Transfer geven duidelijker aan welke elementen leiden tot de illegaliteit van een patent pool. De oude Technologie Transfer Groepsvrijstelling is nooit toegepast op klassieke vormen van patent pools, waardoor de Europese Unie niet heeft geanticipeerd op de ontwikkeling van nieuwe ondernemingsvormen en strategieën welke sterke gelijkenis hebben met patent pools.

In tegenstelling tot de Amerikaanse mededingingsautoriteiten is de Commissie relatief streng in haar oordeel omtrent de legaliteit van het bundelen van niet-essentiele en complementaire octrooien in de patent pool. Een van de belangrijkste problemen blijft het beoordelen van de machtspositie welke door middel van een patent pool wordt ingenomen. Binnen technologiemarkten is het zeer moeilijk om een onderscheid te 
kunnen maken tussen technologische en productmarkten. Dientengevolge blijft het de vraag of de machtspositie is verkregen door middel van superieure technologie of door middel van een ondernemingstrategie welke bewust de Europese mededingingsregels doet overschrijden.

Een volledige "full-effects" benadering van patent pools zou tot een betere analyse leiden van het effect welk patent pools hebben op mededinging. De huidige trend van de grote toename van het aantal octrooien in een patent pool, kan ook leiden tot meer mogelijkheden van misbruik. Ook binnen de EU context doemt de vraag op of patent pools dienen te worden gereguleerd door het intellectuele eigendomsrecht of door het mededingingsrecht? De verschillende benaderingen in de Nederlandse rechtspraak ( waar het intellectueel eigendomsrecht prevaleert) en de Duitse jurisprudentie (meer aandacht voor mededingingsrecht) illustreren de discussies tussen de Lidstaten van de Europese Unie. Onduidelijkheden en verschillende de nationale rechtssystemen kunnen forum-shopping tot gevolg hebben. De bevoegdheidsverdeling op dit terrein, tussen het Hof van Justitie en de Europese Commissie is nog onvoldoende duidelijk op dit moment. Ondanks de "Orange Book" jurisprudentie is het nog steeds mogelijk dat "formally willing licensees" strategisch gedrag vertonen binnen standaardiseringsprocessen. Zoals reeds eerder vermeld verklaart de Europese Commissie het juridische speelveld inzake patent pools in de Technologie Transfer richtlijnen. Deze hebben voornamelijk betrekking op de oprichting en het management van patent pools. De Europese Commissie laat zich hoofdzakelijk door mededingingsoverwegingen leiden bij de analyse van patent pools. Dit heeft tot gevolg dat de oorzaken van sommige problemen ( de kwaliteit van octrooien, ongeldigheid en de toename van het grote aantal standaardessentiele octrooien) welke gerelateerd zijn aan het intellectueel eigendomsrecht onderbelicht blijven. Licentienemers verkeren op dit moment binnen de Europese Unie in een uitstekende positie om de geldigheid van octrooien binnen een patent pool aan te vechten. Het is te vroeg om een oordeel te vellen maar wellicht dat de Technologie Transfer Groepsvrijstelling de balans in het voordeel van de licentienemers laat overslaan hetgeen een negatieve invloed kan hebben op standaardisering en de bereidheid om deel te nemen aan patent pools. De eigenaren van essentiele patenten dienen in de toekomst de keuze tussen kruislicentiering en patent pools zorgvuldig af te wegen.

\section{De positie van patent pools in China}

Patent pools kunnen een belangrijke rol spelen bij het huidige transitieproces inzake intellectueel eigendom in China. Chinese ondernemingen welke zich richten op exportactiviteiten zouden kunnen profiteren van het gebruik van Westerse patent pools. Het voornaamste voordeel bestaat uit het feit dat patent pools de hoogte van de licentievergoedingen verlagen, hetgeen kan resulteren in meer productie in China. Een goed functionerende patent pool kan het begrip en respect voor intellectueel eigendom binnen het Chinese bedrijfsleven verbeteren. 
Het huidige concept van de Chinese wetgeving betreffende het misbruik van intellectueel eigendomsrecht binnen het mededingingsrecht, suggereert dat in sommige gevallen patent pools dienen te worden geanalyseerd met een per se benadering. De toepassing van het concept van " essential facilities" met betrekking tot essentiele standaardoctrooien en de Chinese houding ten aanzien van het implementeren van essentiele en niet-essentiele octrooien dienen beiden goed te worden gevolgd door Westerse patent pools.

De conceptversie van de mededingingsregels $(A M L)$ betreffende patent pools noemt de volgende overwegingen:

- De deelname aan de patent pool moet open en niet-discriminerend zijn

- Bezitten ondernemingen binnen de patent pool een machtspositie?

- Blokkeren de ondernemingen binnen de patent pool de ontwikkeling van technologie door derde partijen?

- Is de patent pool in staat om de ontwikkeling van concurrerende patent pools te verhinderen?

In tegenstelling tot de Verenigde Staten en de Europese Unie geeft China nauwelijks een leidraad of uitleg van de conceptversies van de nationale wetgeving inzake patent pools. Deskundigen hebben soms het vermoeden dat het gebrek aan transparantie en uitleg, een bewuste strategische zet is van de Chinese autoriteiten. Het belangrijkste motief hiervoor zou zijn dat op deze manier een maximale flexibiliteit kan worden bereikt in de toepassing van Chinese rechtsregels in relatie tot buitenlandse bedrijven welke werkzaam zijn in China. Binnen de Westerse wereld wordt dit vaak als een terugkeer van Chinees "techno-nationalisme" uitgelegd. In alle redelijkheid kan worden gesteld dat ook Chinese ondernemingen worden vervolgd maar overwegingen van Chinees industriebeleid blijven een belangrijke rol spelen bij de evaluatie van buitenlandse bedrijven in China en met name bij de toepassing van het mededingingsrecht. Patent pools kunnen op uitstekende wijze de samenwerking tussen Chinese en Westerse bedrijven op het gebied van internationale standaarden ondersteunen. Op dit moment worden patent pools in China echter gereguleerd door een grote hoeveelheid van nationale voorschriften, interim wetten en voorlopige concepten, welke zich in diverse stadia van ontwikkeling bevinden.

De meest recente ontwikkeling met betrekking tot patent pools in China, wijst op een terugkeer naar een meer conservatieve houding ten aanzien van technologietransfer in zijn algemeenheid en patent pools in het bijzonder. De toepassing van de Chinese mededingingswetgeving wordt ook medebepaald door overwegingen van nationaal industriebeleid. 
Vraag 2: Wat is de invloed van de managementregels van een patent pool op de beoordeling van de legaliteit van de patent pool?

\section{Verenigde Staten}

Economisch onderzoek kan nog geen uitsluitsel geven over de effectiviteit van ex ante bekendmakingsregels versus ex post toezicht door mededingingsautoriteiten. De meeste standaardiseringsorganisaties hebben specifieke regels opgesteld ten aanzien van de bekendmakingseisen binnen hun IE-beleid. Recente jurisprudentie in de Verenigde Staten (Princo) lijkt de legaliteit van patent pools te versterken middels de toepassing van de doctrine van "patent misuse". De toepassing van deze doctrine binnen het spanningsveld tussen standaarden, octrooien en mededingingsrecht leidt tot een breder perspectief en beperkt de oplossingen niet alleen tot de toepassing van de antitrust-wetgeving. Alhoewel de juist interpretatie en draagwijdte van de Princo-uitspraak nog niet helder is, lijkt er binnen de VS meer ruimte te ontstaan voor het opnemen van zowel essentiele alsook niet-essentiele octrooien binnen een patent pool. Indien de implementatie van niet-essentiele octrooien niet tot hogere licentievergoedingen leidt, kunnen deze als legaal worden beschouwd. Een van de praktische gevolgen van deze conclusie zou zijn dat patent pools de kwalificatie van hun octrooien wederom controleren en eventuele hun strategie met betrekking tot de licentievergoedingen dientengevolge aanpassen. De evaluatie van de status van het octrooi binnen de patent pool zou weer meer invloed en expertise van octrooirecht rechtvaardigen. De discussie omtrent de evaluatie van het type octrooi binnen de patent pool laat enige verschillen in de Amerikaanse en Europese benadering zien, welke interessant kunnen zijn voor de Chinese regelgevers.

Met betrekking tot de gezamenlijke ex ante royalty besprekingen, kan worden gesteld dat de FTC tegenwoordig neigt naar een toepassing van de rule of reason benadering en de per se analyse niet langer automatisch zal toepassen. Deze verandering in haar beleid wordt ondersteund door recent economisch onderzoek. In de Verenigde Staten tonen de mededingingsautoriteiten geen voorkeur met betrekking tot de partij welke het management en beheer van de patent pool voor haar rekening neemt. Vreemd genoeg kennen sommige bedrijven welke in een patent pool deelnemen, een sterke verticaal geïntegreerde structuur waardoor er ook mogelijke effecten op consumentenmarkten kunnen optreden. De mededingingsautoriteiten lijken geen belangstelling te tonen voor deze effecten op de consumentenmarkten. Het Amerikaans beleid toont aan dat sommige patent pools geen structurele keuze maken voor het inzetten van onafhankelijke deskundigen en dat de autoriteiten hun aandacht voornamelijk vestigen op de start en de oprichting van de patent pool. De mogelijke negatieve gevolgen van het management van een patent pool krijgen niet altijd de aandacht van de mededingingsautoriteiten. De sterke toename van het aantal octrooien in patent pool, maken het bijna onmogelijk om de geldigheid en essentie van octrooien te onder- 
zoeken. Bij de beoordeling van de positieve invloed op de mededinging door patent pools, zijn de groeiende complexiteit en de toename in de omvang beperkende factoren. Omvangrijke patent pools hebben het vermogen om de concurrentie te onderdrukken en de kosten van de concurrentie te verhogen. Nadat de patent pool de toestemming heeft verkregen van de Amerikaanse mededingingsautoriteiten, contoleren laatstgenoemde niet meer de hoogte van de licentievergoedingen of de geldigheid van de octrooien. In zijn algemeenheid toont de Verenigde Staten, in vergelijking met de EU een soepelere houding ten aanzien van de hoogte van licentievergoedingen en beoordeelt dezen via een economics-based toezicht welke ook sterk rekening houdt met mogelijke effecten op de technologiemarkt.

\section{De Europese Unie}

Monopolistische gedragingen van een patent pool wekken de interesse van de Europese Commissie. Dit gedrag kan de vorm aannemen van het weigeren van licentieovereenkomsten, of onredelijke licentievoorwaarden, zoals buitengewoon hoge licentievergoedingen. Met betrekking tot de mogelijkheid van dwangbevelen toont de Orange Book zaak een nieuwe richting. Indien mogelijke overtreders van essentiele octrooien zich als goede licentienemers gedragen, hebben licentiegevers geen mogelijkheid meer om dwangbevelen toe te passen. De reikwijdte van deze jurisprudentie zou in de toekomst wel erg ver kunnen zijn. De Europese Commissie lijkt een grotere bereidheid te tonen om de hoogte van de gevraagde licentievergoedingen te beoordelen. Binnen de discussie omtrent patent pools lijkt de invloed van het mededingingsrecht de meest bepalende factor, alhoewel hierover nog niet het laatste woord is gesproken. De Europese Commissie heeft een grote voorkeur voor patent pools welke alle relevante ondernemingen hebben uitgenodigd om deel te nemen aan de patent poolovereenkomst. Ondanks het feit dat het systeem van de onafhankelijke deskundigen wordt uitgelegd in de Technologie Transfer richtlijnen, lijkt de EU niet het enthousiasme van de VS hieromtrent te delen. De Technologie Transfer Groepsvrijstelling bespreekt niet de positie van patent pools buiten de standardiseringscontext. Patent pools welke geen dominante positie op de markt innemen zullen door de Europese Commissie middels de regels omtrent buitensporige prijzen worden aangesproken op hun hoge licentievergoedingen. De bepaling van de redelijkheid van de licentie vergoedingen (speciaal in verband met een FRAND-belofte) zal voorlopig een heet hangijzer blijven. Nationale rechters binnen de EU (bijvoorbeeld Nederland, Duitsland en het Verenigd Koninkrijk) hebben verschillende interpretaties van de begrippen licentievergoedingen en dwangbevelen. Dientengevolge kan er forum-shopping ontstaan, hetgeen de effectiviteit van het mededingingsrecht zal ondermijnen. De uitspraak in een prejudiciële procedure welke door een Duitse rechtbank is aangevraagd heeft niet to een duidelijke uitleg van het Hof van Justitie geleid. 


\section{China}

Zoals reeds eerder vermeld, suggereert het huidige concept van de Chinese wetgeving betreffende het misbruik van intellectueel eigendomsrecht binnen het mededingingsrecht, dat in sommige gevallen patent pools dienen te worden geanalyseerd met een per se benadering. Voor partijen binnen een patent pool in China, zijn de toepassing van de essential facilities doctrine en de implementatie van essentiele en niet-essentiele octrooien belangrijke aandachtspunten. Mede gelet op de grote toename van Chinese patenten en de mogelijke slechte kwaliteit blijft het risico bestaan dat niet-essentiele octrooien worden opgenomen in een patent pool. Andere belangrijke aspecten zijn: de weigering om een licentie te verstrekken, het vragen van licentievergoedingen voor verlopen octrooien en de basis van de prijsberekening van licentievergoedingen. De recente interim richtlijn van het Chinese SAC en SIPO geeft aan dat patent pools alle essentiele octrooien welke men bezit of kennis van heeft moet bekendmaken. Dit dient onafhankelijk van de vraag te geschieden, of men wel of niet aan standaardiseringsactiviteiten deelneemt in China. Indien ondernemingen niet aan dit vereiste voldoen, handelt men in strijd met de goede trouw. Partijen binnen een patent pool in China dienen dus zorgvuldig te onderzoeken of hun octrooien betrekking hebben op standaarden welke belangrijk zijn voor de Chinese economie ( bijvoorbeeld de vierde generatie Chinese telecom standaard.). Indien dit laatste het geval is moeten buitenlandse ondernemingen met de "speciale positie van de Chinese technologiemarkt" rekening houden. Buitenlandse bedrijven kunnen door verschillende Chinese autoriteiten aan vervolging worden blootgesteld, en het belang van de standaard zal de beleidsagenda van de Chinese mededingingsautoriteiten mede bepalen. Daarom zouden buitenlandse ondernemingen een waarschuwingssysteem moeten ontwikkelen welke de eerste signalen van een terugkerend "Techno-nationalisme" zou detecteren. Het opnemen van Chinese octrooien binnen de patent pool ligt voor de hand maar kan weer leiden tot de implementatie van niet-essentiele octrooien binnen een standaard. Daarnaast zijn er ook zorgwekkende geruchten omtrent een extraterritoriale toepassing van het Chinese mededingingsrecht met betrekking to buitenlandse ondernemingen.

Dit onderzoek toont aan dat het management van een patent pool een bepaald niveau van communicatie tussen de deelnemende partijen vereist, welke vaak ook concurrenten zijn op dezelfde technologiemarkt. Deze vorm van horizontale coördinatie kan een negatief effect vertonen op de prijzen en output op consumentenmarkten, tot prijsafspraken leiden of tot de uitsluiting van derde partijen op technologiemarkten. Mededingingsautoriteiten in de VS, EU en China hebben nog onvoldoende aandacht geschonken aan de interne beheersregels van patent pools, de basis van de verdeling van de licentievergoedingen en gemeenschappelijke verdedigingsmechanismen. De belangrijkste conclusie is dat patent pools een positief effect op de mededinging hebben indien zij: complementaire technologische oplossingen bevatten, transactiekosten 
reduceren en blokkerende octrooien verwijderen. Dit type van patent pools zal tot minder rechtszaken leiden en de verspreiding van nieuwe technologie ondersteunen.

\section{Vraag 3: Op welke wijze verschilt het standaardiseringsbeleid in de drie landen en welke invloed heeft dit op de mededinging?}

\section{Standaarden in de Verenigde Staten}

Een van de problemen van patent pools is de intensieve communicatie tussen mogelijke concurrenten binnen de pool, welke tot het uitwisselen van relevante marktinformatie kan leiden. Hetzelfde gevaar is ook aanwezig bij standaardiseringsprocessen, omdat de deelnemers discussies voeren omtrent de juiste technologie welke moet worden opgenomen binnen de standaard. Deze beslissingen kunnen al leiden tot het uitsluiten van concurrerende technologie. Standaardisering biedt de mogelijk tot strategische manipulatie of het illegaal beheer van octrooien binnen de standaard. Gedurende het standaardiseringsproces kunnen het niet openbaar maken van octrooien, discriminerende licentievoorwaarden en het innen van licentievergoedingen al leiden tot overtreding van de mededingingsregels. Jurisprudentie heeft aangetoond dat concurrerende technologie al in de pre-commerciele fase van de standaard kan worden uitgesloten. Standaardiseringsorganisaties leggen hun principes vast in een intellectueel eigendomsbeleid. Deze IE-regels omvatten zeer vaak bepalingen omtrent de ex ante bekendmakingseisen en het afgeven van FRAND- beloftes. Deelnemende partijen zijn verplicht om essentiele octrooien te openbaren om patent ambush en patent hold-up te vermijden. Economisch onderzoek heeft nog geen eenduidig antwoord gegeven op de effectiviteit van ex ante bekendmakingsregels in relatie tot patent ambush en patent hold-up. Als gevolg van de recente rechtszaken omtrent dwangbevelen lijkt zich in de VS een consensus te ontwikkelen met betrekking tot de interpretatie van de FRAND-beloftes.

Standaardisering is van strategisch belang voor innovatie en dientengevolge voor het mededingingsbeleid van de VS, EU en China. Standaarden spelen een belangrijke rol bij de huidige onderhandelingen betreffende het Transatlantic Trade and Investment Partnership (TTIP) verdrag tussen de Verenigde Staten en de Europese Unie. De toepassing en de inhoud van het mededingingsbeleid inzake patent pools wordt direct beinvloed door het strategisch belang van internationaal geaccepteerde standaarden welke in de EU zijn ontwikkeld.

Standaarden zijn in de VS gereguleerd via de Standards Development Organization Act en de National Cooperative Research and Production Act. Beide wetten benadrukken het vrijwillige karakter van het Amerikaanse standaardiseringsysteem. Dit betreft een gedecentraliseerd systeem, waarbij de standaarden moet worden ontwikkeld middels het functioneren van de markt en niet worden voorgeschreven door de Amerikaanse regering. De Amerikaanse standaardorganisaties richten hun aandacht momenteel op de Patent Assertion Entities (PAEs) en op de Non-Practising Enterprises (NPEs). Deze 
nieuwe ondernemingsmodellen hebben enige overeenkomsten met patent pools. Ondanks hun overwegend negatief imago, is de daadwerkelijke impact van PAEs en NPEs op innovatie en standaardisering nog onvoldoende duidelijk. Door hun beperkte gemeenschappelijkheid met patent pools, beïnvloeden deze nieuwe bedrijfsmodellen wel de discussie omtrent patent pools.

\section{Standaarden in de Europese Unie}

Het formele standaardiseringsproces is de verantwoordelijkheid van de drie Europese standaardorganisaties: CEN, ETSI en CENELEC. ETSI heeft een transparant IE-beleid geformuleerd welke het strategisch gebruik van octrooien reguleert. Belangrijk is om op te merken dat ETSI geen FRAND-koersen bepaalt maar dit overlaat aan de ondernemingen of aan de rechter. Sommige deskundigen beschouwen dit als een gemiste kans en zien hier een taak voor de standaardorganisaties weggelegd. Binnen de software sector leidde de frustratie omtrent de traditionele licentiemethodes tot de ontwikkelen van open source standaarden. De Europese Commissie ondersteunt de ontwikkeling van open source standaarden hetgeen heeft geresulteerd in de opkomst van nieuwe bedrijfsvormen (bijvoorbeeld FLOSS) in de software industrie. De Europese Unie wenst de hoeveelheid interoperability standaarden drastisch te verhogen. Beleidsinitiatieven zoals de "Digitale Agenda" onderstrepen het belang van innovatie en standaarden voor de Europese Unie. Economisch onderzoek is echter nog verdeeld over de precieze bijdrage welke patent pools aan innovatie leveren. De positieve bijdrage van patent pools aan innovatie kan ernstig worden ondermijnd door het volume en de timing van de octrooiregistraties binnen het standaardiseringsproces. Het opnemen van een onnodig hoog aantal octrooien in een patent pool staat haaks op de oorspronkelijke doelstelling van de patent pool, namelijk het vermijden van patent thickets en het verhogen van de efficiëntie. De EU-wetgeving en jurisprudentie richt zich niet direct tot de facto standaarden. De positie van de facto standaarden binnen de discussie omtrent FRANDbeloftes of dwangbevelen is niet duidelijk. Niettemin spelen de facto standaarden toch een uiterst belangrijke rol in innovatie.

\section{Standaarden in China}

Het strategisch belang van standaarden (en dus de belangrijke invloed op mededingingsrecht) wordt geillustreerd door het zogenaamde "indigenous innovatiebeleid" in China. Het zogenaamde "indigenous innovatiebeleid " van de Chinese regering moet ervoor zorg dragen dat Chinese bedrijven niet langer uitsluitend afnemers van Westerse industriestandaarden zijn maar in de toekomst als belangrijkste ontwikkelaars van deze industriestandaarden worden beschouwd. Gedurende de verschillende ontwikkelingsfases van dit innovatiebeleid werd een erg strikte interpretatie als basis genomen, waarbij het Chinese eigendom van de octrooirechten binnen standaarden als belangrijkste eis gold. Deze strikte benadering leidde tot hevige kritiek in de Verenigde Staten en ( in 
mindere mate) de Europese Unie. Als reactie op deze kritiek heeft China toegestemd in de actieve participatie in overlegorganen en consultatie van Amerikaanse en Europese belanghebbenden. Bij de ontwikkeling van het intellectueel eigendomsbeleid inzake standaardisering en later ook bij de ontwikkeling van mededingingsrecht in relatie tot intellectueel eigendomsrecht hadden buitenlandse partijen voldoende mogelijkheden om hun kennis en mening in te brengen, via publieke consultaties. De belangrijkste conclusie is echter dat het Chinese innovatiebeleid en haar invloed op buitenlandse bedrijven onvoldoende helder is geformuleerd. De ontwikkelingsfase van het Chinese innovatiebeleid toont een vast stramien. Aanvankelijk wordt het concept strikt toegepast, maar na raadpleging van de VS en EU volgt er een meer liberale toepassing van het innovatieconcept. De TTIP noopt China tot een grotere harmonisatie van haar standaardsysteem met de VS en de EU. Het gebrek aan gemeenschappelijke belangen en de ongecoördineerde aanpak van standaardisering in China vormen een risicofactor voor buitenlandse ondernemingen in China. Recente ontwikkelingen (bijvoorbeeld Qualcomm en de vierde generatie Chinese telecom standaard) tonen aan dat politieke overwegingen (industrieel beleid) de mededingingsagenda van de Chinese regering bepalen. Een vergelijking van de ontwikkelingsgeschiedenis van de Chinese WAPI en Koreaanse WIPI telecommunicatiestandaarden toont de noodzaak aan van meer open en toegankelijkere standaardisering. De Chinese WAPI-standaard werd geen commercieel succes door het gebrek aan vertrouwen van de Chinese consument. Het aantal Chinese afnemers van de WAPI-standaarden was te laag om een kritische massa te vormen welke zou kunnen profiteren van de zogenaamde: netwerkeffecten.

Het nationale systeem met betrekking tot standaardisering in China heeft overeenkomsten met het Europese systeem. De beperkte invloed van de Europese Unie op standaardiseringsorganisaties staat in schril contrast tot het Amerikaanse systeem, waarbij er vooral op de marktwerking, innovatiekracht van ondernemingen en geen overheidsinvloed wordt ingezet.

\section{Vraag 4: Welke nieuwe ondernemingsvormen ten aanzien van intellectueel} eigendom kunnen er worden onderscheiden en welke invloed oefenen deze uit op de discussie omtrent standaarden en octrooien?

\section{Verenigde Staten}

De interesse van mededingingsautoriteiten in PAEs en NPEs concentreert zich voornamelijk in de Verenigde Staten. De literatuur is verdeeld met betrekking tot de impact welke deze nieuwe bedrijfsmodellen hebben op innovatie en standaarden. Voor onze discussie zijn twee zaken van belang. Op de eerste plaats het feit dat PAEs enkele overeenkomsten vertonen met patent pools en ten tweede dat PAEs zich vaak schuldig maken aan patent hold-up hetgeen een onderdeel van hun bedrijfsstrategie is. Deze strategie richt zich voornamelijk op het dreigen met rechtszaken. PAEs uiten hun be- 
schuldigen betreffende octrooi-inbreuk vaak op het midden en kleinbedrijf. Het antwoord van de Amerikaanse regering houdt direct verband met deze strategie. Amerikaanse instanties zien als oplossing een verandering naar een systeem waarbij de verliezer van de rechtszaak alle kosten betaald en het verbeteren van de kennis omtrent het daadwerkelijke eigendom van octrooien. De discussie treft ook patent pools, aangezien PAE-activiteiten reeds hebben geleid tot de oprichting van defensieve patent portefeuilles, waarbij een onafhankelijke onderneming octrooien koopt en deze vervolgens verdedigt tegen PAEs. Dit dient te worden onderscheiden van " privateering" waarbij een onderneming haar octrooien aan een derde partij overdraagt, welke deze vervolgens exploiteert. Bijvoorbeeld Nokia en de beheersmaatschappij Mosaid. In de dagelijkse praktijk is het erg lastig om de verschillende activiteiten van PAEs, NPEs, patent trolls, bepaalde vormen van patent pools en privateering beheersmaatschappijen van elkaar te onderscheiden. Mededingingsautoriteiten dienen derhalve hun aandacht niet te richten op een specifieke verschijningsvorm maar op het marktgedrag en de eventuele impact hiervan op de concurrentieverhoudingen, om de legaliteit te beoordelen. De BRL inzake IXPI toont reeds aan dat de FTC op dit moment erg huiverig is om nieuwe innovatieve bedrijfsmodellen in technologiemarkten te accepteren.

\section{$E U$}

De Europese Unie vermeldt de risico's van PAEs in de nieuwe Technologie Transfer richtlijnen, maar het gebrek aan substantiële PAE-rechtszaken rechtvaardigt op dit moment het feit dat de Europese Commissie weinig aandacht heeft voor dit fenomeen. Deskundigen verwijzen naar het reeds bestaande systeem waarbij de verliezer de kosten betaald en het feit dat de nationale rechtspraak in de Lidstasten de kansen op een patent hold-up vermindert. Daarnaast zijn Europese octrooien doorgaans van betere kwaliteit maar het gebrek aan economisch onderzoek betreffende PAEs ondermijnt de discussie in de Europese Unie. De EU onderzocht de " privateering" elementen bij de overname van een deel van Nokia's octrooien door Microsoft, maar had geen bezwaren vanuit concurrentieoverwegingen.

\section{China}

Het ontwerp van SAIC betreffende het misbruik van IPRs in relatie tot mededinging vermeldt de volgende passage: : Undertakings with dominant market positions shall not, upon the expiration or invalidation of their intellectual property rights or in the circumstance that sufficient evidence has been provided by other party to prove relevant act does not constitute infringement of intellectual property rights, excessively issue infringement warning letters to eliminate or restrict competition. De tekst kan op verschillende manieren worden uitgelegd. Op dit moment heeft de Chinese regering nog weinig aandacht voor PAEs, maar het risico bestaat dat Chinese rechters de Westerse jurispru- 
dentie op een verkeerde manier gaan interpreteren hetgeen tot mogelijk negatieve gevolgen voor patent pools kan leiden.

Vraag 5: Wat zijn de belangrijkste ontwikkelingen binnen de drie landen omtrent de begrippen FRAND-voorwaarden, standaard-essentiele octrooien en het gebruik van dwangbevelen?

\section{Verenigde Staten}

In de Verenigde Staten wordt de FRAND-belofte gezien als een contractuele verplichting, welke ertoe leidt dat alle partijen in " good faith" moeten onderhandelen met betrekking tot de licentievoorwaarden. De redelijkheid van de licentievergoedingen wordt aan de hand van de volgende factoren beoordeeld: de economische waarde van het octrooi, het belang van het octrooi voor de standaard, de waarde van de standaard in relatie tot het product, en de waarde van vergelijkbare octrooien. Daarnaast dienen rechters te waken voor het verschijnsel van royalty stacking bij het bepalen van de juiste hoogte van licentievergoedingen.

Dwangbevelen voor essentiele octrooien met een FRAND-belofte kunnen slechts op een zeer beperkte schaal worden verleend. Alhoewel aan de hand van de rechtszaak; eBay v. MercExchange een consensus leek te ontstaan ten aanzien van dwangbevelen wijzen recente ontwikkelingen weer in een andere richting. Op dit moment hanteren Amerikaanse rechters "equity" -principes om in vergelijkbare zaken een individueel vonnis te geven. Voor patent pools is van belang dat een aantal zaken nog niet duidelijk omschreven zijn. Elementen zoals "willing licensee", of het opnemen en verbinden van essentiele en niet-essentiele octrooien kunnen voor patent pools nog altijd risicoelementen vormen.

\section{$E U$}

De Europese Commissie heeft in het Motorola memorandum duidelijk aangegeven dat zij geen rol wenst te spelen bij het bepalen van de daadwerkelijke hoogte van redelijke licentievergoedingen. Deze taak dient door nationale rechters of arbiters te worden overgenomen. Het voorbeeld van Samsung toont, dat ondernemingen een proactieve houding aannemen om de risico's betreffende het gebruik van dwangbevelen uit te sluiten. Recente uitspraken lijken te bevestigen dat de Commissie een voorkeur heeft voor het bepalen van FRAND-vergoedingen middels onafhankelijke derde partijen maar dat hierdoor niet het recht mag worden aangetast om de geldigheid of kwalificatie van een octrooi aan te vechten. Binnen het EU-systeem is er volgens de Commissie ook geen rol weggelegd voor nationale mededingingsautoriteiten in de bepaling van FRANDtarieven.

Sommige verschillen tussen de EU en de Verenigde Staten behoeven nog nadere verduidelijking. Het Europese systeem heeft alleen betrekking op octrooien welke in de 
EU zijn verleend en op dwangbevelen binnen de EU. Het Amerikaanse systeem kan haar invloed uitstrekken op octrooien welke wereldwijd zijn geregistreerd. Indien dit verschil zich daadwerkelijk gaat bevestigen in de praktijk, kan dit grote gevolgen hebben voor forum-shopping en de registratie van essentiele octrooien in de verschillende landen. Binnen de EU moeten alle partijen zich bereid verklaren om de zaak aan arbitrage voor te leggen terwijl in de VS de licentienemer dit al alleen kan vragen. Binnen de EU kan het vragen van een dwangbevel voor essentiele octrooien met een FRAND-belofte al leiden tot een dominante marktpositie. Dwangbevelen welke eisen dat de licentienemer hun eigen onderzoek naar de geldigheid of de inbreuk op octrooien stopt, zijn niet toegestaan.

\section{China}

De rechtszaken Huawei/InterDigital hebben beiden betrekking op standaard-essentiele octrooien in China. In de eerste uitspraak werden vier vormen van gedragingen als illegaal gekwalificeerd: buitengewoon hoge licentievergoedingen, het koppelen van essentiele en niet-essentiele octrooien, het vragen van grant-back voorzieningen en het feit dat InterDigital al een zaak tegen Huawei was gestart in de VS, terwijl beide partijen nog onderhandelden. Het belangrijkste element van de tweede uitspraak was het feit dat InterDigital de verplichting had om haar essentiele octrooien op FRAND-basis aan te bieden, alhoewel deze belofte nooit was uitgesproken door InterDigital. De Interim regels van het SAC en SIPO geven duidelijk aan dat standaard-essentiele octrooien moeten worden bekendgemaakt en worden gelicentieerd op FRAND-basis. Indien partijen dit niet doen, zullen Chinese overheidsinstanties gaan onderhandelen en uiteindelijk zelf de FRAND-tarieven bepalen.

Het SAIC voorstel van juli 2014 inzake misbuik van intellectueel eigendom en mededinging kent interessante voorzieningen. Het voorstel kent de regel dat houders van essentiele octrooien een bekendmakingsverplichting hebben onafhankelijk van het feit of men deelneemt aan standaardiseringsactiviteiten in China. Dit zou verstrekkende gevolgen hebben omdat houders van essentiele octrooien een verplichting zouden hebben om altijd hun octrooi met een FRAND-belofte af te geven. Het feit of men wel of niet participeert in de ontwikkeling van een standaard in China is hierbij irrelevant. Ook wanneer de standaardorganisatie geen FRAND-verplichting in haar IE-beleid heeft opgenomen, blijft deze toch een wettelijke noodzaak en zou dit de Chinese AML overtreden. Sommige deskundigen zijn van mening dat deze verplichting in strijd is met het Chinese octrooirecht. In praktisch opzicht, opent dit de deur voor Chinees misbruik van buitenlandse essentiele octrooien binnen de ontwikkeling van standaarden. Recente ontwikkelingen tonen een grotere bereidheid van Chinese rechters om hun nationale mededingingswetten tegen buitenlandse ondernemingen in te zetten en hierbij hoge boetes uit te spreken. De aanbeveling voor buitenlandse ondernemingen in China is dan ook om het gebruik van essentiele octrooien in China en de voorwaarden waarop zorg- 
vuldig af te wegen. Momenteel is er al een grote discrepantie tussen het Amerikaanse, het Europese en Chinese beleid inzake patenten en standaarden. Het voorbeeld van de "essential facilities" concept, wordt in China op een heel andere wijze geïnterpreteerd dan bijvoorbeeld in de Verenigde Staten of in de Europese Unie.

\section{Afsluitende opmerkingen:}

In de Verenigde Staten gaat momenteel de meeste aandacht uit naar patent trolls, PAEs en NPEs. Deze nieuwe bedrijfsvormen hebben enige overeenkomsten met patent pools. In de VS zijn de volgende elementen belangrijk voor de beoordeling van een patent pool: de kwalificatie van het octrooi, de mogelijkheid om buiten de patent pool te licentieren, niet-exclusieve grant-backs en geen uitwisseling van marktgerelateerde informatie tussen de deelnemers in de pool. Andere factoren zijn: FRAND-voorwaarden, de onafhankelijkheid van de beheersorganisatie, de inzet van onafhankelijke deskundigen en de vrijheid om alternatieve technologie buiten de pool te ontwikkelen. Patent pools hebben een positieve invloed op innovatie indien zij: verschillende technologieën integreren, transactie kosten verminderen en blokkerende octrooien opheffen. Deze patent pools zullen tot een vermindering van het aantal rechtszaken leiden en een betere verspreiding van kennis.

In de Europese Unie moet de patent pool opletten zodra deze een dominante positie op de markt bereikt. Met name in technologiemarkten in het zeer ingewikkeld om technologie en productmarkt van elkaar te onderscheiden. Dit leidt ook weer tot problemen bij de identificatie van mogelijke illegale prijsstrategieen, of het vaststellen van onredelijke licentievoorwaarden. De Orange Book zaak illustreert de complexiteit van de FRAND discussie en het probleem van de Europese autoriteiten om een passend antwoord te vinden. De recente ontwikkelingen inzake Motorola en Samsung verhelderen de positie betreffende dwangbevelen maar gedeeltelijk. De dreiging van dwangbevelen kan de licentieonderhandelingen negatief beïnvloeden en tot onredelijke licentievergoedingen leiden.

Het belang van een beter begrip van toegepast economisch onderzoek op het gebied van patent pool kan niet genoeg worden onderschreven.

De Chinese mededingingswetgeving en de specifieke richtlijnen met betrekking tot de toepassing van concurrentieregels inzake intellectueel eigendom zijn nog voordurend in beweging. Het vinden van het juiste mededingingskader met betrekking tot patent pools zal geen gemakkelijke opgave zijn, gelet op de relatieve jonge historie van de Chinese mededingingsregels en het gebrek aan ervaring van de Chinese magistratuur. Binnen het Chinese technologiebeleid nemen industriestandaarden een belangrijke plaats in. In tegenstelling tot de Verenigde Staten en de Europese Unie zijn ondernemingen in China niet vrij in het deelnemen aan en bepalen van de inhoud van internationale standaarden. In China wordt de agenda van (staats) ondernemingen niet hoofdzakelijk gevoed door de marktwerking, maar vooral door politieke en economi- 
sche overwegingen van de centrale regering. De wens om een sterkere economische groei en conversie te bewerkstelligen ondermijnt de effectiviteit van de deelname van Chinese ondernemingen aan het formuleren van internationale standaarden. Hetzelfde geldt voor de beleidsdoelstellingen van de Chinese rechtbanken en mededingingsautoriteiten, welke het strategisch gebruik van octrooien binnen Chinese industriestandaarden zouden moeten tegengaan. De onduidelijkheid en onervarenheid omtrent de regelgeving en toepassing van de mededingingsregels binnen het kader van intellectueel eigendom, vormen nog steeds een risicofactor voor buitenlandse investeerders welke actief zijn op de Chinese markt. Patent pools vormen een interessant alternatief voor de huidige vormen van intellectueel eigendom in industriestandaarden in China. Binnen de patent pool zouden Chinese ondernemingen kunnen profiteren van Westerse technologie in gezamenlijk ontwikkelde standaarden. Westerse ondernemingen hebben baat bij de verhoogde rechtszekerheid van de gezamenlijk beheerde patent pools en kunnen via deze pools zonder veel risico ook meer hoogstaande productie van goederen overhevelen naar China en/of gezamenlijk ontwikkelen met Chinese ondernemingen.

Zowel de Amerikaanse alsook de Europese autoriteiten zoeken naar het juiste juridische kader om de positie van patent pools binnen de discussie omtrent standaardisering en mededingingsrecht te bepalen. Het economisch onderzoek naar de werking van patent pools is erg verdeeld en niet altijd onafhankelijk. De Chinese discussie speelt zich af binnen een andere context. China heeft pas laat zijn intrede gedaan in de discussie omtrent strategisch gebruik van octrooien en aanvankelijk werd deze discussie geleid door de hoge licentievergoedingen die Chinese bedrijven moesten voldoen voor het gebruik van Westerse essentiele octrooien binnen internationale standaarden. De Chinese economie wil een sprong vooruit maken met betrekking tot de aard van economische activiteiten. Het goedkoop produceren van producten op basis van Westerse octrooien dient te worden vervangen door het vervaardigen van meer hoogwaardige producten welke gebaseerd zijn op Chinese octrooien en nationale industriestandaarden. Deze doelstelling kan alleen worden bereikt middels, een goed functionerend innovatiebeleid ondersteund door nationaal beleid inzake standaardisering en ondersteunend mededingingsrecht.

De Chinese mededingingswetgeving en de specifieke richtlijnen met betrekking tot de toepassing van concurrentieregels inzake intellectueel eigendom zijn nog voordurend in beweging. Het vinden van het juiste mededingingskader met betrekking tot patent pools zal geen gemakkelijke opgave zijn, gelet op de relatieve jonge historie van de Chinese mededingingsregels en het gebrek aan ervaring van de Chinese magistratuur.

\section{Toekomstige ontwikkelingen}

De huidige beleidsagenda van de mededingingsautoriteiten richt zich voornamelijk op het moment van oprichting van de patent pool. Managementbesluiten aangaande de 
hoogte van de licentievergoedingen, en het verwijderen van verlopen octrooien worden niet onderzocht, aangezien patent pools in principe een positief effect hebben op innovatie en de mededinging. Het ontstaan van steeds omvangrijkere patent pools roept vragen op met betrekking tot de geldigheid van octrooien maar ook met betrekking tot het mogelijk afsluiten van consumentenmarkten.

Mededingingsautoriteiten hebben nog weinig aandacht voor het effect dat patent pools hebben middels open source ontwikkelingen. Open source technologie heeft niet de beschikking over grote octrooi-portefeuilles, maar zou middels een patent pool weerstand kunnen bieden aan grote ondernemingen.

Een van de conclusies van dit onderzoek is dat het opnemen van niet-essentiele octrooien in een patent pool zowel positieve alsook negatieve effecten kan hebben. Economisch onderzoek heeft nog geen eensluidend antwoord gegeven en het veranderende karakter van technologiemarkten en de nieuwe bedrijfsvormen vormen een noodzaak tot het aanleveren van economisch onderzoek welk de mededingingsbesluiten kan ondersteunen.

De economische literatuur verschaft duidelijkheid met betrekking tot het positieve effect van standaarden op innovatie. De beperkingen welke voortvloeien uit dwangbevelen kunnen een reden zijn voor innovatieve ondernemingen om niet meer deel te nemen aan activiteiten van standaardorganisaties. Het is interessant om het verschil in behandeling met betrekking tot FRAND-beloftes binnen en buiten formele standaardiseringsorganisaties te onderzoeken. Indien het opereren buiten formele standaardorganisaties tot betere resultaten zal leiden, kan dit in de ontwikkeling van meer de facto standaarden resulteren. Deskundigen zijn van mening dat de facto standaarden een grote betekenis hebben voor innovatie en mededinging.

De Chinese standaardorganisaties zullen meer geneigd zijn om het Europese standaardsysteem te volgen dan het Amerikaanse systeem. Het TTIP-verdrag kan mogelijkerwijs tot een grotere globale harmonisatie leiden op het gebied van standaarden. China zal een strategische reactie moeten geven op deze ontwikkelingen, welke de discussie omtrent standaarden, octrooien en patent pools sterk zal veranderen. Om de Chinese positie binnen de internationale standaardiseringswereld te verbeteren zal de Chinese regering meer transparantie moeten leveren betreffende het juridische kader van standaarden en mededinging. Zowel in de VS alsook in de EU wordt dit juridische kader gecommuniceerd via richtlijnen maar ook gemotiveerde en gepubliceerde rechterlijke uitspraken. Een beter begrip van het Chinese juridische kader zal ook tot een groter enthousiasme leiden van buitenlandse bedrijven om deel te nemen aan de ontwikkeling van nieuwe globale standaarden in China. 


\section{Bibliography}

\section{Blog}

Simon.F. (2013). EU Lawmaker: " TTIP is not a monster". Retrieved from http://static.euractiv.com/files/ euractiv_special_report_-_eu-us_trade.pdf

\section{Book}

ABA Section of Antitrust Law. (2004). Handbook on the Antitrust Aspects of Standards Setting. Chicago: ABA Book Publishing

American Bar Association. (2007). Intellectual Property and Antitrust Handbook. Chicago: American Bar Association.

Baldwin.R, \& Wyplosz.C. (2009). Economics of European Integration: McGraw-Hill.

Baskoy.T. (2008). The political economy of European Union competition policy: a case study of the telecommunications industry: Routledge.

Bekkers.R. (2001). The Development of European Mobile Telecommunications Standards: An Assessment of the SUccess of GSM, TETRA, ERMES and UMTS: Proefschrift: Technische Universiteit Eindhoven.

Berleur.J, Hercheui.M, \& Hilty.L. (2010). What kind of information society? Governance, virtuality, surveillance, sustainability, resilience: Springer.

Blind, K. (2004). The Economics of Standards: Theory, Evidence, Policy Cheltenham, UK: Edward Elgar.

Colston.C, \& Galloway.J. (2010). Modern intellectual property law: Routledge.

Cooter, R., \& Ulen, T. (2000). Law \& Economics (Third Edition ed.). USA: Addison-Wesley.

Cournot.A, \& Fisher.I. (1929). Researches into the mathematical principles of the theory of wealth/by Augustin Cournot, 1838; translated by Nathaniel T. Bacon; with an essay on Cournot and mathematical economics and a bibliography of mathematical economics by Irving Fisher.

Dapp.M, \& Bernauer.T. (2009). Hot Debate About Chilling Effects: Do Software Patterns Hamper/Free Open Source Software Development? Zurich: Center for Comparative and International Studies (ETH Zurich and University of Zurich).

Dinwoodie.G. (2013). Methods and Perspectives in Intellectual Property (1st ed.). Cheltenham: Edward Elgar

Drexl.J. (2008). Research handbook on Intellectual property and Competition law: Edward Elgar Publishing.

Drexl.J, Kerber.W, \& Podszun.R. (2011). Competition policy and the economic approach: foundations and limitations: Edward Elgar Publishing.

Fagerberg, J., Mowery.D, \& Nelson.R. (2006). The Oxford handbook of innovation: Oxford Handbooks

Farrell.J, \& Klemperer.P. (2007). Coordination and lock-in: Competition with switching costs and network effects (Vol. 3).

Faure.M, \& Zhang.X. (2011). Competition policy and regulation: Recent developments in China, the US and Europe: Edward Elgar Publishing.

Faure.M, \& Zhang.X. (2013). The Chinese Anti-Monopoly Law: Edward Elgar Publishing.

Helberger.N. (2005). Controlling access to content: regulating conditional access in digital broadcasting (Vol. 15): Kluwer Law International.

Jacques.M. (2012). When China rules the world: Penguin group.

Janis.M, \& Lemley.M. (2008). IP and antitrust: An analysis of antitrust principles applied to intellectual property law: Aspen Publishers Online.

Kariyawasam.R. (2011). Chinese intellectual property and technology laws. Cheltenham: Edward Elgar Publishing. 
Kennedy.S, Suttmeier.R, \& Su.J. (2008). Standards, stakeholders, and innovation: China's evolving role in the global knowledge economy: National Bureau of Asian Research.

Lemley.M. (2009). IP and antitrust: an analysis of antitrust principles applied to intellectual property law: Aspen Publishers Online.

Lundqvist.B. (2014). Standardization Under EU Competition Rules and US Antitrust Laws: The Rise and Limits of Self-regulation. Cheltenham: Edward Elgar Publishing.

Lundvall.B. (2010). National systems of innovation: Toward a theory of innovation and interactive learning (Vol. 2): Anthem Press.

Monti.G. (2007). EC competition law: Cambridge University Press.

Motta.M. (2004). Competition policy: theory and practice: Cambridge University Press.

Mowery.D. (1999). Sources of industrial leadership: studies of seven industries: Cambridge University Press.

Orcutt.J, \& Shen.H. (2012). Shaping China's Innovation Future University Technology Transfer in Transition. Cheltenham: Edward Elgar Publishing.

Organisation for Economic Co-operation Development (OECD). (2007). OECD Science, Technology and Industry Scoreboard 2007: Innovation and Performance in the Global Economy. Paris: Organisation for Economic Co-operation and Development.

Park.J. (2010). Patents and industry standards: Edward Elgar Publishing.

Roach.S. (2009). Stephen Roach on the next Asia: Opportunities and Challenges for a new globalization: John Wiley \& Sons.

Rugman.A. (2009). The Oxford handbook of international business. Oxford: Oxford Handbooks online.

Rugman.A, \& Collinson.S. (2009). International business: Pearson Education.

Schilling.M. (2005). Strategic management of technological innovation: McGraw-Hill Education.

Steinfeld.E. (2010). Playing Our Game: Why China's Rise does not Threathen the West: New York: Oxford University Press.

Tapia.C. (2010). Industrial Property Rights, Technical Standards and Licensing Practices (FRAND) in the Telecommunications Industry: Carl Heymanns.

Whish.R. (2012). Competition law (sixth edition ed.): Oxford University Press.

Yahong.L. (2010). Imitation to innovation in China: the role of patents in biotechnology and pharmaceutical industries. Cheltenham: Edward Elgar.

\section{Book section}

Boskin, M., \& Lau, L. (1992). Capital, Technology, and Economic Growth In N. Rosenberg, R. Landau \& D. Mowery (Eds.), Technology and the Wealth of Nations (pp. 17).

Cheng.T. (2008). Striking a Balance between Competition Law Enforcement and Patent Policy: A Developing Country's Perspective. In H. Q. a. G. Lipimile (Ed.), The effects of anti-competitive business practices on developing countries and their development prospects (pp. 633-659). Geneva: UNCTAD.

Economides, N. (2008). Antitrust issues in network industries. In loannis Kokkoris and loannis Lianos (Ed.), The Reform of EC Competition Law (pp. 24): Kluwer.

Ginsburg.D, \& Fraser.E. (2010). The Role of Economic Analysis in Competition Law Getting the balance right: Intellectual property, competition law and economics in Asia lan McEwin, ed., Hart Publishing.

Hovenkamp.E, \& Hovenkamp.H. (2015). Patent Pools and related Technology Sharing. In Blair.R \& Sokol.D (Eds.), Cambridge University Press Antitrust Intellectual Property and High Tech Handbook. Cambridge: Cambridge University Press.

Jones.K, Whitham.M, Handler.P, Krattiger.A, Mahoney.R, Nelsen.L, Graff.G. (2007). Problems with royalty rates, royalty stacking, and royalty packibng issues. IP Handbook of Best Practices (pp. 1121-1126).

Lerner.J, \& Tirole.J. (2008). Public policy toward patent pools Innovation Policy and the Economy, Volume 8 (Vol. 8, pp. 157-186): University of Chicago Press.

Narula.R, \& Zanfei.A. (2005). Globalisation of innovation. In D. M. Jan Fagerberg, and Richard R. Nelson (Ed.), Oxford Handbook of Innovation (pp. 318-345). Oxford Oxford University press. 
Shapiro.C. (2001). Navigating the patent thicket: Cross licenses, patent pools, and standard setting Innovation Policy and the Economy, Volume 1 (pp. 119-150): MIT press.

Simcoe.T. (2005). Open Standards and Intellectual Property Rights Open Innovation: Researching a New Paradigm. Oxford Oxford University Press.

Ulen.T. (2011). The uneasy case for competition law and regulation as decisive factors in development: some lessons for China. In Faure.M \& Zhang.X (Eds.), Competition Policy and Regulation. Recent Developments in China, the US and Europe (pp. 13-44). Cheltenham: Edward Elgar

\section{Cases}

United States v. General Electric Co, No. 272 U.S. 476 (Supreme Court of the United States 1926).

Standard Oil Co. of New Jersey v. United States, No. 378 (US Supreme Court 1931).

Manufactures Aircraft Assoc. Inc. v United States, No. 77 Ct. Cl. 481, 487 (US Supreme Court 1933).

Hartford-Empire Co. v. United States, No. 323 U.S. 386 (U.S. Supreme Court 1945).

Hartford-Empire Co. v. United States - 323 U.S. 386 (1945)

No. 323 U.S. 386 (U.S. Supreme Court 1945).

United States v. National Lead Co, No. 332 U.S. 319 (U.S. Supreme Court 1947).

United States v. Line Material Co. No. 333 U.S. 287 (U.S. Supreme Court 1948).

United States v. Singer Manufacturing Co, No. 374 U.S. 174 (U.S. Supreme Court 1963).

International Manufacturing Co. v. Landon, Inc., No. 336 F.2d 723 (9th Cir. 1964) (United States Court of Appeals Ninth Circuit 1964).

Federal Trade Commission v. Sperry \& Hutchinson Co, No. 405 U.S. 233 (U.S. Supreme Court 1972).

Broadcast Music, Inc. v. CBS, Inc. 441 U.S. 1, No. No. 77-1578 (U.S. Supreme Court 1979).

Broadcast Music, Inc. v. Columbia Broadcasting System, Inc, No. 441 U.S. 1 (U.S. Supreme Court 1979).

Usm Corporation v. Sps Technologies Inc., No. 84-1397 (United States Court of Appeals, Federal Circuit 1985).

Windsurfing Intl, Inc v. AMF, Inc, No. 782 F2.D 995, 1001 (Federal Circuit 1986).

AB Volvo v. Erik Veng Ltd, No. ECR 1988 (Court of Justice of the European Union 1988).

Allied Tube v. Indian Head, Inc, No. 488 U.S. 492 (U.S. Supreme Court 1988).

Brooke Group Ltd. v. Brown \& Williamson Tobacco Corp., No. No. 92-466 (United States Supreme Court 1993).

RTE \& ITP v. Commission (Magill) (Court of Justice of the European Union 1995).

ITT Promedia NV v Commission of the European Communities, No. T-111/96 (the Court of First Instance of the European Union 1998).

Monsanto Company v. McFarling No. 03-1177, 03-1228 (United States Court of Appeals, Federal Circuit 2004). NDC Health v. IMS Health, No. ECR 2004 (Court of Justice of the European Union 2004).

Standardized Tight Head Drum, No. KZR 40/02 (German Federal Supreme Court 2004).

Verizon Communications Inc. v. LawOffices of Curtis. V. Trinko, LLP 540 US 398, No. 02-682 (United States Supreme Court 2004).

U.S. Philips Corp. v. International Trade Commission, No. 424 F.3d 1179 (United States Court of Appeals, Federal Circuit 2005).

Union Oil Company of California, In the Matter of, No. 9305 (United States Federal Trade Commission 2005). eBay Inc. et al. v. Mercexchange, L.L.C.. No. No. 05-130. (U.S. Supreme Court 2006).

Illinois Tool Works Inc. v. Independent Ink, Inc., No. 04-1329 (Supreme Court of the United States 2006).

Broadcom Corporation, v. Qualcomm Incorporated, No. No. 06-4292 (United States Court of Appeals for the Third Circuit 2007).

Broadcomm Corp. v. Qualcomm Inc., No. No. 06-4292 (United States Court of Appeals for the Third Circuit 2007).

Chint v. Schneider Electric Low Voltage (Tianjin) Co., Ltd. (Wenzhou Intermediate People's Court 2007).

Microsoft v. Commission of the European Union No. T-201/04 (Court of First Instance of the European Union 2007). 
Philips v. LG, No. 261913 (The Hague District Court the Netherlands 2007).

Sandisk Corporation v. Stmicroelectronics Inc NV, No. No.05-1300 (United States Court of Appeals, Federal Circuit 2007).

Sot. Lélos kai Sia EE and Others v GlaxoSmithKline AEVE, No. C-468/06 to C-478/06 (Court of Justice of the European Union 2008).

TruePosition Inc. v. Andrew Corp No. 568 F. Supp. 2d 500, 531 (District Court of Delaware 2008).

Rambus Inc., In the Matter of, No. 9302 (Federal Trade Commission 2009).

Deutsche Telekom v Commission No. C-280/08P (Court of Justice of the European Union 2010).

Koninklijke Philips Electronics N.V. v. SK Kassetten GmbH \& Co. KG, No. No. 316533/HA ZA 08-2522 and 316535/HA ZA 08-2524 (District Court The Hague, the Netherlands 2010).

Princo Corporation and Princo America Corporation, v. International Trade Commission,and U.S. Philips Corporation,, No. 2007-1386 (United States Court of Appeals for the Federal Circuit 2010).

France Telecom, TDF and others vs. TCT Mobile Europe, Orange Vallee, No. 10/18196 RG (Paris, Court of First Instance 2012).

Protégé International v Commission No. T-119/09 (Court of Justice of the European Union 2012).

Samsung Electronics Co. Ltd v. Apple Inc., No. 400367 / HA ZA 11-2212, 400376 / HA ZA 11-2213 and 400385 / HA ZA 11-2215 (District Court The Hague, The Netherlands 2012).

Telefónica and Telefónica de España v Commission No. T-336/07 (Court of Justice of the European Union 2012).

TruePosition, Inc v. LM Ericsson Telephone Co., No. No.11-4574 (The United States District Court for the Eastern District of Pennsylvania 2012).

Microsoft v Motorola, , No. United States District Court for Western District of Washington (United States District Court for Western District of Washington 2013).

ERICSSON, INC. 2 v. D-LINK SYSTEMS, INC., No. 2013-1625, -1631, -1632, -1633 (United States Court of Appeals for the Federal Circuit 2014).

Scandlines Sverige AB v Port of Helsingborg, Case COMP/A.36.568/D3 (Commission of the European Union 2004).

Court of Justice of the European Union PRESS RELEASE No 155/14 Luxembourg, 20 November 2014 Advocate General's Opinion in Case C-170/13 Huawei Technologies Co. Ltd v ZTE Corp., ZTE Deutschland GmbH (European Union 2014 ).

Opinion of the Advocate General Wathelet delivered on 20 November 2014 Case C-170\13 Huawei v ZTE Court of Justice of the European Union Press Release No 155/14 Luxembourg, 20 November 2014 No. C170\13 (Court of Justice of the European Union 2014).

Huawei Technologies Co. Ltd v. ZTE Corp., ZTE Deutschland GmbH, No. C-170/13 (Court of Justice of the European Union 2015)

\section{Conference proceedings}

Almunia.J. (2010, 7 July 2010). Competition in Digital Media and the Internet

Paper presented at the Jevons Colloquium on Competition Policy in the Digital Media and the Internet, London.

Almunia.J. (2012, 15 June 2012). Higher Duty for Competition Enforcers. Paper presented at the International Bar Association Antitrust Conference, Madrid

American Bar Association. Section of Antitrust Law. (2004). Handbook on the Antitrust Aspects of Standards Setting.

Baron, J., \& Pohlmann, T. (2011). Patent pools and patent inflation. Paper presented at the Conference Proceedings: 4th ZEW Conference on the Economics of Innovation and Patenting, Mannheim, Germany.

Brufani.S. (2011). Patent Pools: The road to successfully establishing them. Paper presented at the TTO Circle 1st Plenary Meeting, Noordwijk, the Netherlands. 
Commission of the European Union, \& European Patent Office. (2010, 22 november 2010). Tensions between intellectual property rights and standardisation: reasons and remedies. Paper presented at the Tensions between intellectual property rights and standardisation: reasons and remedies, Brussels, Belgium.

Commission, U. S. F. T. (2011, June 21, 2011). Tools to prevent patent "hold-out" Official Transcript, Washington D.C. .

Dolmans.M. (2013). Trolls and Privateers. Paper presented at the IP and Competition Law IBC 2013, Brussels.

Dolmans.M. (2014). Patent aggregation, disaggregation and innovation Paper presented at the EPO Economic and Scientific Advisotry Board (ESAB), Munich Germany.

Drexl.J. (2011). Competition Law Defenses to Patent Infringement in Germany. Paper presented at the Fordhamipconference, .

Economides.N, \& Himmelberg.C. (1995). Critical mass and network evolution in telecommunications. Paper presented at the Toward a competitive telecommunications industry: Selected papers from the 1994 telecommunications policy research conference.

Farrar.A. (2011). FTC Workshop on Intellectual Property Rights in standard setting: Tools to prevent patent hold-up. Paper presented at the FTC Workshop on Intellectual Property Rights in standard setting: Tools to prevent patent hold-up, Washington D.C.

Hermele, D. (2012). Patent Pools: Pros, cons, misconceptions and recommendations. . Paper presented at the Transparency and Predictability of Licensing in ICT through Patent Pools?, Brussels.

Jakobs.K. (2013). Looking East-How Does Europe Perceive the (Future) Role of China in ICT Standardisation? Paper presented at the Workshop 'A New Wave in Global Standardization from Asia', Seoul, SouthKorea.

Kallay.D. (2008, 4 October 2008 ). China's new anti monopoly law: an international antitrust convergence perspective Paper presented at the Unleashing the Tiger? Competition Law in China and Hong Kong" Conference, Melbourne, Australia.

Kroes.N. (2008, 10 June 2008). Being open about standards. Paper presented at the Open Forum Europe, Brussels.

Kroes.N. (2010, 10 June 2010). How to get more interoperability in Europe

Paper presented at the Open Forum Europe 2010 Summit: 'Openness at the heart of the EU Digital Agenda', Brussels

Masoudi, G. (2007, 10 May 2007). Antitrust Enforcement and Standard Setting: The VITA and IEEE letters and the "IP2" report Paper presented at the Spring Meeting of the American Intellectual Property Law Association Boston, Massachusetts, Boston, Massachusetts USA

Masoudi, G. (2007, 21 July 2007 ). Some comments on the abuse-of-dominance provisions of the China's draft antimonopoly law Paper presented at the UIBE Competition Law Center Conference on abuse of dominant position: theory and practice Beijing

Masoudi.G. (2007, January 18, 2007). Efficiency in analysis of antitrust, standard setting and intellectual property. Paper presented at the High-Level Workshop on Standardization, IP Licensing, and Antitrust Tilburg Law \& Economic Center, Tilburg University, Washington D.C USA.

Murphree.M, \& Breznitz.D. (2011). Standardized Confusion? The Political Logic of China's Technology Standards Policy. Paper presented at the Industry Studies Association Conference.

O'Connell.J. (2008, April 19, 2008). Maximizing Incentives to Innovate Under China's Anti-Monopoly Law: Some Fundamental Principle Paper presented at the Symposium on Innovation and Competition: A Forum on IPR-Related Antitrust Rules, Beijing.

Pate.R. (2002). Antitrust and Intellectual Property. Paper presented at the American Intellectual Property Law Association 2003 Mid-Winter Institute, Marco Island, Florida.

Pattloch.T. (2010, 10 Dec 2010). Patent case law in China and its impact on protection of innovation. Paper presented at the EPIP, Maastricht

Petit.N, \& Neyrinck.N. (2012). Industrial Policy and Competition Enforcement: Is There, Could There and Should There Be a Nexus? Paper presented at the 2012 GCLC Annual Conference, Brussels. http://papers.ssrn.com/sol3/papers.cfm?abstract_id=2225903 
Platt Majoras, D. (2005, 23 September 2005). Recognizing the procompetitive potential of royalty discussions in standard setting. Paper presented at the Standardization and the law: Developing the golden mean for global trade Stanford, California.

Raes.S. (2011, 19-20 December 2011). Patent Pool: a possible means to reduce aggregated royalties. Paper presented at the ITU Workshop on Standards and Intellectual Property Rights (IPR) Issues, New Dehli, India

Ross.R. (2012, 18 April 2012). Building and running a patent pool. Paper presented at the Transparency and Predictability of Licensing in ICT through Patent Pools?, Brussels

Smith.K. (2013). Standardsetting and IP. Paper presented at the IP and Competition Law Conference IBC 2013, Brussels.

Standardization, C. N. I. o. (2008, 18 January 2005). Study on Strategy of Chinese Technical Standards.

Wong-Ervin, K. (2015, 16 April 2015). Antitrust and IP in China: Quo Vadis? Paper presented at the ABA Spring Meeting 2015.

Wright.J. (2013). What Role Should Antitrust Play in Regulating the Activities of Patent Assertion Entities? Paper presented at the Dechert Client Annual Antitrust Spring Seminar, Philadelphia, PA.

\section{Electronic article}

Philips withdraws patents from Chinese DVD-pool (2006). Managing Intellectual Property. Retrieved from http://www.managingip.com/Article/1257473/Philips-withdraws-patent-from-Chinese-DVD-pool.html

Abrams.S. (2013). The Economist Pops the China Patent Bubble. China Hearsay Retrieved from http://www.chinahearsay.com/the-economist-pops-the-china-patent-bubble/

American Bar Association Intellectual Property Committee. (2013). Chinese Court Issues Landmark Decision Determining a FRAND Royalty Rate. tidBits, (1-5 April 2013). Retrieved from http://www.americanbar .org/content/dam/aba/publications/antitrust_law/at315000_tidbits_20130405.authcheckdam.pdf

Aziz. K. (2011). Swimming in the patent pool. Intellectual Property Magazine. Retrieved from http://www.intellectualpropertymagazine.com/patent/swimming-in-the-patent-pool-90246.htm?origin= internalSearch

Bailey.E. (2010). Behavioral economics: implications for antitrust practitioners. The Antitrust Source. Retrieved from http://www.nera.com/content/dam/nera/publications/archive2/PUB_AT_Source_Behavioral.pdf

Balto, A., \& Coffman., B. (2013). Guest Post on Patent Pools and Competition. Patentlyo Retrieved from Guest Post on Patent Pools and Competition website: http://patentlyo.com/patent/2013/03/guest-editorialon-patent-pools-and-competition.html

Barraclough. E. (2013). Concerns raised over Chinese Patent Law amendment Managing Intellectual Property Retrieved from Concerns raised over Chinese Patent Law amendment website: http://www.managingip. com/Article/3194021/Concerns-raised-over-Chinese-patent-law-amendment.html

Barraclough.E, \& Ollier.P. (2006). Philips withdraws patent from Chinese DVD pool. Managing Intellectual Property Magazine. Retrieved from http://www.managingip.com/Article/1257473/Philips-withdrawspatent-from-Chinese-DVD-pool.html

Blenkinsop. P. (2013). EU resistant to China telecoms trade case : Sweden. Reuters.com. Retrieved from EU resistant to China telecoms trade case : Sweden website: http://www.reuters.com/article/2013/04/18/ us-eu-trade-china-idUSBRE93H11Q20130418

Bucknell.D. (2011). China's National Patent Development Strategy (2011-2020). Global Intellectual Property Strategy. Retrieved from http://duncanbucknell.com/2011/02/15/chinas-national-patent-developmentstrategy-2011-2020/

Burns.R. (2007). Will China Become the World Leader in Patent Litigation?. Lexis Nexis China Legal Review. Retrieved from http://www.finnegan.com/resources/articles/articlesdetail.aspx?news=5baf9931-12cd4d65-8f27-4644b9010b98

Cargill. (2012). Technical Standards during 'China's 12th Five Year Plan'. Blogs.adobe.com. Retrieved from http://blogs.adobe.com/standards/2012/08/18/technical-standards-during-chinas-12th-five-year-plan/ 
Chen.S. (2010). Draft provisional rules - national standards involving patents. TwoBirds. Retrieved from http://www.twobirds.com/en/news/articles/2012/draft-provisional-rules-china-national-standardsinvolving-patents

Cohen.M. (2013). Qualcomm Subject of AML Investigation - Other Developments on the Way. chinaipr.com. Retrieved from http://chinaipr.com/2013/11/26/qualcomm-subject-of-aml-investigation-other-developments-on-the-way/

Cohen.M. (2013). Through a Glass Less Darkly: China's March to Administrative Enforcement Transparency China IPR. Retrieved from http://chinaipr.com/2013/11/24/through-a-glass-less-darkly-chinas-march-toadministrative-enforcement-transparency/

Cohen.M. (2014). Microsoft under Chinese Antitrust Scrutiny? China IPR. Retrieved from http://chinaipr.com/2014/07/29/microsoft-under-chinese-antitrust-scrutiny/

Cohen.M. (2014). A Quick Report on the MIIT Conference Including SAIC's IP Abuse Rules, Patent Law Amendments, MIIT Standardization Policies, Standards and IP Abuse... China IPR. Retrieved from China IPR website: A Quick Report on the MIIT Conference Including SAIC's IP Abuse Rules, Patent Law Amendments, MIIT Standardization Policies, Standards and IP Abuse... China IPR - Intellectual Property Developments in China.mht!http://chinaipr.com/2014/12/11/a-quick-report-on-the-miit-conferenceincluding-saics-ip-abuse-rules-patent-law-amendments-miit-standardization-policies-standards-and-ipabuse/

Cohen.M. (2014). Some Comments on MIIT's Template for IP Policies in Industry Standards Organizations China IPR. Retrieved from http://chinaipr.com/2014/11/28/some-comments-on-miits-template-for-ippolicies-in-industry-standards-organizations/

Cohen.M. (2014). SPC Publishes Revised Judicial Interpretation on Patent Infringement Litigation for Public Comments chinaipr.com. Retrieved from http://chinaipr.com/2014/07/19/spc-publishes-revised-judicialinterpretation-on-patent-infringement-litigation-for-public-comments/

Cohen.M. (2014). SPC Publishes Revised Judicial Interpretation on Patent Infringement Litigation for Public Comments China IPR. Retrieved from http://chinaipr.com/2014/07/19/spc-publishes-revised-judicialinterpretation-on-patent-infringement-litigation-for-public-comments/

Cohen.M. (2014). State Council's New Opinion on Market Order CHINA IPR. Retrieved from http://chinaipr.com/2014/07/16/state-councils-new-opinion-on-market-order/

Cohen.M. (2014). Update on Specialized IP Courts China IPR. Retrieved from China IPR website: http://chinaipr.com/2014/10/31/update-on-specialized-ip-courts/

Cohen.M. (2015). A Quick Report on the EIPC MIIT Conference Including SAIC's IP Abuse Rules, Patent Law Amendments, EIPC MIIT Standardization Policies, Standards and IP Abuse.... China IPR. Retrieved from http://chinaipr.com/2014/12/11/a-quick-report-on-the-miit-conference-including-saics-ip-abuse-rulespatent-law-amendments-miit-standardization-policies-standards-and-ip-abuse/

Commission of the European Union. (2007). EU-US Summit - Washington, 30 April 2007. L'Union europenne dans le monde. Retrieved from http://www.eu-un.europa.eu/articles/fr/article_6991_fr.htm

Dummett.B. (2011). Nokia Sells 2,000 Patents Mosaid Technologies Will Share in Revenue Wrung From Wireless Know-How The Wall Street Journal Tech. Retrieved from http://online.wsj.com/news/articles/ SB10001424053111904716604576544441441198816

Emch.A. (2013). High tech under scrutiny in China. Kluwer Competition Law Blog. Retrieved from http://kluwercompetitionlawblog.com/2013/05/17/high-tech-under-scrutiny-in-china/

Gilbert.D. (2014). Xiaomi smartphones banned from sale in India over patent dispute. International Business Times Retrieved from http://www.ibtimes.co.uk/xiaomi-smartphones-banned-sale-india-over-patentdispute-1479045

Han.M. (2013). Huawei v. InterDigital: China at the Crossroads of Antitrust and Intellectual Property, Competition and Innovation. Competition Policy International (CPI). Retrieved from https://www.competitionpolicyinternational.com/huawei-v-interdigital-china-at-the-crossroads-of-antitrust-and-intellectualproperty-competition-and-innovation/ 
Heinze.W. (2005). FTC Chairman Addresses Patentee "Hold-Up" of Standards-Setting Organizations. I/P Updates. Retrieved from FTC Chairman Addresses Patentee "Hold-Up" of Standards-Setting Organization website: http://ip-updates.blogspot.nl/2005/09/ftc-chairman-addresses-patentee-hold.html

Heyue.P. (2010). China's Indigenous Innovation Policy and its Effect on Foreign Intellectual Property Rights Holders. China Law Insight. Retrieved from http://www.chinalawinsight.com/2010/09/articles/ intellectual-property/chinas-indigenous-innovation-policy-and-its-effect-on-foreign-intellectual-property-rightsholders/

Hongjian.C. (2013). The Transatlantic Trade and Investment Partnership: Origins, Objectives and Impact. China International Studies,(September/October 2013)

p.100-118

Retrieved from http://www.ciis.org.cn/english/2013-11/07/content_6440336.htm

Ingen-Housz.C, Batchelor.B, \& Jing-Legrand.H. (2012). Resale price maintenance (RPM) investigated by Chinese regulator

Competition Law Insight. Retrieved from http://www.competitionlawinsight.com/regulatory/daimler-in-china61144.htm

Intellectual Ventures. (2014). Mitigating the Invention Gap. Intellectual Ventures Retrieved from http://www.intellectualventures.com/license/licensing-overview/

Liyao.L. (2011). Top 10 greatest inventions of ancient China. China.org.cn. Retrieved from http://www.china.org.cn/top10/2011-03/04/content_22054243_8.htm

Mallinson.K. (2013). Absurd (F)RAND licensing-rate determinations for SEPs. IP Finance Retrieved from Absurd (F)RAND licensing-rate determinations for SEPs website: http://ipfinance.blogspot.nl/2013/11/absurdfrand-licensing-rate.html

Mallinson.K. (2014). Licensing mobile technology will become even more essential FierceWirelessEurope. Retrieved from FierceWirelessEurope website: http://www.fiercewireless.com/europe/story/mallinsonlicensing-mobile-technology-will-become-even-more-essential/2014-11-26

Millien.R. (2012 ). Defensive Patent Pools: There are Surprisingly Few Options IP Watchdog Retrieved from http://www.ipwatchdog.com/2012/12/10/defensive-patent-pools-there-are-surprisingly-few-options$2 /$ id $=31233 /$

Mueller.F. (2012). Companies worth \$1 trillion are suing others over Android's alleged patent infringement FOSS Patents. Retrieved from http://www.fosspatents.com/2012/07/companies-worth-1-trillion-aresuing.html

Mukherjee.S, \& Alawadhi.N. (2013). China probe may be aimed at Qualcomm's 4G royalties. Reuters.com. Retrieved from http://www.reuters.com/article/2013/11/26/us-qualcomm-china-idUSBRE9AO0E820131126

National Intellectual Property Strategy of China. (2010). China's Intellectual Property Protection in 2009. Retrieved from National Intellectual Property Strategy of China website: http://www.nipso.cn/ onews.asp?id=9599

Ning.S, Peng. K, \& Wei.L. (2015). NDRC's Qualcomm Decision: A warning to patent-heavy companies China Law Inight. Retrieved from http://www.chinalawinsight.com/2015/03/articles/corporate/antitrustcompetition/ndrcs-qualcomm-decision\%EF\%BC\%9Aa-warning-to-patent-heavy-companies/

Ong.R. (2011). Strategies for Participating in China's Standards Regime. China Business Review. Retrieved from http://www.chinabusinessreview.com/strategies-for-participating-in-chinas-standards-regime/

Parr.B. (2012). Jobs gets wish in 'thermonuclear war,' at least for now. cnet. Retrieved from http://www.cnet.com/news/jobs-gets-wish-in-thermonuclear-war-at-least-for-now/

Patent Freedom. (2014). Exposure by Industry. Patent Freedom. Retrieved from https://www. patentfreedom. com/about-npes/industry/

Petit, N. (2014). 'Stealth Licensing'-Or Antitrust Law and Trade Regulation Squeezing Patent Rights. Available at SSRN 2426782. Retrieved from http://papers.ssrn.com/sol3/papers.cfm?abstract_id=2426782

Quinney.J, \& Jephcott.M. (2012). China's MOFCOM clears Google/Motorola with conditions: another example of China's divergence from the EU and US antitrust regimes? Lexology Retrieved from http://www.lexology.com/library/detail.aspx?g=e790bcc5-5f9e-4ce5-bed7-737ff9ba5501 
Ress.M. (2014). Leaked EU analysis of TTIP IPR negotiations. Knowledge Ecology International Retrieved from http://keionline.org/node/1984

Saunders.S. (2013). German Court Rules in Huawei vs ZTE. Lightreading networking the telecom industry. Retrieved from German Court Rules in Huawei vs ZTE website: http://www.lightreading.com/financial/ german-court-rules-in-huawei-vs-zte/d/d-id/701924

Scissors.D (2013). Theft by other means: China"a assault on foreign companies. AEldeas (American Enterprise Institute 19 December ) https://www.aei.org/publication/theft-by-other-means-chinas-assault-onforeign-companies/Shira.D. (2012). Comments Sought for Draft Revision to Patent Law. China Briefing Retrieved from Comments Sought for Draft Revision to Patent Law website: http://www.chinabriefing.com/news/2012/08/16/comments-sought-for-draft-revision-to-patent-law.htmlState Intellectual Property Office of the People's Republic of China (SIPO). (2012). Comments Sought for Draft Revision to Patent Law. China Briefing. Retrieved from http://www.china-briefing.com/news/2012/08/16/comments-sought-for-draft-revision-to-patent-law.html

Steinbock.D. (2013, October 14). The Emerging US-EU-Asia Trade Triangle. China US Focus. Retrieved from China US Focus website: http://www.chinausfocus.com/finance-economy/the-emerging-us-eu-asiatrade-triangle/

Tiezzi.S. (2013). US Clash Kills IT Trade Agreement. The Diplomat. Retrieved from http://thediplomat.com/ 2013/11/china-u-s-clash-kills-it-trade-agreement/

Wang.P. (2007 ). New Chinese Anti-Monopoly Law. Jones Day. Retrieved from http://www.jonesday.com/ New_Chinese_Anti-Monopoly_Law/

Willingwyre.G. (2010). Inside Views: China's Latest Draft Disposal Rules For Patents In Standards A Step Forward? Intellectual Property Watch. Retrieved from http://www.ip-watch.org/2010/04/01/china\%E2 $\% 80 \% 99$ s-latest-draft-disposal-rules-for-patents-in-standards-a-step-forward/

Winn.J. (2009). ICT Standards and Indigenous Innovation in China. Talk Standards. Retrieved from http://www.talkstandards.com/ict-standards-and-indigenous-innovation-in-china-jane-k-winn/\#

Wong-Ervin.K. (2013). Chinese Court Issues Landmark Decision Determining a FRAND Royalty Rate. ABA Intellectual Property Committee tidBits Retrieved from http://www.americanbar.org/content/dam/aba/ publications/antitrust_law/at315000_tidbits_20130405.authcheckdam.pdf

Ying.L. (2008). BCCC cautiously optimistic over impact on FDI of new Anti-Monopoly Law. China Intellectual Property, 21. Retrieved from http://www.chinaipmagazine.com/en/journal-show.asp?id=401

Yong.H. (2008). The concept of "abuse of IPRs" in Anti-Monopoly Law. China Intellectual Property Magazine, Volume 21 2008. Retrieved from http://www.chinaipmagazine.com/en/journal-show.asp?id=399

Yong.H. (2010). Basic IP Principles of Antitrust Law. China Intellectual Property Magazine. Retrieved from http://www.chinaipmagazine.com/en/journal-show.asp?id=640

\section{Generic source}

Blumenfeld.J. (2007). Antitrust risk in patent pools and SSOs avoiding price-fixing, exclusionairy conduct Washington D.C.: Crowell and Moring

CEN-CENELEC. (2014). Guidance documents Faster delivery of European Standards and other deliverables

Commission of the European Union. (1992). Communication from the Commission 'Intellectual property rights and standardisation' (COM (92) 445 Final ed.). Brussels: Commission of the European Union.

Commission of the European Union. (2008). 2010-2013 ICT Standardisation Work Programme for industrial innovation. Brussels: Commission of the European Union.

Commission of the European Union. (2008). Communication from the Commission to the European Parliament, the Council and the European Economic and Social Committee An Industrial Property Rights Strategy for Europe (pp. 20). Brussels: European Union

Commission of the European Union. (2008). Towards an increased contribution of standardisation to innovation in Europe; Communication of the Commission to the Council, the European Parliament and the Economic and Social Committee Brussels: The Commission of the European Union 
Commission of the European Union. (2010). An Integrated Industrial Policy for the Globalisation Era Putting Competitiveness and Sustainability at Centre Stage (Vol. SEC(2010) 1272/SEC(2010) 1276). Brussels.

Commission of the European Union. (2011). Building Bridges Between the U.S. and EU Standards Systems. In T. E. Council (Ed.). Brussels: European Union

Commission of the European Union. (2012). Antitrust: Commission opens proceedings against Motorola. Brussels: European Union.

Commission of the European Union. (2012). Commission Staff Working Document /Annual European standardisation work programme 2012. Brussels: The European Union

Commission of the European Union. (2012). Memo Samsung - Enforcement of ETSI standards essential patents (SEPS). Brussels: Commission of the European Union.

Commission of the European Union. (2012). Samsung - Enforcement of ETSI standards essential patents (SEPs). Brussels: European Union

Commission of the European Union. (2013). Antitrust: Commission sends Statement of Objections to Motorola Mobility on potential misuse of mobile phone standard-essential patents. Brussels.

Commission of the European Union. (2013). EU-US Transatlantic Trade and Investment Partnership Technical barriers to Trade Initial EU Position Paper. Brussels European Union

Commission of the European Union. (2013). Public consultations Draft proposal for a revised block exemption for technology transfer agreements and for revised guidelines. Brussels: Commission of the European Union.

Commission of the European Union. (2013). TTIP position paper on technical barriers /Initial EU Position Paper on TTIP: Technical Barriers to Trade Brussels.

Commission of the European Union. (2014). Antitrust: Commission accepts legally binding commitments by Samsung Electronics on standard essential patent injunctions Brussels: European Union.

Commission of the European Union. (2014). Antitrust: Commission finds that Motorola Mobility infringed EU competition rules by misusing standard essential patents. Brussels: European Union.

Commission of the European Union. (2014). Guidelines on the application of Article 101 of the Treaty on the Functioning of the European Union to technology transfer agreements Brussels: Commission of the European Union.

Commission of the European Union. (2014). Introductory remarks on Motorola and Samsung decisions on standard essential patents (pp. Press Release). Brussels: Commission of the European Union.

Digital Video Broadcasting Project (DVB). (2008). IPR Policy. Geneva, Switzerland DVB.

Ericsson. (2013). Ericsson's comments on DG COMP's draft proposal for a revised block exemption for technology transfer agreements and for revised guidelines (pp. 3). Stockholm Sweden: TELEFONAKTIEBOLAGET LM ERICSSON.

European Chemical Industry Council. (2013). The European Chemical Industry Comments on the Commission proposal for revised competition regime for Technology Transfer Agreements. Brussels: European Chemical Industry Council.

European Telecommunications Standards Institute. (2013). ETSI Rules of Procedure, 20 March 2013 Annex 6: ETSI Intellectual Property Rights Policy.

European Telecommunications Standards Institute. (2014). ETSI IPR policy. Sophia Antipolis France: ETSI.

European Union and the United States. (2007). Framework for advancing transatlantic economic integration between the European Union and the United States of America Washington D.C.: The European Union and the United States

Gallagher.P. (2011). Standardization Feedback for Sub-Committee on Standards Comments of the American Intellectual Property Law Association (AIPLA) (18 February 2011 ed.). Arlington USA: American Intellectual Property Association

Hu.K. (2011). Huawei Open letter (pp. Statement by Deputy Chairman of Huawei Technologies, Chairman of Huawei USA

Huawei.

International Organization for Standardization (ISO). (1991). ISO/IEC Guide 2:2004 Standardization and related activities -- General vocabulary (Vol. Guide 2:2004). Geneva, Switzerland: ISO. 
Kamerling.A, Gillespie.D, \& Rees.M. (2013). Proposed Amendments to EU law on Technology Transfer Agreements: DLA Piper.

Leveque.F. (2008). Standards and Patent Hold-up. Zurich Switzerland: ETH.

Ministry of Industry and Information Technology of the People's Republic of China (MIIT). (2014). MIIT's Template for IP Policies in Industry Standards Organizations Beijing Ministry of Industry and Information Technology of the People's Republic of China (MIIT).

Moga.T. (2012). China's Utility Model Patent System: Innovation Driver or Deterrent Asia U.S. Chamber of Commerce: U.S. Chamber of Commerce.

Qualcomm. (2015). Qualcomm Press Release, “Qualcomm and China's National Development and Reform Commission Reach Resolution -NDRC Accepts Qualcomm's Rectification Plan -Qualcomm Raises Midpoints of Fiscal 2015 Revenue and Non-GAAP EPS Guidance.

Solow.M. (1987). Prize lecture Growth Theory and After, The Sveriges Risksbank Prize in Economic Sciences in Memory of Alfred Nobel.

Standardization Administration of China. (2009). Proposal by Standardization Administration of China (SAC) "Regulations on Administration of Formulating and Revising National Standards Involving Patents". Beijing China: Standardization Administration of China.

State Administration for Industry and Commerce of the People's Republic of China. (2012 ). Guide on antimonopoly law enforcement in the field of intellectual property rights (Fifth draft) (Vol. Fifth Draft ). Beijing State Administration for Industry and Commerce odf the People's Republic of China.

Supreme Court of the People's Republic of China. (2004). Interpretation of the Supreme People's Court concerning Some Issues on Application of Law for the Trial of Cases on Disputes over Technology Contracts (Promulgated December 16th, 2004, Effective January 1st, 2005). Beijing China.

Supreme Court of the People's Republic of China. (2004). Interpretation of the Supreme People's Court concerning Some Issues on Application of Law for the Trial of Cases on Disputes over Technology Contracts Beijing: Supreme Court of the People's Republic of China.

Supreme Court of the People's Republic of China. (2008). Letter of the Supreme People's Court on the Issue of Whether the Exploitation of a Patent in the Specification for the Design of Ram-compaction Piles with a Composite Bearing Base, an Industry Standard Issued by the Ministry of Construction, by Chaoyang Xingnuo Company Which Has Conducted Design and Construction according to the Standard Constitutes a Patent Infringement. Beijing: Supreme Court of the People's Republic of China.

Wang.C. (2009). Study on Patents involved in National Standards (pp. 24). Beijing: China National Institute of Standardisation.

World Trade Organization. (2006). Fourth Triennial Review of the Operation and Implementation of the Agreement on Technical Barriers to Trade under Article 15.4. Geneva

Xianlin.W. (2010). Identification of Abuse of Intellectual Property Rights and Monopoly Conducts Changsha: Law School of Shanghai Jiao Tong University

Zhuoliang.M, \& Rongping.W. (2005). The role of standards in national technology policy in China: Chinese Academy of Sciences.

\section{Government documents}

Barnett.T. (2007). Maximizing welfare through technological innovation Washington D.C.: U.S. Department of Justice Retrieved from http://www.justice.gov/atr/public/speeches/227291.pdf.

Barnett.T. (2008). Response to RFID Consortium LLC's Request for Business Review Letter.mht. Washington D.C.: Retrieved from http://www.justice.gov/atr/public/busreview/238429.htm.

Espinel.V. (2010). 2010 Joint Strategic Plan on Intellectual Property Enforcement. Washington D.C. : Retrieved from http://www.whitehouse.gov/sites/default/files/omb/assets/intellectualproperty/intellectualproperty_strategic_plan.pdf. 
Executive Office of the President of the United States. (2010). 2010 Joint Strategic Plan on Intellectual Property Enforcement. Washington D.C.: Retrieved from https://www.whitehouse.gov/sites/default/files/omb/ assets/intellectualproperty/intellectualproperty_strategic_plan.pdf.

Froman.M. (2013). Remarks by U.S. Trade Representative Michael Froman on the United States, the European Union, and the Transatlantic Trade and Investment Partnership. Washington D.C.: Office of the United States Trade Representative Retrieved from https://ustr.gov/about-us/policy-offices/press-office/ speeches/transcripts/2013/september/froman-us-eu-ttip.

Government of the People's Republic China. (2005). Government of China, "Intellectual Property Right (IPRs) Issues in Standardization, Communication from the People's Republic of China, (G/TBT/W/251, 25 May 2005). Geneva World Trade Organization Retrieved from www.wto.org.

Klein.J. (1997). Business Review Letter MPEG-2 Washington D.C. : United States Department of Justice Retrieved from http://www.justice.gov/atr/public/busreview/215742.htm.

Ministry of Science and Technology. Ministry of Finance and State Administration of Taxation of the People's Republic of China. (2008). Notice of the Ministry of Science and Technology, Ministry of Finance and State Administration of Taxation on Issuing the Administrative Measures for Determination of High and New Tech Enterprises Beijing: Retrieved from http://www1.lawinfochina.com/display.aspx?lib=law\& $\mathrm{id}=6795$.

Office of the Inter-Ministerial Joint Meeting for Implementation of the National Intellectual Property Strategy of the People's Republic of China. (2013). Promotion Plan for the Implementation of the National Intellectual Property Strategy in 2013. Beijing Office of the Inter-Ministerial Joint Meeting for Implementation of the National Intellectual Property Strategy of the People;s Republic of China Retrieved from http://www.cipnews.com.cn/showArticle.asp?Articleid=26744.

Pangratis, A. (2014). EU statement on 5th Trade Policy Review of China. Geneva European Union Retrieved from http://trade.ec.europa.eu/doclib/docs/2012/june/tradoc_149542.pdf.

Pangratis.A. (2012). EU Statement By EU Ambassador to the World Trade Organisation Angelos Pangratis Fourth Trade Policy Review of China. European Union Retrieved from http://trade.ec.europa.eu/doclib/ docs/2012/june/tradoc_149542.pdf.

Standards Administration Commission of China (SAC). (2009). Draft Rules on National Standards involving Patents. Beijing The Standards Administration Commission of China (SAC) Retrieved from http://english.sipo.gov.cn/laws/developing/201204/t20120410_667158.html.

Standards Administration of China (SAC). (2009). Draft "Provisional Rules Regarding Administration of the Establishment and the Revision of National Standards Involving Patents" Beijing: Standards Administration of China (SAC) Retrieved from http://www.sac.gov.cn/templet/default/ShowArticle.jsp?id=5298 [^].

State Council of the People's Republic of China. (2014). Several Opinions of the State Council on Promoting Fair Market Competition and Maintaining Normal Market Order. Beijing Retrieved from http://www.gov.cn/english/official/2014-07/22/content_2722344.htm.

State Council of the People's Republic of China. (2008). Outline of the National Intellectual Property Strategy Beijing Retrieved from http://www.gov.cn/english/2008-06/21/content_1023471.htm.

State Council of the People's Republic of China. (2010). Decision of the State Council on Accelerating the Fostering and Development of Strategic Emerging Industries. Beijing State Council of China Retrieved from http://www.lawinfochina.com/display.aspx?lib=law\&id=8570.

State Intellectual Property Office of the People;s Republic China (SIPO). (2010). Chinese National Patent Development Strategy (2011-2020) Beijing: SIPO Retrieved from www.chinaipr.gov.cn/newsarticle/ news/.../201011/977969_1.html.

State Intellectual Property Office of the People's Republic of China (SIPO). (2012). Promotion Plan for the Implementation of the National Intellectual Property Strategy in 2012. Beijing SIPO Retrieved from http://english.sipo.gov.cn/laws/developing/201204/t20120410_667158.html.

United States Chamber of Commerce. (June 25, 2010). Comments in Response to Draft Guidelines on the Applicability of Article 101 of the Treaty on the Functioning of the European Union to Horizontal Cooperation Agreements. Washington D.C. : U.S. Chamber of Commerce Retrieved from http://ec.europa.eu/ competition/consultations/2010_horizontals/usa_chamcom_en.pdf. 
United States Department of Commerce. (2014). Fact Sheet: 25th U.S.-China Joint Commission on Commerce and Trade. Washington D.C. : United States Department of Commerce Retrieved from http://www.commerce.gov/print/news/fact-sheets/2014/12/19/fact-sheet-25th-us-china-jointcommission-commerce-and-trade.

United States Department of Justice. (1998). Response To Koninklijke Philips Electronics, N.V.'s, Sony Corporation Of Japan's And Pioneer Electronic Corporation Of Japan's Request For Business Review Letter. Washington D.C.: United States Department of Justice Retrieved from http://www.justice.gov/atr/responsekoninklijke-philips-electronics-nvs-sony-corporation-japans-and-pioneer-electronic.

United States Department of Justice. (1999). DVD 6C Business Review Letter. Washington D.C. : United States Department of Justice Retrieved from http://www.justice.gov/atr/public/busreview/2485.pdf.

United States Department of Justice. (1999). Response To Hitachi, Ltd.'s, Matsushita Electric Industrial Co., Ltd.'s, Mitsubishi Electric Corporation's, Time Warner Inc. 's, Toshiba Corporation's, And Victor Company Of Japan, Ltd.'s Request For Business Review Letter. Washington D.C.: United States Department of Justice Retrieved from http://www.justice.gov/atr/response-hitachi-Itds-matsushita-electric-industrial-coItds-mitsubishi-electric-corporations.

United States Department of Justice. (2002). 3G Patent Platform Partnership Business Review Letter. Washington D.C.: United States Department of Justice, Retrieved from http://www.justice.gov/archive/atr/public/ busreview/200455.htm.

United States Department of Justice. (2002). Business Review Letter $3 G$ Patent Platform Partnership Washington D.C.: Retrieved from http://www.justice.gov/sites/default/files/atr/legacy/2006/04/27/200455.pdf.

United States Department of Justice. (2008). Business Review Letter to RFID Consortium LLC. Washington D.C.: United States Department of Justice Retrieved from http://www.justice.gov/archive/atr/public/busreview/ 238429.htm.

United States Department of Justice. (2013). Response To Intellectual Property Exchange International, Inc.'s Request For Business Review Letter. Washington D.C.: United States Department of Justice Retrieved from http://www.justice.gov/atr/response-intellectual-property-exchange-international-incs-request-businessreview-letter.

United States Department of Justice, \& Federal Trade Commission. (1995). Antitrust Guidelines for the Licensing of Intellectual Property. Washington D.C. : Retrieved from http://www.justice.gov/atr/public/guidelines/ 0558.pdf.

United States Federal Trade Commission. (1997). In the Matter of Ciba-Geigy Limited, Ciba-Geigy Corporation, Chiron Corporation, Sandoz Ltd., Sandoz Corporation, and Novartis AG. (C-3725

Washington D.. United States Federal Trade Commission Retrieved from https://www.ftc.gov/enforcement/cases-proceedings/961-0055/ciba-geigy-limited-sandoz-ltd-novartis-ag-et-al-matter.

United States Federal Trade Commission. (2012). Analysis of the proposed consent order to aid public comment In the Matter of Motorola Mobility LLC and Google Inc.,. Washington D.C.: United States Federal Trade Commission Retrieved from https://www.ftc.gov/sites/default/files/documents/cases/2013/01/ 130103googlemotorolaanalysis.pdf.

United States Federal Trade Commission. (2013). Analysis of Proposed Consent Order to aid public comment In the Matter of Motorola Mobility LLC and Google Inc.,. Washington D.C.: United States Federal Trade Commission Retrieved from http://www.ftc.gov/sites/default/files/documents/cases/2013/01/130103 googlemotorolaanalysis.pdf.

United States International Trade Commission. (2009, March). Section 337 Investigations Answers to Frequently Asked Questions. Washington DC 20436: United States International Trade Commission Retrieved from http://www.usitc.gov/intellectual_property/documents/337_faqs.pdf.

United States Standards Strategy Committee. (2010). United States Standards Strategy. New York: American National Standards Institute Retrieved from http://publicaa.ansi.org/sites/apdl/Documents/Standards \%20Activities/NSSC/USSS_Third_edition/USSS\%202010-sm.pdf. 


\section{Hearing}

Will China protect intellectual property? New developments in counterfeiting, piracy, and forced technology transfer, Congressional-Executive Commission on China, One Hundred Eleventh Congress Second Session Sess. 56 (2010).

Hearing: Assessing China's Efforts to Become an "Innovation Society" - A Progress Report, (2012).

Statement of FTC Chairman Deborah Platt Majoras Before the Antitrust Modernization Commission Concerning Modernization of Antitrust Law, (2006).

Hearing: China's Five-Year Plan, Indigenous Innovation and Technology Transfers, and Outsourcing, (2011).

Assessing China's Efforts to Become an Innovation Society A Progress Report, (2012).

Will China protect intellectual property? New developments in counterfeiting, piracy and force technology transfer. Hearing before the Congressional-Executive Commission on China. One hundred eleventh Congress Second Session (2010).

\section{Journal article}

Allen, R., \& Sriram, R. (2000). The role of standards in innovation. Technological Forecasting and Social Change, 64(2), 171-181.

Amir, R., \& Lazzati, N. (2011). Network effects, market structure and industry performance. Journal of Economic theory, 146(6), 2389-2419.

Andewelt. R. (1984). Analysis of patent pools under the antitrust laws. Antitrust Law Journal, Vol. 53, No. 3(National Institute on Industrial and Intellectual Property), 611-639.

Baron, J., \& Delcamp, H. (2010). Strategic inputs into patent pools. CERNA Mines ParisTech Working Pa$\operatorname{per}(2010), 05$.

Bekkers, R., Verspagen, B., \& Smits, J. (2002). Intellectual property rights and standardization: the case of GSM. Telecommunications Policy, 26(3), 171-188.

Besen, S., \& Farrell, J. (1994). Choosing how to compete: Strategies and tactics in standardization. Journal of economic perspectives, 8, 117-117.

Blind, K., \& Jungmittag, A. (2005). Trade and the Impact of Innovations and Standards: The Case of Germany and the UK. Applied Economics, 37(12), 1385-1398.

Blind, K., \& Jungmittag, A. (2008). The impact of patents and standards on macroeconomic growth: a panel approach covering four countries and 12 sectors. Journal of Productivity Analysis, 29(1), 51-60.

Block.J, \& Kollinger.P. (2007). Peer Pressure in Network Markets: An Empirical Investigation. Schmalenbach Business Review, 59(4).

Bohannon C. (2011). IP Misuse and Foreclosure, lowa Law Review, 96 IOWA L. REV. 475

Bonadio.E. (2013). Standardization agreements, intellectual property rights and anti-competitive concerns. Queen Mary Journal of Intellectual Property(1), 22-42.

Brodley.J. (1987). The Economic Goals of Antitrust: Efficiency, Consumer Welfare, and Technoclogical Progress. NYUL Rev., 62, 1020.

Cantwell.J, \& Piscitello.L. (2002). The location of technological activities of MNCs in European regions: The role of spillovers and local competencies. Journal of International Management, 8(1), 69-96.

Chen, M., Xiaoyang, \& Mattoo, A. (2008). Regionalism in standards: good or bad for trade? Canadian Journal of Economics/Revue canadienne d'économique, 41(3), 838-863.

Cheng.T. (2012). A Developmental Approach to the Patent-Antitrust Interface. Northwestern Journal of International Law and Business, 33(1), 1-79.

Chien, C., \& Lemley, M. (2012). Patent holdup. the ITC and the public interest Cornell Law Review, 98(1).

Choi.J. (2010). Patent pools and cross-licensing in the shadow of patent litigation. International Economic Review 51(2), 441-460.

Choumelova.D. (2003). Competition law analysis of patent licensing arrangements - the particular case of 3G3P. Competition Policy Newsletter, Number 1 Spring 2003. 
Cohen.M. (2014). China's Antitrust Enforcement Continues to Grab the Domestic and International Spotlight chinaipr.com.

Colangelo.G. (2004). Avoiding the tragedy of the anticommons: collective rights organizations, patent pools and the role of antitrust. LUISS Law and Economics Lab Working Paper (No. IP-01-2004)

Coppi.L, \& Trento.S. (2012). Patent Wars and Technology Transfer Agreements: Should the EU Rules Change? Antitrust Chronicle, 4.

Dolmans.M. (2010). A Tale of Two Tragedies-A plea for open standards. International Free and Open Source Software Law Review, 2(2), 115-136.

Dolmans.M, \& Ilan.D. (2012). European Antitrust and Patent Acquisitions: Trolls in the Patent Thickets. Competition L. Int'l, 8, 7 .

Drahos.P, \& Maher.I. (2004). Innovation, competition, standards and intellectual property: policy perspectives from economics and law. Information Economics and Policy, 16(1), 1-11.

Economides.N. (1996). Network externalities, complementarities, and invitations to enter. European Journal of Political Economy, 12(2), 211-233.

Economides.N. (2006). Competition policy in network industries: an introduction. The New Economy and Beyond. Cheltenham, UK and Northampton, Mass.: Edward Elgar, 96-121.

Economides.N, \& Skrzypacz.A. (2003). Standards Coalitions Formation and Market Structure in Network Industries. Stern School of Business, NYU Working Paper.

Eltzroth.C. (2008). IPR Policy of the DVB Project: Negative Disclosure, FR\&ND Arbitration Unless Pool Rules OK Part 1. International Journal of IT Standards and Standardization Research (IJITSR), 6(2), 21-47.

Emch.A. (2014). Chinese Antitrust Institutions-Many Cooks in the Kitchen. Competition Policy international.

Ernst, D., Lee, H., \& Kwak, J. (2014). Standards, innovation, and latecomer economic development: Conceptual issues and policy challenges. Telecommunications Policy, 38(10), 853-862.

Ernst.D. (2013). America's voluntary standards systems: a'best practice'model for Asian innovation policies? Policy Studies, No.66.

Ernst.D, \& Kim.L. (2002). Global production networks, knowledge diffusion, and local capability formation. Research policy, 31(8), 1417-1429.

Evans.D, Zhang.V, \& Zhang.X. (2014). Assessing Unfair Pricing Under China's Anti-Monopoly Law for Innovation-Intensive Industries. Competition Policy International 10 (One Spring 2014), 46.

Evans.D., \& Zhang.V. (2013). The Qihoo v. Tencent Landmark Decision. Competition Law International

Farrell.J, Hayes, J., Shapiro.C, \& Sullivan.T. (2007). Standard setting, patents, and hold-up. Antitrust Law Journal(3), 603-670.

Farrell.J, \& Shapiro.C. (2008). How strong are weak patents? The American economic review, 1347-1369.

Faure, M., \& Zhang.X. (2013). Towards an Extraterritorial Application of the Chinese Anti-Monopoly Law That Avoids Trade Conflicts. Geo. Wash. Int'I L. Rev., 45, 501.

Feldman.R. (2008). Patent and Antitrust: Differing Shades of Meaning. Virginia Journal of Law and Technology, 13(2), 5-7.

Fomin.V, Su.J, \& Gao.P. (2011). Indigenous standard development in the presence of dominant international standards: The case of the AVS standard in China. Technology Analysis \& Strategic Management, 23(7), 745-758.

Gallasch.S. (2013). The referral of Huawei v ZTE to the CJEU:Determining the futureof remedies in the context of standard-essential patents. European Competition Law Review, 34(8).

Gallini.N. (2011). Competitive Price Coordination in Technology Sharing Agreements. Economics working papers / Vancouver School of Economics.

Gandal.N. (2002). Compatibility, standardization, and network effects: Some policy implications. Oxford Review of Economic Policy, 18(1), 80-91.

Geradin.D. (2013). The European Commission policy towards the licensing of standard-essential patents: where do we stand? Journal of Competition Law and Economics, 9(4), 1125-1145.

Geradin.D, \& Layne-Farrar.A. (2007). The logic and limits of ex ante competition in a standard-setting environment. Competition Policy International, 3(1), 79-106. 
Gilbert.R. (2004). Antitrust for patent pools: A century of policy evolution. Stanford Technology Law Review, 2004.

Gilbert.R. (2010). The Essentialty Test for Patent Pools. University of California, Berkeley From the SelectedWorks of Richard J Gilbert.

Gu.S, \& Lundvall.B. (2006). China's innovation system and the move toward harmonious growth and endogenous innovation. Innovation: management, policy \& practice, 8(1), 1-26.

Guangzhou Hu.A. (2010). Propensity to Patent, Competition and China's Foreign Patenting Surge. Research Policy, 39(7), 985-993.

Hadjis.A. (2004). Patent pools gain popularity. The National Law Journal

Heller.M, \& Eisenberg.R. (1998). Can patents deter innovation? The anticommons in biomedical research. Science Magazine, 280(5364), 698-701.

Hemphill.T, \& Vonortas.S. (2005). U.S. Antitrust Policy, Interface Compatibility Standards, and Information Technology. Knowledge, Technology \& Policy, 18(2), 40.

Henderson, J., Dicken, P., Hess, M., Coe, N., \& Yeung, H. W.-C. (2002). Global production networks and the analysis of economic development. Review of international political economy, 9(3), 436-464.

Homiller.D. (2006). Patent Misuse in Patent Pool Licensing: From National Harrow to" The Nine No-Nos" to Not Likely. Duke L. \& Tech. Rev., 2006, 7-20.

Hovenkamp.E. (2013). Tacit Patent Pooling. SSRN Electronic Journal 05/2013. doi: 10.2139

Hovenkamp.H. (2010). Patent Deception in Standard Setting: The Case for Antitrust Policy. University of lowa Legal Studies Research Paper.

Hovenkamp.H. (2011). Notice and Patent Remedies. Tex. Law Rev., 88, 221.

Hovenkamp.H. (2014). Consumer Welfare In Competition And Intellectual Property Law. Competition Policy International, 9(53).

Huang.T, Gao.W, \& Reader.C. (2006). A New Approach for Developing Open Standards with a More Reasonable Patent Licensing Policy. The Chinese Academy of Sciences.

Jing.H. (2014). China Patent: Standards and patent policy finally issued. Managing IP.

Jodar-Rossel.S, \& Guai.J. (2010). The strange couple: Regulation and competition policy in network industries. CESifo DICE Report(3/2010), 5.

Junghoon.K. (2004). Technical Standard-Setting and Patent Pooling, and Competition Policy. IIP Bulletin.

Kanter.J. (2013). What a Difference a Year Makes: An Emerging Consensus on the Treatment of StandardEssential Patents. Competition Policy International, October, 2013(1), 8.

Katz.M, \& Shapiro.C. (1985). Network externalities, competition, and compatibility. The American economic review, 424-440.

Katz.M, \& Shapiro.C. (1994). Systems competition and network effects. The Journal of Economic Perspectives, 8(2), 93-115.

Kennedy.S. (2006). The political economy of standards coalitions: Explaining China's involvement in high-tech standards wars. Asia Policy, 2(1), 41-62.

Kramer.M. (2006). Valuation and Assessment of Patents and Patent Portfolios Through Analytical Techniques. John Marshall Revue of Intellectual Property Law, 6.

Krechmer.K. (2006). Open standards requirements. International Journal of IT Standards and Standardization Research (IJITSR), 4(1), 43-61.

Kung-Chung.L. (2012). A More Economic and Cross-Jurisdiction Study on Patent Pools. National Taiwan University Law Review., 7, 49.

Lambardi.G. (2010). Software innovation and the open source threat. Borradores de Economía y Finanzas(22).

Layne-Farrar.A, \& Lerner.J. (2011). To join or not to join: Examining patent pool participation and rent sharing rules. International Journal of Industrial Organization, 29(2), 294-303.

Le Bas.C, \& Patel.P. (2007). The determinants of home-base-augmenting and home-base-exploiting Technological activities: some new results on multinationals' locational strategies. Science and Technology Policy Research, 164.

Lee.H, \& Oh.S. (2008). The political economy of standards setting by newcomers: China's WAPI and South Korea's WIPI. Telecommunications Policy, 32(9), 662-671. 
Lemley.M, \& Shapiro.C. (2005). Probabilistic patents. Journal of economic perspectives, 19, 75-98.

Lemley.M, \& Shapiro.C. (2006). Patent holdup and royalty stacking. Texas. Law Revue, 85, 1991.

Lerner.J, \& Tirole.J. (2002). Efficient patent pools. The American economic review, 94(3), 691-711.

Mehra, S., \& Yanbei.M. (2008). Against Antitrust Functionalism: Reconsidering China's Antimonopoly Law. Virginia Journal of International Law, 49(2), 379.

Merges.R. (1999). Institutions for intellectual property transactions: the case of patent pools. University of California at Berkeley Working Paper.

Nelson.P. (2006). Patent Pools: An Economic Assessment of Current Law and Policy. Rutgers Law Journal, 38, 539.

Newberg.J. (2000). Antitrust, patent pools, and the management of uncertainty. Atlantic Law Journal, 3(1), 130.

Peters.R. (2011). One-Blue: a blueprint for patent pools in high-tech. Intellectual Asset Management(September-October 2011).

Piesiewicz.G, \& Schellingerhout.R. (2007). Intellectual property rights in standard setting from a competition law perspective. Competition policy newsletter(3), 36-38.

Ping.Z. (2008). Analysis on antitrust regulation of patent pools Peking University Journal of Legal Studies

Pitowsky.R, Patterson.D, \& Hooks.J. (2010). The essential facilities doctrine under US antitrust George Town Law Faculty Publications.

Priest.G. (2007). Rethinking Antitrust Law in an age of network industries. Yale Law \& Economics Research Paper(352).

Rayna.T, \& Striukova.L. (2010). Large-scale open innovation: open source vs. patent pools. International Journal of Technology Management, 52(3), 477-496.

Redfearn.N. (2009). Patent pools in China. Intangible Asset Management Magazine, 11(37).

Schmalensee.R. (1979). On the use of economic models in antitrust: the Realemon case. University of Pennsylvania Law Review, 127, 994-1050.

Shapiro.C. (2003). Antitrust limits to patent settlements. RAND Journal of Economics, 34(2), 391-411.

Sidak.G. (2009). Patent Holdup and Oligopsonistic Collusion in Standard-Setting Organizations. Journal of Competition Law and Economics, 5(1), 123-188.

Smith.H. (2012). China's MOFCOM clears Google/Motorola with conditions: another example of China's divergence from the EU and US antitrust regimes? Lexology.com.

Sokol.D, \& Zheng, W. (2013). Frand in China. Texas Intellectual Property Law Journal, 22, 71-93.

Stembridge.B. (2010). Chinese utility models -a lesser-known IP strategy. Intellectual Asset Management(42).

Stewart, J., Shen.X, Wang.C, \& Graham.I. (2011). From 3 G to 4G: standards and the development of mobile broadband in China. Technology Analysis \& Strategic Management, 23(7), 773-788.

Suttmeier.R. (2005). A new technonationalism? China and the development of technical standards. Communications of the $A C M, 48(4)$.

Tian.Y. (2009). Intellectual property (IP) protection versus IP abuses: The recent development of Chinese IP abuse rules and recommendations for foreign technology-driven companies. Computer Law \& Security Review, 25(4), 352-366.

Tian.Y. (2010). The Impacts of the Chinese Anti-Monopoly Law on IP Commercialization in China \& General Strategies for Technology-Driven Companies and Future Regulators. Duke Law \& Technology Revue(4).

Tiemann.M. (2006). An objective definition of open standards. Computer Standards \& Interfaces, 28(5), 495507.

Uijl den.S, Bekkers.R, \& de Vries.H. (2013). Managing Intellectual Property Using Patent Pool: Lessons from three generations of pools in the optical disc industry. California Management Review, 55(4).

Van Overwalle.G, Van Zimmeren.E, Verbeure.B, \& Matthijs.G. (2007). Dealing with patent fragmentation in ICT and genetics: Patent pools and clearing houses. First Monday, 12(6).

Verbeure.B, van Zimmeren.E, Matthijs.G, \& Van Overwalle.G. (2006). Patent pools and diagnostic testing. TRENDS in Biotechnology, 24(3), 115-120.

Wang.P, Kwak.J, \& Lee.H. (2014). The latecomer strategy for global ICT standardization: Indigenous innovation and its dilemma. Telecommunications Policy, 38(10), 933-943. 
Whalley.J, Zhou.W, \& An.X. (2009). Chinese experience with global 3G standard-setting. CESifo Working Paper Series (No. 2537).

Wu.T. (2013). Intellectual Property Experimentalism By Way Of Competition Law. Competition Policy International 30(9).

Yan.H. (2007). The $3 G$ standard setting strategy and indigenous innovation policy in China: Is T-SCDMA a flagship. Danish Research Unit for Industrial Dynamics (DRUID) working paper(07-01).

Yao.X, Tan.A, \& Suttmeier.R. (2009). Standards of Power? Technology, Institutions, and Politics in the Development of China's National Standards Strategy. Geopolitics, History, and International Relations(1), 4684.

Yuhzen.D, Wei.S, Xiaobao.P, Zhou.H, \& Lei.L. (2013). Patent pool analysis based on technical standards: A case study of indigenous alliances in China. International Journal of Business and Social Research, 3(2).

Zhan.Y, \& Zhu.X. (2007). Intellectual property right abuses in the patent licensing of technology standards from developed countries to developing countries: A study of some typical cases from China. The Journal of World Intellectual Property, 10(3-4), 187-200.

\section{Legal rule or regulation}

Commission Regulation (EC) No 772/2004 of 27 April 2004 on the application of Article 81(3) of the Treaty to categories of technology transfer agreements (2004).

Guidelines on the applicability of Article 101 of the Treaty on the Functioning of the European Union to horizontal co-operation agreements (2011).

Guidelines on the application of Article 101 of the Treaty on the Functioning of the European Union to technology transfer agreements Draft communication of the Commission (2013).

Commission Regulation (EU) No 316/2014 of 21 March 2014 on the application of Article 101(3) of the Treaty on the Functioning of the European Union to categories of technology transfer agreements (2014).

Regulation on European standardisation (2012).

Directive 98/34/EC 98/34/EC C.F.R. (1998).

Regulation (EU) No 1025/2012 of the European Parliament and of the Council of 25 October 2012 on European standardisation, amending Council Directives 89/686/EEC and 93/15/EEC and Directives 94/9/EC, 94/25/EC, 95/16/EC, 97/23/EC, 98/34/EC, 2004/22/EC, 2007/23/EC, 2009/23/EC and 2009/105/EC of the European Parliament and of the Council and repealing Council Decision 87/95/EEC and Decision No 1673/2006/EC of the European Parliament and of the Council (2012).

Standardization Law of the People's Republic of China (1988).

Decisions and recommendations adoptd by the WTO Committee on Technical Barriers to Trade since January 1995 (2011).

Full text of Communique of the Fifth Plenum of the 17th CPC Central Committee (2010).

Anti-Monopoly Law of the People's Republic of China (2007).

Patent Law of the People's Republic of China (2008).

Interim Regulations on National Standards Involving Patents (2014).

Regulation on Several Issues Concerning the Application of Law in the Trial of Civil Cases arising from Monopolistic Conducts (2012).

Standards Development Organization Advancement Act of 2004 (2004).

Uruguay Round Agreement: TRIPS Agreement Annex $1 \mathrm{C}$ to the Agreement establishing the World Trade Organization Agreement on Trade-Related Aspects of Intellectual Property Rights (1994).

\section{Manuscript}

De Hauteclocque.A. (2008, May 2008). Legal uncertainty and competition policy in deregulated network industries: the case of long-term vertical contracts in the EU electricity markets. Working paper LARSEN. 


\section{Newspaper article}

Gough.N, Buckley.C, \& Wingfield.N. (2014, 10 August 2014). China's Energetic Enforcement of Antitrust Rules Alarms Foreign Firms, The New York Times. Retrieved from http://www.nytimes.com/2014/08/11/business/ international/china8217s-energetic-enforcement-of-antitrust-rules-alarms-foreign-firms.html?_r=2

\section{Online database}

OECD. (2009). OECD Science, Technology and Industry Scoreboard / 2009 / International trade by technology intensity from OECD http://www.oecd-ilibrary.org/sites/sti_scoreboard-2009-en/03/02/index.html;jsession id=1j3tvro98nkpf.x-oecd-live-01?contentType=\&itemld=\%2Fcontent\%2Fchapter\%2Fsti_scoreboard-200934-en\&mimeType=text\%2FhtmI\&containerltemld=\%2Fcontent\%2Fserial\%2F20725345\&accessltemlds= \%2Fcontent\%2Fbook\%2Fsti_scoreboard-2009-en

State Intellectual Property Office of the People's Republic of China (SIPO). (2011-2015). SIPO Monthly Statistics Reports from SIPO State Intellectual Property Office of the P.R.C. http://english.sipo.gov.cn/statistics/

World Intellectual Property Organization. (2013). Statistical Country Profiles China from World Intellectual Property Organization WIPO http://www.wipo.int/ipstats/en/statistics/country_profile/profile.jsp?code=CN

World Intellectual Property Organization. (2014). Statistical Country Profiles China. from WIPO http://www.wipo.int/ipstats/en/statistics/country_profile/profile.jsp?code=CN

World Intellectual Property Organization. (2014). Statistical Country Profiles USA. from WIPO http://www.wipo.int/ipstats/en/statistics/country_profile/profile.jsp?code=US

World Intellectual Property Organization. (2014). Statistical Country Profiles USA. from World Intellectual Property Organization WIPO http://www.wipo.int/ipstats/en/statistics/country_profile/profile.jsp?code=US

\section{Report}

Assessing China's Efforts to Become an "Innovation Society" - A Progress Report (2012) U.S.-China Economic and Security Review Commission. Washington D.C.: U.S.-China Economic and Security Review Commission.

Addy.G, \& Douglas.E. (2014). Trolls, Hopping, Ambush and Hold-up: Emerging International Approaches to the Intersection of Competition and Patent Law. Canada: DWPV.

American Bar Association, \& Section of Intellectual Property Law. (2013). Re: Joint Comments of the American Bar Association Section of Intellectual Property Law and Section of International Law on the Draft Regulatory Measures on National Standards Involving Patents (interim) for the People's Republic of China. Chicago: American Bar Association.

American Bar Association (ABA). (2014). Joint comments of the American Bar Association section of antitrust law, section of intellectual property law, and section of international law in the SAIC draft rules on the prohibition of abuses of intellectual prperty rights for the purposes of eliminating or restricting competition. Chicago ABA.

American Bar Association, S. O. A. L., Section of Intellectual Property Law, and Section of International Law. (2012). Joint Comments of the American Bar Association section of antitrust law, section of intellectual property law, and

section of international law on the SAIC draft guide on anti-monopoly law enforcement in the field of intellectual property rights American Bar Association.

American Bar Association, S. o. A. L., Section of Intellectual Property Law, and Section of International Law. (2012). Joint comments of the American Bar Association section of antitrust law, section of intellectual property law, and section of international law on the SAIC draft Guide on Antimonopoly law enforcement in the field of intellectual property rights (pp. 440). Chicago American Bar Association, Section of Antitrust Law, Section of Intellectual Property Law, and Section of International Law. 
American Bar Association, S. o. A. L., Section of Intellectual Property Law, and Section of International Law. (2013). Joint Comments of the American Bar Association Section of Intellectual Property Law and Section of International Law on the Draft Regulatory Measures on National Standards Involving Patents (interim) for the People's Republic of China. Chicago American Bar Association (ABA).

American Chamber of Commerce to the European Union. (2013). AmCham EU's response to DG Competition's draft proposal for a revised block exemption for technology transfer agreements and for revised guidelines (pp. 9). Brussels: American Chamber of Commerce to the European Union.

Atkinson. R. (2012). Enough is Enough: Confronting Chinese Innovation Mercantilism. Washington D.C.: The information and technology foundation (itif).

Atkinson. R. (2014). The Middle Kingdom Galapagos Islands Syndrome: The Cul de Sac of Chinese Technology Standards The Information and technology foundation (itif).

Audio Video Coding Standard Working Group of China. (2008). Intellectual Property Rights Policy of the Audio Video Coding Standard Working Group of China. Beijing: Audio Video Coding Standard Working Group of China.

Balto. D. (2013). Barriers to Competition on the Innovation Superhighway: How the Lack of Antitrust Scrutiny of Patent Pools Deters Competition. Washington D.C.: dcantitrustlaw.

Barry, C., Arad, R., Ansell, L., \& Clark, E. (2013). 2013 Patent Litigation Study Big cases make headlines, while patent cases proliferate. Atlanta, United States Price Waterhouse Coopers

Barry, C., Arad, R., Johnston, A., Parent, A., Ansell, L., \& Arnold, M. (2012). Patent Litigation Study 2012 Litigation continues to rise amid growing awareness of patent value Atlanta, USA: Price Waterhouse Coopers

Barry. C. (2012). 2012 Patent Litigation Study PWC Patent Litigation Study: PriceWaterhouse Coopers PWC.

CEN- (2010). Standardization for a competitive and innovative Europe: a vision for 2020. Brussels.

CEN - European Committee for Standardization, \& CENELEC - European Committee for Electrotechnical Standardization. (2013). Position Paper on EU-US Transatlantic Trade and Investment Partnership (TTIP) - Technical Barriers to Trade - Initial EU Position Paper: CEN/CENELEC.

Central Committee of Communist Party of China. (2010). Communique of the Fifth Plenum of the 17th Central Committee of Communist Party of China (pp. 9). Beijing China: Central Committee of Communist Party of China,

Charlton. B, \& Wei. L. (2010). Doing Business in China (pp. 110): DLA Piper.

China State Council. (2014). "Opinion on Making Publicly Available According to Law Information on Administrative Penalties Concerning the Production and Sale of Fake, Counterfeit and Sub-standard Goods and Intellectual Property Rights Infringement" Beijing: China State Council.

Commission of the European Union. (2008). Industrial Property Rights Strategy Brussels.

Commission of the European Union. (2010). A Digital Agenda for Europe. Brussels European Union.

Commission of the European Union. (2010). An Integrated Industrial Policy for the Globalisation Era Putting Competitiveness and Sustainability at Centre Stage. Brussels: European Union

Commission of the European Union. (2011). European Competitiveness Report 2011 (Accompanying the document Communication from the Commission to the European Parliament, the Council, the European Economic and Social Committee and the Committee of the Regions Industrial Policy: reinforcing competitiveness) (pp. 131). Brussels: European Union.

Commission of the European Union. (2013). The Transatlantic Trade and Investment Partnership: The Economic Analysis explained.

Commission on the theft of American Intellectual Property. (2013). The IP Commission Report (pp. 100). USA: National Bureau on Asian Research USA.

Commission, U. S. F. T. (2006). FTC Staff Report Concerning Enforcement Perspectives on the NoerrPennington Doctrine. Washington D.C.: United States Federal Trade Commission

Cooper.C, DeWoskin.K, Haller.M, Hoffman.D, \& Kates.L. (2005). Redefining Intellectual Property Value the Case of China (pp. 76): Price Waterhouse Coopers.

Embassy of the United States Beijing China. (2012). U.S.-CHINA Strategic and economic dialogue 2012. Beijing Embassy of the United States Beijing China. 
Ernst.D. (2011). Indigenous Innovation and Globalization: The Challenge for China's Standardization Strategy (pp. 123). Honolulu: UC Institute on Global Conflict and Cooperation.

EU-China Standards Information Platform. (2014). Guide on the Implementation of Standards in China (Draft). Beijing, China EU-China Standards Information Platform.

European Committee for Standardization (CEN), \& European Committee for Electrotechnical Standardization (CENELEC) (2013). Position Paper on EU-US Transatlantic Trade and Investment Partnership (TTIP) Technical Barriers to Trade - Initial EU Position Paper. Brussels.

European Patent Organization. (2007). Scenarios for the Future. Munich Germany: European Patent Organization

European Telecommunications Standards Institute. (2006). ETSI Guide on IPRs, Version endorsed by General Assembly \#48 on 22 November 2006. Sophia Antipolis (France): ETSI.

Felbermayr.G, Larch.M, Flach.L, Yalcin.E, \& Benz.S. (2013). Dimensionen und Auswirkungen eines Freihandelsabkommens zwischen der EU und den USA: Ifo Institut Leibniz Institut fur Wirtschaftsforschung.

Harhoff.D. (2007). The strategic use of patents and its implications for enterprise and competition policies (pp. 307). Brussels: Commission of the European Union.

Intellectual Property Lawyers Association and Law Society of England \& Wales. (2013). Response of Intellectual Property Lawyers Association and Law Society of England \& Wales toEuropean Commission consultation on: (1) draft Technology Transfer Block Exemption Regulation ("TTBER"); and (2) draft Guidelines on Technology Transfer Agreements ("Guidelines") (pp. 15): The Intellectual Property Lawyers Association and Law Society of England \& Wales.

Lampe, R. L., \& Moser, P. (2012). Do patent pools encourage innovation? evidence from 20 us industries under the new deal: National Bureau of Economic Research.

Lampe.R, \& Moser.P. (2011). Patent Pools and the Direction of Innovation-Evidence from the 19th-century Sewing Machine Industry: National Bureau of Economic Research.

Loke-Thoon.T, \& Simone.J. (2012). Intellectual Property Guide China: Baker and McKenzie

McGregor.J. (2010). China's Drive for 'Indigenous Innovation' A Web of Industrial Policies Global Regulatory Cooperation Project: United States Chamber of Commerce.

Office of the United States Trade Representative. (2013). 2013 Special 301 Report (pp. 59). Washington D.C. : Office of the United States Trade Representative.

Prud'homme.D. (August 2012). Dulling the Cutting Edge: How Patent-Related Policies and Practices Hamper Innovation (pp. 235). Shanghai: European Chamber of Commerce in China.

Regibeau.P, \& Rockett.K. (2011). Assessment of potential anticompetitive conduct in the field of intellectual property rights and assessment of the interplay between competition policy and ipr protection. Brussels: EUR-OP/ Commission of the European Union.

Signals Research Group. (2010). The Essentials of Intellectual Property, Quantifying technology leadership in the development of the LTE standard (White Paper). Oakland, California USA: Ericsson

State Intellectual Property Office of the People's Republic of China (SIPO). (2010). National Patent Development Strategy (2011-2020). Beijing.

Supreme Court of the People's Republic of China. (2014). "Decision of the SPC Regarding Questions of Application of Law in Adjudication of Patent Cases", . China: Supreme Court.

U.S.President's Council of Economic Advisers, the National Economic Council, \& the Office of Science \& Technology Policy. (2013). Patent assertion and U.S. Innovation (pp. 17). Washington D.C. : Executive Office of the President.

United States Department of Commerce. (2012). Doing Business in China 2012 Country Commercial Guide for U.S. Companies. Washington D.C. : US Department of Commerce, Bureau of Industry and Security

United States Department of Justice and the Federal Trade Commission. (2007). Antitrust enforcement and Intellectual property rights: Promoting Innovation and Competition (pp. 217). Washington D.C. : U.S. Department of Justice and the Federal Trade Commission.

United States Department of the Treasury. (2014). Sixth Meeting of the U.S.-China Strategic and Economic Dialogue U.S. Fact Sheet - Economic Track. Washington D.C. : U.S. Department of the Treasury. 
United States Federal Trade Commission Staff. (2006). Enforcement Perspective on the Noerr-Pennington Doctrine (pp. 41). Washington D.C. : United States Federal Trade Commission.

United States International Trade Commission. (2010). China: Intellectual Property Infringement, Indigenous Innovation Policies, and Frameworks for Measuring the Effects on the U.S. Economy (pp. 196). Washington D.C.: United States International Trade Commission.

United States International Trade Commission. (2011). China: Effects of Intellectual Property Infringement and Indigenous Innovation Policies on the U.S. Economy (USITC Publication 4226 ed., pp. 308). Washington D.C. : United States International Trade Commission.

United States International Trade Commission. (2014). Trade Barriers That U.S. Small and Medium-sized Enterprises Perceive as Affecting Exports to the European Union (Vol. Investigation No. 332-541). Washington D.C.: United States International Trade Commission

US-China Business Council (USCBC). (2010). USCBC Comments on Draft National Standard Disposition Rules for the Inclusion of Patents in National Standards Washington D.C.: US-China Business Council (USCBC).

US-China Business Council (USCBC). (2013). USCBC 2013 China Business Environment Survey Results: Tempered Optimism Continues amid Moderating Growth, Rising Costs, and Persistent Market Barriers China Business Environment Survey. Washington, DC: The US-CHINA Business Council.

Wang.P, Wang.Y, \& Hill.J. (2010). Standardization Strategy of China, Achievements and Challenges Economics Series. Honolulu: East-West Center, Economics Study Area.

Wang.Y. (2013). Recent Developments in Antitrust Enforcement and Litigation in China Involving Resale Price Maintenance. New York City NERA Economic consulting

Willesden.J, \& Keeley.J. (2007). China: The next science superpower? London: DEMOS.

World Intellectual Property Organization. (2013 ). 2013 World Intellectual Property Indicators Report World Intellectual Property Indicators Report. Geneva, Switzerland.

World Intellectual Property Organization Standing Committee on the law of patents. (2009). Standards and patents (Vol. Thirteenth Session). WIPO Geneva: WIPO.

World Trade Organization. (2012). Trade Policy Review: China Trade Policy Review. Geneva, Switzerland: World Trade Organization.

World Trade Organization Committee on the Technical Barriers to Trade. (2009). Fifth triennial review of the operation and implementation of the agreement on technical barriers to trade under article 15.4 Geneva World Trade Organization.

Xielin.L, \& Cheng.P. (2011). Is China's Indigenous Innovation Strategy Compatible with Globalization. In E.-W. Center (Ed.). Honolulu, Hawai: East-West Center.

\section{Thesis}

Dapp.M. (2009). The effects of software patent policy on the motivation and innovation of free and open source software developers. Diss., Eidgenössische Technische Hochschule ETH Zürich, Nr. 18544, 2009. Retrieved from http://e-collection.library.ethz.ch/view/eth:736

Pohlmann.T. (2012). Six essays on patenting and coordination in ICT standardization: Empirical analyses of essential patents, patent pools, and standards consortia. Universitätder Technischen Universität Berlin. Retrieved from http://dx.doi.org/10.14279/depositonce-3367

\section{Webpage}

3 GPP Standard. (2014). 3 GPP Standard specifications, from http://www.3gpp.org/specifications

Amstrong.A, Mueller.J, \& Syrett.T. (2014, 29 May 2014). The Smartphone Royalty Stack: Surveying Royalty Demands for the Components Within Modern Smartphones, from http://papers.ssrn.com/sol3/papers. cfm?abstract_id $=2443848$ 
International Telecommunications Union (ITU). (2014). Definition of "Open Standards", from http://www.itu.int/en/ITU-T/ipr/Pages/open.aspx

U.S.-China Joint Commission on Commerce and Trade. (2014, 29 December 2014 ). U.S.-China Fact Sheet on 25th Joint Commerce and Trade Commission from http://iipdigital.usembassy.gov/st/english/texttrans/ 2014/12/20141229312598.html\#axzz3jMSTGm6W

World Intellectual Property Organization (WIPO). (2014). WIPO ADR for FRAND Disputes, from http://www.wipo.int/amc/en/center/specific-sectors/ict/frand/

World Trade Organization. WTO Analytical Index: Agreement on Technical Barriers to Trade from http://www.wto.org/english/res_e/booksp_e/analytic_index_e/tbt_01_e.htm 



\section{Curriculum Vitae}

Matt Heckman (Heerlen, 1963) studied law at Maastricht University and Lancaster University (UK). In 1986 he obtained his bachelor in law, and in 1988 he obtained a master in International and European Law from the Vrije Universiteit Brussels (Belgium). During his studies he gained working experience at the European Commission.

He teaches European law and European economic integration at various universities in the Netherlands. He was responsible for international relations (for 14 years) at a Dutch Polytechnic and is currently teaching at various graduate programs in the Netherlands, UK, Hong Kong and the USA.

Presently he is researcher and principal lecturer. He was external examiner at DIT Dublin for four years and still acts as a consultant to both public and private companies. Matt is also a founding member of the research center on innovative entrepreneurship and risk management at Zuyd Polytechnic. 


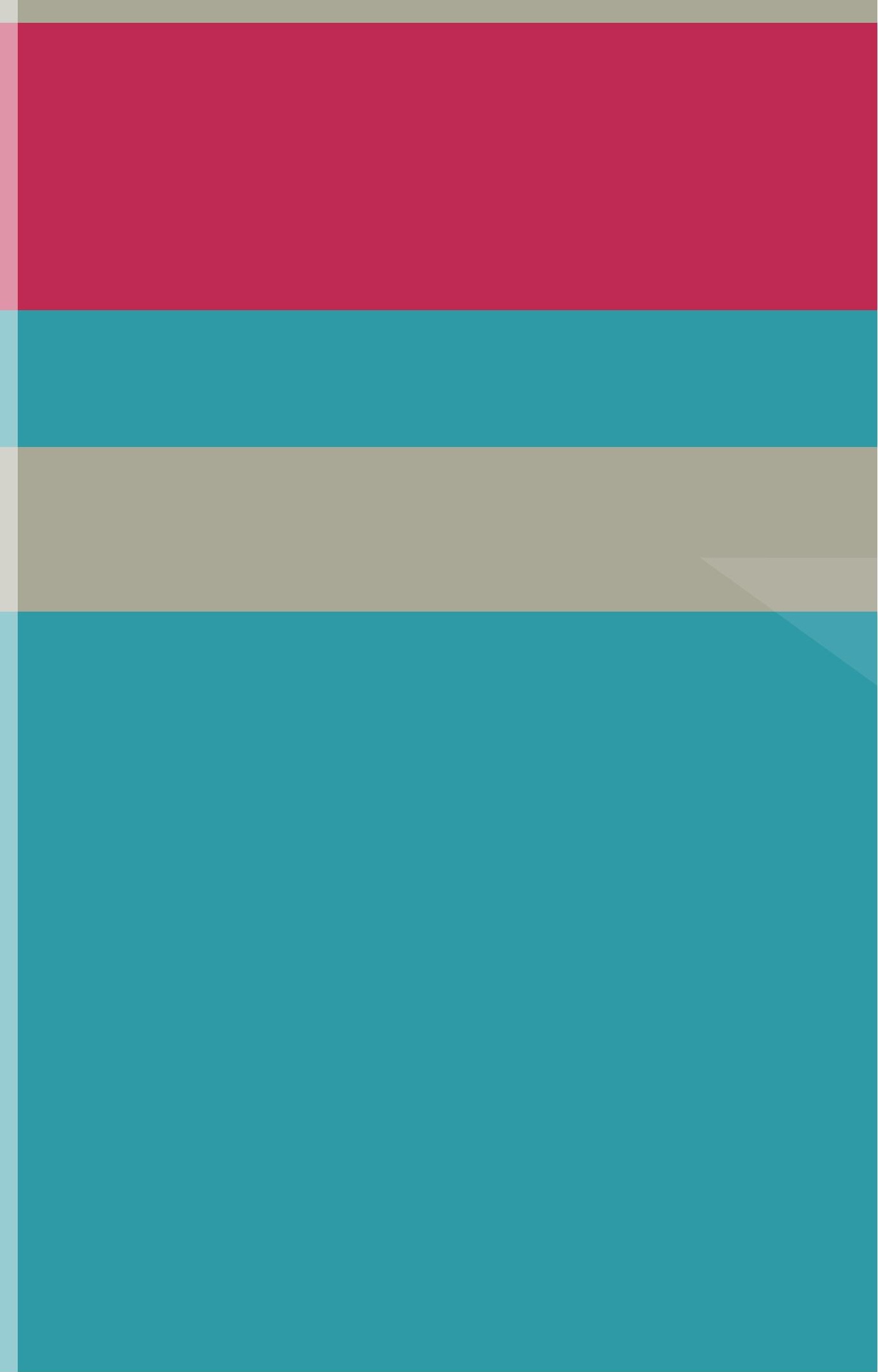

